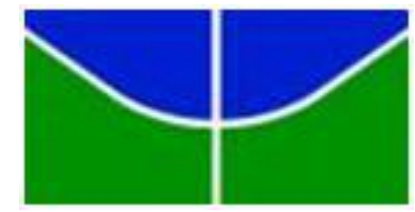

UNIVERSIDADE DE BRASÍLIA INSTITUTO DE GEOCIÊNCIAS

Programa de Pós-graduação em Geologia

ISÓTOPOS DE ND E SR EM MINERAIS DE DIFERENTES SÉRIES PETROGENÉTICAS NOS COMPLEXOS ALCALINO-CARBONATÍTICOS De SAlitre e Catalão I

\author{
Ítalo Lopes de Oliveira
}

Dissertação de Mestrado

$\mathrm{N}^{\mathrm{o}} 343$

Brasília, DF 
UNIVERSIDADE DE BRASÍLIA

INSTITUTO DE GEOCIÊNCIAS

Programa de Pós-graduação em Geologia

\title{
ISÓTOPOS DE ND E SR EM MINERAIS DE DIFERENTES SÉRIES PETROGENÉTICAS NOS COMPLEXOS ALCALINO-CARBONATÍTICOS de Salitre e Catalão I
}

\author{
Ítalo Lopes de Oliveira
}

Dissertação de Mestrado

$\mathrm{N}^{\mathrm{o}} 343$

Área de Concentração: Geoquímica Orientador: Prof. Dr. José Affonso Brod Co-Orientador: Prof. Dr. Elton Luiz Dantas

Banca Examinadora: Prof. Dr. Márcio Martins Pimentel (UnB) Prof. Dr. Sérgio de Castro Valente (UFRRJ) Suplente: Prof. ${ }^{a}$ Dra. Maria Emilia Schutesky Della Giustina (UnB) 


\section{AGRADECIMENTOS}

Aos meus familiares pelo apoio, compreensão, e principalmente, pela paciência ao longo desses anos de mestrado.

Aos meus orientadores, em especial ao Prof. Dr. José Affonso Brod, pelo incentivo, pelas diversas discussões geológicas ou não, e por toda confiança e suporte ao longo do trabalho, mesmo a distância.

Ao Prof. Dr. Koji Kawashita, por todo o auxilio, sugestões e inúmeros esclarecimentos relacionados aos isótopos radiogênicos, em especial, à aplicação do método $\mathrm{Rb}-\mathrm{Sr}$.

Ao Prof. Dr. Márcio Martins Pimentel, por toda sua paciência nas "breves" e muito proveitosas discussões.

À Prof. ${ }^{a}$ Dra. Maria Emilia Schutesky Della Giustina, pelo auxilio e incentivo durante a realização deste trabalho, em especial, nas análises do MEV.

Aos membros da equipe do Laboratório de Geocronologia da Universidade de Brasília por fornecerem todo o suporte necessário para a realização das diversas análises, além de me acolherem e terem muita paciência durante esses quase dois anos de "Pós-Doc" no laboratório! Em especial, gostaria de agradecer à Barbara e à Jeane pela ajuda e dedicação durante a preparação química das amostras, e ao Érico pelo auxilio e enorme paciência no processo de separação dos minerais.

Aos meus colegas de laboratório, mestrado, mas acima de tudo meus amigos, Felipe, Karin e Rachel, pelas várias discussões geológicas, químicas e, principalmente, pelas conversas fora do laboratório.

Aos meus amigos de graduação por todo o incentivo e apoio, mesmo a distância.

À Capes e ao $\mathrm{CNPq}$ pela concessão da bolsa de mestrado e pelo apoio financeiro relativo ao projeto 550376/2010-0, respectivamente.

Ao Laboratório de Microssonda Eletrônica do Instituto de Geociências da UnB.

E finalmente, a todos aqueles que contribuíram para a realização desta dissertação. 
"The simplest explanation for some phenomenon is more likely to be accurate than more complicated explanations."

Ockham's Razor Principle 


\section{RESUMO}

Esta dissertação investiga em detalhe processos petrogenéticos atuantes na formação dos complexos alcalino-carbonatíticos de Salitre I e Catalão I, utilizando a composição isotópica de $\mathrm{Nd}$ e $\mathrm{Sr}$ em diversos minerais de diferentes tipos de rochas. Incialmente faz-se uma revisão do estado da arte dos sistemas isotópicos $\mathrm{Rb}-\mathrm{Sr}$ e $\mathrm{Sm}-\mathrm{Nd}$, e em seguida são apresentados os resultados, na forma de três artigos para publicação.

O primeiro artigo aborda o resultado de diversos experimentos de lixiviação destinados a remover seletivamente o carbonato em concentrados de apatita, a fim de obter a elevada pureza, necessária para análises isotópicas. Imagens de $\mathrm{MEV}$ mostram que $\mathrm{HCl}$, mesmo diluído, deve ser evitado, pois ataca a estrutura da apatita numa direção preferencial, e ocasiona mudanças na sua composição isotópica de $\mathrm{Nd}$. Testes com ácido acético diluído e aquecido revelaram-se promissores, pois removeram todos os carbonatos superficiais sem atacar a estrutura da apatita, preservando as razões isotópicas originais deste mineral.

O segundo artigo investiga variações isotópicas de $\mathrm{Nd}$ e $\mathrm{Sr}$ em minerais e rochas do complexo alcalino-foscorito-carbonatítico de Salitre I. Variações de ${ }^{87} \mathrm{Sr}^{86} \mathrm{Sr}_{\mathrm{i}}$ nos minerais, concordantes com a ordem de cristalização, apontam para um sistema aberto durante a evolução magmática. Desequilíbrio isotópico de $\mathrm{Nd}$ entre minerais e rochas foscoríticas sugerem processos metassomáticos tardios. Modelagem petrogenética mostra que contaminação crustal $(<10 \%)$ concomitante a processos de cristalização fracionada e imiscibilidade de líquidos (AFCLI) pode explicar as variações isotópicas dos carbonatitos e rochas silicáticas alcalinas de Salitre I. Um espectro limitado de composições isotópicas de $\mathrm{Nd}-\mathrm{Sr}$ nos magmas carbonatíticos sugere que os magmas parentais de Salitre I derivaram de um manto litosférico subcontinental metassomatizado, semelhante ao componente EM-I.

O terceiro estudo discute os dados isotópicos de $\mathrm{Nd}$ e $\mathrm{Sr}$ em minerais e rochas do complexo carbonatítico de Catalão I. Uma investigação detalhada destes dados isotópicos sugere que as rochas mais evoluídas de Catalão I formaram-se a partir de dois trends evolutivos distintos. É proposto que mudanças na assembleia mineral fracionante de magmas carbonatíticos tardios ou de sistemas carbo-hidrotermais possam explicar tais variações isotópicas entre os dois trends desde que esses magmas e/ou fluidos tenham interagido com componentes crustais durante a diferenciação (AFC). 


\begin{abstract}
The foremost motivation of this M.Sc. thesis is to investigate in detail the petrogenetic processes responsible for the origin and evolution of the alkaline-carbonatite complexes of Salitre I and Catalão I, characterizing the $\mathrm{Nd}$ and $\mathrm{Sr}$ isotope compositions of several mineral phases taken from different rock types in each complex. The thesis comprises a background review of $\mathrm{Rb}-\mathrm{Sr}$ and $\mathrm{Sm}-\mathrm{Nd}$ systematics followed by three individual papers containing the results of this study.

The first paper presents the investigation of an adequate leaching method for the removal of carbonate impurities from an apatite-carbonate mixture, in order to obtain a high level of purity in apatite separates. SEM images show that hydrochloric acid should be avoided, even in diluted concentrations, since it attacks the structure of apatite in a preferred direction, shifting considerably their $\mathrm{Nd}$ isotope composition. On the other hand, a procedure using warm diluted acetic acid seems to be valuable in order to leach all surface carbonate contaminants without attacking the apatite structure, therefore preserving their $\mathrm{Sr}$ and $\mathrm{Nd}$ primary isotopic signatures.
\end{abstract}

The second paper discusses the $\mathrm{Sr}$ and $\mathrm{Nd}$ isotope variations in mineral separates and whole-rocks from the alkaline-phoscorite-carbonatite complex of Salitre I. The increase in ${ }^{87} \mathrm{Sr} /{ }^{86} \mathrm{Sr}_{\mathrm{i}}$ toward the late-crystallizing phases implies open-system behaviour during the magmatic evolution. Mineral-rock $\mathrm{Nd}$ isotopic disequilibrium found in most studied phoscorites indicates a probably late-stage metasomatic alteration. AFCLI modelling shows that minor crustal contamination $(<10 \%)$ concurrent with fractional crystallization and liquid immiscibility could explain the $\mathrm{Nd}-\mathrm{Sr}$ isotopic heterogeneities observed in Salitre I carbonatites and alkaline silicate rocks. A limited range of $\mathrm{Nd}-\mathrm{Sr}$ isotopes for carbonate melts suggests that Salitre I carbonated-silicate parental magmas derived from a metasomatized subcontinental lithospheric source similar to the EM-I mantle component.

The third paper focuses on understand the major isotope variations in the late-stage rocks of the Catalão I carbonatite complex. A detailed investigation of isotope data suggests two evolution paths for the most evolved rocks of the complex. It has been proposed that changes in the fractionating assemblage of a late-stage magmatic or carbo-hydrothermal systems undergoing realistic amounts of crustal contamination could explain such trends. 


\section{LISTA DE ILUSTRAÇÕES}

Figura 1.1. Variação entre as razões isotópicas iniciais ${ }^{143} \mathrm{Nd} /{ }^{144} \mathrm{Nd} \mathrm{e}{ }^{87} \mathrm{Sr} /{ }^{86} \mathrm{Sr}$ das séries petrogenéticas que compõem os complexos alcalino-carbonatíticos de Salitre e Catalão I, APIP. 3

$\begin{array}{lr}\text { Figura 1.2. Diagrama de classificação da série foscorítica. } & 8\end{array}$

Figura 1.3. Classificação química dos carbonatitos para rochas com $\mathrm{SiO}_{2}<20 \%$. 9

Figura 2.1. Tabela periódica com destaque para os elementos Terras Raras, os elementos radioativos e

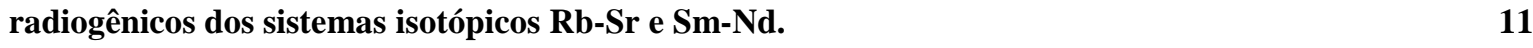

Figura 2.2. Diagrama Rb-Sr esquemático do principio da isócrona. 15

$\begin{array}{lr}\text { Figura 2.3. Evolução isotópica do Sr na Terra. } & 17\end{array}$

Figura 2.4. Diagrama Sm-Nd esquemático do principio da isócrona. 23

$\begin{array}{ll}\text { Figura 2.5. Princípio das idades modelo Sm-Nd. } & 27\end{array}$

Figura 2.6. Evolução isotópica do Nd na Terra. $\quad 28$

Figura 2.7. Correlação isotópica entre ${ }^{143} \mathrm{Nd} /{ }^{144} \mathrm{Nd} \mathrm{e}{ }^{87} \mathrm{Sr} /{ }^{86} \mathrm{Sr}$ em basaltos oceânicos jovens (< $\left.25 \mathrm{Ma}\right) . \quad 29$

Figura 2.8. Comparação entre carbonatitos jovens (< 200 Ma) e basaltos oceânicos no diagrama de correlação isotópica ${ }^{143} \mathrm{Nd} /{ }^{144} \mathrm{Nd} \mathrm{e}{ }^{87} \mathrm{Sr} /{ }^{86} \mathrm{Sr}$.

Figura 2.9. Assinatura isotópica inicial de $\mathrm{Nd}$ e $\mathrm{Sr}$ para os carbonatitos da Província Alcalina de Kola, Rússia ( 380 Ma) e do Complexo de Phalaborwa, África do Sul ( 2.0 Ga). 33

Figura 2.10. ${ }^{87} \mathrm{Sr} /{ }^{86} \mathrm{Sr}$ versus tempo para carbonatitos do Canadá, Fennoscândia e Groenlândia. 35

Figura 2.11. $\varepsilon N d(T)$ versus tempo para carbonatitos do Canadá, Fennoscândia e Groenlândia. 35

Figura 2.12. Diagrama ${ }^{143} \mathrm{Nd} /{ }^{144} \mathrm{Nd} \times{ }^{87} \mathrm{Sr} /{ }^{86} \mathrm{Sr}$ associando diferentes ambientes geodinâmicos e "tipos de manto" com a composição isotópica de rochas alcalinas, carbonatitos e lamproítos. 36

Figura 3.1. Desenho esquemático do processo de desagregação eletrodinâmica. 38

Figura 3.2. a) Procedimento de introdução de amostra no SELFRAG ${ }^{\circledR}$ Lab S2.0 High Voltage Pulse Power

Fragmentation. b) Ilustração de um corte vertical no recipiente de processamento das amostras. 39

Figura 3.3. Procedimento de abertura das amostras silicáticas em Savillex ${ }^{\circledR}$ 42

Figura 3.4. Detalhe dos principais sistemas que compõem o espectrômetro de massa Thermo Scientific

\begin{tabular}{lr} 
TRITON & $\mathbf{T M}$ Plus. \\
\hline
\end{tabular}

Figura 3.5. Desenho esquemático do funcionamento dos filamentos em arranjo simples (a) e duplo (b). 46

Figura 4.1. Imagens de BSE e elétrons secundários (SE) da amostra piloto antes de ser submetida aos

procedimentos de lixiviação. $\quad 5$

Figura 4.2. Imagens de elétrons retroespalhados (BSE) das amostras submetidas ao Teste 1. 57

Figura 4.3. Imagens de BSE das amostras submetidas aos testes 2 (A) e 3 (B, C, D). 58

$\begin{array}{lr}\text { Figura 4.4. Análises semiquantitativas em modo EDS. } & 58\end{array}$

Figura 4.5. Imagens de BSE e SE das amostras submetidas ao Teste 4 (I).

Figura 4.6. Imagens de BSE e SE das amostras submetidas ao Teste 4 (II).

Figura 4.7. Correlação entre as razões ${ }^{143} \mathrm{Nd} /{ }^{144} \mathrm{Nd}$ e $\mathrm{Sm} / \mathrm{Nd}$ das amostras listadas na Tabela 4.2. 62

Figura 4.8. Mistura binária simples entre a média dos carbonatos de Catalão I e a apatita do Teste 4.2. 66 
Figure 5.1. Geological setting of the Alto Paranaíba Igneous Province.

Figure 5.2. Schematic geological map of the Salitre complex.

Figure 5.3. Petrographic features of the studied Salitre $I$ samples $\left(1^{\text {st }}\right.$ and $2^{\text {nd }}$ intrusive stages).

Figure 5.4. Petrographic features of the studied Salitre I samples ( $3^{\text {rd }}$ and $4^{\text {th }}$ intrusive stages).

Figure 5.5. Textural features of two carbonate varieties in a $\mathrm{C} 1$ magnesiocarbonatite (Sample 20B-94). 82

Figure 5.6. $\mathrm{Rb}$ versus $\mathrm{Sr}$ concentrations in the whole-rock samples analysed for $\mathrm{Sr}$ isotopes.

Figure 5.7. Plot of $f_{\mathrm{Sm} / \mathrm{Nd}}$ versus $\mathrm{Ca} / \mathrm{Sr}$.

Figure 5.8. Rb-Sr whole-rock isotope data from the Salitre I complex plotted in an isochron diagram. 96

Figure 5.9. Sm-Nd whole-rock isotope data from the Salitre I complex plotted in an isochron diagram. 97 Figure 5.10. Histogram of whole-rock ${ }^{87} \mathrm{Sr}^{86} \mathrm{Sr}_{\mathrm{i}}(\mathrm{A})$ and ${ }^{143} \mathrm{Nd} /{ }^{144} \mathrm{Nd}_{\mathrm{i}}(\mathrm{B})$ for the rock types of Salitre I. 99

Figure 5.11. Plot of ${ }^{87} \mathrm{Sr} /{ }^{86} \mathrm{Sr}_{\mathrm{i}}$ versus $\mathrm{Sr}$ content. 100

Figure 5.12. Plot of ${ }^{143} \mathrm{Nd} /{ }^{144} \mathrm{Nd}_{\mathrm{i}}$ versus $\mathrm{Nd}$ content. 101

Figure 5.13. Histogram of ${ }^{87} \mathrm{Sr}^{86} \mathrm{Sr}_{\mathrm{i}}$ for minerals from the main rock types of the Salitre I complex. 102

Figure 5.14. Initial ${ }^{87} \mathrm{Sr} /{ }^{86} \mathrm{Sr}$ ratios for whole rocks and corresponding mineral separates.

Figure 5.15. Plot of ${ }^{87} \mathrm{Sr}^{86} \mathrm{Sr}_{\mathrm{i}}$ vs Sr contents for apatite, calcite, dolomite and perovskite.

Figure 5.16. Histogram of minerals ${ }^{143} \mathrm{Nd} /{ }^{144} \mathrm{Nd}_{\mathrm{i}}$ for the main rock types of the Salitre I complex. 107

Figure 5.17. ${ }^{143} \mathrm{Nd} /{ }^{144} \mathrm{Nd}_{\mathrm{i}}$ for whole rocks and corresponding mineral separates. 108

Figure 5.18. ${ }^{143} \mathrm{Nd} /{ }^{144} \mathrm{Nd} \mathrm{m}_{\mathrm{ms}}{ }^{147} \mathrm{Sm} /{ }^{144} \mathrm{Nd}$ for minerals and whole-rock from sample FSALT81. 109

Figure 5.19. ${ }^{143} \mathrm{Nd} /{ }^{144} \mathrm{Nd}_{\mathrm{m}} \mathrm{vs}^{147} \mathrm{Sm} /{ }^{144} \mathrm{Nd}$ for minerals and whole-rock from sample FSALT96. 110

Figure 5.20. Sm-Nd mineral isochron diagram for sample FSALT96. 110

Figure 5.21. ${ }^{143} \mathrm{Nd} /{ }^{144} \mathrm{Nd}_{\mathrm{i}}$ vs $\mathrm{Nd}(\mathrm{A})$ and ${ }^{87} \mathrm{Sr}^{86} \mathrm{Sr}_{\mathrm{i}} \mathrm{vs} \mathrm{Sr}(\mathrm{B})$ for the parental magma of the APIP. $\quad 113$

Figure 5.22. (A), (B) and (C) illustrates the geochemical linear correlations ongoing between $\mathrm{SiO}_{2}, \mathrm{CaO}$ $\begin{array}{lr}\text { and Sr content for the parental magmas of the APIP. } & 114\end{array}$

Figure 5.23. ${ }^{87} \mathrm{Sr} /{ }^{86} \mathrm{Sr}_{\mathrm{i}}$ vs $\mathrm{Sr}$ contents for the parental magma of the APIP carbonatite complexes. 116

Figure 5.24. ${ }^{143} \mathrm{Nd} /{ }^{144} \mathrm{Nd}_{\mathrm{i}}$ vs $\mathrm{Nd}$ contents for the parental magma of the APIP carbonatite complexes. 117

Figure 5.25. Plot of initial ${ }^{87} \mathrm{Sr} /{ }^{86} \mathrm{Sr}$ ratios versus $\mathrm{Sr}$ content of bebedourites and carbonatites from the

Salitre I complex. The continuous black lines represent the AFCLI model curves.

Figure 5.26. Nd isotope compositions from Salitre I minerals and rocks.

Figure 5.27. Comparison of initial $\mathrm{Nd}$ and $\mathrm{Sr}$ isotopic ratios of the APIP carbonatites with other young (<200 Ma) carbonatites worldwide.

Figure 6.1. Geological sketch from the Catalão I complex.

Figure 6.2. Photograph of drill-cores from the Catalão I carbonatite complex. 156

Figure 6.3. ${ }^{87} \mathrm{Sr} /{ }^{86} \mathrm{Sr}_{\mathrm{i}}$ obtained for mineral separates from $\mathrm{N} 1$ and $\mathrm{N} 2$ nelsonites. 159

Figure 6.4. ${ }^{143} \mathrm{Nd} /{ }^{144} \mathrm{Nd}_{\mathrm{i}}$ obtained for mineral separates from $\mathrm{N} 1$ and $\mathrm{N} 2$ nelsonites.

Figure 6.5. Comparison between the evolution stages of Catalão I and Salitre I rocks. 163

Figure 6.6. ${ }^{87} \mathrm{Sr} /{ }^{86} \mathrm{Sr}_{\mathrm{i}}$ vs $\mathrm{Sr}$ content comparing the composition of Salitre I and Catalão I rocks. 164 Figure 6.7. ${ }^{143} \mathrm{Nd} /{ }^{144} \mathrm{Nd}_{\mathrm{i}} \mathrm{vs}^{87} \mathrm{Sr}^{86} \mathrm{Sr}_{\mathrm{i}}$ correlation diagram for Catalão I rocks. $\quad 165$

Figure 6.8. Plot of ${ }^{143} \mathrm{Nd} /{ }^{144} \mathrm{Nd}_{\mathrm{i}}$ vs $\mathrm{Nd}$ content for the most evolved rocks from the Catalão I complex. 166 Figure 6.9. ${ }^{143} \mathrm{Nd} /{ }^{144} \mathrm{Nd}_{\mathrm{i}}$ vs ${ }^{87} \mathrm{Sr}^{86} \mathrm{Sr}_{\mathrm{i}}$ correlation diagram for Catalão I samples. Also shown are the calculated AFC model curves for each evolution path. 


\section{LISTA DE TABELAS}

Tabela 2.1. Abundância isotópica aproximada de estrôncio (Sr).

Tabela 2.2. Abundâncias isotópicas de neodímio (Nd) e samário (Sm).

Tabela 4.1. Detalhe dos procedimentos de lixiviação realizados durante o Teste 04.

Tabela 4.2. Composição isotópica de Nd e Sr dos concentrados de apatita submetidos a diferentes procedimentos de lixiviação.

Table 5.1. Successive emplacement stages proposed for rocks of the Salitre I complex.

Table 5.2. Whole-rock Sr isotopic data from the Salitre I complex.

Table 5.3. Whole-rock Nd isotopic data from the Salitre I complex.

Table 5.4. Sr isotopic data of the minerals from the Salitre I rocks.

Table 5.5. Nd isotopic data of the minerals from the Salitre I rocks.

Table 5.6. Sr and Nd isotope data for the phlogopite picrite dykes of the APIP alkaline-carbonatite complexes.

Table 5.7. Mineral-melt partition coefficients $\left(K_{D}\right)$ used in the modelling calculations.

Table 6.1. Sr and Nd isotopic data from the Catalão I samples. 
AGRADECIMENTOS I

RESUMO III

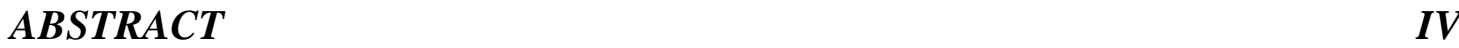

LISTA DE ILUSTRAÇÕES V V

LISTA DE TABELAS VII

1. INTRODUÇ̃̃O 1

1.1. Justificativa 2

1.2. Objetivos 4

1.3. Estrutura da Dissertação 5

1.4. Complexos Alcalino-Carbonatíticos 5

1.5. Séries Petrogenéticas 6

$\begin{array}{lr}\text { Série Silicática } & 6\end{array}$

Série Foscorítica $\quad 7$

$\begin{array}{lr}\text { Série Carbonatítica } & 9\end{array}$

2. GEOQUÍMICA ISOTÓPICA 11

2.1. O Sistema $\mathrm{Rb}-\mathrm{Sr} \quad 11$

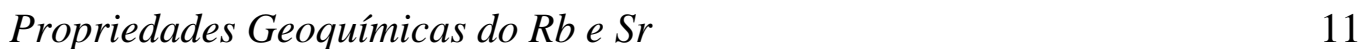

A Constante de Decaimento do ${ }^{87} R b \quad 13$

Geocronologia $\mathrm{Rb}-\mathrm{Sr} \quad 14$

Evolução Isotópica do Sr 16

$\begin{array}{lr}\text { Notações } \varepsilon_{S r} \text { e } f_{R b / S r} & 18\end{array}$

2.2. O Sistema $\mathrm{Sm}-\mathrm{Nd} \quad 20$

Propriedades Geoquímicas do Sm e Nd 20

A Constante de Decaimento do ${ }^{147} \mathrm{Sm} \quad 21$

Geocronologia Sm-Nd 22

Notações $\varepsilon_{N d}$ e $f_{S m / N d}$ 
Idades Modelo $\tau_{C H U R}$ e $\tau_{D M}$

Evolução Isotópica do Nd 27

Correlação Isotópica entre Nd-Sr e Heterogeneidades do Manto 28

2.3. Sistemática de Isótopos Radiogênicos em Carbonatitos 31

3. MATERIAIS \& MÉTODOS 37

3.1. Amostragem 37

3.2. Separação e Concentração dos Minerais 37

3.3. Lixiviação dos Minerais 41

3.4. Análises Isotópicas de Sm-Nd 41

3.5. Análises Isotópicas de $\mathrm{Sr} 43$

3.6. ID-TIMS (Isotope Dilution - Thermal Ionization Mass Spectrometry) 44

Sistema de Entrada (Inlet System) 45

Sistema Analisador (Analyzer System) 46

Sistema Detector (Multicollector System) 46

3.7. Microssonda Eletrônica (EMPA) 47

3.8. Microscópio Eletrônico de Varredura (SEM) 47

4. DETERMINAÇÃO DE ISÓtOPOS DE ND-SR EM APATITA DE COMPLEXOS ALCALINO-CARBONATÍTICOS: IMPLICAÇÕES DE DISTINTOS MÉTODOS DE LIXIVIAÇÃO, INVESTIGADOS POR MICROSCOPIA ELETRÔNICA DE VARREDURA.

$\begin{array}{ll}\text { Abstract } & 48\end{array}$

4.1. Introdução 49

4.2. Materiais e Métodos 51

Teste 1-Lixiviação com ácido acético diluído a quente.

Teste 2 - Aumento no tempo de aquecimento do Teste 1, bem como lixiviação com $\mathrm{HCl}$ diluído.

Teste 3 - Lavagem com ultrassom em ácidos acético e clorídrico diluídos. $\quad 52$

Teste 4 - Lixiviação com ácidos acético e clorídrico a frio.

Imageamento por Microscópio Eletrônico de Varredura (SEM) 53

Análises Isotópicas de Nd e Sr 53 
4.3. Resultados

Microscopia Eletrônica de Varredura (SEM)

Isótopos Radiogênicos de Nd e Sr 62

4.4. Discussões 63

4.5. Conclusões 66

$\begin{array}{ll}\text { Agradecimentos } & 67\end{array}$

$\begin{array}{ll}\text { Referências } & 67\end{array}$

5. ND AND SR ISOTOPIC SYSTEMATICS IN MINERALS FROM THE SALITRE I ALKALINE-PHOSCORITE-CARBONATITE COMPLEX, SE BRAZIL: EVIDENCE FOR OPEN-SYSTEM BEHAVIOUR DURING MAGMATIC EVOLUTION.

$\begin{array}{ll}\text { Abstract } & 70\end{array}$

5.1. Introduction 71

5.2. Geological Setting 73

Cretaceous Alkaline Magmatism $\quad 73$

Alto Paranaíba Igneous Province $\quad 74$

5.3. Salitre Complex 76

Bebedourites, Phoscorites and Carbonatites $\quad 77$

Sample Petrography $\quad 79$

5.4. Analytical Methods 83

Mineral Separates $\quad 83$

Leaching Procedures $\quad 83$

Nd Isotope Analyses $\quad 84$

Sr Isotope Analyses $\quad 85$

5.5. Results 86

Whole-rock Isotope Data 94

Mineral Isotope Data 101

$\begin{array}{lll}\text { 5.6. Discussion } & 111\end{array}$

Nd-Sr Isotope Composition of the APIP Parental Magma 112

Isotopic Constraints on the Petrogenesis of the Salitre I complex 119

Nd-Sr Isotope Decoupling and Mineral-Rock Nd Isotopic Disequilibrium: Evidence for Post-Magmatic Processes 121

Mantle Source and Geodynamic Setting 123 
5.7. Conclusions 126

$\begin{array}{ll}\text { Acknowledgements } & 127\end{array}$

References 128

6. ISOTOPIC COMPOSITION OF STRONTIUM AND NEODYMIUM IN APATITE, BARITE, PYROCHLORE, TETRAFERRIPHLOGOPITE AND CARBONATES FROM NIOBIUM-RICH ROCKS OF THE CATALÃO I CARBONATITE COMPLEX, BRAZIL.

Abstract

6.1. Introduction

6.2. The Catalão I Complex

Sample Descriptions

156

6.3. Analytical Procedures

6.4. Results

6.5. Discussion and Conclusions

Acknowledgements

References

7. CONCLUSÕES

REFERÊNCIAS BIBLIOGRÁFICAS

182

ANEXOS A:

DADOS QUÍMICOS DE SALITRE I

ANEXOS B:

PADRÕES E CALIBRAÇÕES

ANEXOS C:

CONCENTRADOS MINERAIS 



\section{INTRODUÇÃO}

A aplicação dos isótopos radiogênicos nas geociências é importante não apenas porque possibilitam a determinação da idade absoluta dos eventos geológicos, mas também porque funcionam como traçadores naturais nos processos geológicos. Isto permite aos geólogos obter informações petrogenéticas muitas vezes essenciais para o entendimento desses processos, assim como possibilita elucidar questões com respeito à evolução geoquímica do nosso planeta (Faure \& Powell, 1972; White, 2005).

Carbonatitos são rochas ígneas relativamente raras, frequentemente associadas a rochas silicáticas alcalinas. Embora ocorram em extensas províncias, são quase exclusivamente continentais, com apenas duas ocorrências conhecidas em ilhas oceânicas (i.e., Ilhas Canárias e Cabo Verde). Magmas carbonatíticos são ricos em voláteis, tem viscosidade muito baixa e elevadas concentrações de Nd e Sr. Tais características permitem rápida ascensão na crosta continental sem que haja modificações significativas em sua composição química (Bell \& Blenkinsop, 1989; Bell \& Tilton, 2002). Portanto, estudos de geoquímica isotópica em carbonatitos são de suma importância para a compreensão e evolução do manto litosférico subcontinental (SCLM em inglês) ao longo do tempo geológico, visto que, essas rochas ocorrem desde o arqueano até os dias atuais (Bell et al., 1982; Bell \& Blenkinsop, 1989; Bell, 1994; Tilton \& Bell, 2000; Bell \& Tilton, 2002; Dickin, 2005).

Diversos trabalhos com isótopos radiogênicos, principalmente $\mathrm{Nd}$ e $\mathrm{Sr}$, vêm sendo realizados em inúmeros complexos alcalino-carbonatíticos ao redor do mundo desde os estudos pioneiros de Powell et al. (1962), Hamilton \& Deans (1963) e Powell et al. (1966). O alvo principal desses trabalhos tem sido esclarecer a origem, bem como os processos atuantes na gênese e diferenciação de magmas tão distintos. Entretanto, após meio século de progresso no conhecimento de carbonatitos, ainda existe muito debate acerca da fonte mantélica e, sobretudo a respeito da relação entre carbonatitos e rochas silicáticas alcalinas (Bell, 1998; Bell et al., 1998; Gittins \& Harmer, 2003; Mitchell, 2005; Woolley \& Kjarsgaard, 2008).

Neste contexto, o presente estudo propõe contribuir com as discussões a respeito da gênese dos carbonatitos e rochas silicáticas alcalinas associadas, bem como elucidar algumas questões abrangendo a temática dos isótopos radiogênicos. Para tal propósito, esta dissertação irá abranger as rochas ígneas dos complexos alcalino-carbonatíticos de Salitre e Catalão I, pertencentes à Província Ígnea do Alto Paranaíba (APIP em inglês). 


\subsection{JUSTIFICATIVA}

A APIP é uma das mais importantes províncias alcalinas máficas ultrapotássicas do mundo (Gibson et al., 1995b). Destaca-se dentre as diversas províncias alcalinas e carbonatíticas brasileiras devido à incomum associação entre magmas kamafugíticos e carbonatíticos (Brod et al., 2000), e pela ocorrência de depósitos minerais de classe mundial, principalmente de fosfato e nióbio.

Ao longo dos últimos anos, diversos estudos petrogenéticos com ênfase na descrição petrográfica, geoquímica de rocha total, química mineral e isótopos estáveis têm sido realizados nos complexos alcalino-carbonatíticos da APIP (Brod, 1999; Barbosa, 2009; Cordeiro, 2009; Grasso, 2010; Cordeiro et al., 2010, 2011b; Gomide, 2011; Barbosa et al., 2012a; Brod et al., 2012; Gomide et al., 2013). Em conjunto, um número apreciável de dados isotópicos de $\mathrm{Nd}$ e $\mathrm{Sr}$, em rocha total, têm sido gerados.

Recentemente, Barbosa (2009) e Cordeiro et al. (2010, 2011b) notaram diferenças substanciais na composição isotópica de $\mathrm{Nd}$ e $\mathrm{Sr}$ entre as distintas séries petrogenéticas que compõem os complexos alcalino-carbonatíticos da APIP (Figura 1.1), o que a priori indicaria a derivação dos magmas a partir de áreas-fonte distintas no manto. Entretanto, a constante relação espacial e temporal, e as evidências geoquímicas ressaltadas nos demais estudos (e.g., Brod, 1999; Barbosa, 2009; Grasso, 2010; Brod et al., 2012), sugerem que essas rochas provêm de um único magma parental por uma intrincada combinação de cristalização fracionada, imiscibilidade de líquidos e desgaseificação.

É amplamente difundida na literatura especializada a ocorrência de uma variação sistemática entre as razões isotópicas iniciais de $\mathrm{Nd}$ e $\mathrm{Sr}$ em carbonatitos e rochas silicáticas alcalinas associadas (Bell \& Blenkinsop, 1989; Bell, 1998; Harmer \& Gittins, 1998; Ray, 2009). Em geral, as rochas silicáticas têm razões isotópicas mais variáveis e com assinatura mais enriquecida (i.e., ${ }^{87} \mathrm{Sr} /{ }^{86} \mathrm{Sr}$ maior; ${ }^{143} \mathrm{Nd} /{ }^{144} \mathrm{Nd}$ menor) do que os carbonatitos associados (Bell \& Blenkinsop, 1989; Harmer \& Gittins, 1998; Ray, 2009). Tal correlação sistemática leva a interpretação de que a geração de carbonatitos e rochas silicáticas alcalinas associadas não pode ser atribuída a simples diferenciação de um mesmo magma parental num sistema fechado (Bell \& Blenkinsop, 1989; Bell, 1998; Bell \& Rukhlov, 2004).

A maioria dos autores interpreta tal variação isotópica sistemática como o resultado de discretos volumes de magma derivados de fontes mantélicas heterogêneas e/ou misturas de 
múltiplos componentes (Eriksson, 1989; Mitchell et al., 1994; Huang et al., 1995; Zaitsev \& Bell, 1995; Harmer \& Gittins 1998; Morikiyo et al., 2000; Verhulst et al., 2000; Dunworth \& Bell, 2001; Bühn \& Trumbull, 2003; Yuhara et al., 2005; Lee et al., 2006; Wu et al., 2011). Outros autores, todavia, propõem processos de contaminação com a crosta continental como os responsáveis por essa variação isotópica (Mitchell \& Crocket, 1972; Roden et al., 1985; Ardersen, 1987; Tilton et al., 1987; Dunworth \& Bell, 2001; Ray, 2009; Wu et al., 2012).

Em alguns complexos alcalino-carbonatíticos com foscoritos também há discrepâncias isotópicas consideráveis entre os últimos e as demais rochas. Contudo, não há uma discussão aprofundada a respeito, provavelmente devido à raridade dos foscoritos e à quantidade reduzida de dados isotópicos. De fato, os dados disponíveis estão restritos a alguns complexos da Província de Kola, na Rússia (e.g., Kovdor - Zaitsev \& Bell, 1995; Lee et al., 2006; Seblyavr - Balaganskaya et al., 2007; Turiy - Dunworth \& Bell, 2001), ao Complexo de Phalaborwa, na África do Sul (e.g., Yuhara, et al., 2005; Wu et al., 2011) e aos complexos da APIP.

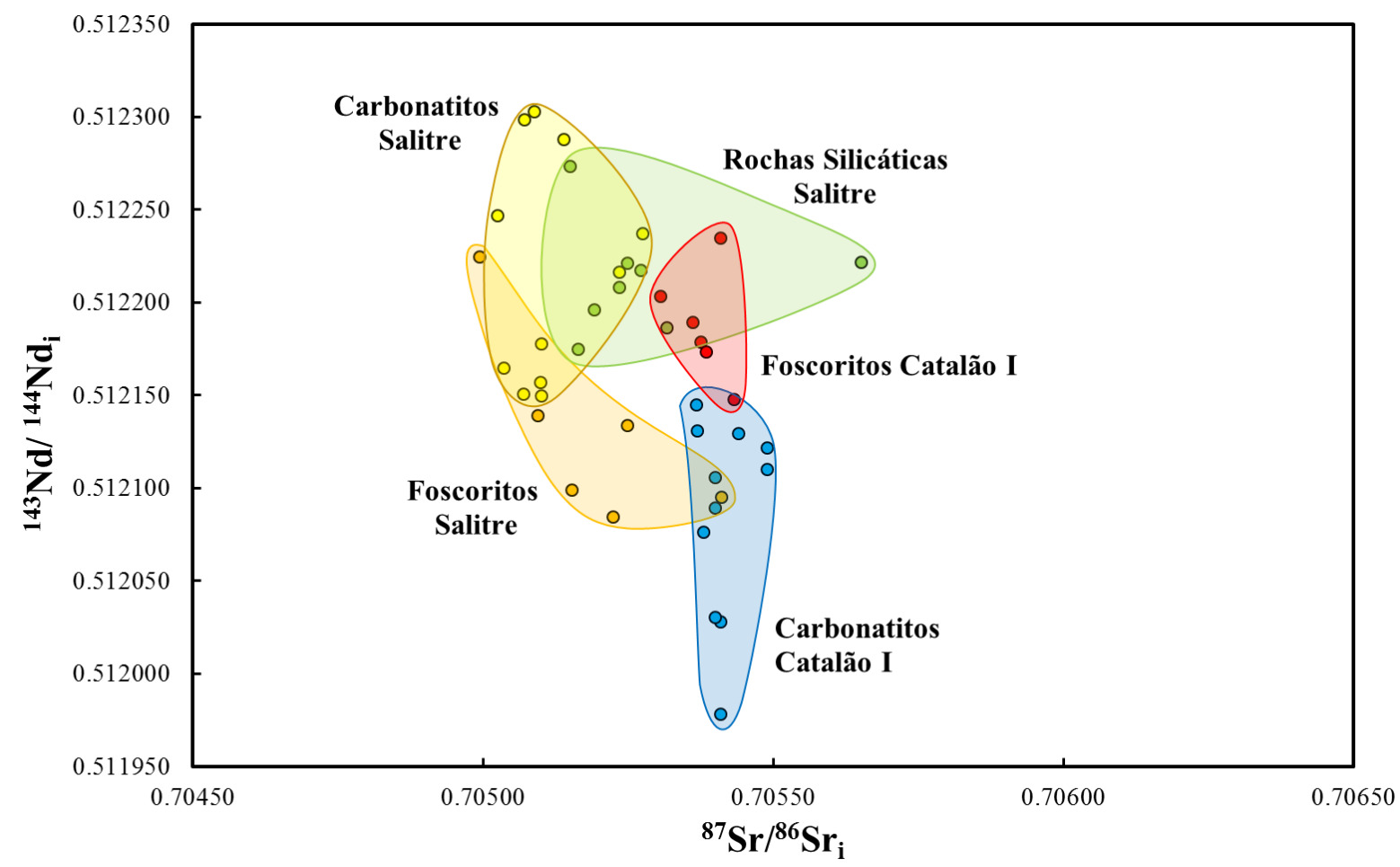

Figura 1.1. Variação entre as razões isotópicas iniciais ${ }^{143} \mathrm{Nd} /{ }^{144} \mathrm{Nd} \mathrm{e}{ }^{87} \mathrm{Sr} /{ }^{86} \mathrm{Sr}$ das séries petrogenéticas que compõem os complexos alcalino-carbonatíticos de Salitre e Catalão I, APIP. Dados de Salitre: Barbosa et al. (2012a) e Barbosa (2009), dados não publicados. Dados de Catalão I retirados de Cordeiro et al. (2010, 2011b). Também estão plotados resultados de rocha total do presente trabalho, para ambos complexos. Todos os dados foram recalculados para a idade $T=85 \mathrm{Ma}$ e constantes de decaimento radioativo $\lambda^{87} \mathrm{Rb}$ $\lambda^{147} \mathrm{Sm}$ igual a $1.393 \times 10^{-11} \mathrm{yr}^{-1}$ e $6.54 \times 10^{-12} \mathrm{yr}^{-1}$, respectivamente. 
$\mathrm{Na}$ APIP, Cordeiro et al. (2010, 2011b) sugerem processos magmáticos e/ou metassomáticos tardios para justificar variações na composição isotópica do complexo alcalino-carbonatítico de Catalão I. Contudo, tanto aqueles autores como Barbosa (2009) ressaltam que o entendimento aprofundado dessa variação isotópica nas diferentes séries petrogenéticas dos complexos carbonatíticos da APIP ainda requer estudos detalhados e sistemáticos com isótopos radiogênicos.

Portanto, a caracterização da composição isotópica detalhada de $\mathrm{Nd}$ e $\mathrm{Sr}$ em fases minerais é crucial para detectar possíveis desequilíbrios isotópicos. Além disso, também permite avaliar quais processos podem ser os responsáveis pela variação nos dados de rocha total das distintas séries petrogenéticas que compõem os complexos da APIP.

\section{2.ОBJETIVOS}

O propósito do presente estudo é investigar o comportamento dos isótopos radiogênicos nos complexos alcalino-carbonatíticos da APIP a partir da determinação da composição isotópica de $\mathrm{Nd}$ e $\mathrm{Sr}$ em fases minerais individuais. Os objetivos específicos são:

a) caracterizar as variações isotópicas entre os diferentes minerais que compõem as rochas das séries bebedourítica, foscorítica e carbonatítica;

b) investigar a presença ou não de desequilíbrio isotópico entre minerais de uma mesma rocha;

c) investigar a presença ou não de desequilíbrio isotópico em rochas de uma mesma série e de um mesmo complexo;

d) comparar os dados obtidos em uma mesma série petrogenética para os diferentes complexos da província.

O presente trabalho representa o primeiro estudo sistemático de geoquímica de isótopos radiogênicos $(\mathrm{Nd}$ e $\mathrm{Sr}$ ) em minerais individuais nos complexos carbonatíticos da $A P I P$, e possibilitará uma definição mais clara sobre os processos petrogenéticos que determinaram a composição isotópica da rocha total e das fases minerais constituintes.

Por fim, esta dissertação busca promover um avanço no entendimento e nas discussões com respeito à gênese e origem dos carbonatitos e rochas alcalinas associadas, por meio de comparação dos resultados isotópicos obtidos com os dados da literatura especializada. 


\subsection{ESTRUTURA DA DiSSERTAÇÃo}

A presente dissertação de mestrado está organizada em sete capítulos. Este primeiro capítulo contempla tópicos introdutórios e uma revisão acerca dos complexos alcalinocarbonatíticos e suas principais séries petrogenéticas.

O capítulo 2 aborda uma revisão completa a respeito dos sistemas isotópicos $\mathrm{Rb}-\mathrm{Sr}$ e Sm-Nd, envolvendo conceitos teóricos de química, geocronologia e geoquímica isotópica. No final do capítulo aborda-se a sistemática de isótopos radiogênicos em carbonatitos, com ênfase na origem mantélica destas rochas.

O capítulo 3 descreve em detalhe os materias e os métodos utilizados, enquanto o capítulo 4 apresenta, no formato de artigo científico, resultados acerca do método de lixiviação desenvolvido no decorrer deste estudo.

Os resultados isotópicos de Nd e Sr também são apresentados no formato de artigos científicos nos capítulos 5 (Complexo de Salitre I) e 6 (Complexo de Catalão I). O capítulo 7 sumariza as principais conclusões obtidas neste estudo.

\subsection{Complexos Alcalino-Carbonatíticos}

Carbonatitos são volumetricamente insignificantes na crosta, porém com uma grande importância petrológica e econômica. Das 527 ocorrências de carbonatitos reportadas por Woolley \& Kjarsgaard (2008), 76\% estão associadas a rochas silicáticas em complexos plutônicos ou vulcânicos. Embora essas rochas sejam predominantemente de afinidade nefelinítica (nefelinitos; ijolitos; fonolitos), uma ampla variedade de rochas silicáticas alcalinas, incluindo rochas ultramáficas, pode estar espacialmente associada a carbonatitos (Bell \& Blenkinsop, 1989; Bell et al., 1998; Mitchell, 2005; Woolley \& Kjarsgaard, 2008).

A relação genética entre carbonatitos e rochas silicáticas tem sido frequentemente proposta na literatura, porém uma gênese simples é improvável visto a diversidade de rochas encontradas nesses complexos (Bell, 1998; Bell et al., 1998). Por outro lado, alguns autores contestam essa relação genética, propondo que a associação entre carbonatitos e rochas silicáticas é, em geral, meramente espacial, dada por magmas mantélicos distintos que ascenderam à superfície através do mesmo sistema de condutos (Gittins \& Harmer, 2003). 
A gênese dos complexos alcalino-carbonatíticos pode envolver múltiplos estágios intrusivos e abranger vários processos de diferenciação magmática tais como cristalização fracionada, imiscibilidade de líquidos e desgaseificação. Na maioria das vezes há pelo menos duas séries petrogenéticas distintas envolvidas (i.e., carbonatítica e silicática). Em casos mais raros, porém de especial interesse petrológico e econômico, uma terceira série petrogenética está presente representada por foscoritos e rochas associadas (Wall \& Zaitsev, 2004).

\subsection{SÉries Petrogenéticas}

Os complexos alcalino-carbonatíticos da APIP são caracteristicamente compostos pelas três séries petrogenéticas: bebedourítica (silicática), foscorítica e carbonatítica (Brod et $a l ., 2004)$, as quais serão abordadas em maior detalhe.

\section{Série Silicática}

As rochas silicáticas de complexos carbonatíticos são alcalinas, geralmente insaturadas em sílica e podem representar produtos de cristalização integral ou, mais frequentemente, cumulados de diferenciação de um magma parental silicático carbonatado. Devido à grande diversidade de rochas silicáticas encontradas em complexos alcalino-carbonatíticos, várias séries magmáticas podem ser distinguidas a partir dessa associação (Mitchell, 2005; Woolley \& Kjarsgaard, 2008). De maneira simplificada, essas séries petrogenéticas podem ser separadas de acordo com a afinidade geoquímica do magma parental, sódica ou potássica.

As séries silicáticas mais comuns (nefelinítica, ijolítica, fonolítica) são derivadas de magmas parentais nefeliníticos (sódicos). Rochas portadoras de melilita também são comuns e podem derivar tanto de magmas sódicos quanto potássicos. Uma associação menos comum é a de carbonatitos com magmas potássicos (kamafugitos, kimberlitos, lamproítos). No caso dos complexos alcalino-carbonatíticos da APIP o magma parental é kamafugítico (Brod et al., 2000), e as rochas plutônicas silicáticas pertencem à série bebedourítica, discutida em detalhe a seguir.

A série bebedourítica compreende rochas ultramáficas cumuláticas derivadas de um magma parental silicático ultrapotássico (Brod et al., 2004). São caracterizadas por grandes variações modais de olivina, clinopiroxênio, flogopita, apatita, magnetita e fases de Ca-Ti (i.e., perovskita, titanita e/ou granada). Cromita e feldspato potássico podem ser importantes nos membros menos e mais evoluidos, respectivamente (Barbosa et al., 2012a). 
Embora sejam relativamente comuns em complexos alcalino-carbonatíticos de afiliação potássica, bebedouritos não tem um sistema formal de classificação, sendo muitas vezes denominados de clinopiroxenitos ou alcali-piroxenitos. Barbosa et al. (2012a) fazem uma abordagem detalhada a cerca da nomenclatura dessas rochas, e propõem a adição de prefixos minerais ao termo bebedourito (e.g., perovskita bebedourito) para a classificação das rochas que compõem a série bebedourítica.

\section{Série Foscorítica}

A série foscorítica é constituída por rochas ígneas raras, compostas essencialmente, por apatita, magnetita e olivina, cristalizadas a partir de magmas ricos em fosfato e óxidos, e são associadas a complexos alcalino-carbonatíticos em algumas poucas províncias mundiais. Krasnova et al. (2004) propõem de maneira mais ampla que os foscoritos são rochas ultramáficas plutônicas, compostas por apatita, magnetita e ao menos um dos seguintes silicatos magnesianos: forsterita, diopsídio ou flogopita. Outros constituintes que podem ter proporções modais importantes são: calcita, dolomita, tetraferriflogopita e richterita. Os minerais acessórios mais comuns são badeleíta, pirocloro, silicatos de $\mathrm{Ca}$, Ti e Zr, e sulfetos.

Alguns autores, como Yegorov (1993), interpretam a presença de carbonatos nas rochas foscoríticas mais tardias como sendo de origem secundária, devido à associação destas com os magmas carbonatíticos. Contudo, evidências texturais, petrográficas e composicionais apontam para uma fonte magmática de tais carbonatos, hipótese mais aceita atualmente (Zaitsev \& Bell, 1995; Krasnova et al., 2004).

Foscoritos normalmente formam stocks, stockworks, diques anelares, lentes e diques retilíneos de espessura variada, bem como, veios e xenólitos em meio aos carbonatitos. Têm texturas bastante heterogêneas, podendo ser de granulação fina a grossa, bandados, e ter feições de deformação plástica, assim como contatos abruptos ou gradacionais com as rochas encaixantes. De modo similar aos carbonatitos, a intrusão de magma foscorítico também provoca intenso metassomatismo nas rochas encaixantes (Yegorov, 1993; Zaitsev \& Bell, 1995; Krasnova et al., 2004).

Conforme discutido por Krasnova et al. (2004), a classificação e nomenclatura das rochas que compõem a serie foscorítica pode ser realizada pela adição de prefixos minerais ao termo foscorito (e.g., apatita-forsterita foscorito) de acordo com a recomendação da IUGS (International Union of Geological Sciences), ou pela utilização do diagrama de classificação 
proposto por Yegorov (1993), segundo a Figura 1.2. Cordeiro et al. (2010) argumentam que o uso de prefixos minerais pode não ser suficientemente claro em rochas que não são foscoritos sensu stricto (e.g., nelsonitos). Além disso, embora sejam necessárias variações do diagrama de Yegorov (1993) para classificar os foscoritos ricos em diopsídio ou flogopita conforme abordado por Krasnova et al. (2004), Cordeiro et al. (2010) sustentam que a fase silicática principal é de extrema importância para a determinação do estágio evolutivo das rochas da série foscorítica. Tendo em vista estes argumentos, o método preferido neste trabalho é a classificação simplificada de Yegorov (1993).

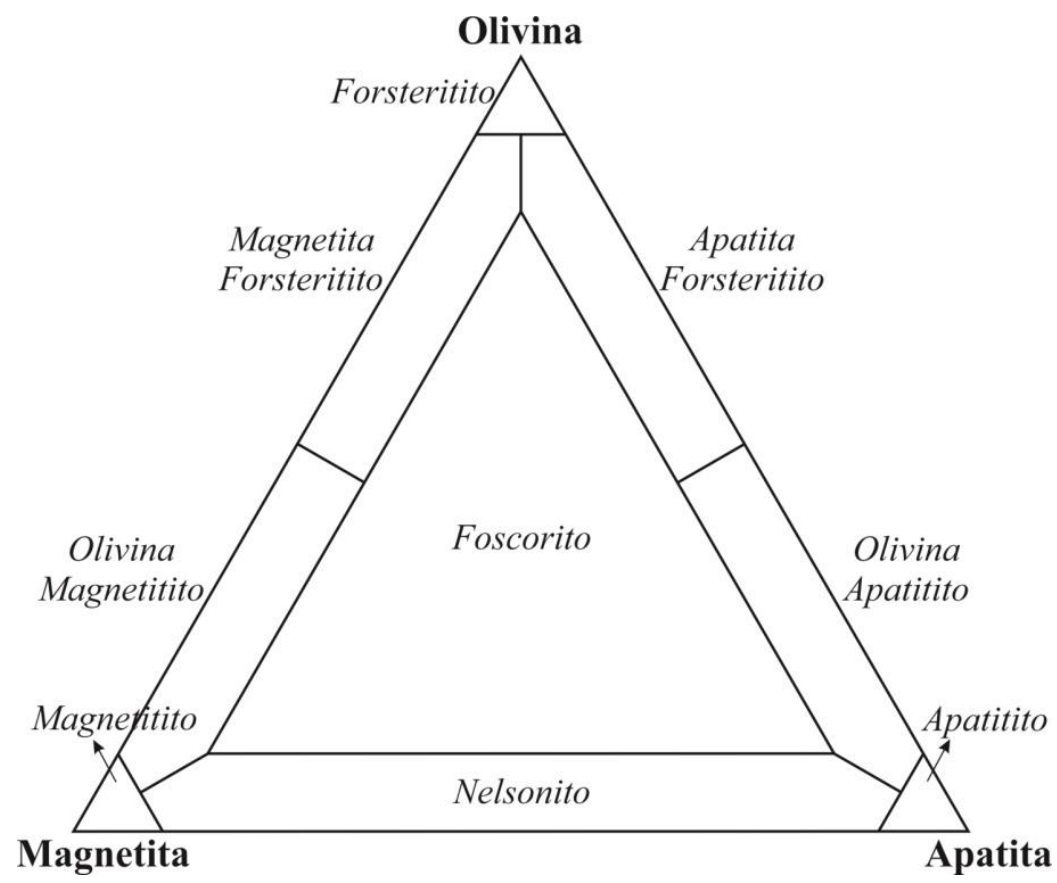

Figura 1.2. Diagrama de classificação da série foscorítica (Yegorov, 1993).

A presença de múltiplas fases intrusivas de foscoritos e carbonatitos, bem como a íntima relação espacial e temporal entre eles sugerem que ambos se desenvolvem por processos petrogenéticos semelhantes em complexos alcalino-carbonatíticos (Krasnova et al., 2004). Foscoritos são formados a partir de magmas mantélicos, de acordo com evidências isotópicas (Zaitsev \& Bell, 1995), e as principais discussões relacionadas à sua gênese são a fonte dos magmas no manto e o papel da cristalização fracionada e/ou imiscibilidade de líquidos na diferenciação e separação destes magmas fosfáticos a partir de magmas carbonatíticos (Yegorov, 1993; Zaitsev \& Bell, 1995; Krasnova et al., 2004). 


\section{Série Carbonatítica}

Carbonatitos, por definição, contêm mais de $50 \%$ em volume de carbonatos (Le Maitre, 2002). Embora predominem carbonatos, mais de 280 minerais são conhecidos nessas rochas, refletindo sua composição química incomum (Winter, 2001). Carbonatitos são classificados de acordo com a fase mineral dominante (e.g., calcita-carbonatito). Caso os carbonatos sejam de granulação muito fina ou formem soluções-sólidas complexas, deve-se utilizar o diagrama de classificação química proposto por Woolley \& Kempe (1989), conforme a Figura 1.3. Rochas com $\mathrm{SiO}_{2}>20 \%$ não podem ser classificadas segundo esse diagrama, e são denominadas de silicocarbonatitos (Le Maitre, 2002). O termo natrocarbonatito deve ser utilizado especificamente para os carbonatitos ricos em carbonatos de Na, K e Ca (Woolley \& Kempe, 1989).

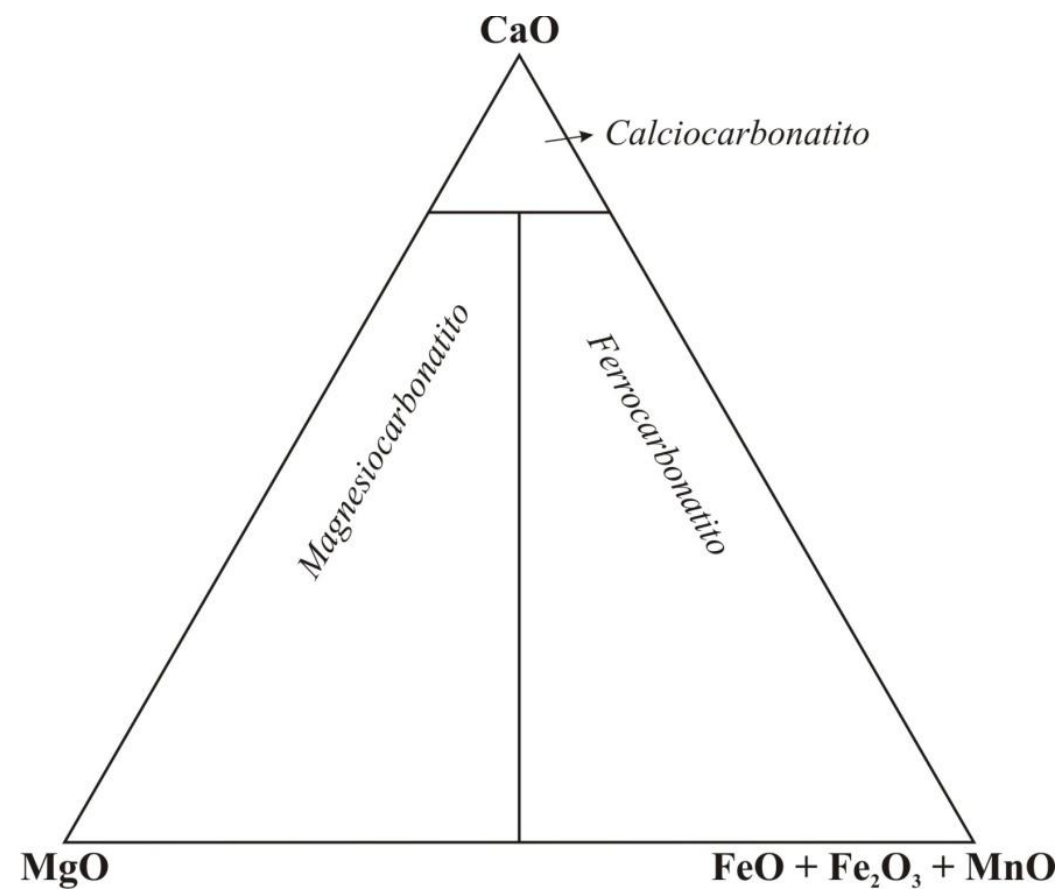

Figura 1.3. Classificação química dos carbonatitos para rochas com $\mathrm{SiO}_{2}<20 \%$ (Woolley \& Kempe 1989).

Magmas carbonatíticos representam líquidos iônicos constituídos por triângulos de $\mathrm{CO}_{3}{ }^{-2}$ e cátions metálicos dissolvidos. Portanto, são magmas de viscosidade extremamente baixa, uma vez que não tem a habilidade de se polimerizar (Jones et al., 2013). Adicionalmente, magmas carbonatíticos são caracterizados pelas elevadas concentrações de elementos incompatíveis (e.g., $\mathrm{Ba}$; $\mathrm{Sr} ; \mathrm{P}, \mathrm{Nb}, \mathrm{LREE}$ ) e voláteis (e.g., $\mathrm{CO}_{2} ; \mathrm{F} ; \mathrm{Cl} ; \mathrm{S}$ ), tornandoos importantes agentes metassomáticos (O’Reilly \& Griffin, 2000; Bell \& Simonetti, 2010; Jones et al., 2013). 
Carbonatitos podem ocorrer como lava, tefra, diques retilíneos, diques anelares, plugs, cone sheets e raros sills (Barker, 1989). O modo de ocorrência mais comum é em complexos intrusivos associados a rochas silicáticas alcalinas. Nestes, os carbonatitos são quase sempre as fases mais tardias (Barker, 1989). Carbonatitos plutônicos, em geral, são marcados por texturas de fluxo, reequilíbrio sub-solidus e extensa perda de voláteis (e álcalis) para as encaixantes (Bailey, 1993). A instalação do magma carbonatítico nos complexos alcalinos deve ocorrer em temperaturas mais baixas do que a dos carbonatitos extrusivos, provavelmente, na forma de crystal mush (Bailey, 1993).

Diversos estudos experimentais envolvendo equilíbrio de fases, bem como dados de gases nobres, isótopos radiogênicos e isótopos estáveis demonstram que a fonte primária dos magmas carbonatíticos é o manto (Bell, 1998; Bell et al., 1998; Bell \& Tilton, 2002). Entretanto, a gênese desses magmas, principalmente no que diz respeito à possível relação genética entre carbonatitos e rochas silicáticas alcalinas, permanece sendo uma questão fundamental a ser resolvida (Bell et al., 1998, Chen et al., 2013).

Três modelos principais são propostos para a origem dos magmas carbonatíticos:

a) Magmas primários que ascendem diretamente do manto, formados por fusão parcial de um peridotito rico em $\mathrm{CO}_{2}$.

b) Resíduo da diferenciação por cristalização fracionada de um magma parental silicático alcalino e carbonatado, gerado no manto.

c) Produto de imiscibilidade de líquidos a partir de um magma parental silicático alcalino saturado em $\mathrm{CO}_{2}$.

Todos estes processos são capazes de gerar magmas ricos em carbonato, não são excludentes entre si, e há evidências experimentais que suportam as três possibilidades (Bell et al., 1998; Winter, 2001; Ray, 2009). Por isso, combinações desses modelos são comuns na literatura (Jones et al., 2013). Deste modo, fica claro que há múltiplas origens para os carbonatitos e que cada ocorrência deve ser tratada individualmente, dentro do seu próprio contexto petrogenético (Bailey, 1993; Woolley \& Kjarsgaard, 2008). Discussões detalhadas a cerca destes modelos são encontradas nos trabalhos de Gittins (1989), Bailey (1993), Bell et al. (1998), Winter (2001), Gittins \& Harmer (2003), Mitchell (2005) e Woolley \& Kjarsgaard (2008). 


\section{GEOQUÍMICA ISOTÓPICA}

\subsection{O SISTEMA RB-SR}

O sistema $\mathrm{Rb}-\mathrm{Sr}$ é baseado no fato de que um dos isótopos estáveis de estrôncio $\left({ }^{87} \mathrm{Sr}\right)$ é produto do decaimento radioativo natural de um dos isótopos naturais de rubídio $\left({ }^{87} \mathrm{Rb}\right)$. Portanto, a quantidade de ${ }^{87} \mathrm{Sr}$ em rochas e minerais aumenta continuamente com o tempo e, assim, possibilita a determinação da idades destes. Adicionalmente, o ${ }^{87} \mathrm{Sr}$ radiogênico (produto do decaimento radioativo) pode ser utilizado como traçador no estudo dos processos petrogenéticos (Faure \& Powell, 1972).

\section{Propriedades Geoquímicas do Rb e Sr}

Rubídio (Rb), cujo número atômico é 37, é um metal alcalino pertencente ao Grupo 1 da tabela periódica (Figura 2.1), assim como lítio (Li), sódio $(\mathrm{Na})$, potássio $(\mathrm{K})$, césio $(\mathrm{Cs})$ e frâncio (Fr). Todos os metais alcalinos se caracterizam por formarem cátions com valência +1 e serem extremamente móveis (Faure \& Powell, 1972; Faure, 1986; 2001; White, 2005).

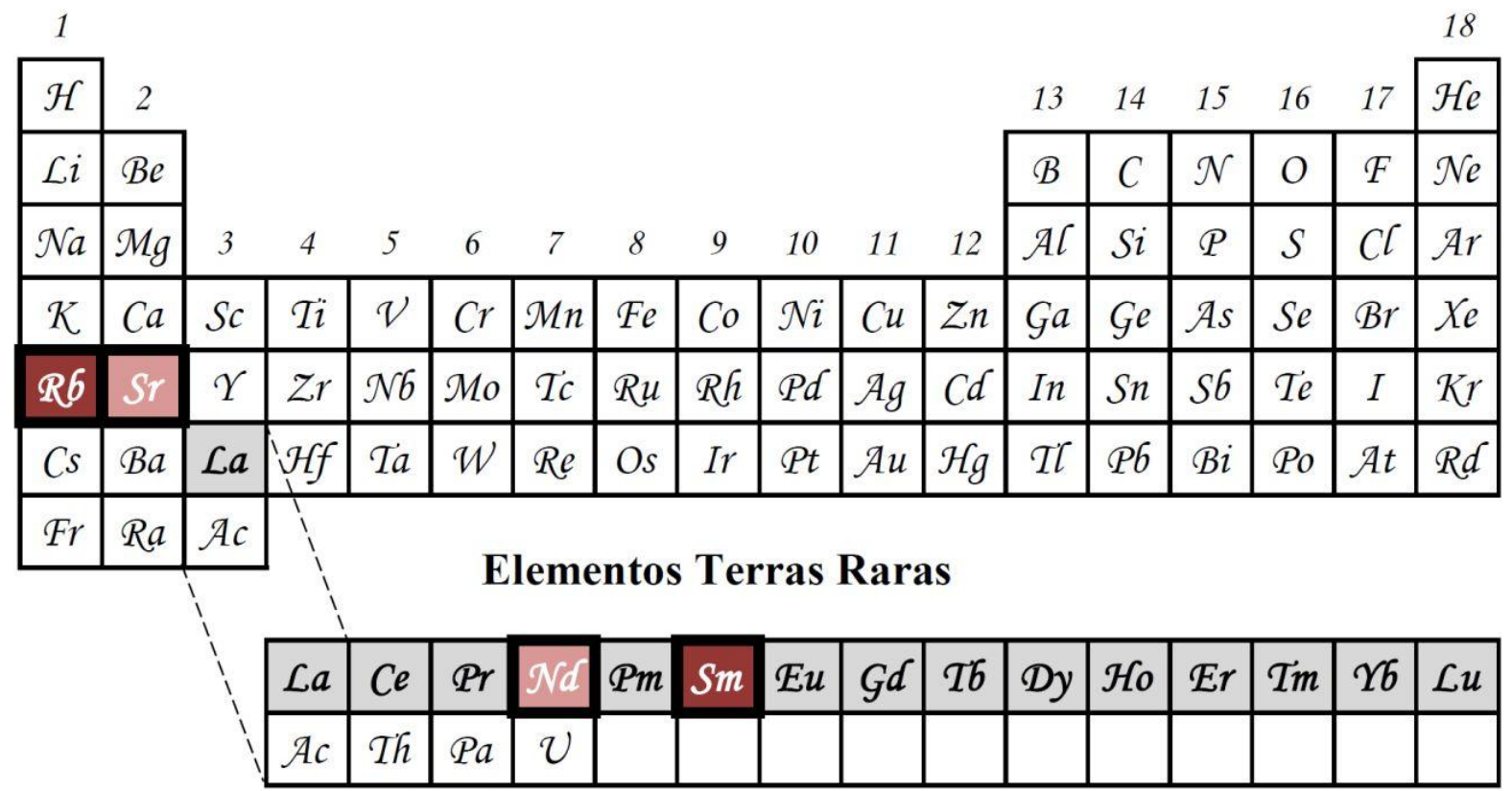

Figura 2.1. Tabela periódica com destaque para os elementos Terras Raras (cinza), os elementos radioativos (vermelho escuro) e radiogênicos (vermelho claro) dos sistemas isotópicos $\mathrm{Rb}-\mathrm{Sr}$ e $\mathrm{Sm}-\mathrm{Nd}$.

A distribuição do $\mathrm{Rb}^{+}$na natureza é controlada por seu raio iônico (1.48 $\AA$ ), similar ao do $\mathrm{K}^{+}(1.33 \AA$ A), permitindo ao rubídio substituir o potássio em minerais como micas e feldspatos potássicos. Por outro lado, o íon $\mathrm{Rb}^{+}$é muito grande para substituir o $\mathrm{Na}^{+}$. O rubídio é um elemento muito incompatível e não se concentra o suficiente para formar seus 
próprios minerais, embora seja, comumente, um elemento traço importante em minerais de potássio (Faure \& Powell, 1972; Faure, 1986; 2001; White, 2005).

O Rb tem dois isótopos naturais, ${ }^{85} \mathrm{Rb}$ (estável) $\mathrm{e}^{87} \mathrm{Rb}$ (radioativo), cujas abundâncias isotópicas são $72.17 \%$ e $27.83 \%$, respectivamente (Berglund \& Wieser, 2011). A composição isotópica do $\mathrm{Rb}$ em rochas e minerais é uniforme por todo o Sistema Solar (Faure \& Powell, 1972; Faure 2001).

Estrôncio (Sr), cujo número atômico é 38, é um metal alcalino terroso pertencente ao Grupo 2 da tabela periódica (Figura 2.1), assim como berílio (Be), magnésio $(\mathrm{Mg})$, cálcio $(\mathrm{Ca})$, bário $(\mathrm{Ba})$ e rádio $(\mathrm{Ra})$. Todos os metais alcalinos terrosos formam cátions com valência +2 e são menos móveis do que os metais alcalinos (Faure \& Powell, 1972; Faure, 1986; 2001; White, 2005).

A extensão com a qual acontece a substituição do $\mathrm{Ca}$ por $\mathrm{Sr}$ é o que governa a ocorrência deste último na natureza. $\mathrm{O} \mathrm{Sr}^{+2}$ tem raio iônico de $1.13 \AA$, ligeiramente maior do que o do $\mathrm{Ca}^{+2}(0.99 \AA)$ e, portanto pode substituí-lo em diversos minerais como: apatita, calcita, clinopiroxênio, plagioclásio e titanita. Entretanto, esta substituição é restrita uma vez que o $\mathrm{Sr}^{+2}$ prefere os sítios cristalográficos de coordenação 8 , enquanto que o $\mathrm{Ca}^{+2}$ pode estar tanto em sítios de coordenação 6 quanto 8. Por essa razão, a quantidade de $\mathrm{Sr}$ no clinopiroxênio é em geral menor do que na apatita ou no plagioclásio, por exemplo. Adicionalmente, $\mathrm{o} \mathrm{Sr}^{+2}$ pode ser capturado pela estrutura dos feldspatos potássicos no lugar do $\mathrm{K}^{+}$, devido à razão carga/raio, ou também, pode formar seus próprios minerais, sendo os mais comuns celestita $\left(\mathrm{SrSO}_{4}\right)$ e estroncianita $\left(\mathrm{SrCO}_{3}\right)$ (Faure \& Powell, 1972; Faure, 1986).

O Sr tem quatro isótopos naturais, ${ }^{84} \mathrm{Sr},{ }^{86} \mathrm{Sr},{ }^{87} \mathrm{Sr}$ e ${ }^{88} \mathrm{Sr}$, todos estáveis. Contudo, a composição isotópica do $\mathrm{Sr}$ é bastante variável e dependente da razão $\mathrm{Rb} / \mathrm{Sr}$, visto que o ${ }^{87} \mathrm{Sr}$ é produzido a partir do decaimento radioativo do ${ }^{87} \mathrm{Rb}$. Os valores das razões e abundâncias isotópicas aproximadas do Sr estão na Tabela 2.1 (Faure \& Powell, 1972; Faure, 1986; 2001).

Tabela 2.1. Abundância isotópica aproximada de estrôncio (Sr).

\begin{tabular}{cccc}
\hline Isótopo de Sr & Abundância* (\%) & Razão Isotópica & Valor \\
\hline${ }^{84} \mathrm{Sr}$ & 0.56 & ${ }^{84} \mathrm{Sr} /{ }^{86} \mathrm{Sr}$ & 0.0568 \\
${ }^{86} \mathrm{Sr}$ & 9.86 & ${ }^{86} \mathrm{Sr} /{ }^{88} \mathrm{Sr}$ & 0.1194 \\
${ }^{87} \mathrm{Sr}$ & 7.00 & ${ }^{87} \mathrm{Sr} /{ }^{86} \mathrm{Sr}$ & 0.7099 \\
${ }^{88} \mathrm{Sr}$ & 82.58 & ${ }^{88} \mathrm{Sr} /{ }^{86} \mathrm{Sr}$ & 8.3753 \\
\hline
\end{tabular}

*Valores segundo Berglund \& Wieser (2011). 
Tendo em vista que o $\mathrm{Rb}$ é um elemento incompatível ele é progressivamente enriquecido no líquido durante a cristalização fracionada, enquanto que o $\mathrm{Sr}$ é compatível em fases cálcicas e, portanto, removido do líquido com a cristalização destas. Consequentemente, a razão $\mathrm{Rb} / \mathrm{Sr}$ tende a aumentar com o grau da diferenciação, nos sistemas magmáticos mais comuns. Adicionalmente, os distintos coeficientes de partição desses elementos também são relevantes durante a fusão parcial, onde o $\mathrm{Rb}$ tende a se enriquecer no magma em relação ao Sr. Isto resulta em uma razão $\mathrm{Rb} / \mathrm{Sr}$ maior no líquido gerado do que no sólido residual. As variações na razão $\mathrm{Rb} / \mathrm{Sr}$ têm importantes implicações na datação dos eventos geológicos, assim como nos estudos petrogenéticos (Faure \& Powell, 1972; Faure, 1986; 2001).

\section{A Constante de Decaimento do ${ }^{87} \mathrm{Rb}$}

$\mathrm{O}^{87} \mathrm{Rb}$ decai para ${ }^{87} \mathrm{Sr}$ por meio de emissão de partículas beta, como descrito abaixo:

$$
{ }_{37}^{87} R b \rightarrow{ }_{38}^{87} \mathrm{Sr}+\beta^{-}+v+Q
$$

Onde $\beta$ - é a partícula beta com carga $-1 ; v$ é o anti-neutrino e $Q$ é a energia de decaimento. O baixo valor de $Q(0.275 \mathrm{MeV})$ emitido durante este processo tem dificultado a determinação acurada da constante de decaimento $\left(\lambda_{\mathrm{Rb}}\right)$ ou tempo de meia-vida $\left(\mathrm{T}_{1 / 2}\right)$ do ${ }^{87} \mathrm{Rb}$. Consequentemente, as diversas tentativas iniciais de medição da taxa de decaimento produziram significativas incertezas sobre o valor de $\lambda_{\mathrm{Rb}}$ (Faure \& Powell, 1972; Faure, 1986; Begemann et al., 2001; Dickin, 2005).

Steiger \& Jäger (1977) recomendaram, com ressalvas em relação às incertezas, o uso do valor $1.42 \pm 0.01 \times 10^{-11} \mathrm{yr}^{-1}$ para $\lambda_{\mathrm{Rb}}\left(\mathrm{T}_{1 / 2}=48.8 \mathrm{Byr}\right)$. Desde então, tal valor tem sido o mais comumente adotado nas publicações internacionais (Dickin, 2005). Contudo, Begemann et al. (2001) fazem extensa critica acerca da validade das constantes utilizadas atualmente nos estudos envolvendo isótopos radiogênicos. Concluem, por exemplo, que o valor de $\lambda_{\mathrm{Rb}}$ recomendado em 1977 por Steiger \& Jäger pode estar até 2\% impreciso. Adicionalmente, Begemann et al. (2001) propõem a redeterminação, com maior exatidão, da constante de decaimento do $\mathrm{Rb}$.

Recentemente, Nebel et al. (2011) e Rotenberg et al. (2012) publicaram novos dados de $\lambda_{\mathrm{Rb}}$, com as melhores precisões já alcançadas. Nebel et al. (2011) obtiveram o valor de $\lambda_{\mathrm{Rb}}$ igual a $1.393 \pm 0.004 \times 10^{-11} \mathrm{yr}^{-1}\left(\mathrm{~T}_{1 / 2}=49.76 \mathrm{Byr}\right)$ por meio de comparação com idades U-Pb. Já Rotenberg et al. (2012) determinaram o valor de $1.397 \pm 0.002 \times 10^{-11} \mathrm{yr}^{-1}\left(\mathrm{~T}_{1 / 2}=49.62 \mathrm{Byr}\right)$ 
para $\lambda_{\mathrm{Rb}}$, por meio do método de acumulação de ${ }^{87} \mathrm{Sr}$. Em ambos os trabalhos, os autores discutem os dados de $\lambda_{\mathrm{Rb}}$ obtidos na última década, e sugerem o abandono do valor recomendado por Steiger \& Jäger (1977), visto que os dados recentes apontam para uma constante de decaimento $2 \%$ menor.

Embora ainda não tenha sido definida por uma comissão da IUGS (International Union of Geological Sciences) a mudança da constante de decaimento do Rb, neste trabalho optou-se por utilizar o valor determinado por Nebel et al. (2011). Tal valor tem maior confiabilidade do que aquele obtido por Rotenberg et al. (2012) visto que, mesmo após discutirem as possíveis fontes de incerteza dos dados, esses autores não identificaram a razão para a distribuição assimétrica nos seus resultados. Ademais, o aumento na exatidão de $\lambda_{\mathrm{Rb}}$ é considerável se comparado ao valor de Steiger \& Jäger (1977), afetando diretamente estudos que requerem um alto nível de detalhe, como o presente trabalho.

\section{Geocronologia $\mathrm{Rb}-\mathrm{Sr}$}

O decaimento de isótopos pai (radioativos) gera isótopos filho (radiogênicos) com o decorrer do tempo, a partir de uma taxa de decaimento fixa $(\lambda)$. Assim, o total de átomos filho de uma rocha ou mineral, no tempo presente, pode ser determinado pela equação geral da geocronologia descrita a seguir:

$$
D=D_{0}+N\left(e^{\lambda t}-1\right)
$$

Em que $D$ é o total de isótopos filho; $D_{0}$ é o número inicial de isótopos filho e $N$ é o número atual de isótopos pai. Esta equação é aplicável para qualquer sistema de decaimento radioativo que envolva um isótopo radioativo transformando-se em um isótopo estável. Logo, ao substituirmos os símbolos correspondentes para o sistema $\mathrm{Rb}-\mathrm{Sr}$, no qual o ${ }^{87} \mathrm{Rb}$ é o isótopo pai e ${ }^{87} \mathrm{Sr}$ é o isótopo filho, temos:

$$
\frac{{ }^{87} S r}{{ }^{86} S r}=\left(\frac{{ }^{87} S r}{{ }^{86} S r}\right)_{i}+\frac{{ }^{87} R b}{{ }^{86} S r}\left(e^{\lambda t}-1\right)
$$

Onde ${ }^{87} \mathrm{Sr}{ }^{86} \mathrm{Sr}$ é a razão atual destes isótopos; $\left({ }^{87} \mathrm{Sr}{ }^{86} \mathrm{Sr}\right)_{i}$ é a razão destes isótopos no tempo de formação da amostra, ou seja, é a razão inicial dos isótopos de $\mathrm{Sr}$, sem nenhuma contribuição de ${ }^{87} \mathrm{Sr}$ radiogênico, incorporada pela rocha ou mineral durante a cristalização; ${ }^{87} \mathrm{Rb} /{ }^{86} \mathrm{Sr}$ é a razão atual destes isótopos; $\lambda$ é a constante de decaimento do ${ }^{87} \mathrm{Rb}\left(\lambda_{\mathrm{Rb}}\right)$ e $t$ é o tempo decorrido desde a última cristalização ou homogeneização isotópica da amostra. Todos 
os termos na equação acima estão divididos por ${ }^{86} \mathrm{Sr}$ devido a determinação mais fácil, e melhor, de razões isotópicas por espectrometria de massa. Esse é um artifício matemático válido, visto que a quantidade de átomos de ${ }^{86} \mathrm{Sr}$, que é um isótopo estável e não radiogênico, é constante na natureza (Faure \& Powell 1972; Faure, 1986; 2001; Dickin, 2005).

Portanto, se a razão inicial ${ }^{87} \mathrm{Sr} /{ }^{86} \mathrm{Sr}$ é conhecida, pode-se calcular o tempo $t$. Contudo, as seguintes premissas devem ser satisfeitas (Faure \& Powell, 1972; Faure, 1986; 2001; Dickin, 2005):

1. O valor da constante de decaimento $\left(\lambda_{\mathrm{Rb}}\right)$ é precisamente conhecido.

2. O sistema isotópico permaneceu fechado após a cristalização da rocha ou mineral, ou seja, não houve nem perda e nem ganho de $\mathrm{Rb}$ ou $\mathrm{Sr}$, por exemplo.

3. Se mais de uma rocha ou mineral são datados em conjunto, estes devem ser cogenéticos, ou seja, ter a mesma idade e razão inicial ${ }^{87} \mathrm{Sr} /{ }^{86} \mathrm{Sr}$.

Quando a razão inicial não é previamente conhecida ou estimada, tem-se uma equação com duas incógnitas, $\left({ }^{87} \mathrm{Sr}{ }^{86} \mathrm{Sr}\right)_{i}$ e $t$. Todavia, como a equação da geocronologia é equivalente a uma equação da reta $(y=a x+b)$, ao plotarmos as razões medidas ${ }^{87} \mathrm{Sr} /{ }^{86} \mathrm{Sr}(\mathrm{y})$ $\mathrm{e}^{87} \mathrm{Rb} /{ }^{86} \mathrm{Sr}(\mathrm{x})$, podemos determinar as duas variáveis restantes (Figura 2.2). Este método de datação é denominado Método da Isócrona (Faure \& Powell, 1972; Dickin, 2005).

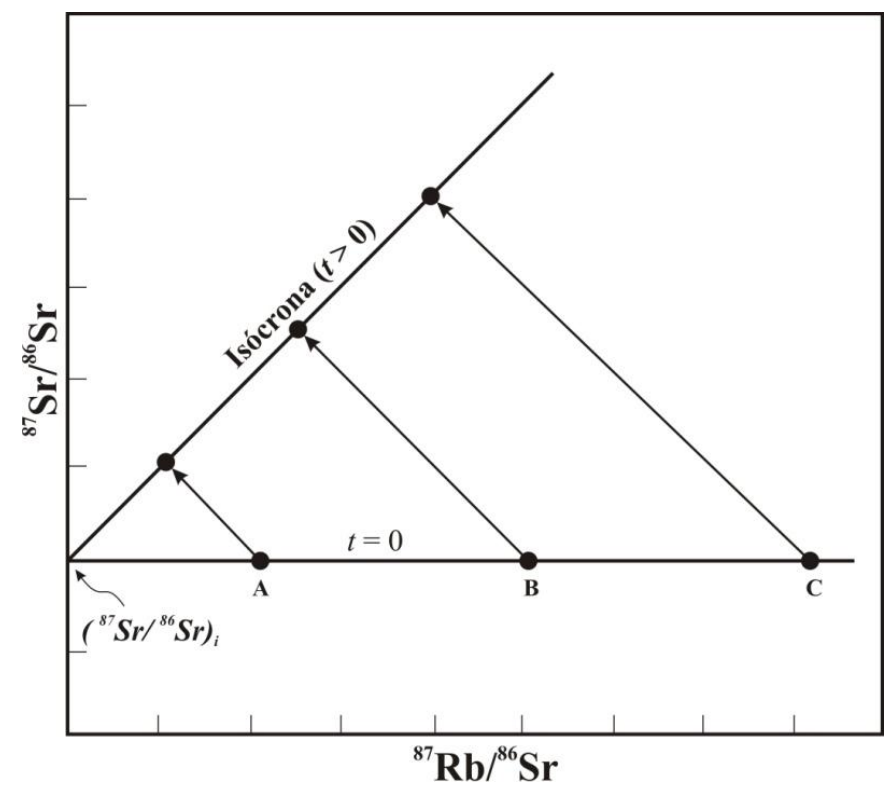

Figura 2.2. Diagrama Rb-Sr esquemático do principio da isócrona. No tempo $t=0$, as rochas ou minerais cogenéticos A, B e C se cristalizaram com a mesma razão inicial ${ }^{87} \mathrm{Sr} /{ }^{86} \mathrm{Sr}$, porém com diferentes razões $\mathrm{Rb} / \mathrm{Sr}$. Após $t$ anos, em sistema fechado, as razões de cada amostra se modificam devido ao decaimento radioativo do ${ }^{87} \mathrm{Rb}$ para ${ }^{87} \mathrm{Sr}$ (setas) e plotam ao longo da reta da isócrona. A inclinação desta reta determina a idade de cristalização enquanto que o ponto de intercepção com o eixo vertical define a razão inicial das amostras (Segundo Faure \& Powell, 1972). 
O método da isócrona requer uma ampla variação na razão $\mathrm{Rb} / \mathrm{Sr}$ das amostras a serem datadas. Se as razões das rochas ou minerais analisados forem muito próximas o método não tem resolução suficiente para gerar uma idade acurada. Logo, o sistema $\mathrm{Rb}$-Sr é mais indicado para a datação de rochas ígneas ácidas e intermediárias, pois essas têm grande variação na razão Rb/Sr (Faure, 1986; Dickin, 2005, White, 2005).

Por fim, deve-se ter cuidado ao interpretar os diagramas da isócrona, pois nem sempre dados alinhados em gráficos do tipo ${ }^{87} \mathrm{Sr} /{ }^{86} \mathrm{Sr} \mathrm{x}{ }^{87} \mathrm{Rb} /{ }^{86} \mathrm{Sr}$ representam a idade de um evento geológico. Tal configuração também pode ser gerada por mistura de dois componentes que tenham diferentes razões ${ }^{87} \mathrm{Sr} /{ }^{86} \mathrm{Sr}$ e ${ }^{87} \mathrm{Rb} /{ }^{86} \mathrm{Sr}$, por exemplo (Bell \& Powell, 1969; Faure \& Powell 1972; Faure, 1986; 2001; Dickin, 2005).

É importante salientar que o processo de decaimento radioativo gera danos na estrutura dos minerais e isto pode facilitar a migração dos isótopos radiogênicos, que têm comportamento geoquímico distinto do isótopo radioativo. No caso do sistema $\mathrm{Rb}-\mathrm{Sr}$, o ${ }^{87} \mathrm{Sr}$ produzido por decaimento do ${ }^{87} \mathrm{Rb}$ nos minerais ricos em $\mathrm{K}$ (e.g., micas) pode ser incorporado por minerais adjacentes nos quais o Sr é muito compatível (e.g., apatita). Os mecanismos que podem afetar a homogeneidade isotópica, principalmente dos minerais, e favorecer tal migração são a recristalização durante o metamorfismo ou a percolação de fluidos hidrotermais (Hofmann, 1979; Dickin, 2005). O processo de difusão também é um mecanismo possível pelo qual os isótopos podem ser transferidos de um mineral para outro, porém é muito mais lento do que qualquer outro processo (Hofmann, 1979). No manto completamente sólido (i.e., $\sim 1000^{\circ} \mathrm{C}$ ), por exemplo, o desequilíbrio isotópico em escala centimétrica pode durar entre $10^{8}$ e $10^{9}$ anos (Hofmann \& Hart, 1978; Dickin, 2005).

\section{Evolução Isotópica do $\mathrm{Sr}$}

O valor de ${ }^{87} \mathrm{Sr} /{ }^{86} \mathrm{Sr}_{\mathrm{i}}$ do magma a partir do qual uma rocha ou mineral se cristalizaram depende não apenas do decaimento do ${ }^{87} \mathrm{Rb}$ para o ${ }^{87} \mathrm{Sr}$, mas também da razão $\mathrm{Rb} / \mathrm{Sr}$ do sistema, que irá variar de acordo com o comportamento geoquímico destes elementos. Atualmente considera-se que os isótopos de $\mathrm{Sr}$, bem como de outros elementos pesados (e.g., $\mathrm{Nd}$ ), não são fracionados durante os processos de fusão parcial em equilíbrio ou cristalização fracionada. Desta maneira, considera-se que a composição isotópica do magma e das rochas cristalizadas a partir dele é igual à composição isotópica da área fonte. Logo, é possível 
utilizar a razão inicial das rochas ou minerais para identificar a origem dos diversos tipos de magma (Faure \& Powell, 1972; Faure, 1986; 2001; White, 2005, Allègre, 2008).

A importância de tais considerações com respeito à evolução isotópica do $\mathrm{Sr}$ nos principais reservatórios terrestres (i.e., crosta e manto) está ilustrada de modo simplificado na Figura 2.3. Ao longo da evolução geológica, a diferenciação química da porção silicática da Terra se desenvolveu a partir da geração de crosta por meio de fusão parcial do manto. Deste modo, a crosta tem sido enriquecida em elementos incompatíveis ou LILE (Large Ion Lithophile Elements em inglês) incorporados nos magmas, enquanto que as porções do manto, inicialmente homogêneo, associadas à formação da crosta têm sido empobrecidas nestes elementos. Devido ao fracionamento entre $\mathrm{Rb}$ e $\mathrm{Sr}$ durante a fusão parcial, o manto empobrecido por extração de magma formou um reservatório com baixa razão $\mathrm{Rb} / \mathrm{Sr}$ na média, enquanto a crosta continental tem alta razão $\mathrm{Rb} / \mathrm{Sr}$, comparativamente ao reservatório homogêneo inicial (Faure \& Powell, 1972; Faure, 1986; 2001; White, 2005; Allègre, 2008).

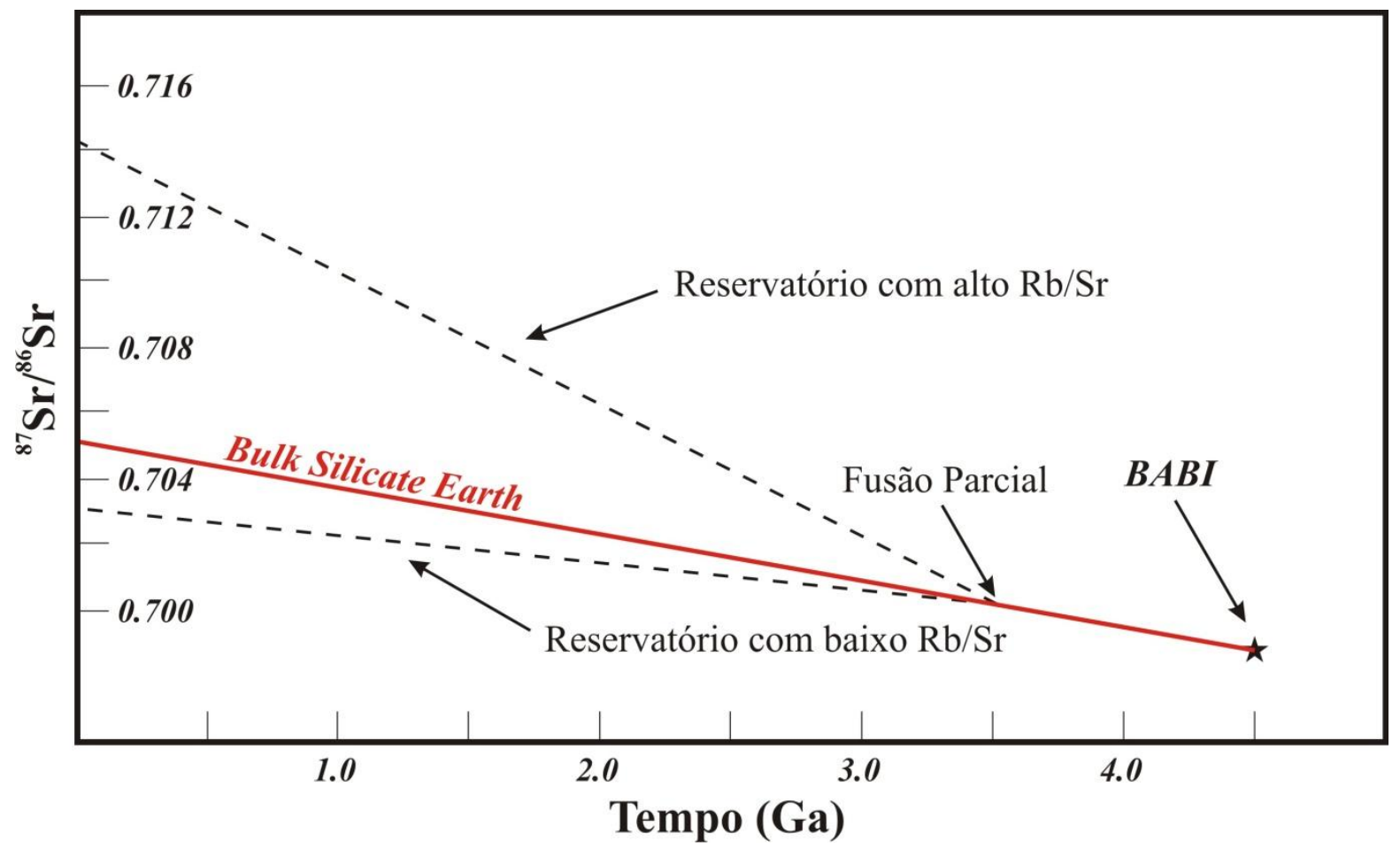

Figura 2.3. Evolução isotópica do Sr na Terra. BABI (Basaltic Achondrite Best Initial) representa o valor inicial de ${ }^{87} \mathrm{Sr} /{ }^{86} \mathrm{Sr}$ do manto homogêneo. A linha Bulk Silicate Earth indica a evolução teórica do reservatório indiferenciado $(B A B I)$ até o presente. Caso os reservatórios formados durante a fusão parcial permaneçam fechados, a evolução da razão ${ }^{87} \mathrm{Sr} /{ }^{86} \mathrm{Sr}$ no tempo acontece ao longo de curvas proporcionais a razão $\mathrm{Rb} / \mathrm{Sr}$ (Segundo White, 2005).

Portanto, magmas gerados por anatexia, em geral, tem razões $\mathrm{Rb} / \mathrm{Sr}$ e ${ }^{87} \mathrm{Sr} /{ }^{86} \mathrm{Sr}$ altas e com amplas variações, enquanto magmas formados por fusão parcial do manto empobrecido tem baixas razões $\mathrm{Rb} / \mathrm{Sr}$ e ${ }^{87} \mathrm{Sr} /{ }^{86} \mathrm{Sr}$. Isto é devido, essencialmente, ao fato de que as rochas 
crustais acumulam mais ${ }^{87} \mathrm{Sr}$ radiogênico do que as mantélicas no tempo geológico e que a crosta, ao contrário do manto convectivo, mantém suas heterogeneidades por mais tempo. Além de determinar se a fonte era enriquecida ou empobrecida em ${ }^{87} \mathrm{Sr}$, as variações de ${ }^{87} \mathrm{Sr} /{ }^{86} \mathrm{Sr}_{\mathrm{i}}$ também podem identificar eventos de mistura de magmas e de assimilação da encaixante (Faure \& Powell, 1972; Faure, 1986; 2001; Allègre, 2008).

\section{Notações $\varepsilon_{S r}$ e $f_{R b / S r}$}

A notação épsilon ( $($ ) foi introduzida por Papanastassiou \& Wasserburg (1969) para expressar a variação de ${ }^{87} \mathrm{Sr} /{ }^{86} \mathrm{Sr}$ em relação a um valor de referência e facilitar a visualização desta razão no diagrama da isócrona, (Jacobsen \& Wasserburg, 1980; Dickin, 2005). Posteriormente, DePaolo \& Wasserburg (1976a) utilizaram o mesmo conceito para representar as variações de ${ }^{143} \mathrm{Nd} /{ }^{144} \mathrm{Nd}$, e por consequência de outros sistemas isotópicos (e.g., Rb-Sr, Lu-Hf), em relação a um reservatório de referência. Assim, o parâmetro $\varepsilon S r(0)$ aponta a variação da razão ${ }^{87} \mathrm{Sr} /{ }^{86} \mathrm{Sr}$ com respeito ao Bulk Silicate Earth (BSE) no tempo presente, e é definido por:

$$
\varepsilon S r(0)=10^{4} *\left[\frac{{ }^{87} S r /{ }^{86} S r_{\text {amostra }}}{{ }^{87} S r /{ }^{86} S r_{B S E}}-1\right]
$$

Onde ${ }^{87} \mathrm{Sr}{ }^{86} \mathrm{Sr}$ é a razão medida diretamente na amostra e ${ }^{87} S r{ }^{86} \mathrm{Sr}_{B S E}$ é a razão atual teórica do reservatório uniforme indiferenciado $(B S E)$, a qual é igual a $0.7045 \pm 0.0005$ (DePaolo \& Wasserburg, 1976b; DePaolo, 1988). Tal valor de ${ }^{87} S r{ }^{86} S r_{B S E}$ é estimado a partir da correlação entre os sistemas isotópicos $\mathrm{Rb}-\mathrm{Sr}$ e $\mathrm{Sm}-\mathrm{Nd}$ para os dados de basaltos oceânicos. Assumindo que a razão inicial de ${ }^{87} \mathrm{Sr} /{ }^{86} \mathrm{Sr}$ da Terra é idêntica ao valor determinado por Papanastassiou \& Wasserburg (1969) para os acondritos (BABI), é possível obter a razão ${ }^{87} \mathrm{Rb} /{ }^{86} \mathrm{Sr}$ do $B S E$, como se segue:

$$
0.7045=\left(\frac{{ }^{87} S r}{{ }^{86} S r}\right)_{B A B I}+\left(\frac{{ }^{87} R b}{{ }^{86} S r}\right)_{B S E}\left(e^{\lambda t}-1\right)
$$

Onde $\left({ }^{87} \mathrm{Sr}{ }^{86} \mathrm{Sr}\right)_{B A B I}$ é igual a $0.69899 ; \lambda$ é a constante de decaimento do ${ }^{87} \mathrm{Rb}\left(\lambda_{\mathrm{Rb}}\right)$ e $t$ é a idade de formação da Terra $(4.55 \mathrm{Ga})$. Deste modo, $\left({ }^{87} \mathrm{Rb} /{ }^{86} \mathrm{Sr}\right)_{\mathrm{BSE}}$ é aproximadamente 0.085 (DePaolo, 1988; Faure, 2001). 
Adicionalmente, pode-se calcular o valor $\varepsilon S r(T)$ para qualquer momento no passado. Basta empregar a razão inicial ${ }^{87} \mathrm{Sr} /{ }^{86} \mathrm{Sr}_{\mathrm{i}}$ da amostra e recalcular a razão ${ }^{87} \mathrm{Sr} /{ }^{86} \mathrm{Sr}$ do $B S E$ para o tempo $t$ adequado, por meio da equação abaixo:

$$
\left(\frac{{ }^{87} S r}{{ }^{86} S r}\right)_{B S E(t)}=0.7045-0.084\left(e^{\lambda t}-1\right)
$$

As notações $\varepsilon S r$ têm valores positivos ou negativos. Valores positivos apontam enriquecimento da rocha ou mineral em ${ }^{87} \mathrm{Sr}$ radiogênico relativo ao $B S E$ enquanto valores negativos indicam empobrecimento deste isótopo relativo ao mesmo reservatório. Este enriquecimento ou empobrecimento em relação ao $B S E$ está relacionado tanto a mudanças na razão $\mathrm{Rb} / \mathrm{Sr}$ da fonte quanto a processos de modificação do magma, como assimilação de crosta antiga ou mistura de fontes. Desta maneira, magmas gerados a partir da crosta continental ou do manto empobrecido terão valores de $\varepsilon \operatorname{Sr}(T)$ positivos ou negativos, respectivamente (Faure \& Powell, 1972; Faure, 1986; 2001; White, 2005). Entretanto, é necessário ressaltar que o manto não é exclusivamente empobrecido e tampouco homogêneo. Em determinados casos, magmas derivados de porções do manto enriquecidas em elementos incompatíveis podem ter valores de $\varepsilon S r(T)$ distintos. Tais magmas poderão ter valores positivos de $\varepsilon \operatorname{Sr}(T)$ mesmo sendo provenientes do manto. Um destes casos específicos será discutido em maior detalhe no tópico 2.3.

Além das variações na razão ${ }^{87} \mathrm{Sr} /{ }^{86} \mathrm{Sr}$, os processos de diferenciação geram modificações, principalmente, na razão ${ }^{87} \mathrm{Rb} /{ }^{86} \mathrm{Sr}$. Para expressar o quanto esta razão é modificada em relação ao reservatório indiferenciado, calcula-se o fator de enriquecimento $\left(f_{\mathrm{Rb} / \mathrm{Sr}}\right)$, adaptado da notação proposta por DePaolo \& Wasserburg (1976a) para o sistema Sm$\mathrm{Nd}$, pela seguinte relação:

$$
f_{R b / S r}=\left[\frac{{ }^{87} R b /{ }^{86} S r_{\text {amostra }}}{{ }^{87} R b /{ }^{86} S r_{B S E}}-1\right]
$$

É importante ressaltar que ambas notações dependem de valores de um reservatório de referência, no caso o $B S E$. Deste modo, sempre que os dados forem apresentados por meio destas notações, estes valores devem ser especificados (Faure, 2001). Devido às incertezas associadas ao cálculo das razões atuais do $B S E$ para o sistema $\mathrm{Rb}-\mathrm{Sr}$, a representação dos dados isotópicos de Sr por meio da notação $\varepsilon S r$ é geralmente preterida em favor da utilização dos valores originais da razão ${ }^{87} \mathrm{Sr} /{ }^{86} \mathrm{Sr}$. 


\subsection{O SISTEMA SM-ND}

O significado do sistema Sm-Nd para a geologia vai além do fato de um dos isótopos naturais de samário $\left({ }^{147} \mathrm{Sm}\right)$ ser radioativo e decair naturalmente para um dos isótopos estáveis de neodímio $\left({ }^{143} \mathrm{Nd}\right)$, permitindo assim a determinação da idade dos eventos geológicos. A real importância deste sistema está relacionada às propriedades geoquímicas dos elementos Sm e Nd. Ambos são elementos refratários e, portanto não são fracionados entre si durante os processos de formação de planetas, ao contrário de outros sistemas isotópicos tradicionais (i.e., U-Pb e Rb-Sr), que envolvem elementos voláteis (DePaolo, 1980; 1988).

Nos processos terrestres, os sistemas $\mathrm{Sm}-\mathrm{Nd}$ e $\mathrm{Rb}-\mathrm{Sr}$ funcionam de maneira oposta. $\mathrm{Rb}$ e $\mathrm{Sr}$ têm comportamentos geoquímicos distintos, resultando num fracionamento químico pronunciado entre os elementos pai e filho. Ao contrário, $\mathrm{Sm}$ e $\mathrm{Nd}$ têm características geoquímicas similares e o grau de separação entre tais elementos é bem menor. Por consequência, esses sistemas isotópicos são complementares (DePaolo, 1980; 1988; Faure \& Mensing, 2005; White, 2005). A relevância deste aspecto no estudo dos processos petrogenéticos será discutida em detalhes nos tópicos seguintes.

\section{Propriedades Geoquímicas do Sm e Nd}

Samário (Sm), cujo número atômico é 62, e Neodímio $(\mathrm{Nd})$, cujo número atômico é 60, pertencem ao Grupo 3 da tabela periódica (Figura 2.1), mais especificamente ao conjunto denominado de Elementos Terras Raras (ETR). Os ETR se caracterizam por formar, em geral, cátions com valência +3 e ser extremamente imóveis (Faure \& Mensing, 2005; White; 2005).

$\mathrm{O}$ raio iônico dos $\mathrm{ETR}^{+3}$ diminui progressivamente com o aumento do número atômico, de 1.15 Å no Lantânio (La, Z=57) até 0.93 Å no Lutécio (Lu, Z=71). Este fenômeno é conhecido como contração dos lantanídeos e resulta em uma variação progressiva nas propriedades geoquímicas desses elementos. Devido à elevada razão carga/raio, todos os ETR são considerados incompatíveis e geralmente ocorrem como elementos traço nos minerais formadores de rocha. Em detalhe, por causa da variação sistemática do raio iônico, os ETR leves são mais incompatíveis dos que os ETR pesados. Os ETR podem ter altas concentrações em minerais economicamente importantes tais como bastnaesita $\left[\operatorname{ETR}\left(\mathrm{CO}_{3}\right) \mathrm{F}\right]$ e monazita [(ETR, Th)PO $\left.\mathrm{PO}_{4}\right]$ (DePaolo, 1988; Faure \& Mensing, 2005; White, 2005). 
Sm e Nd pertencem aos ETR leves e, desta forma tem características bastante similares. Contudo, o $\mathrm{Sm}^{+3}$ tem raio iônico ligeiramente menor do que o $\mathrm{Nd}^{+3}\left(\mathrm{Sm}^{+3}=1.04 \AA\right.$; $\mathrm{Nd}^{+3}=1.08 \AA$ ) e, portanto, é menos incompatível. Isto tem implicações importantes no comportamento geoquímico destes elementos durante a cristalização fracionada e a fusão parcial, visto que o $\mathrm{Nd}$ terá uma preferência mais acentuada pela fase líquida do que o Sm. Tendo em vista a disposição destes elementos dentro do grupo dos ETR, a razão $\mathrm{Sm} / \mathrm{Nd}$ reflete o padrão geral de fracionamento deste grupo de elementos. Baixas razões $\mathrm{Sm} / \mathrm{Nd}$ indicam enriquecimento em ETR leves e altas razões $\mathrm{Sm} / \mathrm{Nd}$ são típicas de empobrecimento em ETR leves relativamente aos ETR pesados (DePaolo, 1988).

O Sm tem sete isótopos naturais, dos quais três são radioativos, ${ }^{147} \mathrm{Sm},{ }^{148} \mathrm{Sm}, \mathrm{e}^{149} \mathrm{Sm}$. Entretanto, os dois últimos têm tempos de meia-vida tão longos $\left(\mathrm{T}_{1 / 2} \approx 10^{16} \mathrm{yr}\right)$ que são considerados praticamente estáveis. O Nd também tem sete isótopos naturais, todos estáveis. A composição isotópica do $\mathrm{Nd}$ é variável e dependente da razão $\mathrm{Sm} / \mathrm{Nd}$, pois ${ }^{143} \mathrm{Nd}$ é gerado a partir do decaimento radioativo do ${ }^{147} \mathrm{Sm}$. Todos os isótopos de $\mathrm{Sm}$ e $\mathrm{Nd}$, com suas respectivas abundâncias aproximadas estão listados na Tabela 2.2 (O'Nions et al., 1979; DePaolo, 1988; Faure, 2001; Dickin, 2005).

Tabela 2.2. Abundâncias isotópicas de neodímio (Nd) e samário (Sm).

\begin{tabular}{cccc}
\hline Isótopo de Nd & Abundância* (\%) & Isótopos de Sm & Abundância (\%) \\
\hline${ }^{142} \mathrm{Nd}$ & 27.17 & ${ }^{144} \mathrm{Sm}$ & 3.07 \\
${ }^{143} \mathrm{Nd}$ & 12.18 & ${ }^{147} \mathrm{Sm}$ & 15.00 \\
${ }^{144} \mathrm{Nd}$ & 23.80 & ${ }^{148} \mathrm{Sm}$ & 11.24 \\
${ }^{145} \mathrm{Nd}$ & 8.29 & ${ }^{149} \mathrm{Sm}$ & 13.82 \\
${ }^{146} \mathrm{Nd}$ & 17.18 & ${ }^{150} \mathrm{Sm}$ & 7.38 \\
${ }^{148} \mathrm{Nd}$ & 5.75 & ${ }^{152} \mathrm{Sm}$ & 26.74 \\
${ }^{150} \mathrm{Nd}$ & 5.63 & ${ }^{154} \mathrm{Sm}$ & 22.75 \\
\hline
\end{tabular}

*Calculada a partir das razões obtidas por Wasserburg et al. (1981).

\section{A Constante de Decaimento do ${ }^{147} \mathrm{Sm}$}

Dentre os isótopos radioativos de samário, apenas o ${ }^{147} \mathrm{Sm}$ tem um tempo de meia-vida curto o suficiente para produzir variações mensuráveis na composição isotópica do $\mathrm{Nd}$, que é o princípio básico do método Sm-Nd (O’Nions et al., 1979; Dickin, 2005).

$\mathrm{O}{ }^{147} \mathrm{Sm}$ decai para o ${ }^{143} \mathrm{Nd}$ por meio de emissão de partículas alfa, do seguinte modo:

$$
{ }^{147} \mathrm{Sm} \rightarrow{ }^{143} \mathrm{Nd}+\alpha^{+2}+Q,
$$


Onde $\alpha$ é a partícula alfa, composta por 2 prótons e 2 nêutrons, igual a um núcleo de Hélio (He), e $Q$ é a energia de decaimento. Em contraste com o sistema $\mathrm{Rb}-\mathrm{Sr}$, o valor de $Q$ produzido no processo acima $(2.31 \mathrm{MeV}$, Su et al., 2010) possibilita a determinação mais acurada da meia-vida do ${ }^{147} \mathrm{Sm}$, bem como, de sua constante de decaimento $\left(\lambda_{\mathrm{Sm}}\right)$.

Desde os trabalhos de Lugmair (1974) e Lugmair \& Marti (1978) tem sido utilizado o valor $6.54 \times 10^{-12} \mathrm{yr}^{-1}$ para $\lambda_{\mathrm{Sm}}\left(\mathrm{T}_{1 / 2}=106.0 \pm 0.8 \mathrm{Byr}\right)$, calculado a partir dos valores mais precisos da época. Begemann et al. (2001) discutem a validade de tal constante de decaimento e, apesar da relativa ausência de medições mais atuais, concluem que o valor de $\lambda_{\mathrm{Sm}}$ determinado por Lugmair \& Marti (1978) é bastante acurado e pode continuar a ser adotado. Recentemente, Kossert et al. (2009) e Su et al. (2010) realizaram novas determinações do tempo de meia-vida do ${ }^{147} \mathrm{Sm}$, que são consistentes com o valor de $\lambda_{\mathrm{Sm}}$ recomendado.

\section{Geocronologia Sm-Nd}

Os princípios que governam a datação por meio do sistema $\mathrm{Sm}-\mathrm{Nd}$ são idênticos àqueles discutido em detalhe para o sistema $\mathrm{Rb}$-Sr. Deste modo, ao substituirmos os símbolos corretos na equação geral da geocronologia, considerando que ${ }^{147} \mathrm{Sm}$ é o isótopo pai e ${ }^{143} \mathrm{Nd}$ é o isótopo filho, temos que:

$$
\frac{{ }^{143} N d}{{ }^{144} N d}=\left(\frac{{ }^{143} N d}{{ }^{144} N d}\right)_{i}+\frac{{ }^{147} S m}{{ }^{144} N d}\left(e^{\lambda t}-1\right)
$$

onde ${ }^{143} N d l^{144} N d$ é a razão atual destes isótopos; $\left({ }^{143} N d /{ }^{144} N d\right)_{i}$ é a razão inicial dos isótopos de $\mathrm{Nd} ;{ }^{147} \mathrm{Sm} /{ }^{144} \mathrm{Nd}$ é a razão atual destes isótopos; $\lambda$ é a constante de decaimento do ${ }^{147} \mathrm{Sm}$ $\left(\lambda_{\mathrm{Sm}}\right)$ e $t$ é o tempo decorrido desde a cristalização ou homogeneização da amostra. De maneira similar ao sistema $\mathrm{Rb}-\mathrm{Sr}$ todos os termos na equação acima estão divididos por ${ }^{144} \mathrm{Nd}$, devido ao espectrômetro de massa determinar mais facilmente, e melhor, razões isotópicas (DePaolo, 1988; Dickin, 2005; Faure \& Mensing, 2005).

A partir das premissas já mencionadas para o sistema $\mathrm{Rb}-\mathrm{Sr}$, usualmente calcula-se a razão inicial a partir de um tempo $t$ pré-estabelecido. Caso contrário, como a equação apresentada tem a mesma forma do que aquela descrita no sistema $\mathrm{Rb}-\mathrm{Sr}$, pode-se aplicar o princípio da isócrona com o intuito de determinar tanto o tempo $t$ quanto a razão inicial ${ }^{143} \mathrm{Nd} /{ }^{144} \mathrm{Nd}_{\mathrm{i}}$, conforme exemplificado na Figura 2.4 (O’Nions et al., 1979; DePaolo, 1988; Dickin, 2005; Faure \& Mensing, 2005). 


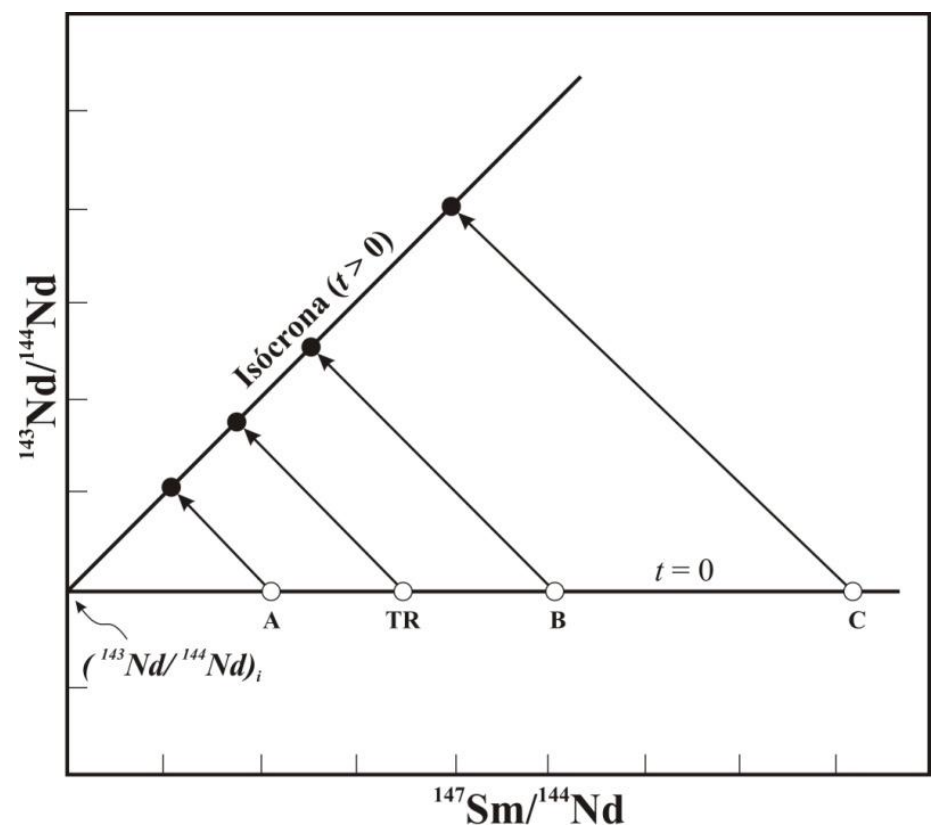

Figura 2.4. Diagrama Sm-Nd esquemático do principio da isócrona. No tempo $t=0$, os minerais cogenéticos $\mathrm{A}$, B e C pertencentes à rocha TR têm valores de razão inicial ${ }^{143} \mathrm{Nd} /{ }^{144} \mathrm{Nd}$ idênticos, porém com diferentes razões ${ }^{147} \mathrm{Sm} /{ }^{144} \mathrm{Nd}$. Após $t$ anos, devido ao decaimento do ${ }^{147} \mathrm{Sm}$ para o ${ }^{143} \mathrm{Nd}$, as razões ${ }^{147} \mathrm{Sm} /{ }^{144} \mathrm{Nd} \mathrm{e}{ }^{143} \mathrm{Nd} /{ }^{144} \mathrm{Nd}$ se modificam ao longo das setas e os pontos $\mathrm{A}, \mathrm{B}, \mathrm{C}$ e TR plotam sobre a reta da isócrona. A inclinação desta reta determina a idade de cristalização enquanto o ponto de intercepção com o eixo vertical define a razão inicial das amostras (Adaptado de DePaolo, 1988).

É importante ressaltar que as variações na razão $\mathrm{Sm} / \mathrm{Nd}$ são, normalmente, bem menores do que aquelas observadas no sistema $\mathrm{Rb}-\mathrm{Sr}$, devido às características geoquímicas similares entre os elementos $\mathrm{Sm}$ e Nd. Desta forma, a datação por meio do sistema $\mathrm{Sm}-\mathrm{Nd}$ é aplicada, sobretudo, quando os outros sistemas isotópicos são ineficientes, tais como a determinação da idade de cristalização de rochas máficas e ultramáficas. Em geral, utilizamse isócronas minerais a fim de se obter a maior variação possível na razão $\mathrm{Sm} / \mathrm{Nd}$. Além disso, devido à meia-vida muito longa do ${ }^{147} \mathrm{Sm}$, este sistema é indicado, essencialmente, para a datação de materiais mais antigos, como rochas arqueanas e meteoritos (O'Nions et al., 1979; DePaolo, 1988; Dickin, 2005).

Graças ao seu comportamento geoquímico, os elementos Sm e Nd são mais resistentes aos processos de alteração hidrotermal e metamorfismo, os quais facilmente ocasionariam a abertura dos demais sistemas isotópicos. Esta é a grande vantagem do sistema $\mathrm{Sm}-\mathrm{Nd}$, pois permite acessar a idade de cristalização, assim como, a razão isotópica inicial de rochas metavulcânicas arqueanas, por exemplo, o que seria virtualmente impossível por meio do sistema Rb-Sr (DePaolo, 1988; Faure, 2001; Faure \& Mensing, 2005; White, 2005). 


\section{Notações $\varepsilon_{N d} e f_{S m / N d}$}

DePaolo \& Wasserburg (1976a) introduziram a notação épsilon ( $(\varepsilon)$ a fim de facilitar a interpretação das variações de ${ }^{143} \mathrm{Nd} /{ }^{144} \mathrm{Nd}$, de maneira similar ao aplicado no sistema $\mathrm{Rb}-\mathrm{Sr}$. O parâmetro $\varepsilon N d(0)$ representa a variação da razão ${ }^{143} \mathrm{Nd} /{ }^{144} \mathrm{Nd}$ com respeito a um reservatório de referência no tempo presente, e é calculado por:

$$
\varepsilon N d(0)=10^{4} *\left[\frac{{ }^{143} N d /{ }^{144} N d_{\text {amostra }}}{{ }^{143} N d /{ }^{144} N d_{C H U R}}-1\right]
$$

Onde ${ }^{143} N d l^{144} N d$ é a razão medida diretamente na amostra e ${ }^{143} N d l^{144} N d d_{C H U R}$ é a razão atual do reservatório de referência denominado de CHUR (Chondritic Uniform Reservoir) por DePaolo \& Wasserburg (1976a).

O valor da razão isotópica ${ }^{143} N d l^{144} N d_{C H U R}$ determinado por Jacobsen \& Wasserburg (1980; 1984) para os condritos é igual a 0.511847, quando corrigida com respeito ao fracionamento pela razão ${ }^{146} \mathrm{Nd} /{ }^{142} \mathrm{Nd}$ igual a 0.636151 . Entretanto, a maioria dos dados de Sm-Nd são normalizados a uma razão ${ }^{146} \mathrm{Nd} /{ }^{144} \mathrm{Nd}$ igual a 0.7219 , o que implica em utilizar o valor ${ }^{143} N d /{ }^{144} N d_{C H U R}$ igual a 0.512638 , recalculado por Wasserburg et al. (1981). Assim, antes de calcular o parâmetro $\varepsilon N d$ deve-se verificar se os dados medidos foram ajustados da mesma maneira que o valor ${ }^{143} N d l^{144} N d_{C H U R}$ aplicado no cálculo (Faure, 2001). Uma discussão detalhada da relação entre estas duas razões de normalização pode ser encontrada em Wasserburg et al. (1981).

É possível obter o valor $\varepsilon N d(T)$ para qualquer tempo $t$ no passado ao empregar, na equação acima, a razão inicial ${ }^{143} \mathrm{Nd} /{ }^{144} \mathrm{Nd}_{\mathrm{i}}$ da amostra e a razão ${ }^{143} \mathrm{Nd} /{ }^{144} \mathrm{Nd}$ do $C H U R$. Esta última deve ser recalculada para o tempo $t$ apropriado segundo a fórmula abaixo:

$$
\left(\frac{{ }^{143} N d}{{ }^{144} N d}\right)_{C H U R}^{t}=\left(\frac{{ }^{143} N d}{{ }^{144} N d}\right)_{C H U R}-\left(\frac{{ }^{147} S m}{{ }^{144} N d}\right)_{C H U R} *\left(e^{\lambda t}-1\right)
$$

em que ${ }^{143} N d l^{144} N d_{C H U R}(t)$ é a razão ${ }^{143} \mathrm{Nd} /{ }^{144} \mathrm{Nd}$ do $C H U R$ no tempo $t ;{ }^{143} N d l^{144} N d_{C H U R}$ é a razão atual do $C H U R ;{ }^{147} \mathrm{Sm} /{ }^{144} \mathrm{Nd} d_{C H U R}$ é a razão atual destes isótopos no $C H U R$, determinado por Jacobsen \& Wasserburg (1980) como 0.1967; $\lambda$ é a constante de decaimento do ${ }^{147} \mathrm{Sm}$ $\left(\lambda_{\mathrm{Sm}}\right)$ e $t$ é a idade referente à razão inicial da amostra. 
A notação $\varepsilon N d(T)$ será igual a zero caso a amostra tenha sido derivada, no tempo $t$, de um reservatório uniforme indiferenciado similar ao CHUR. Do mesmo modo, valores de $\varepsilon N d(T)$ diferentes de zero indicam que a região fonte foi diferenciada em relação ao $C H U R$ num tempo anterior a $t$ (DePaolo \& Wasserburg, 1976a). Tal fato tem implicações importantes nos estudos petrogenéticos a partir do conceito de idades modelo Sm-Nd (ver adiante). Valores de $\varepsilon N d(T)$ positivos ou negativos apontam, respectivamente, para enriquecimento ou empobrecimento da fonte em ${ }^{143} \mathrm{Nd}$ radiogênico relativo ao $C H U R$ (DePaolo, 1988; Faure, 2001; Faure \& Mensing, 2005; White, 2005).

Adicionalmente à notação $\varepsilon N d$, DePaolo \& Wasserburg (1976a) propuseram o fator de enriquecimento $f_{\mathrm{Sm} / \mathrm{Nd}}$ a fim de expressar as variações da razão ${ }^{147} \mathrm{Sm} /{ }^{144} \mathrm{Nd}$ com respeito ao CHUR ocasionadas pelos processos de diferenciação. Tal fator é obtido da seguinte maneira:

$$
f_{\text {Sm } / N d}=\left[\frac{{ }^{147} S m /{ }^{144} N d_{\text {amostra }}}{{ }^{147} S m /{ }^{144} N d_{C H U R}}-1\right]
$$

Deste modo, rochas ou minerais com razão $\mathrm{Sm} / \mathrm{Nd}$ maior do que a do $C H U R$ tem valores positivos de $f_{\mathrm{Sm} / \mathrm{Nd}}$ e amostras com razão $\mathrm{Sm} / \mathrm{Nd}$ menores tem valores negativos de $f_{\mathrm{Sm} / \mathrm{Nd}}$. No caso do sistema Sm-Nd, o fator de enriquecimento também indica a tendência geral do padrão de fracionamento dos ETR (DePaolo, 1988).

\section{Idades Modelo $\tau_{C H U R} e \tau_{D M}$}

Visto que os elementos Sm e Nd são relativamente imóveis e por isso só fracionam entre si durante processos ígneos, pode-se usar as razões ${ }^{147} \mathrm{Sm} /{ }^{144} \mathrm{Nd}$ e ${ }^{143} \mathrm{Nd} /{ }^{144} \mathrm{Nd}$ atuais de uma rocha crustal para estimar a idade de diferenciação desta com respeito a sua fonte mantélica, desde que o sistema tenha permanecido fechado (DePaolo, 1981a; White, 2005). Apesar disso, é necessário assumir um modelo pré-estabelecido que presuma como a razão ${ }^{143} \mathrm{Nd} /{ }^{144} \mathrm{Nd}$ da fonte evoluiu ao longo do tempo. Deste modo, DePaolo \& Wasserburg (1976b) definiram que a idade modelo $T_{C H U R}$ de um sistema é o tempo decorrido desde que este teve uma razão ${ }^{143} \mathrm{Nd} /{ }^{144} \mathrm{Nd}$ igual a do $C H U R$, ou seja, teve $\varepsilon N d(T)$ igual a zero. Consequentemente, tal modelo considera que a razão isotópica da fonte (i.e., manto) tenha evoluído de maneira idêntica à dos condritos, sendo que $T_{C H U R}$ é calculada por:

$$
T_{\text {CHUR }}=\frac{1}{\lambda} \ln \left[\frac{{ }^{143} N d /{ }^{144} N d_{\text {amostra }}-{ }^{143} N d /{ }^{144} N d_{C H U R}}{{ }^{147} S m /{ }^{144} N d_{\text {amostra }}-{ }^{147} S m /{ }^{144} N d_{C H U R}}+1\right]
$$


Onde ${ }^{143} N d / l^{144} N d_{\text {amostra }} \mathrm{e}^{147} \mathrm{Sm} /{ }^{144} \mathrm{Nd} d_{\text {amostra }}$ são as razões medidas da amostra; ${ }^{143} \mathrm{Nd} /{ }^{144} \mathrm{Nd} d_{C H U R}$ e ${ }^{147} \mathrm{Sm} /{ }^{144} N d_{C H U R}$ são as razões atuais do $C H U R$ e $\lambda$ é a constante de decaimento do ${ }^{147} \mathrm{Sm}$ $\left(\lambda_{\mathrm{Sm}}\right)$.

No entanto, DePaolo (1981a) notou que a crosta continental tem sido formada a partir de um reservatório (i.e, uma fonte) com razão $\mathrm{Sm} / \mathrm{Nd}$ maior do que a razão do $C H U R$, e por consequência, com $\varepsilon N d>0$. Deste modo, propôs o cálculo da idade modelo $T_{D M}$ em relação à curva de evolução do manto empobrecido (Depleted Mantle em inglês), definida por:

$$
\varepsilon N d(T)^{*}=0.25 T^{2}-3 T+8.5
$$

Onde $\varepsilon N d(T)^{*}$ representa a composição do manto empobrecido, relativo ao $C H U R$, no tempo T. A partir das razões ${ }^{143} \mathrm{Nd} /{ }^{144} \mathrm{Nd}$ e ${ }^{147} \mathrm{Sm} /{ }^{144} \mathrm{Nd}$ medidas da amostra e da equação acima, são obtidas as idades modelo $T_{D M}$ por meio do software Isoplot 4.15 (Ludwig, 2008).

A idade modelo $T_{D M}$ aponta o tempo transcorrido deste que a fonte do magma teve o $\varepsilon N d(T)$ igual ao do manto empobrecido. Desta forma, a idade $T_{D M}$ tem uma aplicação mais ampla do que a idade $T_{C H U R}$. Contudo, é importante salientar que a curva de evolução do manto empobrecido proposta por DePaolo (1981a) para a idade $T_{D M}$ foi fundamentada por dados provenientes de magmas associados a arcos de ilha (Dickin, 2005).

Outros autores (Goldstein et al., 1984; White, 2005) consideram que o manto empobrecido tem evoluído linearmente desde a formação da Terra $(4.55 \mathrm{Ga})$ e sugerem que uma idade modelo mais abrangente do que a calculada em relação ao manto empobrecido de DePaolo (1981a) pode ser obtida utilizando as razões ${ }^{143} \mathrm{Nd} /{ }^{144} \mathrm{Nd} \mathrm{e}{ }^{147} \mathrm{Sm} /{ }^{144} \mathrm{Nd}$ médias dos MORBs (Mid-Ocean Ridge Basalts) atuais, substituindo-as na fórmula do $T_{C H U R}$ (Dickin, 2005). Esta idade modelo é um pouco mais antiga do que a obtida segundo DePaolo (1981a), uma vez que a razões médias do manto empobrecido considerado neste modelo são maiores do que as do magmatismo em arcos de ilha (Dickin, 2005).

Em todos os casos, a idade modelo nada mais é do que uma extrapolação da razão ${ }^{143} \mathrm{Nd} /{ }^{144} \mathrm{Nd}$ medida até um tempo $T$ no passado, onde esta razão intercepta a curva de evolução do manto como exemplificado na Figura 2.5. 


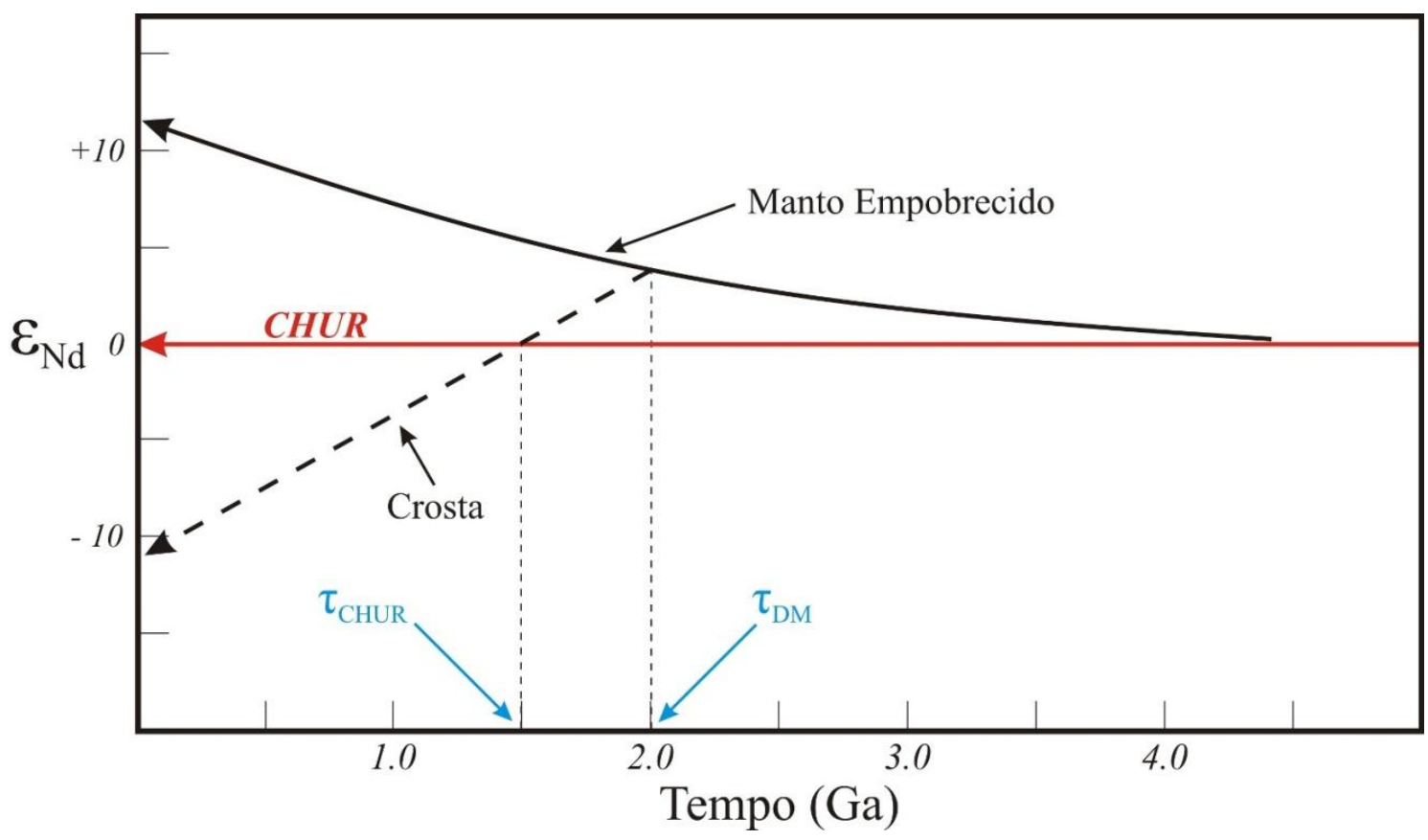

Figura 2.5. Princípio das idades modelo Sm-Nd. No exemplo ilustrado, a idade $T_{C H U R}$ igual a 1.5 Ga representa o momento no qual a fonte do magma em questão teve $\varepsilon N d(T)=0$. Já a idade $T_{D M}$ representa o instante no qual esta fonte teve razão ${ }^{143} \mathrm{Nd} /{ }^{144} \mathrm{Nd}$ igual a do manto empobrecido (Segundo DePaolo, 1988).

\section{Evolução Isotópica do $\mathrm{Nd}$}

A partir da razão inicial ${ }^{143} \mathrm{Nd} /{ }^{144} \mathrm{Nd}_{\mathrm{i}}$ de uma rocha ou mineral pode-se determinar a fonte do magma a partir do qual os mesmos se cristalizaram. Tal afirmativa é verdadeira se consideramos que o magma e a fonte residual estavam em equilíbrio isotópico no momento da extração do primeiro para a superfície, conforme discutido para o sistema $\mathrm{Rb}$-Sr. Assim, ao assumirmos que a crosta da Terra tem sido formada a partir de fusão parcial do manto, podese ilustrar a evolução isotópica do Nd nos reservatórios terrestres de acordo com a Figura 2.6 (DePaolo, 1988; Faure \& Mensing, 2005; White, 2005).

O modelo mais aceito atualmente é de que a Terra como um todo, à exceção do núcleo, tem razão ${ }^{143} \mathrm{Nd} /{ }^{144} \mathrm{Nd} \mathrm{e}{ }^{147} \mathrm{Sm} /{ }^{144} \mathrm{Nd}$ semelhante à dos meteoritos condritos, por isto os valores do $C H U R$ são utilizados como referência de reservatório uniforme indiferenciado. Desta maneira e segundo as características geoquímicas abordadas, a crosta formada por fusão do manto irá ter baixa razão $\mathrm{Sm} / \mathrm{Nd}$ e consequentemente, baixa razão ${ }^{143} \mathrm{Nd} /{ }^{144} \mathrm{Nd}$ com o tempo, enquanto o manto residual terá altas razões $\mathrm{Sm} / \mathrm{Nd}$ e ${ }^{143} \mathrm{Nd} /{ }^{144} \mathrm{Nd}$, se comparado ao CHUR. Portanto, magmas gerados a partir do manto empobrecido ou da crosta continental irão ter de um modo geral valores de $\varepsilon N d(T)$ positivos ou negativos, respectivamente (DePaolo, 1988; Faure \& Mensing, 2005). Este comportamento é oposto ao do sistema Rb-Sr e será mais bem abordado no próximo tópico devido a sua importância petrogenética. 


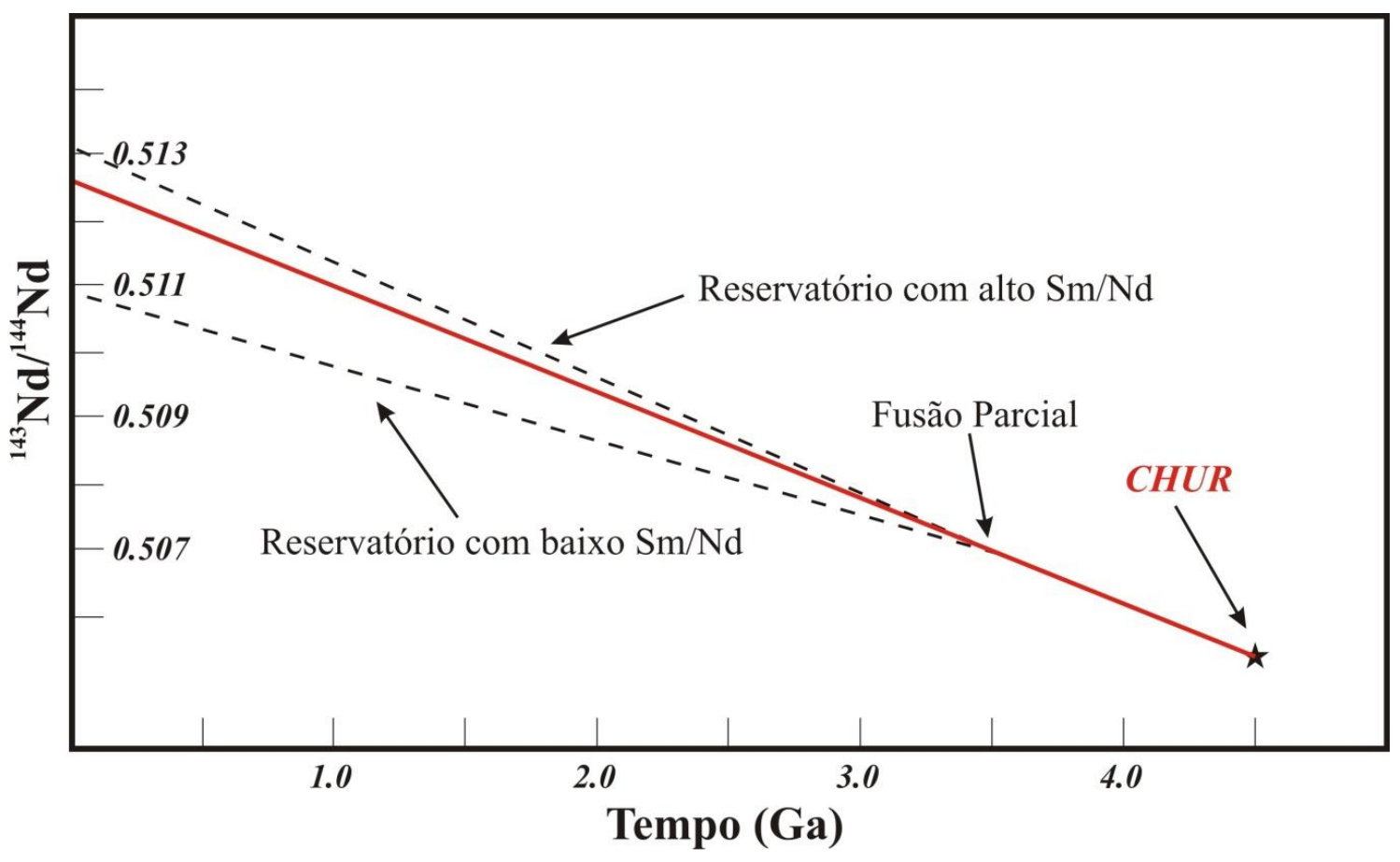

Figura 2.6. Evolução isotópica do Nd na Terra. CHUR (Chondritic Uniform Reservoir) é assumido como o valor inicial de ${ }^{143} \mathrm{Nd} /{ }^{144} \mathrm{Nd}$ da Terra indiferenciada. A linha vermelha indica a evolução do reservatório indiferenciado $(C H U R)$ até o presente. Caso os reservatórios formados durante a fusão parcial permaneçam fechados, a evolução da razão ${ }^{143} \mathrm{Nd} /{ }^{144} \mathrm{Nd}$ no tempo acontece ao longo das curvas tracejadas proporcionais à razão $\mathrm{Sm} / \mathrm{Nd}$ (Adaptado de White, 2005).

\section{Correlação Isotópica entre Nd-Sr e Heterogeneidades do Manto}

Evidências de correlação entre as variações isotópicas de $\mathrm{Nd}$ e $\mathrm{Sr}$ foram inicialmente descritas, em amostras de basaltos oceânicos jovens, por DePaolo \& Wasserburg (1976b), Richard et al. (1976) e O'Nions et al. (1977). Desde então, a correlação entre os sistemas isotópicos $\mathrm{Sm}-\mathrm{Nd}$ e $\mathrm{Rb}-\mathrm{Sr}$ tem sido muito importante nos estudos relacionados à origem das rochas ígneas, bem como para o entendimento da evolução do manto terrestre (Faure, 1986; Hofmann, 1997; Dickin, 2005; White, 2005).

A Figura 2.7 ilustra a variação dos dados isotópicos de $\mathrm{Nd}$ e $\mathrm{Sr}$ para basaltos jovens dos tipos MORB (Mid-Ocean Ridge Basalts) e OIB (Ocean Island Basalts). É notável a correlação negativa entre as razões isotópicas de $\mathrm{Nd}$ e $\mathrm{Sr}$, frequentemente denominada de Mantle Array (DePaolo \& Wasserburg, 1979). Esta correlação isotópica é consistente com as propriedades geoquímicas opostas dos sistemas $\mathrm{Sm}-\mathrm{Nd}$ e $\mathrm{Rb}-\mathrm{Sr}$ durante os processos magmáticos e reflete processos de mistura e diferenciação de todo o manto terrestre ao longo do tempo geológico (DePaolo \& Wasserburg, 1979; Allègre, 2008). O Mantle Array é uma linha-base para os estudos de magmas mantélicos a partir da qual desvios significativos requerem condições petrogenéticas especiais (i.e., processos outros além da fusão parcial). 
Em geral, estes desvios são associados à contaminação crustal ou mistura de distintas fontes (DePaolo \& Wasserburg, 1979). É também a partir dessa correlação isotópica entre Nd e Sr que pode se estimar a razão ${ }^{87} \mathrm{Sr} /{ }^{86} \mathrm{Sr}$ do $B S E$, uma vez que o valor de $\varepsilon N d(T)$ igual a zero representa um reservatório indiferenciado (Bell \& Blenkinsop, 1987a; DePaolo, 1988).

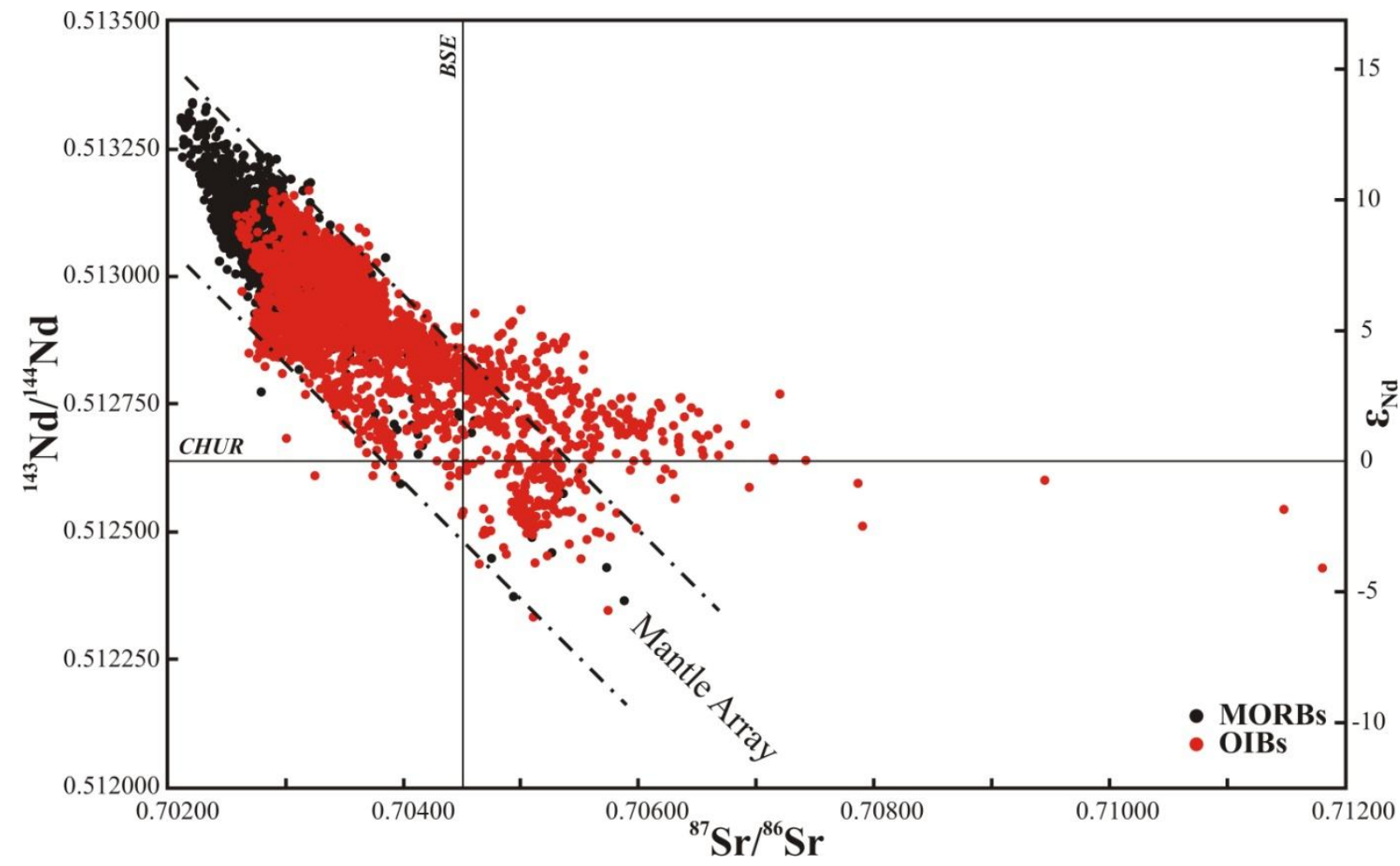

Figura 2.7. Correlação isotópica entre ${ }^{143} \mathrm{Nd} /{ }^{144} \mathrm{Nd}$ e ${ }^{87} \mathrm{Sr} /{ }^{86} \mathrm{Sr}$ em basaltos oceânicos jovens (< $\left.25 \mathrm{Ma}\right)$. Razões medidas consideradas como sendo iniciais visto que a correção com respeito à idade é mínima. Linha horizontal refere-se ao valor ${ }^{143} \mathrm{Nd} /{ }^{144} \mathrm{Nd}$ atual do $C H U R(0.512638)$ e linha vertical indica a razão ${ }^{87} \mathrm{Sr} /{ }^{86} \mathrm{Sr}$ atual teórica do $\mathrm{BSE}(\mathbf{0 . 7 0 4 5 )}$. Dados de $1733 \mathrm{MORB}$ plotados foram retirados da base de dados PetDB (http://www.petdb.org), enquanto dados de 2995 OIB plotados são do banco de dados GEOROC (http://georoc.mpch-mainz.gwdg.de/georoc/), ambos descarregados em Junho de 2013.

Adicionalmente, a posição dos pontos em relação às linhas de referência $B S E$ e $C H U R$ (Figura 2.7) apontam se a região fonte de determinado magma era empobrecida ou enriquecida em isótopos radiogênicos de $\mathrm{Sr}$ e $\mathrm{Nd}$ e, por consequência, em LILE. Pontos no quadrante superior esquerdo indicam fonte empobrecida, enquanto que pontos no quadrante inferior direito refletem uma fonte enriquecida (Bell \& Blenkinsop, 1987a, DePaolo, 1988).

Deste modo, as razões isotópicas de $\mathrm{Nd}$ e $\mathrm{Sr}$ comportam-se como um par de traçadores acoplados, o que possibilita a caracterização dos reservatórios terrestres (i.e., crosta e manto) e, portanto, se tornam essenciais para o entendimento da origem das rochas ígneas e dos processos magmáticos atuantes durante a sua formação (DePaolo, 1988; White, 2005). 
É válido ressaltar que a distribuição dos dados de $O I B s$ na Figura 2.7 claramente evidencia que tais basaltos derivam de fontes mantélicas isotopicamente distintas daquela dos MORBs (White \& Hofmann, 1982), variando desde uma fonte mantélica tipicamente empobrecida em elementos incompatíveis (i.e., manto residual) até fontes enriquecidas em isótopos radiogênicos com relação ao $B S E$.

De fato, diversos estudos isotópicos e com elementos traço em basaltos oceânicos tem mostrado que o manto terrestre é heterogêneo (ver Stracke, 2012 para revisão atualizada). Além disso, as áreas fontes no manto são formadas, na sua maioria, por complexas misturas de dois ou mais componentes quimicamente independentes, em diferentes proporções, e sem a necessidade de existir reservatórios fisicamente distintos (Zindler et al., 1982). Contudo, embora o manto terrestre seja heterogêneo, há uma variação sistemática nas razões isotópicas dos MORBs e OIBs. Assim, alguns autores (White, 1985; Zindler \& Hart, 1986; Hart, 1988) definiram e/ou caracterizaram ao menos quatro componentes mantélicos principais com base nos dados isotópicos de $\mathrm{Nd}, \mathrm{Sr}$ e Pb dos basaltos oceânicos: (1) DMM - Depleted MORB mantle (i.e., manto residual empobrecido); (2) HIMU - High- ${ }^{206} \mathrm{~Pb}^{204} \mathrm{~Pb}$ mantle (i.e., manto com alta razão U/Pb); (3) EM-I - Enriched Mantle I (i.e., manto enriquecido I); (4) EM-II Enriched Mantle II (i.e., manto enriquecido II).

Hart et al. (1992) e Hauri et al. (1994) propuseram ainda um quinto componente mantélico comum aos $O I B s$, supostamente situado no manto inferior, denominado de FOZO (i.e., Focus Zone). A posição desses cinco componentes mantélicos no diagrama de correlação isotópica Nd-Sr está ilustrada na Figura 2.8 (Tópico 2.3). Revisões detalhadas das características isotópicas, bem como de alguns modelos propostos para explicar a origem de tais componentes, podem ser encontradas em Hofmann et al. (1997) e Stracke (2012).

Tais heterogeneidades mantélicas (i.e., processos de enriquecimento do manto) são comumente associadas à reciclagem da litosfera oceânica e crosta continental nas zonas de subducção (White \& Hofmann, 1982; Zindler \& Hart 1986; Hofmann, 1997; Stracke, 2012). Entretanto, exceto pela concordância de que o componente exclusivo dos MORBs (i.e., DMM) está situado no manto superior convectivo (Collerson et al., 2010), muito debate ainda existe acerca da origem e dos processos formadores dos demais componentes mantélicos, tipicamente relacionados aos OIBs/plumas mantélicas (Collerson et al., 2010; White, 2010). 


\subsection{SISTEMÁtICA DE ISÓTOPOS RADIOGÊNICOS EM CARBONATITOS}

Devido à sua composição geoquímica incomum (i.e., extremamente enriquecidos em elementos como o $\mathrm{Nd}$ e o $\mathrm{Sr}$ ) e a ampla distribuição temporal e espacial, os carbonatitos têm sido muito importantes no estudo da composição e evolução do manto terrestre sob os continentes (e.g., Bell \& Tilton, 2002; Bizzarro et al., 2002) embora ainda ocorra bastante discussão acerca da fonte mantélica destas rochas (i.e., litosférica, Woolley \& Bailey, 2012; ou sublitosférica, Bell \& Simonetti, 2010). Ademais, carbonatitos são formados por magmas provenientes tanto de um manto empobrecido quanto enriquecido em isótopos radiogênicos (Figura 2.8 e Figura 2.9) e, portanto, podem ter valores positivos ou negativos de $\varepsilon N d(T)$ e $\varepsilon \operatorname{Sr}(T)$

Dados isotópicos de $\mathrm{Nd}, \mathrm{Sr}$ e $\mathrm{Pb}$ em diversos carbonatitos ao redor do mundo indicam que a maioria dos carbonatitos jovens $(<200 \mathrm{Ma})$ tem uma sistemática isotópica similar a dos OIBs (Bell \& Blenkinsop, 1987a; Nelson, 1988; Bell \& Blenkinsop, 1989; Bell, 1994; Bell \& Tilton, 2002; Bell \& Simonetti, 2010). De fato, as assinaturas isotópicas de carbonatitos da América do Norte, Europa Central, Nova Zelândia, Rift do Leste da África (EAR em inglês), Ilhas Canárias e Arquipélago de Cabo Verde são caracterizadas por misturas de vários componentes mantélicos, particularmente, HIMU, EM-I e FOZO (Figura 2.8). Esta similaridade isotópica entre os carbonatitos e os OIBs sugere que ambos são derivados de fontes mantélicas com uma história evolutiva em comum (Bell \& Blenkinsop, 1989; Bell, 1994). Adicionalmente, a presença de tais componentes mantélicos modernos sob os continentes implica que existem semelhanças consideráveis entre porções do manto suboceânico e do manto subcontinental (Bell \& Tilton, 2002; Bell \& Simonetti, 2010).

Uma importante característica dos carbonatitos, e também dos OIBs, é a relativa ausência do componente mantélico DMM (Bell \& Blenkinsop, 1989; Bell \& Simonetti, 2010). Embora carbonatitos com assinatura isotópica $\mathrm{Nd}-\mathrm{Sr}$ empobrecida sejam comuns, raramente tais assinaturas sobrepõem o campo dos MORBs. Isto indica nitidamente que ambos têm uma origem a partir de regiões distintas do manto. Bell \& Tilton (2002) e Collerson et al. (2010) interpretam que as afinidades isotópicas entre os carbonatitos e $O I B s$, em conjunto com dados de gases nobres, corroboram a ideia de que os componentes mantélicos HIMU e EM-I são derivados do manto sublitosférico. Aqueles autores argumentam ainda ser improvável que tais componentes mantélicos tão uniformes estejam relacionados ao processo de subducção visto que materiais crustais distintos foram introduzidos no manto em diferentes épocas. 


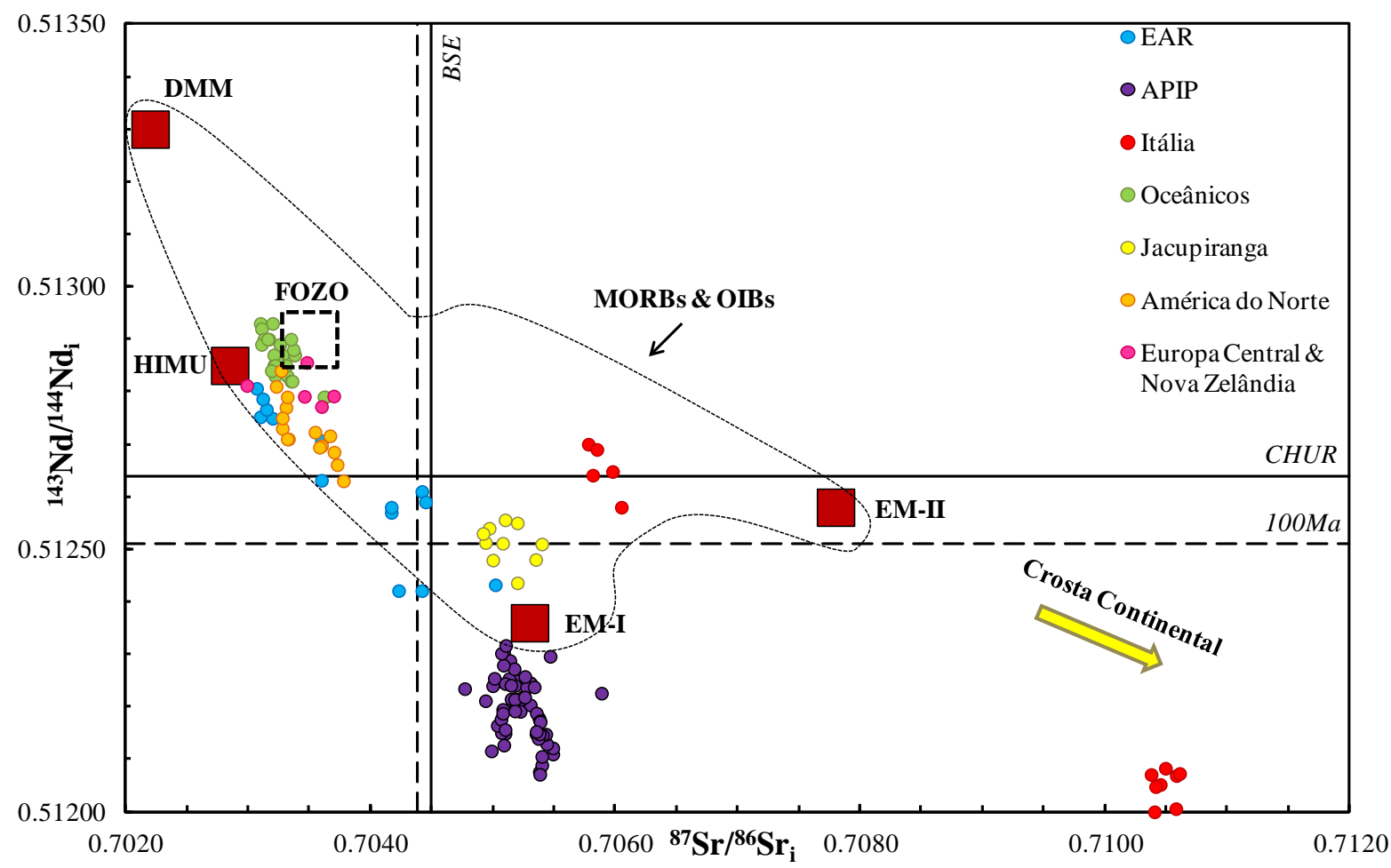

Figura 2.8. Comparação entre carbonatitos jovens $(<200$ Ma) e basaltos oceânicos no diagrama de correlação isotópica ${ }^{143} \mathrm{Nd} /{ }^{144} \mathrm{Nd} \mathrm{e}{ }^{87} \mathrm{Sr} /{ }^{86} \mathrm{Sr}$. Campo tracejado dos MORBs e OIBs delimitado com base nos dados plotados na Figura 2.7. DMM, HIMU, EM-I e EM-II são aproximações dos componentes mantélicos segundo Hart et al. (1992). FOZO segundo Hauri et al. (1994). Seta amarela aponta para a média da crosta continental $\left({ }^{87} \mathrm{Sr} /{ }^{86} \mathrm{Sr}=0.720 ;{ }^{143} \mathrm{Nd} /{ }^{144} \mathrm{Nd}=0.5118\right.$ - Hofmann, 1997). Linhas vertical e horizontal tracejadas indicam os valores do BSE e CHUR calculado a 100 Ma. Fonte dos dados: East African Rift $(E A R)$ - Bell \& Blenkinsop (1987a), Nelson et al. (1988); Itália - Castorina et al. (2000), Rosatelli et al. (2007); APIP - Gomes \& Comin-Chiaramonti (2005), Cordeiro et al. (2010, 2011b), Barbosa et al. (2012a) e dados não publicados de Brod (1999), Barbosa (2009), Grasso (2010), Palmieri (2011), Oliveira (2015). Carbonatitos Oceânicos - Hoernle et al. (2002); Jacupiranga - Roden et al. (1985), Nelson et al. (1988), Huang et al. (1995); América do Norte - Bell \& Blenkinsop (1987b), Tilton et al. (1987), Wen et al. (1987), Nelson et al. (1988); Europa Central \& Nova Zelândia - Barreiro \& Copper (1987), Nelson et al. (1988). Todos os dados plotados são razões iniciais. Dados da $A P I P$ foram recalculados para a idade $\mathrm{T}=85 \mathrm{Ma}$ e constantes de decaimento radioativo $\lambda_{\mathrm{Rb}}^{87}$ e $\lambda_{\mathrm{Sm}}^{147}$ igual a $1.393 \times 10^{-11} \mathrm{yr}^{-1}$ e $6.54 \times 10^{-12} \mathrm{yr}^{-1}$, respectivamente.

Não obstante a notável correlação isotópica existente entre carbonatitos e $O I B s$, alguns carbonatitos jovens da Itália (Figura 2.8) e da China (Ying et al., 2004), por exemplo, tem razões isotópicas muito mais enriquecidas do que a maioria dos carbonatitos ao redor do mundo, especialmente em ${ }^{87} \mathrm{Sr}^{86} \mathrm{Sr}_{\mathrm{i}}$. Tais composições isotópicas têm sido interpretadas como resultado de uma influência direta do manto litosférico metassomatizado na formação destas rochas (Ying et al., 2004). Além disso, parece haver uma correlação entre o tipo de afiliação do magmatismo carbonatítico (i.e., sódica ou potássica) e a sua composição isotópica $\mathrm{Nd}-\mathrm{Sr}$ (Cordeiro et al., 2010). Carbonatitos de várias idades associados a magmatismo potássico (e.g., Itália - Recente; APIP - $85 \mathrm{Ma}$; Phalaborwa - $2.0 \mathrm{Ga}$ ) têm assinatura mantélica enriquecida à medida que carbonatitos de afiliação sódica (e.g., Ilhas Oceânicas - < 20 Ma; América do Norte - 100 Ma; Província de Kola - 380 Ma) tem uma assinatura típica de manto 
empobrecido (Figura 2.8 e Figura 2.9). Cordeiro et al. (2010) sugerem que esta possível correlação geoquímico-isotópica indica uma origem a partir de regiões distintas no manto (i.e., magmas potássicos - SCLM metassomatizado; magmas sódicos - manto astenosférico).

Um fato contraditório na sistemática isotópica de alguns carbonatitos é que embora os isótopos de $\mathrm{Nd}$ e $\mathrm{Sr}$ revelem uma fonte mantélica empobrecida em LILE, carbonatitos e rochas alcalinas são tipicamente caracterizados por terem concentrações extremamente elevadas destes elementos (Andersen, 1987; Bell \& Blenkinsop, 1987b; Hode Vuorinen, 2005; Kogarko et al., 2010). O forte enriquecimento em elementos incompatíveis evidenciado nos carbonatitos e em diversas rochas alcalinas é difícil de ser explicado, mesmo por taxas muito pequenas de fusão parcial (Kogarko et al., 2010). Deste modo, este "desacoplamento" entre a composição isotópica e a concentrações de LILE só pode ser explicado pela adição desses elementos numa fonte previamente empobrecida (i.e., metassomatismo mantélico). Nesses casos o enriquecimento deve ser recente, ou seja, precisa ocorrer um pouco antes ou no momento da geração dos magmas para que não haja modificações significativas na assinatura isotópica empobrecida da área fonte (Andersen, 1987; Kogarko et al., 2010).

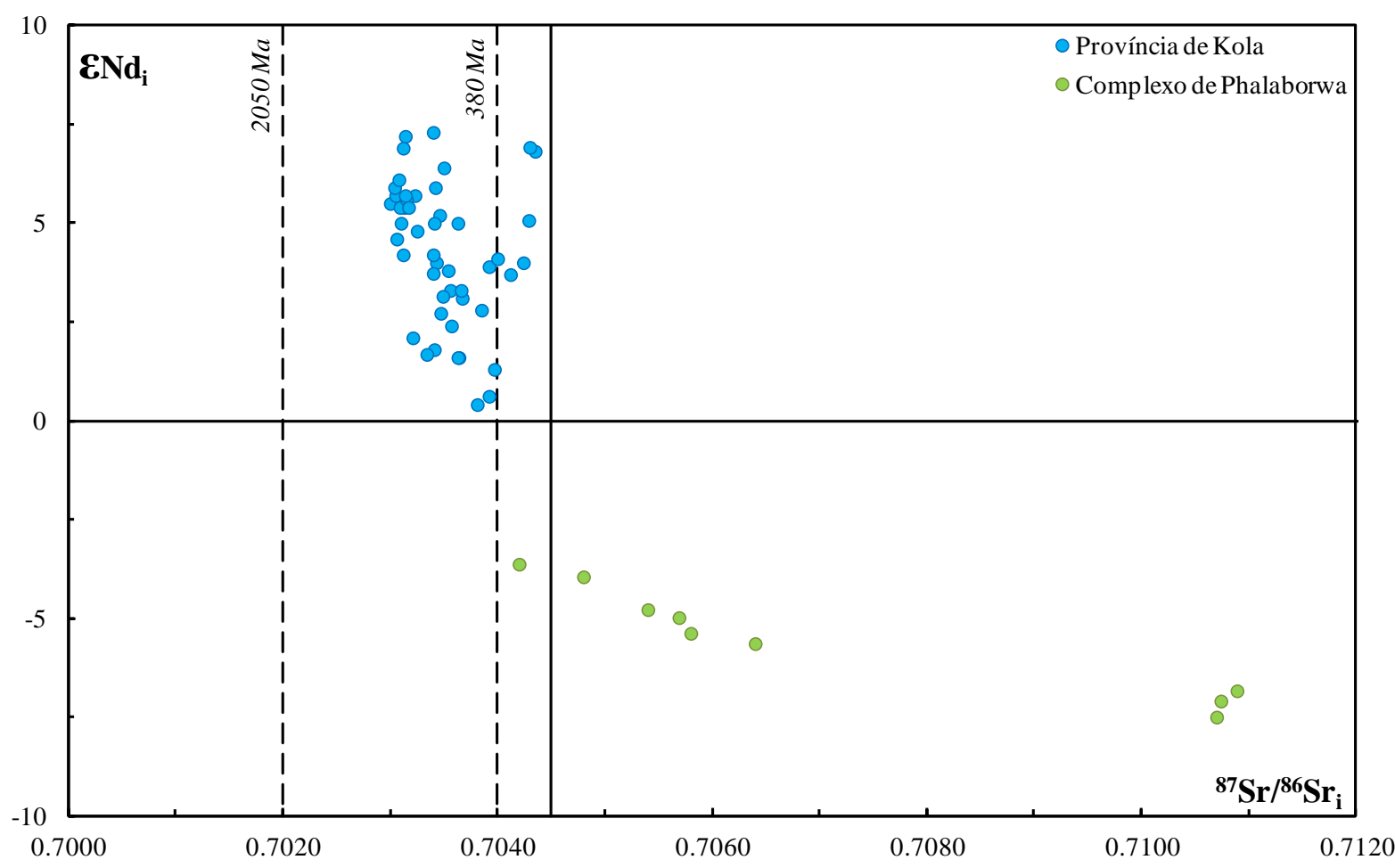

Figura 2.9. Assinatura isotópica inicial de $\mathrm{Nd}$ e $\mathrm{Sr}$ para os carbonatitos da Província Alcalina de Kola, Rússia ( 380 Ma) e do Complexo de Phalaborwa, África do Sul ( 2.0 Ga). Linhas tracejadas verticais indicam os valores do $B S E$ calculados para as idades de referência de 380 Ma e 2050 Ma, respectivamente. Dados retirados de Zaitsev \& Bell (1995), Dunworth \& Bell (2001) e Downes et al. (2005) - Província Alcalina de Kola; Yuhara et al. (2005) e Wu et al. (2011) - Complexo de Phalaborwa. 
O metassomatismo mantélico provoca não só um enriquecimento em LILE no manto superior empobrecido (e.g., SCLM), necessário para justificar a composição química dos carbonatitos e demais rochas alcalinas, mas também é capaz de produzir assinaturas isotópicas enriquecidas. Meen et al. (1989) definem metassomatismo mantélico como o processo pelo qual materiais são acrescidos ao manto por difusão ou por infiltração de fases fluídas e/ou melts. Este processo forma um sistema de diques e veios compostos por material enriquecido meio a uma matriz tipicamente empobrecida. Assim, magmas produzidos por diferentes proporções destas duas fases (i.e., manto heterogêneo) irão descrever uma correlação isotópica linear entre as composições do veio e do manto empobrecido (Meen et al., 1989). Segundo Roden \& Murthy (1985), o enriquecimento em ETR leves é uma característica diagnóstica do metassomatismo mantélico, e caso haja tempo suficiente entre o evento metassomático e a geração dos magmas, as regiões metassomatizadas irão produzir razões isotópicas bem distintas daquelas do manto empobrecido. Além disso, o limite superior da idade do metassomatismo pode ser determinado com base nas idades modelo de $\mathrm{Nd}$ se considerarmos que a área fonte do manto permaneceu isotopicamente fechada desde que o evento metassomático reduziu a razão $\mathrm{Sm} / \mathrm{Nd}$ da área fonte (Roden \& Murthy, 1985). Outros efeitos do metassomatismo mantélico no processo de geração das rochas alcalinas e carbonatitos encontram-se detalhados em Meen et al. (1989).

A Figura 2.10 mostra a evolução isotópica de $\mathrm{Sr}$ com o tempo para diversos carbonatitos do Canadá, Groenlândia e Fennoscândia (i.e., Escudo Báltico). Estes dados sugerem que a fonte mantélica dos carbonatitos nestas regiões permaneceu isolada por longos períodos de tempo, em alguns casos desde o Arqueano (Bell \& Tilton, 2002; Bell \& Simonetti, 2010). As linhas de evolução indicam que duas fontes mantélicas, uma empobrecida e outra enriquecida, podem ter se formado a partir do reservatório mantélico indiferenciado (i.e., BSE) á cerca de 3.0 Ga (Bell \& Tilton, 2002; Bell \& Rukhlov, 2004; Bell $\&$ Simonetti, 2010). Contudo, dados isotópicos de Nd para as mesmas amostras (Figura 2.11) sugerem que o manto nestas regiões já era empobrecido antes de 3.0 Ga (Bell \& Tilton, 2002). Segundo Rukhlov \& Bell (2003), isótopos Nd e Hf em diversos carbonatitos ao redor do mundo apontam para a formação de um manto empobrecido logo nos primórdios da história evolutiva da Terra. Ao mesmo tempo, dados isotópicos recentes de $\mathrm{Nd}, \mathrm{Sr}$ e $\mathrm{Hf}$ em alguns carbonatitos Pré-Cambrianos evidenciam a existência de fontes mantélicas isotopicamente enriquecidas desde pelo menos o Paleoproterozóico (Wu et al., 2011; Ye et al., 2013). 


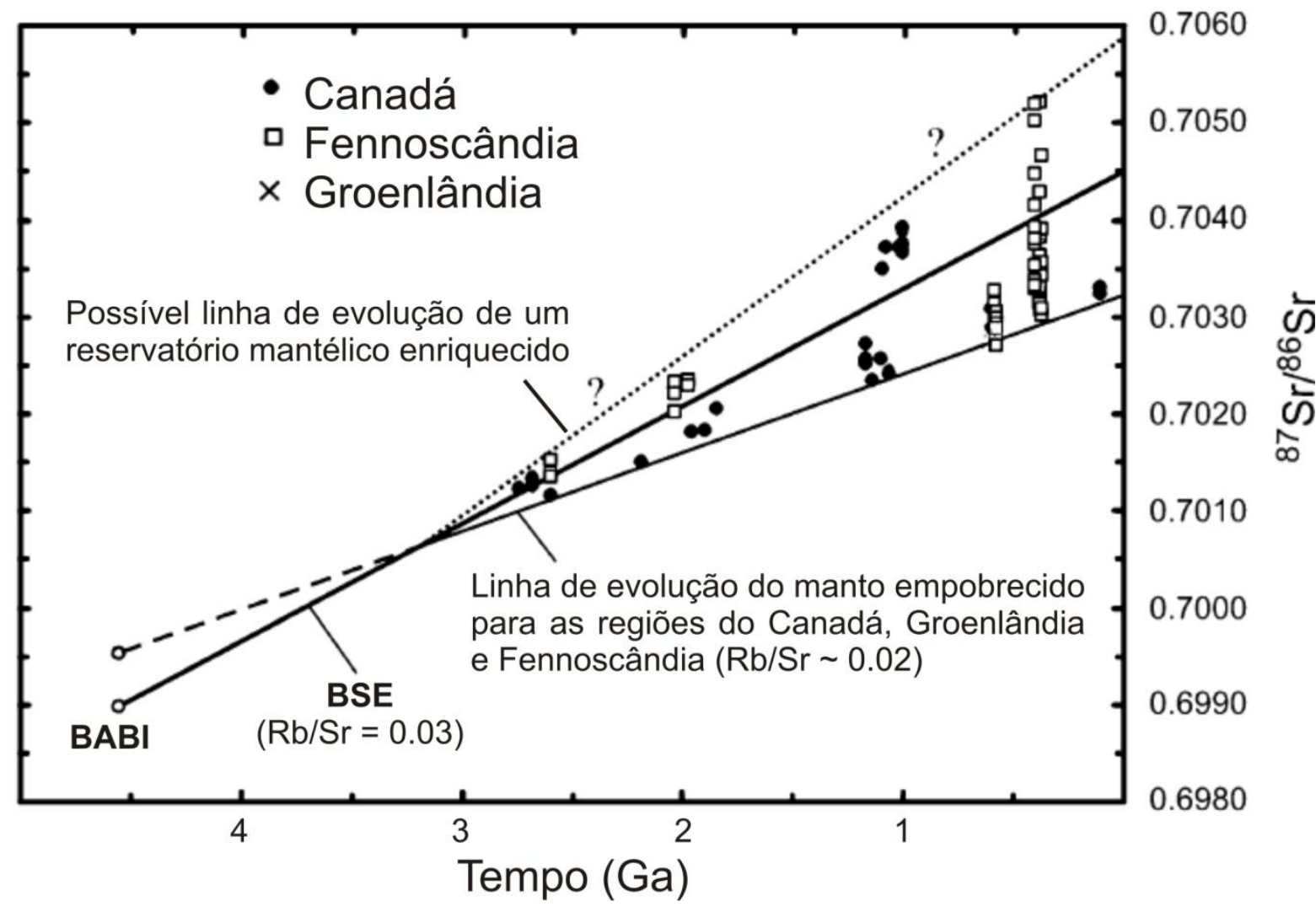

Figura 2.10. ${ }^{87} \mathrm{Sr} /{ }^{86} \mathrm{Sr}$ versus tempo para carbonatitos do Canadá, Fennoscândia e Groenlândia. Notar que a linhas de evolução do manto empobrecido intersecta a linha do $B S E$ em $\sim 3$ Ga. BABI representa o valor inicial de ${ }^{87} \mathrm{Sr} /{ }^{86} \mathrm{Sr}$ da Terra indiferenciada (Adaptado de Bell \& Simonetti, 2010).

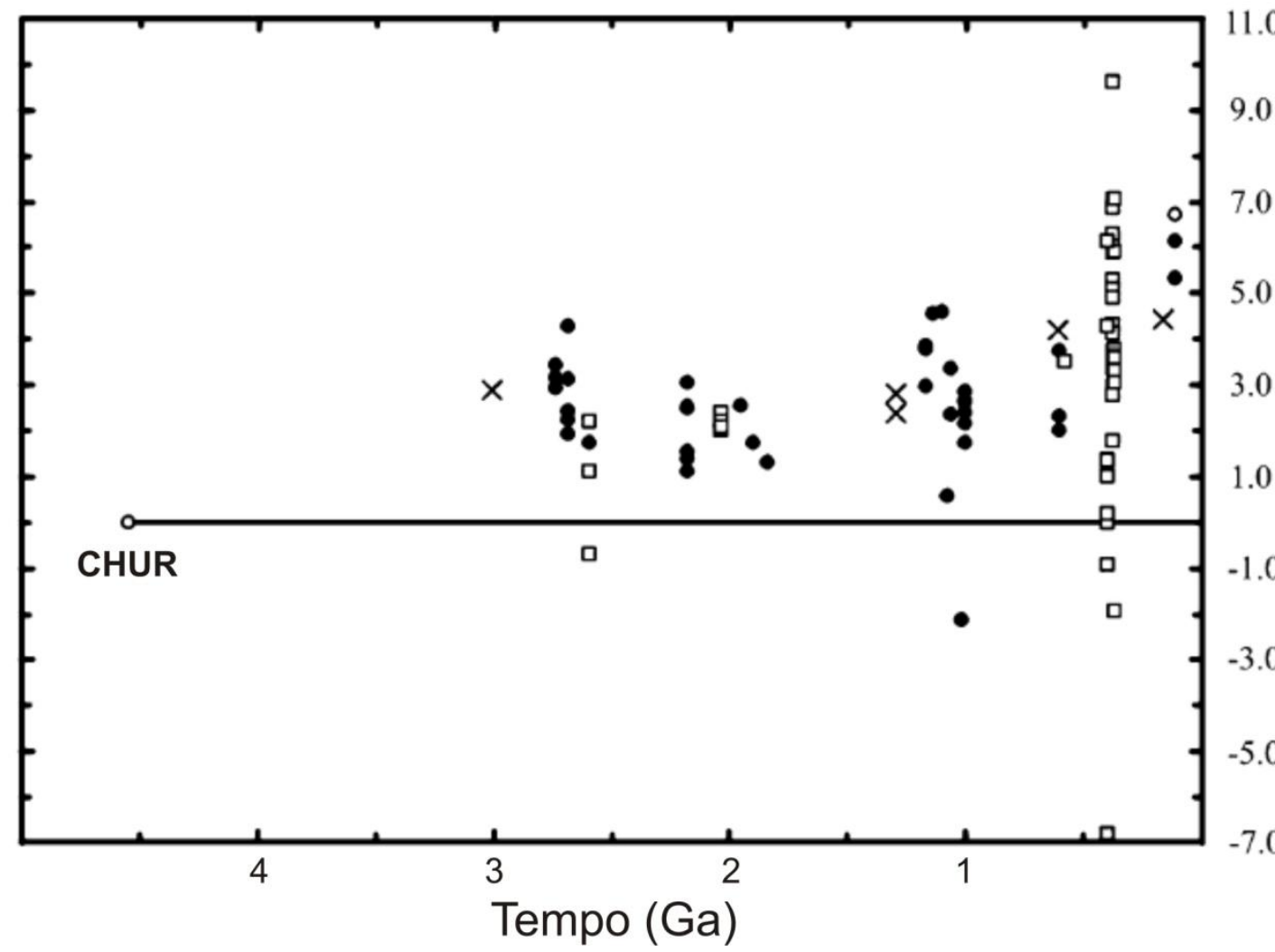

Figura 2.11. $\varepsilon N d(T)$ versus tempo para carbonatitos do Canadá, Fennoscândia e Groenlândia. Notar que quase todos os valores de $\varepsilon N d(T)$ são positivos, sugerindo um empobrecimento anterior a 3.0 Ga. $C H U R$ representa a Terra indiferenciada. Símbolos como na Figura 2.10 (Adaptado de Bell \& Simonetti, 2010). 
Vladykin et al. (2004; 2005) correlacionam, empiricamente, a composição isotópica do manto fonte das rochas alcalinas e carbonatitos com os diversos ambientes geodinâmicos (Figura 2.12). Tal correlação é sugerida devido à multiplicidade de ambientes tectônicos em que estas rochas podem ocorrer, além da ampla, porém sistemática variação das assinaturas isotópicas. Segundo aqueles autores, diferentes "tipos de manto" são caracterizados por ambientes geodinâmicos distintos de geração das rochas alcalinas. Portanto, a partir do estudo de rochas alcalinas e carbonatitos da Sibéria e Mongólia, Vladykin et al. (2005) propõem que: (1) Estas rochas associadas à riftes intracontinentais têm assinaturas isotópicas enriquecidas, similares ao componente mantélico EM-I; (2) Rochas alcalinas e carbonatitos situados exclusivamente em faixas móveis têm assinatura isotópica enriquecida que se estende além do componente mantélico EM-II; e (3) complexos alcalino-carbonatíticos localizados em áreas de plataformas têm assinatura isotópica típica de um manto empobrecido (Figura 2.12).

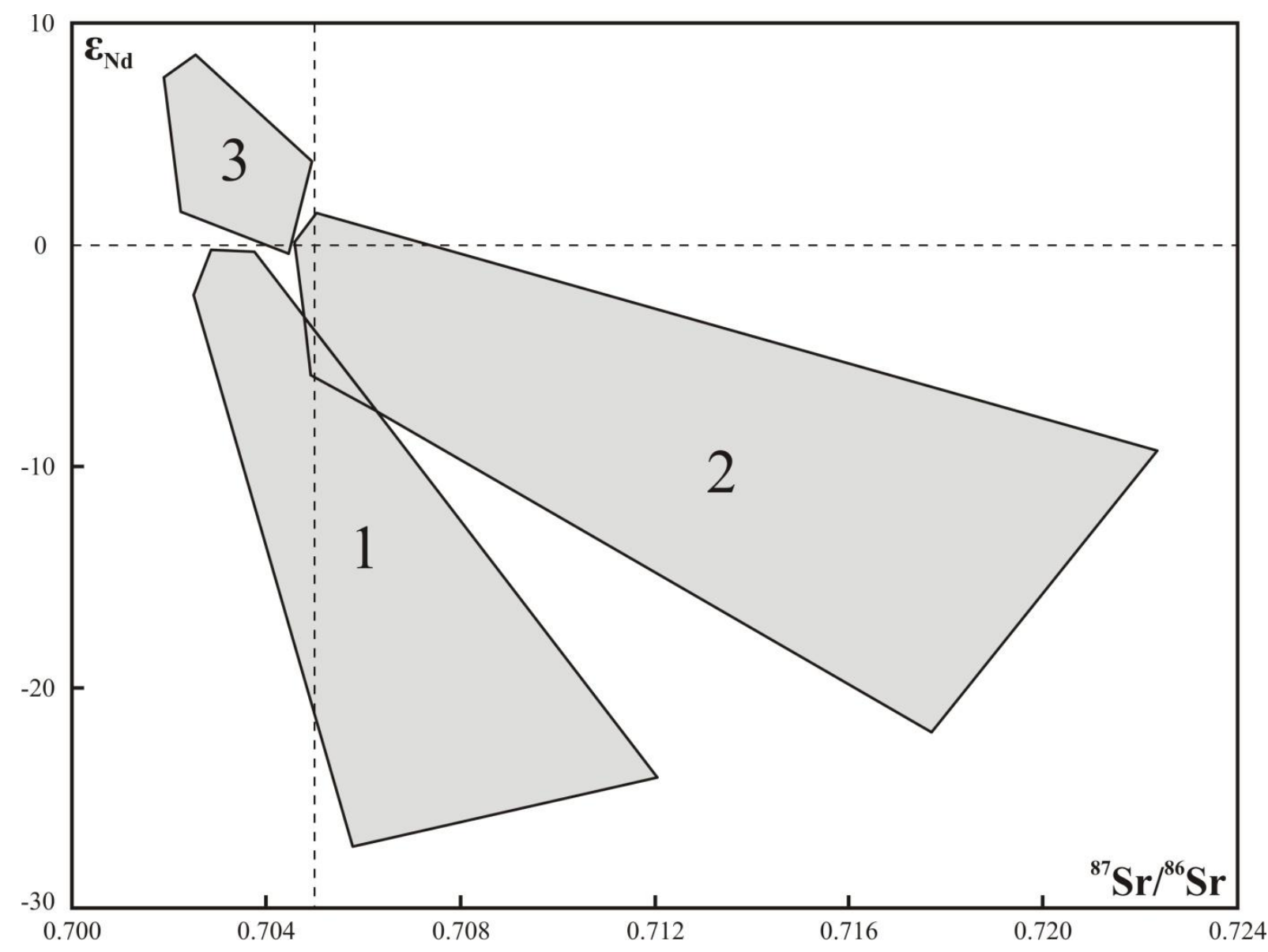

Figura 2.12. Diagrama ${ }^{143} \mathrm{Nd} /{ }^{144} \mathrm{Nd} \mathrm{x}{ }^{87} \mathrm{Sr} /{ }^{86} \mathrm{Sr}$ associando diferentes ambientes geodinâmicos e "tipos de manto" com a composição isotópica de rochas alcalinas, carbonatitos e lamproítos. 1- rochas alcalinas, carbonatitos e lamproítos da América do Norte e Sibéria localizados em Zonas de Rifte; 2- rochas alcalinas, carbonatitos e lamproítos da Austrália, Espanha, Mongólia e Sibéria situados em Faixas Móveis; 3- rochas alcalinas e carbonatitos da Plataforma Siberiana (Segundo Vladykin et al., 2005). 


\section{MATERIAIS \& MÉTODOS}

\subsection{Amostragem}

As amostras utilizadas no presente estudo são exemplares representativos das três séries petrogenéticas que compõem os complexos alcalino-carbonatíticos da APIP, selecionadas dentre as disponíveis no acervo do Grupo de Pesquisa de Rochas Alcalinas e Mineralizações Associadas. Quatorze amostras foram escolhidas, quatro pertencentes ao Complexo de Catalão I e as demais ao Complexo de Salitre, de modo a representar a maior amplitude composicional possível. Optou-se por amostras que não tinham evidências de alterações hidrotermais ou metassomáticas, as quais poderiam interferir nos dados isotópicos.

Após a seleção, realizou-se um estudo detalhado das feições mineralógicas e texturais por microscopia de luz transmitida e refletida em todas as amostras. Esta analise petrográfica teve o objetivo de determinar a composição modal e a relação entre as fases minerais, além de guiar a escolha de minerais para a realização das analises isotópicas.

Os dados de química de rocha total, tanto de elementos maiores quanto de elementos traço, utilizados neste trabalho foram obtidos por Cordeiro (2009), e Barbosa (2009) para as amostras dos complexos de Catalão I e Salitre, respectivamente.

\subsection{SEPARAÇÃo E CONCENTRAÇÃo dOS Minerais}

Os minerais escolhidos para determinação da composição isotópica foram apatita, barita, calcita, clinopiroxênio, dolomita, flogopita, granada, magnetita, norsethita, olivina, perovskita e pirocloro.

Para a obtenção de separados minerais, inicialmente é necessária a cominuição das amostras. Usualmente, este processo é manual, com o auxilio de almofariz e pistilo de ágata, os quais objetivam a maior preservação dos minerais em relação à utilização dos tradicionais britadores de mandíbula e moinhos de disco.

No presente estudo utilizou-se a técnica de desagregação eletrodinâmica para a fragmentação das amostras. A desagregação eletrodinâmica consiste em incidir descargas elétricas de alta voltagem e em curtos períodos de tempo sobre uma amostra, a qual deve estar imersa em um líquido dielétrico (e.g., água) (Figura 3.1). Como resultado, uma corrente elétrica é induzida a passar através da amostra, o que gera ondas de choque. Estas ondas 
fragmentam o material por esforços tracionais atuantes nos planos de descontinuidade física (Andres, 1995; 1996; Gnos et al., 2007; Giese et al., 2010). Este método permite a liberação das fases minerais paralelamente aos limites dos grãos, bem como, ao longo de descontinuidades internas (e.g., lamelas de exsolução, planos de geminação, etc.), o que produz uma fragmentação seletiva da amostra e aumenta a qualidade dos separados minerais (Andres, 1996; Gnos et al., 2007; Giese et al., 2010).
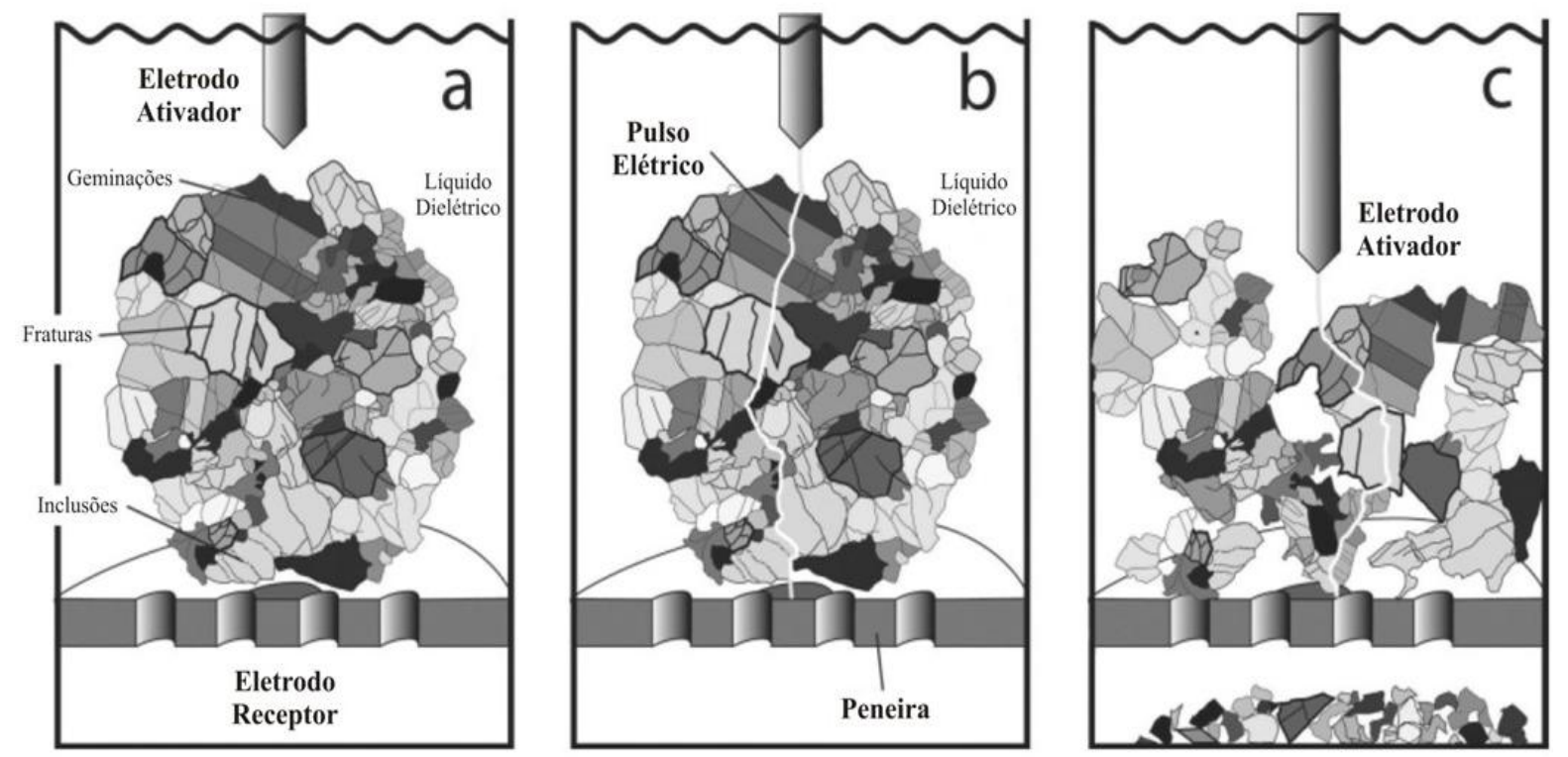

Figura 3.1. Desenho esquemático do processo de desagregação eletrodinâmica. A amostra imersa em água (a) é atingida por pulsos elétricos de alta voltagem e curta duração $(b, c)$. Isto provoca a passagem da descarga através da amostra e produz ondas de choque que quebram o material ao longo das descontinuidades (segundo Giese et al., 2010).

Apenas recentemente a desagregação eletrodinâmica tornou-se uma alternativa comercialmente viável em relação aos processos clássicos de desintegração de rochas para a obtenção de separados minerais (Gnos et al., 2007; Wang et al., 2012). Malarkey (2010) empregou esta técnica para a obtenção de apatita e calcita em kimberlitos com pequenas proporções modais destes minerais, devido à melhor preservação dos cristais quando comparada aos procedimentos mecânicos. No presente trabalho, esse método também auxiliou na separação de fases minerais que ocorrem em proporção modal de menos de 5\%, tais como barita e pirocloro. Além disso, a desagregação eletrodinâmica evita qualquer possível contaminação entre a amostra e o equipamento, pois não há interação mecânica, e reduz drasticamente a quantidade de fragmentos multiminerálicos, o que facilita a seleção manual dos minerais puros (Andres, 1996; Gnos et al., 2007). 
As amostras utilizadas nesta dissertação foram cominuídas por meio do fragmentador SELFRAG ${ }^{\circledR}$ Lab S2.0 High Voltage Pulse Power Fragmentation no Laboratório de Estudos Geodinâmicos, Geocronológicos e Ambientais do Instituto de Geociências da Universidade de Brasília. As condições operacionais estão resumidas na Tabela B1 (anexos). Após o processamento de cada amostra teve-se o cuidado de desmontar, lavar e remontar todo o recipiente no qual são colocadas as amostras. As porções do equipamento em contato direto com o recipiente de processamento também foram limpas a cada nova amostra (Figura 3.2).

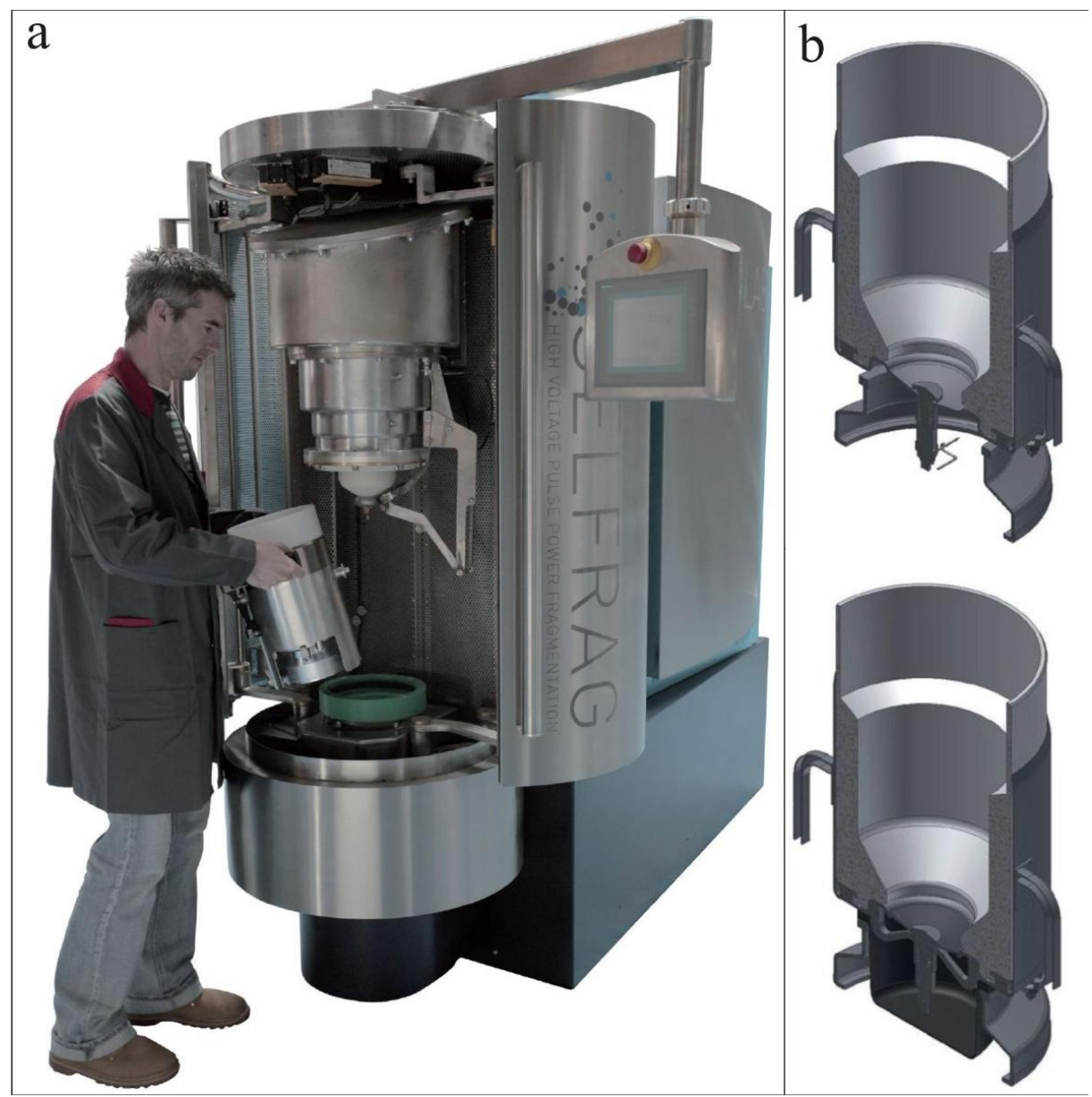

Figura 3.2. a) Procedimento de introdução de amostra no SELFRAG ${ }^{\circledR}$ Lab S2.0 High Voltage Pulse Power Fragmentation. b) Ilustração de um corte vertical no recipiente de processamento das amostras. Notar eletrodo receptor e vaso coletor nas figuras superior e inferior, respectivamente (Retirado de http://selfrag.com/products.php).

Após a fragmentação, as amostras foram secadas com auxílio de lâmpadas de infravermelho, e peneiradas em três frações granulométricas $(<300 \mu \mathrm{m}, 300-500 \mu \mathrm{m}$ e $>$ $500 \mu \mathrm{m}$ ) de modo a facilitar a obtenção dos separados minerais de acordo com a granulação observada no estudo microscópico. Uma vez que as amostras estudadas continham, em geral, grande quantidade de magnetita, utilizou-se um imã de mão para retirar o excesso e, ao 
mesmo tempo, pré-concentrar este mineral. Em seguida, as frações mais finas foram préprocessadas com um separador magnético isodinâmico Frantz ${ }^{\circledR}$.

Tal separação é realizada com base nas diferentes suceptibilidades magnéticas dos minerais, que podem ser classificados em ferromagnéticos, paramagnéticos e diamagnéticos (Rosenblum \& Brownfield, 2000). Ao atravessar o campo magnético fixo do instrumento, os minerais são separados conforme sua maior ou menor interação com o campo. Variações na intensidade da corrente elétrica permitem selecionar diferentes minerais a partir de suas características magnéticas (Rosenblum, 1958; Rosenblum \& Brownfield, 2000). Detalhes das condições operacionais estão na Tabela B2 (anexos).

Durante a operação do separador Frantz ${ }^{\circledR}$, entre cada amostra, tomou-se o cuidado de desmontar, limpar e remontar todas as partes nas quais houve contato da amostra com o instrumento. Em geral, foram separadas três frações por amostra: (1) muito magnética composta por magnetita e minerais ricos em inclusões desta; (2) magnética com silicatos mais ou menos discriminados; (3) não magnética, formada essencialmente por apatita e carbonatos.

A seguir realizou-se a concentração manual dos minerais com estereomicroscopios binoculares Nikon ${ }^{\circledR}$ SMZ800 e Leica ${ }^{\circledR}$ EZ4, ambos com ampliação entre 20x e 40x. O uso deste intervalo de magnificação permitiu evitar cristais com inclusões ou com fragmentos de outros minerais aderidos a superficie, de modo a obter concentrados monominerálicos com, no mínimo, 99\% de pureza (ver Anexo C para imagens dos concentrados minerais).

Nos casos dos concentrados de magnetita e pirocloro do Complexo de Catalão I não foi possível obter uma separação com este grau de pureza, pois tais minerais estão intimamente associados (e.g., abundantes inclusões de pirocloro em magnetita). Nestes casos, o grau de pureza do concentrado ficou em torno de $90 \%$. Entretanto, tendo em vista as concentrações extremamente baixas de $\mathrm{Rb}, \mathrm{Sr}, \mathrm{Sm}$ e $\mathrm{Nd}$ na magnetita, não se espera uma interferência relevante deste mineral nos resultados isotópicos do pirocloro. Todavia, a recíproca não é verdadeira, e os resultados de concentrados de magnetita com contribuição significativa de pirocloro provavelmente refletem a composição isotópica deste último, e devem ser interpretados com cuidado. 


\subsection{LiXIVIAÇÃO DOS MINERAIS}

A partir da discussão dos trabalhos de Machado et al. (1986) e Wittig et al. (2009), optou-se por utilizar procedimentos de lixiviação semelhantes aos recomendados pelos últimos. Alíquotas de aproximadamente 50-200 mg, dependendo da concentração dos analitos em cada fase mineral, foram lixiviadas de acordo com os procedimentos descritos a seguir:

Etapa 1 - Os concentrados minerais foram lavados no ultrassom com água deionizada ultrapura (Milli- $\mathrm{Q}^{\circledR}$ - resistividade de $18.2 \mathrm{M} \Omega \cdot \mathrm{cm}^{-1}$ à $25^{\circ} \mathrm{C}$ ), em béquer de vidro protegido com Parafilm ${ }^{\circledR} \mathrm{M}$, por 30 minutos.

Etapa 2 - Os concentrados foram enxaguados com água Milli- $\mathrm{Q}^{\circledR}$ e novamente lavados no ultrassom sob as mesmas condições por +30 minutos

$\underline{\text { Etapa } 3}$ - Os minerais foram outra vez enxaguados com água Milli-Q ${ }^{\circledR}$ e após a remoção da água, foram lixiviados com $\mathrm{HCl} 2.5 \mathrm{~N}$ por 30 minutos a $80-100^{\circ} \mathrm{C}$.

Etapa 4 - Barita, flogopita, olivina, perovskita e pirocloro foram mais uma vez enxaguados com água Milli- $\mathrm{Q}^{\circledR}$ e colocados para secar. Os concentrados de clinopiroxênio, granada e magnetita foram lixiviados com $\mathrm{HCl} 6 \mathrm{~N}$ por +30 minutos a $80-100^{\circ} \mathrm{C}$.

Etapa 5 - Clinopiroxênio, granada e magnetita foram finalmente enxaguados com água Milli-Q ${ }^{\circledR}$ e colocados para secar.

Os carbonatos foram submetidos apenas à primeira etapa de lixiviação, visto que são rapidamente dissolvidos em ácidos inorgânicos, mesmo que diluídos. A apatita foi lixiviada de acordo com o método desenvolvido no presente trabalho, discutido no capítulo 4, que consiste em lixiviação dos concentrados com ácido acético $0.5 \mathrm{~N}$ a quente, precedida de purificação manual dos mesmos em microscópio binocular. Toda a conduta de lixiviação foi realizada em salas limpas classe 10.000 no Laboratório de Estudos Geodinâmicos, Geocronológicos e Ambientais do Instituto de Geociências da Universidade de Brasília.

\subsection{ANÁLISES ISOTÓPICAS DE SM-ND}

Após a lixiviação, os concentrados minerais foram pesados e misturados a solução spike de ${ }^{149} \mathrm{Sm}^{-}{ }^{150} \mathrm{Nd}$. As amostras de barita, clinopiroxênio, flogopita, granada, magnetita, perovskita e pirocloro foram digeridas com uma mistura de ácido nítrico destilado $\left(\mathrm{HNO}_{3}\right)$ $14 \mathrm{~N}$ e ácido fluorídrico destilado (HF) $27 \mathrm{~N}$, em bombas Parr Teflon ${ }^{\circledR}$ conforme Gioia \& 
Pimentel (2000). No caso da barita, foi necessário repetir o processo de abertura e utilizar maior quantidade de $\mathrm{HNO}_{3}$, uma vez que este mineral tem solubilidade muito baixa (Puchelt \& Setiobudi, 1989; Deer et al., 1992).

As amostras de carbonato e apatita foram digeridas com $2 \mathrm{ml}$ de $\mathrm{HCl} 6 \mathrm{~N}$ (carbonatos) e $2 \mathrm{ml}$ de $\mathrm{HNO}_{3} 14 \mathrm{~N}$ (apatitas), ambas em fracos Savillex ${ }^{\circledR}$ por 1 dia a $80-100^{\circ} \mathrm{C}$.

Amostras de rocha total para as quais não existiam determinações isotópicas prévias foram pulverizadas, pesadas e misturadas com a solução spike e dissolvidas segundo o procedimento resumido na Figura 3.3. Os concentrados de olivina foram preparados utilizando o mesmo método, à exceção da etapa de pulverização.

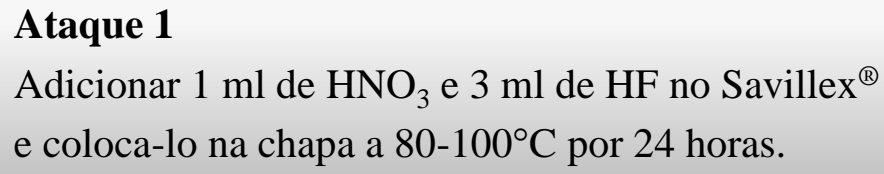

\section{Ataque 2}

Após evaporar, adicionar $1 \mathrm{ml}$ de $\mathrm{HNO}_{3}$ e $3 \mathrm{ml}$ de $\mathrm{HF}$ no Savillex ${ }^{\circledR}$ e coloca-lo na chapa a $80-100^{\circ} \mathrm{C}$ por 4 dias.

\section{Ataque 3}

Após evaporar, adicionar $1 \mathrm{ml}$ de $\mathrm{HNO}_{3}$ no

Savillex ${ }^{\circledR}$ e evaporar novamente logo em seguida.

Ataque 4

Adicionar $3 \mathrm{ml}$ de $\mathrm{HCl} 6 \mathrm{~N}$ no Savillex ${ }^{\circledR} \mathrm{e}$ coloca-lo na chapa a $80-100^{\circ} \mathrm{C}$ por 24 horas.

Figura 3.3. Procedimento de abertura das amostras silicáticas em Savillex ${ }^{\circledR}$. Após o ataque 4, caso a amostra não esteja homogênea, é necessário repetir todo o procedimento. As concentrações dos ácidos $\mathrm{HNO}_{3}$ e HF utilizados são $14 \mathrm{~N}$ e $27 \mathrm{~N}$, respectivamente.

Em seguida à abertura das amostras, utilizou-se colunas de vidro e Teflon ${ }^{\circledR}$ preenchidas com $7 \mathrm{~cm}$ de resina de troca catiônica DOWEX ${ }^{\circledR}$ AG-50W-X8 100-200 mesh para a separação dos elementos terras raras (ETR) da matriz. Posteriormente, as frações de $\mathrm{Sm}$ e Nd foram extraídas por meio de colunas de Teflon ${ }^{\circledR}$ preenchidas com resina Eichrom ${ }^{\circledR}$ LN-Spec 100-150 $\mu \mathrm{m}$. Os procedimentos químicos de separação cromatográfica seguiram a rotina estabelecida por Gioia \& Pimentel (2000). 
As determinações isotópicas foram efetuadas com o equipamento Thermo Scientific TRITON $^{\mathrm{TM}}$ Plus Thermal Ionization Mass Spectrometry (TIMS) no Laboratório de Estudos Geodinâmicos, Geocronológicos e Ambientais do Instituto de Geociências da Universidade de Brasília. As amostras foram depositadas com $\mathrm{HNO}_{3} 50 \%$ em filamentos de Re de arranjo duplo (Figura 3.5). Sm e Nd foram analisados em modo estático multicoletor, onde as razões isotópicas são compostas por 8-12 blocos de 10 ciclos cada, com tempo de integração de 4 segundos por ciclo, totalizando entre 5-8 minutos de análise para cada elemento por amostra. Detalhes da configuração dos coletores estão na Tabela B3 (anexos).

As razões isotópicas ${ }^{143} \mathrm{Nd} /{ }^{144} \mathrm{Nd}$ medidas foram corrigidas devido ao fracionamento de massa instrumental por meio da razão ${ }^{146} \mathrm{Nd} /{ }^{144} \mathrm{Nd}$ igual a 0.7219 , empregando uma lei exponencial. A precisão das concentrações de Sm e Nd determinadas por diluição isotópica é melhor que $0.1 \%$. Análises do padrão internacional BHVO-1 e do padrão interno J\&M foram realizadas em conjunto com as amostras, ao longo de todo o estudo, a fim de verificar a reprodutibilidade do método. O valor médio da razão ${ }^{143} \mathrm{Nd} /{ }^{144} \mathrm{Nd}$ do BHVO-1 foi igual a $0.512996 \pm 0.000006$ ( $2 S D ; n=7)$, o qual é consistente com os valores publicados na literatura (e.g., 0.512986 \pm 0.000009 Weis et al., 2005). As razões isotópicas obtidas para o padrão BHVO-1 estão detalhadas na Tabela B4 (anexos). Os valores dos brancos laboratoriais foram de aproximadamente $250 \mathrm{pg}$ para o $\mathrm{Nd} \mathrm{e} 40 \mathrm{pg}$ para o $\mathrm{Sm}$.

\subsection{ANÁlises ISOTÓPICAS DE SR}

A abertura das amostras para as determinações isotópicas de $\mathrm{Sr}$ ocorreu de acordo com os métodos descritos anteriormente para as análises de $\mathrm{Sm}$ e Nd. Posteriormente à digestão, utilizou-se colunas de Teflon ${ }^{\circledR}$ com aproximadamente $83 \mathrm{mg}$ de resina Eichrom ${ }^{\circledR}$ Sr-Spec 50 $100 \mu \mathrm{m}$ para a separação do Sr da matriz.

As amostras de apatita, carbonatos e pirocloro foram analisadas ao natural (i.e., sem a adição de solução spike), uma vez que a razão $\mathrm{Rb} / \mathrm{Sr}$ nesses minerais é geralmente menor do que 0.001, e a correção da razão isotópica relativa ao Sr radiogênico seria menor do que o erro analítico. Os concentrados de clinopiroxênio, perovskita e granada também foram analisados ao natural, seguindo o mesmo procedimento, visto que esses minerais usualmente têm altas concentrações de $\mathrm{Sr}$ em rochas associadas a carbonatitos. Contudo, correções menores do que $0.005 \%$ (à exceção da granada; 0.02\%) foram necessárias nas razões 
medidas de modo a se obter uma razão ${ }^{87} \mathrm{Sr} /{ }^{86} \mathrm{Sr}$ inicial mais representativa para essas amostras, pois estimativas semiquantitativas indicaram razões $\mathrm{Rb} / \mathrm{Sr}$ maiores do que 0.001 .

As determinações isotópicas foram realizadas por meio do Thermo Scientific TRITON $^{\mathrm{TM}}$ Plus Thermal Ionization Mass Spectrometry (TIMS) no Laboratório de Estudos Geodinâmicos, Geocronológicos e Ambientais do Instituto de Geociências da Universidade de Brasília. As amostras foram depositadas com $\mathrm{HNO}_{3} 50 \%$ em filamentos de Re de arranjo duplo. O Sr foi analisado em modo rotacional multicoletor (multi-dynamic), onde as razões isotópicas são compostas por 10 blocos de 15 ciclos cada, com tempo de integração de 17 segundos por ciclo, totalizando cerca de 40 minutos de análise para cada amostra. Detalhes da configuração dos coletores estão na Tabela B3 (anexos). Nas amostras provenientes dos testes de lixiviação, o Sr foi analisado em modo estático multicoletor, onde as razões isotópicas são compostas por 10 blocos de 10 ciclos cada, com tempo de integração de 4 segundos por ciclo, totalizando entre 6-7 minutos de análise para cada amostra.

O fracionamento de massa do instrumento para as razões isotópicas de $\mathrm{Sr}$ foi corrigido por meio da razão ${ }^{88} \mathrm{Sr} /{ }^{86} \mathrm{Sr}$ igual a 8.375209 (equivalente a razão ${ }^{86} \mathrm{Sr} /{ }^{88} \mathrm{Sr}$ igual a 0.1194 , mais frequentemente utilizada) empregando uma lei exponencial. Repetidas determinações do padrão internacional NBS-987 foram feitas no decorrer deste estudo com intenção de examinar a reprodutibilidade do método. O valor médio da razão ${ }^{87} \mathrm{Sr} /{ }^{86} \mathrm{Sr}$ obtido pelo método rotacional para o NBS-987 foi igual a $0.710257 \pm 0.000007(2 S D ; n=9)$. Para o método estático, apenas um valor igual a $0.71026 \pm 0.00002$ (2SD) foi aferido. Ambos os resultados estão de acordo, dentro do erro analítico, com o valor usualmente recomendado na literatura, em torno de 0.71025 (Thirlwall, 1991; Faure, 2001; Machado, 2013). Detalhes da composição isotópica de Sr adquirida para o padrão NBS-987 estão listados na Tabela B5 (anexos).

\subsection{ID-TIMS (ISOTOPE DILUTION - THERMAL IONIZATION MASS SPECTROMETRY)}

A técnica de espectrometria de massa por ionização térmica (TIMS em inglês) consiste em depositar uma amostra sólida sobre um filamento de Pt, Ta, Re ou W e aquecer o mesmo no vácuo até ocorrer a ionização. No entanto, este processo só é eficaz se houver a extração da matriz da rocha e obtenção de amostras monoelementares, pois apenas um elemento pode ser ionizado de modo eficiente por vez (Dickin, 2005). Deste modo, para evitar interferências isobáricas utilizam-se colunas cromatográficas de troca catiônica durante o processo de diluição isotópica (ID em inglês). 
Os principais componentes de um espectrômetro de massa por ionização térmica são a fonte de íons ou sistema de entrada de amostras (Inlet System), o setor magnético ou sistema analisador (Analyzer System) e o sistema detector (Multicollector System), todos mantidos em vácuo de $10^{-7}$ a $10^{-9}$ milibares (Figura 3.4 ).

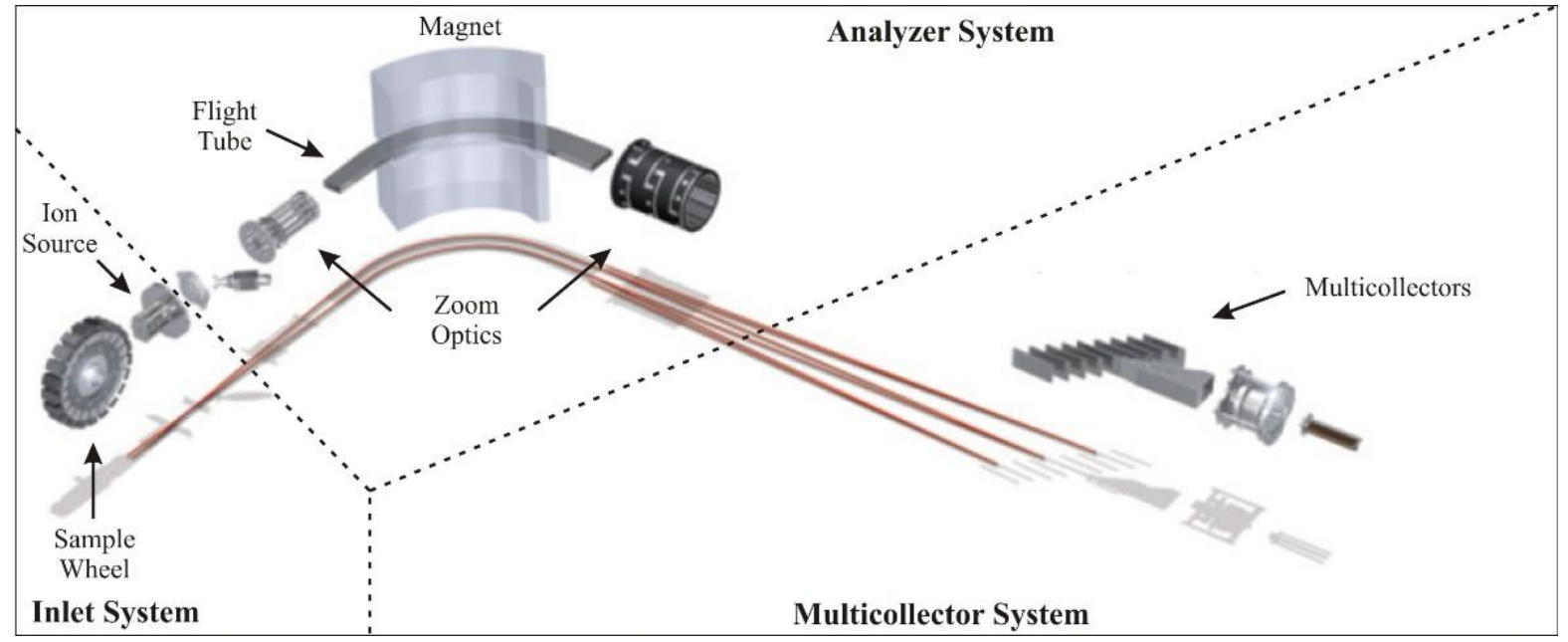

Figura 3.4. Detalhe dos principais sistemas que compõem o espectrômetro de massa Thermo Scientific TRITON $^{\mathrm{TM}}$ Plus (TRITON ${ }^{\mathrm{TM}}$ Plus Hardware Manual, 2010).

\section{Sistema de Entrada (Inlet System)}

O sistema de entrada ou fonte tem três funções principais. A primeira é permitir a entrada de amostras sem perder todo o vácuo do instrumento. A segunda é produzir a ionização térmica de modo a gerar uma nuvem de íons, que podem ser positivos $(\mathrm{Sr}, \mathrm{Nd}) \mathrm{ou}$ negativos (Os). E por fim, tem a função de acelerar e condensar a nuvem de íons, por meio de lentes elétricas (Allègre, 2008; TRITON ${ }^{\mathrm{TM}}$ Plus Hardware Manual, 2010).

As amostras são introduzidas, manualmente, no equipamento por meio da sample wheel, a qual comporta 21 pares de filamentos. O processo de evaporação e ionização das amostras nos filamentos ocorre por aquecimento do mesmo durante a passagem de uma corrente elétrica com cerca de $10 \mathrm{kV}$ (TRITON $^{\mathrm{TM}}$ Plus Hardware Manual, 2010). Inghram \& Chupka (1953) notaram que os processos de evaporação e ionização da maioria dos elementos ocorrem em diferentes temperaturas. Assim, estes autores propuseram arranjos de múltiplos filamentos a fim de incrementar a eficiência da ionização térmica (Figura 3.5).

Após a amostra ser ionizada, o feixe de íons se desloca através de lentes elétricas, as quais tem a função de acelerar e dar forma ao feixe, até que o mesmo alcance o sistema analisador (Allègre, 2008). 


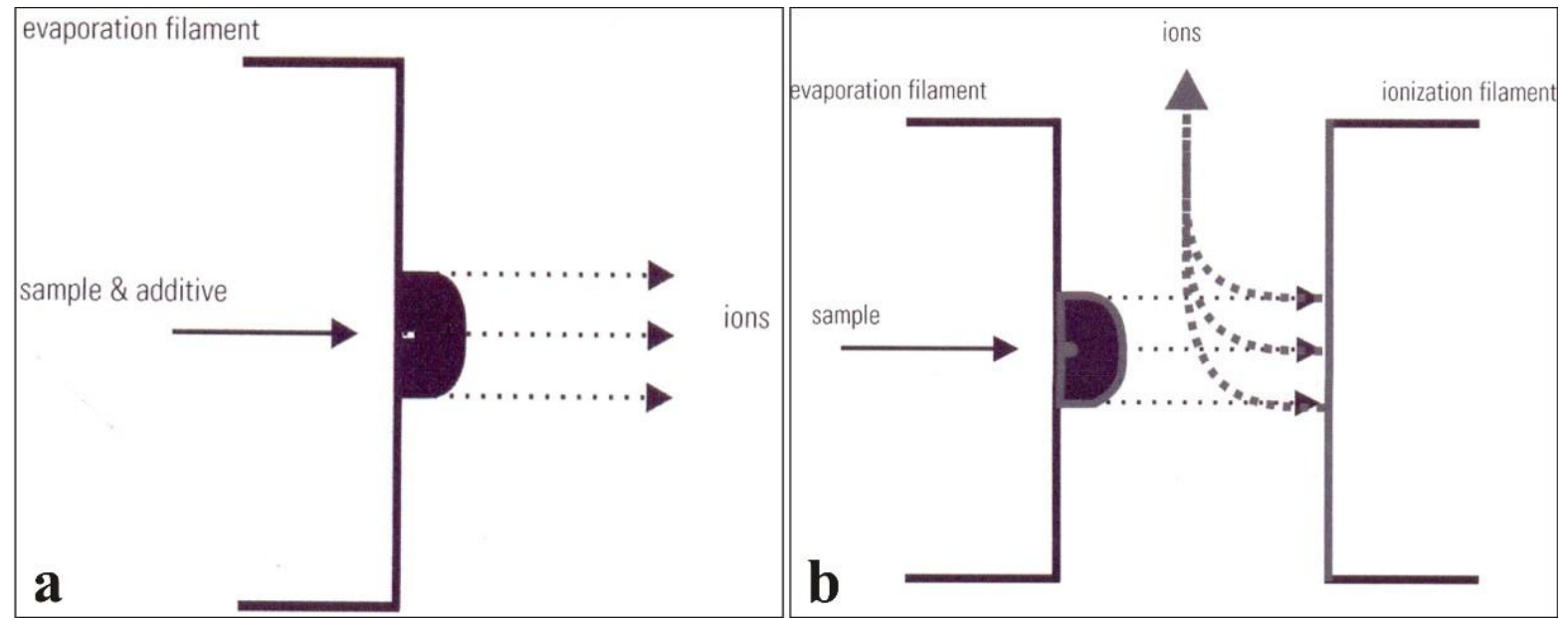

Figura 3.5. Desenho esquemático do funcionamento dos filamentos em arranjo simples (a) e duplo (b) segundo Inghram \& Chupka (1953). Durante a ionização térmica com arranjo duplo (b), a evaporação e ionização da amostra ocorrem em filamentos distintos, com diferentes temperaturas de superfície (TRITON $^{\mathrm{TM}}$ Plus Hardware Manual, 2010).

\section{Sistema Analisador (Analyzer System)}

O sistema analisador ou setor magnético é composto por instrumentos de focalização óptica, pelo tubo de voo e pelo setor magnético. O sistema de focalização óptica, situado antes e depois do setor magnético, tem a propriedade de determinar como o feixe de íons é acelerado, focalizado, separado e conduzido até o sistema detector. Já o setor magnético ou magneto, exerce a função principal do espectrômetro de massa, a qual é separar um único feixe de íons em vários, de acordo com a relação massa/carga (Dickin, 2005; Allègre, 2008; TRITON $^{\mathrm{TM}}$ Plus Hardware Manual, 2010).

\section{Sistema Detector (Multicollector System)}

O sistema detector ou coletor tem a função de capturar os feixes de íons separados no setor magnético e transformá-los em corrente elétrica, a qual pode ser mensurada. Usualmente, os multicoletores têm dois tipos de detectores: os copos Faraday e os multiplicadores de elétrons ou íons (Multiplier Ion Counting - MICs).

Os copos Faraday têm como princípio neutralizar o fluxo de íons coletados, transformando-o em corrente elétrica. Por meio de um resistor, gera-se uma diferença de potencial que permite calcular a intensidade desta corrente. Já os MICs são detectores extremamente sensíveis que medem a quantidade de íons por tempo (Cps). As razões isotópicas da amostra são obtidas a partir da razão entre os sinais elétricos de dois detectores (Thirlwall, 1997; Allègre, 2008; TRITON $^{\mathrm{TM}}$ Plus Hardware Manual, 2010). Durante o presente trabalho as amostras foram analisadas com coletores do tipo copo Faraday. 


\subsection{MICROSSONDA ELETRÔNICA (EMPA)}

A composição química das fases minerais foi determinada por meio da microssonda eletrônica JEOL ${ }^{\circledR}$ JXA-8230 Superprobe, operando em modo WDS (Wavelength Dispersive X-Ray Spectrometry), no Laboratório de Microssonda Eletrônica da Universidade de Brasília. As condições analíticas e os padrões de calibração empregados estão sumarizados nas Tabela B6 e Tabela B7 (anexos).

Os dados de química mineral obtidos nesta dissertação (Anexo A) são complementares aos obtidos por Barbosa (2009) para as amostras selecionadas do complexo de Salitre.

\subsection{Microscópio Eletrônico de VARREdura (SEM)}

Imagens de elétrons secundários ( $S E$ em inglês), elétrons retroespalhados (BSE em inglês) e análises semiquantitativas em modo EDS (Energy Dispersive X-Ray Spectrometry), foram realizadas por meio do microscópio eletrônico de varredura FEI Quanta ${ }^{\mathrm{TM}} 450$ no Laboratório de Estudos Geodinâmicos, Geocronológicos e Ambientais do Instituto de Geociências da Universidade de Brasília. Este equipamento tem acoplado um detector de EDS modelo EDAX® ${ }^{\circledR}$ SDD e um pacote de softwares EDAX ${ }^{\circledR}$ TEAM $^{\mathrm{TM}}$ EDS versão 3.1 necessário para a obtenção e tratamento dos dados de EDS. As condições operacionais usadas foram $15 \mathrm{kV}$ de voltagem, $100 \mu \mathrm{A}$ de corrente e spot size de $6 \mu \mathrm{m}$. 


\section{DETERMINAÇÃO DE ISÓTOPOS DE ND-SR EM APATITA} DE COMPLEXOS ALCALINO-CARBONATÍTICOS: IMPLICAÇÕES DE DISTINTOS MÉTODOS DE LIXIVIAÇÃO, INVESTIGADOS POR MICROSCOPIA ELETRÔNICA DE VARREDURA.

$\mathrm{Nd}$-Sr isotopic determinations in apatite from alkaline-carbonatite complexes: Implications of distinct leaching procedures investigated by SEM

Ítalo Lopes de Oliveira ${ }^{1}$, José Affonso Brod ${ }^{1,2}$, Jeane Grasyelle Chaves ${ }^{1}$, Elton Luiz Dantas ${ }^{1}$.

${ }^{I}$ Instituto de Geociências, Universidade de Brasília (UnB), Campus Universitário Darcy Ribeiro, Asa Norte, CEP 70.910-900, Brasília, DF, Brazil.

${ }^{2}$ Unidade Acadêmica Especial de Ciências e Tecnologia, Campus Aparecida de Goiânia, Universidade Federal de Goiás (UFG), CEP 74.968-755, Aparecida de Goiânia, GO, Brazil.

\section{Abstract}

In order to obtain a high level of purity in apatite concentrates used for radiogenic isotope determinations, several leaching experiments were carried out with the aim of removing all carbonate impurities from an apatite-carbonate mixture. The results collected from SEM images show that: (1) warm diluted acetic acid $\left(\mathrm{CH}_{3} \mathrm{COOH}\right)$ removes all surface impurities without attacking the apatite structure, but could not dissolved the large carbonate grains; (2) cold hydrochloric acid $(\mathrm{HCl})$ removes all carbonates but, also attacks the apatite structure in a preferential direction, even in diluted concentrations. $\mathrm{Sr}$ and $\mathrm{Nd}$ radiogenic isotopes indicate that leaching methods tested in this study do not modify the ${ }^{87} \mathrm{Sr} /{ }^{86} \mathrm{Sr}$ ratios for those minerals. Nevertheless, for the Sm-Nd system, significant changes were noted in the element and isotopic ratios between sample aliquots leached with $\mathrm{CH}_{3} \mathrm{COOH}$ and $\mathrm{HCl}$. Consequently, $\mathrm{HCl}$ leaching of apatite concentrates should be avoided, given that this acid attacks the apatite structure and may modify its $\mathrm{Nd}$ isotopic ratios. The leaching procedure with warm diluted $\mathrm{CH}_{3} \mathrm{COOH}$ presented in this paper seems to be useful to leach minor surface contaminants from previously purified apatite concentrates. Such method does not dissolve the apatite structure and conserves its $\mathrm{Sr}$ and $\mathrm{Nd}$ primary isotopic signatures. 


\subsection{INTRODUÇÃOO}

Com o avanço da geoquímica analítica, estudos com isótopos radiogênicos em minerais estão cada vez mais frequentes, e de imediato, apresentam-se duas possibilidades para a obtenção dos dados: (1) concentração do mineral de interesse por meios físicos seguida de sua dissolução em meio ácido, separação química dos interferentes por cromatografia e analise por espectrometria de fonte sólida $(T I M S)$; ou (2) extração da amostra diretamente a partir do material sólido, por sistemas de ablação com laser (LA-ICPMS).

A extração in situ com laser tem a vantagem de ser rápida (i.e., análise isotópica em minutos), dispensa procedimentos morosos e caros de preparação química e tem a possibilidade de controlar a resolução espacial dos dados em escala de subgrão (Wu, 2010). Entretanto, o LA-ICPMS é mais bem aplicado no caso de altas concentrações do elemento de interesse e, ao mesmo tempo, baixas quantidades de elementos interferentes no mineral a ser analisado (Davidson et al., 2007). Ademais, esta técnica produz apenas dados relativos e necessitam de vários padrões para controlar o desempenho durante a análise, bem como potenciais efeitos de matriz ( $\mathrm{Wu}, 2010)$.

Por outro lado, a concentração física do mineral e sua análise após digestão ácida permitem melhor controle e correção de interferências, visto que esta técnica envolve a separação química e purificação dos elementos de interesse. Adicionalmente, a maior estabilidade do TIMS permite obter resultados com excelente precisão, além de ler concentrações muito baixas dos analitos. As principais desvantagens do TIMS são a demora e custo da preparação da amostra, e o fato do método fornecer um resultado médio dos grãos analisados (i.e., ausência de resolução espacial), no caso de concentrados minerais (Gill, 1997; Dickin, 2005; Davidson et al., 2007).

Assim, embora tenha algumas desvantagens, muitas vezes ainda é necessário ou desejável fazer a separação física do mineral e sua analise após a digestão ácida do concentrado.

Um dos principais desafios para a obtenção de dados isotópicos confiáveis a partir de separados minerais é garantir a pureza do concentrado. No caso de estudos isotópicos de $\mathrm{Sr}$ e $\mathrm{Nd}$ em minerais de rochas alcalinas e carbonatitos é necessário cuidado redobrado, pois diversas fases primárias presentes nestas rochas possuem teores elevados de ETR e/ou $\mathrm{Sr}$ (e.g., apatita, carbonato, perovskita, pirocloro, monazita), enquanto outras têm concentrações 
muito baixas destes elementos (e.g. flogopita, olivina, clinopiroxênio). Além disso, os separados minerais devem ser "limpos", comumente por meio de procedimentos de lixiviação, antes das determinações isotópicas a fim de eliminar todas as contaminações decorrentes da preparação dos mesmos (Machado et al., 1986). Estas contaminações podem ser desde "poeira" antropogênica a partículas finas de outros minerais, que ficaram aderidas a superfície dos grãos, como também intercrescimentos não observados durante a separação no microscópio binocular, ou ainda, contaminações durante o próprio manuseio da amostra. Wittig et al. (2009) considera que a interação com águas meteóricas ou fluídos hidrotermais também podem gerar agentes contaminantes, os quais devem ser removidos na lixiviação.

Machado et al. (1986) foram um dos grupos pioneiros no estudo de procedimentos de lixiviação e limpeza de separados minerais e da implicação dos mesmos na determinação das razões isotópicas de Nd e Sr. Segundo aqueles autores, ácido fluorídrico (HF) não deve ser utilizado nesses procedimentos, mesmo que diluído, pois destrói a estrutura cristalina dos silicatos, ocasionando fracionamento entre elementos radioativos e radiogênicos. Aqueles autores determinaram também que o grau de extração de um elemento é proporcional à razão entre sua carga e seu raio iônico, de modo que K e Rb são removidos mais facilmente do que Sr e Ba, por exemplo.

Recentemente, Wittig et al. (2009) retomaram a discussão da validade dos procedimentos de lixiviação descritos na literatura para a obtenção de dados isotópicos precisos, uma vez que muitos dados eram gerados sem o devido cuidado. Aqueles autores realizaram um estudo detalhado em clinopiroxênios mantélicos para os principais sistemas isotópicos (i.e., Sm-Nd, Rb-Sr, Lu-Hf, U-Th-Pb) e obtiveram conclusões semelhantes à de Machado et al. (1986) em relação aos procedimentos de lixiviação. Wittig et al. (2009) também demonstraram que a lixiviação em múltiplas etapas de curta duração, conduzida com ácido clorídrico $(\mathrm{HCl})$ e água ultrapura, é o suficiente para a remoção dos contaminantes superficiais sem resultar em fracionamento de pares de elementos radioativos e radiogênicos.

Concentrados de apatita obtidos a partir de rochas de complexos alcalinocarbonatíticos por métodos como separação magnética e flotação podem ainda estar contaminados por carbonatos (i.e., calcita, dolomita, norsethita). Estes são fases abundantes na rocha original e podem ser ricos em Sr e/ou ETR, impactando diretamente nos resultados de estudos isotópicos de Nd-Sr. A separação entre apatita e carbonato por seleção manual ao microscópio binocular é um procedimento moroso e nem sempre eficiente. A alternativa 
tradicional é a segregação por líquidos densos, mas restrições quanto à toxicidade deste tipo de insumo levam à necessidade e conveniência de estabelecer outras técnicas de purificação dos concentrados de apatita.

A lixiviação com ácidos inorgânicos é geralmente pouco útil para a purificação de apatita, tendo em vista que este mineral é facilmente solúvel naqueles meios (Deer et al., 1992; Malarkey, 2010). Alguns trabalhos das décadas de 1950 e 60 (Silverman et al., 1952; Smith \& Lehr, 1966; McClellan \& Lehr, 1969) descrevem técnicas com citrato de amônia para a extração de carbonatos dos concentrados de apatita, devido à diferença de solubilidade entre os dois minerais. No entanto, estas técnicas não são completamente eficientes e tampouco viáveis para analises isotópicas, pois não existem reagentes disponíveis com o grau de pureza isotópica desejado.

Em trabalhos desenvolvidos com concentrados minerais de complexos alcalinocarbonatíticos, Hornig-Kjarsgaard (1998) utilizou ácido acético $\left(\mathrm{CH}_{3} \mathrm{COOH}\right)$ com o objetivo de remover poeira e intercrescimento de carbonatos, porém sem o devido estudo da eficácia do procedimento. Já Dunworth \& Bell (2001) citam a utilização de ácido clorídrico (HCl) diluído por 10 minutos, na lixiviação de concentrados de apatita, mas não fornecem maiores detalhes.

Neste trabalho conduzimos diferentes experimentos com o uso de ácido acético e ácido clorídrico, visando melhor avaliar a efetividade da remoção do carbonato, presente como macro-cristais, partículas de poeira e/ou intercrescimentos, preservando, ao mesmo tempo, os cristais de apatita para as analises isotópicas de $\mathrm{Nd}$ e $\mathrm{Sr}$.

\subsection{MAteriais E MÉtodos}

Como amostra piloto para os distintos testes de lixiviação utilizou-se um concentrado de flotação do minério de fosfato do Complexo Alcalino-Carbonatítico de Catalão, composto por cerca de $90 \%$ apatita e $10 \%$ carbonato. Após cada um dos quatro procedimentos testados, denominados de Teste 1 a 4, realizou-se uma analise detalhada das amostras resultantes por microscópio eletrônico de varredura, o que auxiliou na elaboração do teste seguinte.

A seguir estão descritos todos os procedimentos adotados nos testes 1 a 4: 


\section{Teste 1 - Lixiviação com ácido acético diluído a quente.}

Duas alíquotas de $50 \mathrm{mg}$ do concentrado previamente limpo de impurezas em microscópio binocular (ver Anexo C para imagens), foram pesadas em frascos Savillex ${ }^{\circledR}$. Em seguida, adicionou-se $5 \mathrm{ml}$ de ácido acético $0.5 \mathrm{~N}$ em cada frasco que foi fechado e aquecido por 1 hora e 30 minutos a $80-100^{\circ} \mathrm{C}$. Posteriormente, as amostras foram transferidas para tubos plásticos e centrifugadas por 45 minutos. Ao final, retirou-se o máximo possível da fração líquida, com o auxilio de pipetas, e colocou-se a fração sólida para secar por 2 horas a $80^{\circ} \mathrm{C}$. Durante o processo de secagem, após 20 minutos, os frascos foram agitados a fim de desmanchar possíveis aglomerados de cristais gerados durante o procedimento.

\section{Teste 2 - Aumento no tempo de aquecimento do Teste 1, bem como lixiviação com}

\section{HCl diluído.}

Duas alíquotas de $100 \mathrm{mg}$ da mesma amostra foram separadas em frascos Savillex ${ }^{\circledR}$. Na sequência, adicionou-se $10 \mathrm{ml}$ de ácido acético num Savillex ${ }^{\circledR}$ (Teste 2.1) e $10 \mathrm{ml}$ de $\mathrm{HCl}$ $1.2 \mathrm{~N}$ no outro (Teste 2.2), ambos foram fechados e aquecidos por 2 horas a $80-100^{\circ} \mathrm{C}$. Após esta etapa, a alíquota com $\mathrm{HCl} 1.2 \mathrm{~N}$ dissolveu-se completamente. A amostra com ácido acético seguiu os mesmos procedimentos de centrifugação e secagem do teste anterior.

\section{Teste 3 - Lavagem com ultrassom em ácidos acético e clorídrico diluídos.}

Duas frações de $50 \mathrm{mg}$ do concentrado foram colocadas em béqueres de vidro. Depois, foram acrescentados $5 \mathrm{ml}$ de $\mathrm{HCl} 1.2 \mathrm{~N}$ num dos béqueres (Teste 3.1) e $5 \mathrm{ml}$ de ácido acético $0.5 \mathrm{~N}$ no outro (Teste 3.2). Ambos foram lavados no ultrassom por aproximadamente 20 minutos. Em seguida, as amostras foram transferidas para tubos plásticos e centrifugadas por +20 minutos. Por fim, colocou-se o precipitado para secar por aproximadamente 1 hora a $80^{\circ} \mathrm{C}$, com a mínima presença de reagentes (fração líquida).

\section{Teste 4 - Lixiviação com ácidos acético e clorídrico a frio.}

Quatro alíquotas de $50 \mathrm{mg}$ do concentrado de fosfato foram pesadas em béqueres de vidro. Em seguida, foram realizados diferentes ataques ácidos, a temperatura ambiente de 16$18^{\circ} \mathrm{C}$, e com durações distintas de acordo com o descrito na Tabela 4.1 a seguir: 
Tabela 4.1. Detalhe dos procedimentos de lixiviação realizados durante o Teste 04.

\begin{tabular}{ccc}
\hline Amostra & Reagente & Duração (min.) \\
\hline 4.1 & $\mathrm{HCl} 2.5 \mathrm{~N}$ & 10 \\
4.2 & $\mathrm{HCl} 1.2 \mathrm{~N}$ & 10 \\
4.3 & $\mathrm{HCl} 1.2 \mathrm{~N}$ & 20 \\
4.4 & $\mathrm{CH}_{3} \mathrm{COOH} 17 \mathrm{~N}$ & 20 \\
4.5 & $\mathrm{HCl} 6 \mathrm{~N}$ & 10 \\
\hline
\end{tabular}

Após o tempo pré-determinado para cada amostra, houve a retirada dos reagentes com uso de pipetas, a fração sólida foi lavada com água Milli- $\mathrm{Q}^{\circledR}$ no ultrassom por 5 minutos. Por fim, retirou-se a água e a fração sólida foi colocada para secar por aproximadamente 30 minutos a $80^{\circ} \mathrm{C}$.

\section{Imageamento por Microscópio Eletrônico de Varredura (SEM)}

Frações das amostras resultantes após terem sido submetidas aos testes de lixiviação foram montadas em lâminas delgadas e metalizadas com películas de carbono ou ouro para subsequente imageamento. Apenas uma fração da amostra piloto pré-lixiviação foi imageada, antes da realização do Teste 1. Para os demais testes, assumiu-se que as alíquotas utilizadas tinham as mesmas características iniciais (Figura 4.1), devido à homogeneidade observada na amostra piloto.

As imagens de elétrons secundários ( $S E$ em inglês), elétrons retroespalhados (BSE em inglês) e análises semiquantitativas em modo EDS (Energy Dispersive X-Ray Spectrometry), foram conduzidas por meio do microscópio eletrônico de varredura FEI Quanta ${ }^{\mathrm{TM}} 450$ no Laboratório de Estudos Geodinâmicos, Geocronológicos e Ambientais do Instituto de Geociências da Universidade de Brasília. Este equipamento tem acoplado um detector de EDS modelo EDAX® ${ }^{\circledR}$ SDD e um pacote de softwares EDAX ${ }^{\circledR}$ TEAM $^{\mathrm{TM}}$ EDS versão 3.1 necessário para a obtenção e tratamento dos dados de EDS. As condições operacionais usadas foram $15 \mathrm{kV}$ de voltagem, $100 \mu \mathrm{A}$ de corrente e spot size de $6 \mu \mathrm{m}$.

\section{Análises Isotópicas de $\mathrm{Nd}$ e $\mathrm{Sr}$}

Alíquotas de $5 \mathrm{mg}$ de diferentes concentrados de apatita foram misturados com solução spike de ${ }^{149} \mathrm{Sm}^{-150} \mathrm{Nd}$ e digeridas com $2 \mathrm{ml}$ de ácido nítrico destilado $\left(\mathrm{HNO}_{3}\right) 14 \mathrm{~N}$, em fracos Savillex ${ }^{\circledR}$ por 1 dia a $80-100^{\circ} \mathrm{C}$. Em seguida à abertura das amostras, utilizou-se colunas de vidro e Teflon® preenchidas com $7 \mathrm{~cm}$ de resina de troca catiônica DOWEX® AG-50W-X8 100-200 mesh para a separação dos elementos terras raras (ETR) da matriz. 
Posteriormente, as frações de $\mathrm{Sm}$ e $\mathrm{Nd}$ foram extraídas por meio de colunas de Teflon® preenchidas com resina Eichrom ${ }^{\circledR} \mathrm{LN}-\mathrm{Spec} 100-150 \mu \mathrm{m}$. Para a separação do Sr, utilizou-se colunas de Teflon ${ }^{\circledR}$ com aproximadamente 83 mg de resina Eichrom ${ }^{\circledR}$ Sr-Spec 50-100 $\mu \mathrm{m}$. Os procedimentos químicos de separação cromatográfica seguiram a rotina estabelecida por Gioia \& Pimentel (2000).

As amostras foram analisadas com o espectrômetro Thermo Scientific TRITON ${ }^{\mathrm{TM}}$ Plus Thermal Ionization Mass Spectrometry (TIMS) no Laboratório de Estudos Geodinâmicos, Geocronológicos e Ambientais do Instituto de Geociências da Universidade de Brasília. Todas as frações de $\mathrm{Sm}, \mathrm{Nd}$ e $\mathrm{Sr}$ foram depositadas com $\mathrm{HNO}_{3} 7 \mathrm{~N}$ em filamentos de $\mathrm{Re}$ de arranjo duplo e analisadas em modo estático multicoletor. As razões isotópicas de $\mathrm{Sm}$ e $\mathrm{Nd}$ são compostas por 8-12 blocos de 10 ciclos cada, com tempo de integração de 4 segundos por ciclo, totalizando entre 5-8 minutos de análise para cada elemento por amostra. Já as razões isotópicas de $\mathrm{Sr}$ são compostas por 10 blocos de 10 ciclos cada, com tempo de integração de 4 segundos por ciclo, totalizando entre 6-7 minutos de análise para cada amostra.

As razões ${ }^{143} \mathrm{Nd} /{ }^{144} \mathrm{Nd} \mathrm{e}{ }^{87} \mathrm{Sr} /{ }^{86} \mathrm{Sr}$ medidas foram corrigidas devido ao fracionamento de massa por meio das razões ${ }^{146} \mathrm{Nd} /{ }^{144} \mathrm{Nd}$ igual a 0.7219 e ${ }^{88} \mathrm{Sr} /{ }^{86} \mathrm{Sr}$ igual a 8.375209 , respectivamente, empregando uma lei exponencial. A precisão das concentrações de $\mathrm{Sm}$ e $\mathrm{Nd}$ determinadas por diluição isotópica é melhor que $0.1 \%$. Análises dos padrões internacionais BHVO-1 e NBS-987 foram realizadas em conjunto com as amostras a fim de verificar a reprodutibilidade do método. O valor médio da razão ${ }^{143} \mathrm{Nd} /{ }^{144} \mathrm{Nd}$ do BHVO-1 foi igual a $0.512996 \pm 0.000006(2 S D ; n=7)$, o qual é consistente com os valores publicados na literatura (e.g., 0.512986 \pm 0.000009 Weis et al., 2005). A razão ${ }^{87} \mathrm{Sr} /{ }^{86} \mathrm{Sr}$ igual a $0.71026 \pm 0.00002$ $(2 S D)$ foi aferida para o padrão NBS-987. Tal resultado está de acordo com o valor usualmente recomendado na literatura, em torno de 0.71025 (Thirlwall, 1991; Faure, 2001; Machado, 2013). Os valores dos brancos laboratoriais foram de aproximadamente 250 pg para o Nd e 40 pg para o Sm.

\subsection{RESULTADOS}

\section{Microscopia Eletrônica de Varredura (SEM)}

Na Figura 4.1 são apresentadas imagens representativas da amostra piloto, antes desta ser submetida a qualquer procedimento de lixiviação. Estas imagens mostram que tanto a superfície dos cristais de apatita quanto à do carbonato contêm uma grande quantidade de 
detritos incrustados. Estes detritos, em geral, são partículas de apatita, barita ou carbonato. Tais materiais aderidos à superfície exemplificam algumas das possíveis contaminações que devem ser removidas por procedimentos de lixiviação antes da dissolução completa dos minerais para a determinação isotópica.

Também é possível notar, especialmente nos cristais de apatita (Figura 4.1A), a presença de películas de carbonatos, e em menor quantidade de silicatos, além de raras inclusões tabulares de minerais de $\mathrm{Zr}$ (i.e., badeleíta e zirconolita).

Os resultados do Teste 1 indicaram que o mesmo não obteve êxito na remoção dos macro-cristais de carbonatos do concentrado. No entanto, este demonstrou eficiência na lixiviação dos detritos superficiais, bem como na preservação dos grãos (Figura 4.2). Devido à eficiência obtida na limpeza dos contaminantes superficiais durante o primeiro experimento, realizou-se uma triplicata adicional, com alíquotas maiores de $100 \mathrm{mg}$ da amostra piloto. Tais experimentos repetiram os excelentes resultados obtidos anteriormente, com a remoção completa dos materiais incrustados na superfície dos cristais. 

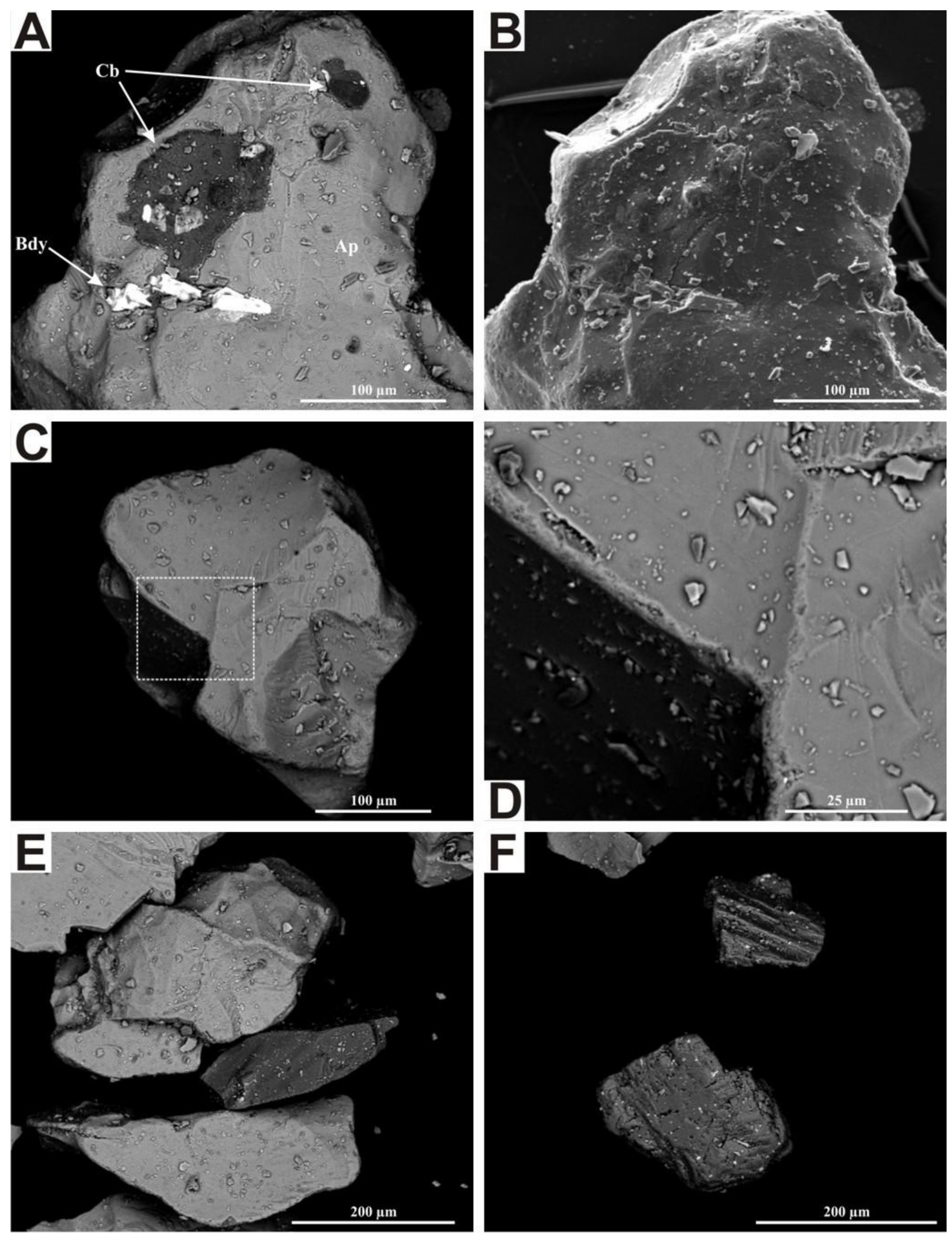

Figura 4.1. Imagens de BSE e elétrons secundários (SE) da amostra piloto antes de ser submetida aos procedimentos de lixiviação. A) Cristal de apatita (Ap) com inclusão de badeleíta (Bdy) e películas de carbonato na superfície (Cb). B) Imagem de SE da figura anterior. Notar o relevo positivo das películas de carbonato. C) Cristal de apatita com diversos fragmentos aderidos a superfície. D) Detalhe da área demarcada na imagem anterior exemplificando o aspecto comum dos materiais na superfície (Ver texto). E) Cristal de carbonato (fase cinza escuro) em meio a cristais de apatita (fase cinza claro). Notar que ambas as fases têm contaminação superficial abundante. F) Cristais de carbonato presentes no concentrado de flotação pré-lixiviação. 

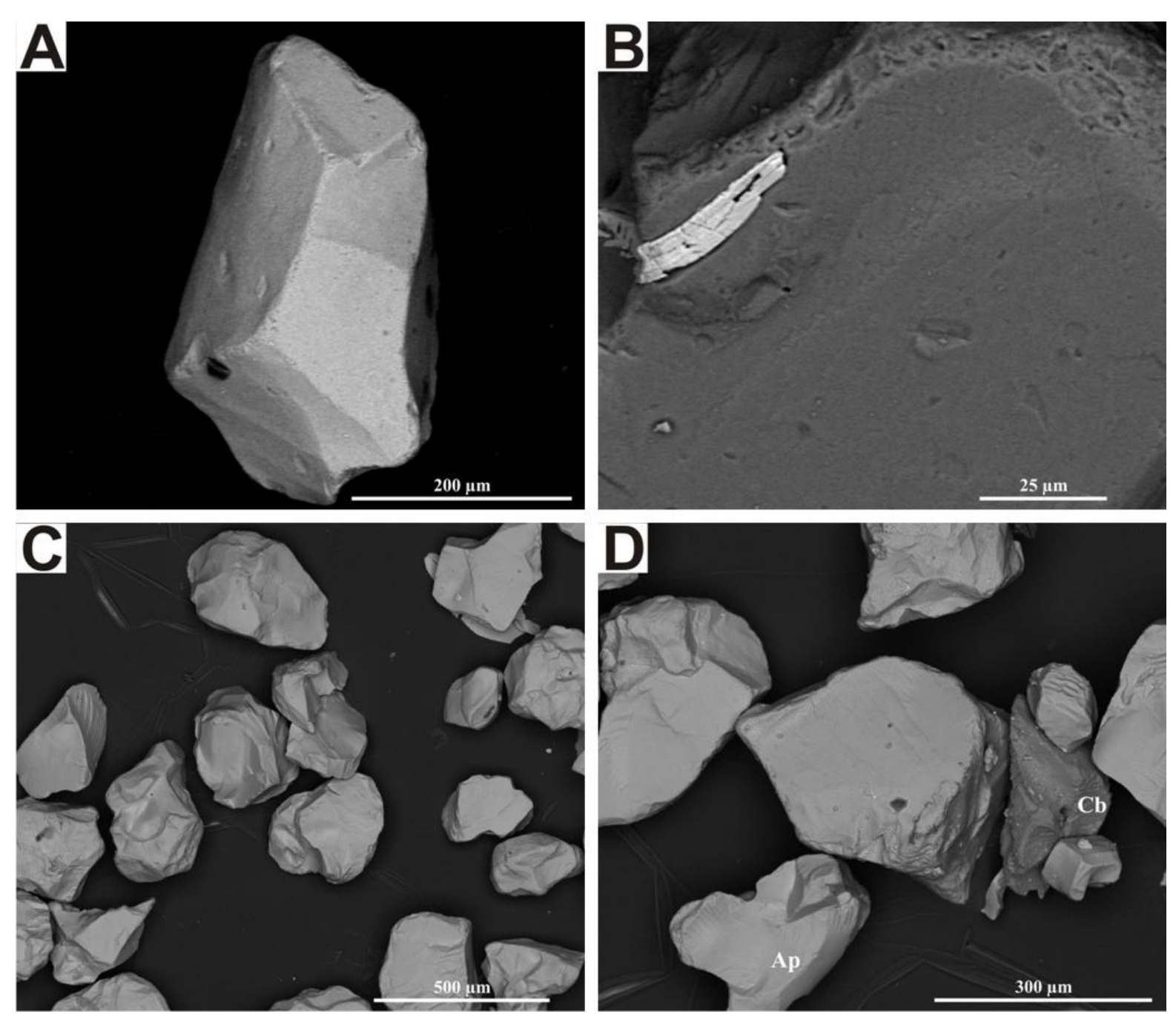

Figura 4.2. Imagens de elétrons retroespalhados (BSE) das amostras submetidas ao Teste 1. A) Cristal de apatita com superfície lisa e livre de contaminações. B) Inclusão de zirconolita? $\left(\mathrm{CaZrTi}_{2} \mathrm{O}_{7}-\right.$ fase cinza claro) na borda da apatita límpida (fase cinza escuro). C) Cristais de apatita com aspecto similar ao observado nas imagens anteriores. D) Cristal de carbonato $(\mathrm{Cb})$ preservado em meio à apatita $(\mathrm{Ap})$.

Os resultados do Teste 2 revelaram que o aumento no tempo de aquecimento do ataque com ácido acético leva à formação de aglomerados de apatita parcialmente dissolvida (Figura 4.3A e Figura 4.4A). Por outro lado, no mesmo Teste 2, evidenciou-se que o uso de $\mathrm{HCl} 1.2 \mathrm{~N}$ aquecido dissolve por completo os cristais de apatita e carbonato.

Os resultados do terceiro experimento com $\mathrm{HCl}$ diluído (Teste 3.1) mostram a cristalização de fase rica em Ca na superfície da apatita (Figura 4.3B). Adicionalmente, o experimento com ácido acético (Teste 3.2) resultou em cristais de apatita com aspecto rugoso e materiais ainda aderidos à superfície, possivelmente devido à presença de contaminantes (e.g., dolomita e silicatos) que não foram completamente dissolvidos (Figura 4.3C). Além disso, em ambos os testes (3.1 e 3.2) formaram-se cristais aciculares compostos por $\mathrm{Cl}, \mathrm{Mg}$ e Ca entre os grãos de apatita (Figura 4.3D e Figura 4.4B). 

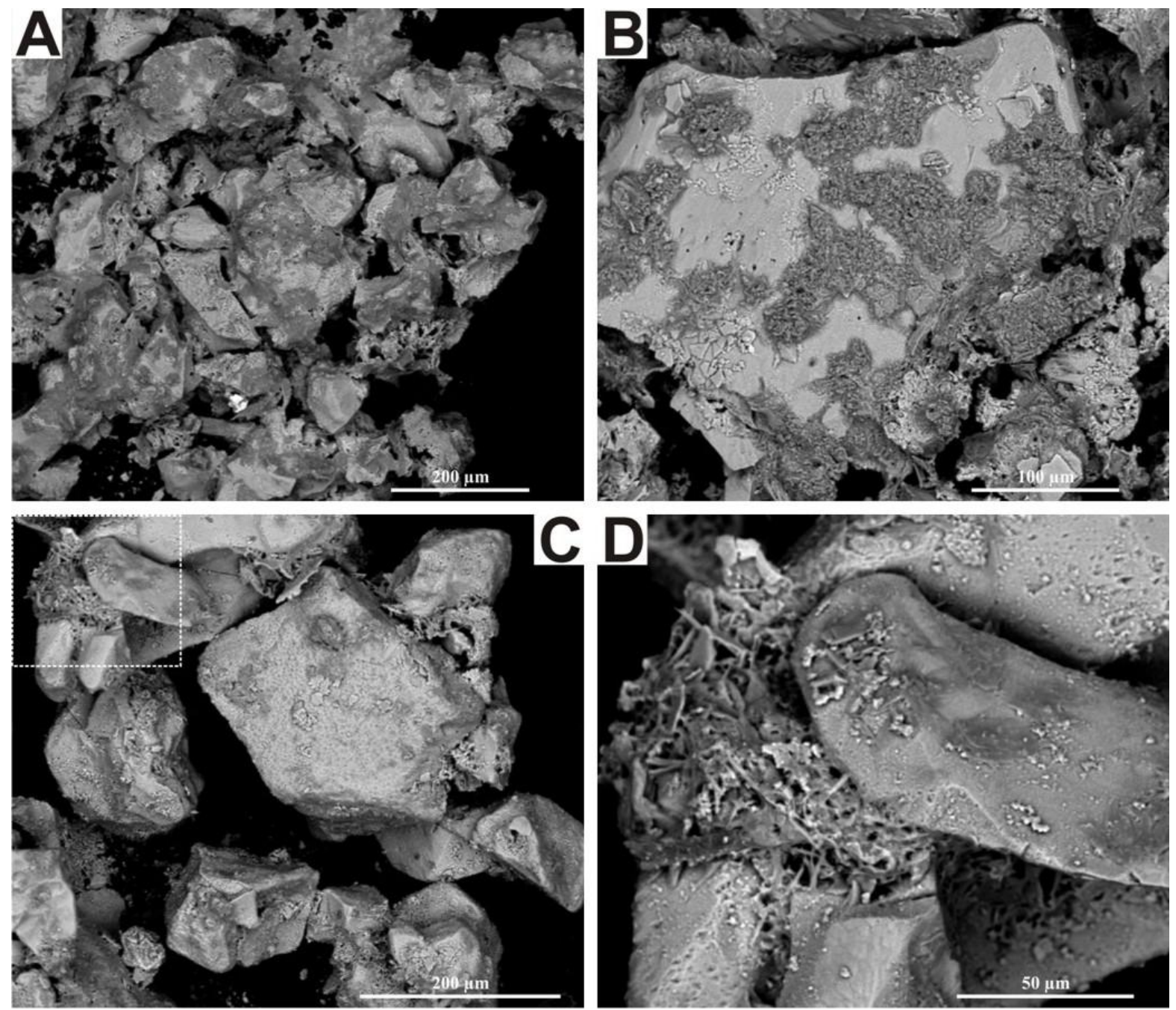

Figura 4.3. Imagens de BSE das amostras submetidas aos testes 2 (A) e 3 (B, C, D). A) Aglomerado de cristais de apatita (fase cinza claro) relativamente dissolvidos associado a material composto por $\mathbf{P}>\mathbf{C a}$ (fase cinza escuro). B) Cristal de apatita (fase cinza claro) recoberto por fase rica em Ca (porção cinza escuro). C) Cristais de apatita (fase cinza claro) com superfície rugosa e material aderido. D) Detalhe da área demarcada na imagem anterior. Notar cristais aciculares entre os grãos de apatita.
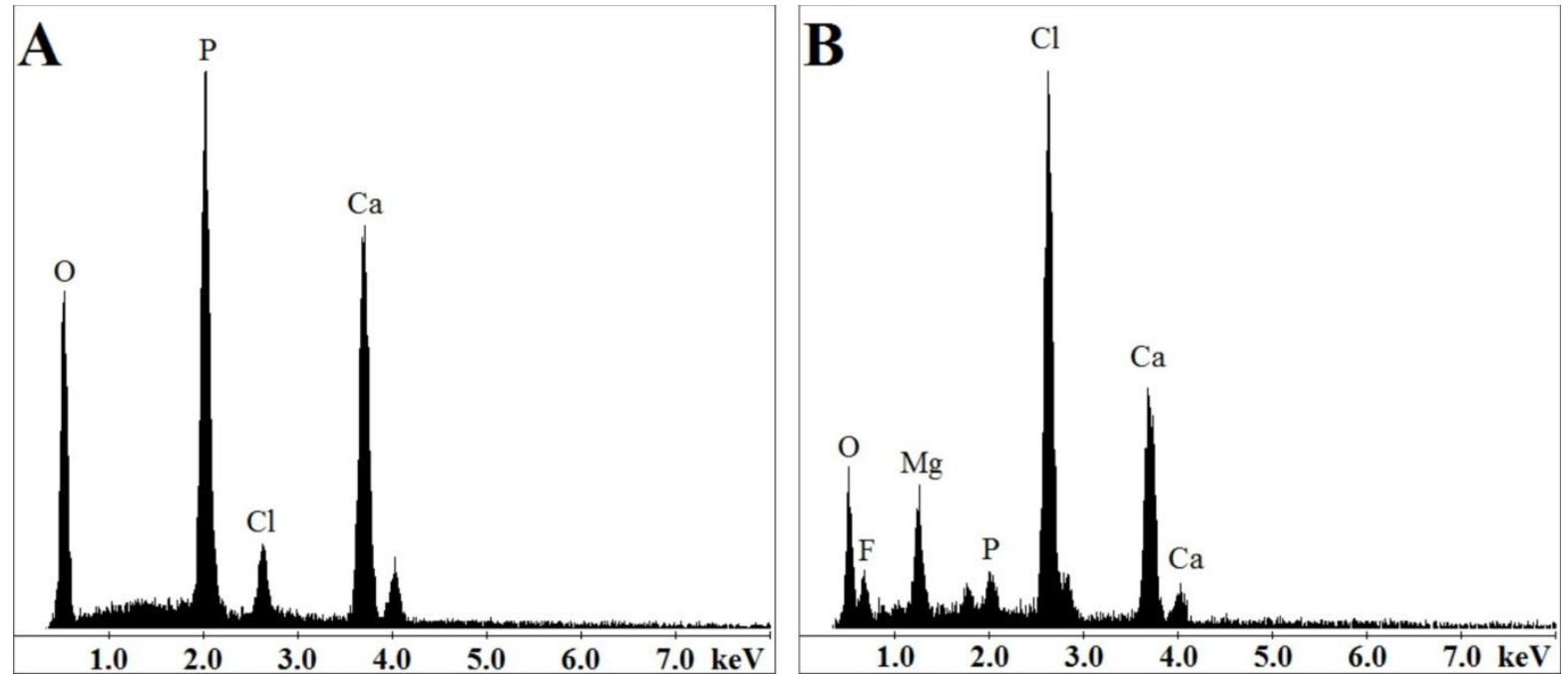

Figura 4.4. Análises semiquantitativas em modo EDS. (A) Composição da fase cinza escuro entre grãos de apatita na Figura 4.3A. (B) Composição dos cristais aciculares formados durante o Teste 3 (Figura 4.3D). 
Os resultados do Teste 4 apontaram para a remoção completa dos carbonatos em todas as amostras, como esperado. Entretanto, os cristais de apatita apesar de límpidos, também se mostraram susceptíveis aos ataques ácidos, principalmente ao $\mathrm{HCl}$, tendo a superfície dos cristais corroída com maior ou menor intensidade dependendo da concentração do ácido (Figura 4.5). Ademais, notou-se que a dissolução da apatita ocorre preferencialmente em uma direção, característica mencionada em trabalhos anteriores (e.g., Costa Junior et al., 2001; Torres, 2008), e que os planos de fratura conchoidal dos cristais praticamente não apresentam evidencias deste processo (Figura 4.5 e Figura 4.6A, B). Adicionalmente, a amostra sujeita ao ácido acético concentrado $(17 \mathrm{~N})$ teve comportamento similar, porém nota-se um filme sobre a superfície dos grãos de apatita (Figura 4.6C, D). 

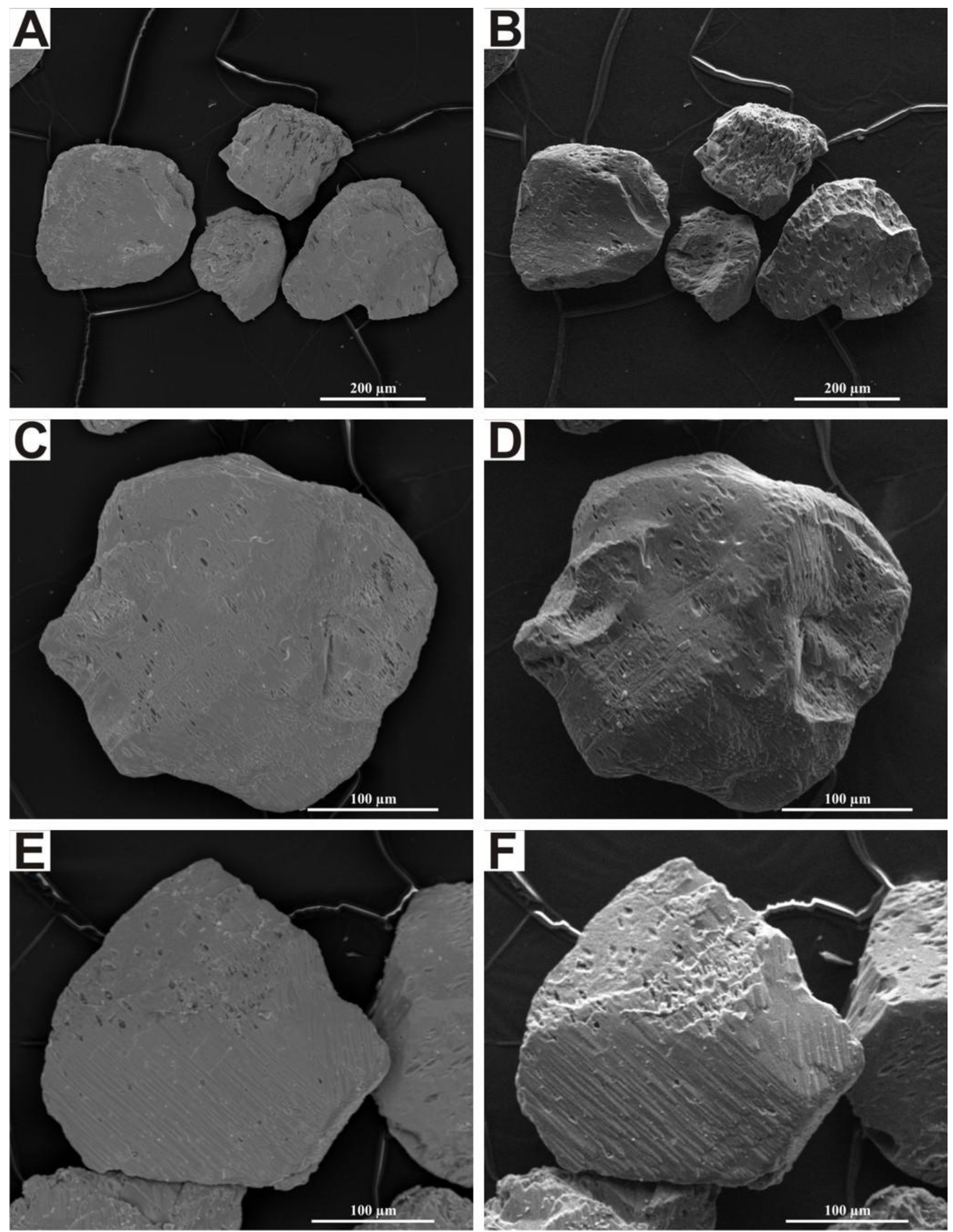

Figura 4.5. Imagens de BSE e SE das amostras submetidas ao Teste 4 (I). A) Cristais de apatita resultantes do Teste 4.1. B) Imagem de SE da figura anterior. Notar as cavidades de dissolução mais nítidas na superfície. C) Cristal de apatita resultantes do Teste 4.2. Notar menor intensidade do processo de corrosão se comparado às figuras acima (cavidades menores). D) Imagem de SE da figura anterior. Notar direção preferencial de dissolução no lado direito da imagem. E) Cristais de apatita resultantes do Teste 4.3. Notar linhas na superfície do cristal ao centro. F) Imagem de SE da figura anterior. Notar a direção preferencial de dissolução bem marcada em duas faces do cristal. Observar também, maior intensidade deste processo se comparado com as figuras $\mathrm{C}$ e $\mathrm{D}$. 

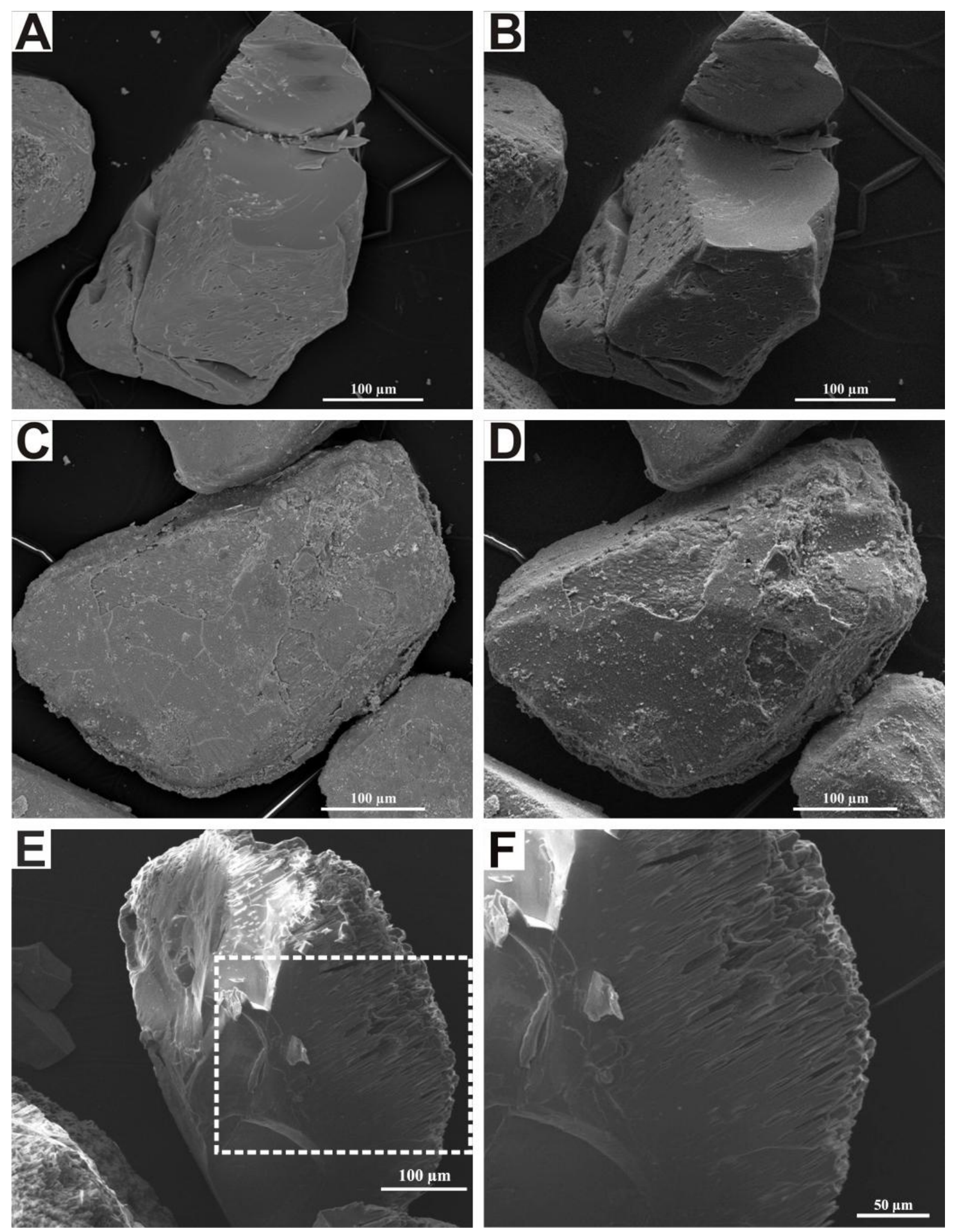

Figura 4.6. Imagens de BSE e SE das amostras submetidas ao Teste 4 (II). A) Cristal de apatita submetido ao Teste 4.2. Notar superfície de fratura conchoidal sem cavidades de dissolução. B) Imagem de SE da figura anterior. Notar nítidas cavidades de corrosão nas faces planas do cristal e ausência dessas na superfície de fratura. C) Cristal de apatita submetido ao Teste 4.4. D) Imagem de SE da figura anterior. Notar presença de fina película aderida à superfície da apatita. E) Cristal de apatita com superfície de fratura conchoidal submetido ao Teste 4.5. F) Detalhe da área demarcada na imagem anterior. Notar as cavidades de corrosão bem expostas pela fratura conchoidal se prolongando para dentro do cristal, fato não observado nos ataques com HCl menos concentrado (Figuras A e B). 


\section{Isótopos Radiogênicos de $\mathrm{Nd}$ e Sr}

A partir dos dados obtidos por microscopia eletrônica de varredura foram realizadas determinações isotópicas de $\mathrm{Nd}$ e $\mathrm{Sr}$ em três amostras com o intuito de avaliar a influência dos procedimentos de lixiviação na composição isotópica da apatita. As amostras analisadas foram: (1) a amostra piloto pré-lixiviação; (2) o concentrado obtido após o Teste 1; (3) o concentrado resultante da lixiviação com $\mathrm{HCl} 1.2 \mathrm{~N}$ por 10 minutos (Teste 4.2). Tais amostras foram selecionadas de modo a comparar a ação dos diferentes ácidos na estrutura da apatita, bem como, devido à semelhança com os procedimentos de lixiviação descritos na literatura.

As composições isotópicas de $\mathrm{Nd}$ e $\mathrm{Sr}$ determinadas para estas três amostras estão listadas na Tabela 4.2 e na Figura 4.7.

Tabela 4.2. Composição isotópica de $\mathrm{Nd}$ e $\mathrm{Sr}$ dos concentrados de apatita submetidos a diferentes procedimentos de lixiviação. Todos os resultados reportados estão dentro do intervalo $2 \sigma$ de confiança.

\begin{tabular}{lccccccc}
\hline Amostras & $\begin{array}{c}\mathbf{S m} \\
(\mathbf{p p m})\end{array}$ & $\begin{array}{c}\mathbf{N d} \\
(\mathbf{p p m})\end{array}$ & $\mathbf{S m} / \mathbf{N d}$ & ${ }^{\mathbf{1 4 3}} \mathbf{N d} /{ }^{\mathbf{1 4 4}} \mathbf{N d}(\mathbf{m})$ & $\mathbf{\pm 2 S E}$ & ${ }^{\mathbf{8 7}} \mathbf{S r} /{ }^{\mathbf{8 6}} \mathbf{S r} \mathbf{r}_{(\mathbf{m})}$ & $\mathbf{\pm 2 S E}$ \\
\hline Piloto & 126.1 & 921.7 & 0.1368 & 0.512328 & 0.000015 & 0.70511 & 0.00001 \\
Teste 1 & - & 950.9 & - & 0.512355 & 0.000003 & - & - \\
Teste 1* & 133.7 & 976.6 & 0.1369 & 0.512350 & 0.000009 & 0.70512 & 0.00001 \\
Teste 4.2 & 125.2 & 909.6 & 0.1377 & 0.512396 & 0.000020 & 0.70511 & 0.00001 \\
\hline
\end{tabular}

*Repetição; - Não determinado; (m) razão medida; 2SE (Standard Error).

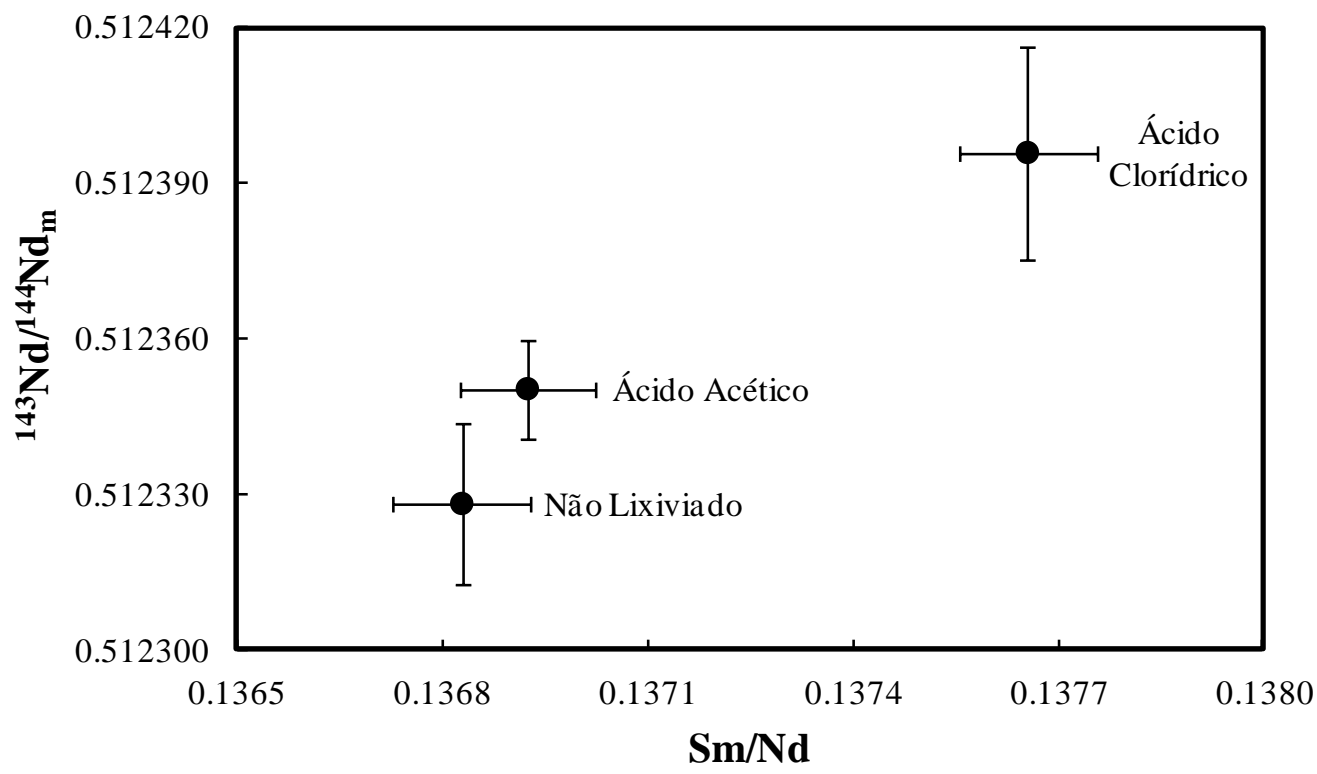

Figura 4.7. Correlação entre as razões ${ }^{143} \mathrm{Nd} /{ }^{144} \mathrm{Nd}_{\mathrm{m}}$ e $\mathrm{Sm} / \mathrm{Nd}$ das amostras listadas na Tabela 4.2. 
A composição isotópica de $\mathrm{Sr}$ das amostras analisadas (Tabela 4.2) é idêntica dentro do erro analítico. Portanto, estes resultados sugerem que a influência dos processos de lixiviação testados é mínima para a determinação da razão ${ }^{87} \mathrm{Sr} /{ }^{86} \mathrm{Sr}$, no caso da apatita. Contudo, é importante salientar que embora não tenham sido determinadas as concentrações de $\mathrm{Rb}$ e Sr, é esperada uma variação considerável nos teores de Sr das amostras analisadas visto que há uma remoção completa do carbonato no Teste 4.2.

De maneira oposta, as razões ${ }^{143} \mathrm{Nd} /{ }^{144} \mathrm{Nd}$ medidas mostram que há uma diferença considerável na composição isotópica de $\mathrm{Nd}$ das amostras. Adicionalmente, pequenas variações na razão $\mathrm{Sm} / \mathrm{Nd}$ sugerem que houve fracionamento entre $\mathrm{Sm}$ e $\mathrm{Nd}$. A Figura 4.7 sugere uma correlação positiva entre as razões ${ }^{143} \mathrm{Nd} /{ }^{144} \mathrm{Nd}$ e $\mathrm{Sm} / \mathrm{Nd}$, o que implicaria num possível controle dos procedimentos de lixiviação adotados, visto que todos os concentrados minerais foram submetidos aos mesmos métodos de dissolução e separação química. Adicionalmente, durante os procedimentos para a determinação isotópica, em nenhuma das etapas notou-se a presença de fases precipitadas ou não dissolvidas, para todas as amostras analisadas, o que ajuda a corroborar o controle dos procedimentos de lixiviação nos dados.

\subsection{DisCUSSÕES}

A utilização de ácido acético diluído resultou na remoção apenas parcial do carbonato a partir do concentrado de apatita (Figura 4.2). Tal fato também já havia sido notado por Hornig-Kjarsgaard (1998) na tentativa da remoção de inclusões. No entanto, o uso deste ácido de acordo com o método descrito no Teste 1 se mostrou eficaz na lixiviação da superfície dos cristais de apatita e, assim, tal procedimento é recomendável para a lixiviação dos concentrados de apatita ultrapuros, previamente preparados com auxílio de microscópio binocular. A dissolução preferencial das partículas finas aderidas à superfície da apatita, mas não a dos grãos maiores de carbonato provavelmente está relacionada à maior superfície de reação disponível no material fino.

Nos testes 2 e 3 houve a formação de compostos de $\mathrm{Cl}, \mathrm{Mg}$ e Ca entre os cristais de apatita (Figura 4.3), possivelmente a partir da dissolução dos carbonatos presentes na amostra, bem como, da própria superfície da apatita. Os aspectos texturais deste material, que se comporta como coberturas superficiais ou como material cimentante entre grãos de apatita, e sua ausência na amostra inicial, indicam claramente sua origem durante o procedimento de lixiviação. Contudo, a presença de cloro na amostra que foi lixiviada apenas com ácido 
acético (Teste 3.2; Figura 4.3C), embora em quantidade muito menor do que nas amostras tratadas com $\mathrm{HCl}$ (Teste 3.1; Figura 4.3B), levanta a suspeita de que tenha ocorrido algum tipo de contaminação com $\mathrm{HCl}$ durante o procedimento, uma vez que os béqueres estavam abertos e foram colocados concomitantemente no ultrassom. A dissolução e recristalização de fases minerais contendo cloro (i.e., cloroapatitas) seria uma alternativa para justificar os compostos observados na Figura 4.3. Contudo, esta explicação é pouco viável visto que dados da literatura (Toledo \& Pereira, 2001) indicam que as apatitas do complexo alcalinocarbonatítico de Catalão são essencialmente fluorapatitas.

A partir dos experimentos realizados com $\mathrm{HCl}$ a frio (Teste 4), conclui-se que apesar de todo o carbonato ter sido removido como o esperado devido à sua alta solubilidade em ácidos inorgânicos (Deer et al., 1992), tal método não pode ser aplicado para a lixiviação do carbonato de uma mistura contendo carbonato e apatita, pois o $\mathrm{HCl}$ também provoca a dissolução parcial da apatita.

De fato, notou-se que o $\mathrm{HCl}$ dissolve a apatita em uma direção cristalografia preferencial (Figura 4.5). Torres (2008) realizou tentativa semelhante para separar apatita do carbonato e também observou a formação de cavidades de corrosão em uma direção especifica. Além disso, aquele autor associou tais feições à direção do eixo "c" cristalográfico, tendo como base os trabalhos de Dorozhkin (1997a, b). Estes últimos propõem que a dissolução da apatita por ácido fosfórico $\left(\mathrm{H}_{3} \mathrm{PO}_{4}\right)$ acontece de maneira incongruente, com a remoção do flúor, cálcio e fosfato, nesta ordem. Costa Junior et al. (2001) chegaram a conclusões similares em experimentos realizados com solução Mehlich III. Esta remoção sequencial seria a responsável por gerar a geometria alongada das cavidades de dissolução, tendo em vista a posição do flúor em canais na estrutura da apatita (Dorozhkin, 1997b; Torres, 2008). É possível que a estrutura da apatita tenha a mesma resposta ao $\mathrm{HCl}$, o que justificaria a dissolução preferencialmente paralela ao eixo "c".

Um ponto interessante a ser observado nos cristais com fratura conchoidal recente (i.e., formadas durante a preparação da amostra para microscopia eletrônica, Figura 4.6A, B) é o caráter superficial das feições de dissolução. O prolongamento das cavidades de dissolução em direção ao centro dos cristais é proporcional à concentração do ácido empregado, como pode ser observado comparando as figuras Figura 4.6B (Teste 4.2) e Figura 4.6F (Teste 4.5). Desta forma, e considerando a dissolução incongruente da apatita, a concentração do ácido utilizado na lixiviação terá influência direta nas concentrações e razões elementares. 
Seguindo Machado et al. (1986), a remoção do $\mathrm{Nd}$ da estrutura da apatita, provavelmente, é facilitada em relação à remoção do $\mathrm{Sm}$, embora ambos estejam no mesmo sítio cristalográfico. O mesmo deve ocorrer no sistema $\mathrm{Rb}-\mathrm{Sr}$, contudo as baixíssimas razões $\mathrm{Rb} / \mathrm{Sr}$ normalmente encontradas na apatita evitam que tal fracionamento elementar seja significativo quanto para o sistema $\mathrm{Sm}-\mathrm{Nd}$.

Os dados isotópicos obtidos comprovam a importância da escolha do método correto de lixiviação antes da determinação de razões isotópicas em concentrados minerais. Embora a composição isotópica de $\mathrm{Sr}$ dentre as amostras analisadas tenha se mantido homogênea, os resultados de $\mathrm{Nd}$ apontam para um controle dos distintos métodos de lixiviação adotados.

Na Figura 4.7 observa-se que há uma correlação positiva entre as razões ${ }^{143} \mathrm{Nd} /{ }^{144} \mathrm{Nd}$ e $\mathrm{Sm} / \mathrm{Nd}$, e que é concordante com a intensidade da lixiviação aplicada (i.e., com o grau de corrosão superficial da apatita). A amostra submetida ao Teste 1 com ácido acético, na qual houve apenas a remoção das impurezas superficiais, tem razões ${ }^{143} \mathrm{Nd} /{ }^{144} \mathrm{Nd}$ e $\mathrm{Sm} / \mathrm{Nd}$ muito próximas da amostra não lixiviada. De maneira oposta, a amostra submetida ao Teste 4.2 com $\mathrm{HCl}$ diluído, na qual ocorreu dissolução total dos carbonatos e corrosão superficial da apatita, tem razões ${ }^{143} \mathrm{Nd} /{ }^{144} \mathrm{Nd}$ e $\mathrm{Sm} / \mathrm{Nd}$ bastante mais altas do que as das outras duas amostras. Por analogia com as conclusões de Machado et al. (1986) para o caso do sistema Rb-Sr, é possível que o $\mathrm{Nd}$ comum (sítios originalmente ocupados por $\mathrm{Nd}$ ) seja removido preferencialmente, em relação ao $\mathrm{Nd}$ radiogênico (sítios originalmente ocupados por $\mathrm{Sm}$ ), com o progressivo aumento na intensidade da corrosão superficial da apatita.

Entretanto, visto que as amostras resultantes dos testes com ácido acético e $\mathrm{HCl}$ tem mineralogias ligeiramente diferentes, a explicação acima não é única. É possível que as fases minerais removidas pelo $\mathrm{HCl}$ (carbonatos) também sejam responsáveis pela variação nas razões ${ }^{143} \mathrm{Nd} /{ }^{144} \mathrm{Nd}$ e $\mathrm{Sm} / \mathrm{Nd}$. Contudo, devido à quantidade reduzida desses minerais, um controle tão significativo na razão ${ }^{143} \mathrm{Nd} /{ }^{144} \mathrm{Nd}$ é improvável. Um modelo de mistura simples, utilizando como membros finais a apatita do Teste 4.2 e a composição isotópica média dos carbonatos de Catalão I (ver Oliveira, 2015), indica a necessidade de pelo menos $50 \%$ de carbonato contaminante na amostra para explicar a razão isotópica da apatita do Teste 1 (Figura 4.8), o que é inconsistente com as observações microscópicas. Além do mais, a presença de cerca de $50 \%$ de carbonato no concentrado mineral não explica a variação observada na razão $\mathrm{Sm} / \mathrm{Nd}$. Isto só ocorreria se considerarmos a curva tracejada produzida a partir dos menores valores das razões isotópicas dentro do intervalo de confiança (i.e., -2SD). 


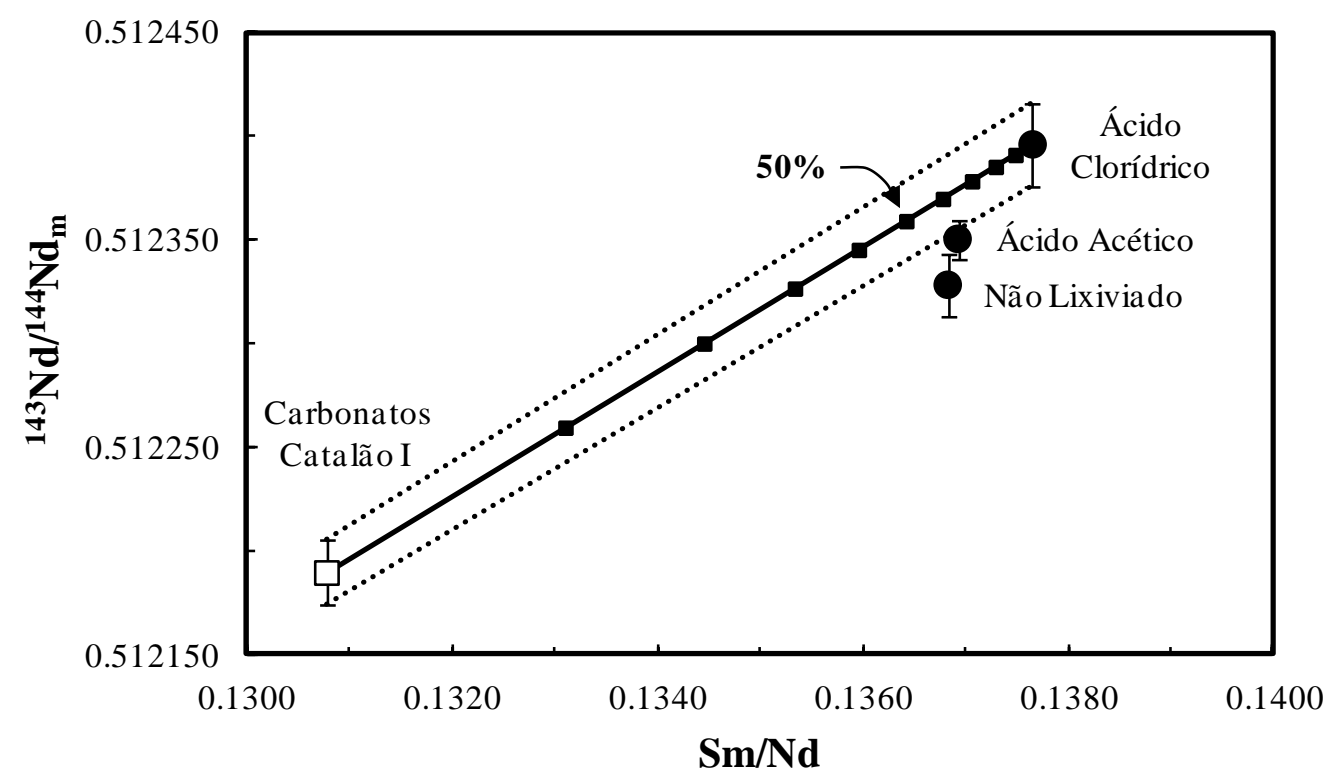

Figura 4.8. Mistura binária simples entre a média dos carbonatos de Catalão I (Oliveira, 2015) e a apatita do Teste 4.2. Linha sólida representa a curva de mistura entre dois membros finais. Símbolos nesta linha indicam o incremento de $10 \%$ no total de carbonato presente na mistura. Linhas pontilhadas são modelos considerando as razões isotópicas máximas (+2SD) e mínimas (-2SD) dos membros finais. Composição média dos carbonatos de Catalão $\mathrm{I}, \mathrm{Sm}=25.8 \mathrm{ppm}, \mathrm{Nd}=197.3 \mathrm{ppm}$ e ${ }^{143} \mathrm{Nd} /{ }^{144} \mathrm{Nd} \mathrm{m}_{\mathrm{m}}=0.512190 \pm 0.000016$.

Adicionalmente, a remoção de fases minerais com composições isotópica distintas provavelmente causaria variações também na razão ${ }^{87} \mathrm{Sr} /{ }^{86} \mathrm{Sr}$, o que não é observado nos dados. Assim, a remoção seletiva de uma fase mineral por lixiviação, por exemplo, carbonato, não é suficiente para explicar a correlação entre os dados isotópicos no sistema $\mathrm{Sm}-\mathrm{Nd}$ em concentrados de apatita, e a intensidade de lixiviação da própria apatita deve desempenhar um papel importante nestas feições.

\subsection{CONCLUSÕES}

Os distintos testes realizados neste trabalho com o intuito de purificar concentrados de apatita portadores de carbonatos suscitaram algumas conclusões importantes, principalmente com respeito a um método eficiente para a lixiviação da superfície dos cristais de apatita em concentrados ultrapuros:

1. Métodos de lixiviação com $\mathrm{HCl}$ devem ser evitados em concentrados minerais de apatita, visto que este ácido, mesmo em concentrações reduzidas, provoca a abertura da estrutura da apatita e a modificação das razões elementares e isotópicas da amostra, principalmente, no caso do sistema Sm-Nd.

2. As feições lineares de dissolução da apatita submetida a ataques com $\mathrm{HCl}$ sugerem que a dissolução ocorre preferencialmente ao longo do eixo "c" cristalográfico, de 
maneira similar à descrita por Dorozhkin (1997a, b), que propôs a dissolução incongruente da apatita a partir de estudos com $\mathrm{H}_{3} \mathrm{PO}_{4}$.

3. Inicialmente, o $\mathrm{HCl}$ ataca apenas a superfície da apatita, mas a dissolução avança em direção ao centro dos grãos conforme aumenta a concentração do ácido.

4. A influência dos procedimentos de lixiviação testados neste estudo, inclusive os testes com $\mathrm{HCl}$, sobre o sistema $\mathrm{Rb}-\mathrm{Sr}$ parece ser mínima. Esta interpretação é válida para o caso da apatita provavelmente devido à baixa razão $\mathrm{Rb} / \mathrm{Sr}$ deste mineral.

5. A lixiviação com ácido acético diluído a quente é útil na remoção das impurezas superficiais da apatita, preservando as características químicas e isotópicas deste mineral. Entretanto, sua incapacidade de dissolver totalmente o carbonato indicam que a aplicação deste método de lixiviação (Teste 1) deve ser precedida de purificação do concentrado de apatita por separação manual sob microscópio binocular. Dentre os métodos testados neste estudo, esse é o procedimento recomendado.

\section{Agradecimentos}

Os autores agradecem ao Laboratório de Estudos Geodinâmicos, Geocronológicos e Ambientais do Instituto de Geociências da Universidade de Brasília pelo suporte analítico e técnico, e as agências de fomento CNPq e CAPES pelas bolsas de pesquisa concedidas. O primeiro autor também agradece a M.E.S.D. Giustina pelo suporte essencial nas análises de microscopia eletrônica de varredura.

\section{Referências}

Costa Junior, C.N., Herrmann, P.S.P. \& Gaspar, J.C. (2001). Dissolution features on igneous apatite due to acid attack investigated by AFM and SEM. Acta Microscopica, Supplement 10(1): 175-180.

Davidson, J.P., Morgan, D.J., Charlier, B.L.A., Harlou, R. \& Hora, J.M. (2007). Microsampling and isotopic analysis of igneous rocks: Implications for the study of magmatic systems. Ann. Rev. Earth and Planet. Sci. 35: 273-311.

Deer, W.A., Howie, R.A. \& Zussman, J. (1992). An introduction to the rock forming minerals, $2^{\text {nd }}$ Edition. Longman, London. $712 \mathrm{pp}$. 
Dickin, A.P. (2005). Radiogenic Isotope Geology, $2^{\text {nd }}$ Edition. Cambridge University Press, New York. 492 pp.

Dorozhkin, S.V. (1997a). Acidic dissolution mechanism of natural fluorapatite I. Journal of Crystal Growth 182: 125-132.

Dorozhkin, S.V. (1997b). Acidic dissolution mechanism of natural fluorapatite II. Journal of Crystal Growth 182: 133-140.

Dunworth, E.A. \& Bell, K. (2001). The Turiy Massif, Kola Peninsula, Russia: Isotopic and geochemical evidence for multi-source evolution. J. Petrology 42(2): 377-405.

Faure, G. (2001). Origin of Igneous Rocks - The Isotopic Evidence. Springer-Verlag, Heidelberg. 496 pp.

Gill, R. (1997). Modern Analytical Geochemistry, $1^{\text {st }}$ Edition. Addison Wesley Longman Limited, England. 329 pp.

Gioia, S.M.C.L. \& Pimentel, M.M. (2000). The Sm-Nd isotopic method in the geochronology laboratory of the University of Brasília. Anais Academ. Bras. Ciências 72(2): 219-145.

Hornig-Kjarsgaard, I. (1998). Rare earth elements in sövitic carbonatites and their mineral phases. J. Petrology 39(11-12): 2105-2121.

Machado, M.C. (2013). Metodologias isotópicas ${ }^{87} \mathrm{Sr} /{ }^{86} \mathrm{Sr}, \delta \mathrm{C}^{13}$ e $\delta \mathrm{O}^{18}$ em estudos geológicos e arqueológicos. Unpublished Ph.D. Thesis, UFRGS, Brazil. 265 pp.

Machado, N., Brooks, C. \& Hart, S.R. (1986). Determination of initial ${ }^{87} \mathrm{Sr} /{ }^{86} \mathrm{Sr}$ and ${ }^{143} \mathrm{Nd} /{ }^{144} \mathrm{Nd}$ in primary minerals from mafic and ultramafic rocks: Experimental procedure and implications for the isotopic characteristics of the Archean mantle under the Abitibi greenstone belt, Canada. Geochim. Cosmochim. Acta 50: 2335-2348.

Malarkey, J. (2010). Micro-geochemistry of the mantle and its volcanic rocks. Doctoral Thesis, Durham University. 238 pp. Available at Durham E-Theses Online: http://etheses.dur.ac.uk/131/

McClellan, G.H. \& Lehr, J.R. (1969). Crystal chemical investigation of natural apatites. The American Mineralogist 54: 1374-1391. 
Oliveira, I.L. (2015). Isótopos de Nd e Sr em minerais de diferentes séries petrogenéticas nos complexos alcalino-carbonatíticos de Salitre e Catalão I. Unpublished MSc Thesis, Universidade de Brasília, Brazil. 240 pp.

Silverman, S.R., Fuyat, R.K. \& Weiser, J.D. (1952). Quantitative determination of calcite associated with carbonate-bearing apatites. The American Mineralogist 37: 211-222.

Smith, J.P. \& Lehr, J.R. (1966). An x-ray investigation of carbonate apatites. J. Agr. Food Chem. 14(4): 342-349.

Thirlwall, M.F. (1991). Long-term reproducibility of multicollector $\mathrm{Sr}$ and $\mathrm{Nd}$ isotope ratio analysis. Chemical Geology 94: 85-104.

Toledo, M.C.M. \& Pereira, V.P. (2001). A variabilidade de composição da apatita associada a carbonatitos: Revista do Instituto Geológico 22(1/2): 27-64.

Torres, M.G. (2008). Composição química superficial e nanotopográfica da apatita do protominério da mina de Barreiro, Araxá-MG. Unpublished Ph.D. Thesis, Universidade de Brasília, Brazil. 184 pp.

Weis, D., Kieffer, B., Maerschalk, C., Pretorius, W. \& Barling, J. (2005). High-precision PbSr-Nd-Hf isotopic characterization of USGS BHVO-1 and BHVO-2 reference materials. Geochemistry Geophysics Geosystems 6(2): 1-10.

Wittig, N., Pearson, D.G., Downes, H. \& Baker, J.A. (2009). The U, Th and Pb elemental and isotope compositions of mantle clinopyroxenes and their grain boundary contamination derived from leaching and digestion experiments. Geochim. Cosmochim. Acta 73: 469-488.

Wu, F.Y. (2010). Geochemical applications of in situ isotopic analyses by laser ablation. Geochemical News 143: 1-16. 


\section{ND AND SR ISOTOPIC SYSTEMATICS IN MINERALS} FROM THE SALITRE I ALKALINE-PHOSCORITECARBONATITE COMPLEX, SE BRAZIL: EVIDENCE FOR OPEN-SYSTEM BEHAVIOUR DURING MAGMATIC EVOLUTION.

Ítalo Lopes de Oliveira ${ }^{1}$, José Affonso Brod ${ }^{1,2}$, Elisa Soares Rocha Barbosa ${ }^{2}$, Elton Luiz Dantas ${ }^{1}$.

${ }^{1}$ Instituto de Geociências, Universidade de Brasília (UnB), Campus Universitário Darcy Ribeiro, Asa Norte, CEP 70.910-900, Brasília, DF, Brazil.

${ }^{2}$ Unidade Acadêmica Especial de Ciências e Tecnologia, Campus Aparecida de Goiânia, Universidade Federal de Goiás (UFG), CEP 74.968-755, Aparecida de Goiânia, GO, Brazil.

\section{Abstract}

Numerous alkaline-carbonatite complexes worldwide exhibit a systematic $\mathrm{Nd}-\mathrm{Sr}$ isotopic variation between carbonatites and the associated alkaline rocks. Whole-rock investigations of carbonatites, phoscorites and silicate rocks (bebedourites) of the Salitre I complex show significant differences in their initial $\mathrm{Nd}$ and $\mathrm{Sr}$ ratios. Such variations are often interpreted as reflecting an isotopically heterogeneous mantle source. However, previous field, petrographic, whole-rock and mineral chemistry data strongly support the interpretation that all petrogenetic series are cogenetic and related to each other through fractional crystallization and liquid immiscibility processes. Our detailed study involving several mineral separates from different rocks of Salitre I reveals that $\mathrm{Sr}$ isotopic compositions become more radiogenic toward the late-crystallizing phases, indicating an open-system condition during magmatic evolution. Using mathematical modelling, we demonstrate that minor crustal contamination $(<10 \%)$ during differentiation of a carbonatedsilicate parental magma (AFCLI model) could explain the isotope heterogeneities in carbonatites and bebedourites. Mineral-rock $\mathrm{Nd}$ isotopic disequilibrium noted in most of the studied phoscorites are probably related to late-stage alteration. The relatively restricted range of enriched $\mathrm{Nd}-\mathrm{Sr}$ isotopic ratios of carbonate melts and phlogopite picrites indicate that Salitre I was formed by parental magmas derived from a metasomatized subcontinental lithospheric source with isotopic composition akin to the EM-I mantle component. 


\subsection{INTRODUCTION}

Carbonatites are rare igneous rocks containing > 50\% carbonate minerals by volume (Le Maitre, 2002), occur almost exclusively on continental settings through a large range of temporal distribution (i.e., from Archean to the Recent), and are commonly associated with a great diversity of alkaline silicate rocks (Woolley \& Kjarsgaard, 2008). Radiogenic, stable and noble gas isotopic data accompanied by several phase equilibrium studies have shown that the ultimate source of carbonatites lies within the mantle (Bell, 1998; Bell et al., 1998; Bell \& Tilton, 2002). In addition, their unusual high concentrations of $\mathrm{Nd}$ and $\mathrm{Sr}$ buffer against crustal contamination effects, retaining the isotopic characteristics of the mantle sources. These aspects make carbonatites ideal for monitoring the geochemical evolution of the sub-continental mantle (Bell, et al., 1982; Bell \& Blenkinsop, 1989; Bell \& Tilton, 2002).

Even after half a century since the recognition that these mantle-derived rocks are definitely generated by magmas (e.g., Dawson, 1962), there is an ongoing debate regarding their origin (i.e., lithospheric or sub-lithospheric mantle sources, Bell \& Simonetti, 2010; Woolley \& Bailey, 2012). Besides, one of the most fundamental questions that remain unsolved in carbonatite petrogenesis is the significance of their close relationship with silicaundersaturated rocks (Bell, 1998; Bell et al., 1998; Gittins \& Harmer, 2003; Mitchell, 2005; Woolley \& Kjarsgaard, 2008; Ray, 2009). Experimental studies have established that carbonatites can be generated as primary magmas through direct partial melting of $\mathrm{CO}_{2}$ bearing mantle peridotite (Eggler, 1989; Harmer \& Gittins, 1998 and references therein). Nevertheless, $\sim 75 \%$ of all carbonatites occurrences are associated with alkaline silicate rocks (Woolley \& Kjarsgaard, 2008) and this undoubtedly implies in a more complex magmatic evolution, involving separation of carbonatite melts from a carbonated-silicate parental magma either by fractional crystallization (i.e., as residual melts - Lee \& Wyllie, 1998), or via carbonate-silicate liquid immiscibility (Brooker \& Kjarsgaard, 2011 and references therein).

Interestingly, radiogenic isotopic data in a number of alkaline-carbonatite complexes worldwide reveal a systematic $\mathrm{Nd}-\mathrm{Sr}$ isotopic variation between carbonatites and the associated alkaline silicate rocks, puzzling their genetic relationship. In general, the latter have initial isotopic ratios that are more variable and more enriched (i.e., higher ${ }^{87} \mathrm{Sr}^{86} \mathrm{Sr}_{\mathrm{i}}$ and lower ${ }^{143} \mathrm{Nd} /{ }^{144} \mathrm{Nd}_{\mathrm{i}}$ ) than the former (Bell \& Blenkinsop, 1989; Bell, 1998; Harmer \& Gittins, 1998; Ray, 2009). Such observations are difficult to reconcile with simple, closed magmatic differentiation from the same parental magma, suggesting a more complicated evolution, in 
some cases with open-system behaviour (Bell \& Blenkinsop, 1989; Bell, 1998; Bell \& Rukhlov, 2004). On the whole, these isotope features have been interpreted as a result of discrete volumes of magma derived from isotopically heterogeneous mantle sources (Eriksson, 1989; Mitchell et al., 1994; Huang et al., 1995; Zaitsev \& Bell, 1995; Harmer \& Gittins 1998; Morikiyo et al., 2000; Verhulst et al., 2000; Bühn \& Trumbull, 2003; Yuhara et al., 2005; Wu et al., 2011) or of crustal contamination, more easily detected in the silicate magmas (Roden et al., 1985; Andersen, 1987; Tilton et al., 1987; Dunworth \& Bell, 2001; Ray, 2009; Wu et al., 2012; Ye et al., 2013).

Most of the previous isotopic investigations of carbonatites have used whole-rock samples assuming that all mineral phases are in isotopic equilibrium and crystallized at the same time. Therefore, bulk analyses simply provide a weighted average isotopic composition for the different minerals. This may be a drawback in complex magmatic systems (e.g., carbonatites) since the results can obscure some important petrogenetic processes such as magma mixing and crustal contamination (Bell, 2001; Bizzarro et al., 2003; Ye et al., 2013). Recently, detailed radiogenic isotopic studies in minerals of some carbonatites evidenced isotopic disequilibrium between co-existing phases (e.g., Bell, 2001; Bizzarro et al., 2003; Wu et al., 2012), confirming that carbonatite melts indeed can evolve by a combination of open-system processes (e.g., magma recharge, assimilation, mixing).

In this context, we attempt to shed new light on the genetic relationship between carbonatites and associated alkaline rocks, as well as the petrogenetic evolution of the Salitre I alkaline-carbonatite complex, Alto Paranaíba Igneous Province (APIP), SE Brazil. Barbosa (2009) reported significant $\mathrm{Nd}-\mathrm{Sr}$ isotope variations in the whole-rock data from carbonatites, phoscorites and alkaline silicate rocks from this complex. Such isotopic features could be interpreted as reflecting distinct mantle sources, but this contrasts with previous petrological studies in the APIP complexes (e.g., Brod, 1999; Barbosa, 2009; Grasso, 2010; Brod et al., 2012), which suggest that the different rock types in each complex are genetic related.

With this background in mind, we carried out a comprehensive $\mathrm{Nd}$ and $\mathrm{Sr}$ isotope investigation in several mineral phases from the different rock types of the Salitre I complex aiming to: (1) characterize the $\mathrm{Nd}-\mathrm{Sr}$ isotope composition of the various minerals and rocks; (2) determine whether the minerals of the same rock are in isotopic equilibrium or not; and (3) identify the cause(s) of the variations in isotope whole-rock data, providing robust constraints on the petrogenetic processes acting in the complex. 


\subsection{Geological SetTing}

\section{Cretaceous Alkaline Magmatism}

Two major magmatic episodes are recorded in Central and Southern Brazil during the Cretaceous. In Early Cretaceous ( $130 \mathrm{Ma})$ widespread alkaline and tholeiitic magmatism occurred in central South America and, less extensively, in southwest Africa, including the Paraná-Etendeka continental flood basalts and numerous alkaline and alkaline-carbonatite complexes of sodic affiliation. The complexes were emplaced mainly along reactivated ancient tectonic lineaments in the eastern and western margins of the Paraná Basin (Herz, 1977; Gibson et al., 1995a; Peate, 1997; Le Roex \& Lanyon, 1998; Comin-Chiaramonti et al., 2005; Riccomini et al., 2005). These igneous rocks have been widely related to the impact of the Tristan da Cunha (TC) mantle plume under the subcontinental lithospheric mantle (SCLM), during the opening of the South Atlantic Ocean (Hawkesworth et al., 1986; Peate et al., 1990; Toyoda et al., 1994; Bizzi et al., 1995; Gibson et al., 1995a; Peate, 1997; Le Roex \& Lanyon, 1998; Gibson et al., 2005).

A second period of intense alkaline magmatism took place from the Late Cretaceous ( 85 Ma) to Eocene along NW-SE trending structures in central and southeastern Brazil (Herz, 1977; Almeida \& Svisero, 1991; Gibson et al., 1995b). The Late Cretaceous provinces surrounding the north and northeast margin of the Paraná Basin are mostly potassic, and have been associated with the Trindade (TD) mantle plume/hotspot track (Herz, 1997; Crough et al., 1980; Gibson et al., 1995a, b; 1997; Thompson et al., 1998; Araújo et al., 2001; Sgarbi et al., 2004). Some authors have argued strongly against the involvement of the TD mantle plume in the Late Cretaceous magmatism in this region, the main arguments being the lack of a clear progressive eastward age decrease and the absence of an isotopic TD plume signature in the alkaline magmas (Meyer et al., 1994; VanDecar et al., 1995; Comin-Chiaramonti et al., 2005; Ernesto, 2005; Riccomini et al., 2005; Guarino et al., 2012).

Gibson et al. $(1995 b, 1997)$ have shown that the effects of the TD mantle plume are recorded in "thinspots" such as the Proterozoic mobile belts in central Brazil. In some cases, the TD plume contributed with a chemical component (e.g., Poxoréu Province, Gibson et al., 1997; Serra do Mar Province, Thompson et al., 1998) and in others it simply acted as a heat source triggering the melting of the readily fusible metasomatized SCLM (e.g., Alto Paranaíba Igneous Province, Gibson et al., 1995b). 
Seismic studies (Assumpção et al., 2002; 2004; Schimmel et al., 2003) support the plume hypothesis, showing that low-velocity anomalies in the upper mantle coincide with the Late Cretaceous alkaline provinces in central Brazil. Assumpção et al. (2004) suggest that these anomalies have a thermal origin related to hot mantle upwelling confined in thinner lithosphere, which is in accordance with TD plume model of Gibson et al. $(1995 b, 1997)$.

\section{Alto Paranaíba Igneous Province}

The Late Cretaceous Alto Paranaíba Igneous Province (APIP) is one of the most voluminous mafic potassic alkaline provinces of the world (Gibson et al., 1995b). It comprises a large number of minor intrusive bodies (dykes, pipes, plugs, diatremes) and a few major plutonic complexes, as well as extensive lavas and pyroclastic deposits; all emplaced into the low-grade Neoproterozoic metasedimentary rocks of the Brasília Belt (Leonardos \& Meyer, 1991; Meyer et al., 1994; Gibson et al., 1995b; Brod et al., 2004; Gomes \& CominChiaramonti, 2005). The APIP lies along the Alto Paranaíba Arch, an important NW-trending tectonic structure situated between the SW border of the Archean São Francisco Craton (SFC) and the NE margin of the Phanerozoic Paraná Basin (Figure 5.1). The uplift of this arch occurred mainly in the Late Cretaceous, contemporaneous with the peak of magmatism, and was responsible for separating the San Franciscan and Paraná sedimentary basins (Almeida, 1983; Gibson et al., 1995b; Campos \& Dardenne, 1997).

The APIP consists of widespread kamafugitic volcanic rocks of the Mata da Corda Group, numerous small subvolcanic bodies of kamafugite with minor kimberlite and lamproite and large carbonatite-bearing plutonic complexes (Seer \& Moraes, 1988; Leonardos et al., 1991; Gibson et al., 1995b; Sgarbi et al., 2000; Araújo et al., 2001, Brod et al., 2004; Gomes \& Comin-Chiaramonti, 2005). The subvolcanic and volcanic rocks often contain xenoliths, including alkali clinopyroxenite and mantle peridotite. The latter are mostly spinel lherzolites, harzbugites and dunites, which attest to a shallow lithospheric source for the APIP magmas. However, unusual garnet lherzolite xenoliths have been reported in some kimberlite intrusions, indicating that at least some of the magmas derived from a deep mantle source (Seer \& Moraes, 1988; Meyer et al., 1994; Bizzi et al., 1994, 1995; Gibson et al., 1995b; Gomes \& Comin-Chiaramonti, 2005; Carlson et al., 2007). Alkali pyroxenite xenoliths are compositionally and texturally similar to the bebedourites occurring in the plutonic carbonatite complexes (e.g., Seer \& Moraes, 1988; Lloyd \& Bailey, 1994; Brod et al., 2000). 


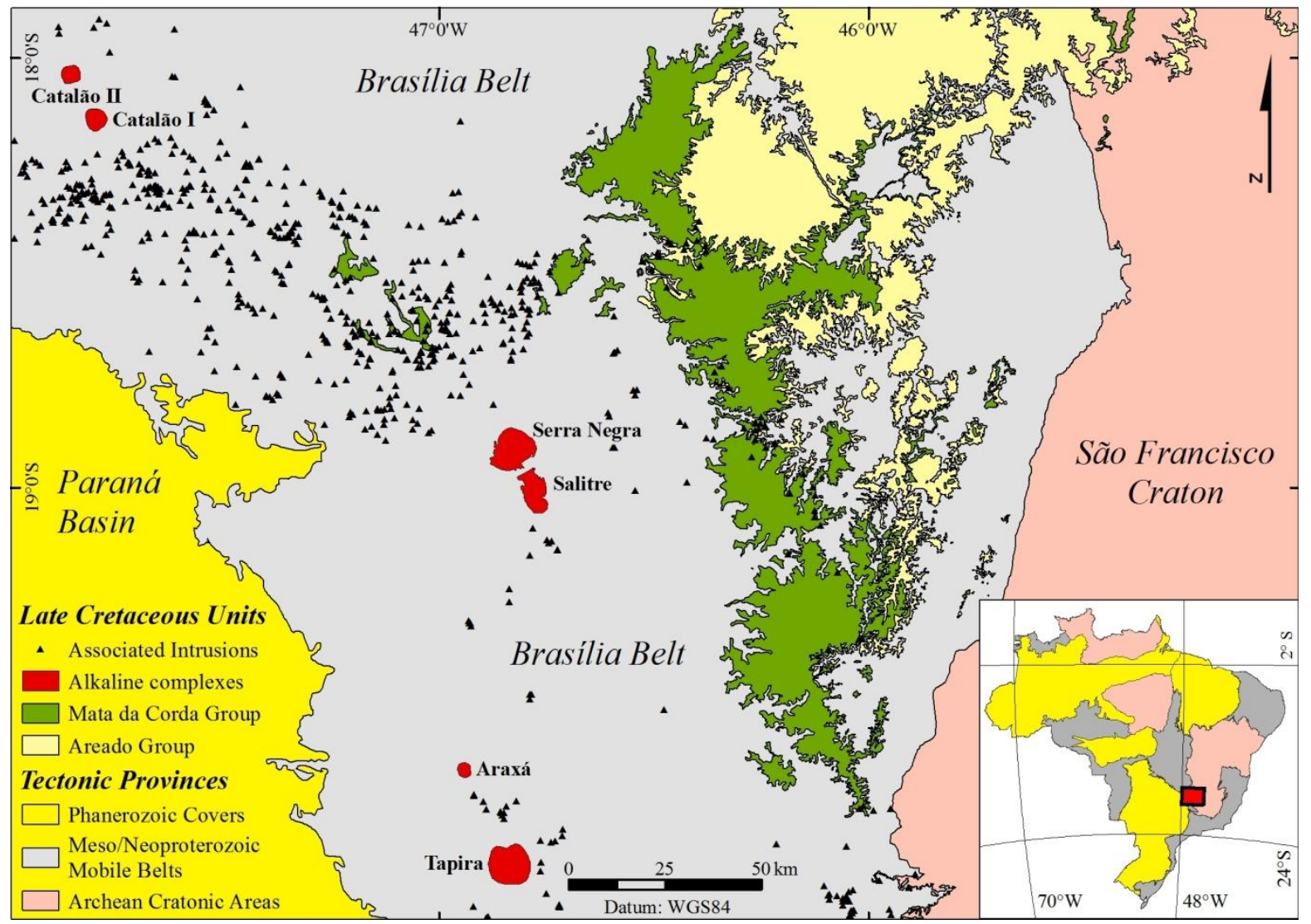

Figure 5.1. Geological setting of the Alto Paranaíba Igneous Province in the Neoproterozoic Brasília Belt, between the SW border of the São Francisco Craton and the NE margin of the Paraná sedimentary basin (Modified from Oliveira et al., 2004). The Mata da Corda Group consists of kamafugite lavas and epiclastic sediments whereas the Areado Group is composed of sedimentary rocks. This two sequences form the San Franciscan Basin in this region. The inset shows the general view of the major cratonic areas (pink), mobile belts (grey) and sedimentary basins (yellow) of Brazil, as well as the location of APIP in relation to them (red square).

Phlogopite picrite dykes (Gibson et al., 1995b) occur throughout the province, but are particularly associated with the plutonic carbonatite complexes (Brod et al., 2000). These rocks have a kamafugitic affinity and are interpreted as the parental magma of the APIP alkaline-carbonatite complexes. Such evidence, together with the temporal and spatial relationship of mafic potassic rocks and carbonatites led Brod et al. (2000) to characterize a kamafugite-carbonatite association in the APIP. Similar associations between ultrapotassic and carbonatitic magmas have been recognized in other regions, such as South Africa (Phalaborwa Complex, Eriksson, 1989), Uganda (Western Branch of the East African Rift, Lloyd et al., 1999; Eby et al., 2003), Italy (Castorina et al., 2000; Lavecchia et al., 2006), Russia (Mitchell et al., 1994) and China (Yang \& Woolley, 2006; Guo et al., 2014).

The large (up to $65 \mathrm{~km}^{2}$ ) APIP carbonatite-bearing plutonic complexes are composed mainly of ultramafic silicate rocks (i.e., bebedourites), phoscorites, carbonatites and rare syenites (Brod et al., 2004). The occurrences include Catalão I and II, Serra Negra, Salitre, 
Araxá and Tapira alkaline complexes (Figure 5.1). These complexes are multi-stage intrusions that generally deformed the Neoproterozoic metasedimentary rocks of the Brasília Belt into dome structures (Brod et al., 2000; 2004).

Intense tropical weathering associated with differential erosion and dissolution of the igneous rocks in the central part of the domes, in contrast to the surrounding, weatherresistant fenitized country rocks, produced a thick soil cover in most of the complexes (Danni et al., 1991; Mariano \& Marchetto 1991; Brod et al., 2004). Supergenic processes have originated residual deposits of phosphate, $\mathrm{Nb}, \mathrm{Ti}, \mathrm{Ba}, \mathrm{REE}$ and vermiculite within this soil cover (Danni et al., 1991; Brod et al., 2004).

\subsection{SAlitre COMPleX}

The Salitre alkaline-phoscorite-carbonatite complex consists of three separate intrusive bodies (Salitre I, II and III) located immediately to the south of Serra Negra complex in the central part of the APIP (19 $03^{\prime} \mathrm{S} ; 4^{\circ} 47^{\prime} \mathrm{W}$; Figure 5.2). Salitre I is the largest of these bodies and has a distorted oval shape with about $35 \mathrm{~km}^{2}$. Salitre II and III are small plugs $\left(2.5 \mathrm{~km}^{2}\right.$ and $4 \mathrm{~km}^{2}$ ) situated to the north and south of Salitre I, respectively (Morbidelli et al., 1997; Brod et al., 2004; Barbosa, 2009; Barbosa et al., 2012a).

Mariano \& Marchetto (1991) reported fission track ages of 83 Ma for Salitre II and 87 Ma for Salitre I, obtained on apatite from pyroxenite (bebedourite) and carbonatite, respectively. K-Ar dating of phlogopite from bebedourites yielded ages of 82.5 $\pm 5.6 \mathrm{Ma}$ and 86.3 $\pm 5.7 \mathrm{Ma}$ (Sonoki \& Garda, 1988). Whole-rock K-Ar dating of phonolites produced ages in the range of 79.0 to 94.5 Ma for this complex (Gomes, quoted by Sonoki \& Garda, 1988).

The Salitre complex comprises alkaline-ultramafic cumulate rocks (perovskite dunites and bebedourites), radial dykes of feldspathic rocks (trachytes, tinguaites and syenites), phoscorites and carbonatites (Mariano \& Marchetto, 1991; Morbidelli et al., 1997). Salitre I contains abundant silicate rocks, mainly perovskite and Ti-garnet bebedourites (Figure 5.2). In addition, a system of interconnected ring plus radial dykes of phoscorites and carbonatites intrudes the northern part of the body (Barbosa et al., 2012a). Salitre II is dominated by perovskite dunites with minor transecting dykes of carbonatites and phlogopite picrites (previously described as lamprophyres, Mariano \& Mitchell, 1991 and Mariano \& Marchetto, 1991). Salitre III is essentially composed of bebedourites associated with local phoscorites in the southern part of the body (Brod et al., 2004; Barbosa et al., 2012a). 


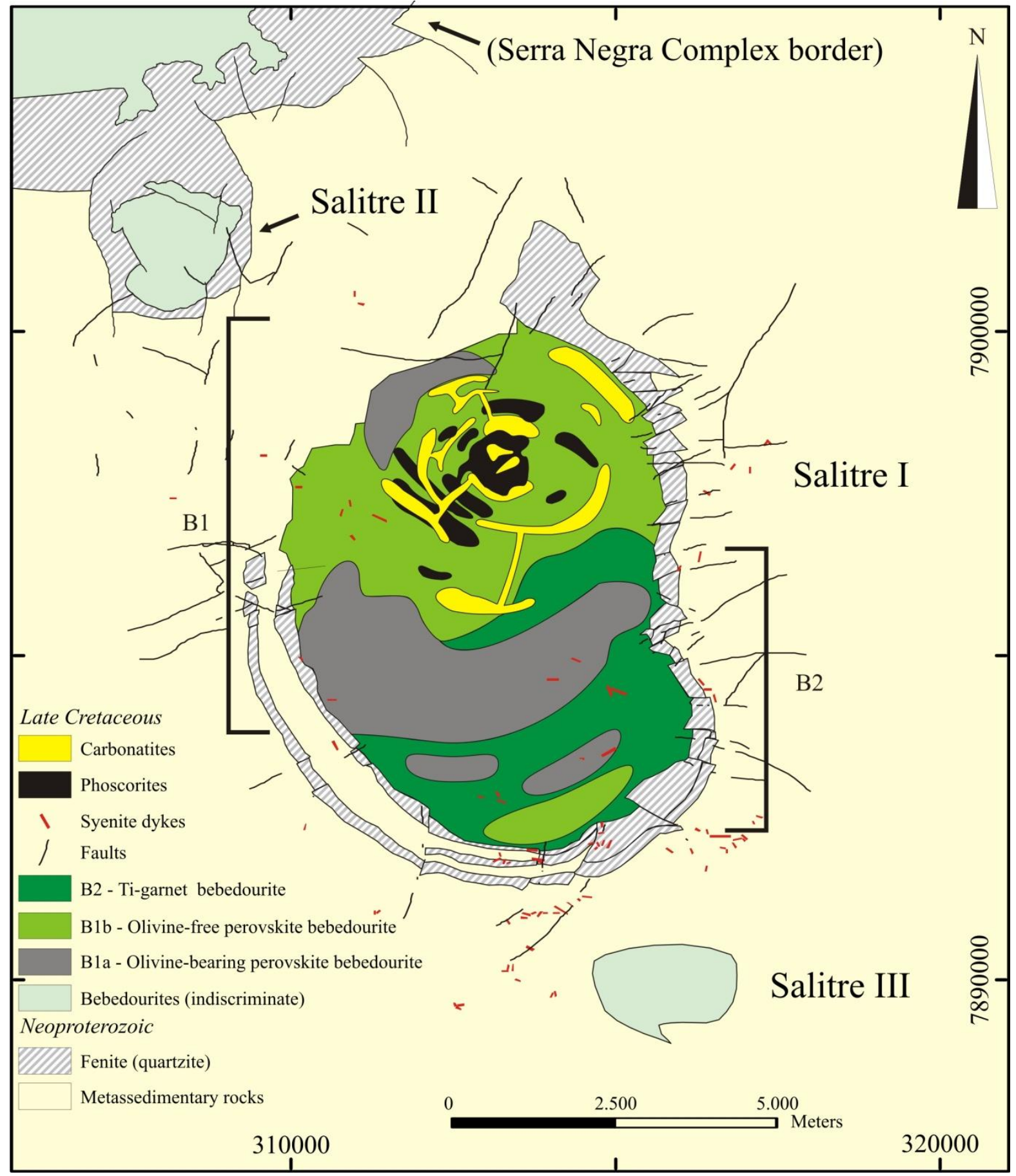

Figure 5.2. Schematic geological map of the Salitre complex (after Barbosa et al., 2012a).

\section{Bebedourites, Phoscorites and Carbonatites}

The geology, petrography and mineral chemistry of the Salitre I rocks have been studied in detail by Mariano \& Mitchell (1991), Morbidelli et al. (1997), Barbosa (2009) and Barbosa et al. (2012a, b, c, d). Only a general description of these rock types is given here.

The bebedourites occur as cumulates or dykes, vary from fine- to coarse-grained, rarely pegmatoidal, with important modal variations of olivine, clinopyroxene, phlogopite, 
perovskite, Ti-rich garnet, titanite, magnetite and apatite. These rocks vary in colour from green to brown and locally exhibit evidence of magmatic layering as well as flow texture. Perovskite-rich bebedourites (B1) occur mainly in the center-northern part of the complex and are subdivided into olivine-bearing (B1a) and olivine-free (B1b). Ti-garnet bebedourites (B2) prevail in the southern part of the complex and occur as dykes within B1. Petrographically the B2 unit is subdivided in three groups (B2a, B2b, B2c) on the basis of the main Ca-Ti phase (perovskite, garnet or titanite). The B2b unit contains significant amounts of interstitial carbonates (Barbosa et al., 2012a).

The phoscorite-series rocks are frequently associated with carbonatites, vary from fine- to coarse-grained, and occur as dykes, breccias and banded rocks. Additionally, they show evidence of ductile deformation that suggests a crystal mush movement (Barbosa et al., 2012b). These rocks are divided in P1 phoscorites, composed of apatite, olivine and phlogopite with minor amounts of magnetite, and P2 phoscorites, which consist essentially of apatite, magnetite and olivine in addition to carbonate pockets and accessory pyrochlore. The carbonate pockets are irregular and usually have elongated crystals of magnetite, olivine and rare apatite in the rims, resembling a comb-layering texture (Barbosa et al., 2012b) similar to that described by Cordeiro et al. (2010) in the Catalão I complex. Some cumulates produced from carbonatite magma (C3a unit, Barbosa et al., 2012c) may have modal composition similar to the bona fide phoscorites or nelsonites (apatite, magnetite, ilmenite and pyrochlore).

The carbonatite-series rocks comprise calciocarbonatites and magnesiocarbonatites that vary from white to grey and from fine- to coarse-grained. They occur mostly as centimetric veins to metric dykes and, occasionally, as layered rocks. Layers of crystal mush are often deformed, similarly to what is observed in the phoscorites. Barbosa et al. (2012c) divided the Salitre I carbonatites into 4 units: C1 and C2 correspond to early-stage magnesiocarbonatites, C3 to calciocarbonatites and D4 to late-stage Ba-rich magnesiocarbonatite dykes. $\mathrm{C} 1$ is composed of dolomite with uneven aggregates of apatite, phlogopite and rare olivine whereas C2 magnesiocarbonatites consist nearly completely of carbonate. C3 carbonatites vary from olivine-rich to almost pure calciocarbonatites, and sometimes contain phoscoritic or nelsonitic cumulates (C3a).

According to Barbosa (2009) and Barbosa et al. (2012c) the Salitre I complex evolved by an intricate combination of fractional crystallization and liquid immiscibility. They proposed the following intrusive sequence for the formation of the complex (Table 5.1). 
Table 5.1. Successive emplacement stages proposed for rocks of the Salitre I complex, based on Barbosa (2009) and Barbosa et al. (2012c).

\begin{tabular}{lll}
\hline Stage & Unit & Rock Type \\
\hline $1^{\text {st }}$ & B1a & Olivine-bearing bebedourite \\
$2^{\text {nd }}$ & B1b & Olivine-free bebedourite \\
& P1 & Phlogopite-rich phoscorite \\
$3^{\text {rd }}$ & B2 & Ti-garnet bebedourite \\
& C1 & Magnesiocarbonatite \\
$4^{\text {th }}$ & C2 & Magnesiocarbonatite \\
& P2 & Carbonate-rich phoscorite \\
& C3 & Calciocarbonatite \\
$5^{\text {th }}$ & C3a & Nelsonitic cumulates \\
& D4 & Ba-rich Magnesiocarbonatite \\
\hline
\end{tabular}

\section{Sample Petrography}

The samples investigated here are representative of all three petrogenetic series (i.e., bebedouritic, phoscoritic and carbonatitic series) that constitute the Salitre I complex. They were selected after careful hand-specimen and thin-section inspection in order to avoid any visible hydrothermal or metasomatic alteration that could affect the isotopic data. A brief petrographic description of the studied samples is presented below. Supplementary data in Appendix A provide a more detailed mineral description as well as modal compositions.

Three samples, one of each unit, were chosen to represent the silicate magmatic series. Olivine-bearing bebedourite (B1a, sample FVL175) consists of a medium- to coarse-grained olivine and perovskite cumulate with minor amounts of intercumulus magnetite and phlogopite. Cumulus crystals have abundant micro-inclusions, mainly in the core. Magnetite, and to a lesser extent phlogopite, are often coated with tiny tetraferriphlogopite laths (Figure 5.3A), possibly due to interaction with some carbonatitic fluids. Olivine-free bebedourite (B1b, sample FSALT81) is composed of medium-grained clinopyroxene, fine- to mediumgrained phlogopite and apatite, with minor amounts of magnetite and perovskite. Magmatic layering is marked by magnetite + perovskite + phlogopite layers alternating with clinopyroxene layers (Figure 5.3B). Apatite may occur as irregular lenses within these layers, suggesting a crystal-mush movement. Clinopyroxene crystals have numerous magnetite inclusions. Ti-garnet bebedourite (B2, sample FSALT96) is a fine- to medium-grained rock, essentially composed of cumulus clinopyroxene and phlogopite, with intercumulus Ti-garnet (Figure 5.4A). Small proportions of apatite, magnetite and residual carbonate are also present. 
Three samples were also selected from phoscorite-series rocks. One is a phlogopiterich phoscorite (P1, sample SF101.5D1) composed of fine- to medium-grained apatite, phlogopite and olivine with minor magnetite. Residual carbonate occurs as an interstitial phase and zirconolite micro-crystals as a rare accessory. Apatite crystals often contain carbonate melt inclusions (Figure 5.3C), suggesting crystallization in equilibrium with a calciocarbonatite melt. Additionally, the presence of clinohumite in the rims of some olivine crystals suggests late-stage interaction with hydrous, F-rich fluids, although it is not clear whether these fluids are residual or metasomatic. Fine-grained magnetite clusters in the groundmass also could be related to these fluids (Figure 5.3D).
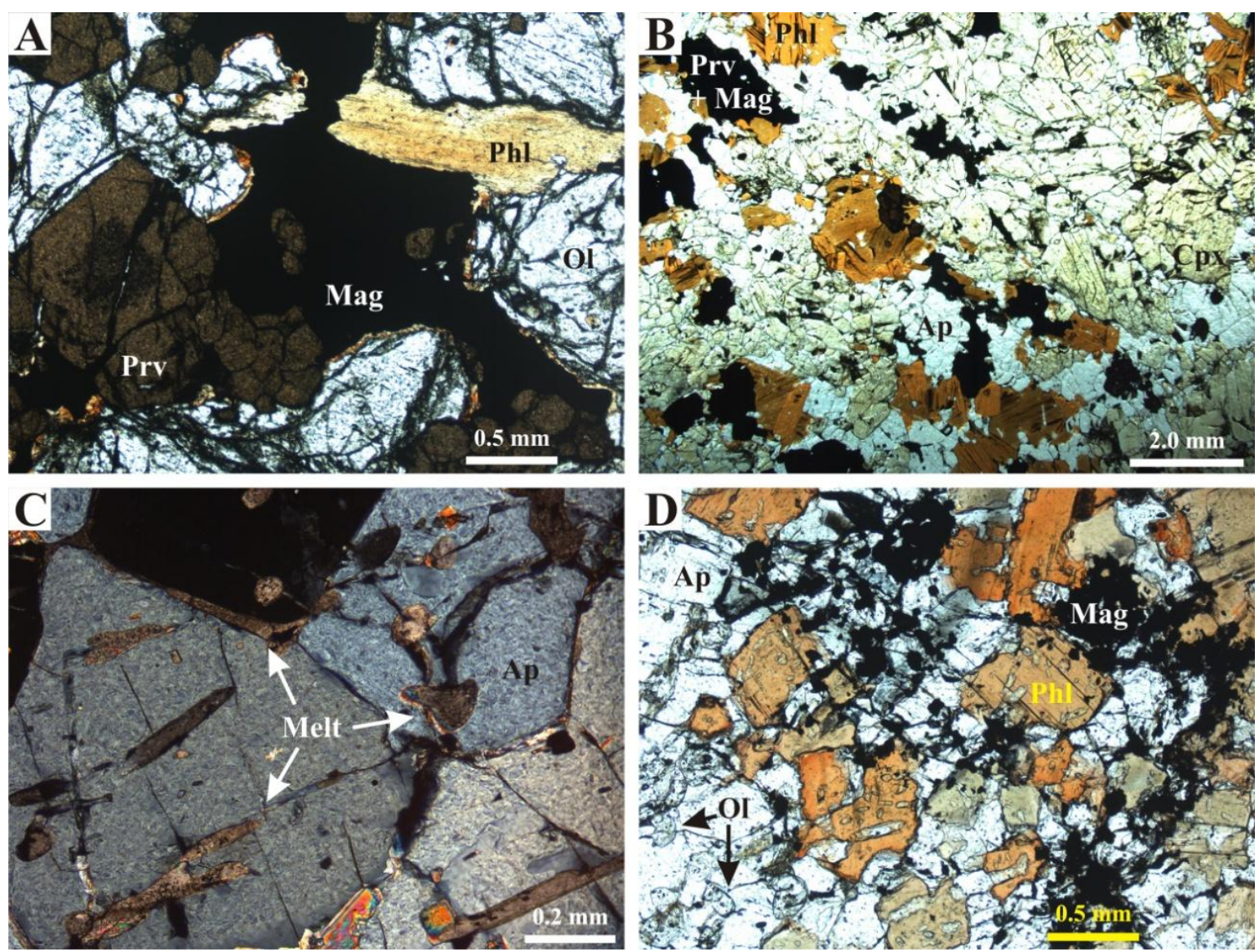

Figure 5.3. Petrographic features of the studied Salitre I samples $\left(1^{\text {st }}\right.$ and $2^{\text {nd }}$ intrusive stages). (A) Intercumulus magnetite coated with tiny tetraferriphlogopite laths. Note the abundant micro-inclusions in the core of perovskite (Sample FVL175). (B) Magmatic layering marked by alternation of apatite + magnetite + perovskite + phlogopite rich layers with clinopyroxene-dominated layers (Sample FSALT81). (C) Carbonate melt inclusions within apatite crystals in a P1 phoscorite. Note the irregular shape of the inclusions (Sample SF101.5D1). (D) Clusters of fine-grained, late-stage magnetite in a P1 phoscorite (Sample SF101.5D1). Plane-polarised light (A, B, D); Cross-polarised light (C). Ap - apatite; Cpx clinopyroxene; Mag - magnetite; Ol - olivine; Prv - perovskite; Phl - phlogopite. 
Medium- to coarse-grained P2 phoscorites (samples F37B-65A; FVL145A) generally consist of two domains: irregular, almost pure, carbonate pockets surrounded by a phoscoritic domain with magnetite, apatite and olivine (Figure 5.4C). Accessory pyrochlore and baddeleyite, and rare tetraferriphlogopite laths also occur in the phoscorite domains. A common feature in almost all samples of this unit is the post-magmatic alteration of olivine crystals to clinohumite.

Four carbonatite samples were chosen for this study, two $\mathrm{C} 1$ magnesiocarbonatites (samples 09B-50; 20B-94) and two C3 calciocarbonatites (samples FF476.6, 10A-41A). Fineto coarse-grained magnesiocarbonatites are almost pure with minor amounts of prismatic apatite and opaque minerals (Figure 5.4B). Pyrochlore and tetraferriphlogopite are accessories. Calciocarbonatite samples consist of fine- to coarse-grained carbonate with minor amounts of scattered fine-grained olivine, apatite, tetraferriphlogopite and opaque minerals. Silicates and oxides often occur as aggregates suggesting that they could be cumulate phases within the carbonatite melt. Thin apatite-, magnetite-, olivine-rich layers may occur locally (Figure 5.4D).

Sample 20B-94 is particularly interesting due to the coexistence of two different carbonate varieties (Figure 5.5): (a) grey coarse-grained carbonate with a cloudy aspect in thin section due to the large amount of exsolved microinclusions; (b) white, fine-grained carbonate consisting of clear, slightly oriented crystals that suggest flow texture. The distinctive characteristics in Figure 5.5 indicate that the grey carbonate is an older, high temperature variety that underwent subsolidus recrystallization. The scale of the sample does not allow us to define whether this feature represents a mixture of two carbonatite magmas or xenoliths of an older carbonatite caught in a younger intrusion. 

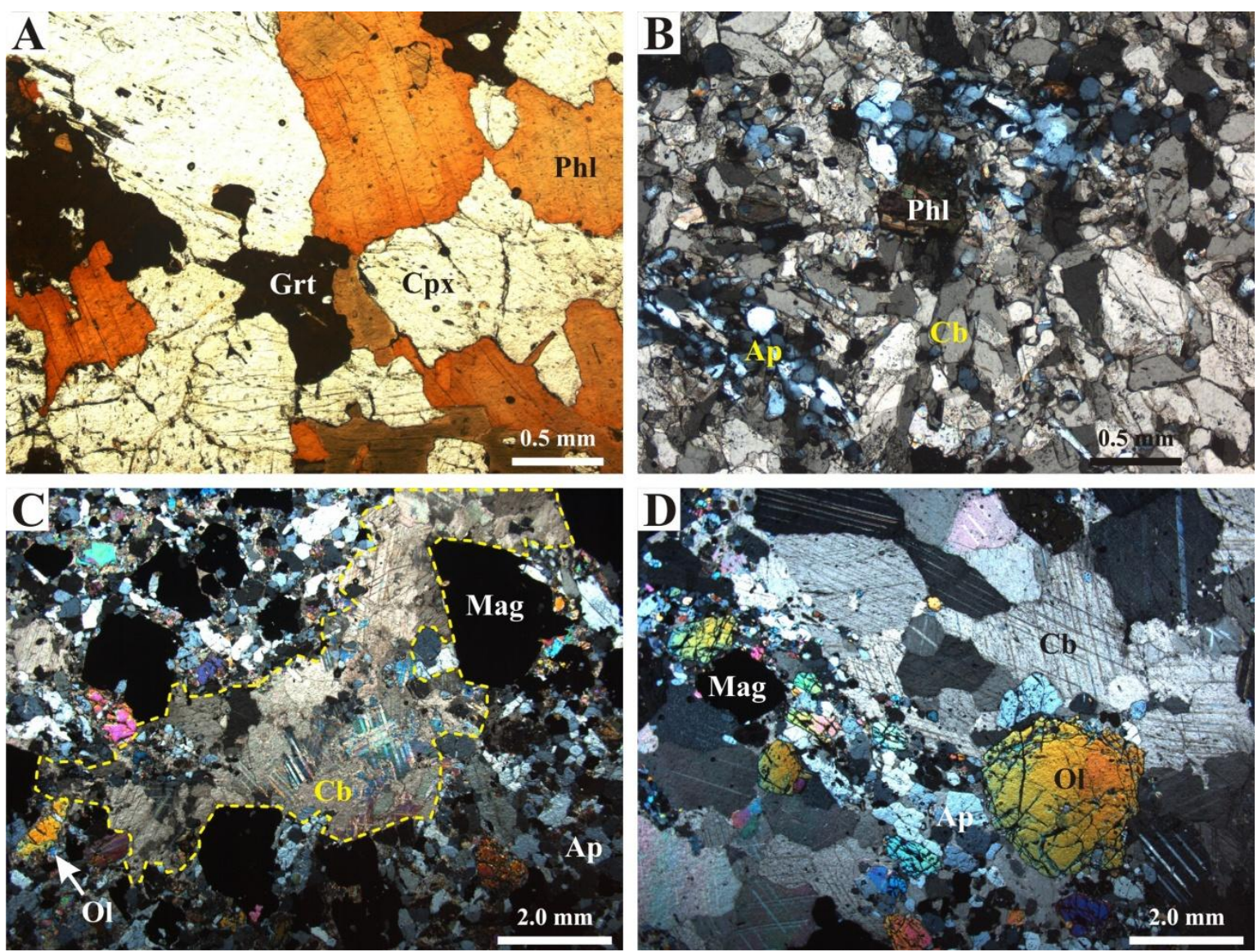

Figure 5.4. Petrographic features of the studied Salitre $I$ samples $\left(3^{\text {rd }}\right.$ and $4^{\text {th }}$ intrusive stages). (A) Intercumulus dark brown garnet surrounded by cumulus clinopyroxene and phlogopite (Sample FSALT96). (B) Aggregates of apatite crystals in a fine-grained C1 magnesiocarbonatite (Sample 09B-50). (C) Carbonate pocket (outlined by the yellow dashed line) surrounded by a phoscoritic domain (Sample FVL145A). (D) Thin phoscoritic cumulate in a C3 calciocarbonatite (Sample 10A-41A). All photomicrographs were taken under cross-polarised light. Ap - apatite; Cb - carbonate; Cpx clinopyroxene; Grt - garnet; Mag - magnetite; Ol - olivine; Phl - phlogopite.
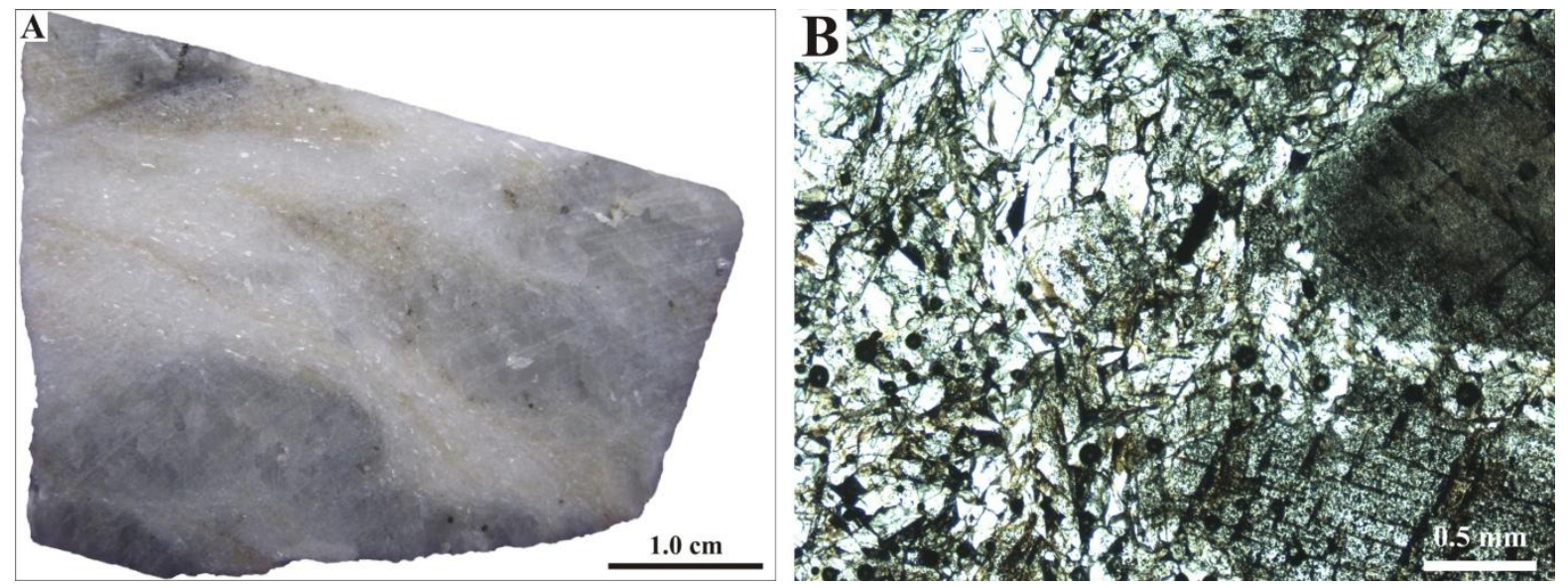

Figure 5.5. Textural features of two carbonate varieties in a C1 magnesiocarbonatite (Sample 20B-94). (A) Coarse-grained grey carbonate surrounded by a fine-grained, flow oriented, white carbonate. (B) Photomicrograph (plane-polarised light), showing the contact between the two types of carbonate. Note the cloudy aspect of coarse carbonate crystals (grey in A) due to the large amount of exsolutions, as opposed to the clear aspect of the fine-grained carbonate variety (white in $\mathrm{A}$ ). 


\subsection{Analytical Methods}

The $\mathrm{Sr}$ and $\mathrm{Nd}$ isotopic composition were determined in mineral separates from bebedourites, phoscorites and carbonatites, and in some whole-rock samples, in order to complement the whole-rock data of Barbosa (2009). All sample preparation procedures and isotope determinations were carried out at the Laboratory of Geodynamics, Geochronology and Environmental Studies of the Institute of Geosciences, University of Brasília.

\section{Mineral Separates}

Mineral phases chosen for isotopic analyses were apatite, calcite, clinopyroxene, dolomite, phlogopite, garnet, magnetite, olivine and perovskite. To obtain mineral separates, whole-rock samples were processed by electrodynamic disaggregation using a SELFRAG ${ }^{\circledR}$ Lab S2.0 High Voltage Pulse Power Fragmentation at voltages of 100-140 kV. In this method, shock waves disintegrate the rock sample immersed in a dielectric liquid (e.g., water) along grain boundaries by tensional stress (Andres, 1996; Gnos et al., 2007; Giese et al., 2010), allowing better preservation of individual phases and drastically reducing the amount of multimineral aggregates (Andres, 1996).

After disaggregation, all samples were dried and then sieved in three fractions $(<300$ $\mu \mathrm{m}, 300-500 \mu \mathrm{m}$ and $>500 \mu \mathrm{m}$ ) to facilitate the hand-picking according to the crystal size observed in thin section. These steps were followed by magnetic separation with a Frantz ${ }^{\circledR}$ Isodynamic device, due to the large amount of magnetite in almost all samples. Finally, minerals of interest were carefully separated by hand-picking under a binocular microscope to ensure at least $99 \%$ of purity for each mineral concentrate.

\section{Leaching Procedures}

Machado et al. (1986) point out that mineral separates should be cleaned prior to dissolution for isotopic analysis, in order to eliminate contamination resulting from the separation procedures. These contaminants may be fine particles of other mineral phases formed during sample fragmentation and/or handling (Machado et al., 1986; Wittig et al., 2009). Additionally, Wittig et al. (2009) state that an exogenous component resulting from interaction with hydrothermal fluids or groundwater at crustal level could also be coating the grain surfaces. 
According to Machado et al. (1986), hydrofluoric acid (HF) should not be used in sample leaching, as it attacks the crystal structure of silicates, leading to fractionation between radioactive and radiogenic elements. Recently, their conclusions are further supported by a comprehensive radiogenic isotope study in clinopyroxene from mantle xenoliths by Wittig et al. (2009). The latter authors also demonstrate that leaching with hydrochloric acid ( $\mathrm{HCl})$ and ultra-pure Milli- $\mathrm{Q}^{\circledR}$ water in several short-duration steps are adequate to remove all the surface contaminants without triggering fractionation between radioactive and radiogenic element pairs in the pyroxene.

We adopt leaching procedures analogous to those of Wittig et al. (2009). Firstly, the mineral separates were washed with ultra-pure Milli- $\mathrm{Q}^{\circledR}$ water at room temperature $\left(16-18^{\circ} \mathrm{C}\right)$ in an ultrasonic bath for 30 minutes (step 1). This water was then removed by pipetting and the minerals were repeatedly rinsed with Milli- $\mathrm{Q}^{\circledR}$ water before being washed for a second time under the same conditions (step 2). The concentrates were rinsed again with Milli-Q ${ }^{\circledR}$ water. After draining, all minerals except apatite and carbonates were leached with $2.5 \mathrm{~N} \mathrm{HCl}$ for 30 minutes at $80-100{ }^{\circ} \mathrm{C}$ (step 3). The leaching acid was removed and the mineral separates were rinsed with Milli- $\mathrm{Q}^{\circledR}$ water. At this stage, olivine, perovskite and phlogopite were dried out, whereas clinopyroxene, garnet and magnetite concentrates were leached one more time with $6 \mathrm{~N} \mathrm{HCl}$ for 30 minutes at 80-100 ${ }^{\circ} \mathrm{C}$ (step 4). Finally, these separates were rinsed with Milli- $\mathrm{Q}^{\circledR}$ water and allowed to dry.

Only the first two steps were used in the leaching of carbonates, since they are readily dissolved in inorganic acids. Leaching of apatite separates followed the method developed by Oliveira et al. (2015, in preparation), which uses dilute acetic acid $(0.5 \mathrm{~N})$ at $80-100{ }^{\circ} \mathrm{C}$. All procedures described were conducted in class 10,000 ultra-clean facilities.

\section{Nd Isotope Analyses}

Five to two hundred milligrams of leached mineral samples, depending on the expected concentration of the analytes in each mineral phase, were spiked with a mixed ${ }^{149} \mathrm{Sm}^{-150} \mathrm{Nd}$ tracer before digestion. Clinopyroxene, garnet, magnetite, perovskite, and phlogopite were dissolved in a mixture of $\mathrm{HF}^{-\mathrm{HNO}_{3}}$ in Parr Teflon ${ }^{\circledR}$ bombs according to the method of Gioia \& Pimentel (2000). Olivine separates and whole rock samples ( 100 mg of sample powder), were digested by the same method, but inside Savillex ${ }^{\circledR}$ vials instead of Parr Teflon ${ }^{\circledR}$ bombs. Apatite and carbonate samples were dissolved with $2 \mathrm{ml}$ of $\mathrm{HCl} 6 \mathrm{~N}$ 
(carbonates) and $2 \mathrm{ml}$ of concentrated $\mathrm{HNO}_{3}$ (apatite) in Savillex ${ }^{\circledR}$ vials placed on a hot plate for 1 day at $80-100{ }^{\circ} \mathrm{C}$.

Separation of the Sm and Nd from the mineral/rock matrix was carried out by two-step ion exchange chromatography, following Gioia \& Pimentel (2000). Firstly, sample solutions were loaded on quartz glass columns packed with DOWEX ${ }^{\circledR}$ AG-50W-X8 cation exchange resin (100-200 mesh) to collect the REE fraction. Subsequently, Sm and Nd were extracted in Eichrom ${ }^{\circledR} \mathrm{LN}-\mathrm{Spec} 100-150 \mu \mathrm{m}$ resin in Teflon ${ }^{\circledR}$ columns.

All samples were analysed using a Thermo Scientific TRITONTM Plus Thermal Ionization Mass Spectrometer (TIMS) operating in the static multi-collector mode. The average ${ }^{143} \mathrm{Nd} /{ }^{144} \mathrm{Nd}$ obtained for the USGS BHVO-1 standard was $0.512996 \pm 0.000006$ $(2 S D ; n=7)$ during the course of this study, which is consistent with the most recently published values (e.g., $0.512986 \pm 0.000009$, Weis et al., 2005). Laboratory blanks were $\sim 0.25 \mathrm{ng}$ for $\mathrm{Nd}$ and $\sim 0.04 \mathrm{ng}$ for $\mathrm{Sm}$. For details on concentration reproducibility and mass fractionation corrections, see the footnotes of Table 5.2 to Table 5.5.

\section{Sr Isotope Analyses}

After digestion, an aliquot of sample solution was directly loaded onto Teflon ${ }^{\circledR}$ columns containing approximately $83 \mathrm{mg}$ of Eichrom ${ }^{\circledR}$ Sr-Spec resin $(50-100 \mu \mathrm{m})$ to separate the $\mathrm{Sr}$ fraction from the matrix.

$\mathrm{Rb}$ concentration of mineral separates could not be determined during this work. In the case of minerals with extremely low $\mathrm{Rb} / \mathrm{Sr}$ (i.e., apatite and carbonates), the measured ${ }^{87} \mathrm{Sr} /{ }^{86} \mathrm{Sr}$ ratios can be considered initial ratios (Bell \& Blenkinsop, 1987b; Zaitsev \& Bell, 1995). On the other hand, clinopyroxene, garnet and perovskite often have high Sr contents in alkaline silicate rocks and carbonatites. Semi-quantitative ICP-MS approximations from the $\mathrm{Sm}-\mathrm{Nd}$ chromatography rejects indicate that these mineral separates have $\mathrm{Rb} / \mathrm{Sr}$ ratio $>0.001$ (a limit value for which measured isotopic ratios can be assumed as initial ones, in view of analytical errors and an $85 \mathrm{Ma}$ age). For that reason, a correction smaller than $0.005 \%$ of the measured value (except for garnet; $\sim 0.02 \%$ ) was applied in the isotopic ratio in order to correct the radiogenic ${ }^{87} \mathrm{Sr}$ interference and to obtain more realistic initial ratio values, as can be seen in Table 5.4. 
Sr isotopic composition of selected samples was determined using a Thermo Scientific TRITONTM Plus Thermal Ionization Mass Spectrometer (TIMS) operating in the multidynamic mode. The average ${ }^{87} \mathrm{Sr} /{ }^{86} \mathrm{Sr}$ obtained for the NBS-987 standard was $0.710257 \pm$ $0.000007(2 S D ; n=9)$ during the course of this study. This value agrees well, within the analytical error, with the most typically recommended value of 0.71025 (Thirlwall, 1991; Faure, 2001; Machado, 2013). For details regarding mass fractionation corrections, see the footnotes of Table 5.2 to Table 5.5.

\subsection{RESULTS}

The $\mathrm{Sr}$ and $\mathrm{Nd}$ isotopic compositions together with $\mathrm{Rb}, \mathrm{Sr}, \mathrm{Sm}$ and $\mathrm{Nd}$ concentrations of whole-rock samples are presented in Table 5.2 and Table 5.3. These include previously unpublished results from Barbosa (2009) and published data from Barbosa et al. (2012a). Table 5.4 and Table 5.5 report the $\mathrm{Sr}$ and $\mathrm{Nd}$ isotope data obtained from mineral separates of the selected samples used in this study. Whole-rock major and trace element data discussed hereafter are from Barbosa (2009). 
Capítulo 5: Complexo de Salitre I

\begin{tabular}{|c|c|c|c|c|c|c|c|c|}
\hline Sample & Rock Type & Unit & $\begin{array}{c}\mathbf{R b} \\
(\mathbf{p p m})^{\mathbf{a}}\end{array}$ & $\begin{array}{c}\mathrm{Sr} \\
(\mathbf{p p m})^{\mathrm{a}}\end{array}$ & $\begin{array}{l}{ }^{86} \mathbf{R b} /{ }^{87} \mathrm{Sr} \\
\text { (atomic) }\end{array}$ & $\begin{array}{c}{ }^{87} \mathrm{Sr} /{ }^{86} \mathrm{Sr}_{\mathrm{m}} \\
(\text { measured) })^{\mathrm{c}}\end{array}$ & $\begin{array}{c}{ }^{87} \mathrm{Sr}^{86} \mathrm{Sr}_{\mathbf{i}} \\
\text { (initial) }{ }^{\mathrm{d}}\end{array}$ & Ref." \\
\hline FVL68 & Bebedourite & B1a & 41.6 & 424.4 & 0.2835 & $0.705500 \pm 0.000030$ & 0.705164 & 1 \\
\hline FVL175 & Bebedourite & B1a & 12.3 & 1273.2 & 0.0279 & $0.705283 \pm 0.000007$ & 0.705250 & This Work \\
\hline FSALT81 & Bebedourite & $\mathrm{B} 1 \mathrm{~b}$ & 27.0 & 1197.8 & 0.0653 & $0.705350 \pm 0.000020$ & 0.705273 & 1 \\
\hline FVL95.7 & Bebedourite & $\mathrm{B} 1 \mathrm{~b}$ & 20.8 & 1647.8 & 0.0365 & $0.705360 \pm 0.000020$ & 0.705317 & 1 \\
\hline FSALT96 & Bebedourite & $\mathrm{B} 2 \mathrm{~b}$ & 124.9 & 971.9 & 0.2580 & $0.705590 \pm 0.000020$ & 0.705149 & 1 \\
\hline 282B & Bebedourite & $\mathrm{B} 2 \mathrm{c}$ & 130.2 & 1460.1 & 0.1589 & $0.705540 \pm 0.000030$ & 0.705234 & 1 \\
\hline 296B & Bebedourite & $\mathrm{B} 2 \mathrm{c}$ & 87.1 & 1585.1 & 0.3874 & $0.705380 \pm 0.000020$ & 0.705192 & 1 \\
\hline 281 & Bebedourite & $\mathrm{B} 2 \mathrm{c}$ & 141.4 & 1056.2 & 0.3719 & $0.706110 \pm 0.000080$ & 0.705651 & 1 \\
\hline SF102.4D2 & Phoscorite & $\mathrm{P} 1$ & 84.1 & 4687.5 & 0.0519 & $0.705310 \pm 0.000020$ & 0.705249 & 2 \\
\hline SF104.2 & Phoscorite & $\mathrm{P} 1$ & 95.7 & 4297.1 & 0.0644 & $0.705300 \pm 0.000030$ & 0.705224 & 2 \\
\hline SF101.5D1 & Phoscorite & $\mathrm{P} 1$ & 44.8 & 3963.3 & 0.0327 & $0.705450 \pm 0.000020$ & 0.705411 & 2 \\
\hline F37B-65A & Phoscorite & $\mathrm{P} 2$ & 4.9 & 2703.5 & 0.0052 & $0.705100 \pm 0.000010$ & 0.705094 & 2 \\
\hline F37B-65B & Phoscorite & $\mathrm{P} 2$ & 6.3 & 2886.8 & 0.0063 & $0.705110 \pm 0.000020$ & 0.705103 & 2 \\
\hline FVL145A & Phoscorite & $\mathrm{P} 2$ & 8.8 & 4724.9 & 0.0054 & $0.705000 \pm 0.000020$ & 0.704994 & 2 \\
\hline 09A-60A & Phoscorite & $\mathrm{P} 2$ & 5.7 & 3179.9 & 0.0052 & $0.705160 \pm 0.000020$ & 0.705154 & 2 \\
\hline ASL31 & Carbonatite & $\mathrm{C} 1$ & 3.3 & 6682.6 & 0.0014 & $0.705090 \pm 0.000010$ & 0.705088 & 2 \\
\hline 20B-94 & Carbonatite & $\mathrm{C} 1$ & 15.3 & 9166.4 & 0.0048 & $0.705240 \pm 0.000010$ & 0.705234 & 2 \\
\hline ASL33 & Carbonatite & $\mathrm{C} 1$ & 2.6 & 6235.5 & 0.0012 & $0.705120 \pm 0.000010$ & 0.705119 & 2 \\
\hline 09B-50 & Carbonatite & $\mathrm{C} 1$ & 0.9 & 7348.0 & 0.0004 & $0.705276 \pm 0.000003$ & 0.705276 & This Work \\
\hline FSALT87 & Carbonatite & $\mathrm{C} 2$ & 0.3 & 7447.0 & 0.0001 & $0.705100 \pm 0.000020$ & 0.705100 & 2 \\
\hline $10 \mathrm{~A}-77 \mathrm{~A}$ & Apatitite & $\mathrm{C} 3 \mathrm{a}$ & - & 11127.1 & - & $0.705100 \pm 0.000030$ & 0.705100 & 2 \\
\hline $277.2 \mathrm{~A} 3$ & Magnetitite & $\mathrm{C} 3 \mathrm{a}$ & 16.4 & 4837.8 & 0.0098 & $0.705010 \pm 0.000030$ & 0.704998 & 2 \\
\hline
\end{tabular}


Table 5.2. Whole-rock Sr isotopic data from the Salitre I complex (Continued).

\begin{tabular}{|c|c|c|c|c|c|c|c|c|}
\hline Sample & Rock Type & Unit & $\begin{array}{c}\mathbf{R b} \\
(\mathbf{p p m})^{\mathbf{a}}\end{array}$ & $\begin{array}{c}\mathrm{Sr} \\
(\mathbf{p p m})^{\mathrm{a}} \\
\end{array}$ & $\begin{array}{l}{ }^{86} \mathrm{Rb} /{ }^{87} \mathrm{Sr} \\
\text { (atomic) }\end{array}$ & $\begin{array}{c}{ }^{87} \mathrm{Sr} /{ }^{86} \mathrm{Sr}_{\mathrm{m}} \\
(\text { measured) }\end{array}$ & $\begin{array}{l}{ }^{87} \mathrm{Sr}^{86} \mathrm{Sr}_{\mathrm{i}} \\
\text { (initial) }^{\mathrm{d}} \\
\end{array}$ & Ref." \\
\hline $277.2 \mathrm{~A} 2$ & Nelsonite & $\mathrm{C} 3 \mathrm{a}$ & 16.1 & 5357.7 & 0.0087 & $0.705080 \pm 0.000010$ & 0.705070 & 2 \\
\hline 407D3 & Ilmenitite & $\mathrm{C} 3 \mathrm{a}$ & 41.2 & 2429.5 & 0.0491 & $0.705130 \pm 0.000010$ & 0.705072 & 2 \\
\hline $10 \mathrm{~A}-41 \mathrm{~A}$ & Carbonatite & $\mathrm{C} 3$ & 1.9 & 6574.0 & 0.0008 & $0.705140 \pm 0.000010$ & 0.705139 & 2 \\
\hline FF219 & Carbonatite & C3 & 6.5 & 14028.2 & 0.0013 & $0.705130 \pm 0.000010$ & 0.705128 & 2 \\
\hline FF476.6 & Carbonatite & $\mathrm{C} 3$ & 11.0 & 10963.6 & 0.0029 & $0.705040 \pm 0.000010$ & 0.705037 & 2 \\
\hline FF292D1 & Carbonatite & $\mathrm{C} 3$ & 6.2 & 10857.3 & 0.0017 & $0.705120 \pm 0.000010$ & 0.705118 & 2 \\
\hline FVL184 & Carbonatite & $\mathrm{C} 3$ & 29.1 & 14003.1 & 0.0060 & $0.705170 \pm 0.000010$ & 0.705163 & 2 \\
\hline 277.2A1 & Carbonatite & $\mathrm{C} 3$ & 2.5 & 11702.2 & 0.0006 & $0.705090 \pm 0.000010$ & 0.705089 & 2 \\
\hline ASL13 & Carbonatite & D4 & 15.3 & 10095.5 & 0.0044 & $0.705030 \pm 0.000010$ & 0.705025 & 2 \\
\hline FVL121.8 & Carbonatite & D4 & 0.6 & 13564.5 & 0.0001 & $0.705100 \pm 0.000010$ & 0.705100 & 2 \\
\hline
\end{tabular}

${ }^{\mathrm{a}} \mathrm{Rb}$ and $\mathrm{Sr}$ concentrations determined by ICP-MS.

${ }^{\mathrm{b}}$ Atomic ratios, calculated from $\mathrm{Rb}$ and $\mathrm{Sr}$ concentrations based on atomic weights and isotopic abundances recommended by IUPAC 2009 (Wieser \& Coplen, 2011; Berglund \& Wieser, 2011, respectively).

${ }^{\mathrm{c}}$ Measured ratios, normalized to ${ }^{88} \mathrm{Sr} /{ }^{86} \mathrm{Sr}=8.375209$ (equivalent to the more commonly used ${ }^{86} \mathrm{Sr} /{ }^{88} \mathrm{Sr}$ ratio of 0.1194 ) using an exponential law; errors are two standard errors (2SE) of the in-run means.

${ }^{\mathrm{d}}$ Initial ratios, calculated at $85 \mathrm{Ma}$ using the ${ }^{87} \mathrm{Rb}$ decay constant $\left(\lambda_{\mathrm{Rb}}\right)$ of $1.393 \times 10^{-11} \mathrm{yr}^{-1}$ (Nebel et al., 2011).

*References: 1- Published data from Barbosa et al. (2012a); 2- Unpublished data from Barbosa (2009).

- Value not determined. 
Capítulo 5: Complexo de Salitre I

\begin{tabular}{|c|c|c|c|c|c|c|c|c|c|c|}
\hline Sample & Unit & $\begin{array}{c}\mathrm{Sm} \\
(\mathbf{p p m})^{\mathrm{a}}\end{array}$ & $\begin{array}{c}\text { Nd } \\
(\mathbf{p p m})^{\mathbf{a}}\end{array}$ & $\begin{array}{c}{ }^{147} \mathrm{Sm} /{ }^{144} \mathrm{Nd} \\
\left(\text { atomic) }^{\mathrm{b}}\right.\end{array}$ & $\begin{array}{l}{ }^{143} \mathrm{Nd} /{ }^{144}{ }^{N d} d_{m} \\
(\text { measured })^{c}\end{array}$ & $\begin{array}{c}{ }^{143} \mathrm{Nd} /{ }^{144} \mathrm{Nd}_{\mathrm{i}} \\
(\text { initial }){ }^{\mathrm{d}}\end{array}$ & $\boldsymbol{E}_{\mathrm{Nd}}(\mathrm{T})^{\mathrm{e}}$ & $\begin{array}{l}\tau_{\text {DM }}{ }^{\mathbf{f}} \\
(\mathbf{G a})\end{array}$ & $\begin{array}{c}f_{\mathrm{Sm} / \mathrm{Nd}}{ }^{\mathrm{g}} \\
(\%)\end{array}$ & Ref." \\
\hline FVL68 & B1a & 55.9 & 463.5 & 0.0729 & $0.512215 \pm 0.000006$ & 0.512174 & $-6.9 \pm 0.1$ & 0.90 & -63.0 & 1 \\
\hline FVL175 & B1a & 172.7 & 1182.8 & 0.0883 & $0.512270 \pm 0.000016$ & 0.512221 & $-6.0 \pm 0.3$ & 0.94 & -55.1 & This Work \\
\hline FSALT81 & B1b & 23.3 & 137.1 & 0.1026 & $0.512274 \pm 0.000006$ & 0.512217 & $-6.1 \pm 0.1$ & 1.05 & -47.8 & 1 \\
\hline FVL95.7 & $\mathrm{B} 1 \mathrm{~b}$ & 37.1 & 211.8 & 0.1058 & $0.512245 \pm 0.000008$ & 0.512186 & $-6.7 \pm 0.2$ & 1.12 & -46.2 & 1 \\
\hline 282B & $\mathrm{B} 2 \mathrm{c}$ & 20.4 & 117.9 & 0.1045 & $0.512266 \pm 0.000008$ & 0.512208 & $-6.3 \pm 0.2$ & 1.08 & -46.9 & 1 \\
\hline 296B & $\mathrm{B} 2 \mathrm{c}$ & 37.6 & 234.2 & 0.0971 & $0.512250 \pm 0.000009$ & 0.512196 & $-6.5 \pm 0.2$ & 1.03 & -50.6 & 1 \\
\hline 281 & $\mathrm{~B} 2 \mathrm{c}$ & 41.4 & 227.4 & 0.1101 & $0.512283 \pm 0.000009$ & 0.512222 & $-6.0 \pm 0.2$ & 1.11 & -44.0 & 1 \\
\hline FSALT96 & $\mathrm{B} 2 \mathrm{~b}$ & 23.9 & 108.8 & 0.1328 & $0.512347 \pm 0.000013$ & 0.512273 & $-5.0 \pm 0.3$ & 1.30 & -32.5 & 1 \\
\hline SF102.4D2 & $\mathrm{P} 1$ & 180.6 & 1257.8 & 0.0868 & $0.512182 \pm 0.000009$ & 0.512134 & $-7.7 \pm 0.2$ & 1.03 & -55.9 & 2 \\
\hline SF104.2 & $\mathrm{P} 1$ & $195.3^{*}$ & $1296.8^{*}$ & 0.0911 & $0.512135 \pm 0.000013$ & 0.512084 & $-8.7 \pm 0.3$ & 1.12 & -53.7 & 2 \\
\hline SF101.5D1 & $\mathrm{P} 1$ & $253.2^{*}$ & $1743.5^{*}$ & 0.0878 & $0.512144 \pm 0.000015$ & 0.512095 & $-8.5 \pm 0.3$ & 1.08 & -55.4 & 2 \\
\hline F37B-65A & $\mathrm{P} 2$ & $130.9^{*}$ & $895.2^{*}$ & 0.0884 & $0.512188 \pm 0.000011$ & 0.512139 & $-7.6 \pm 0.2$ & 1.04 & -55.1 & 2 \\
\hline F37B-65B & $\mathrm{P} 2$ & $118.9^{*}$ & $916.7^{*}$ & - & $-\quad \quad-$ & - & $-\quad \quad-$ & - & - & 2 \\
\hline FVL145A & $\mathrm{P} 2$ & $81.7^{*}$ & $615.7^{*}$ & 0.0802 & $0.512269 \pm 0.000007$ & 0.512224 & $-5.9 \pm 0.1$ & 0.88 & -59.2 & 2 \\
\hline 09A-60A & $\mathrm{P} 2$ & $72.3^{*}$ & $565.5^{*}$ & 0.0772 & $0.512142 \pm 0.000008$ & 0.512099 & $-8.4 \pm 0.2$ & 1.00 & -60.7 & 2 \\
\hline ASL31 & $\mathrm{C} 1$ & 79.4 & 554.5 & 0.0865 & $0.512351 \pm 0.000018$ & 0.512303 & $-4.4 \pm 0.4$ & 0.83 & -56.0 & 2 \\
\hline 20B-94 & $\mathrm{C} 1$ & 62.2 & 448.1 & 0.0838 & $0.512263 \pm 0.000009$ & 0.512216 & $-6.1 \pm 0.2$ & 0.92 & -57.4 & 2 \\
\hline ASL33 & $\mathrm{C} 1$ & - & $192.0^{*}$ & - & - & - & $-\quad \quad-$ & - & - & 2 \\
\hline 09B-50 & $\mathrm{C} 1$ & 32.2 & 224.4 & 0.0866 & $0.512285 \pm 0.000012$ & 0.512237 & $-5.7 \pm 0.2$ & 0.91 & -56.0 & This Work \\
\hline FSALT87 & $\mathrm{C} 2$ & 14.8 & 119.3 & 0.0749 & $0.512191 \pm 0.000021$ & 0.512149 & $-7.4 \pm 0.4$ & 0.94 & -61.9 & 2 \\
\hline $10 \mathrm{~A}-77 \mathrm{~A}$ & $\mathrm{C} 3 \mathrm{a}$ & 143.6 & 1108.0 & 0.0784 & $0.512221 \pm 0.000021$ & 0.512177 & $-6.9 \pm 0.4$ & 0.93 & -60.2 & 2 \\
\hline $277.2 \mathrm{~A} 3$ & $\mathrm{C} 3 \mathrm{a}$ & $21.8^{*}$ & $166.2^{*}$ & - & - & - & $-\quad \quad-$ & - & - & 2 \\
\hline
\end{tabular}


I. L. de Oliveira

Table 5.3. Whole-rock Nd isotopic data from the Salitre I complex (Continued).

\begin{tabular}{|c|c|c|c|c|c|c|c|c|c|c|}
\hline Sample & Unit & $\begin{array}{c}\mathrm{Sm} \\
(\mathbf{p p m})^{\mathrm{a}}\end{array}$ & $\begin{array}{c}\text { Nd } \\
(\mathbf{p p m})^{\mathrm{a}}\end{array}$ & $\begin{array}{c}{ }^{147} \mathrm{Sm} /{ }^{144} \mathrm{Nd} \\
(\text { atomic) }\end{array}$ & $\begin{array}{l}{ }^{143} \mathrm{Nd} /{ }^{144} \mathrm{Nd}_{\mathrm{m}} \\
\text { (measured) }^{\mathrm{c}}\end{array}$ & $\begin{array}{c}{ }^{143} \mathrm{Nd} /{ }^{144} \mathrm{Nd}_{\mathrm{i}} \\
(\text { initial })^{\mathrm{d}}\end{array}$ & $\boldsymbol{E}_{N d}(T)^{\mathbf{e}}$ & $\begin{array}{l}\tau_{\mathrm{DM}} \mathbf{f} \\
(\mathbf{G a})\end{array}$ & $\begin{array}{c}f_{\mathrm{Sm} / \mathrm{Nd}}{ }^{\mathrm{g}} \\
(\%)\end{array}$ & Ref." \\
\hline 277.2A2 & $\mathrm{C} 3 \mathrm{a}$ & $75.5^{*}$ & $572.5^{*}$ & 0.0797 & $0.512195 \pm 0.000011$ & 0.512151 & $-7.4 \pm 0.2$ & 0.96 & -59.5 & 2 \\
\hline 407D3 & $\mathrm{C} 3 \mathrm{a}$ & 110.3 & 523.3 & 0.1274 & $0.512369 \pm 0.000019$ & 0.512298 & $-4.5 \pm 0.4$ & 1.18 & -35.2 & 2 \\
\hline $10 \mathrm{~A}-41 \mathrm{~A}$ & $\mathrm{C} 3$ & 125.2 & 894.2 & 0.0846 & $0.512335 \pm 0.000014$ & 0.512288 & $-4.7 \pm 0.3$ & 0.84 & -57.0 & 2 \\
\hline FF219 & $\mathrm{C} 3$ & $54.6^{*}$ & $486.9^{*}$ & - & - & - & - & - & - & 2 \\
\hline FF476.6 & $\mathrm{C} 3$ & 42.4 & 327.5 & 0.0783 & $0.512208 \pm 0.000021$ & 0.512164 & $-7.1 \pm 0.4$ & 0.94 & -60.2 & 2 \\
\hline FF292D1 & $\mathrm{C} 3$ & $76.3^{*}$ & $625.2^{*}$ & - & $-\quad \quad-$ & - & $-\quad \quad-$ & - & - & 2 \\
\hline FVL184 & $\mathrm{C} 3$ & $49.6^{*}$ & $447.4^{*}$ & - & - & - & - & - & - & 2 \\
\hline $277.2 \mathrm{~A} 1$ & $\mathrm{C} 3$ & $29.5^{*}$ & $240.1^{*}$ & - & - & - & - & - & - & 2 \\
\hline ASL13 & D4 & 200.3 & 1458.6 & 0.0830 & $0.512293 \pm 0.000006$ & 0.512247 & $-5.5 \pm 0.1$ & 0.88 & -57.8 & 2 \\
\hline FVL121.8 & D4 & 45.4 & 602.2 & 0.0455 & $0.512182 \pm 0.000020$ & 0.512157 & $-7.3 \pm 0.4$ & 0.78 & -76.8 & 2 \\
\hline
\end{tabular}

${ }^{\mathrm{a}} \mathrm{Sm}$ and $\mathrm{Nd}$ concentrations determined by isotopic dilution, with analytical precision of $\pm 0.1 \%$; *Concentrations determined by ICP-MS.

${ }^{\mathrm{b}}$ Atomic ratios, calculated from Sm and Nd concentrations according to Gioia \& Pimentel (2000).

${ }^{\mathrm{c}}$ Measured ratios, normalized to ${ }^{146} \mathrm{Nd} /{ }^{144} \mathrm{Nd}=0.7219$ using an exponential law; errors are two standard errors (2SE) of the in-run means.

${ }^{\mathrm{d}}$ Initial ratios, calculated at $85 \mathrm{Ma}$ using the ${ }^{147} \mathrm{Sm}$ decay constant $\left(\lambda_{\mathrm{Sm}}\right)$ of $6.54 \times 10^{-12} \mathrm{yr}^{-1}$.

${ }^{\mathrm{e}} \mathrm{E}_{\mathrm{Nd}}(\mathrm{T})=\left[\left({ }^{143} \mathrm{Nd} /{ }^{144} \mathrm{Nd}_{\mathrm{T}}\right)_{\text {sample }} /\left({ }^{143} \mathrm{Nd} /{ }^{144} \mathrm{Nd}_{\mathrm{T}}\right)_{\mathrm{CHUR}}-1\right] \times 10^{4} ; \mathrm{T}=85$ Ma. Present-day Chondritic Uniform Reservoir (CHUR) parameters are ${ }^{143} \mathrm{Nd} /{ }^{144} \mathrm{Nd}=0.512638$ and ${ }^{147} \mathrm{Sm} /{ }^{144} \mathrm{Nd}=0.1967$.

${ }^{\mathrm{f}}$ Model Age $\left(\mathrm{T}_{\mathrm{DM}}\right)$ calculated following DePaolo (1981a), using the software Isoplot 4.15 (Ludwig, 2008). CHUR values are the same as above.

${ }^{\mathrm{g}} f_{\mathrm{Sm} / \mathrm{Nd}}=\left[\left({ }^{147} \mathrm{Sm} /{ }^{144} \mathrm{Nd}\right)_{\text {sample }} /\left({ }^{147} \mathrm{Sm} /{ }^{144} \mathrm{Nd}\right)_{\mathrm{CHUR}}-1\right] \times 10^{2} .\left({ }^{147} \mathrm{Sm} /{ }^{144} \mathrm{Nd}\right)_{\mathrm{CHUR}}$ value is the same as already mentioned.

\# References: 1- Published data from Barbosa et al. (2012a); 2- Unpublished data from Barbosa (2009). - Value not determined. 
Capítulo 5: Complexo de Salitre I

Table 5.4. Sr isotopic data of the minerals from the Salitre I rocks.

\begin{tabular}{llll}
\hline Sample & \multicolumn{1}{c}{ Mineral } & $\begin{array}{c}{ }^{\mathbf{8 7}} \mathbf{S r} /{ }^{\mathbf{8 6}} \mathbf{S r}_{\mathbf{m}} \\
(\mathbf{m e a s u r e d})\end{array}$ & $\begin{array}{c}{ }^{\mathbf{8 7}} \mathbf{S r}^{\mathbf{8 6}} \mathbf{S r}_{\mathbf{i}} \\
(\mathbf{i n i t i a l})\end{array}$ \\
\hline FVL175 & Perovskite & $0.705251 \pm 0.000003$ & 0.705220 \\
FSALT81 & Clinopyroxene & $0.705398 \pm 0.000003$ & 0.705383 \\
FSALT81 & Apatite & $0.705206 \pm 0.000006$ & 0.705206 \\
FSALT81 & Perovskite & $0.705710 \pm 0.000006$ & 0.705679 \\
FSALT96 & Clinopyroxene & $0.705142 \pm 0.000003$ & 0.705127 \\
FSALT96 & Apatite & $0.705187 \pm 0.000003$ & 0.705187 \\
FSALT96 & Garnet & $0.705369 \pm 0.000004$ & 0.705232 \\
SF101.5D1 & Apatite & $0.705191 \pm 0.000003$ & 0.705191 \\
F37B-65A & Apatite & $0.705051 \pm 0.000003$ & 0.705051 \\
FVL145A & Apatite & $0.704992 \pm 0.000002$ & 0.704992 \\
FVL145A & Calcite & $0.705000 \pm 0.000003$ & 0.705000 \\
FF476.6 & Calcite & $0.705012 \pm 0.000002$ & 0.705012 \\
10A-41A & Apatite & $0.705079 \pm 0.000007$ & 0.705079 \\
10A-41A & Calcite & $0.705089 \pm 0.000006$ & 0.705089 \\
20B-94 & White Dolomite & $0.705260 \pm 0.000005$ & 0.705260 \\
20B-94 & Grey Dolomite & $0.705338 \pm 0.000006$ & 0.705338 \\
20B-94 & Apatite & $0.705148 \pm 0.000003$ & 0.705148 \\
09B-50 & Dolomite & $0.705261 \pm 0.000003$ & 0.705261 \\
\hline
\end{tabular}

${ }^{a}$ Measured ratios, normalized to ${ }^{88} \mathrm{Sr} /{ }^{86} \mathrm{Sr}=8.375209$ using an exponential law; errors are two standard errors (2SE) of the in-run means, at $95 \%$ confidence level $(2 \sigma)$.

${ }^{\mathrm{b}}$ Initial ratios, when necessary, were corrected by radiogenic ingrowth at the age of $85 \mathrm{Ma}$ using the ${ }^{87} \mathrm{Rb}$ decay constant $\left(\lambda_{\mathrm{Rb}}\right)$ of $1.393 \times 10^{-11} \mathrm{yr}^{-1}$ (Nebel et al., 2011) and the $\mathrm{Rb} / \mathrm{Sr}$ ratios of 0.0045 (clinopyroxenes); 0.009 (perovskites) and 0.04 (garnet). See text for further discussion. 
I. L. de Oliveira

Table 5.5. Nd isotopic data of the minerals from the Salitre I rocks.

\begin{tabular}{|c|c|c|c|c|c|c|c|c|c|}
\hline Sample & Mineral & $\begin{array}{c}\mathrm{Sm} \\
(\mathbf{p p m})^{\mathrm{a}}\end{array}$ & $\begin{array}{c}\mathrm{Nd} \\
(\mathbf{p p m})^{\mathrm{a}}\end{array}$ & $\begin{array}{c}{ }^{147} \mathrm{Sm} /{ }^{144} \mathrm{Nd} \\
\text { (atomic) }^{\mathrm{b}}\end{array}$ & 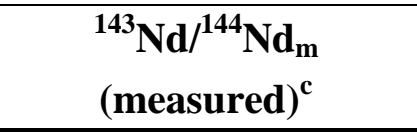 & $\begin{array}{c}{ }^{143} \mathrm{Nd} /{ }^{144} \mathrm{Nd}_{\mathrm{i}} \\
\text { (initial })^{\mathrm{d}}\end{array}$ & $\varepsilon_{N d}(T)^{e}$ & $\begin{array}{l}\tau_{\mathrm{DM}}^{\mathrm{f}} \\
(\mathbf{G a})\end{array}$ & $\begin{array}{c}f_{\mathrm{Sm} / \mathrm{Nd}}{ }^{\mathrm{g}} \\
(\%)\end{array}$ \\
\hline FVL175 & Perovskite & 624.63 & 4410.10 & 0.0856 & $0.512289 \pm 0.000019$ & 0.512241 & $-5.6 \pm 0.4$ & 0.90 & -56.5 \\
\hline FVL175 & Olivine & 16.45 & 115.18 & 0.0863 & $0.512268 \pm 0.000010$ & 0.512220 & $-6.0 \pm 0.2$ & 0.93 & -56.1 \\
\hline FVL175 & Phlogopite & 14.94 & 106.12 & 0.0851 & $0.512291 \pm 0.000017$ & 0.512244 & $-5.6 \pm 0.3$ & 0.89 & -56.7 \\
\hline FSALT81 & Clinopyroxene & 2.71 & 11.19 & 0.1464 & $0.512274 \pm 0.000009$ & 0.512193 & $-6.5 \pm 0.2$ & 1.72 & -25.6 \\
\hline FSALT81 & Apatite & 73.00 & 350.58 & 0.1259 & $0.512276 \pm 0.000003$ & 0.512206 & $-6.3 \pm 0.1$ & 1.32 & -36.0 \\
\hline FSALT81 & Magnetite & 17.89 & 104.96 & 0.1030 & $0.512276 \pm 0.000015$ & 0.512219 & $-6.0 \pm 0.3$ & 1.05 & -47.6 \\
\hline FSALT81 & Perovskite & 655.70 & 5165.50 & 0.0767 & $0.512241 \pm 0.000009$ & 0.512198 & $-6.4 \pm 0.2$ & 0.89 & -61.0 \\
\hline FSALT81 & Phlogopite & 1.15 & 5.96 & 0.1163 & $0.512285 \pm 0.000017$ & 0.512220 & $-6.0 \pm 0.3$ & 1.18 & -40.9 \\
\hline FSALT96 & Clinopyroxene & 0.64 & 3.84 & 0.1013 & $0.512278 \pm 0.000009$ & 0.512222 & $-6.0 \pm 0.2$ & 1.03 & -48.5 \\
\hline FSALT96 & Apatite & 76.24 & 622.76 & 0.0740 & $0.512255 \pm 0.000013$ & 0.512214 & $-6.1 \pm 0.3$ & 0.86 & -62.4 \\
\hline FSALT96 & Phlogopite & 1.42 & 4.48 & 0.1910 & $0.512330 \pm 0.000013$ & 0.512224 & $-5.9 \pm 0.3$ & - & -2.9 \\
\hline FSALT96 & Garnet & 78.41 & 226.21 & 0.2096 & $0.512338 \pm 0.000015$ & 0.512221 & $-6.0 \pm 0.3$ & - & 6.5 \\
\hline SF101.5D1 & Olivine & 6.68 & 46.34 & 0.0872 & $0.512307 \pm 0.000014$ & 0.512258 & $-5.3 \pm 0.3$ & 0.89 & -55.7 \\
\hline SF101.5D1 & Apatite & 414.64 & 2858.58 & 0.0877 & $0.512272 \pm 0.000007$ & 0.512223 & $-6.0 \pm 0.1$ & 0.93 & -55.4 \\
\hline SF101.5D1 & Apatite* & 2733.69 & 17561.95 & 0.0941 & $0.512262 \pm 0.000006$ & 0.512210 & $-6.2 \pm 0.1$ & 0.99 & -52.2 \\
\hline SF101.5D1 & Phlogopite & 6.49 & 41.79 & 0.0939 & $0.512288 \pm 0.000018$ & 0.512235 & $-5.7 \pm 0.4$ & 0.96 & -52.3 \\
\hline F37B-65A & Apatite & 252.49 & 1791.70 & 0.0852 & $0.512318 \pm 0.000018$ & 0.512270 & $-5.0 \pm 0.4$ & 0.86 & -56.7 \\
\hline F37B-65A & Magnetite & 0.45 & 2.90 & 0.0936 & $0.512271 \pm 0.000025$ & 0.512219 & $-6.0 \pm 0.5$ & 0.98 & -52.4 \\
\hline F37B-65A & Olivine & 2.47 & 17.26 & 0.0864 & $0.512317 \pm 0.000011$ & 0.512269 & $-5.1 \pm 0.2$ & 0.87 & -56.1 \\
\hline FVL145A & Olivine & 0.38 & 2.05 & 0.1111 & $0.512346 \pm 0.000010$ & 0.512284 & $-4.8 \pm 0.2$ & 1.03 & -43.5 \\
\hline FVL145A & Apatite & 180.93 & 1222.40 & 0.0895 & $0.512311 \pm 0.000011$ & 0.512262 & $-5.2 \pm 0.2$ & 0.90 & -54.5 \\
\hline FVL145A & Calcite & 20.94 & 143.17 & 0.0884 & $0.512321 \pm 0.000008$ & 0.512272 & $-5.0 \pm 0.2$ & 0.88 & -55.1 \\
\hline
\end{tabular}


Capítulo 5: Complexo de Salitre I

Table 5.5. Nd isotopic data of the minerals from the Salitre I rocks (Continued).

\begin{tabular}{|c|c|c|c|c|c|c|c|c|c|}
\hline Sample & Mineral & $\begin{array}{c}\mathrm{Sm} \\
(\mathrm{ppm})^{\mathrm{a}}\end{array}$ & $\begin{array}{c}\text { Nd } \\
(\mathbf{p p m})^{\mathrm{a}}\end{array}$ & $\begin{array}{c}{ }^{147} \mathrm{Sm} /{ }^{144} \mathrm{Nd} \\
(\text { atomic) }\end{array}$ & $\begin{array}{l}{ }^{143} \mathrm{Nd} /{ }^{144} \mathrm{Nd}_{\mathrm{m}} \\
\text { (measured) }^{\mathrm{c}}\end{array}$ & $\begin{array}{c}{ }^{143} \mathrm{Nd} /{ }^{144} \mathrm{Nd}_{i} \\
\text { (initial) }^{\mathrm{d}}\end{array}$ & $\varepsilon_{N d}(T)^{e}$ & $\begin{array}{l}\tau_{\text {DM }}{ }^{\mathrm{f}} \\
(\mathrm{Ga}) \\
\end{array}$ & $\begin{array}{c}f_{\mathrm{Sm} / \mathrm{Nd}}{ }^{\mathrm{g}} \\
(\%)\end{array}$ \\
\hline FF 476.6 & Calcite & 30.44 & 242.25 & 0.0760 & $0.512296 \pm 0.000014$ & 0.512254 & $-5.4 \pm 0.3$ & 0.83 & -61.4 \\
\hline $10 \mathrm{~A}-41 \mathrm{~A}$ & Apatite & 398.38 & 2879.41 & 0.0836 & $0.512341 \pm 0.000015$ & 0.512295 & $-4.6 \pm 0.3$ & 0.82 & -57.5 \\
\hline $10 \mathrm{~A}-41 \mathrm{~A}$ & Calcite & 33.67 & 259.72 & 0.0784 & $0.512297 \pm 0.000012$ & 0.512253 & $-5.4 \pm 0.2$ & 0.84 & -60.2 \\
\hline 20B-94 & White Dolomite & 8.06 & 61.62 & 0.0791 & $0.512262 \pm 0.000007$ & 0.512218 & $-6.1 \pm 0.1$ & 0.88 & -59.8 \\
\hline 20B-94 & Grey Dolomite & 7.17 & 54.84 & 0.0790 & $0.512282 \pm 0.000011$ & 0.512238 & $-5.7 \pm 0.2$ & 0.86 & -59.8 \\
\hline 20B-94 & Apatite & 168.44 & 1215.74 & 0.0838 & $0.512288 \pm 0.000010$ & 0.512241 & $-5.6 \pm 0.2$ & 0.89 & -57.4 \\
\hline 09B-50 & Dolomite & 4.71 & 36.74 & 0.0776 & $0.512301 \pm 0.000015$ & 0.512258 & $-5.3 \pm 0.3$ & 0.83 & -60.6 \\
\hline
\end{tabular}

${ }^{\text {a }} \mathrm{Sm}$ and Nd concentrations determined by isotopic dilution; analytical precision of $\pm 0.1 \%$.

${ }^{\mathrm{b}}$ Atomic ratios, calculated from Sm and Nd concentrations according to Gioia \& Pimentel (2000).

${ }^{\mathrm{c}}$ Measured ratios, normalized to ${ }^{146} \mathrm{Nd} /{ }^{144} \mathrm{Nd}=0.7219$ using an exponential law; errors are two standard errors (2SE) of the in-run means, at $95 \%$ confidence level $(2 \sigma)$.

${ }^{\mathrm{d}}$ Initial ratios, calculated at $85 \mathrm{Ma}$ using the ${ }^{147} \mathrm{Sm}$ decay constant $\left(\lambda_{\mathrm{Sm}}\right)$ of $6.54 \times 10^{-12} \mathrm{yr}^{-1}$.

${ }^{\mathrm{e}} \mathrm{E}_{\mathrm{Nd}}(\mathrm{T})=\left[\left({ }^{143} \mathrm{Nd} /{ }^{144} \mathrm{Nd}_{\mathrm{T}}\right)_{\text {sample }} /\left({ }^{143} \mathrm{Nd} /{ }^{144} \mathrm{Nd}_{\mathrm{T}}\right)_{\mathrm{CHUR}}-1\right] \times 10^{4} ; \mathrm{T}=85 \mathrm{Ma}$; Present-day Chondritic Uniform Reservoir (CHUR) parameters are ${ }^{143} \mathrm{Nd} /{ }^{144} \mathrm{Nd}=0.512638$ and ${ }^{147} \mathrm{Sm} /{ }^{144} \mathrm{Nd}=0.1967$.

${ }^{\mathrm{f}}$ Model Age $\left(\mathrm{T}_{\mathrm{DM}}\right)$ calculated following DePaolo (1981a), using the software Isoplot 4.15 (Ludwig, 2008); $\mathrm{T}_{\mathrm{DM}}$ of samples with ${ }^{147} \mathrm{Sm} /{ }^{144} \mathrm{Nd}>0.19$ are not calculated. CHUR values are the same as above.

${ }^{\mathrm{g}} f_{\mathrm{Sm} / \mathrm{Nd}}=\left[\left({ }^{147} \mathrm{Sm} /{ }^{144} \mathrm{Nd}\right)_{\text {sample }} /\left({ }^{147} \mathrm{Sm} /{ }^{144} \mathrm{Nd}\right)_{\mathrm{CHUR}}-1\right] \times 10^{2} .\left({ }^{147} \mathrm{Sm} /{ }^{144} \mathrm{Nd}\right)_{\mathrm{CHUR}}$ value is the same as already mentioned.

* Concentrate of apatite from sample SF101.5D1 containing micro-crystals of zirconolite ( 5\%). 


\section{Whole-rock Isotope Data}

The concentration of $\mathrm{Sr}$ in all analysed whole-rock samples is very high. In contrast, significant amounts of $\mathrm{Rb}$ appear only in silicate-rich rocks. A systematic variation between $\mathrm{Rb}$ and $\mathrm{Sr}$ contents for different group of rocks can be noted in Figure 5.6. Bebedourites and $\mathrm{P} 1$ phoscorites are characterized by wide $\mathrm{Rb}$ ranges and a much narrower $\mathrm{Sr}$ range. In the case of bebedourites, increasing $\mathrm{Rb}$ is correlated with magma differentiation from $\mathrm{B} 1 \mathrm{a}$ through B1b to B2, but the phoscorites appear to have evolved in the opposite direction (decreasing $\mathrm{Rb}$ from $\mathrm{P} 1$ to $\mathrm{P} 2$ ), at slightly higher $\mathrm{Sr}$ contents. Carbonatites are characterized by a wide $\mathrm{Sr}$ range and a narrow $\mathrm{Rb}$ range. The composition of calciocarbonatite and magnesiocarbonatite overlap each other. Strontium contents increase from bebedourites (424-1648 ppm) through phoscorites (2704-4725 ppm) to carbonatites (6236-14028 ppm; excluding C3a rocks). Such variation may be linked with increase in modal apatite and carbonate during magmatic differentiation. Positive correlation between $\mathrm{Sr}$ and $\mathrm{CaO}$ (not shown) supports this interpretation. On the other hand, rubidium distribution seems to be related to the amount of phlogopite in each rock sample, as its content reaches a maximum of $141.4 \mathrm{ppm}$ in phlogopite-rich bebedourites (B2). The strong positive correlation between $\mathrm{Rb}$ and $\mathrm{K}_{2} \mathrm{O}$ confirm this suggestion.

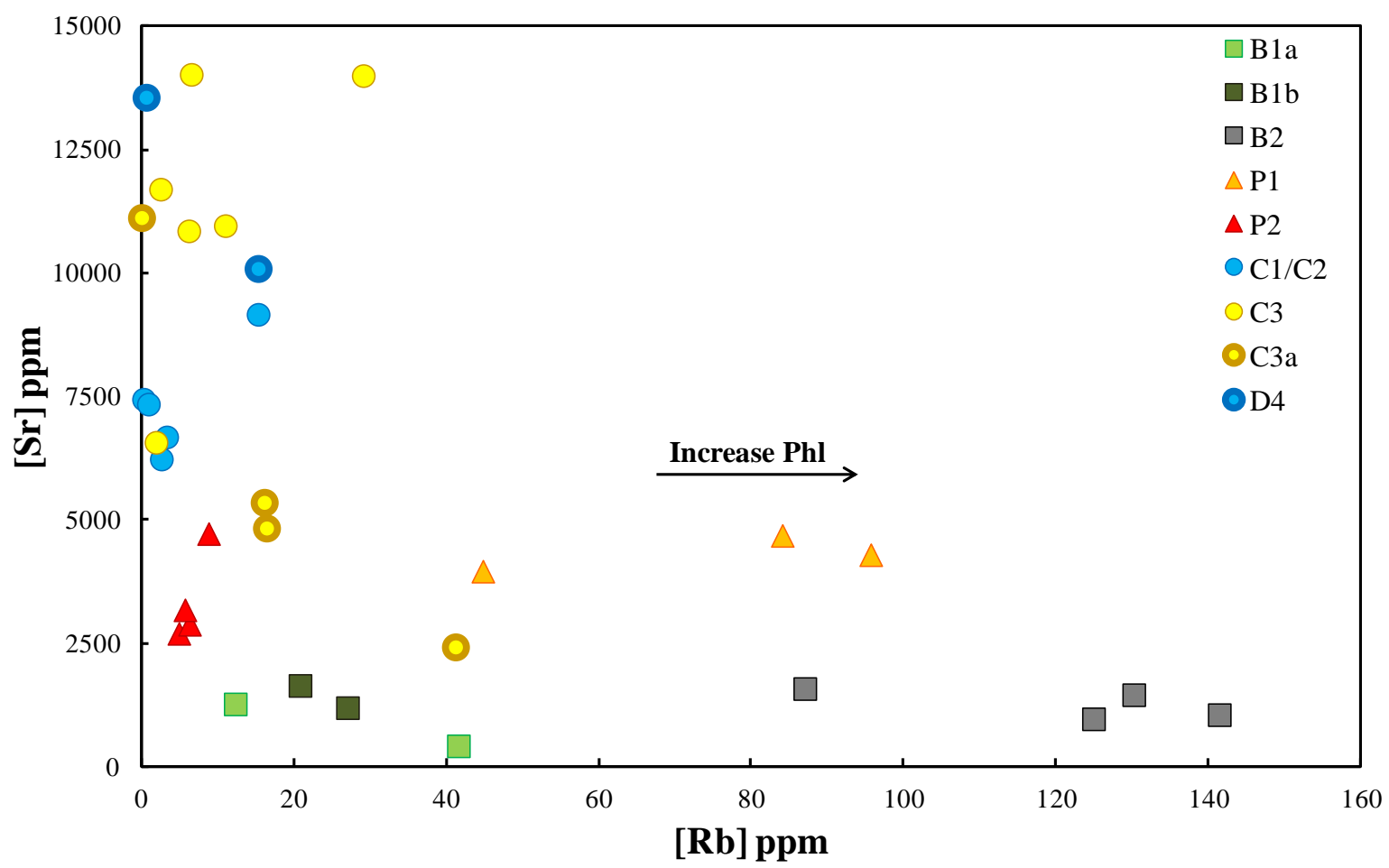

Figure 5.6. $\mathrm{Rb}$ versus $\mathrm{Sr}$ concentrations in the whole-rock samples analysed for $\mathrm{Sr}$ isotopes. Increase in $\mathrm{Rb}$ in the same magmatic series is associated with increase in phlogopite (Phl) whereas the range in $\mathrm{Sr}$ contents is related to the apatite and carbonate abundances. 
The above $\mathrm{Rb}$ and $\mathrm{Sr}$ features illustrate the importance of fractional crystallization during the evolution of Salitre I magmas, as already demonstrated by Morbidelli et al. (1997), Barbosa (2009) and Barbosa et al. (2012a) based on mineral chemistry.

For the Sm-Nd system, almost all samples have high contents of $\mathrm{Sm}$ and $\mathrm{Nd}$. The abundance of these elements is highest in phoscorites (Sm: 72-253 ppm; Nd: 566-1744 ppm), intermediate in carbonatites (Sm: 15-200 ppm; $\mathrm{Nd}$ : 119-1459 ppm) and lowest in bebedourites (Sm: 20-173 ppm; 109-1183 ppm). Interestingly, there is a systematic variation in the $\mathrm{Sm} / \mathrm{Nd}$ ratios (i.e., the $f_{\mathrm{Sm} / \mathrm{Nd}}$ parameter, see caption of Table 5.3 for definition) from bebedourites to late-stage D4 magnesiocarbonatites (Figure 5.7). Bebedourites, in general, have higher $f_{\mathrm{Sm} / \mathrm{Nd}}$ and lower Sm and $\mathrm{Nd}$ contents, and are easily distinguished (Table 5.3). On the other hand, carbonatites and phoscorites show significant overlapping of these variables.

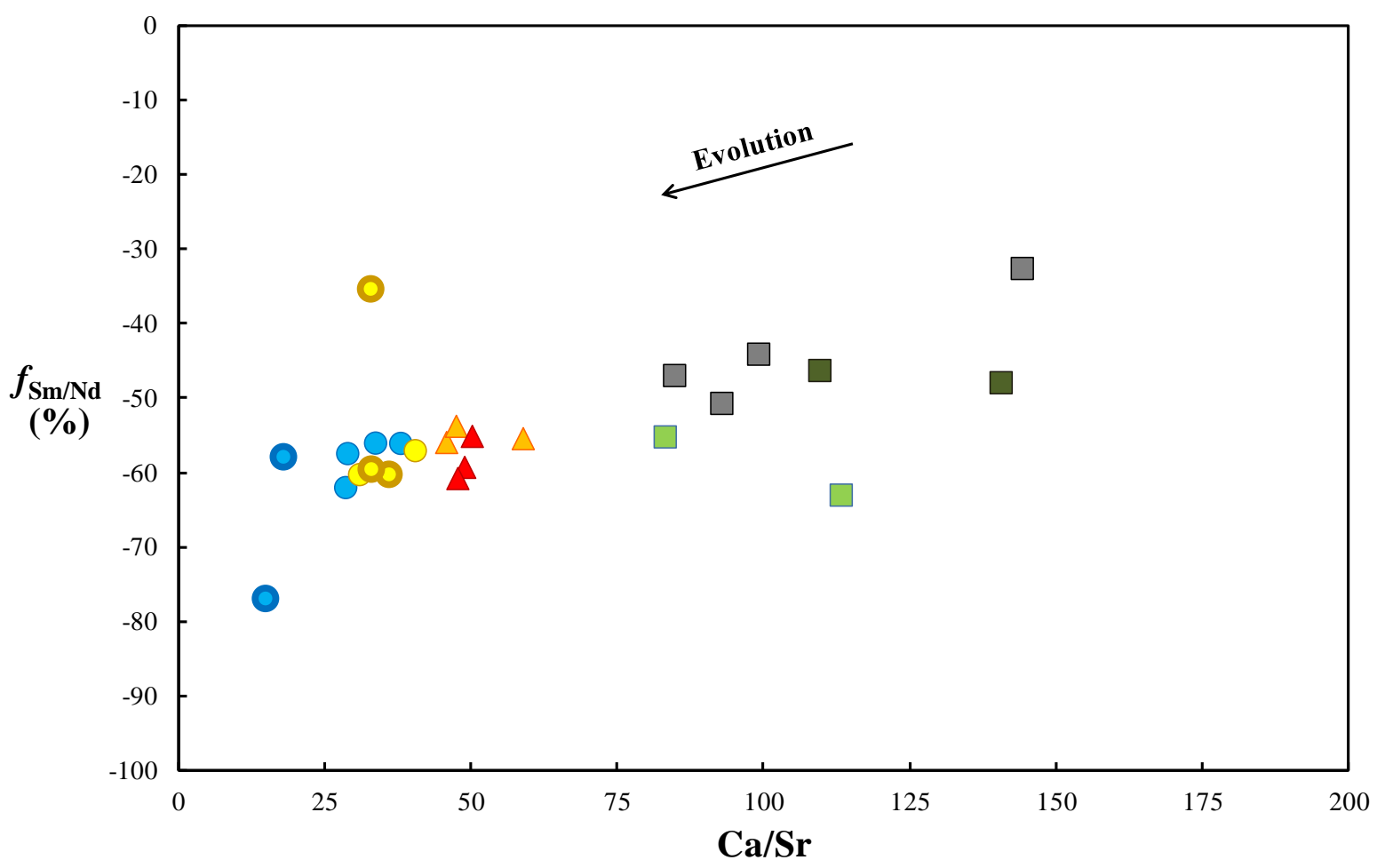

Figure 5.7. Plot of $f_{\mathrm{Sm} / \mathrm{Nd}}$ versus $\mathrm{Ca} / \mathrm{Sr}$. Symbols as in Figure 5.6.

The $f_{\mathrm{Sm} / \mathrm{Nd}}$ parameter indicates the degree of enrichment or depletion in LREE of a rock in relation to chondrite values (DePaolo \& Wasserburg, 1976). All samples of this study have negative values of $f_{\mathrm{Sm} / \mathrm{Nd}}$, so all are enriched in LREE. Overall, they are ca. $50 \%$ more enriched than chondrites (Table 5.3). Figure 5.7 shows a negative correlation between $f_{\mathrm{Sm} / \mathrm{Nd}}$ parameter and $\mathrm{Ca} / \mathrm{Sr}$ elemental ratio. More importantly, this ratio discriminates different Salitre I petrogenetic series, decreasing consistently from bebedourites through phoscorites to carbonatites. This trend corresponds to progressively more evolved series in the complex, and 
the $\mathrm{Ca} / \mathrm{Sr}$ ratio may be used as a differentiation index. However, it is not adequate to gauge evolution within each series. The correlation of $\mathrm{Ca} / \mathrm{Sr}$ with $f_{\mathrm{Sm} / \mathrm{Nd}}$ suggests that the magma becomes gradually more enriched in LREE through differentiation in Salitre I.

\section{Evaluation of $\mathrm{Rb}-\mathrm{Sr}$ and Sm-Nd Isochrons}

Despite the very low $\mathrm{Rb}$ content in almost all samples, there is a considerable range in the ${ }^{87} \mathrm{Rb} /{ }^{86} \mathrm{Sr}$ ratios, mainly in the silicate rocks (Table 5.2). Therefore, it would be theoretically possible to produce an isochron age, considering these rocks as cogenetic. However, the measured ${ }^{87} \mathrm{Sr} /{ }^{86} \mathrm{Sr}$ plotted against ${ }^{87} \mathrm{Rb} /{ }^{86} \mathrm{Sr}$ (Figure 5.8) does not yield any reliable age. Even if only the silicate rocks are considered, the data are too scattered to produce a significant isochron. Reference isochrons plotted in Figure 5.8 show that the ${ }^{87} \mathrm{Sr} /{ }^{86} \mathrm{Sr}$ range observed in samples with low ${ }^{87} \mathrm{Rb} /{ }^{86} \mathrm{Sr}$ (i.e., $<0.01$ ) cannot be explained exclusively by radioactive decay of ${ }^{87} \mathrm{Rb}$ (e.g., Faure, 2001, p. 302; Malarkey, 2010). In fact, due to the very low $\mathrm{Rb} / \mathrm{Sr}$ ratios of some samples, particularly the carbonatites, and the relatively short timespan ( $\sim 85 \mathrm{Ma})$ since the emplacement, the range of ${ }^{87} \mathrm{Sr}^{86}{ }^{86} r_{\mathrm{m}}$ depicted in Figure 5.8 must reflect variations in the initial ${ }^{87} \mathrm{Sr} /{ }^{86} \mathrm{Sr}$ ratios.

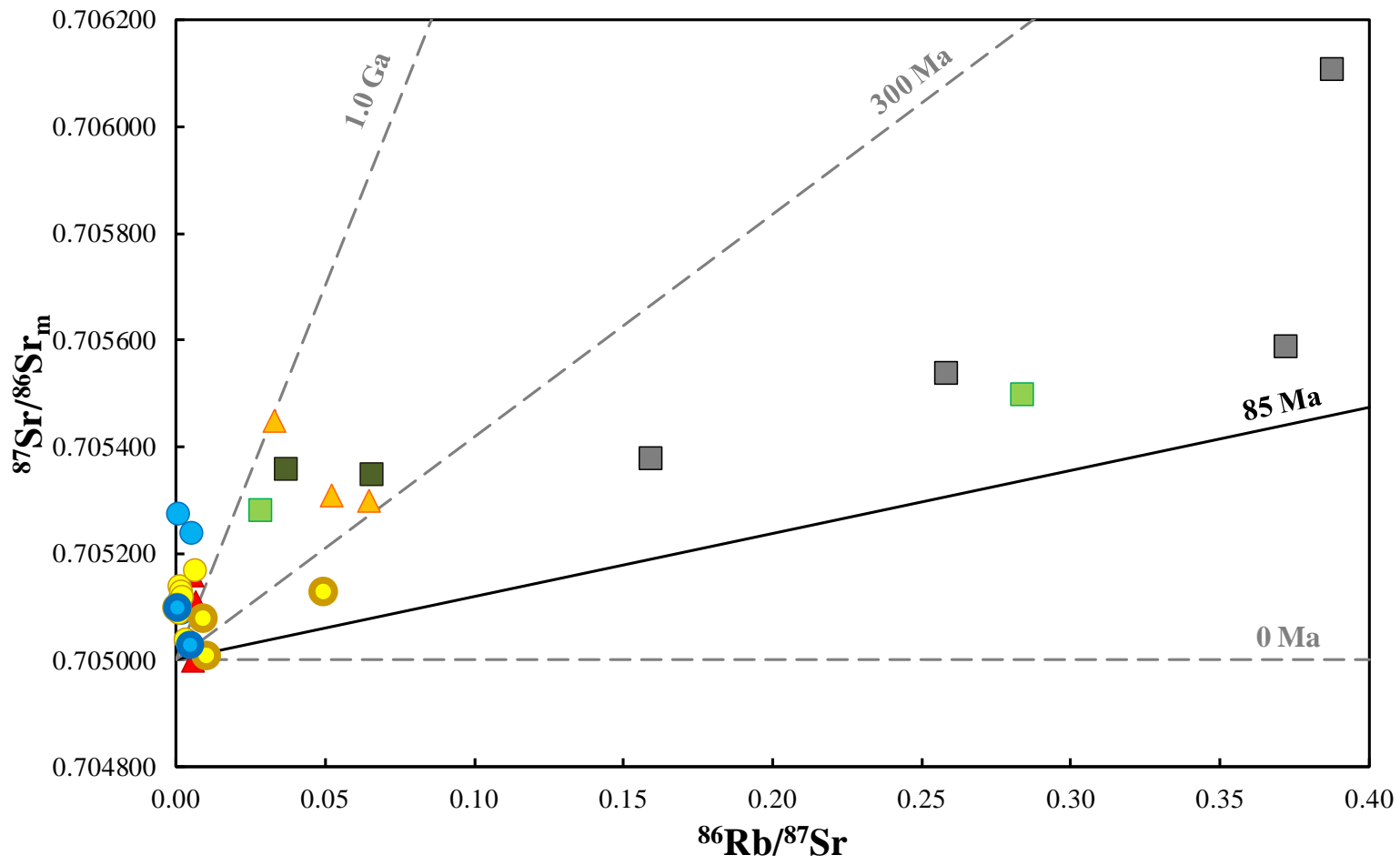

Figure 5.8. Rb-Sr whole-rock isotope data from the Salitre I complex plotted in an isochron diagram. The black solid line illustrates the average estimated age ( 85 Ma) for emplacement of APIP alkalinecarbonatite complexes (Gibson et al., 1995b). Reference isochrons (grey dashed lines) are plotted for comparison. Symbols as in Figure 5.6. 
A much narrower range occurs in the ${ }^{147} \mathrm{Sm} /{ }^{144} \mathrm{Nd}$ ratios of the investigated samples (Table 5.3). Moreover, the long half-life of ${ }^{147} \mathrm{Sm}$ limits the consistency of Sm-Nd isochron ages for young rocks (O’Nions et al., 1979).

Figure 5.9 presents an unsuccessful attempt to obtain a $\mathrm{Sm}-\mathrm{Nd}$ isochron age for the Salitre I rocks. However, the real importance of this diagram is to show that the broad differences in measured ${ }^{143} \mathrm{Nd} /{ }^{144} \mathrm{Nd}$ occur over a limited spread of ${ }^{147} \mathrm{Sm} /{ }^{144} \mathrm{Nd}$. An average ${ }^{147} \mathrm{Sm} /{ }^{144} \mathrm{Nd}$ of $\sim 0.09$ for these rocks would increase the initial ${ }^{143} \mathrm{Nd} /{ }^{144} \mathrm{Nd}$ by only 0.000050 , in a timespan of $85 \mathrm{Ma}$. Therefore, the wide range detected in ${ }^{143} \mathrm{Nd} /{ }^{144} \mathrm{Nd}_{\mathrm{m}}$ could not be produced by radiogenic ingrowth, since more than $350 \mathrm{Ma}$ would be required for this to happen at that rate, which is inconsistent with the spectrum of age determinations in the APIP. Consequently, if all rocks of the Salitre I complex were cogenetic, the lack of acceptable Rb$\mathrm{Sr}$ and $\mathrm{Sm}-\mathrm{Nd}$ isochrons is evidence for an open-system behaviour during the evolution of the parental magma. Roden et al. (1985), Andersen (1987) and Huang et al. (1995) described similar difficulties in obtaining $\mathrm{Rb}-\mathrm{Sr}$ and $\mathrm{Sm}-\mathrm{Nd}$ isochron ages in several carbonatite complexes around the world using whole-rock isotopic data.

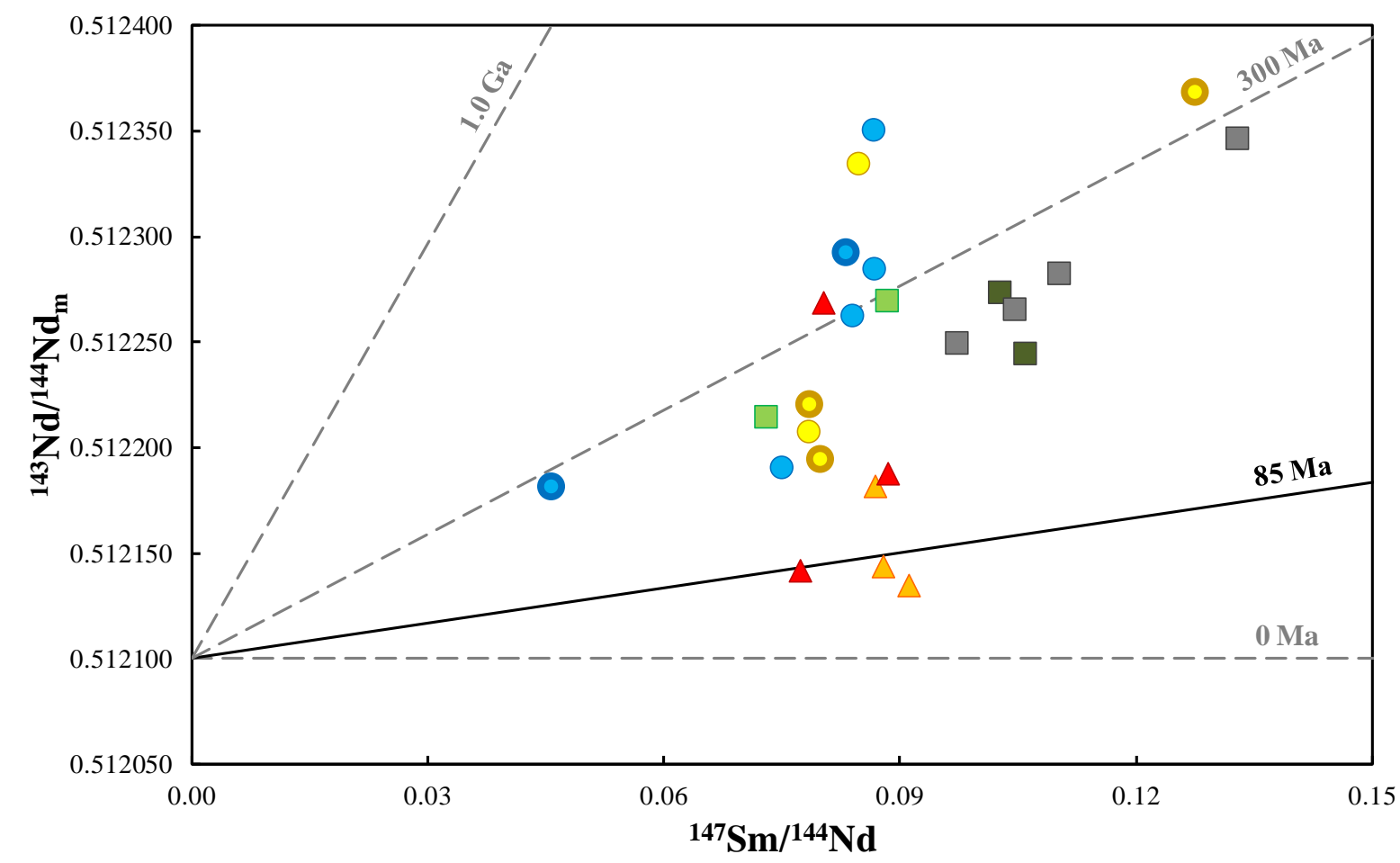

Figure 5.9. Sm-Nd whole-rock isotope data from the Salitre I complex plotted in an isochron diagram. Black solid line illustrate the best age estimated ( 85 Ma, Gibson et al., 1995b) for the emplacement of APIP alkaline-carbonatite complexes. Reference isochrons (grey dashed lines) are plotted for comparison. Symbols as in Figure 5.6. 


\section{Variations on ${ }^{87} \mathrm{Sr} /{ }^{86} \mathrm{Sr}$ and ${ }^{143} \mathrm{Nd} /{ }^{144} \mathrm{Nd}$ initial ratios}

Initial $\mathrm{Sr}$ and $\mathrm{Nd}$ isotopic composition for all studied whole-rock samples was calculated at $85 \mathrm{Ma}$ (Table 5.2 and Table 5.3), due to the lack of high-resolution dating of different petrogenetic series in the Salitre I complex, and according to the suggestion of Gibson et al. (1995b).

The ${ }^{87} \mathrm{Sr} /{ }^{86} \mathrm{Sr}_{\mathrm{i}}$ of the Salitre I main rock-types vary widely as shown in Figure 5.10A. Bebedourites have the most enriched $\mathrm{Sr}$ isotopic signature with ${ }^{87} \mathrm{Sr}^{86} \mathrm{Sr}_{\mathrm{i}}$ ranging from 0.705149 to 0.705317 , and one sample reaching the remarkable value of 0.705651 . On the other hand, carbonatites have the less radiogenic ${ }^{87} \mathrm{Sr}$ isotopic composition, ranging from 0.704998 to 0.705276 . If calciocarbonatites alone were considered, the highest ${ }^{87} \mathrm{Sr}^{86} \mathrm{Sr}_{\mathrm{i}}$ would be 0.705163 . Salitre I phoscorites can be divided in two groups, according to the units defined by Barbosa (2009). P1 phoscorites have ${ }^{87} \mathrm{Sr} /{ }^{86} \mathrm{Sr}_{\mathrm{i}}$ between 0.705224 and 0.705411 , similar to those from the bebedourites, whereas P2 phoscorites have ${ }^{87} \mathrm{Sr}^{86} \mathrm{Sr}_{\mathrm{i}}$ between 0.704994 and 0.705154 , within the range of the calciocarbonatites. These characteristics suggest a possible genetic relationship of P1 and P2 phoscorites with bebedourites and carbonatites, respectively.

Initial $\mathrm{Nd}$ isotopic composition also varies widely between the different rock types of the Salitre I complex, as can be seen in Figure 5.10B. Carbonatites and bebedourites have very similar ${ }^{143} \mathrm{Nd} /{ }^{144} \mathrm{Nd}_{\mathrm{i}}$ ranges $(0.512149$ to 0.512303 and 0.512174 to 0.512273 , respectively), although slightly wider in the case of the former. Nearly all phoscorites display lower values of ${ }^{143} \mathrm{Nd} /{ }^{144} \mathrm{Nd}_{\mathrm{i}}$, ranging from 0.512084 to 0.512139 , with only one sample in the ${ }^{143} \mathrm{Nd} /{ }^{144} \mathrm{Nd}_{\mathrm{i}}$ range of bebedourites and carbonatites (Figure 5.10B). Barbosa (2009) have already noted the contrasting $\mathrm{Nd}$ isotope signatures of these samples. In the Catalão I complex, Cordeiro et al. (2010) describe a similar behaviour for more evolved phoscoritic and carbonatitic rocks.

It is noteworthy that although the silicate rocks are slightly more enriched in radiogenic ${ }^{87} \mathrm{Sr}$ than the carbonatites (Figure 5.10A), both the minimum ${ }^{87} \mathrm{Sr}^{86} \mathrm{Sr}_{\mathrm{i}}$ and the maximum ${ }^{143} \mathrm{Nd} /{ }^{144} \mathrm{Nd}_{\mathrm{i}}$ of the alkaline silicate rocks is rather similar to those found in the carbonatites (Figure 5.10). Such significant overlap between their initial radiogenic isotopic ratios points toward a common petrogenetic evolution (Ray, 2009). 

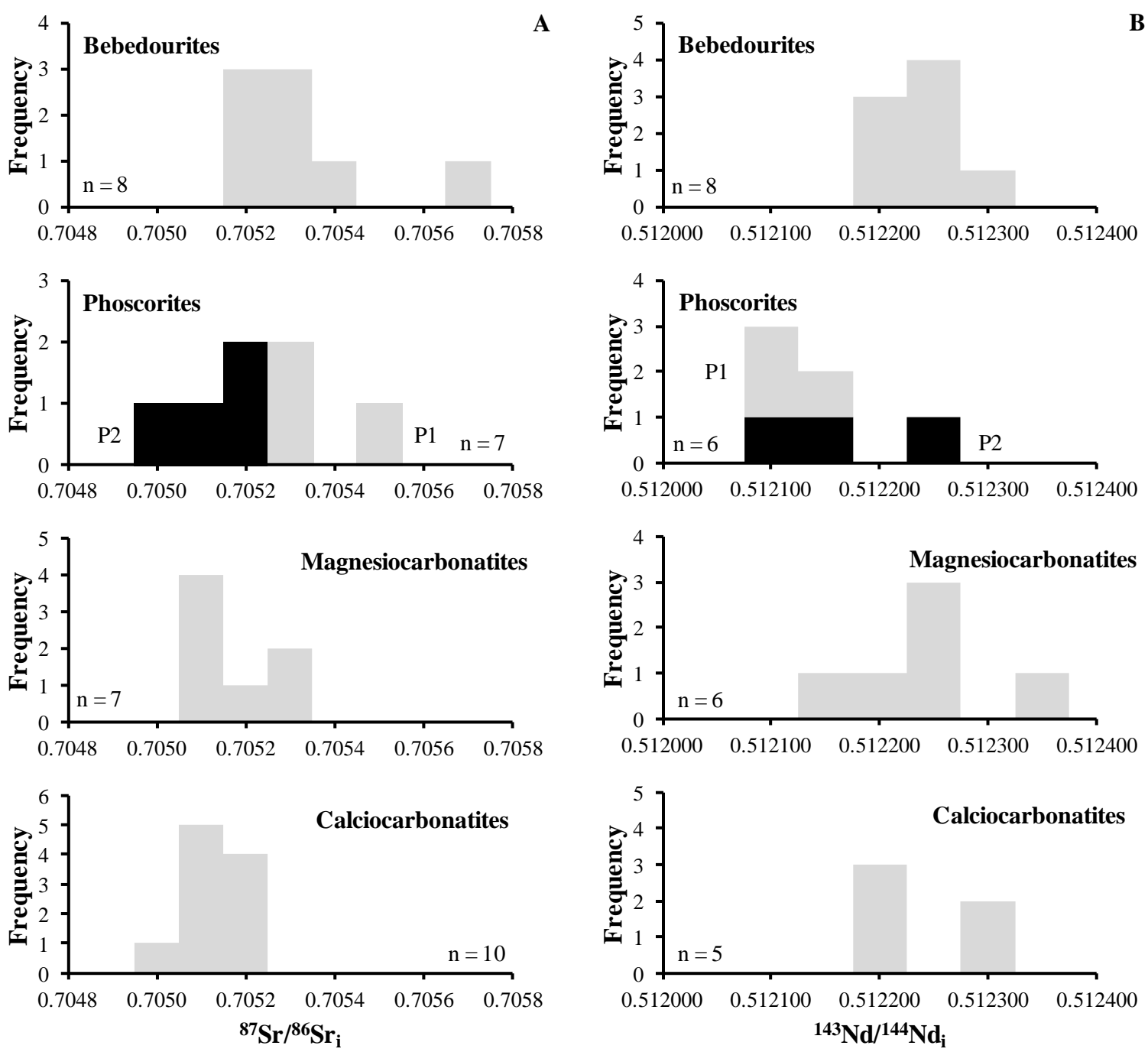

Figure 5.10. Histogram distribution of whole-rock ${ }^{87} \mathrm{Sr} /{ }^{86} \mathrm{Sr}_{\mathrm{i}}(\mathrm{A})$ and ${ }^{143} \mathrm{Nd} /{ }^{144} \mathrm{Nd}_{\mathrm{i}}(\mathrm{B})$ for the main rock types of the Salitre I alkaline-carbonatite complex. P1 and P2 represent different units of phoscorites according to Barbosa (2009). " $n$ " is the number of samples in each individual chart.

Figure 5.11 shows initial ${ }^{87} \mathrm{Sr} /{ }^{86} \mathrm{Sr}$ ratios versus the $\mathrm{Sr}$ content. Most B2 bebedourites have less radiogenic ${ }^{87} \mathrm{Sr} /{ }^{86} \mathrm{Sr}_{\mathrm{i}}$ than B1b bebedourites, although they were emplaced later, as noted by Barbosa et al. (2012a). Carbonatites show limited variation in ${ }^{87} \mathrm{Sr}^{86} \mathrm{Sr}_{\mathrm{i}}$, with the exception of two (C1) magnesiocarbonatite samples. Nelsonitic cumulates (C3a unit) are within the same range of carbonatites, but with the least radiogenic ${ }^{87} \mathrm{Sr}$ values.

Nevertheless, the most striking feature in Figure 5.11 is that ${ }^{87} \mathrm{Sr}^{86} \mathrm{Sr}_{\mathrm{i}}$ increases with decreasing Sr content, roughly defining a hyperbola, although with considerable scatter. Several authors (Faure \& Powell, 1972; Powell \& Bell, 1974; Bell \& Blenkinsop, 1989) argue that processes like fractional crystallization and/or liquid immiscibility can only change element concentrations but not the initial $\mathrm{Sr}$ isotopic composition of the magma, interpreting such hyperbolic patterns as evidence against closed chemical evolution of the magma. Indeed, 
plotting radiogenic isotopic ratios versus element contents will construct a hyperbola correlation if mixture processes are involved (Langmuir et al., 1978). Consequently, magmatic processes like mixing of magmas or sources, or crustal contamination could all be reasonable explanations for the pattern observed in Figure 5.11. These hypotheses will be tested and discussed in detail in section 5.5.

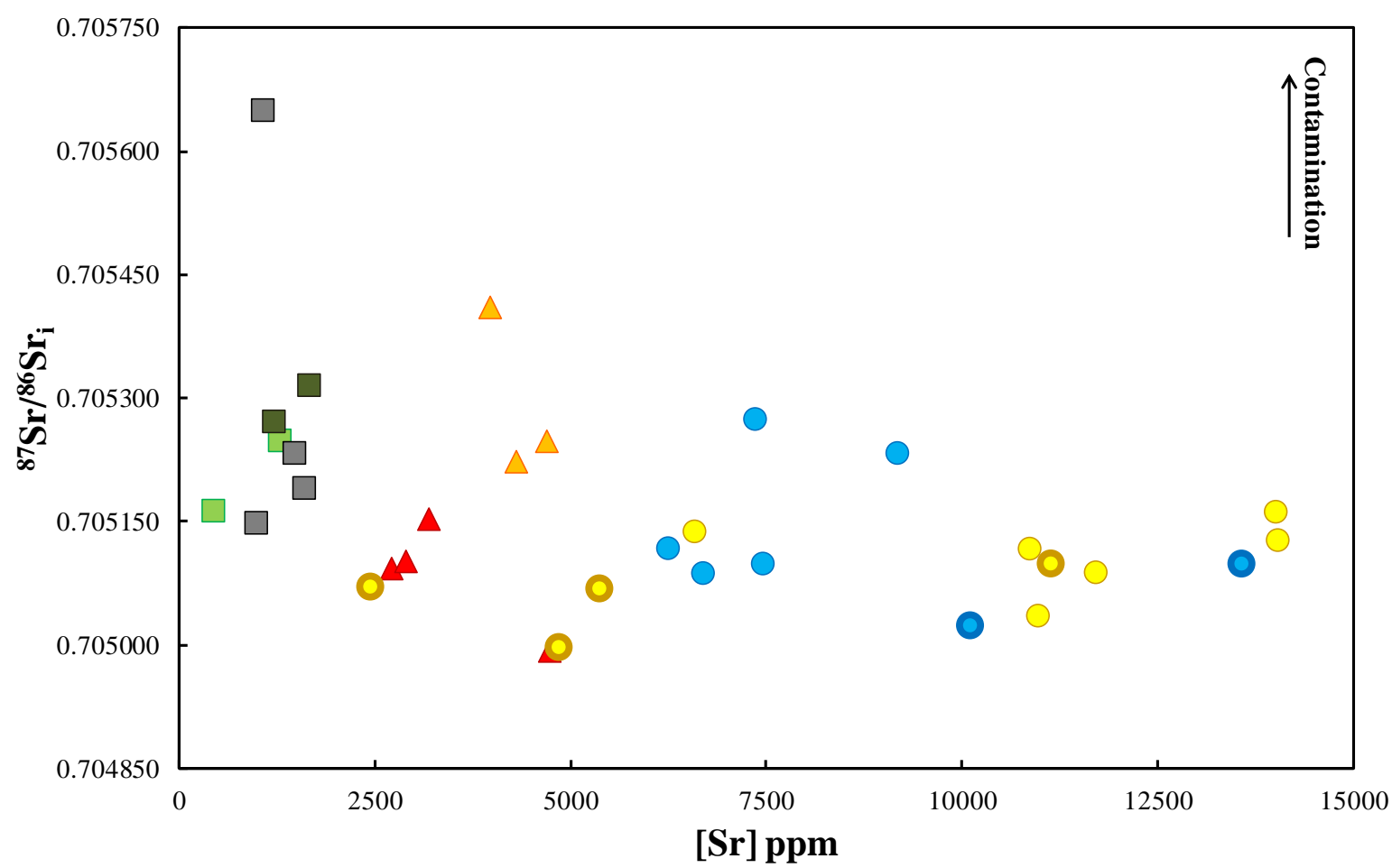

Figure 5.11. Plot of ${ }^{87} \mathrm{Sr}^{86} \mathrm{Sr}_{\mathrm{i}}$ versus $\mathrm{Sr}$ content. Differentiation processes like fractional crystallization and/or liquid immiscibility only modify the $\mathrm{Sr}$ contents (i.e., data points vary horizontally). Vertical arrow illustrates the changes due to crustal contamination. Symbols as in Figure 5.6.

It is clear from the plot of initial ${ }^{143} \mathrm{Nd} /{ }^{144} \mathrm{Nd}$ versus $\mathrm{Nd}$ (Figure 5.12) that most phoscorites are in divergence with other rocks in terms of $\mathrm{Nd}$ isotopic composition, showing significantly lower ${ }^{143} \mathrm{Nd} /{ }^{144} \mathrm{Nd}_{\mathrm{i}}$. However, phoscorites usually have the highest $\mathrm{Nd}$ contents. Most of nelsonitic cumulates (C3a unit) also display enriched $\mathrm{Nd}$ isotopic ratios, clearly in contrast with their least radiogenic ${ }^{87} \mathrm{Sr}$ signature. This decoupling between the $\mathrm{Sr}$ and $\mathrm{Nd}$ isotopic systems suggests that these rocks result from more than one petrogenetic process. The lack of any obvious correlation in Figure 5.12 lends additional support to this interpretation. Besides, some of the silicate-rock and carbonatite data scattered on the righthand side of the Figure 5.12 could represent the product of differentiation starting from more or less contaminated magmas. Nevertheless, such interpretation implies that several batches of parental magma were involved in the formation of the Salitre I rocks, and that such magmas were contaminated at different rates during ascent and emplacement. 


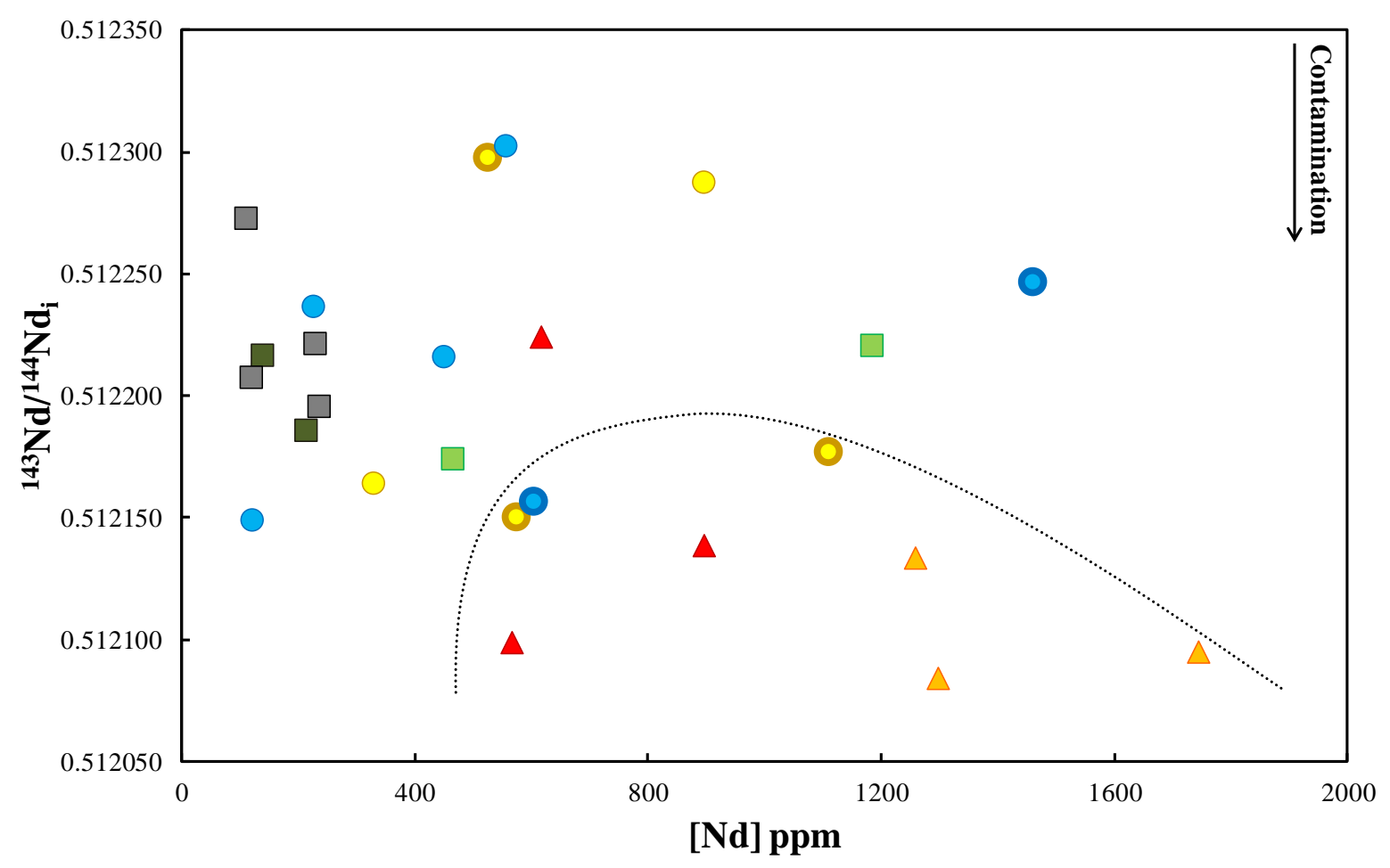

Figure 5.12. Plot of ${ }^{143} \mathrm{Nd} /{ }^{144} \mathrm{Nd}_{\mathrm{i}}$ versus $\mathrm{Nd}$ content. Differentiation processes only modify the Nd contents (i.e., data points vary horizontally). Vertical arrow illustrates the changes due to crustal contamination. Dotted line delimitates an enriched field for the majority of phoscorites and nelsonitic cumulates points. Symbols as in Figure 5.6.

\section{Mineral Isotope Data}

\section{Sr isotopic composition}

As a rule, the ${ }^{87} \mathrm{Sr}^{86} \mathrm{Sr}_{\mathrm{i}}$ for all analysed mineral phases is very similar to the overall whole-rock range (e.g., compare Figure 5.10A and Figure 5.13). Unfortunately, we were not able to determine the $\mathrm{Sr}$ isotopic composition of the mica separates. This limits the construction of mineral isochrons since all other minerals except phlogopite have very low $\mathrm{Rb} / \mathrm{Sr}$ ratios.

The most important difference between the mineral and whole-rock isotopic datasets is the more restricted range of values achieved for calciocarbonatite and phoscorite minerals (Figure 5.13), although only apatite and carbonates have been analysed from these rocks. In spite of the analogous range of initial ${ }^{87} \mathrm{Sr} /{ }^{86} \mathrm{Sr}$ ratios, a remarkable $\mathrm{Sr}$ isotopic disequilibrium occurs between the mineral phases from the same rock, and consequently, between minerals and whole-rock data. These differences are contrasted in Figure 5.14 and become even more significant taking in consideration the high precision of the $\mathrm{Sr}$ isotopic data obtained for the mineral separates (i.e., all analytical errors are less than 0.000007). 

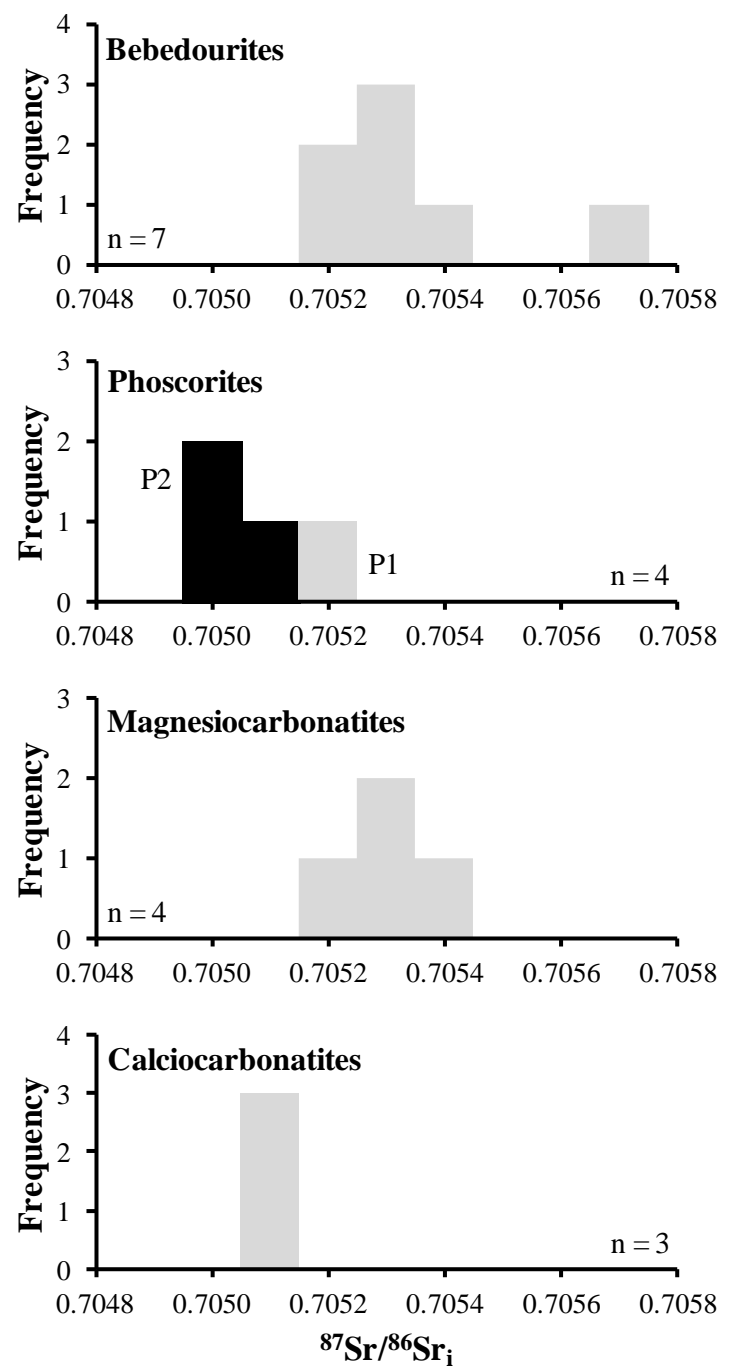

Figure 5.13. Histogram distribution of ${ }^{87} \mathrm{Sr} /{ }^{86} \mathrm{Sr}_{i}$ for mineral separates from the main rock types of the Salitre I alkaline-carbonatite complex. P1 and P2 represent different units of phoscorites according to Barbosa (2009). "n" is the number of samples in each individual chart.

Apart from one P2 phoscorite (sample FVL145A) and one C1 magnesiocarbonatite (sample 09B-50), all other samples plotted in Figure 5.14 demonstrate $\mathrm{Sr}$ isotopic disequilibrium between whole-rock data and their mineral phases. The most notable differences occur in the B1b bebedourite (sample FSALT81) and in the P1 phoscorite (sample SF101.5D1). B2 minerals (sample FSALT96) show a narrower isotope range and the less radiogenic ${ }^{87} \mathrm{Sr} /{ }^{86} \mathrm{Sr}_{\mathrm{i}}$ amongst all bebedourites.

The mineral isotopic data can be divided in two major groups: one characterized by high initial ${ }^{87} \mathrm{Sr} /{ }^{86} \mathrm{Sr}$ ratios (0.705127-0.705679), comprising B1a, B1b and B2 bebedourites, $\mathrm{P} 1$ phoscorite and $\mathrm{C} 1$ magnesiocarbonatite and the other characterized by lower initial ${ }^{87} \mathrm{Sr} /{ }^{86} \mathrm{Sr}$ ratios (0.704992-0.705089), consisting of $\mathrm{P} 2$ phoscorites and C3 calciocarbonatites. Furthermore, it is noteworthy that although the mineral data from a single rock sample show a 
significant scatter, the lowest ratios of a particular evolution stage (Figure 5.14) are essentially identical within the errors. This argues in favour of a genetic relationship between the different series, at least for those belonging to the same emplacement stage.

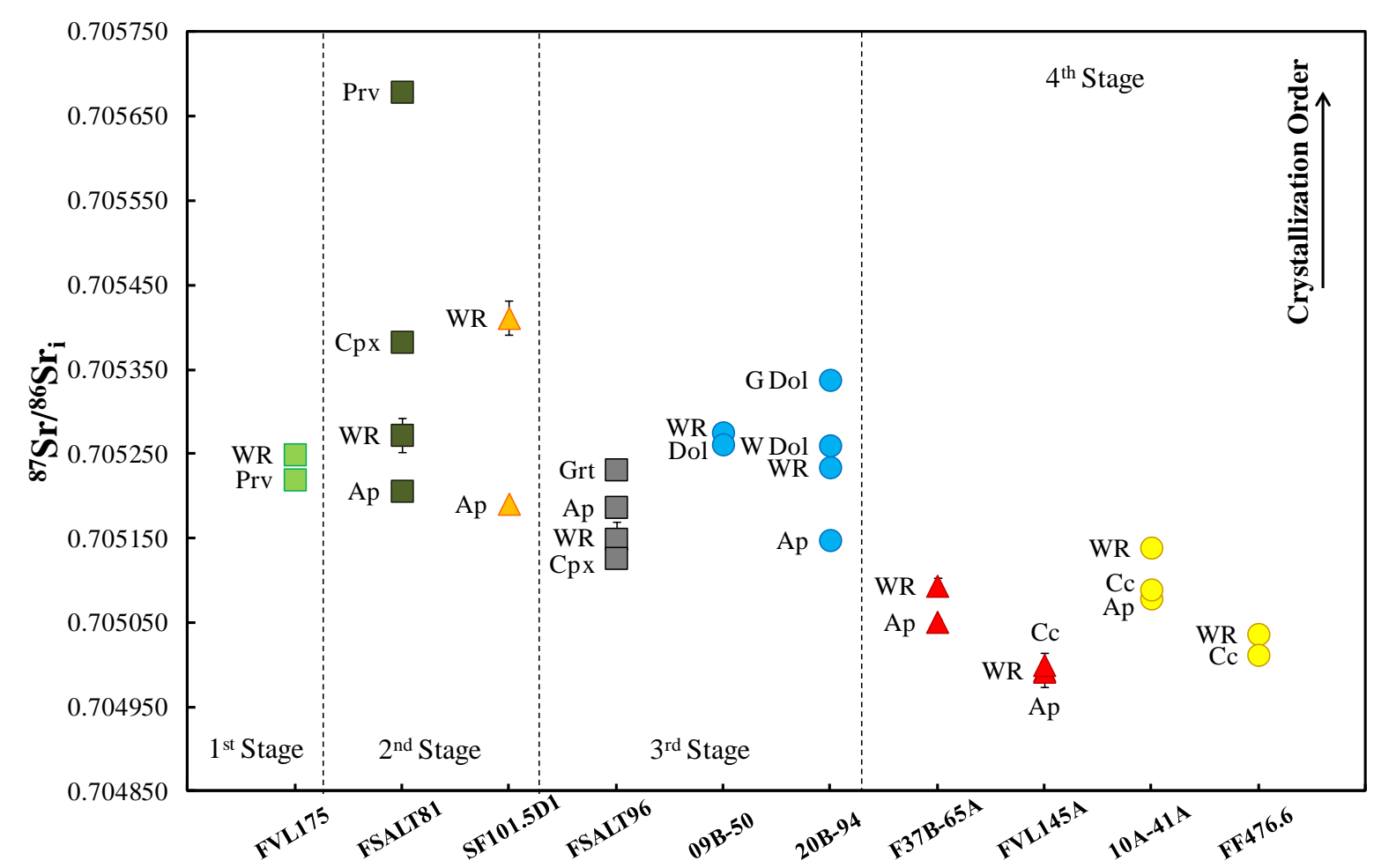

Figure 5.14. Initial ${ }^{87} \mathrm{Sr} /{ }^{86} \mathrm{Sr}$ ratios for whole rocks and corresponding mineral separates. Dashed lines divide the successive emplacement stages from Barbosa (2009) and Barbosa et al. (2012c). The error bars represent $\pm 2 \mathrm{SE}$ and are plotted only when they are larger than the symbol size. Symbols as in Figure 5.6. WR - whole-rock; Ap - apatite; Cc - calcite; Cpx - clinopyroxene; Dol - dolomite; G Dol - grey dolomite; W Dol - white dolomite; Grt - garnet; Prv - perovskite.

Interestingly, apatite has the least radiogenic ${ }^{87} \mathrm{Sr} /{ }^{86} \mathrm{Sr}_{\mathrm{i}}$ in six of the seven samples where it is present (Figure 5.14), the exception being the B2 bebedourite (sample FSALT96). Perovskite is present in only two samples, but exhibits a contrasting behaviour. In the B1a bebedourite (sample FVL175), perovskite has a ${ }^{87} \mathrm{Sr}^{86} \mathrm{Sr}_{\mathrm{i}}$ similar to the corresponding wholerock, whereas in the B1b bebedourite (sample FSALT81) this mineral displays the most enriched Sr isotopic composition of all mineral separates. Petrographically, both perovskites contains many microinclusions (e.g., titanite, phlogopite, priderite, geikielite) in the core of the crystals, but this does not seem to be the reason for these contrasting isotopic compositions, since even an unrealistically high amount of $10 \%$ Rb-rich minerals such as phlogopite $\left(\mathrm{Sr}=100 \mathrm{ppm} ;{ }^{87} \mathrm{Sr} /{ }^{86} \mathrm{Sr}_{\mathrm{m}}=0.725\right)$ would lead to a change of only 0.000050 in the ${ }^{87} \mathrm{Sr} /{ }^{86} \mathrm{Sr}_{\mathrm{m}}$. 
The progressive increase of the ${ }^{87} \mathrm{Sr}^{86} \mathrm{Sr}_{\mathrm{i}}$ from apatite (0.705206) to clinopyroxene (0.705383) and perovskite (0.705679) in the B1b bebedourite (sample FSALT81) corresponds exactly to the crystallization order of these minerals in the rock (Figure 5.14). This relation is also true for the B2 bebedourite (sample FSALT96), where the values increase from clinopyroxene (0.705127) to apatite (0.705187) and garnet (0.705232). Although with a much smaller spread, all other samples in Figure 5.13 show an increase in radiogenic ${ }^{87} \mathrm{Sr}$ toward the late-crystallizing minerals. This is interpreted here as a strong indication that the enrichment in radiogenic ${ }^{87} \mathrm{Sr}$ of the magma has occurred simultaneously with petrogenetic evolution.

Of special significance is the $\mathrm{Sr}$ isotopic variation found in the two carbonates varieties from sample 20B-94 (C1 magnesiocarbonatite, see Figure 5.5). The fine-grained, white, clear dolomite has lower ${ }^{87} \mathrm{Sr}^{86} \mathrm{Sr}_{\mathrm{i}}$ than the earlier, coarse-grained, grey, cloudy dolomite. Apatite from the fine-grained groundmass has even less radiogenic ${ }^{87} \mathrm{Sr}^{86} \mathrm{Sr}_{\mathrm{i}}$. These isotopic results suggest the coexistence of magnesiocarbonatites with distinct $\mathrm{Sr}$ isotopic composition, in the Salitre I complex. The explanation for these features is not straightforward. They could be the result of: (a) primary carbonatite magmas originated from different mantle sources; (b) if derived from the same source, they could be originated (i.e., by liquid immiscibility) from parental magmas at different degrees of contamination; (c) low temperature, subsolidus isotopic changes in the earlier grey magnesiocarbonatite, previously to its incorporation in the younger carbonatite magma.

Figure 5.15 is a plot of ${ }^{87} \mathrm{Sr} /{ }^{86} \mathrm{Sr}_{\mathrm{i}}$ versus $\mathrm{Sr}$ contents for apatite, carbonates and perovskite. Among the studied minerals, only these three contain high enough $\mathrm{Sr}$ contents for reliable electron probe microanalyses. The values plotted represent the average of at least 10 analytical points. Sr concentrations in apatite vary widely, from 5751 to 11240 ppm, without any clear correlation. This range seems to be controlled by the carbonate assemblage associated with apatite in each rock type (i.e., dolomite or calcite) and the bulk Sr content in the magma. Dolomites from C1 magnesiocarbonatites have high Sr contents (7603-8271 ppm), compared with those reported for some African carbonatites (Dawson et al., 1996; Dawson \& Hinton, 2003). Nevertheless, Cordeiro et al. (2011) found similar or even higher Sr contents in dolomites from Catalão I complex. The distinct dolomite varieties from sample 20B-94 show different ${ }^{87} \mathrm{Sr} /{ }^{86} \mathrm{Sr}_{\mathrm{i}}$ ratios but essentially the same $\mathrm{Sr}$ content. Calcite has the highest Sr abundance (9509-12723 ppm) amongst of the investigated minerals, which agrees 
very well with values described in the literature for other magmatic calcites (Zaitsev \& Bell, 1995; Dawson et al., 1996; Dawson \& Hinton, 2003). In contrast, perovskite shows the lowest Sr concentrations (3462-4418 ppm), but are consistent with the range observed for other APIP perovskites (Araújo et al., 2001; Barbosa et al., 2012a).

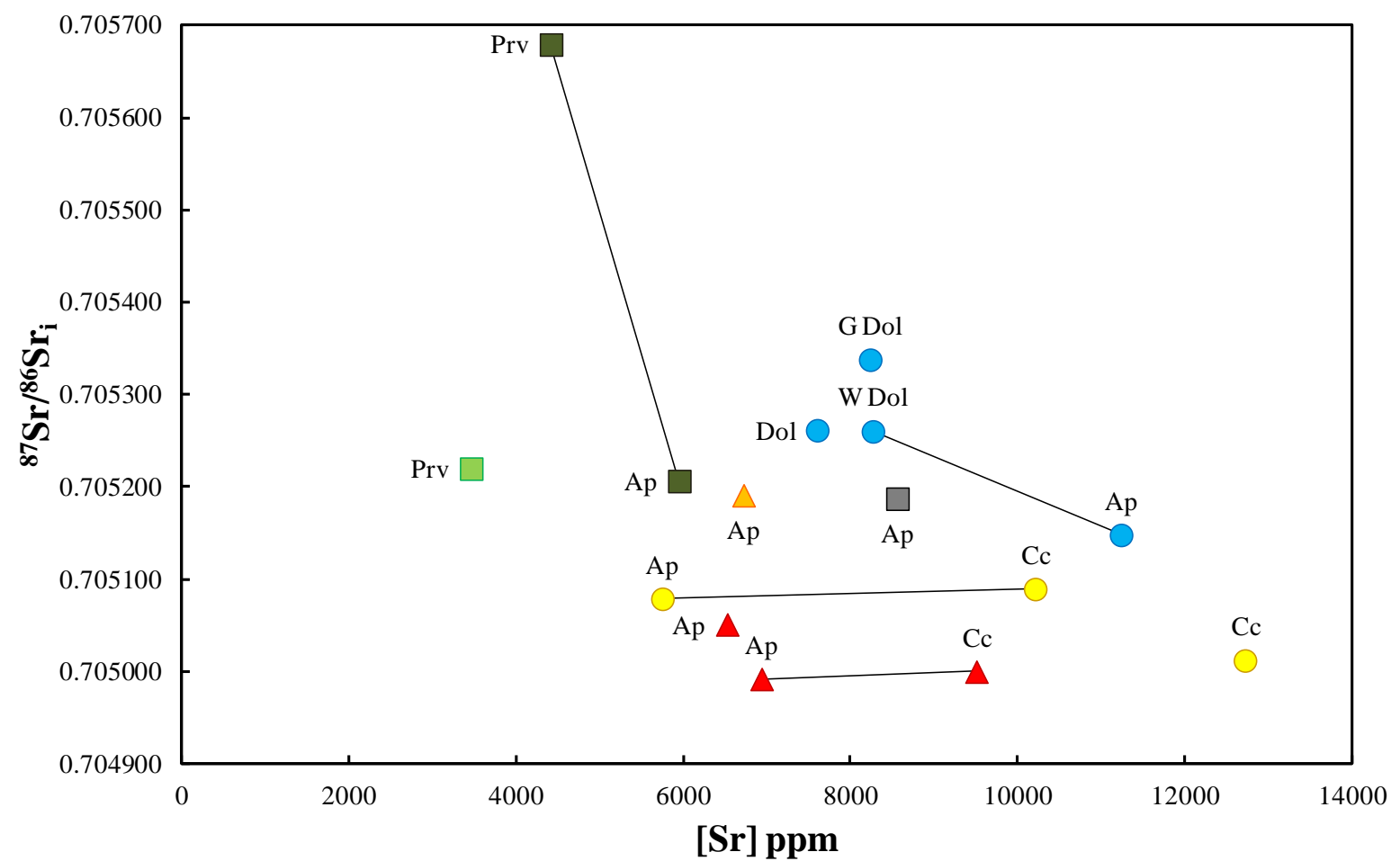

Figure 5.15. Plot of ${ }^{87} \mathrm{Sr} /{ }^{86} \mathrm{Sr}_{\mathrm{i}}$ versus $\mathrm{Sr}$ contents for apatite (Ap), calcite (Cc), dolomite (Dol) and perovskite (Prv). Tie lines join the minerals from the same sample. G Dol - grey dolomite; W Dol - white dolomite. Symbols as in Figure 5.6.

Semiquantitative Sr partition coefficients $\left(\mathrm{K}_{\mathrm{D}}\right)$ can be estimated for pairs of minerals from the same rock sample. The perovskite/apatite $K_{D}$ in $B 1 b$ bebedourite yields a value of 0.74. In the $C 1$ magnesiocarbonatite, we found a dolomite/apatite $K_{D}$ of 0.73 , whilst Zaitsev $\&$ Bell (1995) report a value of 0.4 for a magnesiocarbonatite from Kovdor Complex (Russia) and Dawson \& Hinton (2003) obtained a value of 0.54 for a carbonatite from Phalaborwa Complex (South Africa). The higher $K_{D}$ value estimated here could be due to the unusually high $\mathrm{Sr}$ contents in dolomites from Salitre I magnesiocarbonatites. For calcite-apatite pairs the $\mathrm{K}_{\mathrm{D}}$ values determined were 1.4 and 1.8, which are in agreement with the range of 1.2 to 2.1 reported by Zaitsev \& Bell (1995) and Dawson \& Hinton (2003). 


\section{Nd Isotopic Composition}

Almost $30 \mathrm{Nd}$ isotopic determinations are reported here for mineral separates from the most representative Salitre I rocks (Table 5.5). This extensive dataset includes data from nine different mineral phases: apatite (7 analyses), calcite (3), clinopyroxene (2), dolomite (3), garnet (1), magnetite (2), olivine (4), perovskite (2) and phlogopite (4).

A first interesting point is that all but two mineral separates analysed are extremely enriched in $\mathrm{Nd}$ when compared to the Sm content. The degree of enrichment in reference to chondrite values (i.e., $f_{\mathrm{Sm} / \mathrm{Nd}}$ parameter) varies from $25 \%$ to more than $60 \%$. The two outliers are the phlogopite and garnet separates from the B2 bebedourite (sample FSALT96). Nevertheless, even garnet exhibits a little depletion in $\mathrm{Nd}$, with ${ }^{147} \mathrm{Sm} /{ }^{144} \mathrm{Nd}$ ratio close to the chondrite value. It is an exceptionally low ratio if compared to the average values found in garnets from lherzolite xenoliths of the APIP (e.g., ${ }^{147} \mathrm{Sm} /{ }^{144} \mathrm{Nd} \sim 0.417$, Dalla Costa, 2012).

In terms of absolute $\mathrm{Nd}$ concentrations determined by isotopic dilution, the values obtained vary widely between the mineral phases (Table 5.5). Perovskite separates show the highest Nd contents, with abundances of 4410 and 5166 ppm. Apatite exhibits a wide range of concentrations, varying from $351 \mathrm{ppm}$ in a bebedourite to more than $2800 \mathrm{ppm}$ in a calciocarbonatite sample (10A-41A) and in a P1 phoscorite (sample SF101.5D1). Among the carbonates, calcite shows higher $\mathrm{Sm}$ and $\mathrm{Nd}$ contents than dolomite, but their $\mathrm{Sm} / \mathrm{Nd}$ ratios are very similar. Dawson \& Hinton (2003) describe analogous behaviour in carbonatites from the Phalaborwa Complex.

In general, silicate minerals exhibit the lowest REE contents, although some samples may show anomalously high $\mathrm{Nd}$ abundances in olivine and phlogopite. These may be attributed to small amounts (i.e., less than 2\%) of REE-rich inclusions such as apatite. Similarly, some magnetite concentrates may have minor perovskite contamination. In most cases, the effect of inclusions in the ${ }^{143} \mathrm{Nd} /{ }^{144} \mathrm{Nd}_{\mathrm{m}}$ of olivine, phlogopite and magnetite, modelled by binary mixing calculations is within the analytical errors. Among the studied samples, the $\mathrm{Nd}$ isotopic composition may have been slightly affected (i.e., less radiogenic than measured value) only in olivine from sample SF101.5D1.

The mineral phases investigated here have a very restricted range of $\mathrm{Nd}$ isotopic composition when compared with whole-rock data (e.g., compare Figure 5.10B and Figure 5.16). Besides, only apatite exhibits a positive correlation between initial ${ }^{143} \mathrm{Nd} /{ }^{144} \mathrm{Nd}$ ratios 
and $\mathrm{Nd}$ contents (not shown). As observed for Sr isotopes, the $\mathrm{Nd}$ data from minerals can also be divided in two major groups, although some overlap exists. The first group has more enriched isotopic compositions (0.512193-0.512258), comprising data from B1a, B1b and B2 bebedourites, P1 phoscorite and C1 magnesiocarbonatite. The second group consists of P2 phoscorite and C3 calciocarbonatite minerals, and is characterized by higher ${ }^{143} \mathrm{Nd} /{ }^{144} \mathrm{Nd}_{\mathrm{i}}$, varying from 0.512219 to 0.512295 .

The ${ }^{143} \mathrm{Nd} /{ }^{144} \mathrm{Nd}_{\mathrm{i}}$ of some minerals deviates significantly from the corresponding whole-rock data, even considering the analytical errors (Figure 5.17). The greatest differences occur in phoscorites, where whole-rock isotope signatures are systematically more enriched than mineral ones. Moreover, all mineral phases analysed have consistently similar ${ }^{143} \mathrm{Nd} /{ }^{144} \mathrm{Nd}_{\mathrm{i}}$ for a single rock sample. The reasons for this are discussed in section 5.6.
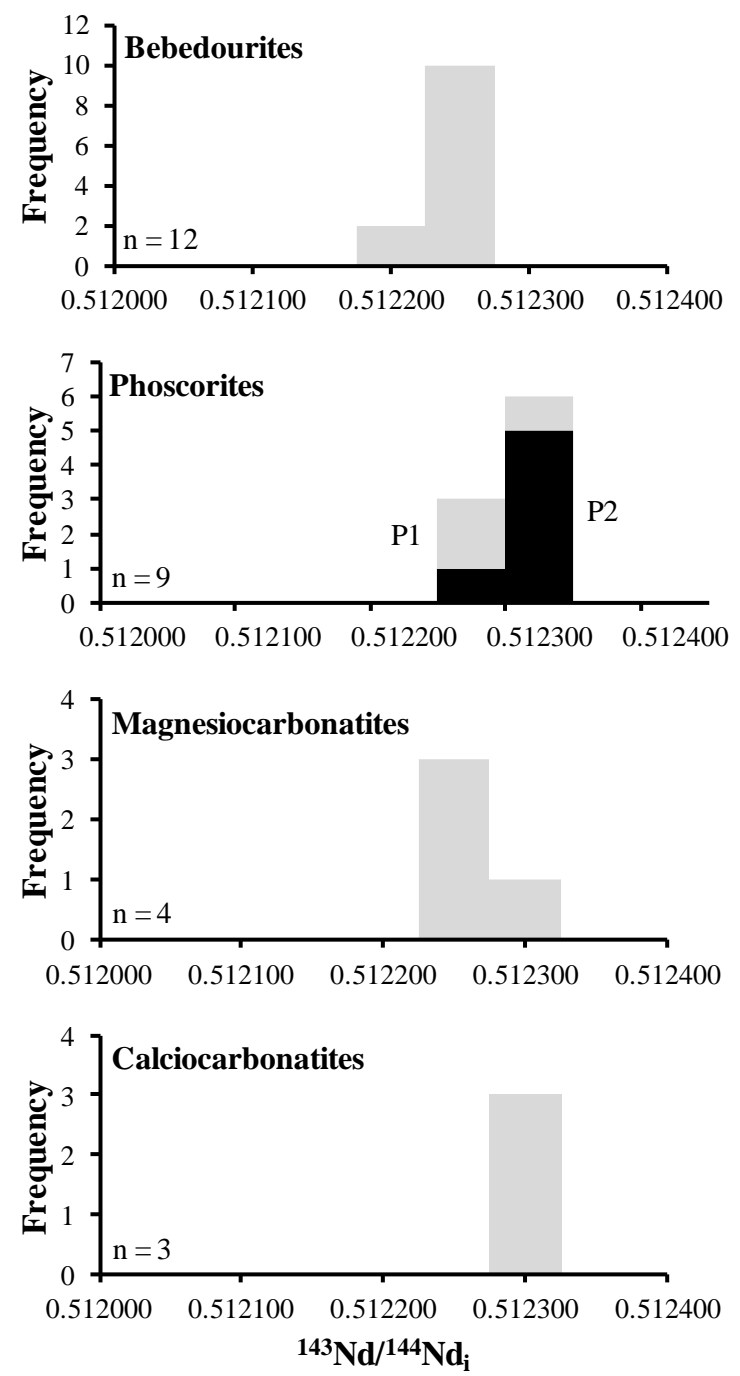

Figure 5.16. Histogram distribution of mineral separates ${ }^{143} \mathrm{Nd} /{ }^{144} \mathrm{Nd}_{\mathrm{i}}$ for the main rock types of the Salitre I complex. P1 and P2 represent different units of phoscorites according to Barbosa (2009). "n" - number of samples in each individual chart. 

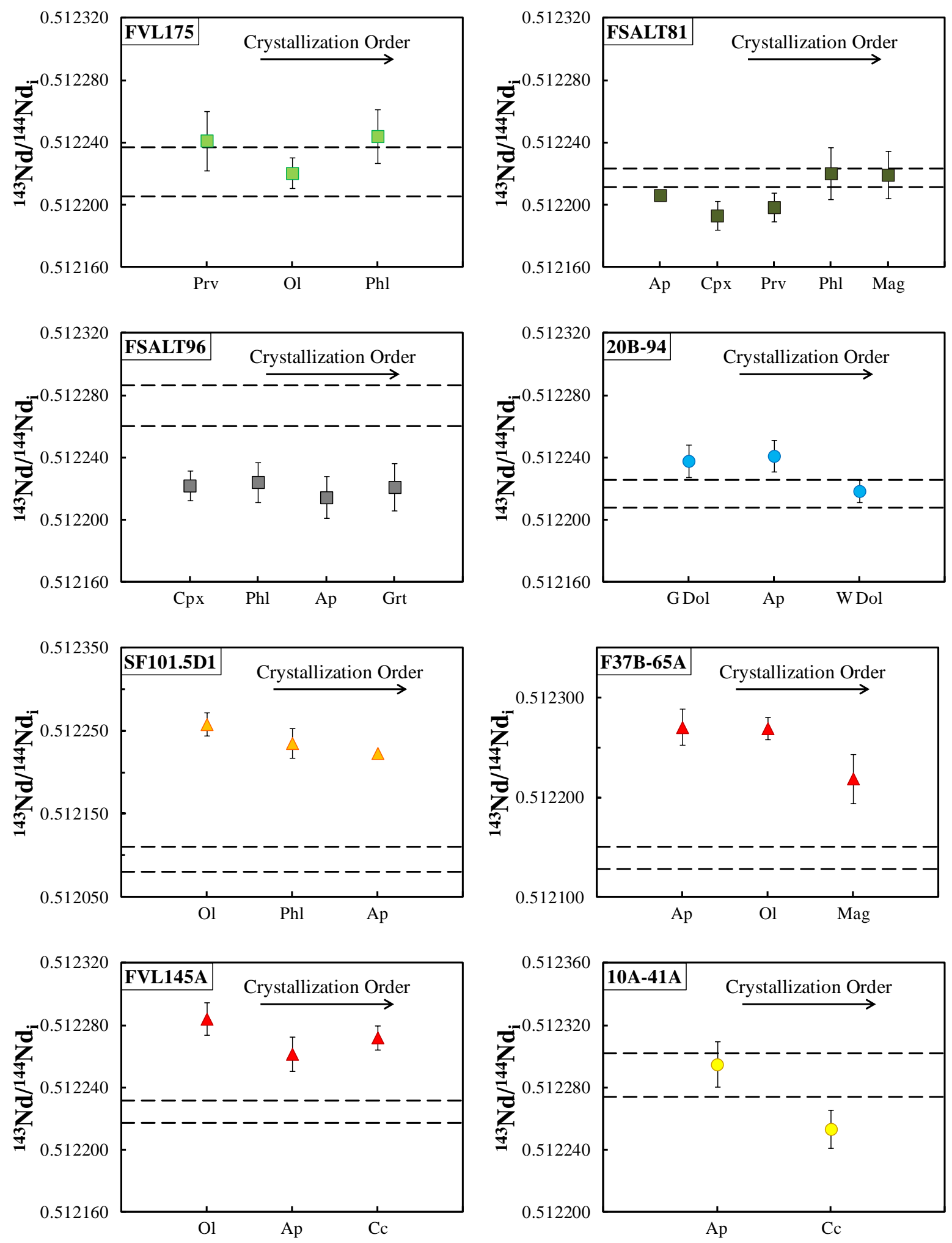

Figure 5.17. ${ }^{143} \mathrm{Nd} /{ }^{144} \mathrm{Nd}_{\mathrm{i}}$ for whole rocks and corresponding mineral separates. The error bars represents \pm 2 SE. Dashed lines in each chart mark the variation determined for whole-rock sample. All charts are to the same vertical scale, except for samples SF101.5D1 and F37B-65A. Ap - apatite; Cc - calcite; Cpx clinopyroxene; Dol - dolomite; G Dol - grey dolomite; W Dol - white dolomite; Grt - garnet; Mag magnetite; Ol - olivine; Prv - perovskite; Phl - phlogopite. Symbols as in Figure 5.6. 
Our findings show that almost all investigated samples have some degree of mineralrock isotopic disequilibrium (Figure 5.17). Although analytical errors are large, in several cases mineral data suggest within-sample isotopic disequilibrium. These features and the limited scattering in ${ }^{147} \mathrm{Sm} /{ }^{144} \mathrm{Nd}$ of the minerals reduce the possibility of obtaining reliable $\mathrm{Sm}-\mathrm{Nd}$ isochron ages to only two bebedourite samples. Figure 5.18 exhibits an errorchron age obtained for sample FSALT81 (B1b bebedourite). There is a clear within-sample isotopic disequilibrium, not so obvious from calculated ${ }^{143} \mathrm{Nd} /{ }^{144} \mathrm{Nd}_{\mathrm{i}}$ ratios due to the analytical errors. Clinopyroxene and perovskite data points seem to plot along a projection of the regression line displayed, while other phases have a more random behaviour.

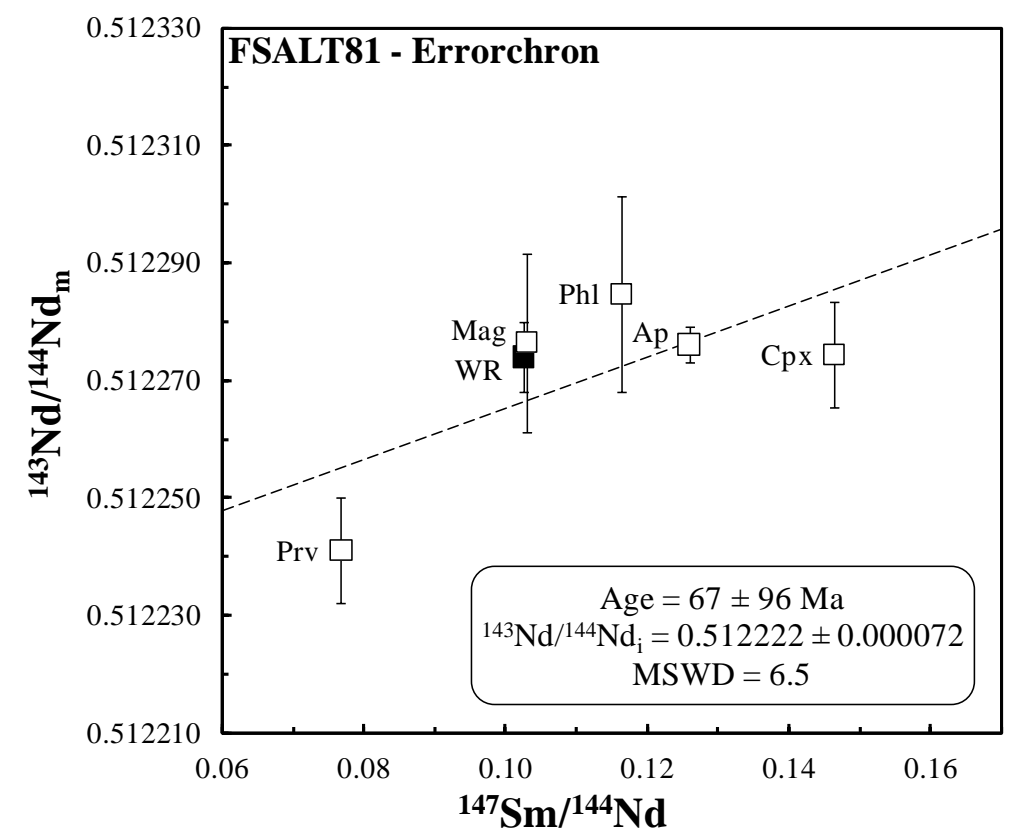

Figure 5.18. ${ }^{143} \mathrm{Nd} /{ }^{144} \mathrm{Nd} d_{\mathrm{m}}$ versus ${ }^{147} \mathrm{Sm} /{ }^{144} \mathrm{Nd}$ for minerals (open symbols) and whole-rock (filled symbol) from sample FSALT81 (B1b bebedourite). WR - whole-rock; Ap - apatite; Cpx - clinopyroxene; Mag magnetite; Prv - perovskite; Phl - phlogopite. The error bars represents $\pm 2 \mathrm{SE}$.

In Figure 5.19, another errorchron is shown for sample FSALT96 (B2 bebedourite), but in this case only the whole-rock composition appears to be in disagreement. Figure 5.20 shows an attempt to produce an isochron age using only mineral data. In this diagram, the isochron line is a very good fit for the mineral points and yields a Sm-Nd age of $91 \pm 17 \mathrm{Ma}$ $\left(\mathrm{MSWD}=0.41 ;{ }^{143} \mathrm{Nd} /{ }^{144} \mathrm{Nd}_{\mathrm{i}}=0.512216\right)$. This age is consistent with those expected for all APIP complexes, around 85 Ma (Gibson et al., 1995b). The large error obtained is probably because of the young age of the rock and the limited spread on ${ }^{147} \mathrm{Sm} /{ }^{144} \mathrm{Nd}$. Initial ${ }^{143} \mathrm{Nd} /{ }^{144} \mathrm{Nd}$ is indistinguishable from the average of those calculated for $85 \mathrm{Ma}$ (Table 5.5). This result suggests an isotopic homogeneity, at least for Sm-Nd system, between the 
minerals of FSALT96 at the time of crystallization. Such finding contrasts with the Sr mineral isotopic disequilibrium described for the same sample.

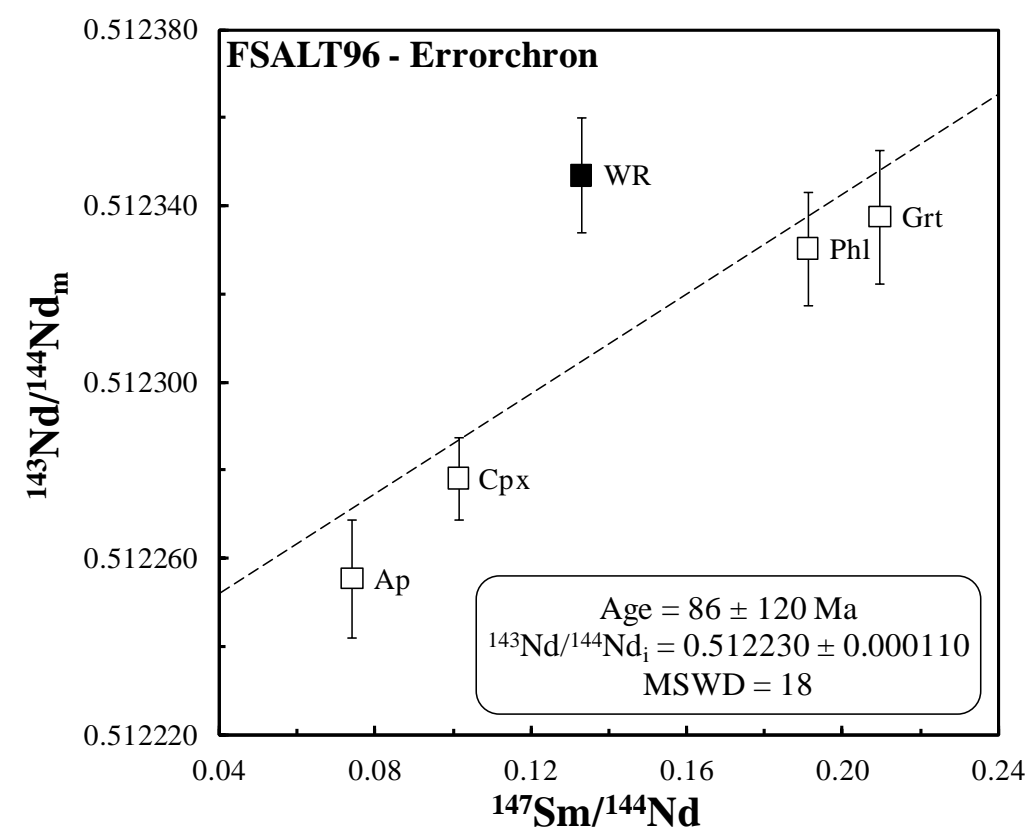

Figure 5.19. ${ }^{143} \mathrm{Nd} /{ }^{144} \mathrm{Nd} d_{\mathrm{m}}$ versus ${ }^{147} \mathrm{Sm} /{ }^{144} \mathrm{Nd}$ for minerals (open symbols) and whole-rock (filled symbol) from sample FSALT96 (B2 bebedourite). WR - whole-rock; Ap - apatite; Cpx - clinopyroxene; Grt garnet; Phl - phlogopite. The error bars represents $\pm 2 \mathrm{SE}$.

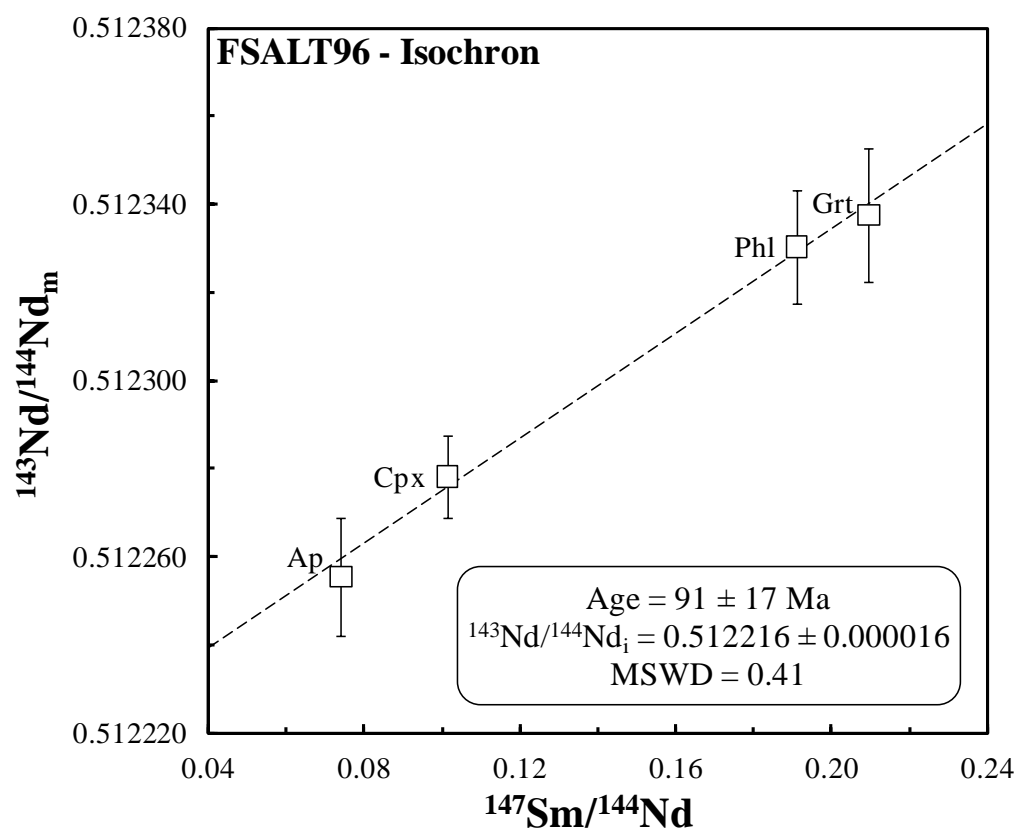

Figure 5.20. Sm-Nd mineral isochron diagram for sample FSALT96. The error bars represents $\pm 2 \mathrm{SE}$. Labels as in Figure 4.18. Note that the removal of the whole-rock data yields a good fit for the mineral points on the regression line. This is evidence of isotopic homogeneity for the Sm-Nd system between the analysed minerals, at the time of crystallization. 
Partition coefficients $\left(K_{D}\right)$ between minerals from the same rock can be determined for $\mathrm{Sm}$ and $\mathrm{Nd}$. Nevertheless, these elements have significant concentrations only in apatite and Ca-Ti phases. Consequently, the $\mathrm{K}_{\mathrm{D}}$ values were calculated exclusively for these minerals.

Perovskite accounts for the most part of the whole-rock REE budget in B1 bebedourites. The $\mathrm{K}_{\mathrm{D}}$ values obtained between perovskite and apatite from sample FSALT81 are $14.7(\mathrm{Nd})$ and $9.0(\mathrm{Sm})$. For garnet-bearing bebedourite (B2), the apatite-garnet pair yields $\mathrm{K}_{\mathrm{D}}$ values of $2.8(\mathrm{Nd})$ and $1.0(\mathrm{Sm})$. In phoscorites and carbonatites, the majority of REE content lies in apatite and in some accessory phases (e.g., Zirconolite, Burbankite). $\mathrm{K}_{\mathrm{D}}$ 's for apatite-calcite are very similar in both rock-types, varying from 8.5 to $11.1(\mathrm{Nd})$ and 8.6 to $11.8(\mathrm{Sm})$. Furthermore, partition coefficients between apatite and dolomite from sample 20B-94 are 19.7 (Nd) and 20.9 (Sm). Dawson \& Hinton (2003) report a comparable value for $\mathrm{Nd}$ in the apatite-dolomite pair from Phalaborwa, but a lower value for apatite-calcite. This is probably due to the higher temperature of the calcites analysed by those authors.

\subsection{DISCUSSION}

The meaning of the close relationship between carbonatites and silica-undersaturated alkaline rocks (e.g., nephelinites, kamafugites, phoscorites) in most worldwide carbonatite occurrences is still the subject of many debates among petrologists (Bell et al., 1998; Gittins \& Harmer, 2003; Mitchell, 2005; Woolley \& Kjarsgaard, 2008; Downes et al., 2012). However, in order to understand all the aspects involved into carbonatite petrogenesis each individual occurrence should be treated on its own merits in view of the fact that experimental evidence indicates numerous different origins for carbonatite magmas (Bailey, 1993; Woolley \& Kjarsgaard, 2008). The Salitre I complex appears to be formed by an intricate combination of fractional crystallization and liquid immiscibility processes in multiple stages (Morbidelli et al., 1997; Barbosa 2009; Barbosa et al., 2012c), a proposal strongly supported by field, petrographic, whole-rock geochemical and mineral chemistry data. Other alkaline-carbonatite complexes of the APIP (e.g., Serra Negra Complex, Grasso, 2010; Tapira Complex, Brod, 1999; Brod et al., 2012) show similar evidence of a complicated evolution involving three cogenetic series (i.e., bebedouritic, phoscoritic and carbonatitic).

In our $\mathrm{Nd}$ and $\mathrm{Sr}$ isotope study, substantial mineral and whole-rock isotopic heterogeneities were recognized. At first sight, such isotopic signatures could be interpreted as distinct mantle sources for the magmas involved in the genesis of the Salitre I complex. 
However, this interpretation is not supported by the geological and geochemical background from previous studies in this complex, and in the entire APIP. The lack of $\mathrm{Rb}-\mathrm{Sr}$ and $\mathrm{Sm}-\mathrm{Nd}$ isochrons ages as well as the $\mathrm{Sr}$ (and maybe $\mathrm{Nd}$ ) isotopic disequilibrium between co-existing mineral phases are strongly suggestive of a magmatic evolution in open-system condition, most likely involving crustal contamination during the differentiation. Nevertheless, it is necessary to assess the radiogenic isotopic composition of the parental magma of the Salitre I complex before we attempt to constrain the petrogenetic processes responsible for those isotope heterogeneities.

\section{Nd-Sr Isotope Composition of the APIP Parental Magma}

Gibson et al. (1995b) and Brod et al. (2000) established through field, petrographic, mineralogical and geochemical evidence that the silica-undersaturated, ultrapotassic, carbonate-rich phlogopite picrite dykes are the best representatives of the parental magmas of APIP complexes. Unfortunately, no well-preserved samples of phlogopite picrite were found in Salitre I (Barbosa 2009). Thus, we decided to evaluate the $\mathrm{Nd}-\mathrm{Sr}$ isotope composition of these rocks through a regional database compiled from the literature. Only data from less than a dozen samples were available since a small number of radiogenic isotopic studies from APIP have been published and even less have concerned with such magmas (Table 5.6).

Table 5.6. Sr and Nd isotope data for the phlogopite picrite dykes of the APIP alkaline-carbonatite complexes. All initial ratios were recalculated at 85 Ma using the same parameters of the tables Table 5.2 and Table 5.3. Model Ages $\left(T_{D M}\right)$ were calculated following DePaolo (1981a), using the CHUR values as in Table 5.3.

\begin{tabular}{lccccc}
\hline \multicolumn{1}{c}{ Complex } & $\begin{array}{c}\mathbf{S r} \\
(\mathbf{p p m})\end{array}$ & $\begin{array}{c}{ }^{\mathbf{8 7}} \mathbf{S r} /{ }^{\mathbf{8 6}} \mathbf{S r} \mathbf{i} \\
\text { (initial) }\end{array}$ & $\begin{array}{c}\mathbf{N d} \\
(\mathbf{p p m})\end{array}$ & $\begin{array}{c}{ }^{\mathbf{1 4 3}} \mathbf{N d} /{ }^{\mathbf{1 4 4}} \mathbf{N d}_{\mathbf{i}} \\
(\mathbf{i n i t i a l})\end{array}$ & $\begin{array}{c}\boldsymbol{\tau}_{\mathbf{D M}} \\
(\mathbf{T}=\mathbf{G a})\end{array}$ \\
\hline${ }^{1}$ Catalão II & 1246 & 0.704811 & 265 & 0.512197 & 0.92 \\
${ }^{1}$ Catalão II & 1804 & 0.704844 & 260 & 0.512210 & 0.91 \\
${ }^{1}$ Serra Negra & 934 & 0.704360 & 193 & 0.512278 & 0.90 \\
${ }^{2}$ Tapira & 2131 & 0.706168 & 204 & 0.512221 & 0.91 \\
${ }^{3}$ Catalão II & 2333 & 0.705124 & 230 & 0.512215 & 1.02 \\
${ }^{3}$ Catalão II & 2184 & 0.705110 & 246 & 0.512183 & 0.95 \\
${ }^{3}$ Catalão II & 4453 & 0.705161 & 202 & 0.512216 & 1.01 \\
${ }^{3}$ Catalão II & 4077 & 0.704929 & 200 & 0.512235 & 0.88 \\
${ }^{4}$ Catalão I & 1619 & 0.704825 & 251 & 0.512203 & 0.92 \\
${ }^{5}$ Serra Negra & 3291 & 0.704935 & 237 & 0.512255 & 1.10 \\
\hline : 1 - Gibson et al. (1995b); 2- Brod (1999); 3 - Guarino et al. (2012); $4-$ Gomes \& Comin- \\
ti (2005); 5 - Grasso (2010).
\end{tabular}


These data show a remarkable $\mathrm{Nd}$ and $\mathrm{Sr}$ isotopic variation in the parental magmas of the APIP carbonatite complexes. The range of ${ }^{143} \mathrm{Nd} /{ }^{144} \mathrm{Nd}_{\mathrm{i}}(0.512183-0.512278)$ for phlogopite picrites is virtually identical to that from Salitre I bebedourites and carbonatites whereas the initial $\mathrm{Sr}$ ratios extend over a much wider range. Interestingly, there is a systematic relationship between the initial $\mathrm{Nd}$ and $\mathrm{Sr}$ isotopic ratios and their elemental concentrations (Figure 5.21A and Figure 5.21B). Several geochemical linear correlations (e.g., Figure 5.22) point toward an increase of $\mathrm{Sr}$ content during the evolution of these ultrapotassic carbonate-silicate parental magmas. The common presence of olivine and $\mathrm{Cr}$ spinel phenocryts also indicate that crystal fractionation processes (Brod et al., 2000; 2012) have affected phlogopite picrites. Such evidence together with the fact that almost all points in the ${ }^{87} \mathrm{Sr} /{ }^{86} \mathrm{Sr}_{\mathrm{i}}$ versus $\mathrm{Sr}$ contents (Figure 5.21B) outline a hyperbolic pattern strongly suggest that post-melting contamination processes taking place within the continental crust is the most likely explanation for these chemical properties.

In addition, Figure 5.22D highlights that the distributions of REE are not in accordance with the increase in the $\mathrm{Sr}$ content through the whole differention of the phlogopite picrites, but only in the earlier stages of the magmatic differentiation. Abrupt shifts, generally rising the LREE amount, suggest that another process capable to modify drastically the REE abundance of the magma should be occurred. Petrographic evidence from phlogopite picrites and kamafugites show that the onset of carbonate-silicate liquid immiscibility may occur very early in the evolution of these rocks (Brod et al., 2012). Thus, the most evolved phlogopite picrites from the database compiled may represent $\mathrm{Cb}$-rich liquids derived from a previous immiscible event, or could contain so many small carbonate pockets that rise the Sr and LREE contents in the whole-rock analysis.
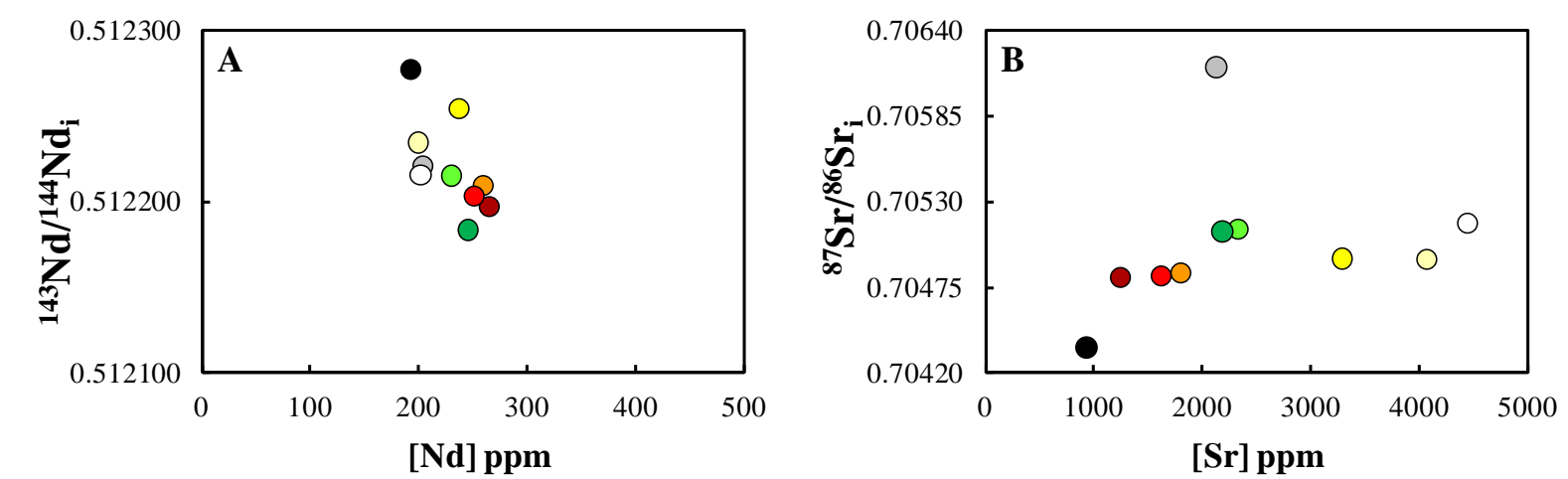

Figure 5.21. ${ }^{143} \mathrm{Nd} /{ }^{144} \mathrm{Nd}_{\mathrm{i}}$ versus $\mathrm{Nd}$ contents (A) and ${ }^{87} \mathrm{Sr}^{86} \mathrm{Sr}_{\mathrm{i}}$ versus $\mathrm{Sr}$ contents (B) for the parental magma of the APIP. Note the rather hyperbolic pattern that covers almost all samples in (B). Matching data points have the same colour in both charts. 

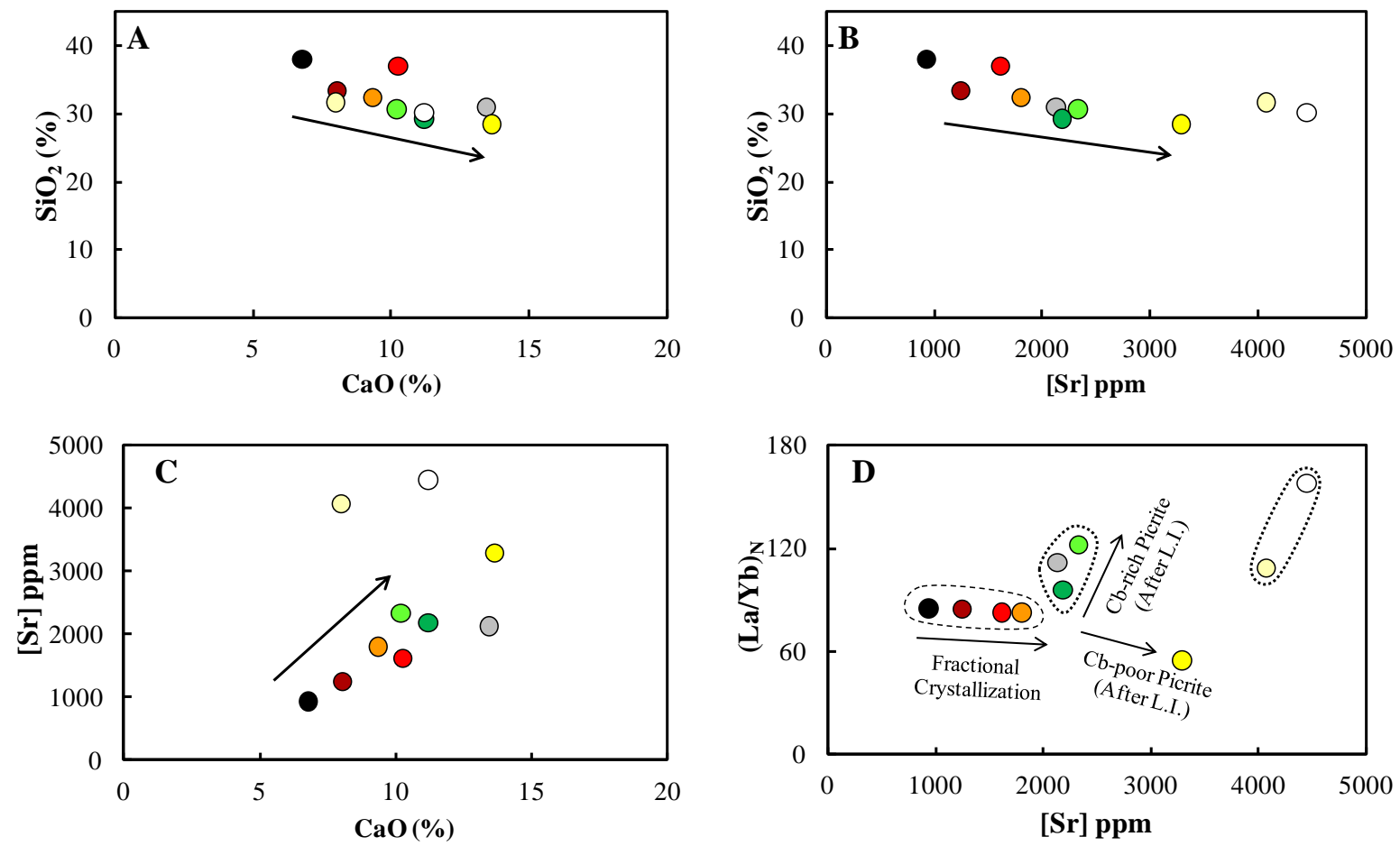

Figure 5.22. (A), (B) and (C) illustrates the geochemical linear correlations ongoing between $\mathrm{SiO}_{2}, \mathrm{CaO}$ and $\mathrm{Sr}$ content for the parental magmas of the APIP. Black arrows indicate the general evolution trends. (D) La/Yb normalized to chondrite values of Sun \& McDonough (1989) versus Sr content. The different trends and groups are related to distinct differentiation processes (see text for details). Note that a particular data point has the same colour in all charts as in Figure 5.21.

We use mathematical modelling to investigate if crustal contamination could cause the $\mathrm{Nd}-\mathrm{Sr}$ isotope variations observed in the parental magma of the APIP carbonatite complexes. Binary mixing models (Langmuir et al., 1978) are often used to evaluate crustal contamination effects (e.g., Andersen, 1987; Dunworth \& Bell, 2001). However, the increase of $\mathrm{Nd}$ and $\mathrm{Sr}$ contents in the direction of the most radiogenic isotope ratios (Figure 5.21) do not support two-component mixing as a likely explanation, at least if one of the end-members was the continental crust. DePaolo (1981b) pointed out that in simple mixing models the concentration of an element in the magma will modify toward that in the wallrock, which is clearly not the case (Figure 5.23 and Figure 5.24). Hence, the $\mathrm{Nd}$ and $\mathrm{Sr}$ ratio variations in such ultrapotassic parental magma are not consistent with a simple mechanical mixing of the least evolved phlogopite picrite sample, with the most depleted isotopic ratios $\left({ }^{143} \mathrm{Nd} /{ }^{144} \mathrm{Nd}_{\mathrm{i}}=\right.$ $\left.0.512278 ;{ }^{87} \mathrm{Sr} /{ }^{86} \mathrm{Sr}_{\mathrm{i}}=0.704360\right)$, and the average composition of the continental crust (Hofmann, 1997; Rudnick \& Gao, 2003).

Another possible assessment of wall-rock assimilation effects in $\mathrm{Nd}-\mathrm{Sr}$ isotopic ratios is the well-known assimilation-fractional crystallization (AFC) model of DePaolo (1981b). This model could be consistent with petrographic and geochemical evidence of fractional 
crystallization operating during differentiation of the phlogopite picrites. AFC model calculations, as any other modelling, require a carefully choose of input parameters based on extensive geological and petrological understanding of the system studied (Ray, 2009). We initially take the same end-members suggested for the binary mixing model, since the crustal level at which the contamination took place, if occurred, is uncertain. Radiogenic isotope data for country rocks exposed near Salitre I are lacking. The $\mathrm{Nd}$ and $\mathrm{Sr}$ partition coefficients $\left(\mathrm{K}_{\mathrm{D}}\right.$ 's) for most of the minerals present in rocks with kamafugitic affinity (e.g., phlogopite picrites) are poorly constrained or even unknown. We thus made some logical assumptions based on the available data from Melluso et al. (2008) and taking into account the values reported for other ultrapotassic and alkaline silicate rocks. The bulk mineral-melt partition coefficients (D) calculated for $\mathrm{Nd}$ and $\mathrm{Sr}$ are respectively 0.8 and 0.2 , assuming a fractionating assemblage composed of olivine (60\%), phlogopite (20\%), Fe-Ti oxides (10\%), apatite $(6 \%)$ and perovskite (4\%). The partition coefficients used are given in Table 5.7. It is noteworthy the exceptionally high $\mathrm{K}_{\mathrm{D}}^{\mathrm{Nd}}$ for perovskite, which makes this mineral very important for the petrogenesis of ultrapotassic magmas given that it can change the $\mathrm{Nd}$ budget of the magma drastically if extensive crystal fractionation occurs.

Table 5.7. Mineral-melt partition coefficients $\left(K_{D}\right)$ used in the modelling calculations. The $K_{D}$ 's of all minerals represent phenocrystal/matrix measured values, except for apatite (based on experimental data).

\begin{tabular}{lll}
\hline \multirow{2}{*}{ Mineral Phase } & \multicolumn{2}{c}{$\begin{array}{c}\text { Partition Coefficient }\left(\mathbf{K}_{\mathbf{D}}\right) \\
\mathbf{N d}\end{array}$} \\
\hline Apatite* & 1.7 & 4.5 \\
Clinopyroxene & 0.31 & 0.329 \\
Olivine & 0.0002 & 0.00008 \\
Perovskite & $1.26^{\mathrm{a}}$ & 12 \\
Phlogopite & $0.183^{\mathrm{b}}$ & 0.0087 \\
Fe-Ti Oxide & 0.0001 & 0.00013 \\
\hline a Value determined from a katungite by Chakmouradian et al. \\
${ }^{\mathrm{b}}$ Value determined from a lamprophyre by Foley et al. (1996). \\
ring those reported by Watson \& Green (1981) and Prowatke \& Klemme (2006).
\end{tabular}

According to our calculations, the majority of Sr isotope variation in the ultrapotassic parental magma of the APIP could be explained by concurrent assimilation and fractional crystallization processes (Figure 5.23) at reasonable r-values (i.e., the ratio between the mass of assimilated material and the mass of crystallized material per unit of time). The " $r$ " values depend on several physical parameters, such as the contrast of temperature between the wallrock and the magma, for instance, and can vary considerably as the magma rises trough 
the crust (DePaolo, 1981b). Taylor (1980) calculated an upper limit value of $\mathrm{r} \sim 0.3$ for assimilation of cold country rock (at $150^{\circ} \mathrm{C}$ - e.g., upper continental crust). Nonetheless, DePaolo (1981b) suggested a higher limit of $\mathrm{r} \sim 1$ for wallrock at $1000^{\circ} \mathrm{C}$ (e.g., lower crust in regions of active volcanism). The AFC model appears to be a plausible explanation at least for the Sr ratio variations in the APIP parental magmas given the amount of assimilation consistent with our data (r-value between 0.1 and 0.25 ).

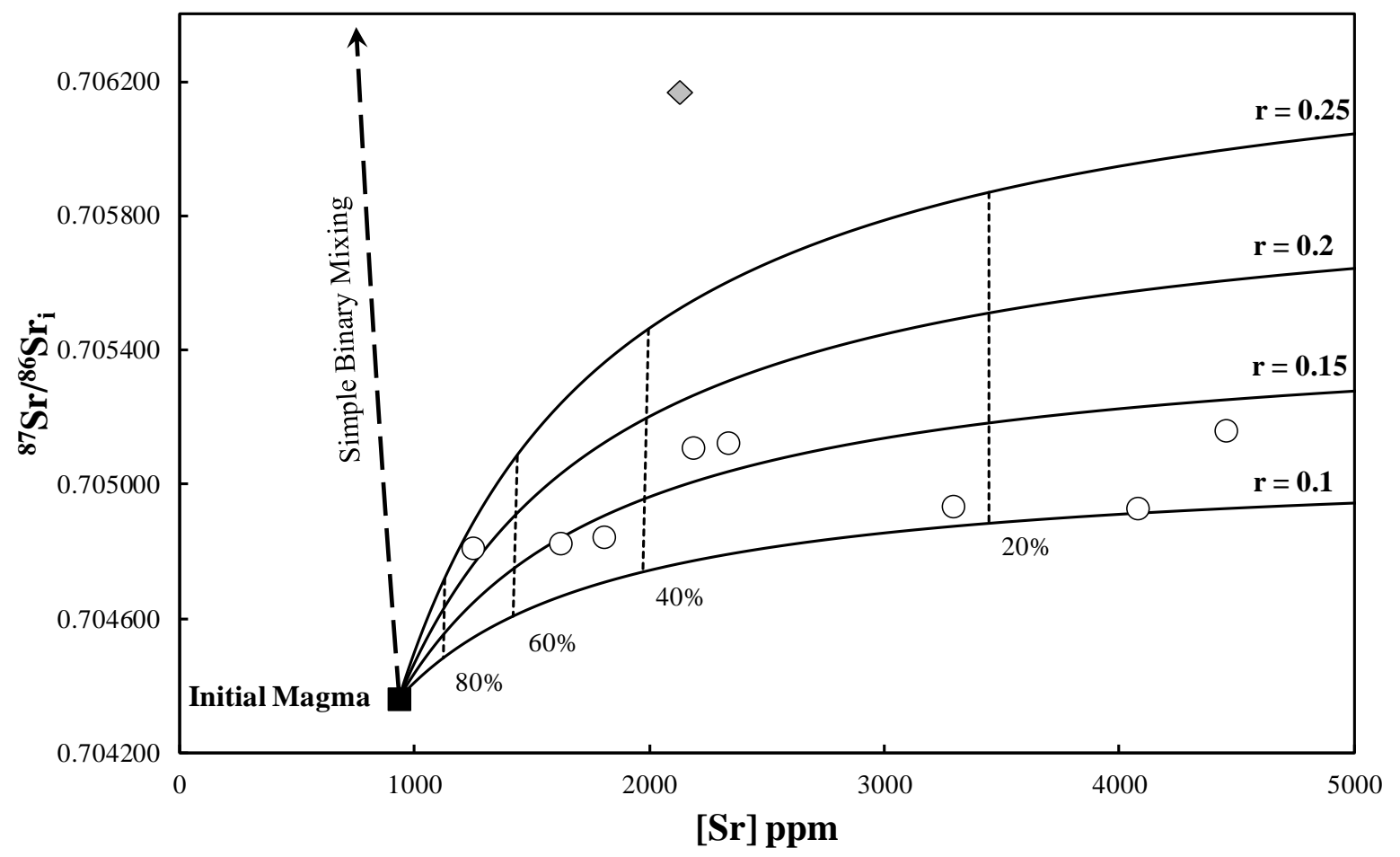

Figure 5.23. ${ }^{87} \mathrm{Sr} /{ }^{86} \mathrm{Sr}_{\mathrm{i}}$ versus $\mathrm{Sr}$ contents for the parental magma of the APIP carbonatite complexes. Continuous lines represent the AFC model curves calculated for different $r$-values using as end-members an initial phlogopite-picrite magma $\left({ }^{87} \mathrm{Sr}^{86} \mathrm{Sr}_{\mathrm{i}}=0.70436\right.$ and $\left.\mathrm{Sr}=934 \mathrm{ppm}\right)$ and the average composition of the continental crust $\left({ }^{87} \mathrm{Sr} /{ }^{86} \mathrm{Sr}=0.72-\right.$ Hofmann, 1997; $\mathrm{Sr}=320 \mathrm{ppm}$ - Rudnick \& Gao, 2003). Dotted lines are the percentage of $\mathrm{F}$ (fraction of magma remaining).

The AFC model becomes particularly sensitive to $\mathrm{Nd}$ contents due to the very high values of $\mathrm{K}_{\mathrm{D}}^{\mathrm{Nd}}$ for perovskite. Applying the same parameters of the Sr modelling, we estimate that less than $5 \%$ of perovskite crystals could accumulate before the $\mathrm{Nd}$ abundance in the magma would start to be drastically reduced. Furthermore, even keeping such constraints some phlogopite picrites with more enriched $\mathrm{Nd}$ isotope signatures required a contaminating material rather different from the average continental crust $\left({ }^{143} \mathrm{Nd} /{ }^{144} \mathrm{Nd}=0.5118\right.$ and $\mathrm{Nd}=$ $20 \mathrm{ppm})$, one with an anomalous higher $\mathrm{Nd}$ content $(\sim 40 \mathrm{ppm})$ or a more radiogenic composition (i.e., much lower ${ }^{143} \mathrm{Nd} /{ }^{144} \mathrm{Nd}_{\mathrm{i}}$ ). Besides, this model requires almost full crystallization of the picrite magma in order to achieve the observed isotopic composition. 
In order to gains insights on the contaminants assimilated by the APIP parental magmas, we have evaluated the average $\mathrm{Nd}$ composition of two distinct crustal components: (1) Neoproterozoic Brasília Belt rocks (Araxá Group + Anápolis-Itauçu Complex, Pimentel et al., 2001; Piuzana et al., 2003a, b); (2) Archean/Paleoproterozoic São Francisco Craton (SFC) rocks (Sato, 1998). On the account of their geographic proximity, both tectonic units could be suitable contaminants. The Brasília Belt comprises the immediate outcropping country rocks for the APIP complexes, but they represent relatively shallow tectonic slices thrusted over the southwest border of the craton, as suggested by geophysics (e.g., Pires, 1986; VanDecar et al., 1995) and isotope data (e.g., Carlson et al., 2007). Therefore, which tectonic unit was the prevailing contaminant will depend on depth. The average isotopic composition of the Brasília Belt rocks, corrected to $85 \mathrm{Ma}$ (i.e., ${ }^{143} \mathrm{Nd} /{ }^{144} \mathrm{Nd}=0.51204 ; \mathrm{Nd}=37.25 \mathrm{ppm}$ ), is more radiogenic than the average continental crust. Consequently, considering such Neoproterozoic crust as contaminant does not significantly change the previous results obtained from the average crust. However, the $\mathrm{Nd}$ isotope composition of the Archean/Paleoproterozoic rocks from the SFC, calculated at $85 \mathrm{Ma}\left(\right.$ i.e., ${ }^{143} \mathrm{Nd} /{ }^{144} \mathrm{Nd}=0.51123$; $\mathrm{Nd}=25.35 \mathrm{ppm}$ ), produce a more realistic contaminant for the parental magmas of the APIP complexes (Figure 5.24).

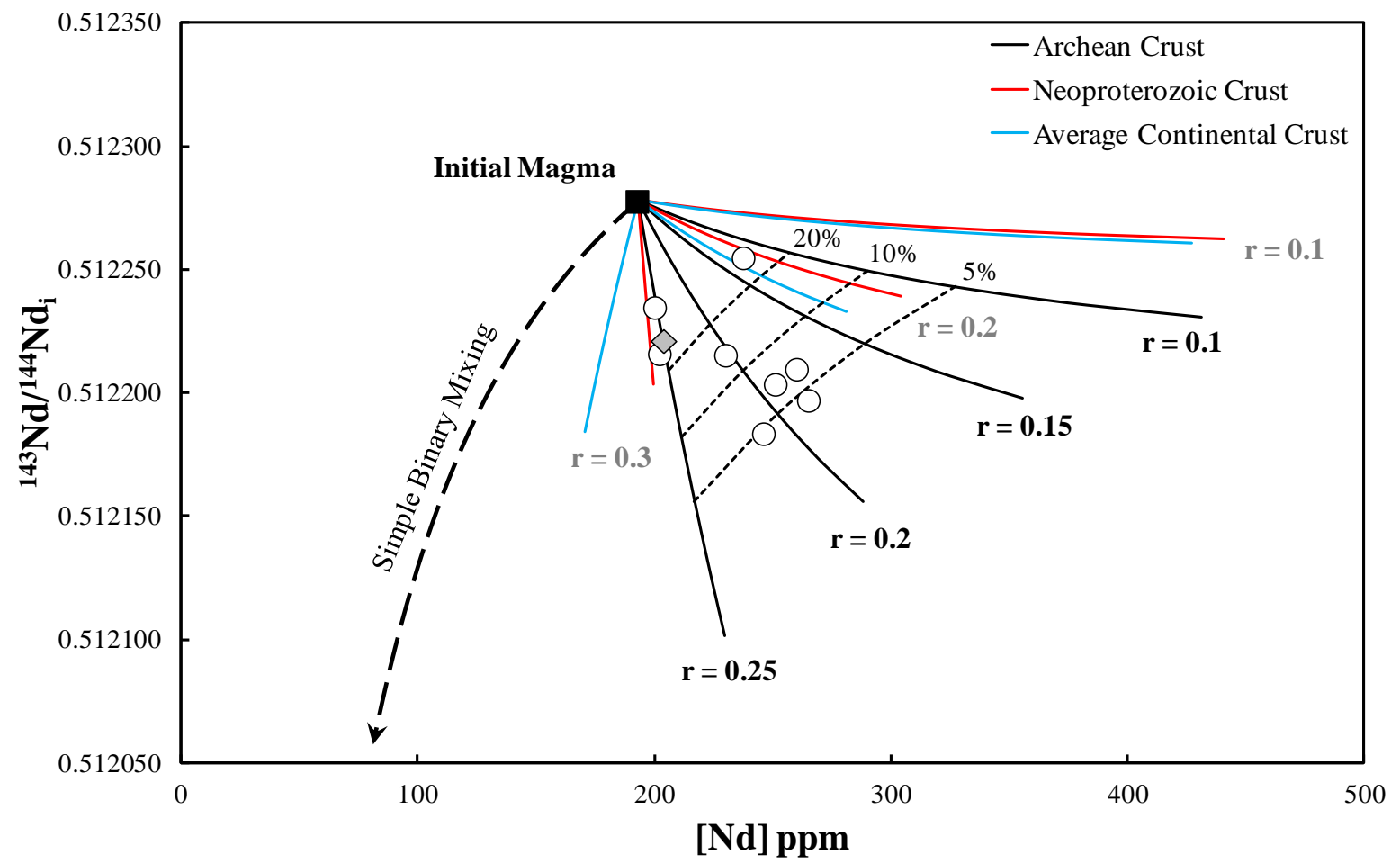

Figure 5.24. ${ }^{143} \mathrm{Nd} /{ }^{144} \mathrm{Nd}_{\mathrm{i}}$ versus $\mathrm{Nd}$ contents for the parental magma of the APIP carbonatite complexes. Continuous lines represent the AFC model curves calculated for different $r$-values and contaminants (see text for details). All curves are limited to the fraction of magma remaining (F) equal to $1 \%$. Dotted lines are the percentage of $\mathrm{F}$. The composition of the initial parental magma is ${ }^{143} \mathrm{Nd} /{ }^{144} \mathrm{Nd}_{\mathrm{i}}=0.512278$ and $\mathrm{Nd}=$ 193 ppm. Contaminant materials compositions are mentioned in the text. 
In any case, AFC modelling using the low r-values obtained from $\mathrm{Sr}$ systematics (i.e., $\mathrm{r}$ between 0.1 and 0.25 ) produces very low ranges of $\mathrm{F}$ (fraction of magma remaining; $\sim 0.01$ considering modern continental crust, $1 \%$ to $10 \%$, considering the Archean crust as the contaminant). These results favour the Archean/Paleoproterozoic crust of the São Francisco Craton over the rocks of the Neoproterozoic Brasília Belt as a contaminant but, because the $\mathrm{Nd}$ system is less sensitive than the $\mathrm{Sr}$ isotopes, a much higher degree of magma crystallization would be required before assimilation became noticeable. If simple AFC is not capable of explaining the $\mathrm{Nd}$ isotope composition of phlogopite picrites, an alternative or additional process is needed.

It is noteworthy from Figure 5.23 that one phlogopite picrite sample (plotted as a grey diamond) is clearly distinguished from the others and from the AFC model curves. This sample has essentially the same Mg-number as the picrite sample chosen as the initial magma for the AFC modelling but a much more enriched isotopic composition. Brod (1999) proposed that crustal assimilation during turbulent magma ascent (ATA - Kerr et al., 1995) could be the reason for such contrasting isotope signatures in rocks with similar degrees of magmatic differentiation. In that model, hot, low-viscosity ultramafic magmas rise to the surface moving under a turbulent flow and forming thin dykes, with low magma to wallrock ratio, are likely to incorporate wallrock materials (i.e., continental crust) very fast. Carbonated ultramafic magmas such as phlogopite-picrites fit very well in these characteristics and, therefore, ATA is an elegant alternative model to explain those isotopic variations that AFC model could not. Regardless of which processes occurred (AFC, ATA or both), crustal contamination seems to have played an important role in the $\mathrm{Nd}-\mathrm{Sr}$ isotope ratio variations in the ultrapotassic parental magma of the APIP carbonatite complexes. In principle, ATA will produce the opposite effect than AFC (i.e., during ATA the most primitive magmas will be the most contaminated) but, unfortunately, the mathematical modelling for such a system has not yet been developed. A third process that may have substantially affected magma evolution in the APIP complexes, and for which there is abundant field, textural, mineralogical and geochemical evidence is liquid immiscibility (Brod et al., 2012). Ray (1998, 2009) proposed through theoretical mathematic modelling that systematic $\mathrm{Nd}-\mathrm{Sr}$ isotopic ratio variations observed in most alkaline-carbonatite complexes worldwide can be explained due to crustal contamination of the carbonated-silicate parental magma during their differentiation and do not require a heterogeneous mantle source. Such model is applied in the section below to the Salitre I rocks. 


\section{Isotopic Constraints on the Petrogenesis of the Salitre I complex}

\section{The Primary Magmatic Isotopic Signature}

Our mineral isotope data show that bulk-rock isotope compositions do not represent the primary isotopic signature of the magma, but are simply a weighted average composition for the different mineral phases. Since the Sr isotopic disequilibrium between minerals is strongly related to the crystallization order (Figure 5.14), the initial $\mathrm{Sr}$ and $\mathrm{Nd}$ isotopic ratios of distinct magmas in Salitre I are best defined by the mineral separates, mainly the early crystallizing phases. Apatite is an early phase in most of Salitre I rocks, recording the less radiogenic $\mathrm{Sr}$ and $\mathrm{Nd}$ isotopic signatures and therefore best represents the primary isotope composition of the magmas. Some authors have also observed in other alkaline-carbonatite complexes (Tichomirowa et al., 2006; Ye et al., 2013) and in kimberlites (Malarkey, 2010) that apatite retains the initial isotope compositions of the magma better than other minerals.

\section{Assimilation, Fractional Crystallization and Liquid Immiscibility (AFCLI Model)}

In the AFCLI model (Ray, 1998; 2009), crustal contamination of the carbonatedsilicate parental magma takes place concurrently with the immiscible separation of carbonate melt and the crystallization of the minerals that give rise to the alkaline silicate rocks. Morbidelli et al. (1997) and Barbosa (2009) have already established that fractional crystallization and liquid immiscibility were important processes in the magmatic evolution of Salitre I. Likewise, the within-mineral isotopic disequilibrium found in this study brings up strong evidence for open-system behaviour during the formation of this complex.

An important aspect of the AFCLI modelling are the input parameters used, mainly, the bulk partition coefficients $\mathrm{D}_{\mathrm{C}}$ and $\mathrm{D}_{\mathrm{L}}$. The bulk mineral/silicate-melt partition coefficient $\left(D_{C}\right)$ was determined based on the partition coefficients from Table 5.7 and the average composition of B1 bebedourites (Barbosa et al., 2012a). Although the number of experimental studies involving partitioning of elements between immiscible liquids has been recently improved (Wendlandt \& Harrison, 1979; Hamilton et al., 1989; Jones et al., 1995; Veksler et al., 1998; 2012; Martin et al., 2012; 2013), for the bulk carbonate-melt/silicatemelt partition coefficient $\left(D_{L}\right)$ the scenario is more complicated. These studies have concerned distinct compositions at very different system conditions, which makes difficult a real comparison between them. Martin et al. (2013) discussed some of the parameters that control the partitioning of trace elements between carbonatite and silicate carbonatite 
magmas. Taking such parameters in consideration, we applied the values determined by Martin et al. (2012) for ultrapotassic melts (i.e., kamafugites) in our modelling (Figure 5.25).

The AFCLI model curves generated for alkaline silicate rocks derived from a carbonated-silicate parental magma (e.g., phlogopite picrite) with an ${ }^{87} \mathrm{Sr}^{86} \mathrm{Sr}_{\mathrm{i}}$ and a $\mathrm{Sr}$ content of $0.70495 \pm 0.0001(1 \sigma)$ and $2500 \mathrm{ppm}$, respectively, demonstrate that the more radiogenic isotopic ratios of Salitre I bebedourites could be explained by less than $10 \%$ of crustal contamination (Figure 5.25). In this modelling, the assimilated material considered is the average composition of the continental crust $\left({ }^{87} \mathrm{Sr} /{ }^{86} \mathrm{Sr}=0.72 ; \mathrm{Sr}=320 \mathrm{ppm}\right)$. Furthermore, the model envisages that the exsolved carbonate melt would have a $\mathrm{Sr}$ isotopic ratio of $0.7051 \pm 0.0001$, which is comparable to that of the parental magma within $1 \sigma$ uncertainty. Following, a simple Rayleigh fractional crystallization of the carbonate magma would explain the linear trend enclosing the most of Salitre I carbonatites (Figure 5.25).

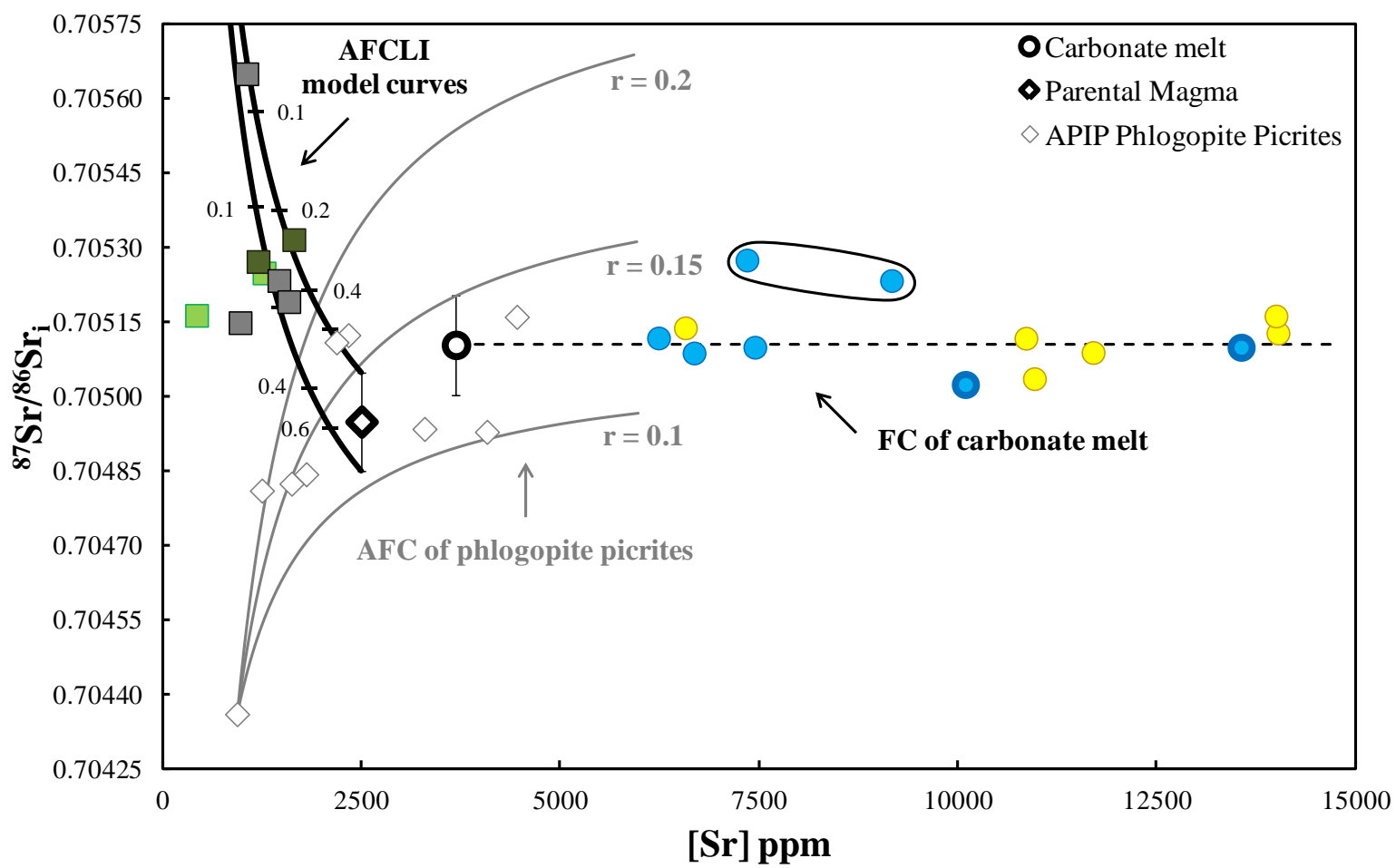

Figure 5.25. Plot of initial ${ }^{87} \mathrm{Sr} /{ }^{86} \mathrm{Sr}$ ratios versus $\mathrm{Sr}$ content of bebedourites and carbonatites from the Salitre I complex - symbols as in Figure 5.6. The continuous black lines represent the AFCLI model curves for the alkaline silicate rocks derived from the carbonated-silicate parental magma having ${ }^{87} \mathrm{Sr}^{86} \mathrm{Sr}_{\mathrm{i}}=0.70495 \pm 0.0001$ and $\mathrm{Sr}=2500 \mathrm{ppm}$. Contaminant composition is the average composition of the continental crust $\left({ }^{87} \mathrm{Sr} /{ }^{86} \mathrm{Sr}=0.72-\right.$ Hofmann, 1997; $\mathrm{Sr}=320 \mathrm{ppm}-$ Rudnick \& Gao, 2003). There are two AFCLI curves for a given starting composition, one each for maximum $(+1 \sigma)$ and minimum $(-1 \sigma)$ starting isotopic ratio. Ticks on the curve are $F$ (fraction of magma remaining) values. Grey lines are the AFC model curves at different r-values (see Figure 5.23) for the parental magma of the APIP carbonatite complexes. Dashed line is the fractional crystallization (FC) curve for the exsolved carbonate melt $\left({ }^{87} \mathrm{Sr} /{ }^{86} \mathrm{Sr}=0.705105 \pm 0.0001, \mathrm{Sr}=3688 \mathrm{ppm}\right)$. Model parameters: $\mathrm{D}_{\mathrm{C}}=0.52, \mathrm{D}_{\mathrm{L}}=1.96, \mathrm{a}=0.15, \mathrm{~b}=0.1$. 
It is important to note that a small degree of assimilation rate (the "a" parameter) is required at the same immiscibility rate (the " $b$ " parameter) for those two bebedourites samples not fitted well by the AFCLI model curves (Figure 5.25). This implies an even lower amount of crustal contamination $(\sim 2 \%)$. Likewise, the two magnesiocarbonatites above the Rayleigh fractional crystallization line could represent carbonate melts derived from different batches of more contaminated parental magma. The distinct $\mathrm{Sr}$ isotopic compositions obtained from the two carbonate varieties found on sample 20B-94 (Figure 5.5) are consistent with such separate batches of carbonatite magma. In addition, the decrease in initial $\mathrm{Sr}$ isotope ratios of the earlier crystallized phases toward the more evolved stages (Figure 5.14) definitely rules out differentiation in a single stage during the formation of Salitre I.

In spite of the straightforward modelling exhibited in Figure 5.25, which presumes only a single initial parental magma composition, AFCLI provides an outstanding model to explain the radiogenic isotopic heterogeneities observed in bebedourites and carbonatites of the Salitre I complex without the need for an isotopically heterogeneous mantle source, validating our preliminary proposition (Oliveira et al., 2014). Phoscorites were intentionally omitted from the model, since the current experimental knowledge does not allow reliable numerical modelling of these rocks. Nevertheless, Barbosa (2009) proposed an intricate petrogenetic model where the early B1 bebedourites and P1 phoscorites are genetic related through fractional crystallization and silicate-phosphate liquid immiscibility. Our $\mathrm{Sr}$ and $\mathrm{Nd}$ isotope data in minerals firmly supports the cogenetic relationship between B1 and P1. A similar connection is observed between $\mathrm{C} 3$ calciocarbonatites and P2 phoscorites, which are also interpreted as cogenetic, linked to each other by fractional crystallization and/or carbonate-phosphate liquid immiscibility (Barbosa, 2009). The more enriched isotope signatures of the B1 and P1 minerals when compared to C3 and P2 ones may be explained by their distinct origins. The former are associated with silicate melts whereas the latter crystallized from carbonate melts and, as predicted by the AFCLI model above, would have a less enriched isotopic composition.

Nd-Sr Isotope Decoupling and Mineral-Rock Nd Isotopic Disequilibrium: Evidence for Post-Magmatic Processes

The radiogenic isotope variations in carbonatites and alkaline silicate rocks from Salitre I are related to crustal contamination, as we demonstrated through AFCLI modelling and mineral isotopic data. The range of $\mathrm{Nd}$ isotopic ratios obtained for phoscorite mineral 
separates is consistent with that of the parental magmas (i.e., phlogopite picrites) and of bebedourites and carbonatites (Figure 5.26). However, phoscorites and several nelsonitic cumulates (i.e., P1, P2 and C3a units) have whole-rock Nd isotopic signatures clearly out of the silicate-carbonatite range (Figure 5.12 and Figure 5.26). In addition, major differences are noted between minerals and the whole-rock composition of their host phoscorite (Figure 5.17). This feature and the fact that such large mineral-rock disequilibrium was not found in $\mathrm{Sr}$ isotopes suggest that some subsolidus process overprinted the original $\mathrm{Nd}$ isotope signature of the Salitre I phoscorites, driving the whole-rock toward more enriched compositions.

Such mineral-rock Nd isotope disequilibrium could be due to accessory phases, chiefly those very rich in REE (e.g., pyrochlore, zirconolite, monazite, REE carbonates). If this was the case, such accessory minerals should have very distinct ${ }^{143} \mathrm{Nd} /{ }^{144} \mathrm{Nd}_{\mathrm{i}}$ in order to produce the observed average whole-rock composition. Contamination with zirconolite micro-crystals was detected in one of the apatite separates (sample SF101.5D1), but this yielded an identical $\mathrm{Nd}$ isotopic signature, within the error, to a further purified version of the same concentrate (Table 5.5). This implies that zirconolite, albeit a Nd-rich mineral, cannot account for the enriched ${ }^{143} \mathrm{Nd} /{ }^{144} \mathrm{Nd}_{\mathrm{i}}$ of the whole-rock sample.

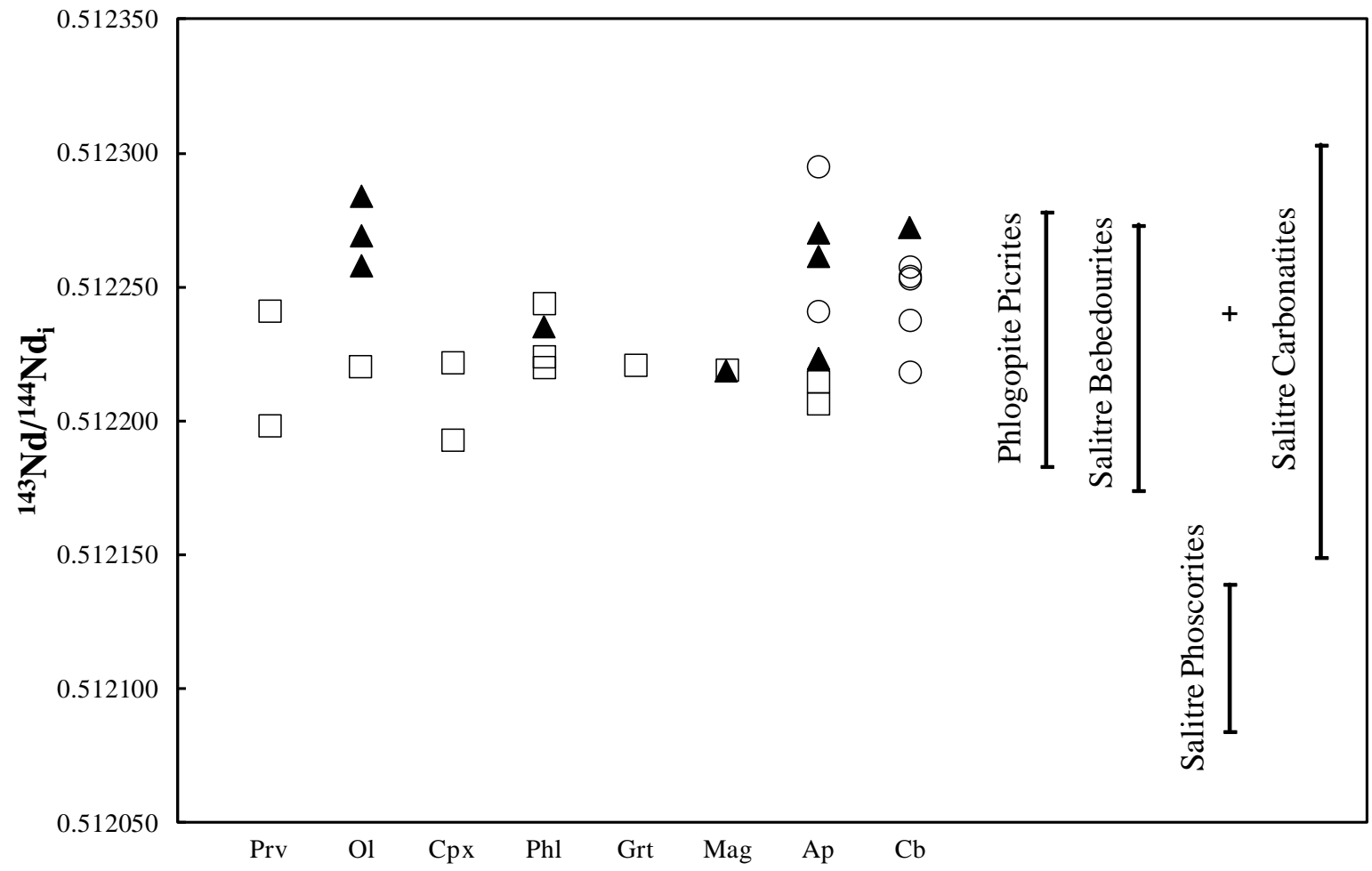

Figure 5.26. Nd isotope compositions from Salitre I minerals and rocks. Black cross is the sample FVL145A (P2). Black triangles - minerals from phoscorites, open squares - minerals from bebedourites and open circles - minerals from carbonatites. Vertical range bars - whole-rock. 
A common petrographic feature in almost all phoscorite samples is the partial or total replacement of olivine by clinohumite, which suggests late-stage interaction of the rock with hydrous, F-rich fluids. If metasomatic alteration changed the whole-rock $\mathrm{Nd}$ isotopes, it did not affect the set of minerals analysed individually (Figure 5.17), and is probably restricted to an unidentified accessory REE-rich phase, perhaps intergranular and too fined-grained to be recognized.

Several isotopic studies of postmagmatic alteration in alkaline-carbonatite complexes (Andersen, 1987; Simonetti \& Bell, 1995; Andrade et al., 1999; Bühn et al., 2003; Tichomirowa et al., 2006) have demonstrated that late-stage interaction with hydrothermal fluids can significantly change the primary $\mathrm{Sr}$ isotope signature of the plutonic rocks but trigger only minor modifications in $\mathrm{Nd}$ isotopes. This is the opposite of what is observed in Salitre I phoscorites. The decoupling between the $\mathrm{Nd}$ and $\mathrm{Sr}$ isotopic systems, together with the more enriched $\mathrm{Nd}$ (instead of $\mathrm{Sr}$ ) isotope signature suggests that late-stage alteration, in this case, probably involved a metasomatic carbonatite-derived fluid (e.g., by degassing).

\section{Mantle Source and Geodynamic Setting}

Carbonatites can be derived from either depleted or enriched mantle sources and can provide key information concerning the geochemical evolution of the sub-continental mantle (Bell, et al., 1982; Bell \& Blenkinsop, 1989; Bell \& Tilton, 2002). Radiogenic and noble gases isotopes from several carbonatite complexes worldwide revealed that most younger carbonatites (<200 Ma) have an isotopic systematics similar to OIBs (Bell \& Simonetti, 2010 and references therein), involving essentially HIMU, EM-I and FOZO mantle components (Zindler \& Hart, 1986; Hart, 1988; Hart et al., 1992; Hauri et al., 1994 - Figure 5.27). A MORB-type mantle component (DMM) does not appear to be involved in the origin of carbonatites albeit their often depleted isotopic composition (Bell \& Blenkinsop, 1989; Hoernle et al., 2002; Bell \& Simonetti, 2010).

The Salitre I complex exhibits significant isotope heterogeneities between different rock types and their minerals (inset in Figure 5.27). This study brings in substantial evidence showing that such variations are triggered by a magmatic evolution in open-system conditions, involving crustal assimilation, and maybe, late-stage metasomatic fluids. Interestingly, initial $\mathrm{Nd}$ and $\mathrm{Sr}$ isotope compositions of carbonatites and associated alkaline rocks clearly overlap, reflecting a derivation from the same mantle source. Although some 
minor crustal contamination has affected the carbonated-silicate parental magmas (i.e., phlogopite picrites) that formed Salitre I rocks, it is generally argued that the extremely high $\mathrm{Nd}$ and $\mathrm{Sr}$ contents of carbonate-rich melts virtually buffer them against such effects. This can be illustrated by the horizontal asymptotic nature of the curves in our mathematical modelling (Figure 5.23). Therefore, the composition of parental magmas and, so, that of the mantle source of Salitre I can be constrained by the most depleted carbonatite signatures. We obtained a very limited range of initial ${ }^{87} \mathrm{Sr} /{ }^{86} \mathrm{Sr}(0.704992-0.705089)$ and $\varepsilon_{\mathrm{Nd}}(\mathrm{T})$ values of 4.6 to -5.4 considering the $\mathrm{P} 2$ and $\mathrm{C} 3$ mineral data as the best representatives of the primary isotope composition of carbonate melts. These values plot within the enriched quadrant showing that carbonate-silicate parental magmas that gave rise to the Salitre I complex were derived from an enriched mantle source, isotopically similar to the EM-I mantle component (Figure 5.27). Stable isotopes of $\mathrm{P} 2$ phoscorites and $\mathrm{C} 3$ carbonatites $\left(\delta^{13} \mathrm{C}_{\mathrm{PDB}}=-6.69\right.$ to -7.74 $\%$ and $\delta^{18} \mathrm{O}_{\mathrm{SMOW}}=6.91$ to $10.61 \%$ - Barbosa et al., 2012c) show a relatively restricted range within the composition of primary carbonatites, supporting the mantle origin for their parental magmas.

Overall, alkaline ultrapotassic rocks (Gibson et al., 1995b) as well as other APIP carbonatites (Figure 5.27) show a tight clustering of enriched $\mathrm{Nd}$ and $\mathrm{Sr}$ isotope signatures closer to the EM-I mantle end-member, suggesting a common widespread mantle source beneath the APIP region. The strongly fractionated REE patterns, the very high amounts of incompatible trace elements and the enriched isotope compositions led Gibson et al. (1995b) to propose a subcontinental lithospheric mantle source previously metasomatized as the source of APIP magmas. Additional evidence in favour of a lithospheric source come from Re-Os isotope studies of Carlson et al. (2007). Those authors established that the source regions of APIP magmatism required an enriched component in order to reproduce the high ${ }^{187} \mathrm{Os} /{ }^{188} \mathrm{Os}_{\mathrm{i}}$ found in kamafugites. Consequently, the source of APIP mantle-derived rocks should be the old lithospheric mantle beneath the São Francisco Craton composed of depleted peridotites (Carlson et al., 2007) that were extensively veined after the infiltration of metasomatic melts or fluids. Although feasible, it is unlikely that this metasomatism have been occurred at the time of Paraná flood-basalt volcanism ( 130Ma) since an unrealistic high $\mathrm{Re} / \mathrm{Os}$ ratios would be needed to explain the Os isotope composition of kamafugitic rocks (Carlson et al., 2007). Nd depleted mantle model ages $\left(\mathrm{T}_{\mathrm{DM}}\right) \sim 1.0 \mathrm{Ga}$ suggest that the mantle metasomatism occurred during the mid to late Proterozoic (Gibson et al. 1995b, Araújo et al., 2001; Carlson et al., 1996; 2007). 
Interestingly, mantle-derived rocks of the entire APIP show normalized trace-element patterns that lack relative depletions in $\mathrm{Nb}$ and $\mathrm{Ta}$, which suggests that the enrichment in the underlying subcontinental lithospheric mantle in incompatible elements was not associated with subduction fluids or melts (Gibson et al., 1995b). Moreover, metasomatism in subduction zones often has short time residence in the above mantle (Faure, 2001 p. 342), which contrasts with the long interval between $\mathrm{T}_{\mathrm{DM}}$ and emplacement ages in the APIP (i.e., $\sim 1.0 \mathrm{Ga}$ and $85 \mathrm{Ma}$, respectively). Vladykin et al. (2004; 2005) proposed that different geodynamic settings where alkaline rocks and carbonatites are generated exhibit singular mantle compositions. According to them, alkaline-carbonatite complexes with EM-I characteristics occur in intracontinental rift zones marginally to the shields or on the shields themselves, which agrees well with the aforementioned position of the APIP in relation to the São Francisco Craton.

Despite the general agreement about the subcontinental lithospheric mantle source, there is still considerable controversy with respect to the geodynamic conditions that triggered the APIP magmatism. Gibson et al. (1995b) postulated a model where the Trindade mantle plume contributes solely as a heat source for melting of volatile-rich parts of the overlying metasomatized lithospheric mantle. Such model has been criticized on the account that the APIP magmas have isotopic similarity with those from Tristan da Cunha plume instead of Trindade, and that of a clear progressive eastward age decrease is lacking (e.g., CominChiaramonti et al., 2005; Knesel et al., 2011; Guarino et al., 2012).

However, Thompson et al. (1998) argued that an eastward age-decreasing pattern is actually present in the Serra do Mar Alkaline Province, to the southeast of the APIP, if K-Ar ages are screened for stoichiometric $\mathrm{K}_{2} \mathrm{O}$ in the analysed micas. On the other hand, the Poxoréu Igneous Province (PIP), located to the west of the APIP and emplaced at the same age ( $~ 84 \mathrm{Ma}$ ) shows isotopic compositions akin to the Trindade plume (Gibson et al., 1997), suggesting that, in the PIP region, lithospheric thinning was enough to allow the plume material to melt. In addition, the present-day composition of Tristan lavas are believed to be contaminated by metasomatized subcontinental lithospheric mantle delaminated from southeast Brazil and south-west Africa during the break-up of Gondwana (Bizzi et al., 1995; Carlson et al., 1996; Gibson et al., 2005). These evidence together with additional seismic data (Assumpção et al., 2004; Schimmel et al., 2003), provides support for the plume model in the APIP. 


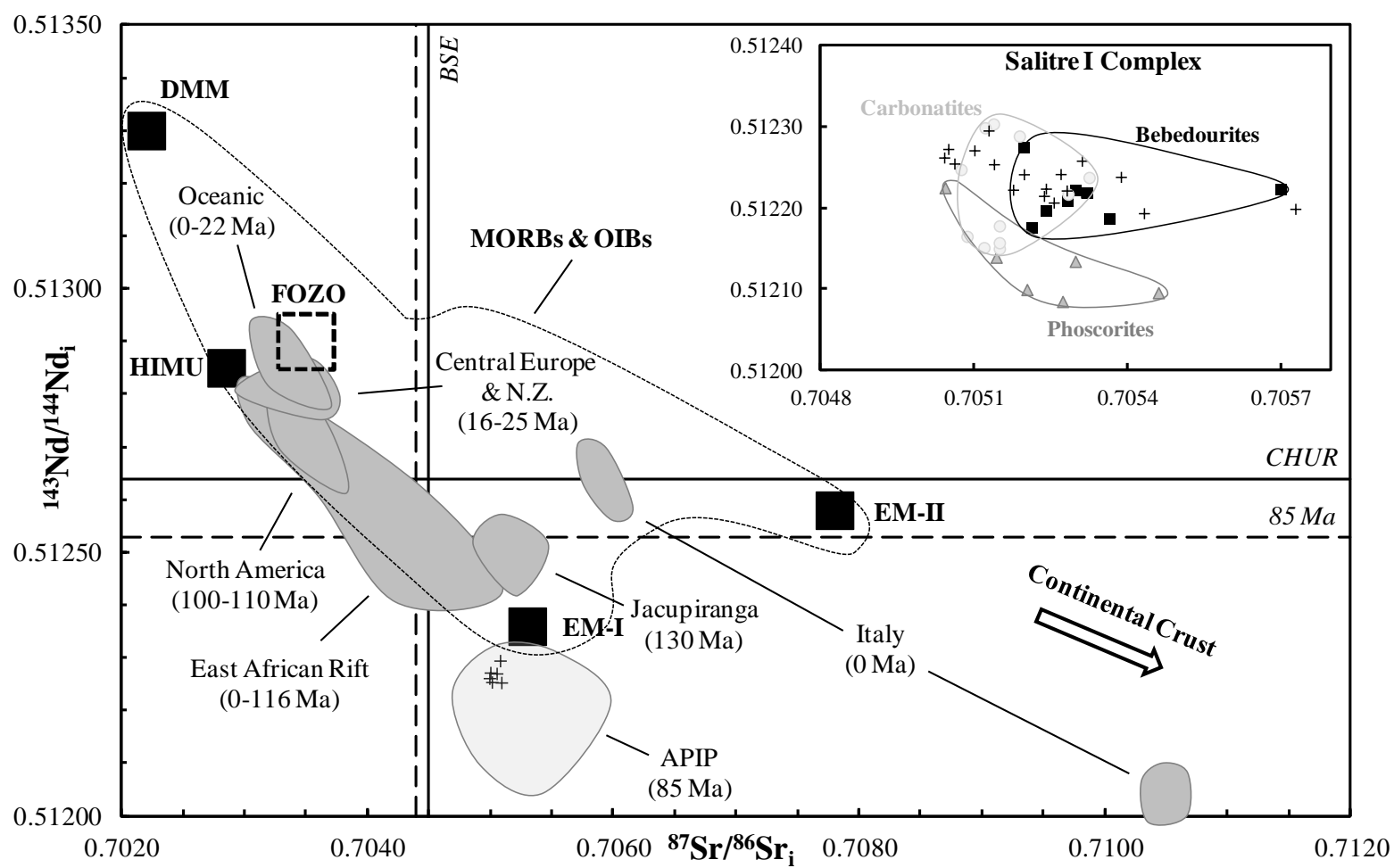

Figure 5.27. Comparison of initial Nd and $\mathrm{Sr}$ isotopic ratios of the APIP carbonatites with other young (<200 Ma) carbonatites worldwide. Crosses in the APIP field show the most likely composition of Salitre I carbonate melts (see text for details). Arrow indicate the average composition of the continental crust $\left({ }^{87} \mathrm{Sr} /{ }^{86} \mathrm{Sr}=0.720 ;{ }^{143} \mathrm{Nd} /{ }^{144} \mathrm{Nd}=\mathbf{0 . 5 1 1 8}\right.$ - Hofmann, 1997). Dashed lines show the model values of BSE (Bulk Silicate Earth) and CHUR (Chondritic Uniform Reservoir) calculated at 100 Ma. DMM, HIMU, EM-I e EM-II are mantle end-member components from Hart et al. (1992). FOZO is from Hauri et al. (1994). Data source: APIP - Gomes \& Comin-Chiaramonti (2005), Cordeiro et al. (2011), Barbosa et al. (2012a) and unpublished data from Brod (1999), Barbosa (2009), Grasso (2010), Oliveira (2015); East African Rift - Bell \& Blenkinsop (1987a), Nelson et al. (1988); Italy - Castorina et al. (2000), Rosatelli et al. (2007); Oceanic - Hoernle et al. (2002); Jacupiranga - Roden et al. (1985), Nelson et al. (1988), Huang et al. (1995); North America - Bell \& Blenkinsop (1987b), Tilton et al. (1987), Wen et al. (1987), Nelson et al. (1988); Central Europe \& New Zealand - Barreiro \& Copper (1987), Nelson et al. (1988). All data plotted are initial ratios. APIP data were recalculated at 85 Ma using decay constants $\lambda^{87}$ Rb and $\lambda^{147}{ }_{S m} 0$ of $1.393 \times 10$ ${ }^{11} \mathrm{yr}^{-1}$ e $6.54 \times 10^{-12} \mathrm{yr}^{-1}$, respectively. Inset shows detailed variation of initial $\mathrm{Nd}$ and $\mathrm{Sr}$ isotopic ratios for the mineral separates (black crosses), and for bebedourites (black squares), phoscorites (grey triangles) and carbonatites (light grey circles) of the Salitre I complex.

\subsection{CONCLUSIONS}

This study shows the importance of detailed isotopic work for alkaline-carbonatite complexes, mainly those where whole-rock $\mathrm{Nd}$ and $\mathrm{Sr}$ isotopic ratio variations are observed. The $\mathrm{Nd}$ and $\mathrm{Sr}$ isotope investigations in several mineral separates from the Salitre I alkalinephoscorite-carbonatite complex allowed us to identify significant $\mathrm{Sr}$ isotopic disequilibrium between minerals of the same rock sample and mineral-rock $\mathrm{Nd}$ isotopic disequilibrium. These features set up new constraints for the magmatic evolution of the Salitre I complex, and, combined with other evidence (e.g., the lack of whole-rock isochron ages), indicate that the entire differentiation of this complex occurred under open-system behaviour. 
Mineral isotope data obtained here reveal that whole-rock isotope analyses in the Salitre I complex represent only a weighted average isotope composition of the different minerals. The primary isotopic signature of the magmas is best represented by the earlycrystallized phases, such as apatite. Furthermore, the correlation of the mineral Sr isotopic disequilibrium with the crystallization order of mineral phases strongly suggests that assimilation occurred concurrently with fractional crystallization. Through mathematical modelling (AFCLI), we demonstrated that minor crustal contamination $(<10 \%)$ coupled with fractional crystallization and liquid immiscibility from a carbonated-silicate parental magma (i.e., phlogopite picrite) could explain the radiogenic isotopic heterogeneities observed in whole-rock data of Salitre I bebedourites and carbonatites. $\mathrm{Nd}$ isotope variations in the phoscoritic rocks (i.e., phoscorites and nelsonitic cumulates) are most likely related to latestage alteration of these rocks by a metasomatic fluid. Our results show that it is not necessary to invoke isotopically heterogeneous mantle sources to explain the genesis of Salitre I.

The enriched $\mathrm{Nd}$ and $\mathrm{Sr}$ isotope signatures of uncontaminated phlogopite picrites at regional scale together with the restricted range of initial ${ }^{87} \mathrm{Sr} /{ }^{86} \mathrm{Sr}(0.704992-0.705089)$ and $\varepsilon_{\mathrm{Nd}}(\mathrm{T})$ values of -4.6 to -5.4 obtained for carbonate melts indicate that the Salitre I complex was formed by carbonate-silicate parental magmas derived from a subcontinental mantle source with isotopic composition akin to the EM-I mantle component. $\mathrm{T}_{\mathrm{DM}} \mathrm{Nd}$ isotope model ages suggest that lithospheric mantle beneath the APIP region was metasomatized in the mid to late Proterozoic.

\section{Acknowledgements}

The authors are grateful to the University of Brasília for access to analytical facilities, in special those at the Laboratory of Geodynamics, Geochronology and Environmental Studies of the Institute of Geosciences. This research was financially supported by Brazilian funding agencies CNPq and CAPES. The first author thanks all members of the lab for their help and patience with the analytical work. 


\section{References}

Almeida F.F.M. (1983). Relações tectônicas das rochas alcalinas mesozóicas da região meridional da Plataforma Sul-Americana. Revista Brasileira de Geociências 13: 139158 (in Portuguese).

Almeida F.F.M. \& Svisero, D.P. (1991). Structural setting and tectonic control of kimberlite and associated rocks of Brazil. In: Fifth International Kimberlite Conference 1991, Araxá, Brazil (Extended Abstracts). pp. 3-5.

Andersen, T. (1987). Mantle and crustal components in a carbonatite complex, and the evolution of carbonatite magma: REE and isotopic evidence from the Fen Complex, Southeast Norway. Chemical Geology 65: 147-166.

Andrade, F.R.D., Möller, P. \& Höhndorf, A. (1999). The effect of hydrothermal alteration on the $\mathrm{Sr}$ and $\mathrm{Nd}$ isotopic signatures of the Barra do Itapirapuã carbonatite, Southern Brazil. Journal of Geology 107: 177-191.

Andres, U. (1996). Disintegration of rock by tension. Resource Processing 43: 122-135.

Araújo, A.L.N., Carlson, R.W., Gaspar, J.C. \& Bizzi, L.A. (2001). Petrology of kamafugites and kimberlites from the Alto Paranaíba Alkaline Province, Minas Gerais, Brazil. Contributions to Mineralogy and Petrology 142: 163-177.

Assumpção, M., Escalante, C.\& Schimmel, M. (2002). Initial impact of the Trindade plume, Goiás, revealed by seismic tomography? In: II Simpósio sobre Vulcanismo e Ambientes Associados 2002, Belém do Pará, Brasil (Abstracts). p. 77.

Assumpção, M., Schimmel, M., Escalante, C., Barbosa, J.R., Rocha, M. \& Barros, L.V. (2004). Intraplate seismicity in SE Brazil: stress concentration in lithospheric thin spots. Geophys. J. Int. 159: 390-399.

Bailey, D.K. (1993). Carbonate magmas. Journal of the Geological Society, London 150: 637651.

Barbosa, E.S.R. (2009). Mineralogia e petrologia do complexo carbonatítico-foscorítico de Salitre, MG. Unpublished Ph.D. Thesis, Universidade de Brasília, Brazil. 257 pp. 
Barbosa E.S.R., Brod J.A., Junqueira-Brod T.C., Dantas E.L., Cordeiro P.F.O. \& Gomide C.S. (2012a). Bebedourite from its type area (Salitre I complex): A key petrogenetic series in the Late-Cretaceous Alto Paranaíba kamafugite-carbonatite-phoscorite association, Central Brazil. Lithos 144-145: 56-72.

Barbosa E.S.R., Brod J.A., Junqueira-Brod T.C., Cordeiro P.F.O., Santos, R.V. \& Dantas E.L., (2012b). Phoscorites from the Salitre alkaline complex, Brazil: Origin and petrogenetic implications. In: $10^{\text {th }}$ International Kimberlite Conference 2012, Bangalore, India (Extended Abstracts). p. 10IKC-229.

Barbosa, E.S.R., Brod, J.A., Junqueira-Brod, T.C., Cordeiro, P.F.O., Dantas, E.L. \& Santos, R.V. (2012c). Mineralogy and petrology of the Salitre I phoscorite-carbonatitealkaline complex, Brazil. In: $10^{\text {th }}$ International Kimberlite Conference 2012, Bangalore, India (Extended Abstracts). p. 10IKC-293.

Barbosa, E.S.R., Brod, J.A., Cordeiro, P.F.O. \& Junqueira-Brod, T.C. (2012d). Variações composicionais de olivinas do complexo alcalino-carbonatítico de Salitre, MG. Revista Brasileira de Geociências 42(4): 729-743.

Barreiro, B.A. \& Cooper, A.F. (1987). A $\mathrm{Sr}, \mathrm{Nd}$ and $\mathrm{Pb}$ isotope study of alkaline lamprophyres and related rocks from Westland and Otago, South Island, New Zealand. In: Mantle metasomatism and alkaline magmatism, Morris, E.M. \& Pasteris, J.D., Editors. Geological Society of America Special Paper 215: 115-125.

Bell, K. (1998). Radiogenic isotope constraints on relationships between carbonatites and associated silicate rocks - A brief review. J. Petrology 39(11-12): 1987-1996.

Bell, K. (2001). Glimpses into the crystallization history of carbonatitic melts - An isotopic approach. In: EUG XI Meeting 2001, Strasbourg, France (Abstract Symposium VPP4). p. 810 .

Bell, K. \& Blenkinsop, J. (1987a). Nd and Sr isotopic compositions of East African carbonatites: Implications for mantle heterogeneity. Geology 15: 99-102.

Bell, K. \& Blenkinsop, J. (1987b). Archean depleted mantle: Evidence from Nd and Sr initial isotopic ratios of carbonatites. Geochim. Cosmochim. Acta 51: 291-298. 
Bell, K. \& Blenkinsop, J. (1989). Neodymium and strontium isotope geochemistry of carbonatites. In: Carbonatites: Genesis and Evolution, K. Bell, Editor. Unwin Hynman, London, pp. 278-300.

Bell, K., Blenkinsop, J., Cole, T.J.S. \& Menagh, D.P. (1982). Evidence from Sr isotopes for long-lived heterogeneities in the upper mantle. Nature 298: 251-253.

Bell, K., Kjarsgaard, B.A. \& Simonetti, A. (1998). Carbonatites into the Twenty-First century. J. Petrology 39(11-12): 1839-1845.

Bell, K. \& Tilton, G.R. (2002). Probing the mantle: The story from carbonatites. EOS, Transactions, American Geophysical Union. 83(25): 273-280.

Bell, K. \& Rukhlov, A.S. (2004). Carbonatite from the Kola Alkaline Province: origin, evolution and source characteristics. In: Phoscorites and Carbonatites from Mantle to Mine - the Key Example of the Kola Alkaline Province, F. Wall, and A.N. Zaitsev, Editors. Mineralogical Society Series, pp. 433-468.

Bell, K. \& Simonetti, A. (2010). Source of parental melts to carbonatites - critical isotopic constraints. Miner. Petrol. 98: 77-89.

Berglund, M. \& Wieser, M.E. (2011). Isotopic compositions of the elements 2009 (IUPAC Technical Report). Pure Appl. Chem. 83(2): 397-410.

Bizzarro, M. Simonetti, A., Stevenson, R.K. \& Kurszlaukis, S. (2003). In situ ${ }^{87} \mathrm{Sr} /{ }^{86} \mathrm{Sr}$ investigation of igneous apatites and carbonates using laser-ablation MC-ICP-MS. Geochim. Cosmochim. Acta 67(2): 289-302.

Bizzi, L.A., Smith, C.B., Wit, M.J., Armstrong, R.A. \& Meyer, H.O.A. (1994). Mesozoic kimberlites and related alkalic rocks in the south-western São Francisco Craton, Brazil: a case for local mantle reservoirs and their interaction. In: Proceedings of the Fifth International Kimberlite Conference 1991, Araxá, Brazil. pp. 156-171.

Bizzi, L.A., Wit, M.J., Smith, C.B., McDonald, I. \& Armstrong, R.A. (1995). Heterogeneous enriched mantle materials and DUPAL-type magmatism along the SW margin of the São Francisco Craton, Brazil. J. Geodynamics 20(4): 469-491. 
Brod, J.A. (1999). Petrology and geochemistry of the Tapira alkaline complex, Minas Gerais State, Brazil. Doctoral Thesis, Durham University. 486 pp. Available at Durham ETheses Online: http://etheses.dur.ac.uk/4971/

Brod, J.A., Gibson, S.A., Thompson, R.N., Junqueira-Brod, T.C., Seer, H.J., Moraes, L.C. \& Boaventura, G.R., (2000). The kamafugite-carbonatite association in the Alto Paranaíba Igneous Province (APIP) southeastern Brazil. Revista Brasileira de Geociências 30(3): 408-412.

Brod, J.A., Ribeiro, C.C., Gaspar, J.C., Junqueira-Brod, T.C., Barbosa, E.S.R., Riffel, B.F., Silva, J.F., Chaban, N. \& Ferrari, A.J.D. (2004). Excursão 1: Geologia e mineralizações dos complexos alcalino-carbonatíticos da Província Ígnea do Alto Paranaíba. Congresso Brasileiro de Geologia, XLII, Araxá, MG, (Field Guide Book). Sociedade Brasileira de Geologia, São Paulo. 29 pp.

Brod, J.A., Junqueira-Brod, T.C., Gaspar, J.C., Petrinovic, I.A., Valente, S.C. \& Corval, A. (2012). Decoupling of paired elements, crossover REE patterns, and mirrored spider diagrams: Fingerprinting liquid immiscibility in the Tapira alkaline-carbonatite complex, SE Brazil. Journal of South American Earth Sciences doi: 10.1016/j.jsames.2012.04.013.

Brooker, R.A. \& Kjarsgaard, B.A. (2011). Silicate-carbonate liquid immiscibility and phase relations in the system $\mathrm{SiO}_{2}-\mathrm{Na}_{2} \mathrm{O}-\mathrm{Al}_{2} \mathrm{O}_{3}-\mathrm{CaO}-\mathrm{CO}_{2}$ at $0.1-2.5 \mathrm{GPa}$ with applications to carbonatite genesis. J. Petrology 52(7-8): 1281-1305.

Bühn, B. \& Trumbull, R.B. (2003). Comparison of petrogenetic signatures between mantlederived alkali silicate intrusives with and without associated carbonatite, Namibia. Lithos 66: 201-221.

Bühn, B., Schneider, J., Dulski, P. \& Rankin, A.H. (2003). Fluid-rock interaction during progressive migration of carbonatitic fluids, derived from small-scale trace element and $\mathrm{Sr}, \mathrm{Pb}$ isotope distribution in hydrothermal fluorite. Geochim. Cosmochim. Acta 67(23): 4577-4595.

Campos J.E.G. \& Dardenne M.A. (1997). Origem e evolução tectônica da bacia Sanfranciscana. Revista Brasileira de Geociências 27(3): 283-294 (in Portuguese). 
Carlson, R.W., Esperança, S. \& Svisero, D.P. (1996). Chemical and Os isotopic study of Cretaceous potassic rocks from Southern Brazil. Contributions to Mineralogy and Petrology 125: 393-405.

Carlson, R.W., Araújo, A.L.N., Junqueira-Brod, T.C., Gaspar, J.C., Brod, J.A., Petrinovic, I.A., Hollanda, M.H.B.M., Pimentel, M.M. \& Sichel, S. (2007). Chemical and isotopic relationships between peridotite xenoliths and mafic-ultrapotassic rocks from Southern Brazil. Chemical Geology 242: 415-434.

Castorina, F., Stoppa, F., Cundari, A. \& Barbieri, M. (2000). An enriched mantle source for Italy's melilitite-carbonatite association as inferred by its $\mathrm{Nd}-\mathrm{Sr}$ isotope signature. Mineralogical Magazine 64(4): 625-639.

Chakhmouradian, A.R., Reguir, E.P., Kamenetsky, V.S., Sharygin, V.V.\& Golovin, A.V. (2013). Trace-element partitioning in perovskite: Implications for the geochemistry of kimberlites and other mantle-derived undersaturated rocks. Chemical Geology 353: $112-131$.

Comin-Chiaramonti, P., Gomes, C.B., Marques, L.S., Censi, P., Ruberti, E. \& Antonini, P. (2005). Carbonatites from southeastern Brazil: Geochemistry, O-C, Sr-Nd-Pb isotopes and relationship with the magmatism from the Paraná-Angola-Namibia province. In: Mesozoic to Cenozoic Alkaline Magmatism in the Brazilian Platform, CominChiaramonti, P. \& Gomes, C.B., Editors. Edusp/Fapesp, São Paulo, pp. 657-688.

Cordeiro, P.F.O., Brod, J.A., Dantas, E.L. \& Barbosa, E.S.R. (2010). Mineral chemistry, isotope geochemistry and petrogenesis of niobium-rich rocks from the Catalão I carbonatite-phoscorite complex, Central Brazil. Lithos 118: 223-237.

Cordeiro, P.F.O., Brod, J.A., Santos, R.V., Oliveira, C.G. \& Barbosa, E.S.R. (2011). Stable $(\mathrm{C}, \mathrm{O})$ and radiogenic $(\mathrm{Sr}, \mathrm{Nd})$ isotopes of carbonates as indicators of magmatic and postmagmatic processes of phoscorite-series rocks and carbonatites from Catalão I, central Brazil. Contributions to Mineralogy and Petrology 161: 451-464.

Crough, S.T., Morgan, W.J. \& Hargraves, R.B. (1980). Kimberlites: their relation to mantle hotspots. Earth and Planetary Sci. Letters 50: 260-274. 
Dalla Costa, M.M. (2012). Petrografia e geoquímica isotópica Sm-Nd em xenólitos mantélicos do kimberlito Canastra-01. Unpublished MSc Thesis, Universidade de Brasília, Brazil. 125 pp.

Danni, J.C.M., Baecker, M.L. \& Ribeiro, C.C. (1991). The geology of the Catalão I carbonatite complex. In: Fifth International Kimberlite Conference 1991, Araxá, Brazil (Field Guide Book). pp. 25-30.

Dawson, J.B. (1962). Sodium carbonate lavas from Oldoinyo Lengai, Tanganyika. Nature 195: 1075-1076.

Dawson, J.B., Steele, I.M., Smith, J.V. \& Rivers, M.L. (1996). Minor and trace element chemistry of carbonates, apatites and magnetites in some African carbonatites. Mineralogical Magazine 60: 415-425.

Dawson, J.B. \& Hinton, R.W. (2003). Trace-element content and partitioning in calcite, dolomite and apatite in carbonatite, Phalaborwa, South Africa. Mineralogical Magazine 67(5): 921-930.

DePaolo, D.J. \& Wasserburg, G.J. (1976). Nd isotopic variations and petrogenetic models. Geophys. Res. Letters 3(5): 249-252.

DePaolo, D.J. (1981a). Neodymium isotopes in the Colorado Front Range and crust-mantle evolution in the Proterozoic. Nature 291: 193-196.

DePaolo, D.J. (1981b). Trace element and isotopic effects of combined wallrock assimilation and fractional crystallization. Earth and Planetary Sci. Letters 53: 189-202.

Downes, H., Wall, F., Demény, A. \& Szabo, Cs. (2012). Continuing the carbonatite controversy. Mineralogical Magazine 76(2): 255-257.

Dunworth, E.A. \& Bell, K. (2001). The Turiy Massif, Kola Peninsula, Russia: Isotopic and geochemical evidence for multi-source evolution. J. Petrology 42(2): 377-405.

Eby, G.N., Lloyd, F.E., Woolley, A.R., Stoppa, F. \& Weaver, S.D. (2003). Geochemistry and mantle source(s) for carbonatitic and potassic lavas, Western Branch of the East African Rift system, SW Uganda. Geolines 15: 23-27. 
Eggler, D.H. (1989). Carbonatites, primary melts, and mantle dynamics. In: Carbonatites: Genesis and Evolution, K. Bell, Editor. Unwin Hynman, London, pp. 561-579.

Eriksson, S.C. (1989). Phalaborwa: A saga of magmatism, metasomatism and miscibility. In: Carbonatites: Genesis and Evolution, K. Bell, Editor. Unwin Hynman, London, pp. 221-254.

Ernesto, M. (2005). Paleomagnetism of the post-Paleozoic alkaline magmatism in the Brazilian platform: Questioning the mantle plume model. In: Mesozoic to Cenozoic Alkaline Magmatism in the Brazilian Platform, Comin-Chiaramonti, P. \& Gomes, C.B., Editors. Edusp/Fapesp, São Paulo, pp. 689-705.

Faure, G. \& Powell, J.L. (1972). Strontium Isotope Geology. Springer-Verlag, Heidelberg. $188 \mathrm{pp}$.

Faure, G. (2001). Origin of Igneous Rocks - The Isotopic Evidence. Springer-Verlag, Heidelberg. 496 pp.

Foley, S.F., Jackson, S.E., Fryer, B.J., Greenough, J.D. \& Jenner, G.A. (1996). Trace element partition coefficients for clinopyroxene and phlogopite in an alkaline lamprophyre from Newfoundland by LAM-ICP-MS. Geochim. Cosmochim. Acta 60(4): 629-638.

Gibson, S.A., Thompson, R.N., Dickin, A.P. \& Leonardos, O.H. (1995a). High-Ti and low-Ti mafic potassic magmas: Key to plume-lithosphere interactions and continental floodbasalt genesis. Earth and Planetary Sci. Letters 136: 149-165.

Gibson, S.A., Thompson, R.N., Leonardos, O.H., Dickin, A.P. \& Mitchell, J.G. (1995b). The Late Cretaceous impact of the Trindade mantle plume: Evidence from large-volume, mafic, potassic magmatism in SE Brazil. J. Petrology 36(1): 189-229.

Gibson, S.A., Thompson, R.N., Weska, R.K., Dickin, A.P. \& Leonardos, O.H. (1997). Late Cretaceous rift-related upwelling and melting of the Trindade starting mantle plume head beneath western Brazil. Contributions to Mineralogy and Petrology 126: 303314.

Gibson, S.A. Thompson, R.N., Day, J.A., Humphris, S.E. \& Dickin, A.P. (2005). Meltgeneration processes associated with the Tristan mantle plume: Constraints on the origin of EM-1. Earth and Planetary Sci. Letters 237: 744-767. 
Giese, J., Seward, D., Stuart, F.M., Wüthrich, E., Gnos, E., Kurz, D., Eggenberger, U. \& Schreurs, G. (2010). Electrodynamic disaggregation - Does it affect apatite fissiontrack and (U-Th)/He analyses? Geostand. Geoanal. Res. 34(1): 39-48.

Gioia, S.M.C.L. \& Pimentel, M.M. (2000). The Sm-Nd isotopic method in the geochronology laboratory of the University of Brasília. Anais Academ. Bras. Ciências 72(2): 219-145.

Gittins, J. \& Harmer, R.E. (2003). Myth and reality in the carbonatite-silicate rock “association”. Per. Mineral. 72: 19-26.

Gnos, E., Kurz, D., Leya, I. \& Eggenberger, U. (2007). Electrodynamic disaggregation of geologic material. In: Goldschmidt Conference 2007, Cologne, Germany (Abstracts). p. A331.

Grasso, C.B. (2010). Petrologia do complexo alcalino-carbonatítico de Serra Negra, MG. Unpublished MSc Thesis, Universidade de Brasília, Brazil. 156 pp.

Guarino, V., Wu, F.Y., Lustrino, M., Melluso, L., Brotzu, P., Gomes, C.B., Ruberti, E., Tassinari, C.C.G. \& Svisero, D.P. (2012). U-Pb ages, Sr-Nd isotope geochemistry, and petrogenesis of kimberlites, kamafugites and phlogopite-picrites of the Alto Paranaíba Igneous Province, Brazil. Chemical Geology doi: 10.1016/j.chemgeo.2012.06.016

Guo, P., Niu, Y. \& Yu, X. (2014). A synthesis and new perspective on the petrogenesis of kamafugites from West Qinling, China, in a global context. Journal of Asian Earth Sciences 79: 86-96.

Hamilton, D.L., Bedson, P. \& Esson, J. (1989). The behavior of trace elements in the evolution of carbonatites. . In: Carbonatites: Genesis and Evolution, K. Bell, Editor. Unwin Hynman, London, pp. 405-427.

Harmer, R.E. \& Gittins, J. (1998). The case for primary, mantle-derived carbonatite magma. J. Petrology 39(11-12): 1895-1903.

Hart, S.R. (1988). Heterogeneous mantle domains: signatures, genesis and mixing chronologies. Earth and Planetary Sci. Letters 90: 273-296.

Hart, S.R., Hauri, E.H., Oschmann, L.A. \& Whitehead, J.A. (1992). Mantle plumes and entrainment: Isotopic evidence. Science 256: 517-520. 
Hauri, E.H., Whitehead, J.A. \& Hart, S.R. (1994). Fluid dynamic and geochemical aspects of entrainment in mantle plumes. Journal of Geophysical Research 99: 24275-24300.

Hawkesworth, C.J., Mantovani, M.S.M., Taylor, P.N. \& Palacz, Z. (1986). Evidence from the Paraná of south Brazil for a continental contribution to Dupal basalts. Nature 322: 356-359.

Herz, N. (1977). Timing of spreading in the South Atlantic: Information from Brazilian alkalic rocks. Geological Society of America Bulletin 88: 101-112.

Hofmann, A.W. (1997). Mantle geochemistry: the message from oceanic volcanism. Nature 385: 219-229.

Hoernle, K., Tilton, G., Le Bas, M.J., Duggen, S. \& Garbe-Schönberg, D. (2002). Geochemistry of oceanic carbonatites compared with continental carbonatites: mantle recycling of oceanic crustal carbonate. Contributions to Mineralogy and Petrology 142: $520-542$.

Huang, Y.-M., Hawkesworth, C.J., van Calsteren, P. \& McDermott, F. (1995). Geochemical characteristics and origin of the Jacupiranga carbonatites, Brazil. Chemical Geology 119: 79-99.

Jones, J.H., Walker, D., Pickett, D.A., Murrell, M.T. \& Beattie, P. (1995). Experimental investigations of the partitioning of $\mathrm{Nb}, \mathrm{Mo}, \mathrm{Ba}, \mathrm{Ce}, \mathrm{Pb}, \mathrm{Ra}, \mathrm{Th}, \mathrm{Pa}$ and $\mathrm{U}$ between immiscible carbonate and silicate liquids. Geochim. Cosmochim. Acta 59(7): 13071320.

Kerr, A.C., Kempton, P.D. \& Thompson, R.N. (1995). Crustal assimilation during turbulent magma ascent (ATA): new isotopic evidence from the Mull Tertiary lava succession, N.W. Scotland. Contributions to Mineralogy and Petrology 119: 142-154.

Knesel, K.M., Souza, Z.S., Vasconcelos, P.M., Cohen, B.E. \& Silveira, F.V. (2011). Young volcanism in the Borborema Province, NE Brazil, show no evidence for a trace of the Fernando de Noronha plume on the continent. Earth and Planetary Sci. Letters 302: $38-50$

Langmuir, C.H., Vocke, R.D., Hanson, G.N. \& Hart, S.R. (1978). A general mixing equation with applications to Icelandic Basalts. Earth and Planetary Sci. Letters 37: 380-392. 
Lavecchia, G., Stoppa, F. \& Creati, N. (2006). Carbonatites and kamafugites in Italy: mantlederived rocks that challenge subduction. Annals of Geophysics, Supplement 49(1): 389-402.

Lee, W.-J. \& Wyllie, P.J. (1998). Processes of crustal carbonatite formation by liquid immiscibility and differentiation, elucidated by model systems. J. Petrology 39(1112): 2005-2013.

Le Maitre, R.W., (2002). Igneous Rocks: A classification and glossary of terms. Recommendations of the International Union of Geological Sciences Subcommission on the Systematics of Igneous Rocks. $2^{\text {nd }}$ Edition. Cambridge University Press, New York. 236pp.

Le Roex, A.P. \& Lanyon, R. (1998). Isotope and trace element geochemistry of Cretaceous Damaraland lamprophyres and carbonatites, NW Namibia: Evidence for plumelithosphere interactions. J. Petrology 39(6): 1117-1146.

Leonardos, O.H. \& Meyer, H.O.A. (1991). Outline of the geology of Western Minas Gerais. In: Fifth International Kimberlite Conference 1991, Araxá, Brazil (Field Guide Book). pp. 17-24.

Leonardos, O.H., Ulbrich, M.N. \& Gaspar, J.C. (1991). The Mata da Corda volcanic rocks. In: Fifth International Kimberlite Conference 1991, Araxá, Brazil (Field Guide Book). pp. 65-73.

Lloyd, F.E. \& Bailey, D.K. (1994). Complex mineral textures in bebedourite: Possible links with alkali clinopyroxenite xenoliths and kamafugitic volcanism. In: Proceedings of the Fifth International Kimberlite Conference 1991, Araxá, Brazil. pp. 263-269.

Lloyd, F.E., Woolley, A.R., Stoppa, F. \& Eby, N.G. (1999). Rift Valley Magmatism - is there Evidence for laterally variable alkali clinopyroxenite mantle? Geolines 9: 76-83.

Ludwig, K.R. (2008). User's manual for Isoplot 3.70 - A geochronological toolkit for Microsoft ${ }^{\circledR}$ Excel. Berkeley Geochronological Center Special Publication 4, pp. 76.

Machado, N., Brooks, C. \& Hart, S.R. (1986). Determination of initial ${ }^{87} \mathrm{Sr} /{ }^{86} \mathrm{Sr}$ and ${ }^{143} \mathrm{Nd} /{ }^{144} \mathrm{Nd}$ in primary minerals from mafic and ultramafic rocks: Experimental 
procedure and implications for the isotopic characteristics of the Archean mantle under the Abitibi greenstone belt, Canada. Geochim. Cosmochim. Acta 50: 2335-2348.

Machado, M.C. (2013). Metodologias isotópicas ${ }^{87} \mathrm{Sr} /{ }^{86} \mathrm{Sr}, \delta \mathrm{C}^{13}$ e $\delta \mathrm{O}^{18}$ em estudos geológicos e arqueológicos. Unpublished Ph.D. Thesis, UFRGS, Brazil. 265 pp.

Malarkey, J. (2010). Micro-geochemistry of the mantle and its volcanic rocks. Doctoral Thesis, Durham University. 238 pp. Available at Durham E-Theses Online: http://etheses.dur.ac.uk/131/

Mariano, A.N. \& Marchetto, M. 1991. Serra Negra and Salitre - Carbonatite alkaline igneous complex. In: Fifth International Kimberlite Conference 1991, Araxá, Brazil (Field Guide Book). pp. 75-79.

Mariano, A.N. \& Mitchell, R.H. 1991. Mineralogy and geochemistry of perovskite-rich pyroxenites. In: Fifth International Kimberlite Conference 1991, Araxá, Brazil (Extended Abstracts). pp. 251-253.

Martin, L.H.J., Schmidt, M.W., Mattson, H.B., Ulmer, P., Hametner, K. \& Günther, D. (2012). Element partitioning between immiscible carbonatite-kamafugite melts with application to the Italian ultrapotassic suite. Chemical Geology 320-321: 96-112.

Martin, L.H.J., Schmidt, M.W., Mattson, H.B. \& Günther, D. (2013). Element partitioning between immiscible carbonatite and silicate melts for dry and $\mathrm{H}_{2} \mathrm{O}$-bearing systems at 1-3 GPa. J. Petrology doi:10.1093/petrology/egt048.

Melluso, L., Lustrino, M., Ruberti, E., Brotzu, P., Gomes, C.B., Morbidelli, L., Morra, V., Svisero, D.P. \& D'Amelio, F. (2008). Major- and Trace-element composition of Olivine, Perovskite, Clinopyroxene, Cr-Fe-Ti oxides, Phlogopite and host kamafugites and kimberlites, Alto Paranaíba, Brazil. The Canadian Mineralogist 46: 19-40.

Meyer, H.O.A., Garwood, B.L., Svisero, D.P. \& Smith, C.B. (1994). Alkaline ultrabasic intrusions in Western Minas Gerais, Brazil. In: Proceedings of the Fifth International Kimberlite Conference 1991, Araxá, Brazil. pp. 140-155.

Mitchell, R.H., Smith, C.B. \& Vladykin, N.V. (1994). Isotopic composition of strontium and neodymium in potassic rocks of the Little Murun complex, Aldan Shield, Siberia. Lithos 32: 243-248. 
Mitchell, R.H. (2005). Carbonatites and carbonatites and carbonatites. The Canadian Mineralogist 43: 2049-2068.

Morbidelli, L., Gomes, C.B., Beccaluva, L., Brotzu, P., Garbarino, C., Riffel, B.F., Ruberti, E. \& Traversa, G. (1997). Parental magma characterization of Salitre cumulate rocks (Alto Paranaíba Alkaline Province, Brazil) as inferred from mineralogical, petrographic, and geochemical data. International Geology Review 39: 723-743.

Morikiyo, T., Takano, K., Miyazaki, T., Kagami, H. \& Vladykin, N.V. (2000). Sr, Nd, C and $\mathrm{O}$ isotopic compositions of carbonatite and peralkaline silicate rocks from the Zhidoy complex, Russia: evidence for binary mixing, liquid immiscibility and a heterogeneous depleted mantle source region. J. Mineral. Petrol. Sciences 95: 162-172.

Nebel, O., Scherer E.E. \& Mezger, K. (2011). Evaluation of the ${ }^{87}$ Rb decay-constant by agecomparison against the U-Pb system. Earth and Planetary Sci. Letters 301: 1-8.

Nelson, D.R., Chivas, A.R., Chappell, B.W. \& McCulloch, M.T. (1988). Geochemical and isotopic systematics in carbonatites and implications for the evolution of ocean-island sources. Geochim. Cosmochim. Acta 52: 1-17.

Oliveira, I.W.B., Sachs, L.L.B., Silva, V.A. \& Batista, I.H. (2004). Folha SE.23-Belo Horizonte, In: Carta geológica do Brasil ao millionésimo: Sistema de Informações Geográficas - SIG e 46 folhas na escala 1: 1.000.000, Schobbenhaus, C., Gonçalves, J.H., Santos, J.O.S., Abram, M.B., Neto, R.L., Matos, G.M.M., Vidotti, R.M., Ramos, M.A.B. \& Jesus, J.D.A., Editors. CPRM, Brasília, CD-ROM Pack.

Oliveira, I.L. (2015). Isótopos de Nd e Sr em minerais de diferentes séries petrogenéticas nos complexos alcalino-carbonatíticos de Salitre e Catalão I. Unpublished MSc Thesis, Universidade de Brasília, Brazil. 240 pp.

Oliveira, I.L., Brod, J.A. \& Barbosa, E.S.R. (2014). Nd and Sr isotopic systematics and the magmatic evolution of the Salitre I alkaline-carbonatite complex, Alto Paranaíba Igneous Province (APIP), SE Brazil. In: $9^{\text {th }}$ South American Symposium on Isotope Geology 2014, São Paulo, Brazil (Program and Abstracts \#115). http://www.acquacon.com.br/9ssagi/programa_ssagi-site.pdf 
Oliveira, I.L., Brod, J.A., Chaves, J.G. \& Dantas, E.L. (2015 In preparation). Nd-Sr isotopic determinations in apatite from alkaline-carbonatite complexes: Implications of distinct leaching procedures investigated by SEM.

O'Nions, R.K., Carter, S.R., Evensen, N.M. \& Hamilton, P.J. (1979). Geochemical and cosmochemical applications of $\mathrm{Nd}$ isotope analysis. Ann. Rev. Earth and Planet. Sci. 7: 11-38.

Peate, D.W., Hawkesworth, C.J., Mantovani, M.S.M. \& Shukowsky, W. (1990). Mantle plumes and flood-basalt stratigraphy in the Paraná, South America. Geology 18(12): 1223-1226.

Peate, D.W. (1997). The Paraná-Etendeka Province. In: Large Igneous Provinces: Continental, Oceanic, and Planetary Flood Volcanism, Mahoney, J.J. \& Coffin, M.F., Editors. American Geophysical Union, Washington, pp. 217-245.

Pimentel, M.M., Dardenne, M.A., Fuck, R.A., Viana, M.G., Junges, S.L., Fischel, D.P., Seer, H.J. \& Dantas, E.L. (2001). Nd isotopes and the provenance of detrital sediments of the Neoproterozoic Brasília Belt, central Brazil. Journal of South American Earth Sciences 14: 571-585.

Pires, F.R.M. (1986). The southern limits of the São Francisco Craton. Anais Academ. Bras. Ciências 58: 139-145.

Piuzana, D., Pimentel, M.M., Fuck, R.A. \& Armstrong, R. (2003a). Neoproterozoic granulite facies metamorphism and coeval granitic magmatism in the Brasília Belt, Central Brazil: regional implications of new SHRIMP U-Pb and Sm-Nd data. Precambrian Research 125: 245-273.

Piuzana, D., Pimentel, M.M., Fuck, R.A. \& Armstrong, R. (2003b). SHRIMP U-Pb and SmNd data for the Araxá Group and associated magmatic rocks: constraints for the age of sedimentation and geodynamic context of southern Brasília Belt, central Brazil. Precambrian Research 125: 139-160.

Powell, J.L. \& Bell, K. (1974). Isotopic composition of strontium in alkalic rocks. In: The Alkaline Rocks, H. Sorensen, Editor. John Wiley and Sons, New York, pp. 412-421. 
Prowatke, S. \& Klemme, S. (2006). Trace element partitioning between apatite and silicate melts. Geochim. Cosmochim. Acta 70: 4513-4527.

Ray, J.S. (1998). Trace element and isotope evolution during concurrent assimilation, fractional crystallization and liquid immiscibility of a carbonated silicate magma. Geochim. Cosmochim. Acta 62(19-20): 3301-3306.

Ray, J.S. (2009). Radiogenic isotopic ratio variations in carbonatites and associated alkaline silicate rocks: role of crustal assimilation. J. Petrology 50(10): 1955-1971.

Riccomini, C., Velázquez, V.F. \& Gomes, C.B. (2005). Tectonic controls of the Mesozoic and Cenozoic alkaline magmatism in central-southeastern Brazilian platform. In: Mesozoic to Cenozoic Alkaline Magmatism in the Brazilian Platform, CominChiaramonti, P. \& Gomes, C.B., Editors. Edusp/Fapesp, São Paulo, pp. 31-55.

Roden, M.F., Murthy, V.R. \& Gaspar, J.C. (1985). Sr and Nd isotopic composition of the Jacupiranga carbonatite. Journal of Geology 93: 212-220.

Rosatelli, G., Wall, F. \& Stoppa, F. (2007). Calcio-carbonatite melts and metasomatism in the mantle beneath Mt. Vulture (Southern Italy). Lithos 99: 229-248.

Rudnick, R.L. \& Gao, S. (2003). Composition of Continental Crust. In: Treatise on Geochemistry Volume 3: The Crust, R.L. Rudnick, Editor. Elsevier Ltd, pp. 1-64.

Sato, K. (1998). Evolução crustal da Plataforma Sul Americana, com base na geoquímica isotópica Sm-Nd. Unpublished Ph.D. Thesis, IGC-USP, Brazil. 299 pp.

Schimmel, M., Assumpção, M. \& VanDecar, J.C. (2003). Seismic velocity anomalies beneath SE Brazil from P and S wave travel time inversions. Journal of Geophysical Research doi: 10.1029/2001JB000187.

Seer, H.J. \& Moraes, L.C. (1988). Estudo petrográfico das rochas ígneas alcalinas da região de Lagoa Formosa, MG. Revista Brasileira de Geociências 18(2): 134-140 (in Portuguese).

Sgarbi, P.B.A., Gaspar, J.C. \& Valença, J.G. (2000). Brazilian Kamafugites. Revista Brasileira de Geociências 30(3): 417-420. 
Sgarbi, P.B.A., Heaman, L.M. \& Gaspar, J.C. (2004). U-Pb perovskite ages for Brazilian kamafugitic rocks: further support for a temporal link to a mantle plume hotspot track. Journal of South American Earth Sciences 16: 715-724.

Simonetti, A. \& Bell, K. (1995). Nd, Pb and Sr isotope systematics of fluorite at the Amba Dongar carbonatite complex, India: Evidence for hydrotermal and crustal fluid mixing. Economic Geology 90: 2018-2027.

Sonoki, I.K. \& Garda, G.M. 1988. Idades K-Ar de rochas alcalinas do Brasil meridional e Paraguai oriental: Compilação e adaptação às novas constantes de decaimento. Boletim IG-USP Série Científica 19: 63-85 (in Portuguese).

Sun, S.-s. \& McDonough, W.F. (1989). Chemical and isotopic systematics of oceanic basalts: implications for mantle composition and processes. Geological Society of London, Special Publications 42: 313-345.

Taylor, H.P. (1980). The effects of assimilation of country rocks by magmas on ${ }^{18} \mathrm{O} /{ }^{16} \mathrm{O}$ and ${ }^{87} \mathrm{Sr} /{ }^{86} \mathrm{Sr}$ systematics in igneous rocks. Earth and Planetary Sci. Letters 47: 243-254.

Thirlwall, M.F. (1991). Long-term reproducibility of multicollector $\mathrm{Sr}$ and $\mathrm{Nd}$ isotope ratio analysis. Chemical Geology 94: 85-104.

Thompson, R.N., Gibson, S.A., Mitchell, J.G., Dickin, A.P., Leonardos, O.H., Brod, J.A. \& Greenwood, J.C. (1998). Migrating Cretaceous-Eocene magmatism in the Serra do Mar alkaline province, SE Brazil: melts from the deflected Trindade mantle plume? J. Petrology 39(8): 1493-1526.

Tilton, G.R., Kwon, S.T. \& Frost, D.M. (1987). Isotopic relationships in Arkansas Cretaceous alkali complexes. In: Mantle metasomatism and alkaline magmatism, Morris, E.M. \& Pasteris, J.D., Editors. Geological Society of America Special Paper 215: 241-248.

Tichomirowa, M., Grosche, G., Götze, J., Belyatsky, B.V., Savva, E.V., Keller, J. \& Todt, W. (2006). The mineral isotope composition of two Precambrian carbonatite complexes from the Kola Alkaline Province - Alteration versus primary magmatic signatures. Lithos 91: 229-249. 
Toyoda, K., Horiuchi, H. \& Tokonami, M. (1994). Dupal anomaly of Brazilian carbonatites: Geochemical correlations with hotspots in the South Atlantic and implications for the mantle source. Earth and Planetary Sci. Letters 126: 315-331.

VanDecar, J.C., James, D.E. \& Assumpção, M. (1995). Seismic evidence for a fossil mantle plume beneath South America and implications for plate driving forces. Nature 378: 25-31.

Veksler, I.V., Petibon, C., Jenner, G.A., Dorfman, A.M. \& Dingwell, D.B. (1998). Trace element partitioning in immiscible silicate-carbonate liquid systems: an initial experimental study using a centrifuge autoclave. J. Petrology 39(11-12): 2095-2104.

Veksler, I.V., Dorfman, A.M., Dulski, P. Kamenetsky, V.S., Danyushevsky, L.V., Jeffries, T. \& Dingwell, D.B. (2012). Partitioning of elements between silicate melt and immiscible fluoride, chloride, carbonate, phosphate and sulfate melts, with implications to the origin of natrocarbonatite. Geochim. Cosmochim. Acta 79: 20-40.

Verhulst, A., Balaganskaya, E., Kirnarsky, Y. \& Demaiffe, D. (2000). Petrological and geochemical (trace elements and Sr-Nd isotopes) characteristics of the Paleozoic Kovdor ultramafic, alkaline and carbonatite intrusion (Kola Peninsula, NW Russia). Lithos 51: 1-25.

Vladykin, N.V., Morikiyo, T. \& Miyazaki, T. (2004). Geochemistry of carbon and oxygen isotopes in carbonatites of Siberia and Mongolia and some geodynamic consequences. In: Deep-seated magmatism: Its sources and their relation to plume processes, N.V. Vladykin, Editor. Vinogradov Institute of Geography, Irkutsk, pp. 96-112.

Vladykin, N.V., Morikiyo, T. \& Miyazaki, T. (2005). Sr and Nd isotopes geochemistry of alkaline and carbonatite complexes of Siberia and Mongolia and some geodynamic consequences. In: Problems of sources of deep magmatism and plumes, N.V. Vladykin, Editor. Vinogradov Inst. Geochem. Publ., Irkutsk, pp. 19-37.

Watson, E.B. \& Green, T.H. (1981). Apatite/liquid partition coefficients for the rare earth elements and strontium. Earth and Planetary Sci. Letters 56: 405-421. 
Weis, D., Kieffer, B., Maerschalk, C., Pretorius, W. \& Barling, J. (2005). High-precision PbSr-Nd-Hf isotopic characterization of USGS BHVO-1 and BHVO-2 reference materials. Geochemistry Geophysics Geosystems 6(2): 1-10.

Wen, J., Bell, K. \& Blenkinsop, J. (1987). Nd and Sr isotope systematics of the Oka complex, Quebec, and their bearing on the evolution of the sub-continental upper mantle. Contributions to Mineralogy and Petrology 97: 433-437.

Wendlandt, R.F. \& Harrison, W.J. (1979). Rare earth partitioning between immiscible carbonate and silicate liquids and $\mathrm{CO}_{2}$ vapor: results and implications for the formation of light rare earth-enriched rocks. Contributions to Mineralogy and Petrology 69: 409-419.

Whitney, D.L. \& Evans, B.W. (2010). Abbreviations for names of rock-forming minerals. American Mineralogist 95: 185-187.

Wieser, M.E. \& Coplen, T.B. (2011). Atomic weights of the elements 2009 (IUPAC Technical Report). Pure Appl. Chem. 83(2): 359-396.

Wittig, N., Pearson, D.G., Downes, H. \& Baker, J.A. (2009). The U, Th and Pb elemental and isotope compositions of mantle clinopyroxenes and their grain boundary contamination derived from leaching and digestion experiments. Geochim. Cosmochim. Acta 73: 469-488.

Woolley, A.R. \& Kjarsgaard, B.A. (2008). Paragenetic types of carbonatite as indicated by the diversity and relative abundances of associated silicate rocks: Evidence from a global database. The Canadian Mineralogist 46: 741-752.

Woolley, A.R. \& Bailey, D.K. (2012). The crucial role of lithospheric structure in the generation and release of carbonatites: geological evidence. Mineralogical Magazine 76(2): 259-270.

Wu, F.Y., Yang, Y.H., Li, Q.L., Mitchell, R.H., Dawson, J.B., Brandl, G. \& Yuhara, M. (2011). In situ determination of $\mathrm{U}-\mathrm{Pb}$ ages and $\mathrm{Sr}-\mathrm{Nd}-\mathrm{Hf}$ isotopic constraints on the petrogenesis of the Phalaborwa carbonatite Complex, South Africa. Lithos 127: 309322. 
Wu, F.Y., Arzamastsev, A.A., Mitchell, R.H., Li, Q.L., Sun, J., Yang, Y.H. \& Wang, R.C. (2012). Emplacement age and Sr-Nd isotopic compositions of the Afrikanda alkaline ultramafic complex, Kola Peninsula, Russia. Chemical Geology doi: 10.1016/j.chemgeo.2012.09.027

Yang, Z. \& Woolley, A. (2006). Carbonatites in China: A review. Journal of Asian Earth Sciences 27: 559-575.

Ye, H-M., Li, X-H. \& Lan, Z-W. (2013). Geochemical and Sr-Nd-Hf-O-C isotopic constraints on the origin of the Neoproterozoic Qieganbulake ultramafic-carbonatite complex from the Tarim Block, Northwest China. Lithos 182-183: 150-164.

Yuhara, M., Hirahara, Y., Nishi, N. \& Kagami, H. (2005). Rb-Sr, Sm-Nd ages of the Phalaborwa Carbonatite Complex, South Africa. Polar Geosci. 18: 101-113.

Zaitsev, A. \& Bell, K. (1995). Sr and Nd isotope data of apatite, calcite and dolomite as indicators of source, and the relationships of phoscorites and carbonatites from the Kovdor Massif, Kola Peninsula, Russia. Contributions to Mineralogy and Petrology 121(3): 324-335.

Zindler, A. \& Hart, S.R. (1986). Chemical Geodynamics. Annu. Rev. Earth Planet. Sci. 14: 493-571. 


\begin{tabular}{|c|c|c|c|c|}
\hline $\begin{array}{l}\text { Sample Name } \\
\text { Rock Type } \\
\text { (Unit) }\end{array}$ & Mineral & $\begin{array}{l}\text { Modal } \\
\%\end{array}$ & $\begin{array}{l}\text { Grain } \\
\text { Size }\end{array}$ & Comments \\
\hline \multirow{4}{*}{$\begin{array}{l}\text { FVL } 51-175 \\
\text { Ol Bebedourite } \\
\text { (B1a) }\end{array}$} & $O l$ & 45 & $\begin{array}{l}\text { Fine to } \\
\text { medium }\end{array}$ & $\begin{array}{l}\text { Subhedral to anhedral cumulus crystals with abundant } M a g \text { and fluid micro-inclusions fairly } \\
\text { oriented. }\end{array}$ \\
\hline & $\operatorname{Prv}$ & 35 & $\begin{array}{l}\text { Fine to } \\
\text { coarse }\end{array}$ & $\begin{array}{l}\text { Euhedral to subhedral cumulus crystals with small inclusions of } P h l, T t n \text { and } O p q \text {, mainly } \\
\text { concentrated in the core; Smaller crystals }(<1 \mathrm{~mm}) \text { containing plenty of inclusions have a } \\
\text { cloudy aspect. }\end{array}$ \\
\hline & Mag & 15 & $\begin{array}{l}\text { Medium } \\
\text { to coarse }\end{array}$ & $\begin{array}{l}\text { Anhedral intercumulus crystals usually coated with tiny } T f P h l \text { laths; Ilm exsolution lamellae } \\
\text { are common; Mag sometimes encloses } O l \text { and Prv crystals. }\end{array}$ \\
\hline & $P h l$ & 5 & $\begin{array}{l}\text { Fine to } \\
\text { medium }\end{array}$ & $\begin{array}{l}\text { Rare anhedral intercumulus lamellae with light green to orange normal pleochroism; often } \\
\text { contains micro-inclusions of Mag; may have a thin rim of } T f P h l \text {, possibly due to interaction } \\
\text { with carbonatitic fluids. }\end{array}$ \\
\hline \multirow{5}{*}{$\begin{array}{l}\text { FSALT 02-81 } \\
\text { Prv Bebedourite } \\
\text { (B1b) }\end{array}$} & $C p x$ & 40 & $\begin{array}{l}\text { Medium } \\
\text { to coarse }\end{array}$ & $\begin{array}{l}\text { Euhedral to subhedral slightly green crystals that compose almost uniform layers with some } \\
\text { scattered } A p \text { and Mag crystals; numerous Mag inclusions are also common. }\end{array}$ \\
\hline & $P h l$ & 23 & $\begin{array}{l}\text { Fine to } \\
\text { medium }\end{array}$ & $\begin{array}{l}\text { Euhedral to subhedral, rare anhedral lamellae with greenish orange to light orange normal } \\
\text { pleochroism; occur frequently in the oxide-rich layers together with Ap crystals; rare Mag } \\
\text { inclusions may be present. }\end{array}$ \\
\hline & $A p$ & 20 & $\begin{array}{l}\text { Fine to } \\
\text { medium }\end{array}$ & $\begin{array}{l}\text { Subhedral to anhedral crystals that appear to form magmatic layers with } P h l \text { lamellae plus } \\
\text { oxides; may also occur as irregular lenses within } C p x \text { layers. }\end{array}$ \\
\hline & Mag & 10 & $\begin{array}{l}\text { Fine to } \\
\text { medium }\end{array}$ & Anhedral crystals associated with $\operatorname{Prv}$; may contain minor $A p$ inclusions. \\
\hline & $\operatorname{Prv}$ & 7 & $\begin{array}{l}\text { Fine to } \\
\text { medium }\end{array}$ & $\begin{array}{l}\text { Subhedral disseminated crystals almost always associated with } M a g+A p \text { (oxide-rich) } \\
\text { layers; inclusions of } O p q \text { are common in the core of crystals. }\end{array}$ \\
\hline
\end{tabular}




\begin{tabular}{|c|c|c|c|c|}
\hline \multirow{6}{*}{$\begin{array}{l}\text { FSALT 26-96 } \\
\text { Grt Bebedourite } \\
\text { (B2) }\end{array}$} & Cpx & 35 & $\begin{array}{l}\text { Fine to } \\
\text { medium }\end{array}$ & $\begin{array}{l}\text { Subhedral cumulus crystals with minor inclusions of } A p \text { and } P h l \text {; often concentrically zoned } \\
\text { (light green core to dark green rim). }\end{array}$ \\
\hline & $G r t$ & 32 & $\begin{array}{l}\text { Fine to } \\
\text { medium }\end{array}$ & $\begin{array}{l}\text { Anhedral intercumulus dark brown crystals that encloses other minerals, mainly } A p \text { and } \\
\text { Opq; Locally Grt crystals appear to have entrapped some carbonate. }\end{array}$ \\
\hline & $P h l$ & 25 & $\begin{array}{l}\text { Fine to } \\
\text { medium }\end{array}$ & $\begin{array}{l}\text { Euhedral to anhedral cumulus to intercumulus lamellae with green to orange normal } \\
\text { pleochroism and compositional zoning well marked in the rims; often encloses } C p x \text { crystals. }\end{array}$ \\
\hline & $A p$ & 4 & Fine & $\begin{array}{l}\text { Anhedral to subhedral disseminated cumulus crystals; sometimes as clusters of } A p \text { crystals } \\
\text { between } C p x \text { grains. }\end{array}$ \\
\hline & $O p q$ & 3 & Fine & $\begin{array}{l}\text { Mostly euhedral to anhedral cumulus crystals of } M a g \text {; subordinated anhedral } C c p \text {; often } \\
\text { included in } G r t \text { and } P h l \text { crystals. }\end{array}$ \\
\hline & $C b$ & 1 & Fine & $\begin{array}{l}\text { Anhedral intercumulus clear crystals; also as interstitial veins or tiny grains between other } \\
\text { mineral phases. }\end{array}$ \\
\hline \multirow{6}{*}{$\begin{array}{l}\text { SF16 101.5D1 } \\
\text { Phl Phoscorite } \\
\text { (P1) }\end{array}$} & $A p$ & 36 & $\begin{array}{l}\text { Fine to } \\
\text { medium }\end{array}$ & $\begin{array}{l}\text { Subhedral to anhedral crystals showing granular texture; may have small, slightly oriented } \\
\text { inclusions of } P h l \text { and } M a g \text {; also occur } C b \text { melt inclusions. }\end{array}$ \\
\hline & $\mathrm{Ol}$ & 27 & $\begin{array}{l}\text { Fine to } \\
\text { medium }\end{array}$ & $\begin{array}{l}\text { Anhedral to subordinate subhedral crystals with abundant } O p q \text { inclusions that mark growth } \\
\text { lines; rarely the rims of } O l \text { crystals are replaced by yellow } C h u \text {. }\end{array}$ \\
\hline & $P h l$ & 25 & $\begin{array}{l}\text { Fine to } \\
\text { medium }\end{array}$ & $\begin{array}{l}\text { Subhedral to anhedral lamellae with green to orange normal pleochroism and compositional } \\
\text { zoning marked in the rims; inclusions of } A p \text { and rare } M a g \text { are common. }\end{array}$ \\
\hline & Mag & 10 & $\begin{array}{l}\text { Fine to } \\
\text { medium }\end{array}$ & $\begin{array}{l}\text { Anhedral crystal clusters (Mag-rich domains) in the groundmass; also occur as small } \\
\text { inclusions in all the other phases. }\end{array}$ \\
\hline & $C b$ & 1 & Fine & $\begin{array}{l}\text { Anhedral to rare euhedral intercumulus (residual melt?) crystals; usually occurs around other } \\
\text { phases as coronas or gulfs (embayment); also happens as irregular melt inclusions in the } A p \\
\text { crystals. }\end{array}$ \\
\hline & Zcn & 1 & Fine & $\begin{array}{l}\text { Identified only by EMPA-BSE images; Euhedral to subhedral micro-crystals dispersed in } \\
\text { the groundmass, often associated with } A p \text { crystals. }\end{array}$ \\
\hline
\end{tabular}




\begin{tabular}{|c|c|c|c|c|}
\hline \multirow{6}{*}{$\begin{array}{l}\text { F37B-65A } \\
\text { Pcl Phoscorite } \\
(\mathrm{P} 2)\end{array}$} & Mag & 40 & $\begin{array}{l}\text { Fine to } \\
\text { coarse }\end{array}$ & $\begin{array}{l}\text { Euhedral to subhedral phenocrysts with } A p \text { and, more rarely, } O l \text { inclusions; In general, } \\
\text { largest crystals have irregular rims suggesting disequilibrium with the melt; small anhedral } \\
\text { crystals }(<1 \mathrm{~mm}) \text { in the groundmass. }\end{array}$ \\
\hline & $A p$ & 25 & Fine & $\begin{array}{l}\text { Euhedral to subhedral clear crystals; constitutes the groundmass, together with fine-grained } \\
\mathrm{Ol} \text { and } \mathrm{Mag} \text {. }\end{array}$ \\
\hline & $\mathrm{Ol}$ & 25 & $\begin{array}{l}\text { Fine to } \\
\text { medium }\end{array}$ & $\begin{array}{l}\text { Subhedral to anhedral crystals with } A p \text { inclusions; Post-magmatic alteration to yellow } C h u \text { is } \\
\text { evident in almost every crystal, probably associated with fluid percolation. }\end{array}$ \\
\hline & $\mathrm{Pcl}$ & 9 & Fine & $\begin{array}{l}\text { Euhedral dark red cubic crystals widespread in the groundmass; generally close to or } \\
\text { overgrowing Mag phenocrysts. }\end{array}$ \\
\hline & TfPhl & 1 & Fine & $\begin{array}{l}\text { Anhedral lamellae disseminated in the groundmass with colorless to orange reverse } \\
\text { pleochroism; almost always associated with } M a g \text { or } C b \text { crystals. }\end{array}$ \\
\hline & $C b$ & $\operatorname{Tr}$ & Fine & $\begin{array}{l}\text { Subhedral interstitial crystals showing mosaic or granular texture; interstitial to } M a g \\
\text { phenocrysts in association with inclusions of } A p \text { and } T f P h l \text {. }\end{array}$ \\
\hline \multirow{5}{*}{$\begin{array}{l}\text { FVL 53-145A } \\
\text { Phoscorite } \\
\text { (P2) }\end{array}$} & Mag & 30 & $\begin{array}{l}\text { Fine to } \\
\text { coarse }\end{array}$ & $\begin{array}{l}\text { Anhedral intergranular crystals at phoscoritic domains and euhedral to subhedral crystals } \\
\text { elongated toward the center of } C b \text { pockets; both types contain inclusions of } A p \text { and } C b \text {. }\end{array}$ \\
\hline & $A p$ & 30 & $\begin{array}{l}\text { Fine to } \\
\text { medium }\end{array}$ & $\begin{array}{l}\text { Euhedral to subhedral crystals with granular texture prevail at phoscoritic domain whereas } \\
\text { prismatic crystals elongated toward the center dominate in the rims of } C b \text { pockets. }\end{array}$ \\
\hline & $C b$ & 25 & Medium & $\begin{array}{l}\text { Subhedral to anhedral crystals, rarely turbid due to the large amount of diffuse exsolutions } \\
\text { (e.g., Cordeiro et al., 2011); mainly as almost pure } C b \text { pockets with scarce } A p \text {, Ol and Mag; } \\
\text { also as an interstitial phase. In the boundary between } C c \text { and Mag have been noted dolomite } \\
\text { residual rims (EMPA-BSE information!). }\end{array}$ \\
\hline & $\mathrm{Ol}$ & 15 & $\begin{array}{l}\text { Fine to } \\
\text { medium }\end{array}$ & $\begin{array}{l}\text { Euhedral to subhedral; partially or completely replaced by yellow } C h u \text {; occurs essentially at } \\
\text { phoscoritic domains. }\end{array}$ \\
\hline & $B d y$ & $\operatorname{Tr}$ & Fine & $\begin{array}{l}\text { Anhedral to rare tabular crystals with yellowish-brown to reddish-brown pleochroism; } \\
\text { occurs close to Mag crystals, exclusively in phoscoritic domains. }\end{array}$ \\
\hline
\end{tabular}




\begin{tabular}{|c|c|c|c|c|}
\hline \multirow{4}{*}{$\begin{array}{l}\text { 09B-50 } \\
\text { Mg Carbonatite } \\
\text { (C1) }\end{array}$} & $C b$ & 92 & $\begin{array}{l}\text { Fine to } \\
\text { medium }\end{array}$ & $\begin{array}{l}\text { Subhedral to anhedral with granular texture; Larger crystals usually have cloudy aspect due } \\
\text { to the amount of exsolutions in the core. }\end{array}$ \\
\hline & $A p$ & 8 & Fine & $\begin{array}{l}\text { Euhedral (prismatic) to anhedral crystals scattered in the groundmass; Locally as clusters or } \\
\text { Ap-rich layers. }\end{array}$ \\
\hline & TfPhl & $\mathrm{Tr}$ & Fine & $\begin{array}{l}\text { Rare, subhedral to anhedral lamellae with colorless to light orange reverse pleochroism; } \\
\text { Occurs scattered in the groundmass. }\end{array}$ \\
\hline & Pcl & $\mathrm{Tr}$ & Fine & $\begin{array}{l}\text { Anhedral to rarely subhedral tiny yellowish-brown crystals; occurs widespread in the } \\
\text { groundmass. }\end{array}$ \\
\hline \multirow{5}{*}{$\begin{array}{l}20 \mathrm{~B}-94 \\
\text { Mg Carbonatite } \\
\text { (C1) }\end{array}$} & $C b$ & 88 & $\begin{array}{l}\text { Fine to } \\
\text { coarse }\end{array}$ & $\begin{array}{l}\text { Euhedral to subhedral coarse crystals transected by anhedral fine crystals; Larger crystals } \\
\text { have extremely cloudy aspect due to the large amount of exsolutions; small clear crystals } \\
\text { dominate in the groundmass and are slightly oriented, suggesting flow texture. }\end{array}$ \\
\hline & $O p q$ & 5 & $\begin{array}{l}\text { Medium } \\
\text { to coarse }\end{array}$ & $\begin{array}{l}\text { Mostly interstitial bladed/skeletal } P y \text { crystals suggesting rapid quenching crystallization } \\
\text { (e.g., Gomide } \text { et al., 2013); Also occur rare euhedral to subhedral Mag crystals dispersed in } \\
\text { coarse } C b \text { domains. }\end{array}$ \\
\hline & $A p$ & 5 & Fine & $\begin{array}{l}\text { Euhedral (prismatic) to rare anhedral crystals scattered in the groundmass; Almost always in } \\
\text { clear } C b \text { domains. }\end{array}$ \\
\hline & Pcl & 1 & Fine & $\begin{array}{l}\text { Euhedral to anhedral yellowish-brown, rarely red, crystals widespread in the groundmass; } \\
\text { occurs exclusively in the clear } C b \text { domains. }\end{array}$ \\
\hline & TfPhl & 1 & Fine & $\begin{array}{l}\text { Subhedral to anhedral lamellae with colorless to orange reverse pleochroism; often around } \\
\text { the coarse } C b \text { domains; Most of } T f P h l \text { crystals are completely replaced by green } C h l \text { ? }\end{array}$ \\
\hline \multirow{3}{*}{$\begin{array}{l}\text { FF500 } 476.6 \\
\text { Ca Carbonatite } \\
\text { (C3) }\end{array}$} & $C b$ & 72 & $\begin{array}{l}\text { Fine to } \\
\text { medium }\end{array}$ & $\begin{array}{l}\text { Subhedral clear crystals showing granular texture; usually twinned; encloses all the other } \\
\text { mineral phases, mainly } A p \text {, suggesting } C b \text { is the last phase to crystallize. }\end{array}$ \\
\hline & $O l$ & 10 & Fine & $\begin{array}{l}\text { Subhedral to anhedral normally in silicate-rich domains with } T f P h l \text { and } O p q \text {; have cloudy } \\
\text { aspect due to the amount of } O p q \text { inclusions. }\end{array}$ \\
\hline & $O p q$ & 8 & $\begin{array}{l}\text { Fine to } \\
\text { medium }\end{array}$ & Similar amounts of anhedral Mag, $P y$ and $P o$ crystals; often associated with $T f P h l$ lamellae. \\
\hline
\end{tabular}




\begin{tabular}{|c|c|c|c|c|}
\hline & $A p$ & 5 & Fine & Subhedral disseminated crystals; dominantly in the silicate-rich domains. \\
\hline & TfPhl & 5 & Fine & $\begin{array}{l}\text { Euhedral to subhedral lamellae with light orange to dark red reverse pleochroism; concentric } \\
\text { compositional zoning; some Opq inclusions; Deformed lamellae are common suggesting } \\
\text { crystal mush movement. }\end{array}$ \\
\hline \multirow{6}{*}{$\begin{array}{l}10 \mathrm{~A}-41 \mathrm{~A} \\
\text { Ca Carbonatite } \\
\text { (C3) }\end{array}$} & $\mathrm{Cb}$ & 34 & $\begin{array}{l}\text { Fine to } \\
\text { coarse }\end{array}$ & $\begin{array}{l}\text { Subhedral to anhedral clear crystals showing granular texture; occurs essentially as pure } \mathrm{Cb} \\
\text { pockets which sometimes are transected by thin phoscoritic layers. }\end{array}$ \\
\hline & $\mathrm{Ol}$ & 30 & $\begin{array}{l}\text { Fine to } \\
\text { coarse }\end{array}$ & $\begin{array}{l}\text { Euhedral to anhedral crystals with } A p \text { and rare } P h l \text { inclusions; have minor replacement by } \\
\text { yellow } C h u \text { at the rims. Small rounded crystals }(<0.5 \mathrm{~mm}) \text { occur mainly in phoscoritic } \\
\text { layers within } C b \text { pockets. }\end{array}$ \\
\hline & $A p$ & 25 & $\begin{array}{l}\text { Fine to } \\
\text { medium }\end{array}$ & $\begin{array}{l}\text { Subhedral to anhedral, associated with } O l \text { and } M a g \text { in phoscoritic domains. Largest crystals } \\
\text { (> } 1 \mathrm{~mm} \text { ) seem early phenocrysts; small crystals dominate in the groundmass. }\end{array}$ \\
\hline & Mag & 10 & $\begin{array}{l}\text { Fine to } \\
\text { medium }\end{array}$ & $\begin{array}{l}\text { Subhedral to anhedral with irregular rims and inclusions of } A p \text { and } T f P h l \text {; occurs at } \\
\text { phoscoritic domains; almost always in contact with } C b \text { crystals. }\end{array}$ \\
\hline & $T f P h l$ & 1 & Fine & $\begin{array}{l}\text { Euhedral to subordinately anhedral; colorless to light orange reverse pleochroism; concentric } \\
\text { compositional zoning; often associated with Mag. }\end{array}$ \\
\hline & $B d y$ & $\operatorname{Tr}$ & Fine & $\begin{array}{l}\text { Tabular to rarely anhedral tiny crystals with yellowish-brown to reddish-brown pleochroism; } \\
\text { Scattered exclusively in coarse phoscoritic domains. }\end{array}$ \\
\hline
\end{tabular}

Mineral abbreviations used in Appendix A (following Whitney \& Evans, 2010): Ap - apatite; Bdy - baddeleyite; Cb - carbonate mineral; Ccp chalcopyrite; Chl - chlorite; Chu - clinohumite; Cpx-clinopyroxene; Grt-garnet; Mag - magnetite; Ol-olivine; Opq-opaque mineral; Prv - perovskite; Phl-phlogopite; Py-pyrite; Pcl-pyrochlore; Po-pyrrhotite; TfPhl-tetraferriphlogopite; Ttn-titanite; Zcn-zirconolite. 


\section{ISOTOPIC COMPOSITION OF STRONTIUM AND NEODYMIUM IN APATITE, BARITE, PYROCHLORE, TETRAFERRIPHLOGOPITE AND CARBONATES FROM NIOBIUM-RICH ROCKS OF THE CATALÃO I CARBONATITE COMPLEX, BRAZIL.}

Ítalo Lopes de Oliveira ${ }^{1}$, José Affonso Brod ${ }^{1},{ }^{2}$, Elton Luiz Dantas ${ }^{1}$, Pedro Filipe de Oliveira Cordeiro ${ }^{3}$.

\footnotetext{
${ }^{1}$ Instituto de Geociências, Universidade de Brasília (UnB), Campus Universitário Darcy Ribeiro, Asa Norte, CEP 70.910-900, Brasília, DF, Brazil.

${ }^{2}$ Unidade Acadêmica Especial de Ciências e Tecnologia, Campus Aparecida de Goiânia, Universidade Federal de Goiás (UFG), CEP 74.968-755, Aparecida de Goiânia, GO, Brazil.
}

${ }^{3}$ Ivanhoe Mines Ltd. Vancouver, BC, Canada.

\section{Abstract}

The Late Cretaceous Catalão I carbonatite complex consists of several dykes, plugs and veins of nelsonites and carbonatites as well as abundant metasomatic phlogopitites, originated from an extensive carbonatitic auto-metasomatism that affected the early alkaline ultramafic rocks and phoscorites of this complex. Late-stage N1 nelsonites, N2 pseudonelsonites (i.e. niobium-rich rocks) and monazite-bearing carbonatites show significant whole-rock $\mathrm{Nd}$ and $\mathrm{Sr}$ isotope variations. In order to elucidate whether magmatic, metasomatic or both processes were responsible for this radiogenic isotope variations we characterized the $\mathrm{Nd}$ and $\mathrm{Sr}$ isotope compositions of the major mineral phases present in some of these late-stage rocks. Overall, mineral isotope data also record the differences observed between $\mathrm{N} 1$ and $\mathrm{N} 2$ nelsonites, whereby N2 minerals and rocks systematically show more enriched isotopic signatures than N1. Sr isotopic disequilibrium among minerals from pseudonelsonites and spatially related dolomite-carbonatite pockets implies that such rocks were formed by batches of carbonate melt with distinct isotope compositions. Through mathematical modelling (AFC model), we propose that the two different evolution paths observed for the most evolved rocks of the Catalão I complex could be explained by changes in the fractionating mineral assemblage of a late-stage magmatic or carbo-hydrothermal systems undergoing reasonable amounts of crustal contamination. 


\subsection{INTRODUCTION}

The isotope composition of carbonatites has established important constraints on the petrogenetic processes involved in the magmatic evolution of the alkaline-carbonatite complexes worldwide (e.g., Andersen, 1987; Simonetti \& Bell, 1994; Bell, 1998; Ray, 2009). Radiogenic, stable and noble gases isotopic data show that carbonatites originate from mantlederived magmas, that some parts of subcontinental lithospheric mantle remain virtually undisturbed over billions of years and that most young carbonatites $(<200 \mathrm{Ma})$ have isotope signatures that can be explained in terms of mixtures of HIMU, EM-I and FOZO mantle components (Bell \& Simonetti et al., 2010 and references therein).

A significant number of recent works report radiogenic isotope studies in minerals from carbonatites and associated alkaline rocks, providing new insights into the complicated histories of some of alkaline-carbonatite complexes (e.g., Zaitsev \& Bell, 1995; Bell, 2001; Dunworth \& Bell 2001; Bizzarro et al., 2003; Tichomirowa et al., 2006; Wu et al., 2011; 2012; Ye et al., 2013; Chen \& Simonetti, 2015). Open-system behaviour involving interaction between melts or fluids derived from mantle and/or crust levels, magma recharge, assimilation, and even isotopically heterogeneous mantle sources have been proposed to explain the major isotopic ratio variations noted between co-existing mineral phases. Therefore, isotope compositions of individual minerals may offer valuable information to clarify the evolution of some carbonatite complexes, mainly those where isotope disequilibria have already been detected in bulk rock analyses.

The Catalão I carbonatite complex is one of the northernmost alkaline-carbonatite complexes of the Late Cretaceous Alto Paranaíba Igneous Province (APIP). The APIP comprises a kamafugite-carbonatite association (Brod et al., 2000), formed by dykes, pipes, plugs and diatremes of kamafugitic, kimberlitic and rare lamproitic compositions along with extensive lava flows and pyroclastic deposits, as well as large carbonatite-bearing intrusions (Gibson et al., 1995; Araújo et al., 2001; Brod et al., 2004; Gomes \& Comin-Chiaramonti, 2005). These alkaline ultrapotassic magmas are emplaced into the Neoproterozoic metasedimentary rocks of the Brasília Belt, between the SW border of the Archean São Francisco Craton and the NE margin of the Phanerozoic Paraná Basin (inset Figure 6.1). Such magmatism is thought to be related to the impact of the Trindade mantle plume beneath the previously metasomatized subcontinental lithospheric mantle (Gibson et al., 1995; 1997; Thompson et al., 1998; Araújo et al., 2001; Sgarbi et al., 2004). 
Significant $\mathrm{Nd}$ and $\mathrm{Sr}$ isotope variations have been reported in the niobium-rich rocks from the Catalão I complex (Cordeiro et al., 2010; 2011b). Those authors suggest that latestage magmatic and/or metasomatic processes could explain such isotope signatures, but stress that a mineral isotope investigation is required in order to elucidate the question. Hence, in this study we characterize the $\mathrm{Sr}$ and $\mathrm{Nd}$ isotopic composition of several individual mineral phases that compose the samples described in Cordeiro et al. (2010, 2011b), in order to verify whether they are in isotopic equilibrium or not. Comparing our isotope data with those from other alkaline-carbonatite complex of the APIP, we attempt to outline new constraints on the processes involved in the final stages of the Catalão I evolution.

\subsection{The Catalão I CompleX}

The Catalão I carbonatite complex, located ca. $20 \mathrm{~km}$ northeast of the city of Catalão in central Brazil $\left(18^{\circ} 08^{\prime} \mathrm{S} ; 47^{\circ} 48^{\prime} \mathrm{W}\right)$, comprises a $\sim 30 \mathrm{~km}^{2}$ multi-stage intrusion with a roughly circular, dome-shaped structure (Figure 6.1), and is emplaced in quartzites and schists of the Araxá Group (Carvalho, 1974; Danni et al., 1991). Sonoki \& Garda (1988) reported a whole-rock K-Ar age of 85.0 \pm 6.9 Ma. A ring of fenitized, weather-resistant country rocks surrounding Catalão I favoured the development of an inward drainage pattern that preserves thick soil covers (up to $150 \mathrm{~m}$ ) over the fresh rocks of the complex. This thick weathering profile hosts important supergenic and residual deposits of phosphate, niobium, titanium, barium, rare earth elements and vermiculite (Gierth \& Baecker, 1986; Hirano et al., 1990; Danni et al., 1991; Carvalho \& Bressan, 1997; Ribeiro, 2008, Cordeiro et al., 2011a).

Studies on fresh igneous rocks of Catalão I are almost always based on drill-core samples. The main recognized rock types are dunites, clinopyroxenites and phoscorites, all extensively transformed into metasomatic phlogopitites, and several later-stage dykes, plugs and veins of nelsonites and carbonatites (Carvalho, 1974; Danni et al., 1991; Araújo, 1996; Ribeiro, 2008). In the entire APIP, the abundance of phlogopitites in Catalão I is comparable only to the Araxá complex. Such rocks have been attributed to an intense auto-metasomatism due to the interaction of early alkaline ultramafic rocks with fluids released by late-stage carbonatite intrusions (Araújo, 1996; Gaspar \& Araújo, 1998). The late-stage nelsonites and carbonatites are mineralized in $\mathrm{Nb}$ and REE, and appear to be unaffected by the extensive phlogopitization that transformed the early ultramafic and phoscoritic rocks of the complex (Cordeiro et al., 2010; Ribeiro et al., 2014). 


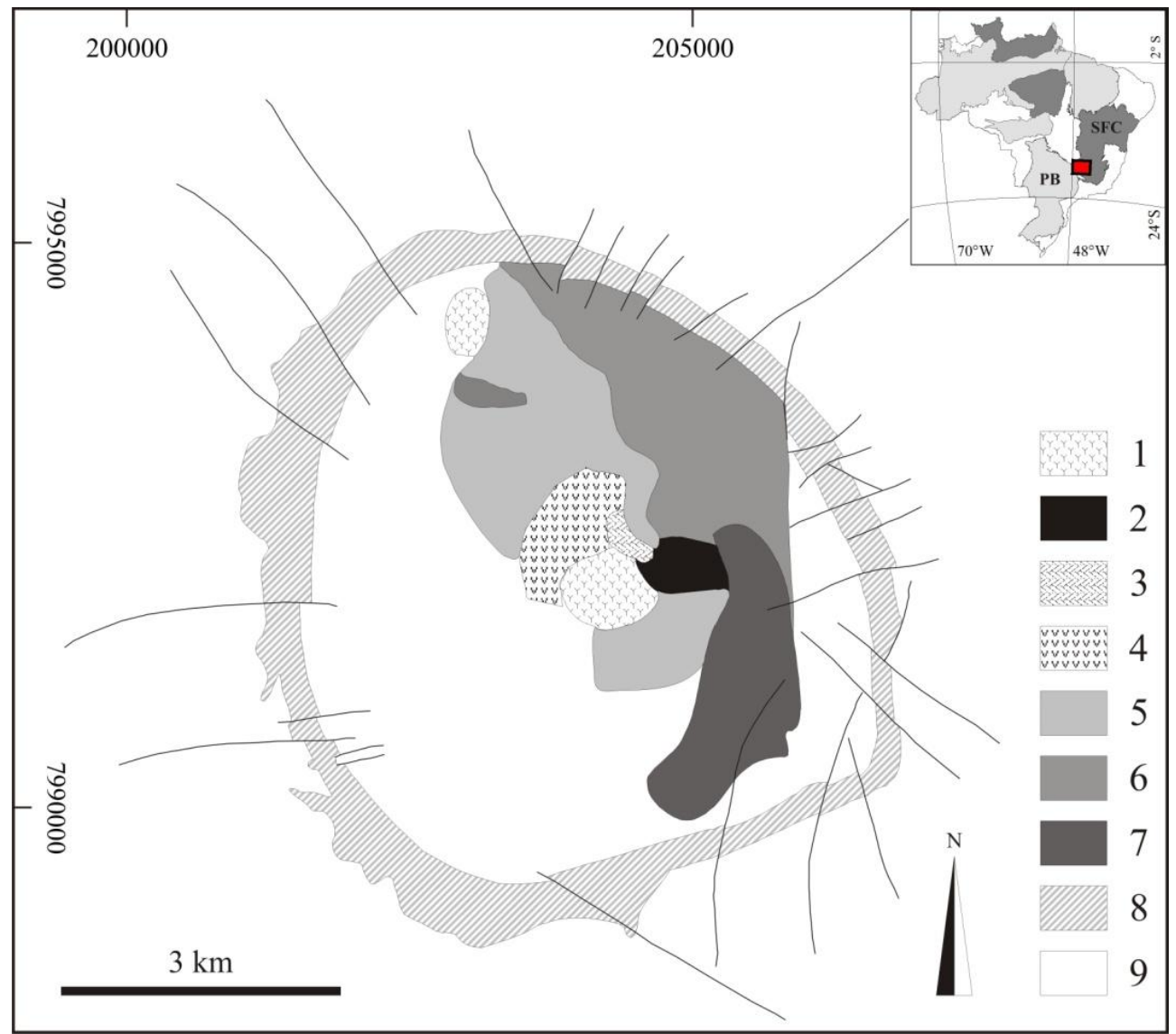

Figure 6.1. Geological sketch from the Catalão I complex (after Ribeiro, 2008). 1- Lacustrine sediments; 2REE-rich carbonatites and monazitites; 3- REE-rich phoscorites and carbonatites; 4- Nelsonites (N1, N2) with magnesiocarbonatites (DC); 5- Phoscorite (P1) with phlogopitite and carbonatite; 6- Phlogopitite with phoscorite and carbonatite; 7- Phlogopitite and serpentinite; 8- Fenite; 9- Area with no outcrops or drillcore information available. Inset shows the location of APIP (red square) between the NE margin of the Paraná Basin (PB - light grey) and the SW border of the São Francisco Craton (SFC - dark grey).

Ribeiro et al. (2014) postulate an evolution of the Catalão I complex by successive and recurrent crystal fractionation and liquid immiscibility events, that produced early-stage ultramafic cumulates (dunites, clinopyroxenites), an intermediate stage characterized by phoscorites, and a late stage formed by nelsonites and dolomite-carbonatites.

Cordeiro et al. $(2010 ; 2011 b)$ detailed the petrography and mineral chemistry of phoscorites, nelsonites and dolomite-carbonatites formed during mid to late-stage evolution of the complex, and associated with the phosphate and niobium ores from Catalão I. Those authors define essentially four stages, briefly described below: (a) Earlier P1 phoscorites consists of coarse- to medium-grained rocks composed essentially of olivine, apatite, phlogopite and magnetite. (b) Late-stage P2 apatite-rich nelsonites and (c) P3 magnetite-rich nelsonites; both composed of apatite, carbonates, magnetite, tetraferriphlogopite and pyrochlore, the latter mineral varying from accessory to up to $50 \%$ vol. in very enriched specimens. The main difference between P2 and P3 nelsonite types is the amount of apatite, 
magnetite and carbonates, the latter reaching up to $20 \%$ vol. in P2 and up to $40 \%$ vol. in P3. Following the suggestion of Palmieri (2011), P2 and P3 are hereafter renamed respectively as N1 and N2. (d) Dolomite carbonatite (DC) pockets coeval with N1 and N2, ranging in size from centimeter to meter, and often comprising an inner zone composed of dolomite, norsethite, and rare barite, surrounded by an outer zone of radial prismatic apatite and elongated crystals of ilmenite, magnetite, pyrochlore and tetraferriphlogopite, similar to a comb-layering texture (Cordeiro et al., 2010).

Field observations at the Boa Vista Niobium Mine, in the nearby Catalão II complex (Palmieri, 2011), show that the DC pockets within N1 and N2 nelsonites have distinct origins. The diffuse outlines observed in N1 DC pockets (Figure 6.2A) and their gradation to interstitial carbonate suggest that they represent immiscible carbonate liquids segregating from the host nelsonite. On the other hand, both N2 nelsonites and their associated DC pockets seem to be related to the percolation of carbonatitic magma through fractures (Figure 6.2B), leading to the progressive incrustation of the walls with different inward-growing mineral phases (e.g., apatite, Fe-Ti oxides, pyrochlore), until the passage becomes completely blocked. The crystallization of carbonates at the final empty would then generate the N2 DC pockets. If this is the case, we can established that carbonates and other solidified phases in the core of the N2 DC pockets represent the last carbonatitic magma to pass through that conduit. It is important to stress that this indicates that $\mathrm{N} 2$ nelsonites are actually produced as wall cumulates from carbonatite, instead of from bona fide phoscorite magmas. Palmieri (2011) argues that these $\mathrm{N} 2$ nelsonitic cumulates should be named pseudonelsonites to reflect their genesis from a carbonate instead of a phosphate-oxide magma. 

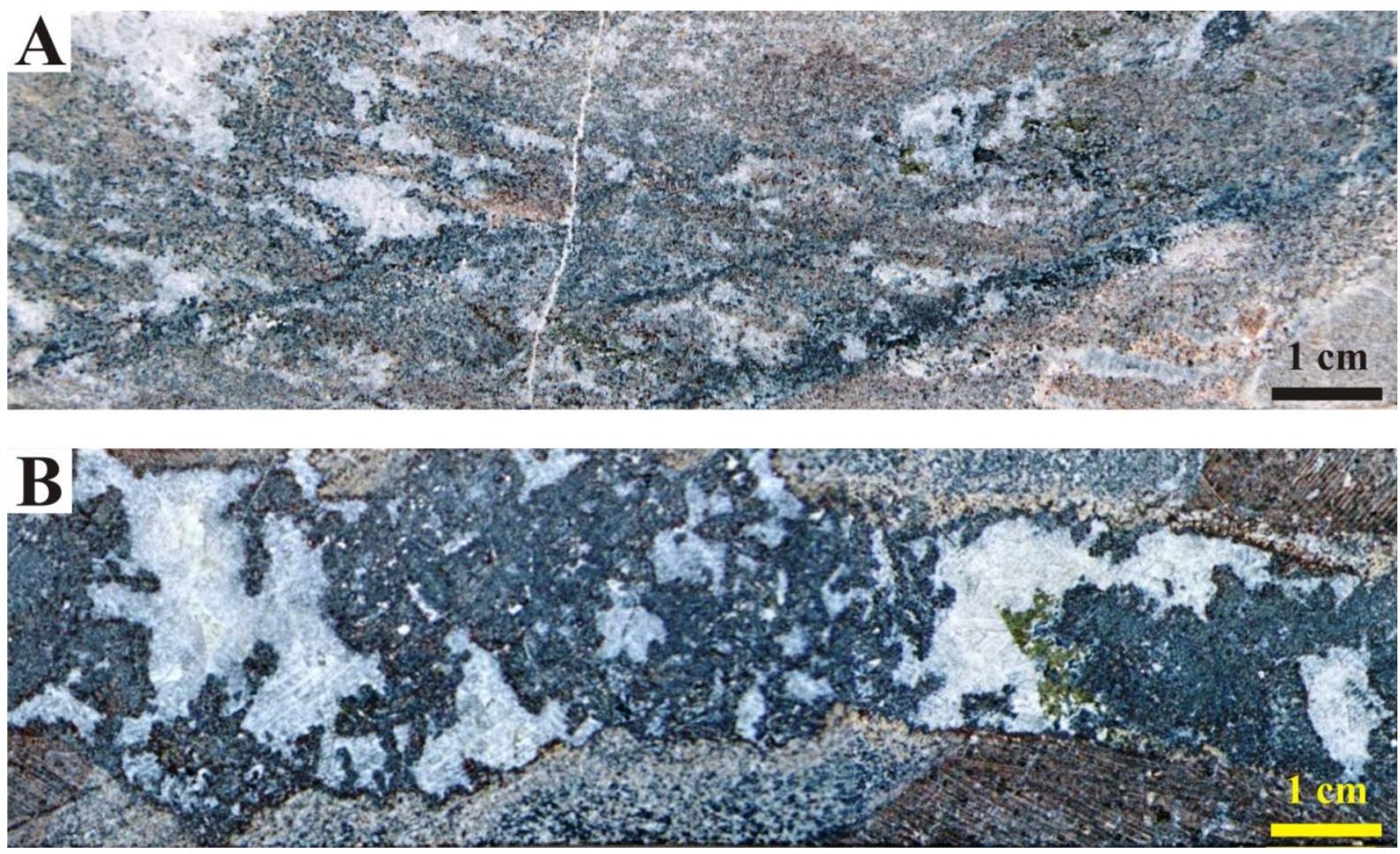

Figure 6.2. Photograph of drill-cores from the Catalão I carbonatite complex. (A) A drill-core sample showing the diffuse texture observed for the DC pockets (white parts) within the apatite-rich N1 nelsonite. (B) Dyke of magnetite-rich $\mathrm{N} 2$ pseudonelsonite and associated DC pockets crosscutting earlier metasomatized rocks. Note that DC pockets are restricted to the dyke walls and seems to be filled the previous empties.

\section{Sample Descriptions}

A brief petrographic description of the four studied niobium-rich rock types is presented below. The samples were careful selected in order to avoid any noticeable alteration. One is an apatite-rich nelsonite (N1, sample NRD339B) consisting of fine- to medium-grained apatite, magnetite, and tetraferriphlogopite, with minor amounts of scattered yellowish-brown pyrochlore and rare clear carbonate crystals. The other three samples (NRD149; NRD170; NRD339B) characterize the association between N2 pseudonelsonites and dolomite carbonatites. These samples are composed of $30-40 \%$ of carbonates, essentially concentrated in pockets surrounded by rims of nelsonitic cumulates. These pseudonelsonite domains consist of fine- to coarse-grained apatite, $\mathrm{Fe}-\mathrm{Ti}$ oxides, tetraferriphlogopite and pyrochlore. Rare barite crystals may occur within the DC pockets (e.g., sample NRD170). A more detailed mineral description, as well as modal compositions, is given in the supplementary data (Appendix A). 


\subsection{Analytical Procedures}

$\mathrm{Nd}$ and $\mathrm{Sr}$ isotopic ratios were determined for two whole-rock samples, in order to complement the whole-rock dataset of Cordeiro et al. (2010; 2011b), and in individual mineral separates comprising apatite, barite, dolomite, magnetite, norsethite, pyrochlore and tetraferriphlogopite from nelsonites, pseudonelsonites and DC pockets. To obtain the mineral separates the rock samples were processed by electrodynamic disaggregation using a SELFRAG $^{\circledR}$ Lab S2.0 High Voltage Pulse Power Fragmentation at voltages of 100-140 kV. This device produces powerful shock waves that disintegrate the rock sample along grain boundaries by tensional stress (Andres, 1996; Gnos et al., 2007; Giese et al., 2010). After disaggregation, all samples were dried and screened in sieves matching the crystal size observed in thin section, to facilitate hand-picking. The minerals of interest were then separated using a Frantz ${ }^{\circledR}$ magnetic separator and careful hand-picking under a binocular microscope to ensure high purity ( $99 \%)$ for each mineral concentrate. Unfortunately, for magnetite and pyrochlore separates such level of purity could not be achieved due to the close association between these two phases. A significant interference of magnetite on the isotopic results of pyrochlore would not be expected given the extremely low concentrations of $\mathrm{Rb}, \mathrm{Sr}$, $\mathrm{Sm}$ and $\mathrm{Nd}$ in magnetite when compared to pyrochlore. However, the opposite assumption is not valid, and the results obtained from magnetite separates would tend to reflect the isotopic composition of the occasional pyrochlore contaminants. Thus, the magnetite isotopic data presented here will be regarded in a conservative way during further interpretations.

Next, we applied leaching procedures analogous to those recommended by Wittig et al. (2009) to our mineral separates. All minerals except apatite were washed with ultra-pure Milli- $\mathrm{Q}^{\circledR}$ water at room temperature $\left(16-18^{\circ} \mathrm{C}\right)$ in an ultrasonic bath for 30 minutes (step 1$)$. After removing this water, the minerals were repeatedly rinsed with Milli- $\mathrm{Q}^{\circledR}$ water before being washed for a second time under the same conditions (step 2). At this stage, carbonates were dried out since they are readily dissolved in inorganic acids. Barite, pyrochlore and tetraferriphlogopite were leached with $2.5 \mathrm{~N} \mathrm{HCl}$ for 30 minutes at $80-100{ }^{\circ} \mathrm{C}$ (step 3). Magnetite concentrates were leached as in step 3 and one more time with $6 \mathrm{~N} \mathrm{HCl}$ for 30 minutes at 80-100 ${ }^{\circ} \mathrm{C}$ (step 4). Between the leaching steps 2, 3, and 4 the minerals were exhaustively rinsed with Milli- $Q^{\circledR}$ water prior to drying out. Apatite was leached following the procedure developed by Oliveira et al. (2015a), which uses dilute acetic acid $(0.5 \mathrm{~N})$ at 80-100 ${ }^{\circ} \mathrm{C}$. All procedures described above were conducted in cleanrooms class 10,000. 
Aliquots of 5 to $10 \mathrm{mg}$ of apatite and pyrochlore, and $100 \mathrm{mg}$ of the other minerals, were spiked with a mixed ${ }^{149} \mathrm{Sm}-{ }^{150} \mathrm{Nd}$ tracer before digestion. Barite, magnetite, pyrochlore, tetraferriphlogopite and whole-rock samples ( $100 \mathrm{mg}$ of sample powder) were dissolved in a mixture of $\mathrm{HF}-\mathrm{HNO}_{3}$ in Parr Teflon ${ }^{\circledR}$ bombs according to the method of Gioia \& Pimentel (2000). For the barite sample, the digestion procedure was repeated because of the very low solubility of this mineral, adding only $\mathrm{HNO}_{3}$ in the second run, as recommended by Puchelt \& Setiobudi (1989). Apatite and carbonate samples were digested with $2 \mathrm{ml}$ of $\mathrm{HCl} 6 \mathrm{~N}$ (carbonates) and $2 \mathrm{ml}$ of concentrated $\mathrm{HNO}_{3}$ (apatite) in Savillex ${ }^{\circledR}$ vials placed on a hot plate for 1 day at $80-100{ }^{\circ} \mathrm{C}$. Once the mineral separates were completed dissolved, two-step ion exchange chromatography was carried out in order to separate $\mathrm{Sm}$ and $\mathrm{Nd}$ fractions from the matrix, following the method developed by Gioia \& Pimentel (2000). An aliquot of $0.5 \mathrm{ml}$ of each sample solution was loaded on quartz glass columns packed with DOWEX ${ }^{\circledR}$ AG-50WX8 cation exchange resin (100-200 mesh) to extract the REE. Sm and Nd fractions were collected via Eichrom ${ }^{\circledR}$ LN-Spec $100-150 \mu \mathrm{m}$ resin in Teflon ${ }^{\circledR}$ columns. Another aliquot of $0.5 \mathrm{ml}$ of the solutions was directly loaded onto Teflon ${ }^{\circledR}$ columns containing approximately $83 \mathrm{mg}$ of Eichrom ${ }^{\circledR}$ Sr-Spec resin $(50-100 \mu \mathrm{m})$ to separate the Sr fraction from the matrix.

Nd isotope measurements were performed using a Thermo Scientific TRITONTM Plus Thermal Ionization Mass Spectrometer operating in the static multi-collector mode whereas $\mathrm{Sr}$ isotopic compositions were determined with the same equipment in the multi-dynamic mode. The average ${ }^{143} \mathrm{Nd} /{ }^{144} \mathrm{Nd}$ obtained for the USGS BHVO-1 standard was $0.512996 \pm$ $0.000006(2 S D ; n=7)$ and the average ${ }^{87} \mathrm{Sr} /{ }^{86} \mathrm{Sr}$ obtained for the NBS-987 standard was $0.710257 \pm 0.000007(2 S D ; n=9)$ during the course of this study. The BHVO-1 result is in excellent agreement with the most recently published values (e.g., $0.512986 \pm 0.000009$ Weis et al., 2005). The value obtained for standard NBS-987 also agrees with the recommended ${ }^{87} \mathrm{Sr} /{ }^{86} \mathrm{Sr}=0.71025$ (Thirlwall, 1991; Machado, 2013). The analytical precision of $\pm 0.1 \%$ is estimated for $\mathrm{Sm}$ and $\mathrm{Nd}$ concentrations determined by isotopic dilution. Sm and Nd blanks were less than $\sim 0.25 \mathrm{ng}$. Although the $\mathrm{Rb}$ and $\mathrm{Sr}$ contents of mineral separates could not be determined in this work, the measured ${ }^{87} \mathrm{Sr} /{ }^{86} \mathrm{Sr}$ ratios of minerals with extremely low $\mathrm{Rb} / \mathrm{Sr}$ (in our study, apatite, carbonates and pyrochlore) can be considered initial ratios (Zaitsev \& Bell, 1995). For details regarding mass fractionation corrections, see the footnotes of Table 6.1. All sample preparation procedures and isotope determinations were carried out at the Laboratory of Geodynamics, Geochronology and Environmental Studies of the Institute of Geosciences, University of Brasília. 


\subsection{RESULTS}

The Sm-Nd and Sr isotopic data for the mineral separates and whole-rock samples are given in Table 6.1. In view of the lack of high-resolution dating for the Catalão I complex, all initial $\mathrm{Sr}$ and $\mathrm{Nd}$ ratios were calculated assuming an age of $85 \mathrm{Ma}$ as representative for the whole of APIP (Gibson et al., 1995).

Overall, minerals taken from the different samples show a remarkable variation in their $\mathrm{Sr}$ isotopic compositions. Initial ${ }^{87} \mathrm{Sr} /{ }^{86} \mathrm{Sr}$ ratios for all mineral separates range from 0.705284 to 0.705404 . N1 apatite has the least radiogenic ${ }^{87} \mathrm{Sr} /{ }^{86} \mathrm{Sr}_{\mathrm{i}}(0.705284)$ among all analysed minerals and, albeit the only mineral phase analysed from N1 nelsonites, its isotopic composition is consistent with the whole-rock data (Figure 6.3).
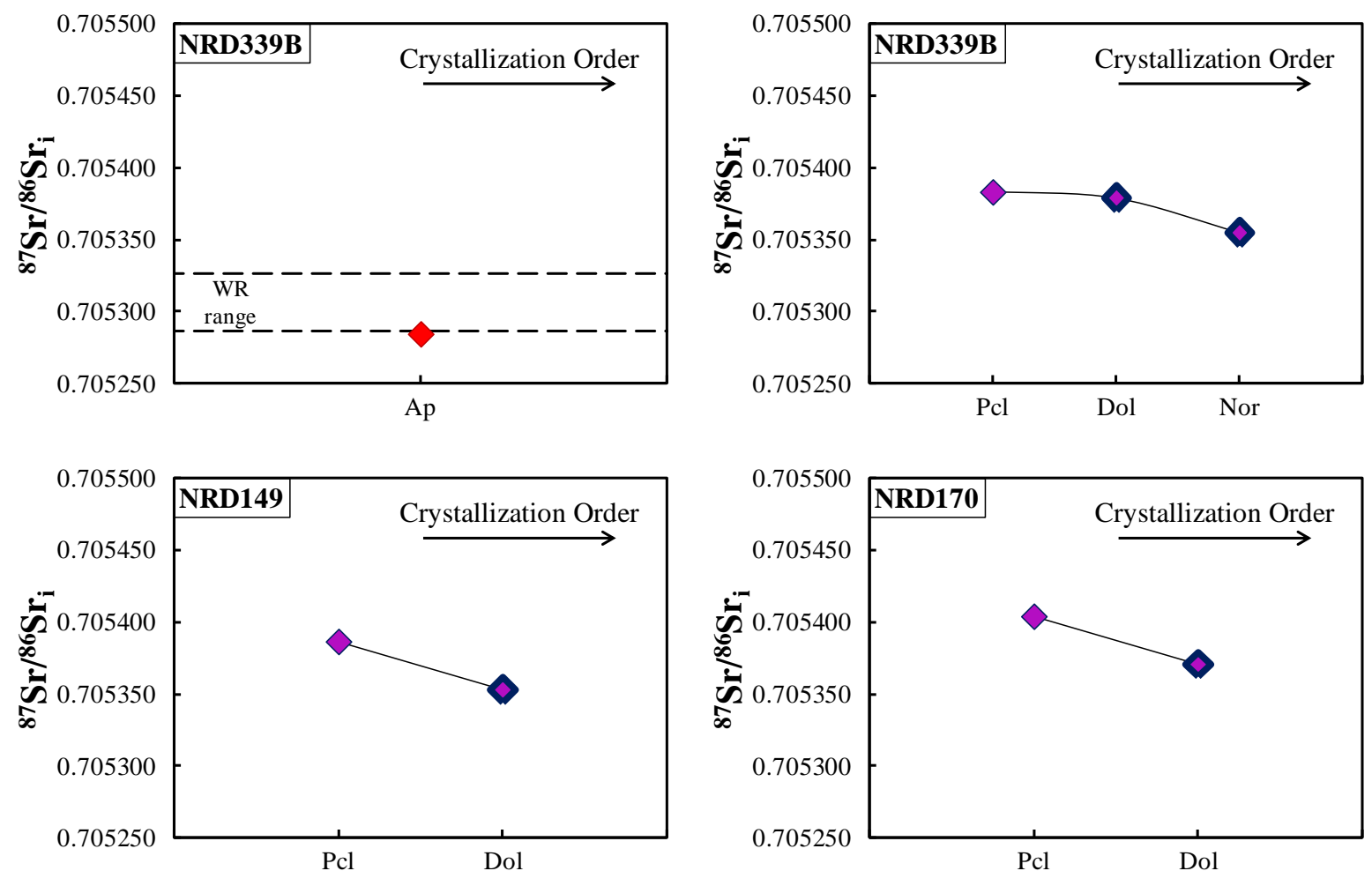

Figure 6.3. ${ }^{87} \mathrm{Sr} /{ }^{86} \mathrm{Sr}_{\mathrm{i}}$ obtained for mineral separates from $\mathrm{N} 1$ (red diamond) and N2 (purple diamonds) nelsonites. Symbols with heavy outlines are carbonates from the DC pockets associated with each nelsonite. All symbols are larger than their associated analytical errors $( \pm 2 \mathrm{SE})$. Dashed lines on the topleft chart mark the compositional variation determined for the whole-rock (WR - Cordeiro et al., 2011b). All charts are to the same vertical scale. Ap - apatite; Dol - dolomite; Nor - norsethite; Pcl - pyrochlore.

Minerals from N2/DC pseudonelsonites display more enriched ${ }^{87} \mathrm{Sr}^{86} \mathrm{Sr}_{\mathrm{i}}$, varying from 0.705353 to 0.705404 , when compared with $\mathrm{N} 1$ apatite and whole-rock values. It is clear that a $\mathrm{Sr}$ isotopic disequilibrium occurs between the late-crystallizing carbonates and the earlier formed pyrochlore in all samples (Figure 6.3). Note that, in the case of sample NRD339B 
(N2/DC), norsethite is the latest carbonate phase to crystallize. Interestingly, pyrochlore exhibits ${ }^{87} \mathrm{Sr}^{86} \mathrm{Sr}_{\mathrm{i}}$ that are systematically higher than those of the corresponding latestcrystallizing carbonate in each sample, by a factor of $\sim 0.000030$. Bearing in mind the high precision of our mineral isotopic data (Table 6.1), such differences are particularly significant.

Although values from pyrochlore concentrates represent an average isotopic composition of individual crystals, their more radiogenic compositions, compared with that of latest crystallizing carbonatite magma recorded in the DC pockets indicates that carbonate melts of distinct ${ }^{87} \mathrm{Sr}^{86}{ }^{86} r_{i}$ passed through the conduits to form such rocks. If there is withingrain isotopic disequilibrium in pyrochlore, some of the carbonate melts involved in the generation of these rocks could be even more enriched in radiogenic ${ }^{87} \mathrm{Sr}$ than the average values obtained here (see discussion in Davidson et al., 2007).

The overall range of ${ }^{143} \mathrm{Nd} /{ }^{144} \mathrm{Nd}_{\mathrm{i}}$ in our mineral separates is 0.512138 to 0.512216 . If only individual minerals from each rock type individually are considered, N1 concentrates show a much narrower range of ${ }^{143} \mathrm{Nd} /{ }^{144} \mathrm{Nd}_{\mathrm{i}}$ than N2/DC minerals (Table 6.1). Furthermore, there is a large difference between the $\mathrm{Nd}$ isotopic compositions of $\mathrm{N} 1$ and $\mathrm{N} 2$ minerals, similar to what was observed in the $\mathrm{Sr}$ isotope data. This must somehow reflect the wide $\mathrm{Nd}$ isotope variations noted by Cordeiro et al. (2010, 2011b) between whole-rock samples.

Apatite and tetraferriphlogopite from $\mathrm{N} 1$ nelsonite have the highest ${ }^{143} \mathrm{Nd} /{ }^{144} \mathrm{Nd}_{\mathrm{i}}$ among all our samples (0.512216 and 0.512211, respectively), are in equilibrium in terms of $\mathrm{Nd}$ isotopes and within the N1 whole-rock range (Figure 6.4). Although apatite contains very high $\mathrm{Sm}$ and $\mathrm{Nd}$, when compared with tetraferriphlogopite, both minerals show similar $\mathrm{Sm} / \mathrm{Nd}$ ratios (Table 6.1) in N1 samples. Minerals from N2 pseudonelsonites and from the associated DC pockets have more enriched $\mathrm{Nd}$ isotopic compositions, ranging from 0.512138 to 0.512182 . Although some overlap exists, initial ${ }^{143} \mathrm{Nd} /{ }^{144} \mathrm{Nd}$ ratios of mineral separates are slightly higher than their corresponding DC pockets (Figure 6.4). A similar situation is described for the Salitre I phoscorites, where whole-rock $\mathrm{Nd}$ isotope signatures are much more enriched than the essential mineral phases (Oliveira et al., 2015b). Despite minor variations between mineral and whole-rock data, no clear distinction can be made between N2 and DC Nd isotopic compositions in our samples. Although ${ }^{143} \mathrm{Nd} /{ }^{144} \mathrm{Nd}_{\mathrm{i}}$ of barite is slightly higher than that of other mineral phases from the sample NRD170, as a general rule all minerals from a particular sample are in isotopic equilibrium, considering the analytical errors. 
Capítulo 6: Complexo de Catalão I

Table 6.1. Sr and Nd isotopic data from the Catalão I samples.

\begin{tabular}{|c|c|c|c|c|c|c|c|c|c|c|c|c|c|}
\hline \multirow{2}{*}{$\begin{array}{c}\text { Sample } \\
\text { NRD339B }\end{array}$} & \multirow{2}{*}{$\frac{\text { Mineral }}{\mathrm{Ap}}$} & \multirow{2}{*}{$\begin{array}{l}\text { Unit } \\
\mathrm{N} 1\end{array}$} & \multirow{2}{*}{$\begin{array}{c}\begin{array}{c}\mathbf{S m} \\
(\mathbf{p p m})\end{array} \\
243.58\end{array}$} & \multirow{2}{*}{$\begin{array}{c}\begin{array}{c}\text { Nd } \\
(\mathbf{p p m})\end{array} \\
1940.57\end{array}$} & \multirow{2}{*}{$\begin{array}{c}{ }^{{ }^{147} \mathbf{S m} /{ }^{144} \mathbf{N d}} \\
\text { (atomic) }^{\mathbf{a}}\end{array}$} & \multicolumn{3}{|c|}{$\begin{array}{l}{ }^{143} \mathrm{Nd} /{ }^{144} \mathrm{Nd}_{\mathrm{m}} \\
(\mathrm{measured}){ }^{\mathrm{b}}\end{array}$} & \multirow{2}{*}{$\begin{array}{c}\begin{array}{c}{ }^{143} \mathbf{N d} /{ }^{144} \\
\text { (initial }^{\mathbf{N}} \mathbf{d}_{\mathbf{i}}\end{array} \\
0.512216\end{array}$} & \multicolumn{3}{|c|}{$\begin{array}{c}{ }^{87} \mathrm{Sr} /{ }^{86} \mathrm{Sr}_{\mathrm{m}} \\
(\text { measured })^{b}\end{array}$} & \multirow{2}{*}{$\begin{array}{c}{ }^{{ }^{87} \mathbf{S r} /{ }^{86} \mathbf{S r}} \\
\text { (initial) } \\
0.705284\end{array}$} \\
\hline & & & & & & 0.512258 & \pm & 0.000022 & & 0.705284 & \pm & 0.000003 & \\
\hline NRD339B & Tfphl & N1 & 11.43 & 86.63 & 0.0798 & 0.512255 & \pm & 0.000012 & 0.512211 & - & & - & - \\
\hline NRD149 & WR & $\mathrm{N} 2$ & 93.7 & 817.8 & 0.0692 & 0.512212 & \pm & 0.000023 & 0.512173 & 0.705420 & \pm & 0.000010 & 0.705384 \\
\hline NRD149 & $\mathrm{Pcl}$ & $\mathrm{N} 2$ & 386.31 & 4353.09 & 0.0536 & 0.512201 & \pm & 0.000003 & 0.512171 & 0.705387 & \pm & 0.000003 & 0.705387 \\
\hline NRD149 & Dol & DC & 8.88 & 81.63 & 0.0657 & 0.512185 & \pm & 0.000017 & 0.512149 & 0.705353 & \pm & 0.000003 & 0.705353 \\
\hline NRD170 & Mag & $\mathrm{N} 2$ & 31.61 & 323.45 & 0.0591 & 0.512171 & \pm & 0.000013 & 0.512138 & - & & - & - \\
\hline NRD170 & Pcl & $\mathrm{N} 2$ & 404.57 & 4983.03 & 0.0491 & 0.512173 & \pm & 0.000014 & 0.512146 & 0.705404 & \pm & 0.000003 & 0.705404 \\
\hline NRD170 & Tfphl & $\mathrm{N} 2$ & 0.99 & 8.86 & 0.0676 & 0.512191 & \pm & 0.000008 & 0.512154 & - & & - & - \\
\hline NRD170 & Dol & DC & 13.00 & 105.84 & 0.0742 & 0.512181 & \pm & 0.000024 & 0.512140 & 0.705371 & \pm & 0.000002 & 0.705371 \\
\hline NRD170 & Brt & DC & 3.49 & 30.40 & 0.0694 & 0.512221 & \pm & 0.000026 & 0.512182 & - & & - & - \\
\hline NRD339B & & $\mathrm{N} 2$ & 5.95 & 66.78 & 0.0538 & 0.512176 & \pm & 0.000011 & 0.512146 & - & & - & - \\
\hline NRD339B & Tfphl & $\mathrm{N} 2$ & 0.66 & 6.61 & 0.0600 & 0.512195 & \pm & 0.000006 & 0.512161 & - & & - & - \\
\hline NRD339B & & $\mathrm{N} 2$ & - & - & - & - & & - & - & 0.705383 & \pm & 0.000003 & 0.705383 \\
\hline NRD339B & WR & DC & 11.2 & 123.8 & 0.0548 & 0.512175 & \pm & 0.000007 & 0.512145 & 0.705367 & \pm & 0.000006 & 0.705367 \\
\hline NRD339B & Dol & DC & 6.14 & 44.95 & 0.0826 & 0.512194 & \pm & 0.000009 & 0.512148 & 0.705379 & \pm & 0.000006 & 0.705379 \\
\hline NRD339B & Nor & DC & 75.18 & 556.63 & 0.0817 & 0.512198 & \pm & 0.000008 & 0.512153 & 0.705355 & \pm & 0.000004 & 0.705355 \\
\hline
\end{tabular}

${ }^{a}$ Atomic ratios, calculated from Sm and Nd concentrations according to Gioia \& Pimentel (2000).

${ }^{\mathrm{b}}$ Measured ratios, normalized to ${ }^{146} \mathrm{Nd} /{ }^{144} \mathrm{Nd}=0.7219$ and ${ }^{88} \mathrm{Sr} /{ }^{86} \mathrm{Sr}=8.375209$ (equivalent to the more commonly used ${ }^{86} \mathrm{Sr} /{ }^{88} \mathrm{Sr}$ ratio of 0.1194 ) using an exponential law; errors are two standard errors (2SE) of the in-run means, at $95 \%$ confidence level $(2 \sigma)$.

${ }^{\mathrm{c}}$ Initial ratios, calculated at $85 \mathrm{Ma}$ using the ${ }^{147} \mathrm{Sm}$ decay constant $\left(\lambda_{\mathrm{Sm}}\right)$ of $6.54 \times 10^{-12} \mathrm{yr}^{-1}$ (Lugmair \& Marti, 1978) and the ${ }^{87} \mathrm{Rb}$ decay constant $\left(\lambda_{\mathrm{Rb}}\right)$ of $1.393 \times 10^{-11} \mathrm{yr}^{-1}$ (Nebel et al., 2011).

- Value not determined. 

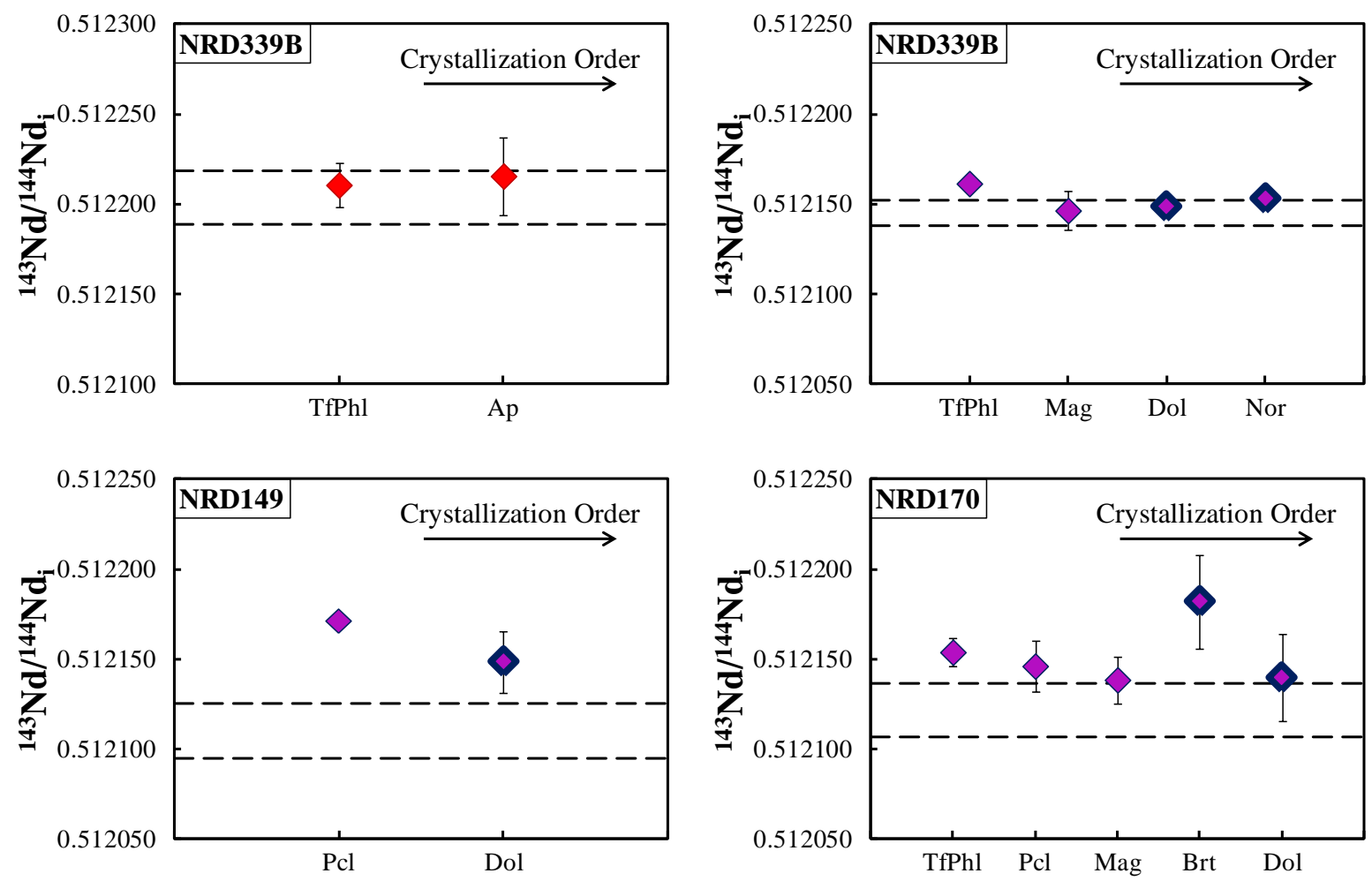

Figure 6.4. ${ }^{143} \mathrm{Nd} /{ }^{144} \mathrm{Nd}_{\mathrm{i}}$ obtained for mineral separates from $\mathrm{N} 1$ (red diamonds) and N2 (purple diamonds) nelsonites. Symbols with heavy outlines are the DC pockets associated with each nelsonite. The error bars represents \pm 2 SE. Dashed lines in each chart mark the variation for whole-rock (N1) and DC pockets (N2), Cordeiro et al., (2011b) and this study. All charts are to the same vertical scale. Ap - apatite; Brt - barite; Dol - dolomite; Mag - magnetite; Nor - norsethite; Pcl - pyrochlore; TfPhl - tetraferriphlogopite.

Interestingly, tetraferriphlogopite, pyrochlore and magnetite from $\mathrm{N} 2$ pseudonelsonites have $\mathrm{Sm} / \mathrm{Nd}$ systematically lower $(0.0572$, on average) than minerals crystallized in the DC pockets (i.e., barite and carbonates, average $\mathrm{Sm} / \mathrm{Nd}$ of 0.0747 ), indicating that those minerals crystallized at the dyke walls are extremely enriched in LREE relatively to HREE. Bulk analyses of the DC pockets (Cordeiro et al., 2011b) also show lower $\mathrm{Sm} / \mathrm{Nd}$ ratios than the carbonate phases separated from them, indicating that bulk samples are more enriched in LREE than single dolomite/norsethite crystals. This may be related with more enriched $\mathrm{Nd}$ isotope compositions obtained for whole-rocks (Figure 6.4), perhaps due to unidentified phases crystallized during post-magmatic processes that did not affect the main minerals.

Notably pyrochlore show very high $\mathrm{Nd}$ abundances (i.e., more than $4000 \mathrm{ppm}$ ), and the occurrence of $\sim 5$ to $10 \%$ pyrochlore inclusions in magnetite crystals should affect the $\mathrm{Nd}$ contents of magnetite separates. In sample NRD170, magnetite yielded over 300 ppm Nd, which is well in excess of the expected $\mathrm{Nd}$ content for this mineral. The ${ }^{143} \mathrm{Nd} /{ }^{144} \mathrm{Nd}_{\mathrm{m}}$ in pyrochlore and magnetite from this sample are virtually identical, suggesting that the ${ }^{143} \mathrm{Nd} /{ }^{144} \mathrm{Nd}$ is strongly controlled by the pyrochlore inclusions. Presumably, the same is true 
for magnetite from sample NRD339B (Figure 6.4), which contains $67 \mathrm{ppm} \mathrm{Nd}$. The ${ }^{143} \mathrm{Nd} /{ }^{144} \mathrm{Nd}_{\mathrm{m}}$ of pyrochlore in this sample yielded too large analytical error and was discarded, but the isotope ratio of magnetite is similar, within the error, to that of NRD170 pyrochlore and magnetite separates. Therefore, if isotopic equilibrium is preserved, as for the other samples, it is unlikely that the NRD339B pyrochlore composition would deviate significantly from that measured in the magnetite concentrate.

\subsection{DISCUSSION AND CONCLUSIONS}

Oliveira et al. (2015b) proposed that successive evolution stages between the petrogenetic series of the APIP alkaline-carbonatite complexes could be marked by a decrease in $\mathrm{Ca} / \mathrm{Sr}$, together with a relative increase in the degree of LREE/HREE enrichment. Field observations, whole-rock geochemistry and mineral chemistry have established that niobium ores of the Catalão I complex were formed during late stages of the magmatic evolution (Ribeiro, 2008; Cordeiro et al., 2010, 2011b; Ribeiro et al., 2014). Following Oliveira et al. (2015b), N1 nelsonites barely overlap the low $\mathrm{Ca} / \mathrm{Sr}$ ratios of the most evolved carbonatites from the Salitre I complex (Figure 6.5) and N2/DC nelsonites show even lower $\mathrm{Ca} / \mathrm{Sr}$ along with higher degrees of LREE enrichment (i.e., more negative values of the $f_{\mathrm{Sm} / \mathrm{Nd}}$ parameter), confirming the more evolved nature of these rocks. In addition, the Catalão I early phoscorites (P1) seem to be already more evolved than any Salitre I phoscorites (Figure 6.5).

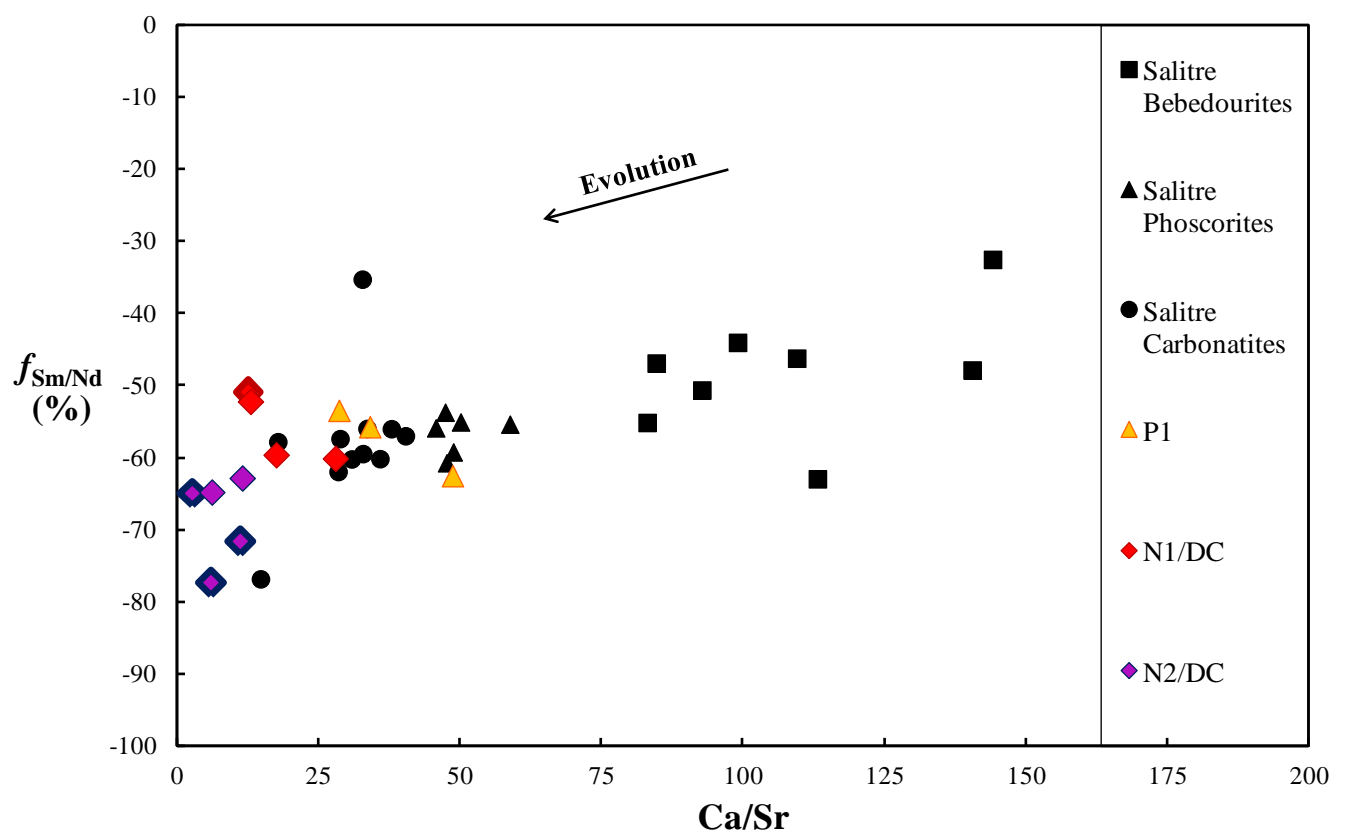

Figure 6.5. Comparison between the evolution stages of Catalão I and Salitre I rocks. Symbols with heavy outlines are the DC pockets associated with each nelsonite (N1 and N2). Data sources: Catalão I Cordeiro et al. $(2010 ; 2011 b)$ and this study; Salitre I - Oliveira et al. $(2015 \mathrm{~b}) . f_{\mathrm{Sm} / \mathrm{Nd}}=\left[\left({ }^{147} \mathrm{Sm} /{ }^{144} \mathrm{Nd}\right)_{\mathrm{sample}} /\right.$ $\left.\left({ }^{147} \mathrm{Sm} /{ }^{144} \mathrm{Nd}\right)_{\mathrm{CHUR}}-1\right]^{* 10^{2}}$ following DePaolo \& Wasserburg $(1976) ;\left({ }^{147} \mathrm{Sm} /{ }^{144} \mathrm{Nd}\right)_{\mathrm{CHUR}}=0.1967$. 
When compared with Salitre I phoscorites and carbonatites, late-stage rocks of the Catalão I complex have more radiogenic Sr isotope compositions (Figure 6.6). Although $\mathrm{Nd}$ and $\mathrm{Sr}$ isotope data are lacking for the Catalão I least evolved rocks, the enriched isotope signatures obtained here could derive from carbonated-silicate parental magmas that underwent higher degrees of crustal contamination than those deduced from AFCLI modelling in the Salitre I complex (Oliveira et al., 2015b). In detail, Sr and $\mathrm{Nd}$ isotopes in minerals clearly show that N1 and N2 nelsonites from Catalão I derived from magmas with distinct isotope compositions. This is consistent with the interpretation that $\mathrm{N} 1$ rocks crystallize from a phosphate-oxide (nelsonitic, or phoscoritic magma) whereas N2 rocks formed as the result of crystal accumulation in the walls of fractures during continuous percolation of carbonatite magma (Palmieri, 2011). The described isotopic features could be explained by several batches of immiscible carbonate melts originated from more or less crust-contaminated carbonate-silicate parental magmas such as phlogopite picrites. The least evolved rocks (N1) are systematically less enriched than most evolved ones (N2/DC), as expected if the isotopic compositions are contamination-driven.

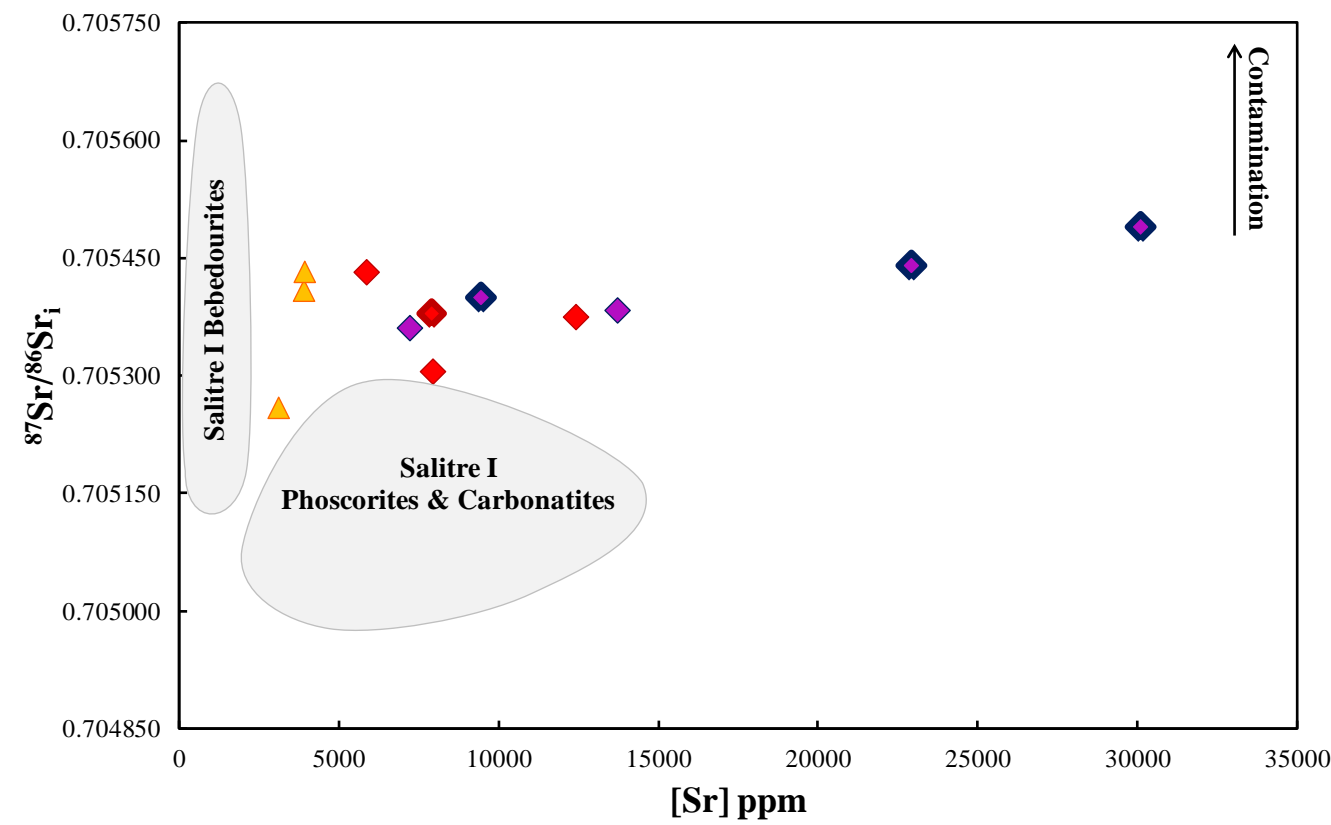

Figure 6.6. Plot of initial ${ }^{87} \mathrm{Sr} /{ }^{86} \mathrm{Sr}$ ratios versus $\mathrm{Sr}$ content comparing the isotopic compositions of Salitre I and Catalão I whole-rocks (see text for details). Vertical arrow illustrates the changes due to crustal contamination. Data from Cordeiro et al. $(2010 ; 2011 b)$ and this study. Fields of Salitre I rocks based on Oliveira et al. $(2015 \mathrm{~b})$. All ${ }^{87} \mathrm{Sr} /{ }^{86} \mathrm{Sr}_{\mathrm{i}}$ were recalculated at $85 \mathrm{Ma}$ using the ${ }^{87} \mathrm{Rb}$ decay constant $\left(\lambda_{\mathrm{Rb}}\right)$ of $1.393 \mathrm{x10}^{-11} \mathrm{yr}^{-1}$ (Nebel et al., 2011). Symbols as in Figure 6.5.

Cordeiro et al. (2010) proposed a progressive magmatic evolution from N1 to N2 nelsonites on the basis of mineral chemistry data. In addition, Cordeiro et al. $(2010 ; 2011 b)$ 
recognized a much wider span in initial $\mathrm{Nd}$ isotope ratios than that of $\mathrm{Sr}$ isotopes in wholerock data. A detailed examination of these isotopic signatures, depicted in Figure 6.7, shows that two distinct trends may be identified. Path $\mathrm{A}$ it a continuous $\mathrm{Sr}$ and $\mathrm{Nd}$ isotopic enrichment trend from N1 nelsonites to the latest-stage N2 pseudonelsonites and DC pockets, which is consistent with crustal contamination, involving either hydrothermal fluid-rock interactions or chemical exchange between the highly reactive carbonate melts and wallrock (e.g., Andersen, 1987; Walter et al., 1995; Tichomirowa et al., 2006; Ray, 2009). The occurrence of the late-stage niobium-rich rocks often emplaced as shallow level dyke/plug stockworks (Ribeiro et al., 2005) should facilitate the input of crustal components in the more evolved carbonate melts. On the other hand, another evolution path toward much more enriched $\mathrm{Nd}$ isotope compositions at nearly constant initial $\mathrm{Sr}$ isotope ratios can be noted in Figure 6.7 (path B). Our isotopic results from mineral separates also plot selectively in one or the other of the two trends (Figure 6.7). Pyrochlore and apatite compositions seem to plot along the path A, whereas dolomite and norsethite separates, together with whole-rock isotopes from monazite-bearing carbonatites and carbonatite vein plot along the path B.

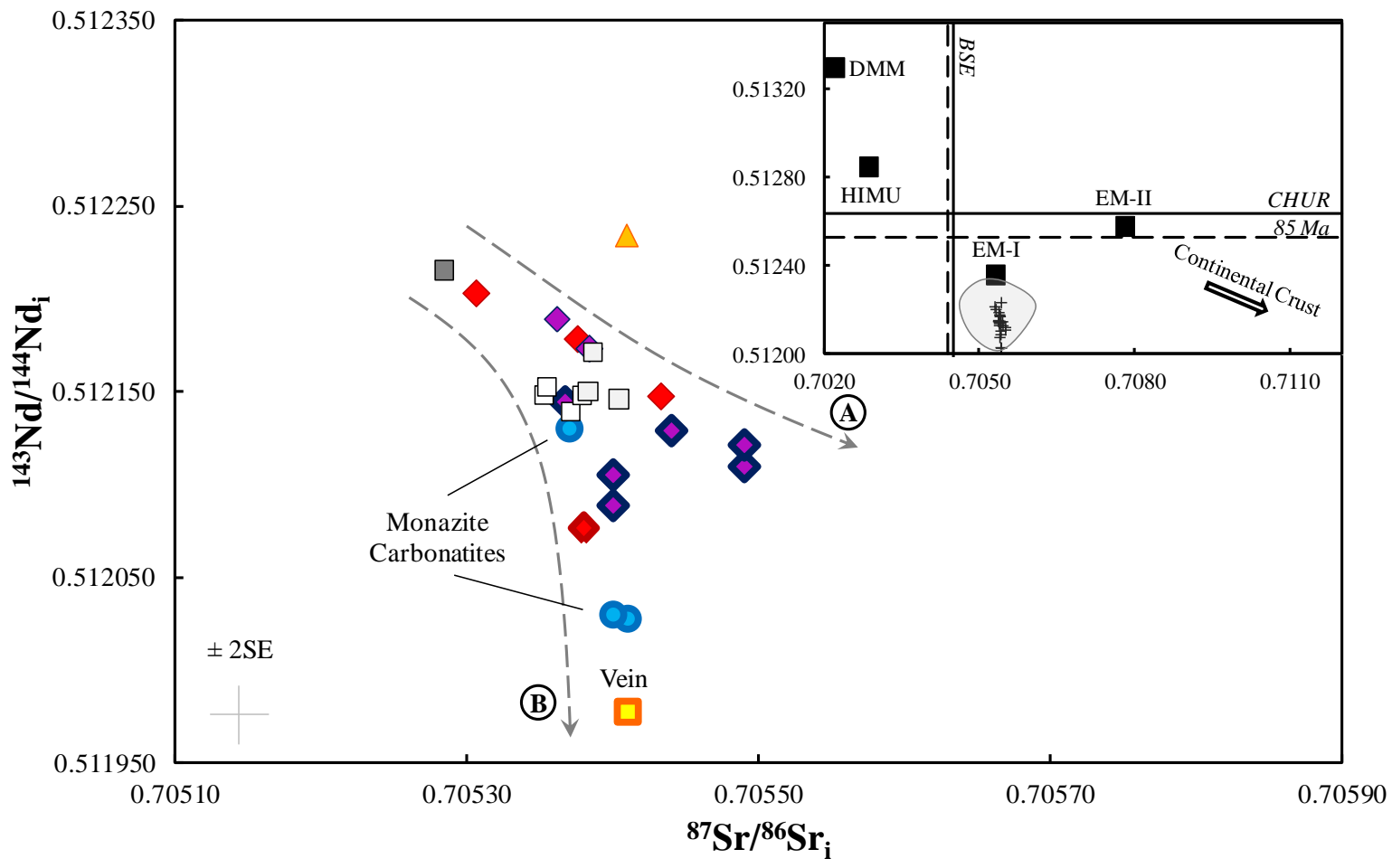

Figure 6.7. ${ }^{143} \mathrm{Nd} /{ }^{144} \mathrm{Nd}_{\mathrm{i}}$ versus ${ }^{87} \mathrm{Sr} /{ }^{86} \mathrm{Sr}_{\mathrm{i}}$ correlation diagram for Catalão I rocks (Symbols as in Figure 6.5) and minerals (apatite - dark grey square; pyrochlore - light grey squares and carbonates - open squares). Also shown are two possible evolution paths (Dashed lines - see text for details). Data from Cordeiro et al. $(2010 ; 2011 b)$ and this study. All isotope data were recalculated to $85 \mathrm{Ma}$ using decay constants $\lambda^{87}{ }_{\mathrm{Rb}}$ and $\lambda^{147}$ Sm of $1.393 \times 10^{-11} \mathrm{yr}^{-1}$ e $6.54 \times 10^{-12} \mathrm{yr}^{-1}$, respectively. Inset shows the APIP carbonatite field (Oliveira $e t$ $a l ., 2015 b)$ with the Catalão I data plotted (black crosses) for comparison. 
Despite their lower ${ }^{143} \mathrm{Nd} /{ }^{144} \mathrm{Nd}_{\mathrm{i}}$, monazite-bearing carbonatites display extremely high Nd abundances (Figure 6.8). A N2/DC pocket with turbid aspect, which is indicative of postmagmatic recrystallization (Cordeiro et al., 2011b), plot close to these carbonatites. Stable isotope $(\mathrm{C}, \mathrm{O})$ data from Catalão I suggest that interaction with crustal materials and/or lowtemperature fluids was widespread (Morikiyo et al.,1990; Toyoda et al., 1994; Santos \& Clayton, 1995; Cordeiro et al., 2011b). In particular, the wide ranges and strong positive correlation in $\delta^{13} \mathrm{C}$ vs $\delta^{18} \mathrm{O}$ diagrams (Cordeiro et al., 2011b) suggest that monazite-bearing carbonatites have formed in a $\mathrm{CO}_{2}-\mathrm{H}_{2} \mathrm{O}$-rich system. There is also evidence from sulphur stable isotopes (Gomide et al., 2013) that recurring degassing events took place at the final stages of evolution of Catalão I, suggesting a major role of carbonatite-derived fluids in the formation of late-stage rocks.

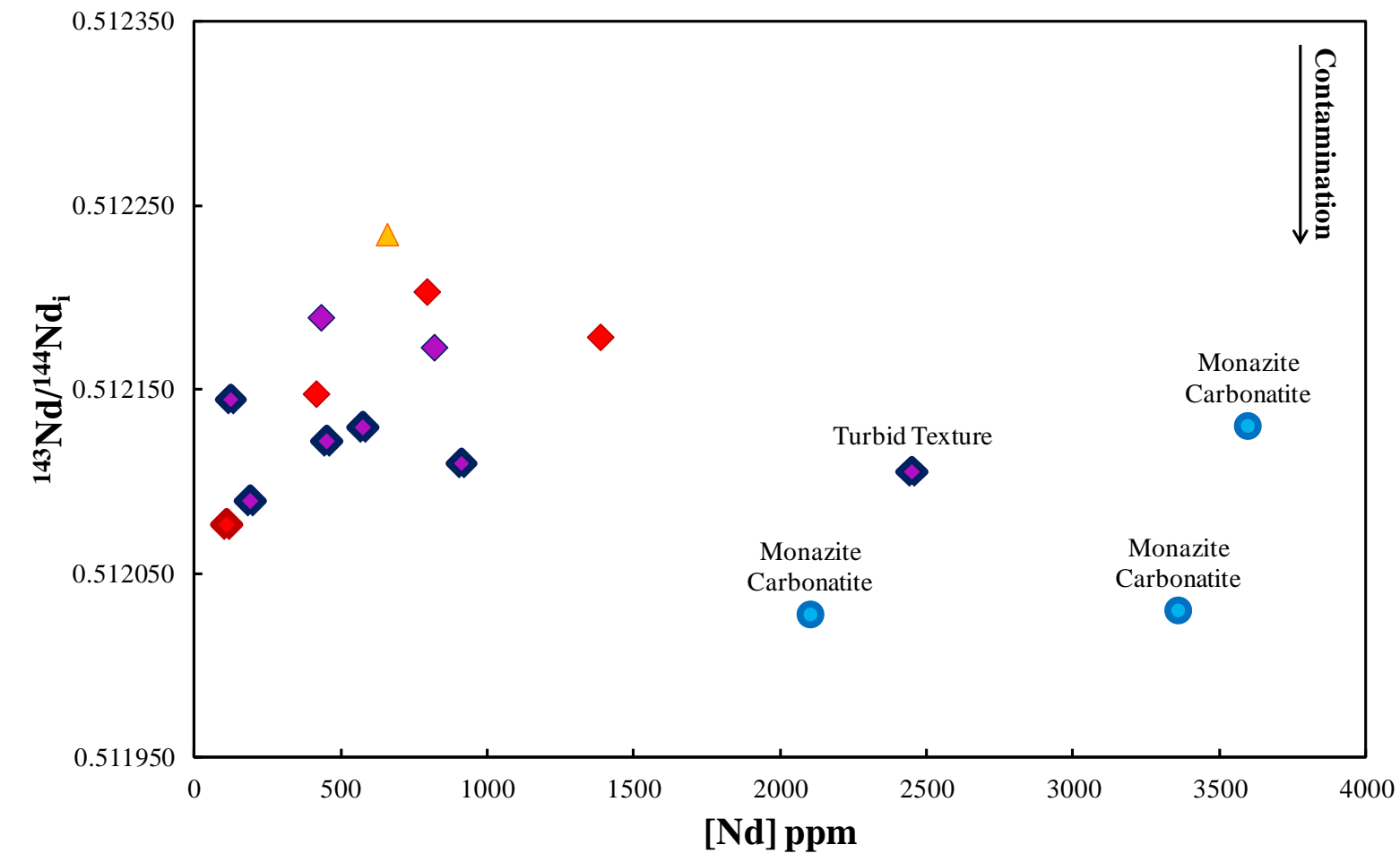

Figure 6.8. Plot of ${ }^{143} \mathrm{Nd} /{ }^{144} \mathrm{Nd}_{\mathrm{i}}$ versus $\mathrm{Nd}$ content for the most evolved rocks from the Catalão I complex. Vertical arrow illustrates the changes due to crustal contamination. Data from Cordeiro et al. (2010; 2011b) and this study. All ${ }^{143} \mathrm{Nd} /{ }^{144} \mathrm{Nd}_{\mathrm{i}}$ were recalculated at $85 \mathrm{Ma}$ using the ${ }^{147} \mathrm{Sm}$ decay constant $\left(\lambda_{\mathrm{Sm}}\right)$ of $6.54 \mathrm{x} 10^{-12} \mathrm{yr}^{-1}$ (Lugmair \& Marti, 1978). Symbols as in Figure 6.5.

The apparent inconsistency among the evolution paths recognized for the most evolved rocks of Catalão I may be explained by a change in the fractionating assemblage of carbonate melts that has been affected by significant fluid-rock chemical exchanges with crustal components. Calculated AFC model curves (DePaolo, 1981) shows that the observed $\mathrm{Sr}$ and $\mathrm{Nd}$ isotope range in path $\mathrm{A}$ may be explained by extensive fractionation of an 
assemblage of apatite (40\%), magnetite (40\%), calcite (15\%) and pyrochlore (5\%), which correspond to a nelsonite of pseudonelsonite system (Figure 6.9). Path B could be explained by fractionation of a monazite-bearing carbonatite assemblage containing $95 \%$ of dolomite plus norsethite, and 5\% of monazite (Figure 6.9). Details of the parameters involved in the mathematical modelling are given in Table 6.2.

Table 6.2. AFC model parameters.

\begin{tabular}{cccccc}
\hline $\begin{array}{c}\text { AFC } \\
\text { Model Curve }\end{array}$ & r & D(Sr) $^{*}$ & D(Nd) $^{*}$ & Starting Carbonate Melt \\
[Sr] & [Nd] \\
\hline Path A & 0.3 & 1.825 & 1.715 & $45000 \mathrm{ppm}$ & $400 \mathrm{ppm}$ \\
Path B & 0.15 & 0.765 & 2.595 & $12000 \mathrm{ppm}$ & $400 \mathrm{ppm}$ \\
\hline
\end{tabular}

*Bulk mineral-rock partition coefficients estimated from assemblages described in the text.

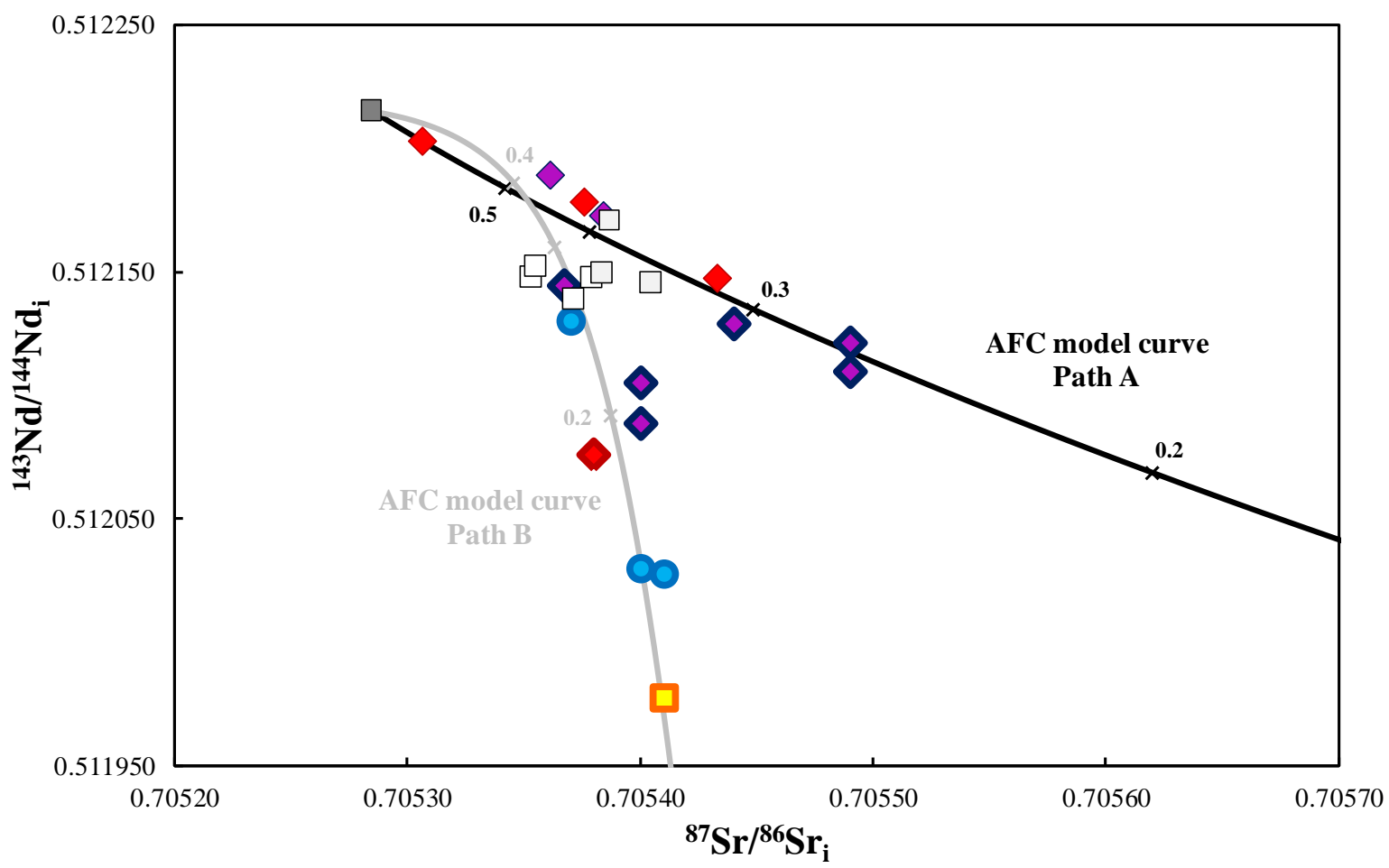

Figure 6.9. ${ }^{143} \mathrm{Nd} /{ }^{144} \mathrm{Nd}_{\mathrm{i}} \mathrm{vs}{ }^{87} \mathrm{Sr} /{ }^{86} \mathrm{Sr}_{\mathrm{i}}$ correlation diagram for Catalão I samples (Symbols as in Figure 6.7). Also shown are the calculated AFC model curves for each evolution path. Both curves emanating from apatite point $\left({ }^{87} \mathrm{Sr} /{ }^{86} \mathrm{Sr}_{\mathrm{i}}=0.705285 ;{ }^{143} \mathrm{Nd} /{ }^{144} \mathrm{Nd}_{\mathrm{i}}=0.512215\right)$, which is the most depleted isotope composition of our dataset and was chosen for the starting composition of carbonate melts. Composition of the contaminant material is the average composition of the continental crust for $\mathrm{Sr}\left({ }^{87} \mathrm{Sr} /{ }^{86} \mathrm{Sr}=\mathbf{0 . 7 2}-\right.$ Hofmann, 1997; $\mathrm{Sr}=320 \mathrm{ppm}$ - Rudnick \& Gao, 2003) and the average composition of regional APIP Archean crust for $\mathrm{Nd}\left({ }^{143} \mathrm{Nd} /{ }^{144} \mathrm{Nd}_{\mathrm{i}}=0.51123 ; \mathrm{Nd}=25.35 \mathrm{ppm}\right.$ - estimated by Oliveira et al., 2015b). Other modelling parameters are given in Table 6.2. Ticks on the curves are $\mathrm{F}$ (fraction of magma remaining).

The " $r$ " value, which means the ratio of mass of assimilated material to mass of crystallized material, determines the amount of crust contamination in the AFC model (DePaolo, 1981). In our modelling, r-values of 0.3 and 0.15 were applied to calculate curves 
$\mathrm{A}$ and $\mathrm{B}$, respectively. These are reasonable amounts for an upper crust contamination (DePaolo, 1981), but we could expect significant less amounts given that the late-stage carbonate melts are highly reactive and interacts with wallrocks and crustal fluids in a pervasive way (e.g. Andersen, 1987).

Our detailed $\mathrm{Nd}$ and $\mathrm{Sr}$ isotope investigation show that the final stages of the evolution of the Catalão I carbonatite complex were marked by events that lead to apparent isotopic inconsistencies in the studied systems (Figure 6.7). Similar isotopic evidence in alkalinecarbonatite complexes worldwide has often been interpreted as indicative of an isotopically heterogeneous mantle source (e.g., Mitchell et al., 1994; Zaitsev \& Bell, 1995; Morikiyo et al., 2000; Wu et al., 2011). However, we have shown that the Catalão I data may be explained by changes in the fractionating assemblage of a late-stage magmatic or carbo-hydrothermal system undergoing realistic amounts of crustal contamination ( $r$-values between 0.15 and 0.3 ).

It is not yet clear whether the wide $\mathrm{Nd}$ isotopic variations in the monazite-rich rocks reflect the crystallization of an extremely differentiated and contaminated carbonate melt or simply a subsolidus carbo-hydrothermal system, but it is most certainly a very late-stage event in the whole evolution of the Catalão I complex. This change coincides with the shift from a $\mathrm{Nb}$-rich to a REE- and Ba-rich mineralization environment (e.g., Ribeiro, 2008; Ribeiro et al., 2014) and may constitute a metallogenetic, as well as a petrogenetic indicator.

\section{Acknowledgements}

The authors thank the $\mathrm{CNPq}$ - Brazilian Council for Research and Development for research grants to J.A.B. and E.L.D., CAPES - Coordination for the Improvement of Higher Education Personnel for M.Sc. grants to I.L.O., and their financial support for the project. The University of Brasília is thanked for access to analytical facilities, in special those at the Laboratory of Geodynamics, Geochronology and Environmental Studies of the Institute of Geosciences. 


\section{References}

Andersen, T. (1987). Mantle and crustal components in a carbonatite complex, and the evolution of carbonatite magma: REE and isotopic evidence from the Fen Complex, Southeast Norway. Chemical Geology 65: 147-166.

Andres, U. (1996). Disintegration of rock by tension. Resource Processing 43: 122-135.

Araújo, A.L.N., Carlson, R.W., Gaspar, J.C. \& Bizzi, L.A. (2001). Petrology of kamafugites and kimberlites from the Alto Paranaíba Alkaline Province, Minas Gerais, Brazil. Contributions to Mineralogy and Petrology 142: 163-177.

Araújo, D.P. (1996). Metassomatismo no complexo carbonatítico Catalão-I: implicações para a composição do magma carbonatítico e para o metassomatismo carbonatítico no manto superior. Unpublished MSc Thesis, Universidade de Brasília, Brazil. 187 pp.

Bell, K. (1998). Radiogenic isotope constraints on relationships between carbonatites and associated silicate rocks - A brief review. J. Petrology 39(11-12): 1987-1996.

Bell, K. (2001). Glimpses into the crystallization history of carbonatitic melts - An isotopic approach. In: EUG XI Meeting 2001, Strasbourg, France (Abstract Symposium VPP4). p. 810.

Bell, K. \& Simonetti, A. (2010). Source of parental melts to carbonatites - critical isotopic constraints. Miner. Petrol. 98: 77-89.

Bizzarro, M. Simonetti, A., Stevenson, R.K. \& Kurszlaukis, S. (2003). In situ ${ }^{87} \mathrm{Sr} /{ }^{86} \mathrm{Sr}$ investigation of igneous apatites and carbonates using laser-ablation MC-ICP-MS. Geochim. Cosmochim. Acta 67(2): 289-302.

Brod, J.A., Gibson, S.A., Thompson, R.N., Junqueira-Brod, T.C., Seer, H.J., Moraes, L.C. \& Boaventura, G.R., (2000). The kamafugite-carbonatite association in the Alto Paranaíba Igneous Province (APIP) southeastern Brazil. Revista Brasileira de Geociências 30(3): 408-412.

Brod, J.A., Ribeiro, C.C., Gaspar, J.C., Junqueira-Brod, T.C., Barbosa, E.S.R., Riffel, B.F., Silva, J.F., Chaban, N. \& Ferrari, A.J.D. (2004). Excursão 1: Geologia e mineralizações dos complexos alcalino-carbonatíticos da Província Ígnea do Alto 
Paranaíba. Congresso Brasileiro de Geologia, XLII, Araxá, MG, (Field Guide Book). Sociedade Brasileira de Geologia, São Paulo. 29 pp (in Portuguese).

Carvalho, W.T. (1974). Aspectos geológicos e petrográficos do complexo ultramáficoalcalino de Catalão I, GO. In: Anais do $28^{\circ}$ Congresso Brasileiro de Geologia, vol. 5, Porto Alegre, Brasil. p. 107-123 (in Portuguese).

Carvalho, W.T. \& Bressan, S.R. (1997). Depósitos de fosfato, nióbio, titânio, terras raras e vermiculita de Catalão I - Goiás. In: Principais Depositos Minerais do Brasil, Vol. IV Rochas e Minerais Industriais, Schobbenhaus, C., Queiroz, E.T. \& Coelho, C.E.S. Editors. MME/DNPM, Brasília, pp. 69-93 (in Portuguese).

Chen, W. \& Simonetti, A. (2015). Isotopic (Pb, Sr, Nd, C, O) evidence for plume-related sampling of an ancient, depleted mantle reservoir. Lithos 216-217: 81-92.

Cordeiro, P.F.O., Brod, J.A., Dantas, E.L. \& Barbosa, E.S.R. (2010). Mineral chemistry, isotope geochemistry and petrogenesis of niobium-rich rocks from the Catalão I carbonatite-phoscorite complex, Central Brazil. Lithos 118: 223-237.

Cordeiro, P.F.O., Brod, J.A., Palmieri, M., Oliveira, C.G., Barbosa, E.S.R., Santos, R.V., Gaspar, J.C. \& Assis, L.C. (2011a). The Catalão I niobium deposit, central Brazil: Resources, geology and pyrochlore chemistry. Ore Geology Reviews 41: 112-121.

Cordeiro, P.F.O., Brod, J.A., Santos, R.V., Oliveira, C.G. \& Barbosa, E.S.R. (2011b). Stable $(\mathrm{C}, \mathrm{O})$ and radiogenic $(\mathrm{Sr}, \mathrm{Nd})$ isotopes of carbonates as indicators of magmatic and postmagmatic processes of phoscorite-series rocks and carbonatites from Catalão I, central Brazil. Contributions to Mineralogy and Petrology 161: 451-464.

Danni, J.C.M., Baecker, M.L. \& Ribeiro, C.C. (1991). The geology of the Catalão I carbonatite complex. In: Fifth International Kimberlite Conference 1991, Araxá, Brazil (Field Guide Book). pp. 25-30.

Davidson, J.P., Morgan, D.J., Charlier, B.L.A., Harlou, R. \& Hora, J.M. (2007). Microsampling and isotopic analysis of igneous rocks: Implications for the study of magmatic systems. Ann. Rev. Earth and Planet. Sci. 35: 273-311.

DePaolo, D.J. \& Wasserburg, G.J. (1976). Nd isotopic variations and petrogenetic models. Geophys. Res. Letters 3(5): 249-252. 
DePaolo, D.J. (1981). Trace element and isotopic effects of combined wallrock assimilation and fractional crystallization. Earth and Planetary Sci. Letters 53: 189-202.

Dunworth, E.A. \& Bell, K. (2001). The Turiy Massif, Kola Peninsula, Russia: Isotopic and geochemical evidence for multi-source evolution. J. Petrology 42(2): 377-405.

Gaspar, J.C. \& Araújo, D.P. (1998). Química das rochas metassomáticas do complexo carbonatítico Catalão-I: implicações para o metassomatismo mantélico. In: Anais do $40^{\circ}$ Congresso Brasileiro de Geologia, Belo Horizonte, Brasil. p. 490 (in Portuguese).

Gibson, S.A., Thompson, R.N., Leonardos, O.H., Dickin, A.P. \& Mitchell, J.G. (1995). The Late Cretaceous impact of the Trindade mantle plume: Evidence from large-volume, mafic, potassic magmatism in SE Brazil. J. Petrology 36(1): 189-229.

Gibson, S.A., Thompson, R.N., Weska, R.K., Dickin, A.P. \& Leonardos, O.H. (1997). Late Cretaceous rift-related upwelling and melting of the Trindade starting mantle plume head beneath western Brazil. Contributions to Mineralogy and Petrology 126: 303314.

Gierth, E. \& Baecker, M.L. (1986). A mineralização de nióbio e as rochas alcalinas associadas no complexo Catalão I, Goiás. In: Principais Depositos Minerais do Brasil, Vol. II - Ferro e Metais da Indústria do Aço, Schobbenhaus, C. \& Coelho, C.E.S. Editors. MME/DNPM, Brasília, pp. 455-462 (in Portuguese).

Giese, J., Seward, D., Stuart, F.M., Wüthrich, E., Gnos, E., Kurz, D., Eggenberger, U. \& Schreurs, G. (2010). Electrodynamic disaggregation - Does it affect apatite fissiontrack and (U-Th)/He analyses? Geostand. Geoanal. Res. 34(1): 39-48.

Gioia, S.M.C.L. \& Pimentel, M.M. (2000). The Sm-Nd isotopic method in the geochronology laboratory of the University of Brasília. Anais Academ. Bras. Ciências 72(2): 219-145.

Gnos, E., Kurz, D., Leya, I. \& Eggenberger, U. (2007). Electrodynamic disaggregation of geologic material. In: Goldschmidt Conference 2007, Cologne, Germany (Abstracts). p. A331.

Gomes, C.B. \& Comin-Chiaramonti, P. (2005). Some notes on the Alto Paranaíba Igneous Province. In: Mesozoic to Cenozoic Alkaline Magmatism in the Brazilian Platform, 
Comin-Chiaramonti, P. \& Gomes, C.B., Editors. Edusp/Fapesp, São Paulo, pp. 317340.

Gomide, C.S., Brod, J.A., Junqueira-Brod, T.C., Bühn, B.M., Santos, R.V., Barbosa, E.S.R., Cordeiro, P.F.O., Palmieri, M., Grasso, C.B. \& Torre, M.G. (2013). Sulfur isotopes from Brazilian alkaline carbonatite complexes. Chemical Geology 341: 38-49.

Hirano, H., Kamitani, M., Sato, T. \& Sudo, S. (1990). Niobium mineralization of Catalão I carbonatite complex, Goiás, Brazil. Bulletin of the Geological Survey of Japan, 41(11): 577-594.

Hofmann, A.W. (1997). Mantle geochemistry: the message from oceanic volcanism. Nature 385: 219-229.

Lugmair, G.W. and Marti, K. (1978). Lunar initial ${ }^{143} \mathrm{Nd} /{ }^{144} \mathrm{Nd}$ : differential evolution of the lunar crust and mantle. Earth and Planetary Sci. Letters 39: 349-357.

Machado, M.C. (2013). Metodologias isotópicas ${ }^{87} \mathrm{Sr} /{ }^{86} \mathrm{Sr}, \delta \mathrm{C}^{13}$ e $\delta \mathrm{O}^{18}$ em estudos geológicos e arqueológicos. Unpublished Ph.D. Thesis, UFRGS, Brazil. 265 pp.

Mitchell, R.H., Smith, C.B. \& Vladykin, N.V. (1994). Isotopic composition of strontium and neodymium in potassic rocks of the Little Murun complex, Aldan Shield, Siberia. Lithos 32: 243-248.

Morikiyo, T., Hirano, H. \& Matsuhisa, Y. (1990). Carbon and Oxygen isotopic composition of the carbonates from the Jacupiranga and Catalão I carbonatite complexes, Brazil. Bulletin of the Geological Survey of Japan, 41(11): 619-626.

Morikiyo, T., Takano, K., Miyazaki, T., Kagami, H. \& Vladykin, N.V. (2000). Sr, Nd, C and $\mathrm{O}$ isotopic compositions of carbonatite and peralkaline silicate rocks from the Zhidoy complex, Russia: evidence for binary mixing, liquid immiscibility and a heterogeneous depleted mantle source region. J. Mineral. Petrol. Sciences 95: 162-172.

Nebel, O., Scherer E.E. \& Mezger, K. (2011). Evaluation of the ${ }^{87} \mathrm{Rb}$ decay-constant by agecomparison against the U-Pb system. Earth and Planetary Sci. Letters 301: 1-8.

Oliveira, I.L., Brod, J.A., Chaves, J.G. \& Dantas, E.L. (2015a). Nd-Sr isotopic determinations in apatite from alkaline-carbonatite complexes: Implications of distinct leaching procedures investigated by SEM. 
Oliveira, I.L., Brod, J.A., Barbosa, E.S.R. \& Dantas, E.L. (2015b). Nd and Sr isotopic systematics in minerals from the Salitre I alkaline-phoscorite-carbonatite complex, SE Brazil: Evidence for open-system behaviour during magmatic evolution.

Palmieri, M. (2011). Modelo geológico e avaliação de recursos minerais do depósito de Nióbio Morro do Padre, complexo alcalino-carbonatítico de Catalão II, GO. Unpublished MSc Thesis, Universidade de Brasília, Brazil. 94 pp.

Puchelt, H. \& Setiobudi, I.J. (1989). New dissolution technique for rarely soluble sulfate minerals for AAS and ICP investigations. Fresenius Z. Anal. Chem. 335: 692-694.

Ray, J.S. (2009). Radiogenic isotopic ratio variations in carbonatites and associated alkaline silicate rocks: role of crustal assimilation. J. Petrology 50(10): 1955-1971.

Ribeiro, C.C. (2008). Geologia, geometalurgia, controles e gênese dos depósitos de fósforo, terras raras e titânio do Complexo Carbonatítico Catalão I, GO. Unpublished Ph.D. Thesis, Universidade de Brasília, Brazil. 473 pp.

Ribeiro, C.C., Brod, J.A., Junqueira-Brod, T.C., Gaspar, J.C. \& Petrinovic, I.A. (2005). Mineralogical and field aspects of magma fragmentation deposits in a carbonatephosphate magma chamber: evidence from the Catalão I complex, Brazil. Journal of South American Earth Sciences 18: 355-369.

Ribeiro, C.C., Brod, J.A., Junqueira-Brod, T.C., Gaspar, J.C., Palmieri, M., Cordeiro, P.F.O., Torres, M.G., Grasso, C.B., Barbosa, E.S.R., Barbosa, P.A.R., Ferrari, A.J.D. \& Gomide, C.S. (2014). Potencial e controles metalogenéticos de ETR, Ti e Nb em províncias alcalino-carbonatíticas brasileiras. In: Metalogênese das Províncias Tectônicas Brasileiras, Silva, M.G., Rocha Neto, M.B., Jost, H., and Kuyumjian, R.M. Editors. CPRM, Belo Horizonte, pp. 559-589 (in Portuguese).

Rudnick, R.L. \& Gao, S. (2003). Composition of Continental Crust. In: Treatise on Geochemistry Volume 3: The Crust, R.L. Rudnick, Editor. Elsevier Ltd, pp. 1-64.

Santos, R.V. \& Clayton, R.N. (1995). Variations of oxygen and carbon isotopes in carbonatites: A study of Brazilian alkaline complexes. Geochim. Cosmochim. Acta 59(7): 1339-1352. 
Sgarbi, P.B.A., Heaman, L.M. \& Gaspar, J.C. (2004). U-Pb perovskite ages for Brazilian kamafugitic rocks: further support for a temporal link to a mantle plume hotspot track. Journal of South American Earth Sciences 16: 715-724.

Simonetti, A \& Bell, K. (1994). Nd, Pb and Sr isotopic data from the Napak carbonatitenephelinite centre, eastern Uganda: an example of open-system crystal fractionation. Contributions to Mineralogy and Petrology 115: 356-366.

Sonoki, I.K. \& Garda, G.M. 1988. Idades K-Ar de rochas alcalinas do Brasil meridional e Paraguai oriental: Compilação e adaptação às novas constantes de decaimento. Boletim IG-USP Série Científica 19: 63-85 (in Portuguese).

Thirlwall, M.F. (1991). Long-term reproducibility of multicollector $\mathrm{Sr}$ and $\mathrm{Nd}$ isotope ratio analysis. Chemical Geology 94: 85-104.

Thompson, R.N., Gibson, S.A., Mitchell, J.G., Dickin, A.P., Leonardos, O.H., Brod, J.A. \& Greenwood, J.C. (1998). Migrating Cretaceous-Eocene magmatism in the Serra do Mar alkaline province, SE Brazil: melts from the deflected Trindade mantle plume? J. Petrology 39(8): 1493-1526.

Tichomirowa, M., Grosche, G., Götze, J., Belyatsky, B.V., Savva, E.V., Keller, J. \& Todt, W. (2006). The mineral isotope composition of two Precambrian carbonatite complexes from the Kola Alkaline Province - Alteration versus primary magmatic signatures. Lithos 91: 229-249.

Toyoda, K., Horiuchi, H. \& Tokonami, M. (1994). Dupal anomaly of Brazilian carbonatites: Geochemical correlations with hotspots in the South Atlantic and implications for the mantle source. Earth and Planetary Sci. Letters 126: 315-331.

Walter, A.V., Flicoteaux, R., Parron, C., Loubet, M. \& Nahon, D. (1995). Rare-earth elements and isotopes $(\mathrm{Sr}, \mathrm{Nd}, \mathrm{O}, \mathrm{C})$ in minerals from the Juquiá carbonatite (Brazil): tracers of a multistage evolution. Chemical Geology 120: 27-44.

Weis, D., Kieffer, B., Maerschalk, C., Pretorius, W. \& Barling, J. (2005). High-precision PbSr-Nd-Hf isotopic characterization of USGS BHVO-1 and BHVO-2 reference materials. Geochemistry Geophysics Geosystems 6(2): 1-10. 
Whitney, D.L. \& Evans, B.W. (2010). Abbreviations for names of rock-forming minerals. American Mineralogist 95: 185-187.

Wittig, N., Pearson, D.G., Downes, H. \& Baker, J.A. (2009). The U, Th and Pb elemental and isotope compositions of mantle clinopyroxenes and their grain boundary contamination derived from leaching and digestion experiments. Geochim. Cosmochim. Acta 73: 469-488.

Wu, F.Y., Yang, Y.H., Li, Q.L., Mitchell, R.H., Dawson, J.B., Brandl, G. \& Yuhara, M. (2011). In situ determination of $\mathrm{U}-\mathrm{Pb}$ ages and $\mathrm{Sr}-\mathrm{Nd}-\mathrm{Hf}$ isotopic constraints on the petrogenesis of the Phalaborwa carbonatite Complex, South Africa. Lithos 127: 309322.

Wu, F.Y., Arzamastsev, A.A., Mitchell, R.H., Li, Q.L., Sun, J., Yang, Y.H. \& Wang, R.C. (2012). Emplacement age and Sr-Nd isotopic compositions of the Afrikanda alkaline ultramafic complex, Kola Peninsula, Russia. Chemical Geology doi: 10.1016/j.chemgeo.2012.09.027

Ye, H-M., Li, X-H. \& Lan, Z-W. (2013). Geochemical and Sr-Nd-Hf-O-C isotopic constraints on the origin of the Neoproterozoic Qieganbulake ultramafic-carbonatite complex from the Tarim Block, Northwest China. Lithos 182-183: 150-164.

Zaitsev, A. \& Bell, K. (1995). Sr and Nd isotope data of apatite, calcite and dolomite as indicators of source, and the relationships of phoscorites and carbonatites from the Kovdor Massif, Kola Peninsula, Russia. Contributions to Mineralogy and Petrology 121(3): 324-335. 


\begin{tabular}{lcccc}
\hline $\begin{array}{l}\text { Sample Name } \\
\text { Rock Type } \\
\text { (Unit) }\end{array}$ & Mineral & $\begin{array}{c}\text { Modal } \\
\%\end{array}$ & $\begin{array}{c}\text { Grain } \\
\text { Size }\end{array}$ & Comments \\
\hline & $C b$ & 40 & $\begin{array}{l}\text { Fine to } \\
\text { coarse }\end{array}$ & $\begin{array}{l}\text { Subhedral to anhedral; cloudy aspect due to large amount of oriented micro-inclusions; } \\
\text { Largest crystals }(>1 \mathrm{~mm}) \text { in the } C b \text { pocket; Small }(<0.5 \text { mm) intercumulus crystals } \\
\text { disseminated in nelsonitic domains. }\end{array}$
\end{tabular}

\begin{tabular}{|c|c|c|c|c|}
\hline \multirow{4}{*}{$\begin{array}{l}\text { NRD149 } \\
\text { Nelsonite } \\
(\mathrm{N} 2 / \mathrm{DC})\end{array}$} & Ilm & 25 & $\begin{array}{l}\text { Fine to } \\
\text { coarse }\end{array}$ & $\begin{array}{l}\text { Anhedral intergranular small }(<1 \mathrm{~mm}) \text { crystals disseminated in nelsonitic domains together } \\
\text { with } P c l \text {; Euhedral to subhedral larger }(>1 \mathrm{~mm}) \text { crystals elongated toward the center of } C b \\
\text { pockets have many } P c l \text { inclusions. }\end{array}$ \\
\hline & TfPhl & 20 & $\begin{array}{l}\text { Fine to } \\
\text { coarse }\end{array}$ & $\begin{array}{l}\text { Euhedral to subhedral; light orange to red reverse pleochroism; occurs at the rims of } C b \\
\text { pockets; generally elongated toward the center of the pocket resembling a comb-layering } \\
\text { texture; rare, tiny }(<0.2 \mathrm{~mm}) \text { anhedral lamellae scattered in nelsonitic domains. }\end{array}$ \\
\hline & Pcl & 10 & Fine & $\begin{array}{l}\text { Subhedral to anhedral yellowish-brown crystals scattered in nelsonitic domains; Larger } \\
\text { crystals }(\sim 0.8 \mathrm{~mm}) \text { in the rims of } C b \text { pocket; both types associated with } O p q \text {. }\end{array}$ \\
\hline & $A p$ & 5 & $\begin{array}{l}\text { Fine to } \\
\text { medium }\end{array}$ & $\begin{array}{l}\text { Radial-prismatic to rare euhedral crystals scattered in nelsonitic domains or at the rims of the } \\
\mathrm{Cb} \text { pocket; Locally micro-crystals with flow texture take place at nelsonitic domains. }\end{array}$ \\
\hline \multirow{3}{*}{$\begin{array}{l}\text { NRD170 } \\
\text { Nelsonite } \\
(\mathrm{N} 2 / \mathrm{DC})\end{array}$} & $O p q$ & 40 & $\begin{array}{l}\text { Fine to } \\
\text { coarse }\end{array}$ & $\begin{array}{l}\text { Euhedral to subhedral } I l m \text { with rare } M a g \text { crystals occur at the rims of } C b \text { pockets; Often with } \\
\text { abundant } P c l \text { and minor } A p, C b \text { and } T f P h l \text { inclusions; small anhedral }(<1 \mathrm{~mm}) I l m \text { crystals } \\
\text { prevail in nelsonitic domains. }\end{array}$ \\
\hline & $C b$ & 30 & $\begin{array}{l}\text { Fine to } \\
\text { medium }\end{array}$ & $\begin{array}{l}\text { Subhedral to anhedral clear crystals in the middle of } C b \text { pocket; fine aggregates of turbid } \\
\text { recrystallized crystals close to the pocket rims; rare and turbid in nelsonitic domains. }\end{array}$ \\
\hline & TfPhl & 15 & $\begin{array}{l}\text { Fine to } \\
\text { coarse }\end{array}$ & $\begin{array}{l}\text { Euhedral to subhedral laths with light orange to red reverse pleochroism elongated toward } \\
\text { the center of } C b \text { pockets; Small }(<0.5 \mathrm{~mm}) \text { anhedral to euhedral lamellae dispersed in } \\
\text { nelsonitic domains. }\end{array}$ \\
\hline
\end{tabular}




\begin{tabular}{|c|c|c|c|c|}
\hline & $A p$ & 8 & $\begin{array}{l}\text { Fine to } \\
\text { medium }\end{array}$ & $\begin{array}{l}\text { Radial-prismatic crystals with } O p q \text { in the rims of } C b \text { pockets; Usually with cloudy aspect } \\
\text { due to large amount of inclusions; Similar crystals also widespread in nelsonitic domains; } \\
\text { Anhedral clear cumulate crystals also occur locally in nelsonitic domains suggesting } \\
\text { segregation of phoscorite melt or a crystal mush pocket. }\end{array}$ \\
\hline & Brt & 5 & $\begin{array}{l}\text { Fine to } \\
\text { medium }\end{array}$ & Subhedral to anhedral disseminated in $C b$ pockets, mostly close to the rims. \\
\hline & Pcl & 2 & Fine & $\begin{array}{l}\text { Euhedral to subhedral yellowish-brown crystals scattered in nelsonitic domains, often } \\
\text { associated with } O p q \text { crystals; At the rims of } C b \text { pockets occurs both as numerous inclusions } \\
\text { in } O p q \text { and as overgrowths on } O p q \text { crystals. }\end{array}$ \\
\hline \multirow{5}{*}{$\begin{array}{l}\text { NRD339B } \\
\text { Nelsonite } \\
\text { (N1) }\end{array}$} & $A p$ & 45 & Fine & $\begin{array}{l}\text { Euhedral to anhedral, with granular texture; associated with } T f P h l \text { laths the groundmass; } \\
\text { Some of the euhedral crystals are slightly oriented, suggesting flow texture. }\end{array}$ \\
\hline & TfPhl & 30 & $\begin{array}{l}\text { Fine to } \\
\text { medium }\end{array}$ & $\begin{array}{l}\text { Euhedral micro-phenocrysts with colorless to orange reverse pleochroism and concentric } \\
\text { compositional zoning; dispersed in the groundmass; Subhedral to anhedral small }(<0.5 \mathrm{~mm}) \\
\text { crystals with light orange to dark orange reverse pleochroism without zoning constitute the } \\
\text { groundmass. }\end{array}$ \\
\hline & Mag & 21 & Fine & Subhedral to anhedral intercumulus crystals that often seems to enclose some $T f P h l$ and $A p$. \\
\hline & Pcl & 3 & Fine & $\begin{array}{l}\text { Subhedral to anhedral, yellowish-brown, commonly scattered in the groundmass; associated } \\
\text { with Mag. }\end{array}$ \\
\hline & $\mathrm{Cb}$ & 1 & Fine & Rare anhedral clear crystals in the groundmass, as veins or intercumulus phase. \\
\hline \multirow{2}{*}{$\begin{array}{l}\text { NRD339B } \\
\text { Nelsonite } \\
\text { (N2/DC) }\end{array}$} & $\mathrm{Cb}$ & 35 & $\begin{array}{l}\text { Fine to } \\
\text { medium }\end{array}$ & $\begin{array}{l}\text { Subhedral to anhedral, rarely euhedral, clear crystals in } \mathrm{Cb} \text { pockets; locally recrystallized; } \\
\text { sometimes with spherulitic or orbicular inclusions that resemble melt inclusions; Clear } \\
\text { intercumulus crystals in nelsonitic domains. }\end{array}$ \\
\hline & Mag & 20 & $\begin{array}{l}\text { Fine to } \\
\text { medium }\end{array}$ & $\begin{array}{l}\text { Subhedral to anhedral } M a g \text { with some } P y \text {; associated with } A p \text { in the rims of } C b \text { pockets; } \\
\text { inclusions of } P c l, A p \text { and rare } T f P h l ; M a g \text { occurs preferentially in } T f P h l \text {-rich layers in } \\
\text { nelsonitic domains. }\end{array}$ \\
\hline
\end{tabular}


Euhedral to subhedral; light orange to dark orange reverse pleochroism; occurs around $C b$

TfPhl 20 Fine to pockets; also between coarse (N2) and fine (N1) nelsonite domains; TfPhl-rich layers, with medium scattered $O p q$ and $C b$ alternate with $A p$-rich layers with scarce $O p q$ in the nelsonitic domains suggesting different magmatic or fluid pulses.

Ap $\quad 15 \quad \begin{aligned} & \text { Fine to } \\ & \text { medium }\end{aligned}$

Radial-prismatic crystals nucleated against $O p q$ in the rims of $C b$ pockets; anhedral to subhedral crystals with $O p q$ inclusions and granular texture; $A p$-rich layers alternate with $T f P h l$-rich layers in nelsonitic domains.

Pcl $\quad 10 \quad$ Fine

Euhedral to anhedral, yellowish-brown, unusual sector zoning; Small $(<0.25 \mathrm{~mm})$ crystals prevail in nelsonitic domains or as inclusions in Mag; Larger crystals occur in the rims of $C b$ pocket.

Mineral abbreviations used in Appendix A (following Whitney \& Evans, 2010): Ap - apatite; Brt - barite; Cb - carbonate mineral; Ilm ilmenite; Mag - magnetite; Opq-opaque mineral; Py-pyrite; Pcl-pyrochlore; TfPhl-tetraferriphlogopite. 


\section{CONCLUSÕES}

As principais conclusões desta dissertação de mestrado, delineadas a partir dos resultados e discussões expostos nos três capítulos anteriores, estão resumidas abaixo:

Testes de lixiviação com ácido clorídrico $(\mathrm{HCl})$ em concentrados minerais de apatita e carbonato mostraram que este ácido deve ser evitado para tal finalidade, visto que mesmo em concentrações diluídas, o HCL gera a abertura da estrutura da apatita e a modificação das razões elementares e isotópicas da amostra, principalmente no caso do sistema Sm-Nd.

$>$ Inicialmente, o $\mathrm{HCl}$ ataca apenas a superfície da apatita, mas a dissolução avança em direção ao centro dos grãos conforme aumenta a concentração do ácido.

> Feições lineares observadas na apatita submetida a ataques com $\mathrm{HCl}$ sugerem que a dissolução ocorre preferencialmente ao longo do eixo "c" cristalográfico, de maneira similar ao reportado por Dorozhkin (1997a, b), que propôs a dissolução incongruente da apatita a partir de estudos com $\mathrm{H}_{3} \mathrm{PO}_{4}$.

> Os procedimentos de lixiviação testados, inclusive os testes com $\mathrm{HCl}$, mostram que a influência sobre o sistema $\mathrm{Rb}$-Sr é mínima. Esta interpretação é válida para o caso da apatita provavelmente devido à baixa razão $\mathrm{Rb} / \mathrm{Sr}$ deste mineral.

Testes de lixiviação com ácido acético diluído a quente foram promissores, visto que houve remoção completa das impurezas superficiais da apatita, preservando as características químicas e isotópicas deste mineral. Entretanto, sua incapacidade de dissolver totalmente o carbonato indicam que a aplicação deste procedimento deve ser necessariamente precedida de purificação do concentrado de apatita, por separação manual sob microscópio binocular.

$\mathrm{O}$ estudo isotópico detalhado de $\mathrm{Nd}$ e $\mathrm{Sr}$ em concentrados minerais, dos diversos tipos de rocha do complexo alcalino-foscorito-carbonatítico de Salitre I, permitiu identificar um significativo desequilíbrio isotópico de $\mathrm{Sr}$ entre os minerais de uma mesma rocha. Além disso, existe um notável desequilíbrio isotópico de $\mathrm{Nd}$ entre os minerais separados de foscoritos e a sua rocha como um todo. 
Os dados isotópicos dos minerais combinado com outras evidências, como a ausência de idades $\mathrm{Rb}-\mathrm{Sr}$ e $\mathrm{Sm}-\mathrm{Nd}$, indicam que a diferenciação do complexo de Salitre I como um todo ocorreu em um sistema aberto.

$>$ Os dados de $\mathrm{Nd}$ e $\mathrm{Sr}$ dos minerais ainda revelam que as análises de rocha total para o complexo de Salitre I representam somente uma média ponderada da composição isotópica das suas diferentes fases minerais. Portanto, a assinatura isotópica primária dos magmas que deram origem a cada rochas do complexo de Salitre I é mais bem caracterizada pelas fases minerais iniciais da cristalização fracionada, tais como a apatita.

$>$ A correlação entre o desequilíbrio isotópico de $\mathrm{Sr}$ nos minerais com a sua ordem de cristalização implica que o magma foi isotopicamente modificado durante os processos de diferenciação.

Aplicando modelagem matemática $(A F C L I)$ é demonstrado que uma baixa taxa de contaminação crustal $(<10 \%)$ associada com cristalização fracionada e imiscibilidade de líquidos, durante a diferenciação de um magma parental silicato-carbonatado, pode explicar as variações nos isótopos de $\mathrm{Nd}$ e $\mathrm{Sr}$ dos carbonatitos e rochas alcalinas silicáticas de Salitre I.

$>\mathrm{O}$ desequilíbrio isotópico de $\mathrm{Nd}$ nas rochas foscoríticas (i.e., foscoritos e cumulados nelsoníticos) está relacionado a processos de alteração pósmagmática, provavelmente por fluidos metassomáticos derivados os magmas carbonatíticos.

$>$ Os resultados deste estudo indicam que não é necessária uma fonte mantélica heterogênea para explicar a origem do complexo alcalino-carbonatítico de Salitre I, e que as rochas mesmo com variações isotópicas de $\mathrm{Nd}$ e $\mathrm{Sr}$ são cogenéticas entre si.

As assinaturas isotópicas enriquecida de $\mathrm{Nd}$ e $\mathrm{Sr}$ dos magmas parentais dos complexos alcalino-carbonatíticos da APIP (i.e., flogopita picritos), em escala conjunto com valores de $\varepsilon_{\mathrm{Nd}}(\mathrm{T})$ entre -4.6 e -5.4 e ${ }^{87} \mathrm{Sr}^{86}{ }^{86} r_{\mathrm{i}}$ entre $0.704992 \mathrm{e}$ 0.705089 obtidos para os carbonatitos de Salitre I, indicam que este complexo se formou a partir de magmas derivados de uma fonte mantélica com composição isotópica similar ao do componente mantélico EM-I. Idades modelo de $\mathrm{Nd}\left(\mathrm{T}_{\mathrm{DM}}\right)$ sugerem que a litosfera sob a região da APIP foi enriquecida em elementos incompatíveis durante o Meso/Neoproterozóico. 
Dados isotópicos de $\mathrm{Nd}$ e $\mathrm{Sr}$ em minerais do complexo carbonatítico de Catalão I indicam que vários pulsos de magma carbonatítico, com composições isotópicas de $\mathrm{Sr}$ distintas, formaram as rochas nelsoníticas mais evoluídas do complexo.

$>$ Uma investigação detalhada dos dados isotópicos de $\mathrm{Nd}$ e $\mathrm{Sr}$ sugerem que as rochas mais evoluídas de Catalão I (i.e., nelsonitos, dolomita-carbonatitos e carbonatitos ricos em monazita) podem ter se formado a partir de dois trends evolutivos distintos.

Modelagem petrogenética (AFC) mostra ser possível explicar a variação isotópica entre esses dois trends a partir da contaminação crustal e de mudanças na assembleia mineral fracionante de magmas carbonatíticos tardios ou de sistemas carbo-hidrotermais.

Dados de isótopos estáveis $(\mathrm{C}, \mathrm{O}, \mathrm{S})$, em conjunto com relações de campo que apontam para um sistema intrusivo relativamente raso na crosta, sugerem que a interação destes magmas carbonatíticos mais evoluídos com componentes crustais diversos, foi um provável e importante processo nos estágios finais de evolução do complexo de Catalão I. 


\section{REFERÊNCIAS BIBLIOGRÁFICAS}

Allègre, C.J. (2008). Isotope Geology. Cambridge University Press, New York. 512 pp.

Almeida F.F.M. (1983). Relações tectônicas das rochas alcalinas mesozóicas da região meridional da Plataforma Sul-Americana. Revista Brasileira de Geociências 13: 139158 (in Portuguese).

Almeida F.F.M. \& Svisero, D.P. (1991). Structural setting and tectonic control of kimberlite and associated rocks of Brazil. In: Fifth International Kimberlite Conference 1991, Araxá, Brazil (Extended Abstracts). pp. 3-5.

Andersen, T. (1987). Mantle and crustal components in a carbonatite complex, and the evolution of carbonatite magma: REE and isotopic evidence from the Fen Complex, Southeast Norway. Chemical Geology 65: 147-166.

Andrade, F.R.D., Möller, P. \& Höhndorf, A. (1999). The effect of hydrothermal alteration on the $\mathrm{Sr}$ and $\mathrm{Nd}$ isotopic signatures of the Barra do Itapirapuã carbonatite, Southern Brazil. Journal of Geology 107: 177-191.

Andres U. (1995). Electrical disintegration of rock. Mineral Processing and Extractive Metallurgy Review 14: 87-110.

Andres, U. (1996). Disintegration of rock by tension. Resource Processing 43: 122-135.

Araújo, A.L.N., Carlson, R.W., Gaspar, J.C. \& Bizzi, L.A. (2001). Petrology of kamafugites and kimberlites from the Alto Paranaíba Alkaline Province, Minas Gerais, Brazil. Contributions to Mineralogy and Petrology 142: 163-177.

Araújo, D.P. (1996). Metassomatismo no complexo carbonatítico Catalão-I: implicações para a composição do magma carbonatítico e para o metassomatismo carbonatítico no manto superior. Unpublished MSc Thesis, Universidade de Brasília, Brazil. 187 pp.

Assumpção, M., Escalante, C.\& Schimmel, M. (2002). Initial impact of the Trindade plume, Goiás, revealed by seismic tomography? In: II Simpósio sobre Vulcanismo e Ambientes Associados 2002, Belém do Pará, Brasil (Abstracts). p. 77. 
Assumpção, M., Schimmel, M., Escalante, C., Barbosa, J.R., Rocha, M. \& Barros, L.V. (2004). Intraplate seismicity in SE Brazil: stress concentration in lithospheric thin spots. Geophys. J. Int. 159: 390-399.

Bailey, D.K. (1993). Carbonate magmas. Journal of the Geological Society, London 150: 637651.

Balaganskaya, E.G., Downes, H. \& Demaiffe, D. (2007). REE and Sr-Nd isotope compositions of clinopyroxenites, phoscorites and carbonatites of the Seblyavr Massif, Kola Peninsula, Russia. Mineralogia Polonica 38(1): 29-44.

Barbosa, E.S.R. (2009). Mineralogia e petrologia do complexo carbonatítico-foscorítico de Salitre, MG. Unpublished Ph.D. Thesis, Universidade de Brasília, Brazil. 257 pp.

Barbosa E.S.R., Brod J.A., Junqueira-Brod T.C., Dantas E.L., Cordeiro P.F.O. \& Gomide C.S. (2012a). Bebedourite from its type area (Salitre I complex): A key petrogenetic series in the Late-Cretaceous Alto Paranaíba kamafugite-carbonatite-phoscorite association, Central Brazil. Lithos 144-145: 56-72.

Barbosa E.S.R., Brod J.A., Junqueira-Brod T.C., Cordeiro P.F.O., Santos, R.V. \& Dantas E.L., (2012b). Phoscorites from the Salitre alkaline complex, Brazil: Origin and petrogenetic implications. In: $10^{\text {th }}$ International Kimberlite Conference 2012, Bangalore, India (Extended Abstracts). p. 10IKC-229.

Barbosa, E.S.R., Brod, J.A., Junqueira-Brod, T.C., Cordeiro, P.F.O., Dantas, E.L. \& Santos, R.V. (2012c). Mineralogy and petrology of the Salitre I phoscorite-carbonatitealkaline complex, Brazil. In: $10^{\text {th }}$ International Kimberlite Conference 2012, Bangalore, India (Extended Abstracts). p. 10IKC-293.

Barbosa, E.S.R., Brod, J.A., Cordeiro, P.F.O. \& Junqueira-Brod, T.C. (2012d). Variações composicionais de olivinas do complexo alcalino-carbonatítico de Salitre, MG. Revista Brasileira de Geociências 42(4): 729-743.

Barker, D.S. (1989). Field relations of carbonatites. In: Carbonatites: Genesis and Evolution, K. Bell, Editor. Unwin Hynman, London, pp. 38-69.

Barreiro, B.A. \& Cooper, A.F. (1987). A $\mathrm{Sr}, \mathrm{Nd}$ and $\mathrm{Pb}$ isotope study of alkaline lamprophyres and related rocks from Westland and Otago, South Island, New Zealand. 
In: Mantle metasomatism and alkaline magmatism, Morris, E.M. \& Pasteris, J.D., Editors. Geological Society of America Special Paper 215: 115-125.

Begemann, F., Ludwig, K.R., Lugmair, G.W., Min, K., Nyquist, L.E., Patchett, P.J., Renne, P.R., Shih, C.-Y., Villa, I.M., \& Walker, R.J. (2001). Call for an improved set of decay constants for geochronological use. Geochim. Cosmochim. Acta 65(1): 111-121.

Bell, K. (1994). Carbonatites and mantle evolution: a review. Mineralogical Magazine 58A: 69-70.

Bell, K. (1998). Radiogenic isotope constraints on relationships between carbonatites and associated silicate rocks - A brief review. J. Petrology 39(11-12): 1987-1996.

Bell, K. (2001). Glimpses into the crystallization history of carbonatitic melts - An isotopic approach. In: EUG XI Meeting 2001, Strasbourg, France (Abstract Symposium VPP4). p. 810.

Bell, K. \& Powell, J.L. (1969). Strontium isotopic studies of alkalic rocks: the potassium-rich lavas of the Birunga and Toro-Ankole regions, East and Central Equatorial Africa. $J$. Petrology 10(3): 536-572.

Bell, K. \& Blenkinsop, J. (1987a). Nd and Sr isotopic compositions of East African carbonatites: Implications for mantle heterogeneity. Geology 15: 99-102.

Bell, K. \& Blenkinsop, J. (1987b). Archean depleted mantle: Evidence from Nd and Sr initial isotopic ratios of carbonatites. Geochim. Cosmochim. Acta 51: 291-298.

Bell, K. \& Blenkinsop, J. (1989). Neodymium and strontium isotope geochemistry of carbonatites. In: Carbonatites: Genesis and Evolution, K. Bell, Editor. Unwin Hynman, London, pp. 278-300.

Bell, K. \& Tilton, G.R. (2002). Probing the mantle: The story from carbonatites. EOS, Transactions, American Geophysical Union. 83(25): 273-280.

Bell, K. \& Rukhlov, A.S. (2004). Carbonatite from the Kola Alkaline Province: origin, evolution and source characteristics. In: Phoscorites and Carbonatites from Mantle to Mine - the Key Example of the Kola Alkaline Province, F. Wall, and A.N. Zaitsev, Editors. Mineralogical Society Series, pp. 433-468. 
Bell, K. \& Simonetti, A. (2010). Source of parental melts to carbonatites - critical isotopic constraints. Miner. Petrol. 98: 77-89.

Bell, K., Blenkinsop, J., Cole, T.J.S. \& Menagh, D.P. (1982). Evidence from Sr isotopes for long-lived heterogeneities in the upper mantle. Nature 298: 251-253.

Bell, K., Kjarsgaard, B.A. \& Simonetti, A. (1998). Carbonatites into the Twenty-First century. J. Petrology 39(11-12): 1839-1845.

Berglund, M. \& Wieser, M.E. (2011). Isotopic compositions of the elements 2009 (IUPAC Technical Report). Pure Appl. Chem. 83(2): 397-410.

Bizzarro, M., Simonetti, A., Stevenson, R.K. \& David, J. (2002). Hf isotope evidence for a hidden mantle reservoir. Geology 30(9): 771-774.

Bizzarro, M. Simonetti, A., Stevenson, R.K. \& Kurszlaukis, S. (2003). In situ ${ }^{87} \mathrm{Sr} /{ }^{86} \mathrm{Sr}$ investigation of igneous apatites and carbonates using laser-ablation MC-ICP-MS. Geochim. Cosmochim. Acta 67(2): 289-302.

Bizzi, L.A., Smith, C.B., Wit, M.J., Armstrong, R.A. \& Meyer, H.O.A. (1994). Mesozoic kimberlites and related alkalic rocks in the south-western São Francisco Craton, Brazil: a case for local mantle reservoirs and their interaction. In: Proceedings of the Fifth International Kimberlite Conference 1991, Araxá, Brazil. pp. 156-171.

Bizzi, L.A., Wit, M.J., Smith, C.B., McDonald, I. \& Armstrong, R.A. (1995). Heterogeneous enriched mantle materials and DUPAL-type magmatism along the SW margin of the São Francisco Craton, Brazil. J. Geodynamics 20(4): 469-491.

Brod, J.A. (1999). Petrology and geochemistry of the Tapira alkaline complex, Minas Gerais State, Brazil. Doctoral Thesis, Durham University. 486 pp. Available at Durham ETheses Online: http://etheses.dur.ac.uk/4971/

Brod, J.A., Gibson, S.A., Thompson, R.N., Junqueira-Brod, T.C., Seer, H.J., Moraes, L.C. \& Boaventura, G.R., (2000). The kamafugite-carbonatite association in the Alto Paranaíba Igneous Province (APIP) southeastern Brazil. Revista Brasileira de Geociências 30(3): 408-412.

Brod, J.A., Ribeiro, C.C., Gaspar, J.C., Junqueira-Brod, T.C., Barbosa, E.S.R., Riffel, B.F., Silva, J.F., Chaban, N. \& Ferrari, A.J.D. (2004). Excursão 1: Geologia e 
mineralizações dos complexos alcalino-carbonatíticos da Província Ígnea do Alto Paranaíba. Congresso Brasileiro de Geologia, XLII, Araxá, MG, (Field Guide Book). Sociedade Brasileira de Geologia, São Paulo. 29 pp (in Portuguese).

Brod, J.A., Junqueira-Brod, T.C., Gaspar, J.C., Petrinovic, I.A., Valente, S.C. \& Corval, A. (2012). Decoupling of paired elements, crossover REE patterns, and mirrored spider diagrams: Fingerprinting liquid immiscibility in the Tapira alkaline-carbonatite complex, SE Brazil. Journal of South American Earth Sciences doi: 10.1016/j.jsames.2012.04.013.

Brooker, R.A. \& Kjarsgaard, B.A. (2011). Silicate-carbonate liquid immiscibility and phase relations in the system $\mathrm{SiO}_{2}-\mathrm{Na}_{2} \mathrm{O}-\mathrm{Al}_{2} \mathrm{O}_{3}-\mathrm{CaO}-\mathrm{CO}_{2}$ at $0.1-2.5 \mathrm{GPa}$ with applications to carbonatite genesis. J. Petrology 52(7-8): 1281-1305.

Bühn, B. \& Trumbull, R.B. (2003). Comparison of petrogenetic signatures between mantlederived alkali silicate intrusives with and without associated carbonatite, Namibia. Lithos 66: 201-221.

Bühn, B., Schneider, J., Dulski, P. \& Rankin, A.H. (2003). Fluid-rock interaction during progressive migration of carbonatitic fluids, derived from small-scale trace element and $\mathrm{Sr}, \mathrm{Pb}$ isotope distribution in hydrothermal fluorite. Geochim. Cosmochim. Acta 67(23): 4577-4595.

Campos J.E.G. \& Dardenne M.A. (1997). Origem e evolução tectônica da bacia Sanfranciscana. Revista Brasileira de Geociências 27(3): 283-294 (in Portuguese).

Carlson, R.W., Esperança, S. \& Svisero, D.P. (1996). Chemical and Os isotopic study of Cretaceous potassic rocks from Southern Brazil. Contributions to Mineralogy and Petrology 125: 393-405.

Carlson, R.W., Araújo, A.L.N., Junqueira-Brod, T.C., Gaspar, J.C., Brod, J.A., Petrinovic, I.A., Hollanda, M.H.B.M., Pimentel, M.M. \& Sichel, S. (2007). Chemical and isotopic relationships between peridotite xenoliths and mafic-ultrapotassic rocks from Southern Brazil. Chemical Geology 242: 415-434. 
Carvalho, W.T. (1974). Aspectos geológicos e petrográficos do complexo ultramáficoalcalino de Catalão I, GO. In: Anais do $28^{\circ}$ Congresso Brasileiro de Geologia, vol. 5, Porto Alegre, Brasil. p. 107-123 (in Portuguese).

Carvalho, W.T. \& Bressan, S.R. (1997). Depósitos de fosfato, nióbio, titânio, terras raras e vermiculita de Catalão I - Goiás. In: Principais Depositos Minerais do Brasil, Vol. IV Rochas e Minerais Industriais, Schobbenhaus, C., Queiroz, E.T. \& Coelho, C.E.S. Editors. MME/DNPM, Brasília, pp. 69-93 (in Portuguese).

Castorina, F., Stoppa, F., Cundari, A. \& Barbieri, M. (2000). An enriched mantle source for Italy's melilitite-carbonatite association as inferred by its $\mathrm{Nd}-\mathrm{Sr}$ isotope signature. Mineralogical Magazine 64(4): 625-639.

Chakhmouradian, A.R., Reguir, E.P., Kamenetsky, V.S., Sharygin, V.V.\& Golovin, A.V. (2013). Trace-element partitioning in perovskite: Implications for the geochemistry of kimberlites and other mantle-derived undersaturated rocks. Chemical Geology 353: 112-131.

Chen, W. \& Simonetti, A. (2015). Isotopic (Pb, Sr, Nd, C, O) evidence for plume-related sampling of an ancient, depleted mantle reservoir. Lithos 216-217: 81-92.

Chen, W., Kamenetsky, V.S. \& Simonetti, A. (2013). Evidence for the alkaline nature of parental carbonatite melts at Oka complex in Canada. Nature Communications 4: 2687 doi: $10.1038 /$ ncomms 3687 .

Collerson, K.D., Williams, Q., Ewart, A.E. \& Murphy, D.T. (2010). Origin of HIMU and EM-1 domains sampled by ocean island basalts, kimberlites and carbonatites: The role of $\mathrm{CO}_{2}$-fluxed lower mantle melting in thermochemical upwellings. Physics of the Earth and Planetary Interiors 181: 112-131.

Comin-Chiaramonti, P., Gomes, C.B., Maruqes, L.S., Censi, P., Ruberti, E. \& Antonini, P. (2005). Carbonatites from southeastern Brazil: Geochemistry, O-C, Sr-Nd-Pb isotopes and relationship with the magmatism from the Paraná-Angola-Namibia province. In: Mesozoic to Cenozoic Alkaline Magmatism in the Brazilian Platform, CominChiaramonti, P. \& Gomes, C.B., Editors. Edusp/Fapesp, São Paulo, pp. 657-688. 
Cordeiro, P.F.O. (2009). Petrologia e metalogenia do depósito primário de nióbio do complexo carbonatítico-foscorítico de Catalão I, GO. Unpublished MSc Thesis, Universidade de Brasília, Brazil. 140 pp.

Cordeiro, P.F.O., Brod, J.A., Dantas, E.L. \& Barbosa, E.S.R. (2010). Mineral chemistry, isotope geochemistry and petrogenesis of niobium-rich rocks from the Catalão I carbonatite-phoscorite complex, Central Brazil. Lithos 118: 223-237.

Cordeiro, P.F.O., Brod, J.A., Palmieri, M., Oliveira, C.G., Barbosa, E.S.R., Santos, R.V., Gaspar, J.C. \& Assis, L.C. (2011a). The Catalão I niobium deposit, central Brazil: Resources, geology and pyrochlore chemistry. Ore Geology Reviews 41: 112-121.

Cordeiro, P.F.O., Brod, J.A., Santos, R.V., Oliveira, C.G. \& Barbosa, E.S.R. (2011b). Stable $(\mathrm{C}, \mathrm{O})$ and radiogenic $(\mathrm{Sr}, \mathrm{Nd})$ isotopes of carbonates as indicators of magmatic and postmagmatic processes of phoscorite-series rocks and carbonatites from Catalão I, central Brazil. Contributions to Mineralogy and Petrology 161: 451-464.

Costa Junior, C.N., Herrmann, P.S.P. \& Gaspar, J.C. (2001). Dissolution features on igneous apatite due to acid attack investigated by AFM and SEM. Acta Microscopica, Supplement 10(1): 175-180.

Crough, S.T., Morgan, W.J. \& Hargraves, R.B. (1980). Kimberlites: their relation to mantle hotspots. Earth and Planetary Sci. Letters 50: 260-274.

Dalla Costa, M.M. (2012). Petrografia e geoquímica isotópica Sm-Nd em xenólitos mantélicos do kimberlito Canastra-01. Unpublished MSc Thesis, Universidade de Brasília, Brazil. 125 pp.

Danni, J.C.M., Baecker, M.L. \& Ribeiro, C.C. (1991). The geology of the Catalão I carbonatite complex. In: Fifth International Kimberlite Conference 1991, Araxá, Brazil (Field Guide Book). pp. 25-30.

Davidson, J.P., Morgan, D.J., Charlier, B.L.A., Harlou, R. \& Hora, J.M. (2007). Microsampling and isotopic analysis of igneous rocks: Implications for the study of magmatic systems. Ann. Rev. Earth and Planet. Sci. 35: 273-311.

Dawson, J.B. (1962). Sodium carbonate lavas from Oldoinyo Lengai, Tanganyika. Nature 195: $1075-1076$. 
Dawson, J.B., Steele, I.M., Smith, J.V. \& Rivers, M.L. (1996). Minor and trace element chemistry of carbonates, apatites and magnetites in some African carbonatites. Mineralogical Magazine 60: 415-425.

Dawson, J.B. \& Hinton, R.W. (2003). Trace-element content and partitioning in calcite, dolomite and apatite in carbonatite, Phalaborwa, South Africa. Mineralogical Magazine 67(5): 921-930.

Deer, W.A., Howie, R.A. \& Zussman, J. (1992). An introduction to the rock forming minerals, $2^{\text {nd }}$ Edition. Longman, London. 712 pp.

DePaolo, D.J. \& Wasserburg, G.J. (1976a). Nd isotopic variations and petrogenetic models. Geophys. Res. Letters 3(5): 249-252.

DePaolo, D.J. \& Wasserburg, G.J. (1976b). Inferences about magma sources and mantle structure from variations of ${ }^{143} \mathrm{Nd} /{ }^{144} \mathrm{Nd}$. Geophys. Res. Letters 3(12): 743-746.

DePaolo, D.J. \& Wasserburg, G.J. (1979). Petrogenetic mixing models and Nd-Sr isotopic patterns. Geochim. Cosmochim. Acta 43: 615-627.

DePaolo, D.J. (1980). Nd isotopic studies: some new perspectives on Earth structure and evolution. $\operatorname{EOS} 62(14):$ 137-140.

DePaolo, D.J. (1981a). Neodymium isotopes in the Colorado Front Range and crust-mantle evolution in the Proterozoic. Nature 291: 193-196.

DePaolo, D.J. (1981b). Trace element and isotopic effects of combined wallrock assimilation and fractional crystallization. Earth and Planetary Sci. Letters 53: 189-202.

DePaolo, D.J. (1988) Neodymium Isotope Geochemistry. Springer-Verlag, Heidelberg. 187 pp.

Dickin, A.P. (2005). Radiogenic Isotope Geology, $2^{\text {nd }}$ Edition. Cambridge University Press, New York. 492 pp.

Dorozhkin, S.V. (1997a). Acidic dissolution mechanism of natural fluorapatite I. Journal of Crystal Growth 182: 125-132.

Dorozhkin, S.V. (1997b). Acidic dissolution mechanism of natural fluorapatite II. Journal of Crystal Growth 182: 133-140. 
Downes, H., Balaganskaya, E., Beard, A., Liferovich, R. \& Demaiffe, D. (2005). Petrogenetic processes in the ultramafic, alkaline and carbonatitic magmatism in the Kola Alkaline Province: A review. Lithos 85: 48-75.

Downes, H., Wall, F., Demény, A. \& Szabo, Cs. (2012). Continuing the carbonatite controversy. Mineralogical Magazine 76(2): 255-257.

Dunworth, E.A. \& Bell, K. (2001). The Turiy Massif, Kola Peninsula, Russia: Isotopic and geochemical evidence for multi-source evolution. J. Petrology 42(2): 377-405.

Eby, G.N., Lloyd, F.E., Woolley, A.R., Stoppa, F. \& Weaver, S.D. (2003). Geochemistry and mantle source(s) for carbonatitic and potassic lavas, Western Branch of the East African Rift system, SW Uganda. Geolines 15: 23-27.

Eggler, D.H. (1989). Carbonatites, primary melts, and mantle dynamics. In: Carbonatites: Genesis and Evolution, K. Bell, Editor. Unwin Hynman, London, pp. 561-579.

Eriksson, S.C. (1989). Phalaborwa: A saga of magmatism, metasomatism and miscibility. In: Carbonatites: Genesis and Evolution, K. Bell, Editor. Unwin Hynman, London, pp. 221-254.

Ernesto, M. (2005). Paleomagnetism of the post-Paleozoic alkaline magmatism in the Brazilian platform: Questioning the mantle plume model. In: Mesozoic to Cenozoic Alkaline Magmatism in the Brazilian Platform, Comin-Chiaramonti, P. \& Gomes, C.B., Editors. Edusp/Fapesp, São Paulo, pp. 689-705.

Faure, G. (1986). Principles of Isotope Geology. John Wiley, New York. 589 pp.

Faure, G. (2001). Origin of Igneous Rocks - The Isotopic Evidence. Springer-Verlag, Heidelberg. 496 pp.

Faure, G. \& Powell, J.L. (1972). Strontium Isotope Geology. Springer-Verlag, Heidelberg. $188 \mathrm{pp}$.

Faure, G. \& Mensing, T.M. (2005). Isotopes - Principles and Applications. $3^{\text {rd }}$ Edition. John Wiley, New York. 928 pp. 
Foley, S.F., Jackson, S.E., Fryer, B.J., Greenough, J.D. \& Jenner, G.A. (1996). Trace element partition coefficients for clinopyroxene and phlogopite in an alkaline lamprophyre from Newfoundland by LAM-ICP-MS. Geochim. Cosmochim. Acta 60(4): 629-638.

Gaspar, J.C. \& Araújo, D.P. (1998). Química das rochas metassomáticas do complexo carbonatítico Catalão-I: implicações para o metassomatismo mantélico. In: Anais do $40^{\circ}$ Congresso Brasileiro de Geologia, Belo Horizonte, Brasil. p. 490 (in Portuguese).

Gibson, S.A., Thompson, R.N., Dickin, A.P. \& Leonardos, O.H. (1995a). High-Ti and low-Ti mafic potassic magmas: Key to plume-lithosphere interactions and continental floodbasalt genesis. Earth and Planetary Sci. Letters 136: 149-165.

Gibson, S.A., Thompson, R.N., Leonardos, O.H., Dickin, A.P. \& Mitchell, J.G. (1995b). The Late Cretaceous impact of the Trindade mantle plume: Evidence from large-volume, mafic, potassic magmatism in SE Brazil. J. Petrology 36(1): 189-229.

Gibson, S.A., Thompson, R.N., Weska, R.K., Dickin, A.P. \& Leonardos, O.H. (1997). Late Cretaceous rift-related upwelling and melting of the Trindade starting mantle plume head beneath western Brazil. Contributions to Mineralogy and Petrology 126: 303314.

Gibson, S.A. Thompson, R.N., Day, J.A., Humphris, S.E. \& Dickin, A.P. (2005). Meltgeneration processes associated with the Tristan mantle plume: Constraints on the origin of EM-1. Earth and Planetary Sci. Letters 237: 744-767.

Gierth, E. \& Baecker, M.L. (1986). A mineralização de nióbio e as rochas alcalinas associadas no complexo Catalão I, Goiás. In: Principais Depositos Minerais do Brasil, Vol. II - Ferro e Metais da Indústria do Aço, Schobbenhaus, C. \& Coelho, C.E.S. Editors. MME/DNPM, Brasília, pp. 455-462 (in Portuguese).

Giese, J., Seward, D., Stuart, F.M., Wüthrich, E., Gnos, E., Kurz, D., Eggenberger, U. \& Schreurs, G. (2010). Electrodynamic disaggregation - Does it affect apatite fissiontrack and (U-Th)/He analyses? Geostand. Geoanal. Res. 34(1): 39-48.

Gill, R. (1997). Modern Analytical Geochemistry, $1^{\text {st }}$ Edition. Addison Wesley Longman Limited, England. 329 pp. 
Gioia, S.M.C.L. \& Pimentel, M.M. (2000). The Sm-Nd isotopic method in the geochronology laboratory of the University of Brasília. Anais Academ. Bras. Ciências 72(2): 219-145.

Gittins, J. \& Harmer, R.E. (2003). Myth and reality in the carbonatite-silicate rock “association”. Per. Mineral. 72: 19-26.

Gnos, E., Kurz, D., Leya, I. \& Eggenberger, U. (2007). Electrodynamic disaggregation of geologic material. In: Goldschmidt Conference 2007, Cologne, Germany (Abstracts). p. A331.

Goldstein, S.L., O’Nions, R.K. \& Hamilton, P.J. (1984). A Sm-Nd isotopic study of atmospheric dusts and particulates from major river systems. Earth and Planet. Sci. Letters 70: 221-236.

Gomes, C.B. \& Comin-Chiaramonti, P. (2005). Some notes on the Alto Paranaíba Igneous Province. In: Mesozoic to Cenozoic Alkaline Magmatism in the Brazilian Platform, Comin-Chiaramonti, P. \& Gomes, C.B., Editors. Edusp/Fapesp, São Paulo, pp. $317-$ 340.

Gomide, C.S. (2011). Isótopos de enxofre de complexos alcalino-carbonatíticos na margem da Bacia do Paraná - Goiás, Minas Gerais e São Paulo. Unpublished MSc Thesis, Universidade de Brasília, Brazil. 73 pp.

Gomide, C.S., Brod, J.A., Junqueira-Brod, T.C., Bühn, B.M., Santos, R.V., Barbosa, E.S.R., Cordeiro, P.F.O., Palmieri, M., Grasso, C.B. \& Torre, M.G. (2013). Sulfur isotopes from Brazilian alkaline carbonatite complexes. Chemical Geology 341: 38-49.

Grasso, C.B. (2010). Petrologia do complexo alcalino-carbonatítico de Serra Negra, MG. Unpublished MSc Thesis, Universidade de Brasília, Brazil. 156 pp.

Guarino, V., Wu, F.Y., Lustrino, M., Melluso, L., Brotzu, P., Gomes, C.B., Ruberti, E., Tassinari, C.C.G. \& Svisero, D.P. (2012). U-Pb ages, Sr-Nd isotope geochemistry, and petrogenesis of kimberlites, kamafugites and phlogopite-picrites of the Alto Paranaíba Igneous Province, Brazil. Chemical Geology doi: 10.1016/j.chemgeo.2012.06.016

Guo, P., Niu, Y. \& Yu, X. (2014). A synthesis and new perspective on the petrogenesis of kamafugites from West Qinling, China, in a global context. Journal of Asian Earth Sciences 79: 86-96. 
Hawkesworth, C.J., Mantovani, M.S.M., Taylor, P.N. \& Palacz, Z. (1986). Evidence from the Paraná of south Brazil for a continental contribution to Dupal basalts. Nature 322: 356-359.

Hamilton, D.L., Bedson, P. \& Esson, J. (1989). The behavior of trace elements in the evolution of carbonatites. . In: Carbonatites: Genesis and Evolution, K. Bell, Editor. Unwin Hynman, London, pp. 405-427.

Hamilton, E.I. \& Deans, T. (1963). Isotopic composition of strontium in some African carbonatites and limestones and in strontium minerals. Nature 198: 776-777.

Harmer, R.E. \& Gittins, J. (1998). The case for primary, mantle-derived carbonatite magma. J. Petrology 39(11-12): 1895-1903.

Hart, S.R. (1988). Heterogeneous mantle domains: signatures, genesis and mixing chronologies. Earth and Planetary Sci. Letters 90: 273-296.

Hart, S.R., Hauri, E.H., Oschmann, L.A. \& Whitehead, J.A. (1992). Mantle plumes and entrainment: Isotopic evidence. Science 256: 517-520.

Hauri, E.H., Whitehead, J.A. \& Hart, S.R. (1994). Fluid dynamic and geochemical aspects of entrainment in mantle plumes. Journal of Geophysical Research 99: 24275-24300.

Herz, N. (1977). Timing of spreading in the South Atlantic: Information from Brazilian alkalic rocks. Geological Society of America Bulletin 88: 101-112.

Hirano, H., Kamitani, M., Sato, T. \& Sudo, S. (1990). Niobium mineralization of Catalão I carbonatite complex, Goiás, Brazil. Bulletin of the Geological Survey of Japan, 41(11): 577-594.

Hode Vuorinen, J. (2005). The Alnö alkaline and carbonatitic complex, east central Sweden a petrogenetic study. Doctoral Thesis, Stockholm University (Summary). 28 pp.

Hoernle, K., Tilton, G., Le Bas, M.J., Duggen, S. \& Garbe-Schönberg, D. (2002). Geochemistry of oceanic carbonatites compared with continental carbonatites: mantle recycling of oceanic crustal carbonate. Contributions to Mineralogy and Petrology 142: 520-542. 
Hofmann, A.W. (1979). Diffusion experiments in isotope geology. In: Lectures in Isotope Geology, E. Jager and J.C. Hunziker, Editors. Springer-Verlag, Heidelberg. pp. 189193.

Hofmann, A.W. (1997). Mantle geochemistry: the message from oceanic volcanism. Nature 385: 219-229.

Hofmann, A.W. \& Hart, S.R. (1978). An assessment of local and regional isotopic equilibrium in the mantle. Earth and Planetary Sci. Letters 38: 44-62.

Hornig-Kjarsgaard, I. (1998). Rare earth elements in sövitic carbonatites and their mineral phases. J. Petrology 39(11-12): 2105-2121.

Huang, Y.-M., Hawkesworth, C.J., van Calsteren, P. \& McDermott, F. (1995). Geochemical characteristics and origin of the Jacupiranga carbonatites, Brazil. Chemical Geology 119: 79-99.

Inghram, M.G. \& Chupka, W.A. (1953). Surface ionization source using multiple filaments. The Review of Scientific Instruments 24(7): 518-520.

Jacobsen, S.B. \& Wasserburg, G.J. (1980). Sm-Nd isotopic evolution of chondrites. Earth and Planetary Sci. Letters 50: 139-155.

Jacobsen, S.B. \& Wasserburg, G.J. (1984). Sm-Nd isotopic evolution of chondrites and achondrites, II. Earth and Planetary Sci. Letters 67: 137-150.

Jones, A.P., Genge, M. \& Carmody, L. (2013). Carbonate melts and carbonatites. Reviews in Mineralogy \& Geochemistry 75: 289-322.

Jones, J.H., Walker, D., Pickett, D.A., Murrell, M.T. \& Beattie, P. (1995). Experimental investigations of the partitioning of $\mathrm{Nb}, \mathrm{Mo}, \mathrm{Ba}, \mathrm{Ce}, \mathrm{Pb}, \mathrm{Ra}, \mathrm{Th}, \mathrm{Pa}$ and $\mathrm{U}$ between immiscible carbonate and silicate liquids. Geochim. Cosmochim. Acta 59(7): 13071320.

Kerr, A.C., Kempton, P.D. \& Thompson, R.N. (1995). Crustal assimilation during turbulent magma ascent (ATA): new isotopic evidence from the Mull Tertiary lava succession, N.W. Scotland. Contributions to Mineralogy and Petrology 119: 142-154. 
Knesel, K.M., Souza, Z.S., Vasconcelos, P.M., Cohen, B.E. \& Silveira, F.V. (2011). Young volcanism in the Borborema Province, NE Brazil, show no evidence for a trace of the Fernando de Noronha plume on the continent. Earth and Planetary Sci. Letters 302: $38-50$.

Kogarko, L.N., Lahaye, Y. \& Brey, G.P. (2010). Plume-related mantle source of super-large rare metal deposits from the Lovozero and Khibina massifs on the Kola Peninsula, Eastern part of Baltic Shield: Sr, Nd and Hf isotope systematics. Miner. Petrol. 98: 197-208.

Kossert, K., Jörg, G., Nähle, O. \& Gostomski, C.L. (2009). High-precision measurement of the half-life of ${ }^{147} \mathrm{Sm}$. Applied Radiation and Isotopes 67: 1702-1706.

Krasnova, N.I., Petrov, T.G., Balaganskaya, E.G., Garcia, D., Moutte, D., Zaitsev, A.N. \& Wall, F. (2004). Introduction to phoscorites: occurrence, composition, nomenclature and petrogenesis. In: Phoscorites and Carbonatites from Mantle to Mine - the Key Example of the Kola Alkaline Province, F. Wall, and A.N. Zaitsev, Editors. Mineralogical Society Series, pp. 45-74.

Lavecchia, G., Stoppa, F. \& Creati, N. (2006). Carbonatites and kamafugites in Italy: mantlederived rocks that challenge subduction. Annals of Geophysics, Supplement 49(1): $389-402$.

Lee, M.J., Lee, I.K., Hur, S.D., Kim, Y., Moutte, J. \& Balaganskaya, E. (2006). Sr-Nd-Pb isotopic composition of Kovdor phoscorite-carbonatite complex, Kola Peninsula, NW Russia. Lithos 91: 250-261.

Lee, W.-J. \& Wyllie, P.J. (1998). Processes of crustal carbonatite formation by liquid immiscibility and differentiation, elucidated by model systems. J. Petrology 39(1112): 2005-2013.

Le Maitre, R.W., (2002). Igneous Rocks: A classification and glossary of terms. Recommendations of the International Union of Geological Sciences Subcommission on the Systematics of Igneous Rocks. $2^{\text {nd }}$ Edition. Cambridge University Press, New York. 236pp. 
Le Roex, A.P. \& Lanyon, R. (1998). Isotope and trace element geochemistry of Cretaceous Damaraland lamprophyres and carbonatites, NW Namibia: Evidence for plumelithosphere interactions. J. Petrology 39(6): 1117-1146.

Leonardos, O.H. \& Meyer, H.O.A. (1991). Outline of the geology of Western Minas Gerais. In: Fifth International Kimberlite Conference 1991, Araxá, Brazil (Field Guide Book). pp. 17-24.

Leonardos, O.H., Ulbrich, M.N. \& Gaspar, J.C. (1991). The Mata da Corda volcanic rocks. In: Fifth International Kimberlite Conference 1991, Araxá, Brazil (Field Guide Book). pp. 65-73.

Lloyd, F.E. \& Bailey, D.K. (1994). Complex mineral textures in bebedourite: Possible links with alkali clinopyroxenite xenoliths and kamafugitic volcanism. In: Proceedings of the Fifth International Kimberlite Conference 1991, Araxá, Brazil. pp. 263-269.

Lloyd, F.E., Woolley, A.R., Stoppa, F. \& Eby, N.G. (1999). Rift Valley Magmatism - is there Evidence for laterally variable alkali clinopyroxenite mantle? Geolines 9: 76-83.

Ludwig, K.R. (2008). User's manual for Isoplot 3.70 - A geochronological toolkit for Microsoft ${ }^{\circledR}$ Excel. Berkeley Geochronological Center Special Publication 4, pp. 76.

Lugmair, G.W. (1974). Sm-Nd ages: A new dating method. Meteoritics 9: 369.

Lugmair, G.W. and Marti, K. (1978). Lunar initial ${ }^{143} \mathrm{Nd} /{ }^{144} \mathrm{Nd}$ : differential evolution of the lunar crust and mantle. Earth and Planetary Sci. Letters 39: 349-357.

Machado, N., Brooks, C. \& Hart, S.R. (1986). Determination of initial ${ }^{87} \mathrm{Sr} /{ }^{86} \mathrm{Sr}$ and ${ }^{143} \mathrm{Nd} /{ }^{144} \mathrm{Nd}$ in primary minerals from mafic and ultramafic rocks: Experimental procedure and implications for the isotopic characteristics of the Archean mantle under the Abitibi greenstone belt, Canada. Geochim. Cosmochim. Acta 50: 2335-2348.

Machado, M.C. (2013). Metodologias isotópicas ${ }^{87} \mathrm{Sr} /{ }^{86} \mathrm{Sr}, \delta \mathrm{C}^{13}$ e $\delta \mathrm{O}^{18}$ em estudos geológicos e arqueológicos. Unpublished Ph.D. Thesis, UFRGS, Brazil. 265 pp.

Malarkey, J. (2010). Micro-geochemistry of the mantle and its volcanic rocks. Doctoral Thesis, Durham University. 238 pp. Available at Durham E-Theses Online: http://etheses.dur.ac.uk/131/ 
Mariano, A.N. \& Marchetto, M. 1991. Serra Negra and Salitre - Carbonatite alkaline igneous complex. In: Fifth International Kimberlite Conference 1991, Araxá, Brazil (Field Guide Book). pp. 75-79.

Mariano, A.N. \& Mitchell, R.H. 1991. Mineralogy and geochemistry of perovskite-rich pyroxenites. In: Fifth International Kimberlite Conference 1991, Araxá, Brazil (Extended Abstracts). pp. 251-253.

Martin, L.H.J., Schmidt, M.W., Mattson, H.B., Ulmer, P., Hametner, K. \& Günther, D. (2012). Element partitioning between immiscible carbonatite-kamafugite melts with application to the Italian ultrapotassic suite. Chemical Geology 320-321: 96-112.

Martin, L.H.J., Schmidt, M.W., Mattson, H.B. \& Günther, D. (2013). Element partitioning between immiscible carbonatite and silicate melts for dry and $\mathrm{H}_{2} \mathrm{O}$-bearing systems at 1-3 GPa. J. Petrology doi:10.1093/petrology/egt048.

McClellan, G.H. \& Lehr, J.R. (1969). Crystal chemical investigation of natural apatites. The American Mineralogist 54: 1374-1391.

Meen, J.K., Ayers, J.C. \& Fregeau, E.J. (1989). A model of mantle metasomatism by carbonated alkaline melts: Trace-element and isotopic compositions of mantle source regions of carbonatite and other continental igneous rocks. In: Carbonatites: Genesis and Evolution, K. Bell, Editor. Unwin Hynman, London, pp. 464-499.

Melluso, L., Lustrino, M., Ruberti, E., Brotzu, P., Gomes, C.B., Morbidelli, L., Morra, V., Svisero, D.P. \& D'Amelio, F. (2008). Major- and Trace-element composition of Olivine, Perovskite, Clinopyroxene, Cr-Fe-Ti oxides, Phlogopite and host kamafugites and kimberlites, Alto Paranaíba, Brazil. The Canadian Mineralogist 46: 19-40.

Meyer, H.O.A., Garwood, B.L., Svisero, D.P. \& Smith, C.B. (1994). Alkaline ultrabasic intrusions in Western Minas Gerais, Brazil. In: Proceedings of the Fifth International Kimberlite Conference 1991, Araxá, Brazil. pp. 140-155.

Mitchell, R.H. \& Crocket, J.H. (1972). Isotopic composition of strontium in rocks of the Fen alkaline complex, South Norway. J. Petrology 13(1): 83-97. 
Mitchell, R.H., Smith, C.B. \& Vladykin, N.V. (1994). Isotopic composition of strontium and neodymium in potassic rocks of the Little Murun complex, Aldan Shield, Siberia. Lithos 32: 243-248.

Mitchell, R.H. (2005). Carbonatites and carbonatites and carbonatites. The Canadian Mineralogist 43: 2049-2068.

Morbidelli, L., Gomes, C.B., Beccaluva, L., Brotzu, P., Garbarino, C., Riffel, B.F., Ruberti, E. \& Traversa, G. (1997). Parental magma characterization of Salitre cumulate rocks (Alto Paranaíba Alkaline Province, Brazil) as inferred from mineralogical, petrographic, and geochemical data. International Geology Review 39: 723-743.

Morikiyo, T., Hirano, H. \& Matsuhisa, Y. (1990). Carbon and Oxygen isotopic composition of the carbonates from the Jacupiranga and Catalão I carbonatite complexes, Brazil. Bulletin of the Geological Survey of Japan, 41(11): 619-626.

Morikiyo, T., Takano, K., Miyazaki, T., Kagami, H. \& Vladykin, N.V. (2000). Sr, Nd, C and O isotopic compositions of carbonatite and peralkaline silicate rocks from the Zhidoy complex, Russia: evidence for binary mixing, liquid immiscibility and a heterogeneous depleted mantle source region. J. Mineral. Petrol. Sciences 95: 162-172.

Nebel, O., Scherer E.E. \& Mezger, K. (2011). Evaluation of the ${ }^{87}$ Rb decay-constant by agecomparison against the U-Pb system. Earth and Planetary Sci. Letters 301: 1-8.

Nelson, D.R., Chivas, A.R., Chappell, B.W. \& McCulloch, M.T. (1988). Geochemical and isotopic systematics in carbonatites and implications for the evolution of ocean-island sources. Geochim. Cosmochim. Acta 52: 1-17.

Oliveira, I.L., Brod, J.A. \& Barbosa, E.S.R. (2014). Nd and Sr isotopic systematics and the magmatic evolution of the Salitre I alkaline-carbonatite complex, Alto Paranaíba Igneous Province (APIP), SE Brazil. In: $9^{\text {th }}$ South American Symposium on Isotope Geology 2014, São Paulo, Brazil (Program and Abstracts \#115). http://www.acquacon.com.br/9ssagi/programa_ssagi-site.pdf

Oliveira, I.L. (2015). Isótopos de Nd e Sr em minerais de diferentes séries petrogenéticas nos complexos alcalino-carbonatíticos de Salitre e Catalão I. Unpublished MSc Thesis, Universidade de Brasília, Brazil. 240 pp. 
Oliveira, I.L., Brod, J.A., Chaves, J.G. \& Dantas, E.L. (2015a). Nd-Sr isotopic determinations in apatite from alkaline-carbonatite complexes: Implications of distinct leaching procedures investigated by SEM.

Oliveira, I.L., Brod, J.A., Barbosa, E.S.R. \& Dantas, E.L. (2015b). Nd and Sr isotopic systematics in minerals from the Salitre I alkaline-phoscorite-carbonatite complex, SE Brazil: Evidence for open-system behaviour during magmatic evolution.

Oliveira, I.W.B., Sachs, L.L.B., Silva, V.A. \& Batista, I.H. (2004). Folha SE.23-Belo Horizonte, In: Carta geológica do Brasil ao millionésimo: Sistema de Informações Geográficas - SIG e 46 folhas na escala 1: 1.000.000, Schobbenhaus, C., Gonçalves, J.H., Santos, J.O.S., Abram, M.B., Neto, R.L., Matos, G.M.M., Vidotti, R.M., Ramos, M.A.B. \& Jesus, J.D.A., Editors. CPRM, Brasília, CD-ROM Pack.

O’Nions, R.K., Hamilton, P.J. \& Evensen, N.M. (1977). Variations in ${ }^{143} \mathrm{Nd} /{ }^{144} \mathrm{Nd}$ and ${ }^{87} \mathrm{Sr} /{ }^{86} \mathrm{Sr}$ ratios in oceanic basalts. Earth and Planetary Sci. Letters 34: 13-22.

O'Nions, R.K., Carter, S.R., Evensen, N.M. \& Hamilton, P.J. (1979). Geochemical and cosmochemical applications of $\mathrm{Nd}$ isotope analysis. Ann. Rev. Earth and Planet. Sci. 7: $11-38$.

O'Reilly, S.Y. \& Griffin, W.L. (2000). Apatite in the mantle: implications for metasomatic processes and high heat production in Phanerozoic mantle. Lithos 53: 217-232.

Palmieri, M. (2011). Modelo geológico e avaliação de recursos minerais do depósito de Nióbio Morro do Padre, complexo alcalino-carbonatítico de Catalão II, GO. Unpublished MSc Thesis, Universidade de Brasília, Brazil. 94 pp.

Papanastassiou, D.A. \& Wasserburg, G.J. (1969). Initial Sr isotopic abundances and the resolution of small time differences in the formation of planetary objects. Earth and Planetary Sci. Letters 5: 361-376.

Peate, D.W., Hawkesworth, C.J., Mantovani, M.S.M. \& Shukowsky, W. (1990). Mantle plumes and flood-basalt stratigraphy in the Paraná, South America. Geology 18(12): 1223-1226. 
Peate, D.W. (1997). The Paraná-Etendeka Province. In: Large Igneous Provinces: Continental, Oceanic, and Planetary Flood Volcanism, Mahoney, J.J. \& Coffin, M.F., Editors. American Geophysical Union, Washington, pp. 217-245.

Pimentel, M.M., Dardenne, M.A., Fuck, R.A., Viana, M.G., Junges, S.L., Fischel, D.P., Seer, H.J. \& Dantas, E.L. (2001). Nd isotopes and the provenance of detrital sediments of the Neoproterozoic Brasília Belt, central Brazil. Journal of South American Earth Sciences 14: 571-585.

Pires, F.R.M. (1986). The southern limits of the São Francisco Craton. Anais Academ. Bras. Ciências 58: 139-145.

Piuzana, D., Pimentel, M.M., Fuck, R.A. \& Armstrong, R. (2003a). Neoproterozoic granulite facies metamorphism and coeval granitic magmatism in the Brasilia Belt, Central Brazil: regional implications of new SHRIMP U-Pb and Sm-Nd data. Precambrian Research 125: 245-273.

Piuzana, D., Pimentel, M.M., Fuck, R.A. \& Armstrong, R. (2003b). SHRIMP U-Pb and Sm$\mathrm{Nd}$ data for the Araxá Group and associated magmatic rocks: constraints for the age of sedimentation and geodynamic context of southern Brasília Belt, central Brazil. Precambrian Research 125: 139-160.

Powell, J.L., Hurley, P.M. \& Fairbairn, H.W. (1962). Isotopic composition of strontium in carbonatites. Nature 196: 1085-1086.

Powell, J.L., Hurley, P.M. \& Fairbairn, H.W. (1966). The strontium isotopic composition and origin of carbonatites. In: Carbonatites, O.F. Tuttle \& J. Gittins, Editors. John Wiley and Sons, NewYork, pp. 365-378.

Powell, J.L. \& Bell, K. (1974). Isotopic composition of strontium in alkalic rocks. In: The Alkaline Rocks, H. Sorensen, Editor. John Wiley and Sons, New York, pp. 412-421.

Puchelt, H. \& Setiobudi, I.J. (1989). New dissolution technique for rarely soluble sulfate minerals for AAS and ICP investigations. Fresenius Z. Anal. Chem. 335: 692-694.

Prowatke, S. \& Klemme, S. (2006). Trace element partitioning between apatite and silicate melts. Geochim. Cosmochim. Acta 70: 4513-4527. 
Ray, J.S. (1998). Trace element and isotope evolution during concurrent assimilation, fractional crystallization and liquid immiscibility of a carbonated silicate magma. Geochim. Cosmochim. Acta 62(19-20): 3301-3306.

Ray, J.S. (2009). Radiogenic isotopic ratio variations in carbonatites and associated alkaline silicate rocks: role of crustal assimilation. J. Petrology 50(10): 1955-1971.

Ribeiro, C.C., Brod, J.A., Junqueira-Brod, T.C., Gaspar, J.C. \& Petrinovic, I.A. (2005). Mineralogical and field aspects of magma fragmentation deposits in a carbonatephosphate magma chamber: evidence from the Catalão I complex, Brazil. Journal of South American Earth Sciences 18: 355-369.

Ribeiro, C.C. (2008). Geologia, geometalurgia, controles e gênese dos depósitos de fósforo, terras raras e titânio do Complexo Carbonatítico Catalão I, GO. Unpublished Ph.D. Thesis, Universidade de Brasília, Brazil. 473 pp.

Ribeiro, C.C., Brod, J.A., Junqueira-Brod, T.C., Gaspar, J.C., Palmieri, M., Cordeiro, P.F.O., Torres, M.G., Grasso, C.B., Barbosa, E.S.R., Barbosa, P.A.R., Ferrari, A.J.D. \& Gomide, C.S. (2014). Potencial e controles metalogenéticos de ETR, Ti e Nb em províncias alcalino-carbonatíticas brasileiras. In: Metalogênese das Províncias Tectônicas Brasileiras, Silva, M.G., Rocha Neto, M.B., Jost, H., and Kuyumjian, R.M. Editors. CPRM, Belo Horizonte, pp. 559-589 (in Portuguese).

Richard, P., Shimizu, N. \& Allègre, C.J. (1976). ${ }^{143} \mathrm{Nd} /{ }^{146} \mathrm{Nd}$, A natural tracer: An application to oceanic basalts. Earth and Planet. Sci. Letters 31: 269-278.

Riccomini, C., Velázquez, V.F. \& Gomes, C.B. (2005). Tectonic controls of the Mesozoic and Cenozoic alkaline magmatism in central-southeastern Brazilian platform. In: Mesozoic to Cenozoic Alkaline Magmatism in the Brazilian Platform, CominChiaramonti, P. \& Gomes, C.B., Editors. Edusp/Fapesp, São Paulo, pp. 31-55.

Roden, M.F. \& Murthy, V.R. (1985). Mantle Metasomatism. Ann. Rev. Earth and Planet. Sci. 13: 269-296.

Roden, M.F., Murthy, V.R. \& Gaspar, J.C. (1985). Sr and Nd isotopic composition of the Jacupiranga carbonatite. Journal of Geology 93: 212-220. 
Rosatelli, G., Wall, F. \& Stoppa, F. (2007). Calcio-carbonatite melts and metasomatism in the mantle beneath Mt. Vulture (Southern Italy). Lithos 99: 229-248.

Rosenblum S. (1958). Magnetic susceptibilities of minerals in the Frantz Isodynamic Magnetic Separator. The American Mineralogist 43: 170-173.

Rosenblum S. \& Brownfield, I.K. (2000). Magnetic susceptibilities of minerals. U.S. Geological Survey Open-File Report 99-529. 37 pp.

Rotenberg, E., Davis, D.W. \& Amelin, Y. (2012). The decay-constant of ${ }^{87} \mathrm{Rb}$ determined by laboratory accumulation of ${ }^{87} \mathrm{Sr}$. Geochim. Cosmochim. Acta 85: 41-57.

Rudnick, R.L. \& Gao, S. (2003). Composition of Continental Crust. In: Treatise on Geochemistry Volume 3: The Crust, R.L. Rudnick, Editor. Elsevier Ltd, pp. 1-64.

Rukhlov, A.S. \& Bell, K. (2003). Depleted mantle: the story from Hf isotopes in zircons and baddeleyites from carbonatites. In: EGS-AGU-EUG Joint Assembly 2003, Nice, France (Abstract \#13944). http://adsabs.harvard.edu/abs/2003EAEJA....13944R

Santos, R.V. \& Clayton, R.N. (1995). Variations of oxygen and carbon isotopes in carbonatites: A study of Brazilian alkaline complexes. Geochim. Cosmochim. Acta 59(7): 1339-1352.

Sato, K. (1998). Evolução crustal da Plataforma Sul Americana, com base na geoquímica isotópica Sm-Nd. Unpublished Ph.D. Thesis, IGC-USP, Brazil. 299 pp.

Schimmel, M., Assumpção, M. \& VanDecar, J.C. (2003). Seismic velocity anomalies beneath SE Brazil from P and S wave travel time inversions. Journal of Geophysical Research doi: 10.1029/2001JB000187.

Seer, H.J. \& Moraes, L.C. (1988). Estudo petrográfico das rochas ígneas alcalinas da região de Lagoa Formosa, MG. Revista Brasileira de Geociências 18(2): 134-140 (in Portuguese).

Sgarbi, P.B.A., Gaspar, J.C. \& Valença, J.G. (2000). Brazilian Kamafugites. Revista Brasileira de Geociências 30(3): 417-420. 
Sgarbi, P.B.A., Heaman, L.M. \& Gaspar, J.C. (2004). U-Pb perovskite ages for Brazilian kamafugitic rocks: further support for a temporal link to a mantle plume hotspot track. Journal of South American Earth Sciences 16: 715-724.

Silverman, S.R., Fuyat, R.K. \& Weiser, J.D. (1952). Quantitative determination of calcite associated with carbonate-bearing apatites. The American Mineralogist 37: 211-222.

Simonetti, A \& Bell, K. (1994). Nd, Pb and Sr isotopic data from the Napak carbonatitenephelinite centre, eastern Uganda: an example of open-system crystal fractionation. Contributions to Mineralogy and Petrology 115: 356-366.

Simonetti, A. \& Bell, K. (1995). Nd, Pb and Sr isotope systematics of fluorite at the Amba Dongar carbonatite complex, India: Evidence for hydrotermal and crustal fluid mixing. Economic Geology 90: 2018-2027.

Smith, J.P. \& Lehr, J.R. (1966). An x-ray investigation of carbonate apatites. J. Agr. Food Chem. 14(4): 342-349.

Sonoki, I.K. \& Garda, G.M. 1988. Idades K-Ar de rochas alcalinas do Brasil meridional e Paraguai oriental: Compilação e adaptação às novas constantes de decaimento. Boletim IG-USP Série Científica 19: 63-85 (in Portuguese).

Steiger, R.H. \& Jäger, E. (1977). Subcommission on Geochronology: Convention on the use of decay constants in geo- and cosmochronology. Earth and Planetary Sci. Letters 36: 359-362.

Stracke, A. (2012). Earth's heterogeneous mantle: A product of convection-driven interaction between crust and mantle. Chemical Geology 330-331: 274-299.

Su, J., Li, Z.H., Zhu, L.C., Lian, G., Bai, X.X., Wang, Y.B., Guo, B., Wang, B.X., Yan, S.Q., Zeng, S., Li, Y.J., Li, E.T., Jin, S.J., Liu, X., Fan, Q.W., Zhang, J.L., Jiang, X.Y., Lu, J.X., Lan, X.F., Tang, X.Z. \& Liu, W.P. (2010). Alpha decay half-life of ${ }^{147} \mathrm{Sm}$ in metal samarium and $\mathrm{Sm}_{2} \mathrm{O}_{3}$. Eur. Phys. Journal A 46: 69-72.

Sun, S.-s. \& McDonough, W.F. (1989). Chemical and isotopic systematics of oceanic basalts: implications for mantle composition and processes. Geological Society of London, Special Publications 42: 313-345. 
Taylor, H.P. (1980). The effects of assimilation of country rocks by magmas on ${ }^{18} \mathrm{O} /{ }^{16} \mathrm{O}$ and ${ }^{87} \mathrm{Sr} /{ }^{86} \mathrm{Sr}$ systematics in igneous rocks. Earth and Planetary Sci. Letters 47: 243-254.

Thirlwall, M.F. (1991). Long-term reproducibility of multicollector $\mathrm{Sr}$ and $\mathrm{Nd}$ isotope ratio analysis. Chemical Geology 94: 85-104.

Thirlwall, M.F. (1997). Thermal ionisation mass spectrometry (TIMS). In: Modern Analytical Geochemistry: An introduction to quantitative chemical analysis techniques for earth, environmental and material scientists, Robin Gill, Editor. Longman, London. pp. 135153.

Thompson, R.N., Gibson, S.A., Mitchell, J.G., Dickin, A.P., Leonardos, O.H., Brod, J.A. \& Greenwood, J.C. (1998). Migrating Cretaceous-Eocene magmatism in the Serra do Mar alkaline province, SE Brazil: melts from the deflected Trindade mantle plume? J. Petrology 39(8): 1493-1526.

Tilton, G.R., Kwon, S.T. \& Frost, D.M. (1987). Isotopic relationships in Arkansas Cretaceous alkali complexes. In: Mantle metasomatism and alkaline magmatism, Morris, E.M. \& Pasteris, J.D., Editors. Geological Society of America Special Paper 215: 241-248.

Tilton, G.R. \& Bell, K. (2000). Probing the mantle: The isotope story from carbonatites. In: Goldschmidt Conference 2000, Oxford, United Kingdom. Journal of Conference Abstracts 5(2): 1008 .

Tichomirowa, M., Grosche, G., Götze, J., Belyatsky, B.V., Savva, E.V., Keller, J. \& Todt, W. (2006). The mineral isotope composition of two Precambrian carbonatite complexes from the Kola Alkaline Province - Alteration versus primary magmatic signatures. Lithos 91: 229-249.

Toledo, M.C.M. \& Pereira, V.P. (2001). A variabilidade de composição da apatita associada a carbonatitos: Revista do Instituto Geológico 22(1/2): 27-64.

Torres, M.G. (2008). Composição química superficial e nanotopográfica da apatita do protominério da mina de Barreiro, Araxá-MG. Unpublished Ph.D. Thesis, Universidade de Brasília, Brazil. 184 pp. 
Toyoda, K., Horiuchi, H. \& Tokonami, M. (1994). Dupal anomaly of Brazilian carbonatites: Geochemical correlations with hotspots in the South Atlantic and implications for the mantle source. Earth and Planetary Sci. Letters 126: 315-331.

VanDecar, J.C., James, D.E. \& Assumpção, M. (1995). Seismic evidence for a fossil mantle plume beneath South America and implications for plate driving forces. Nature 378: 25-31.

Veksler, I.V., Petibon, C., Jenner, G.A., Dorfman, A.M. \& Dingwell, D.B. (1998). Trace element partitioning in immiscible silicate-carbonate liquid systems: an initial experimental study using a centrifuge autoclave. J. Petrology 39(11-12): 2095-2104.

Veksler, I.V., Dorfman, A.M., Dulski, P. Kamenetsky, V.S., Danyushevsky, L.V., Jeffries, T. \& Dingwell, D.B. (2012). Partitioning of elements between silicate melt and immiscible fluoride, chloride, carbonate, phosphate and sulfate melts, with implications to the origin of natrocarbonatite. Geochim. Cosmochim. Acta 79: 20-40.

Verhulst, A., Balaganskaya, E., Kirnarsky, Y. \& Demaiffe, D. (2000). Petrological and geochemical (trace elements and Sr-Nd isotopes) characteristics of the Paleozoic Kovdor ultramafic, alkaline and carbonatite intrusion (Kola Peninsula, NW Russia). Lithos 51: 1-25.

Vladykin, N.V., Morikiyo, T. \& Miyazaki, T. (2004). Geochemistry of carbon and oxygen isotopes in carbonatites of Siberia and Mongolia and some geodynamic consequences. In: Deep-seated magmatism: Its sources and their relation to plume processes, N.V. Vladykin, Editor. Vinogradov Institute of Geography, Irkutsk, pp. 96-112.

Vladykin, N.V., Morikiyo, T. \& Miyazaki, T. (2005). Sr and Nd isotopes geochemistry of alkaline and carbonatite complexes of Siberia and Mongolia and some geodynamic consequences. In: Problems of sources of deep magmatism and plumes, N.V. Vladykin, Editor. Vinogradov Inst. Geochem. Publ., Irkutsk, pp. 19-37.

Wall, F. \& Zaitsev, A.N. (2004). Phoscorites and Carbonatites from Mantle to Mine: the Key Example of the Kola Alkaline Province. The Mineralogical Society of Great Britain and Ireland, London. Mineralogical Society Series 10, 498 pp. 
Walter, A.V., Flicoteaux, R., Parron, C., Loubet, M. \& Nahon, D. (1995). Rare-earth elements and isotopes ( $\mathrm{Sr}, \mathrm{Nd}, \mathrm{O}, \mathrm{C}$ ) in minerals from the Juquiá carbonatite (Brazil): tracers of a multistage evolution. Chemical Geology 120: 27-44.

Wang, E., Shi, F. \& Manlapig, E. (2012). Mineral liberation by high voltage pulses and conventional comminution with same specific energy levels. Minerals Engineering 27-28: 28-36.

Wasserburg, G.J., Jacobsen, S.B., DePaolo, D.J., McCulloch, M.T. \& Wen, T. (1981). Precise determination of $\mathrm{Sm} / \mathrm{Nd}$ ratios, $\mathrm{Sm}$ and $\mathrm{Nd}$ isotopic abundances in standard solutions. Geochim. Cosmochim. Acta 45: 2311-2323.

Watson, E.B. \& Green, T.H. (1981). Apatite/liquid partition coefficients for the rare earth elements and strontium. Earth and Planetary Sci. Letters 56: 405-421.

Weis, D., Kieffer, B., Maerschalk, C., Pretorius, W. \& Barling, J. (2005). High-precision PbSr-Nd-Hf isotopic characterization of USGS BHVO-1 and BHVO-2 reference materials. Geochemistry Geophysics Geosystems 6(2): 1-10.

Wen, J., Bell, K. \& Blenkinsop, J. (1987). Nd and Sr isotope systematics of the Oka complex, Quebec, and their bearing on the evolution of the sub-continental upper mantle. Contributions to Mineralogy and Petrology 97: 433-437.

Wendlandt, R.F. \& Harrison, W.J. (1979). Rare earth partitioning between immiscible carbonate and silicate liquids and $\mathrm{CO}_{2}$ vapor: results and implications for the formation of light rare earth-enriched rocks. Contributions to Mineralogy and Petrology 69: 409-419.

White, W.M. (1985). Sources of oceanic basalts: Radiogenic isotopic evidence. Geology 13: 115-118.

White, W.M. (2005). Geochemistry. On-line textbook, Cornell University, New York. 700 pp.

White, W.M. (2010). Oceanic island basalts and mantle plumes: The geochemical perspective. Annu. Rev. Earth Planet. Sci. 38: 133-160.

White, W.M. \& Hofmann, A.W. (1982). Sr and Nd isotope geochemistry of oceanic basalts and mantle evolution. Nature 296: 821-25. 
Whitney, D.L. \& Evans, B.W. (2010). Abbreviations for names of rock-forming minerals. American Mineralogist 95: 185-187.

Wieser, M.E. \& Coplen, T.B. (2011). Atomic weights of the elements 2009 (IUPAC Technical Report). Pure Appl. Chem. 83(2): 359-396.

Williams, C.T. \& Gieré, R. (1996). Zirconolite: a review of localities worldwide, and a compilation of its chemical compositions. Bulletin of the Natural History Museum of London (Geology Section) 52(1): 1-24.

Winter, J.D. (2001). An introduction to Igneous and Metamorphic petrology. Prentice Hall, New Jersey. pp. 362-400.

Wittig, N., Pearson, D.G., Downes, H. \& Baker, J.A. (2009). The U, Th and Pb elemental and isotope compositions of mantle clinopyroxenes and their grain boundary contamination derived from leaching and digestion experiments. Geochim. Cosmochim. Acta 73: 469-488.

Woolley, A.R. \& Kempe, D.R.C. (1989). Carbonatites: nomenclature, average chemical compositions, and element distribution. In: Carbonatites: Genesis and Evolution, K. Bell, Editor. Unwin Hynman, London, pp. 1-14.

Woolley, A.R. \& Kjarsgaard, B.A. (2008). Paragenetic types of carbonatite as indicated by the diversity and relative abundances of associated silicate rocks: Evidence from a global database. The Canadian Mineralogist 46: 741-752.

Woolley, A.R. \& Bailey, D.K. (2012). The crucial role of lithospheric structure in the generation and release of carbonatites: geological evidence. Mineralogical Magazine 76(2): 259-270.

Wu, F.Y. (2010). Geochemical applications of in situ isotopic analyses by laser ablation. Geochemical News 143: 1-16.

Wu, F.Y., Yang, Y.H., Li, Q.L., Mitchell, R.H., Dawson, J.B., Brandl, G. \& Yuhara, M. (2011). In situ determination of $\mathrm{U}-\mathrm{Pb}$ ages and $\mathrm{Sr}-\mathrm{Nd}-\mathrm{Hf}$ isotopic constraints on the petrogenesis of the Phalaborwa carbonatite Complex, South Africa. Lithos 127: 309322. 
Wu, F.Y., Arzamastsev, A.A., Mitchell, R.H., Li, Q.L., Sun, J., Yang, Y.H. \& Wang, R.C. (2012). Emplacement age and Sr-Nd isotopic compositions of the Afrikanda alkaline ultramafic complex, Kola Peninsula, Russia. Chemical Geology doi: 10.1016/j.chemgeo.2012.09.027

Yang, Z. \& Woolley, A. (2006). Carbonatites in China: A review. Journal of Asian Earth Sciences 27: 559-575.

Ye, H-M., Li, X-H. \& Lan, Z-W. (2013). Geochemical and Sr-Nd-Hf-O-C isotopic constraints on the origin of the Neoproterozoic Qieganbulake ultramafic-carbonatite complex from the Tarim Block, Northwest China. Lithos 182-183: 150-164.

Yegorov, L.S. (1993). Phoscorites of the Maymecha-Kotuy ijolite-carbonatite association. Int. Geol. Rev. 35: 346-358.

Ying, J., Zhou, X. \& Zhang, H. (2004). Geochemical and isotopic investigation of the LaiwuZibo carbonatites from western Shandong Province, China, and implications for their petrogenesis and enriched mantle source. Lithos 75: 413-426.

Yuhara, M., Hirahara, Y., Nishi, N. \& Kagami, H. (2005). Rb-Sr, Sm-Nd ages of the Phalaborwa Carbonatite Complex, South Africa. Polar Geosci. 18: 101-113.

Zaitsev, A. \& Bell, K. (1995). Sr and Nd isotope data of apatite, calcite and dolomite as indicators of source, and the relationships of phoscorites and carbonatites from the Kovdor Massif, Kola Peninsula, Russia. Contributions to Mineralogy and Petrology 121(3): 324-335.

Zindler, A. \& Hart, S.R. (1986). Chemical Geodynamics. Annu. Rev. Earth Planet. Sci. 14: 493-571.

Zindler, A., Jagoutz, E. \& Goldstein, S. (1982). Nd, Sr and Pb isotopic systematics in a threecomponent mantle: a new perspective. Nature 298: 519-523. 
ANEXOS A:

DADOS QUÍMICOS DE SALITRE I 
I. L. de Oliveira

\begin{tabular}{|c|c|c|c|c|c|c|c|c|c|c|c|}
\hline Amostra & $9 B-50$ & $9 B-50$ & $9 B-50$ & $9 B-50$ & $9 B-50$ & $9 B-50$ & $9 B-50$ & $9 B-50$ & $9 B-50$ & $9 B-50$ & $9 B-50$ \\
\hline Unidade & $\mathrm{C} 1$ & $\mathrm{C} 1$ & $\mathrm{C} 1$ & $\mathrm{C} 1$ & $\mathrm{C} 1$ & $\mathrm{C} 1$ & $\mathrm{C} 1$ & $\mathrm{C} 1$ & $\mathrm{C} 1$ & $\mathrm{C} 1$ & $\mathrm{C} 1$ \\
\hline Posição & Rim & $\operatorname{Rim}$ & Core & Rim & Rim & Core & Rim & Rim & Core & Core & Rim \\
\hline \multicolumn{12}{|l|}{$w t \%$} \\
\hline $\mathrm{SiO}_{2}$ & 0.00 & 0.00 & 0.00 & 0.01 & 0.04 & 0.00 & 0.02 & 0.00 & 0.00 & 0.01 & 0.21 \\
\hline $\mathrm{Al}_{2} \mathrm{O}_{3}$ & 0.02 & 0.00 & 0.00 & 0.00 & 0.00 & 0.01 & 0.00 & 0.00 & 0.01 & 0.00 & 0.01 \\
\hline $\mathrm{FeO}_{\mathrm{t}}$ & 0.00 & 0.00 & 0.06 & 0.05 & 0.00 & 0.04 & 0.00 & 0.05 & 0.00 & 0.03 & 0.04 \\
\hline $\mathrm{MnO}$ & 0.06 & 0.03 & 0.02 & 0.01 & 0.08 & 0.04 & 0.03 & 0.00 & 0.00 & 0.02 & 0.02 \\
\hline $\mathrm{MgO}$ & 0.09 & 0.06 & 0.13 & 0.12 & 0.11 & 0.02 & 0.03 & 0.04 & 0.09 & 0.12 & 0.46 \\
\hline $\mathrm{CaO}$ & 54.54 & 54.47 & 53.90 & 54.94 & 54.50 & 54.55 & 53.62 & 54.22 & 53.98 & 53.87 & 50.41 \\
\hline $\mathrm{Na}_{2} \mathrm{O}$ & 0.18 & 0.15 & 0.37 & 0.35 & 0.35 & 0.13 & 0.22 & 0.20 & 0.13 & 0.39 & 0.18 \\
\hline $\mathrm{P}_{2} \mathrm{O}_{5}$ & 41.80 & 42.74 & 42.10 & 42.01 & 40.55 & 42.49 & 42.95 & 43.54 & 42.22 & 41.43 & 39.94 \\
\hline $\mathrm{BaO}$ & 0.00 & 0.00 & 0.04 & 0.00 & 0.03 & 0.00 & 0.00 & 0.00 & 0.10 & 0.00 & 0.00 \\
\hline $\mathrm{SrO}$ & 1.26 & 0.96 & 1.37 & 1.15 & 1.27 & 1.04 & 1.05 & 1.22 & 1.23 & 1.16 & 1.19 \\
\hline $\mathrm{La}_{2} \mathrm{O}_{3}$ & 0.10 & 0.09 & 0.10 & 0.06 & 0.13 & 0.00 & 0.16 & 0.08 & 0.09 & 0.09 & 0.07 \\
\hline $\mathrm{Ce}_{2} \mathrm{O}_{3}$ & 0.18 & 0.13 & 0.48 & 0.16 & 0.38 & 0.27 & 0.21 & 0.32 & 0.19 & 0.33 & 0.13 \\
\hline $\mathrm{Nd}_{2} \mathrm{O}_{3}$ & 0.31 & 0.31 & 0.04 & 0.11 & 0.15 & 0.23 & 0.07 & 0.18 & 0.00 & 0.01 & 0.23 \\
\hline $\mathrm{Y}_{2} \mathrm{O}_{3}$ & 0.00 & 0.00 & 0.09 & 0.00 & 0.08 & 0.00 & 0.05 & 0.00 & 0.00 & 0.00 & 0.01 \\
\hline $\mathrm{SO}_{3}$ & 0.00 & 0.03 & 0.03 & 0.04 & 0.02 & 0.02 & 0.00 & 0.00 & 0.03 & 0.07 & 0.11 \\
\hline $\mathrm{F}$ & 2.14 & 1.98 & 1.95 & 1.71 & 1.56 & 1.59 & 2.72 & 2.59 & 1.91 & 1.98 & 2.15 \\
\hline $\mathrm{Cl}$ & 0.01 & 0.00 & 0.00 & 0.00 & 0.00 & 0.00 & 0.02 & 0.03 & 0.00 & 0.00 & 0.00 \\
\hline Total & 100.71 & 100.95 & 100.67 & 100.70 & 99.24 & 100.43 & 101.13 & 102.48 & 99.97 & 99.51 & 95.16 \\
\hline
\end{tabular}


Anexos A: Dados Químicos de Salitre I

\begin{tabular}{|c|c|c|c|c|c|c|c|c|c|c|c|}
\hline Amostra & 20B-94 & 20B-94 & 20B-94 & 20B-94 & 20B-94 & 20B-94 & 20B-94 & 20B-94 & 20B-94 & 20B-94 & 20B-94 \\
\hline Unidade & $\mathrm{C} 1$ & $\mathrm{C} 1$ & C1 & C1 & $\mathrm{C} 1$ & $\mathrm{C} 1$ & C1 & $\mathrm{C} 1$ & $\mathrm{C} 1$ & $\mathrm{C} 1$ & $\mathrm{C} 1$ \\
\hline Posição & Rim & Rim & Core & Rim & Rim & Core & Rim & Rim & Rim & Rim & Core \\
\hline \multicolumn{12}{|l|}{$w t \%$} \\
\hline $\mathrm{SiO}_{2}$ & 0.03 & 0.00 & 0.02 & 0.02 & 0.00 & 0.01 & 0.00 & 0.00 & 0.00 & 0.05 & 0.01 \\
\hline $\mathrm{Al}_{2} \mathrm{O}_{3}$ & 0.00 & 0.00 & 0.00 & 0.03 & 0.01 & 0.00 & 0.00 & 0.00 & 0.00 & 0.00 & 0.04 \\
\hline $\mathrm{FeO}_{\mathrm{t}}$ & 0.00 & 0.00 & 0.00 & 0.05 & 0.00 & 0.03 & 0.09 & 0.05 & 0.00 & 0.09 & 0.03 \\
\hline $\mathrm{MnO}$ & 0.04 & 0.00 & 0.00 & 0.04 & 0.08 & 0.04 & 0.07 & 0.06 & 0.01 & 0.02 & 0.07 \\
\hline $\mathrm{MgO}$ & 0.01 & 0.02 & 0.09 & 0.10 & 0.08 & 0.09 & 0.10 & 0.04 & 0.02 & 0.05 & 0.05 \\
\hline $\mathrm{CaO}$ & 54.35 & 54.34 & 53.33 & 53.46 & 54.10 & 54.29 & 53.46 & 54.10 & 54.22 & 53.65 & 53.61 \\
\hline $\mathrm{Na}_{2} \mathrm{O}$ & 0.19 & 0.24 & 0.47 & 0.52 & 0.15 & 0.17 & 0.35 & 0.29 & 0.17 & 0.19 & 0.25 \\
\hline $\mathrm{P}_{2} \mathrm{O}_{5}$ & 42.97 & 42.23 & 42.91 & 41.36 & 42.63 & 43.54 & 42.78 & 43.01 & 43.84 & 41.97 & 42.93 \\
\hline $\mathrm{BaO}$ & 0.00 & 0.00 & 0.00 & 0.00 & 0.00 & 0.01 & 0.05 & 0.05 & 0.00 & 0.00 & 0.00 \\
\hline $\mathrm{SrO}$ & 1.41 & 1.30 & 1.56 & 1.29 & 1.18 & 1.31 & 1.23 & 1.33 & 1.05 & 1.50 & 1.23 \\
\hline $\mathrm{La}_{2} \mathrm{O}_{3}$ & 0.09 & 0.14 & 0.21 & 0.21 & 0.07 & 0.18 & 0.16 & 0.10 & 0.11 & 0.14 & 0.20 \\
\hline $\mathrm{Ce}_{2} \mathrm{O}_{3}$ & 0.17 & 0.25 & 0.65 & 0.42 & 0.20 & 0.36 & 0.38 & 0.30 & 0.28 & 0.35 & 0.36 \\
\hline $\mathrm{Nd}_{2} \mathrm{O}_{3}$ & 0.17 & 0.23 & 0.27 & 0.18 & 0.00 & 0.13 & 0.23 & 0.25 & 0.22 & 0.27 & 0.20 \\
\hline $\mathrm{Y}_{2} \mathrm{O}_{3}$ & 0.00 & 0.04 & 0.00 & 0.02 & 0.00 & 0.00 & 0.00 & 0.13 & 0.00 & 0.04 & 0.00 \\
\hline $\mathrm{SO}_{3}$ & 0.04 & 0.03 & 0.00 & 0.02 & 0.01 & 0.02 & 0.01 & 0.06 & 0.01 & 0.01 & 0.00 \\
\hline $\mathrm{F}$ & 1.98 & 2.14 & 2.46 & 2.45 & 2.88 & 2.27 & 2.74 & 2.43 & 2.37 & 2.58 & 2.71 \\
\hline $\mathrm{Cl}$ & 0.01 & 0.00 & 0.00 & 0.02 & 0.01 & 0.00 & 0.03 & 0.00 & 0.00 & 0.01 & 0.01 \\
\hline Total & 101.47 & 100.95 & 101.97 & 100.19 & 101.40 & 102.44 & 101.67 & 102.20 & 102.28 & 100.89 & 101.70 \\
\hline
\end{tabular}


I. L. de Oliveira

\begin{tabular}{|c|c|c|c|c|c|c|c|c|c|c|c|}
\hline Amostra & 20B-94 & 20B-94 & $10 \mathrm{~A}-41 \mathrm{~A}$ & $10 \mathrm{~A}-41 \mathrm{~A}$ & $10 \mathrm{~A}-41 \mathrm{~A}$ & $10 \mathrm{~A}-41 \mathrm{~A}$ & $10 \mathrm{~A}-41 \mathrm{~A}$ & $10 \mathrm{~A}-41 \mathrm{~A}$ & $10 \mathrm{~A}-41 \mathrm{~A}$ & $10 \mathrm{~A}-41 \mathrm{~A}$ & $10 \mathrm{~A}-41 \mathrm{~A}$ \\
\hline Unidade & $\mathrm{C} 1$ & $\mathrm{C} 1$ & $\mathrm{C} 3$ & $\mathrm{C} 3$ & $\mathrm{C} 3$ & $\mathrm{C} 3$ & $\mathrm{C} 3$ & $\mathrm{C} 3$ & $\mathrm{C} 3$ & $\mathrm{C} 3$ & $\mathrm{C} 3$ \\
\hline Posição & Core & Rim & Rim & Rim & Core & Core & Rim & Core & Rim & Rim & Core \\
\hline \multicolumn{12}{|l|}{$w t \%$} \\
\hline $\mathrm{SiO}_{2}$ & 0.02 & 0.00 & 0.18 & 0.34 & 0.18 & 0.36 & 0.23 & 0.63 & 0.04 & 0.51 & 0.52 \\
\hline $\mathrm{Al}_{2} \mathrm{O}_{3}$ & 0.00 & 0.00 & 0.01 & 0.00 & 0.00 & 0.00 & 0.00 & 0.00 & 0.00 & 0.00 & 0.00 \\
\hline $\mathrm{FeO}_{\mathrm{t}}$ & 0.00 & 0.00 & 0.04 & 0.01 & 0.00 & 0.00 & 0.02 & 0.07 & 0.04 & 0.02 & 0.00 \\
\hline $\mathrm{MnO}$ & 0.01 & 0.01 & 0.00 & 0.02 & 0.00 & 0.00 & 0.06 & 0.04 & 0.00 & 0.00 & 0.00 \\
\hline $\mathrm{MgO}$ & 0.08 & 0.04 & 0.04 & 0.04 & 0.02 & 0.01 & 0.07 & 0.02 & 0.02 & 0.02 & 0.00 \\
\hline $\mathrm{CaO}$ & 53.30 & 54.15 & 54.12 & 53.46 & 54.16 & 53.36 & 53.78 & 53.20 & 53.91 & 53.41 & 53.99 \\
\hline $\mathrm{Na}_{2} \mathrm{O}$ & 0.41 & 0.22 & 0.11 & 0.18 & 0.19 & 0.18 & 0.17 & 0.14 & 0.20 & 0.09 & 0.13 \\
\hline $\mathrm{P}_{2} \mathrm{O}_{5}$ & 42.15 & 43.09 & 42.93 & 42.60 & 42.23 & 42.41 & 42.70 & 40.87 & 42.94 & 42.05 & 41.66 \\
\hline $\mathrm{BaO}$ & 0.00 & 0.05 & 0.00 & 0.00 & 0.00 & 0.00 & 0.10 & 0.00 & 0.00 & 0.00 & 0.01 \\
\hline $\mathrm{SrO}$ & 1.49 & 1.29 & 0.88 & 0.60 & 0.55 & 0.81 & 0.64 & 0.62 & 0.54 & 0.63 & 0.65 \\
\hline $\mathrm{La}_{2} \mathrm{O}_{3}$ & 0.20 & 0.12 & 0.08 & 0.12 & 0.05 & 0.11 & 0.12 & 0.13 & 0.17 & 0.14 & 0.12 \\
\hline $\mathrm{Ce}_{2} \mathrm{O}_{3}$ & 0.53 & 0.17 & 0.30 & 0.54 & 0.30 & 0.61 & 0.47 & 0.56 & 0.48 & 0.62 & 0.63 \\
\hline $\mathrm{Nd}_{2} \mathrm{O}_{3}$ & 0.18 & 0.15 & 0.10 & 0.40 & 0.25 & 0.26 & 0.14 & 0.19 & 0.22 & 0.22 & 0.30 \\
\hline $\mathrm{Y}_{2} \mathrm{O}_{3}$ & 0.00 & 0.00 & - & - & - & - & - & - & - & - & - \\
\hline $\mathrm{SO}_{3}$ & 0.07 & 0.03 & 0.03 & 0.00 & 0.03 & 0.00 & 0.03 & 0.01 & 0.00 & 0.08 & 0.05 \\
\hline $\mathrm{F}$ & 2.92 & 2.75 & 1.90 & 1.79 & 1.67 & 1.85 & 1.77 & 1.99 & 1.82 & 1.64 & 1.91 \\
\hline $\mathrm{Cl}$ & 0.00 & 0.01 & 0.01 & 0.01 & 0.00 & 0.01 & 0.00 & 0.00 & 0.01 & 0.01 & 0.01 \\
\hline Total & 101.36 & 102.06 & 100.70 & 100.09 & 99.63 & 99.97 & 100.29 & 98.46 & 100.37 & 99.43 & 99.98 \\
\hline
\end{tabular}


Tabela A1. Composição química da apatita dos carbonatitos (C1 e C3) de Salitre I obtida por microscopia eletrônica, em modo WDS (Continuação).

\begin{tabular}{|c|c|c|c|c|c|}
\hline Amostra & $10 \mathrm{~A}-41 \mathrm{~A}$ & $10 \mathrm{~A}-41 \mathrm{~A}$ & $10 \mathrm{~A}-41 \mathrm{~A}$ & $10 \mathrm{~A}-41 \mathrm{~A}$ & $10 \mathrm{~A}-41 \mathrm{~A}$ \\
\hline Unidade & C3 & C3 & C3 & C3 & C3 \\
\hline Posição & Rim & Rim & Core & $\operatorname{Rim}$ & Core \\
\hline \multicolumn{6}{|l|}{$w t \%$} \\
\hline $\mathrm{SiO}_{2}$ & 0.41 & 0.44 & 0.29 & 0.57 & 0.32 \\
\hline $\mathrm{Al}_{2} \mathrm{O}_{3}$ & 0.00 & 0.00 & 0.00 & 0.00 & 0.00 \\
\hline $\mathrm{FeO}_{\mathrm{t}}$ & 0.03 & 0.01 & 0.08 & 0.13 & 0.00 \\
\hline $\mathrm{MnO}$ & 0.00 & 0.04 & 0.04 & 0.06 & 0.12 \\
\hline $\mathrm{MgO}$ & 0.03 & 0.01 & 0.07 & 0.03 & 0.07 \\
\hline $\mathrm{CaO}$ & 53.19 & 53.56 & 54.27 & 54.17 & 53.72 \\
\hline $\mathrm{Na}_{2} \mathrm{O}$ & 0.15 & 0.11 & 0.16 & 0.10 & 0.18 \\
\hline $\mathrm{P}_{2} \mathrm{O}_{5}$ & 43.10 & 41.14 & 42.18 & 41.88 & 42.04 \\
\hline $\mathrm{BaO}$ & 0.00 & 0.00 & 0.00 & 0.00 & 0.00 \\
\hline $\mathrm{SrO}$ & 0.74 & 0.66 & 0.72 & 0.84 & 0.76 \\
\hline $\mathrm{La}_{2} \mathrm{O}_{3}$ & 0.09 & 0.14 & 0.12 & 0.10 & 0.08 \\
\hline $\mathrm{Ce}_{2} \mathrm{O}_{3}$ & 0.54 & 0.46 & 0.43 & 0.48 & 0.53 \\
\hline $\mathrm{Nd}_{2} \mathrm{O}_{3}$ & 0.39 & 0.35 & 0.26 & 0.21 & 0.22 \\
\hline $\mathrm{Y}_{2} \mathrm{O}_{3}$ & - & - & - & - & - \\
\hline $\mathrm{SO}_{3}$ & 0.00 & 0.06 & 0.06 & 0.03 & 0.01 \\
\hline $\mathrm{F}$ & 1.94 & 1.97 & 2.12 & 2.24 & 1.65 \\
\hline $\mathrm{Cl}$ & 0.02 & 0.00 & 0.03 & 0.01 & 0.00 \\
\hline Total & 100.62 & 98.95 & 100.81 & 100.84 & 99.68 \\
\hline
\end{tabular}


I. L. de Oliveira

\begin{tabular}{|c|c|c|c|c|c|c|c|c|c|c|c|}
\hline Amostra & FVL145 & FVL145 & FVL145 & FVL145 & FVL145 & FVL145 & FVL145 & FVL145 & FVL145 & 9B-50 & $9 B-50$ \\
\hline Unidade & P2 & P2 & P2 & P2 & P2 & P2 & P2 & P2 & P2 & $\mathrm{C} 1$ & $\mathrm{C} 1$ \\
\hline Posição & Rim & Core & Rim & Core & Rim & Rim & Rim & Core & Core & & \\
\hline \multicolumn{12}{|l|}{$w t \%$} \\
\hline $\mathrm{FeO}$ & 0.07 & 0.00 & 0.17 & 0.00 & 0.04 & 0.15 & 0.20 & 0.00 & 0.03 & 0.47 & 0.52 \\
\hline $\mathrm{MnO}$ & 0.06 & 0.09 & 0.06 & 0.06 & 0.05 & 0.09 & 0.10 & 0.11 & 0.11 & 0.25 & 0.17 \\
\hline $\mathrm{MgO}$ & 0.73 & 1.35 & 0.50 & 1.03 & 0.89 & 0.66 & 1.09 & 0.66 & 1.17 & 22.23 & 22.15 \\
\hline $\mathrm{CaO}$ & 53.09 & 51.99 & 53.71 & 52.32 & 52.67 & 53.45 & 51.80 & 53.12 & 52.38 & 31.51 & 31.32 \\
\hline $\mathrm{Na}_{2} \mathrm{O}$ & 0.01 & 0.04 & 0.02 & 0.00 & 0.00 & 0.01 & 0.06 & 0.00 & 0.03 & 0.00 & 0.00 \\
\hline $\mathrm{K}_{2} \mathrm{O}$ & 0.01 & 0.00 & 0.01 & 0.02 & 0.00 & 0.00 & 0.00 & 0.00 & 0.01 & 0.02 & 0.01 \\
\hline $\mathrm{BaO}$ & 0.05 & 0.13 & 0.00 & 0.06 & 0.00 & 0.00 & 0.17 & 0.04 & 0.02 & 0.00 & 0.10 \\
\hline $\mathrm{SrO}$ & 0.87 & 1.21 & 0.81 & 1.21 & 1.33 & 1.01 & 1.13 & 1.11 & 1.44 & 0.83 & 1.01 \\
\hline Amostra & 9B-50 & 9B-50 & 9B-50 & $9 B-50$ & $9 B-50$ & 9B-50 & 9B-50 & 9B-50 & 9B-50 & 9B-50 & $20 \mathrm{~B}-94^{\mathrm{a}}$ \\
\hline $\begin{array}{l}\text { Unidade } \\
\text { Posição }\end{array}$ & $\mathrm{C} 1$ & $\mathrm{C} 1$ & $\mathrm{C} 1$ & $\mathrm{C} 1$ & $\mathrm{C} 1$ & $\mathrm{C} 1$ & $\mathrm{C} 1$ & $\mathrm{C} 1$ & $\mathrm{C} 1$ & $\mathrm{C} 1$ & $\mathrm{C} 1$ \\
\hline \multicolumn{12}{|l|}{$w t \%$} \\
\hline $\mathrm{FeO}$ & 0.57 & 0.64 & 0.46 & 0.41 & 0.45 & 0.54 & 0.58 & 0.50 & 0.46 & 0.55 & 0.25 \\
\hline $\mathrm{MnO}$ & 0.18 & 0.28 & 0.27 & 0.26 & 0.21 & 0.21 & 0.24 & 0.17 & 0.27 & 0.21 & 0.26 \\
\hline $\mathrm{MgO}$ & 22.81 & 22.27 & 21.99 & 22.04 & 22.34 & 22.56 & 22.30 & 23.54 & 22.74 & 22.20 & 22.98 \\
\hline $\mathrm{CaO}$ & 31.26 & 31.05 & 31.98 & 31.46 & 32.11 & 31.92 & 31.77 & 33.14 & 32.39 & 31.46 & 31.68 \\
\hline $\mathrm{Na}_{2} \mathrm{O}$ & 0.05 & 0.00 & 0.00 & 0.04 & 0.00 & 0.00 & 0.00 & 0.00 & 0.00 & 0.00 & 0.00 \\
\hline $\mathrm{K}_{2} \mathrm{O}$ & 0.01 & 0.01 & 0.01 & 0.00 & 0.01 & 0.00 & 0.00 & 0.01 & 0.00 & 0.00 & 0.01 \\
\hline $\mathrm{BaO}$ & 0.14 & 0.00 & 0.00 & 0.03 & 0.00 & 0.12 & 0.00 & 0.00 & 0.04 & 0.06 & 0.00 \\
\hline $\mathrm{SrO}$ & 0.99 & 0.86 & 0.88 & 0.83 & 0.88 & 0.99 & 0.83 & 0.82 & 0.95 & 0.92 & 0.96 \\
\hline
\end{tabular}


Anexos A: Dados Químicos de Salitre I Tabela A2. Composição química dos carbonatos em foscoritos (P2) e carbonatitos (C1 e C3) de Salitre I obtida por microscopia eletrônica, em modo WDS (Continuação).

\begin{tabular}{|c|c|c|c|c|c|c|c|c|c|c|c|}
\hline $\begin{array}{l}\text { Amostra } \\
\text { Unidade } \\
\text { Posição }\end{array}$ & $\begin{array}{c}20 \mathrm{~B}-94^{\mathrm{a}} \\
\mathrm{C} 1\end{array}$ & $\begin{array}{c}20 B-94^{\mathrm{a}} \\
\mathrm{C} 1\end{array}$ & $\begin{array}{c}20 \mathrm{~B}-94^{\mathrm{a}} \\
\mathrm{C} 1\end{array}$ & $\begin{array}{c}20 B-94^{\mathrm{a}} \\
\mathrm{C} 1\end{array}$ & $\begin{array}{c}20 B-94^{\mathrm{a}} \\
\mathrm{C} 1\end{array}$ & $\begin{array}{c}20 \mathrm{~B}-94^{\mathrm{a}} \\
\mathrm{C} 1\end{array}$ & $\begin{array}{c}20 \mathrm{~B}-94^{\mathrm{a}} \\
\mathrm{C} 1\end{array}$ & $\begin{array}{c}20 \mathrm{~B}-94^{\mathrm{a}} \\
\mathrm{C} 1\end{array}$ & $\begin{array}{c}20 B-94^{\mathrm{a}} \\
\mathrm{C} 1\end{array}$ & $\begin{array}{c}20 \mathrm{~B}-94^{\mathrm{a}} \\
\mathrm{C} 1\end{array}$ & $\begin{array}{c}20 \mathrm{~B}-94^{\mathrm{b}} \\
\mathrm{C} 1\end{array}$ \\
\hline \multicolumn{12}{|l|}{$w t \%$} \\
\hline $\mathrm{FeO}$ & 0.40 & 0.34 & 0.37 & 0.80 & 0.32 & 0.58 & 0.34 & 0.38 & 0.36 & 0.39 & 0.63 \\
\hline $\mathrm{MnO}$ & 0.27 & 0.27 & 0.30 & 0.28 & 0.27 & 0.25 & 0.26 & 0.30 & 0.33 & 0.31 & 0.21 \\
\hline $\mathrm{MgO}$ & 23.47 & 22.91 & 23.48 & 23.65 & 22.62 & 21.81 & 23.19 & 25.25 & 22.38 & 23.75 & 23.05 \\
\hline $\mathrm{CaO}$ & 32.56 & 32.74 & 31.14 & 32.11 & 31.81 & 32.99 & 33.36 & 32.60 & 33.07 & 33.24 & 32.52 \\
\hline $\mathrm{Na}_{2} \mathrm{O}$ & 0.00 & 0.04 & 0.00 & 0.01 & 0.00 & 0.01 & 0.00 & 0.02 & 0.00 & 0.03 & 0.00 \\
\hline $\mathrm{K}_{2} \mathrm{O}$ & 0.00 & 0.00 & 0.02 & 0.02 & 0.02 & 0.00 & 0.01 & 0.00 & 0.04 & 0.00 & 0.01 \\
\hline $\mathrm{BaO}$ & 0.04 & 0.00 & 0.11 & 0.07 & 0.00 & 0.00 & 0.00 & 0.00 & 0.12 & 0.00 & 0.00 \\
\hline $\mathrm{SrO}$ & 0.51 & 1.08 & 0.96 & 0.24 & 0.94 & 1.10 & 0.94 & 1.12 & 1.21 & 0.93 & 0.94 \\
\hline Amostra & $20 B-94^{b}$ & $20 B-94^{b}$ & $20 B-94^{b}$ & $20 B-94^{b}$ & $20 B-94^{b}$ & $20 B-94^{b}$ & $20 B-94^{b}$ & $20 B-94^{b}$ & $20 B-94^{b}$ & $20 B-94^{b}$ & $20 B-94^{b}$ \\
\hline $\begin{array}{l}\text { Unidade } \\
\text { Posição }\end{array}$ & \multicolumn{10}{|c|}{ Posição } & C1 \\
\hline \multicolumn{12}{|l|}{$w t \%$} \\
\hline $\mathrm{FeO}$ & 0.98 & 0.65 & 0.63 & 0.44 & 0.51 & 0.47 & 0.62 & 0.52 & 0.44 & 0.30 & 0.48 \\
\hline $\mathrm{MnO}$ & 0.28 & 0.28 & 0.30 & 0.22 & 0.23 & 0.18 & 0.29 & 0.31 & 0.27 & 0.27 & 0.29 \\
\hline $\mathrm{MgO}$ & 22.58 & 23.68 & 22.06 & 22.05 & 23.01 & 21.42 & 22.87 & 23.72 & 23.95 & 24.06 & 23.06 \\
\hline $\mathrm{CaO}$ & 32.51 & 32.49 & 32.78 & 32.88 & 32.95 & 32.58 & 32.44 & 32.50 & 32.39 & 33.16 & 33.18 \\
\hline $\mathrm{Na}_{2} \mathrm{O}$ & 0.00 & 0.02 & 0.00 & 0.01 & 0.00 & 0.00 & 0.01 & 0.04 & 0.02 & 0.00 & 0.05 \\
\hline $\mathrm{K}_{2} \mathrm{O}$ & 0.00 & 0.01 & 0.00 & 0.00 & 0.00 & 0.01 & 0.00 & 0.00 & 0.00 & 0.01 & 0.00 \\
\hline $\mathrm{BaO}$ & 0.09 & 0.04 & 0.07 & 0.00 & 0.05 & 0.14 & 0.00 & 0.00 & 0.00 & 0.00 & 0.04 \\
\hline $\mathrm{SrO}$ & 0.93 & 0.92 & 1.13 & 0.99 & 0.97 & 1.02 & 1.20 & 0.80 & 1.00 & 0.86 & 0.98 \\
\hline
\end{tabular}


I. L. de Oliveira Tabela A2. Composição química dos carbonatos em foscoritos (P2) e carbonatitos (C1 e C3) de Salitre I obtida por microscopia eletrônica, em modo WDS (Continuação).

\begin{tabular}{|c|c|c|c|c|c|c|c|c|c|c|c|}
\hline Amostra & FF476.6 & FF476.6 & FF476.6 & FF476.6 & FF476.6 & FF476.6 & FF476.6 & FF476.6 & FF476.6 & FF476.6 & FF476.6 \\
\hline Unidade & C3 & C3 & C3 & C3 & C3 & C3 & C3 & C3 & C3 & C3 & C3 \\
\hline Posição & Core & Rim & Rim & Core & Rim & Core & Rim & Rim & Core & Rim & Rim \\
\hline \multicolumn{12}{|l|}{$w t \%$} \\
\hline $\mathrm{FeO}$ & 0.10 & 0.15 & 0.06 & 0.12 & 0.12 & 0.13 & 0.13 & 0.16 & 0.15 & 0.08 & 0.01 \\
\hline $\mathrm{MnO}$ & 0.18 & 0.15 & 0.15 & 0.20 & 0.17 & 0.15 & 0.18 & 0.19 & 0.26 & 0.11 & 0.14 \\
\hline $\mathrm{MgO}$ & 0.77 & 0.77 & 0.79 & 0.76 & 0.77 & 0.77 & 0.73 & 0.80 & 0.73 & 0.73 & 0.76 \\
\hline $\mathrm{CaO}$ & 54.61 & 54.22 & 54.21 & 55.54 & 54.45 & 55.54 & 55.84 & 55.47 & 55.09 & 55.07 & 54.81 \\
\hline $\mathrm{Na}_{2} \mathrm{O}$ & 0.02 & 0.00 & 0.02 & 0.02 & 0.04 & 0.00 & 0.03 & 0.01 & 0.01 & 0.03 & 0.02 \\
\hline $\mathrm{K}_{2} \mathrm{O}$ & 0.02 & 0.00 & 0.00 & 0.00 & 0.00 & 0.01 & 0.00 & 0.00 & 0.02 & 0.01 & 0.00 \\
\hline $\mathrm{BaO}$ & 0.25 & 0.50 & 0.38 & 0.44 & 0.35 & 0.25 & 0.04 & 0.21 & 0.21 & 0.18 & 0.37 \\
\hline $\mathrm{SrO}$ & 1.47 & 1.49 & 1.60 & 1.45 & 1.35 & 1.52 & 1.25 & 1.45 & 1.48 & 1.83 & 1.50 \\
\hline Amostra & FF476.6 & FF476.6 & FF476.6 & $10 \mathrm{~A} 41 \mathrm{~A}$ & $10 \mathrm{~A} 41 \mathrm{~A}$ & $10 \mathrm{~A} 41 \mathrm{~A}$ & $10 \mathrm{~A} 41 \mathrm{~A}$ & $10 \mathrm{~A} 41 \mathrm{~A}$ & $10 \mathrm{~A} 41 \mathrm{~A}$ & $10 \mathrm{~A} 41 \mathrm{~A}$ & $10 \mathrm{~A} 41 \mathrm{~A}$ \\
\hline Unidade & C3 & C3 & C3 & C3 & C3 & C3 & C3 & C3 & C3 & C3 & C3 \\
\hline Posição & Core & $\operatorname{Rim}$ & $\operatorname{Rim}$ & Core & Rim & $\operatorname{Rim}$ & Core & Rim & Rim & Core & Rim \\
\hline \multicolumn{12}{|l|}{$w t \%$} \\
\hline $\mathrm{FeO}$ & 0.12 & 0.07 & 0.16 & 0.04 & 0.10 & 0.08 & 0.00 & 0.02 & 0.05 & 0.06 & 0.09 \\
\hline $\mathrm{MnO}$ & 0.21 & 0.17 & 0.17 & 0.07 & 0.17 & 0.17 & 0.09 & 0.18 & 0.12 & 0.12 & 0.08 \\
\hline $\mathrm{MgO}$ & 0.65 & 0.80 & 0.74 & 0.79 & 0.97 & 0.79 & 0.76 & 0.86 & 0.39 & 0.63 & 0.96 \\
\hline $\mathrm{CaO}$ & 55.49 & 54.35 & 53.30 & 53.09 & 52.83 & 53.80 & 55.05 & 55.16 & 55.08 & 54.47 & 53.32 \\
\hline $\mathrm{Na}_{2} \mathrm{O}$ & 0.05 & 0.03 & 0.00 & 0.02 & 0.08 & 0.03 & 0.01 & 0.04 & 0.01 & 0.02 & 0.07 \\
\hline $\mathrm{K}_{2} \mathrm{O}$ & 0.01 & 0.00 & 0.00 & 0.00 & 0.00 & 0.01 & 0.02 & 0.00 & 0.00 & 0.01 & 0.01 \\
\hline $\mathrm{BaO}$ & 0.21 & 0.29 & 0.37 & 0.21 & 0.35 & 0.35 & 0.43 & 0.22 & 0.31 & 0.32 & 0.47 \\
\hline $\mathrm{SrO}$ & 1.55 & 1.48 & 1.66 & 1.15 & 1.37 & 1.29 & 1.20 & 1.04 & 1.16 & 1.35 & 1.01 \\
\hline
\end{tabular}


Anexos A: Dados Químicos de Salitre I Tabela A2. Composição química dos carbonatos em foscoritos (P2) e carbonatitos (C1 e C3) de Salitre I obtida por microscopia eletrônica, em modo WDS (Continuação).

\begin{tabular}{lrrrr}
\hline Amostra & $10 \mathrm{~A} 41 \mathrm{~A}$ & $10 \mathrm{~A} 41 \mathrm{~A}$ & $10 \mathrm{~A} 41 \mathrm{~A}$ & $10 \mathrm{~A} 41 \mathrm{~A}$ \\
Unidade & \multicolumn{1}{c}{$\mathrm{C} 3$} & \multicolumn{1}{c}{$\mathrm{C} 3$} & \multicolumn{1}{c}{$\mathrm{C} 3$} & \multicolumn{1}{c}{$\mathrm{C} 3$} \\
Posição & \multicolumn{1}{c}{$\mathrm{Rim}$} & \multicolumn{1}{c}{$\mathrm{Core}$} & \multicolumn{1}{c}{$\mathrm{Rim}$} & \multicolumn{1}{c}{ Rim } \\
\hline & & & & \\
$w t \%$ & & & & \\
$\mathrm{FeO}$ & 0.07 & 0.05 & 0.02 & 0.03 \\
$\mathrm{MnO}$ & 0.14 & 0.15 & 0.16 & 0.23 \\
$\mathrm{MgO}$ & 0.70 & 1.06 & 0.90 & 0.98 \\
$\mathrm{CaO}$ & 53.13 & 52.54 & 52.33 & 53.14 \\
$\mathrm{Na} 2 \mathrm{O}$ & 0.00 & 0.01 & 0.02 & 0.00 \\
$\mathrm{~K}_{2} \mathrm{O}$ & 0.01 & 0.00 & 0.01 & 0.02 \\
$\mathrm{BaO}$ & 0.09 & 0.10 & 0.24 & 0.31 \\
$\mathrm{SrO}$ & 0.68 & 1.28 & 1.41 & 1.55 \\
\hline
\end{tabular}


I. L. de Oliveira

\begin{tabular}{|c|c|c|c|c|c|c|c|c|c|c|c|}
\hline Amostra & FVL175 & FVL175 & FVL175 & FVL175 & FVL175 & FVL175 & FVL175 & FVL175 & FVL175 & FVL175 & FVL175 \\
\hline Unidade & B1a & B1a & B1a & B1a & B1a & B1a & B1a & B1a & B1a & B1a & B1a \\
\hline Posição & 1 & 2 & 3 & 4 & 5 & 6 & 7 & 8 & 9 & 1 & 2 \\
\hline \multicolumn{12}{|l|}{$w t \%$} \\
\hline $\mathrm{SiO}_{2}$ & 0.00 & 0.00 & 0.00 & 0.02 & 0.03 & 0.00 & 0.01 & 0.00 & 0.04 & 0.03 & 0.01 \\
\hline $\mathrm{TiO}_{2}$ & 56.73 & 54.16 & 53.65 & 53.98 & 54.33 & 54.71 & 54.53 & 54.81 & 56.16 & 55.88 & 56.61 \\
\hline $\mathrm{Al}_{2} \mathrm{O}_{3}$ & 0.06 & 0.08 & 0.08 & 0.06 & 0.05 & 0.07 & 0.04 & 0.06 & 0.07 & 0.06 & 0.06 \\
\hline $\mathrm{FeO}_{\mathrm{t}}$ & 0.81 & 1.91 & 1.94 & 1.96 & 1.87 & 1.88 & 1.94 & 1.62 & 0.91 & 1.07 & 0.90 \\
\hline $\mathrm{MnO}$ & 0.03 & 0.02 & 0.04 & 0.00 & 0.00 & 0.00 & 0.00 & 0.00 & 0.00 & 0.00 & 0.01 \\
\hline $\mathrm{MgO}$ & 0.02 & 0.02 & 0.01 & 0.00 & 0.01 & 0.05 & 0.02 & 0.03 & 0.03 & 0.00 & 0.00 \\
\hline $\mathrm{CaO}$ & 40.22 & 38.65 & 38.33 & 38.35 & 38.35 & 38.39 & 38.09 & 38.27 & 39.57 & 40.45 & 40.69 \\
\hline $\mathrm{Na}_{2} \mathrm{O}$ & 0.27 & 0.42 & 0.36 & 0.52 & 0.44 & 0.44 & 0.40 & 0.61 & 0.28 & 0.26 & 0.15 \\
\hline $\mathrm{SrO}$ & 0.39 & 0.57 & 0.51 & 0.50 & 0.45 & 0.44 & 0.52 & 0.34 & 0.45 & 0.39 & 0.32 \\
\hline $\mathrm{ZrO}_{2}$ & - & - & - & - & - & - & - & - & - & - & - \\
\hline $\mathrm{Nb}_{2} \mathrm{O}_{5}$ & 0.23 & 0.55 & 1.00 & 0.95 & 0.79 & 0.95 & 0.54 & 0.62 & 0.51 & 0.23 & 0.15 \\
\hline $\mathrm{Ta}_{2} \mathrm{O}_{5}$ & 0.04 & 0.04 & 0.01 & 0.10 & 0.06 & 0.03 & 0.00 & 0.00 & 0.05 & 0.04 & 0.03 \\
\hline $\mathrm{V}_{2} \mathrm{O}_{5}$ & 0.49 & 0.42 & 0.44 & 0.43 & 0.48 & 0.39 & 0.41 & 0.48 & 0.47 & 0.54 & 0.45 \\
\hline $\mathrm{ThO}_{2}$ & 0.06 & 0.07 & 0.00 & 0.00 & 0.01 & 0.02 & 0.04 & 0.00 & 0.03 & 0.00 & 0.03 \\
\hline $\mathrm{La}_{2} \mathrm{O}_{3}$ & 0.56 & 1.16 & 1.05 & 1.16 & 1.20 & 1.17 & 1.04 & 1.06 & 0.52 & 0.47 & 0.51 \\
\hline $\mathrm{Ce}_{2} \mathrm{O}_{3}$ & 0.00 & 0.97 & 1.00 & 1.25 & 1.04 & 1.20 & 1.13 & 1.22 & 0.24 & 0.12 & 0.04 \\
\hline $\mathrm{Nd}_{2} \mathrm{O}_{3}$ & 0.00 & 1.25 & 0.18 & 1.40 & 0.62 & 0.35 & 0.55 & 0.20 & 1.02 & 0.00 & 0.27 \\
\hline $\mathrm{Y}_{2} \mathrm{O}_{3}$ & 0.00 & 0.06 & 0.00 & 0.01 & 0.01 & 0.03 & 0.03 & 0.00 & 0.00 & 0.02 & 0.00 \\
\hline Total & 99.92 & 100.34 & 98.59 & 100.70 & 99.74 & 100.13 & 99.29 & 99.32 & 100.33 & 99.55 & 100.22 \\
\hline
\end{tabular}


Anexos A: Dados Químicos de Salitre I

\begin{tabular}{|c|c|c|c|c|c|c|c|c|c|c|c|}
\hline Amostra & FVL175 & FVL175 & FVL175 & FVL175 & FVL175 & FVL175 & FVL175 & FVL175 & FVL175 & FVL175 & FVL175 \\
\hline Unidade & $\mathrm{B} 1 \mathrm{a}$ & $\mathrm{B} 1 \mathrm{a}$ & B1a & B1a & B1a & B1a & B1a & B1a & B1a & B1a & B1a \\
\hline Posição & 3 & 4 & 5 & 6 & 7 & 8 & 9 & 10 & 11 & 1 & 2 \\
\hline \multicolumn{12}{|l|}{$w t \%$} \\
\hline $\mathrm{SiO}_{2}$ & 0.00 & 0.35 & 0.01 & 0.63 & 0.05 & 0.00 & 0.10 & 0.02 & 0.00 & 0.02 & 0.05 \\
\hline $\mathrm{TiO}_{2}$ & 56.81 & 55.77 & 55.87 & 55.78 & 56.11 & 55.96 & 55.63 & 57.26 & 56.58 & 56.11 & 56.17 \\
\hline $\mathrm{Al}_{2} \mathrm{O}_{3}$ & 0.02 & 0.11 & 0.05 & 0.07 & 0.05 & 0.02 & 0.07 & 0.03 & 0.09 & 0.04 & 0.04 \\
\hline $\mathrm{FeO}_{\mathrm{t}}$ & 0.95 & 1.10 & 1.18 & 1.03 & 1.14 & 1.09 & 0.94 & 0.74 & 1.01 & 1.02 & 0.85 \\
\hline $\mathrm{MnO}$ & 0.00 & 0.00 & 0.00 & 0.05 & 0.03 & 0.04 & 0.03 & 0.02 & 0.00 & 0.00 & 0.02 \\
\hline $\mathrm{MgO}$ & 0.00 & 0.09 & 0.00 & 0.00 & 0.01 & 0.00 & 0.04 & 0.00 & 0.02 & 0.00 & 0.00 \\
\hline $\mathrm{CaO}$ & 39.62 & 39.26 & 39.63 & 39.71 & 39.14 & 39.73 & 39.83 & 40.26 & 40.16 & 39.81 & 40.07 \\
\hline $\mathrm{Na}_{2} \mathrm{O}$ & 0.23 & 0.33 & 0.30 & 0.31 & 0.31 & 0.44 & 0.35 & 0.25 & 0.32 & 0.18 & 0.28 \\
\hline $\mathrm{SrO}$ & 0.44 & 0.43 & 0.41 & 0.38 & 0.50 & 0.27 & 0.23 & 0.37 & 0.29 & 0.35 & 0.44 \\
\hline $\mathrm{ZrO}_{2}$ & - & - & - & - & - & - & - & - & - & - & - \\
\hline $\mathrm{Nb}_{2} \mathrm{O}_{5}$ & 0.17 & 0.45 & 0.23 & 0.16 & 0.28 & 0.35 & 0.22 & 0.11 & 0.14 & 0.32 & 0.24 \\
\hline $\mathrm{Ta}_{2} \mathrm{O}_{5}$ & 0.05 & 0.03 & 0.04 & 0.04 & 0.04 & 0.03 & 0.03 & 0.03 & 0.03 & 0.04 & 0.00 \\
\hline $\mathrm{V}_{2} \mathrm{O}_{5}$ & 0.56 & 0.57 & 0.45 & 0.46 & 0.55 & 0.58 & 0.42 & 0.48 & 0.49 & 0.54 & 0.52 \\
\hline $\mathrm{ThO}_{2}$ & 0.11 & 0.03 & 0.11 & 0.10 & 0.05 & 0.04 & 0.00 & 0.00 & 0.01 & 0.02 & 0.10 \\
\hline $\mathrm{La}_{2} \mathrm{O}_{3}$ & 0.52 & 0.52 & 0.56 & 0.53 & 0.61 & 0.64 & 0.46 & 0.50 & 0.58 & 0.45 & 0.54 \\
\hline $\mathrm{Ce}_{2} \mathrm{O}_{3}$ & 0.00 & 0.44 & 0.55 & 0.33 & 0.19 & 0.51 & 0.00 & 0.13 & 0.57 & 0.33 & 0.03 \\
\hline $\mathrm{Nd}_{2} \mathrm{O}_{3}$ & 0.00 & 0.00 & 0.37 & 0.62 & 0.00 & 0.16 & 0.00 & 0.00 & 0.00 & 0.19 & 0.00 \\
\hline $\mathrm{Y}_{2} \mathrm{O}_{3}$ & 0.02 & 0.00 & 0.00 & 0.00 & 0.00 & 0.02 & 0.00 & 0.06 & 0.06 & 0.01 & 0.05 \\
\hline Total & 99.50 & 99.48 & 99.75 & 100.21 & 99.05 & 99.86 & 98.33 & 100.24 & 100.37 & 99.42 & 99.39 \\
\hline
\end{tabular}




\begin{tabular}{|c|c|c|c|c|c|c|c|c|}
\hline Amostra & FVL175 & FVL175 & FVL175 & FVL175 & FVL175 & FVL175 & FVL175 & FVL175 \\
\hline Unidade & B1a & B1a & B1a & B1a & B1a & B1a & B1a & B1a \\
\hline Posição & 3 & 4 & 5 & 6 & 7 & 8 & 9 & 10 \\
\hline \multicolumn{9}{|l|}{$w t \%$} \\
\hline $\mathrm{SiO}_{2}$ & 0.03 & 0.02 & 0.00 & 0.07 & 0.00 & 0.00 & 0.01 & 0.01 \\
\hline $\mathrm{TiO}_{2}$ & 56.47 & 55.70 & 55.78 & 56.49 & 56.36 & 56.16 & 55.78 & 56.37 \\
\hline $\mathrm{Al}_{2} \mathrm{O}_{3}$ & 0.02 & 0.05 & 0.03 & 0.06 & 0.04 & 0.05 & 0.06 & 0.04 \\
\hline $\mathrm{FeO}_{\mathrm{t}}$ & 0.95 & 1.13 & 1.21 & 1.06 & 1.23 & 0.98 & 1.06 & 1.21 \\
\hline $\mathrm{MnO}$ & 0.00 & 0.06 & 0.02 & 0.00 & 0.08 & 0.03 & 0.00 & 0.00 \\
\hline $\mathrm{MgO}$ & 0.02 & 0.01 & 0.02 & 0.03 & 0.01 & 0.01 & 0.00 & 0.01 \\
\hline $\mathrm{CaO}$ & 39.68 & 39.77 & 39.65 & 39.38 & 39.56 & 39.86 & 40.13 & 39.94 \\
\hline $\mathrm{Na}_{2} \mathrm{O}$ & 0.40 & 0.34 & 0.24 & 0.29 & 0.22 & 0.38 & 0.27 & 0.20 \\
\hline $\mathrm{SrO}$ & 0.45 & 0.43 & 0.51 & 0.37 & 0.45 & 0.37 & 0.29 & 0.43 \\
\hline $\mathrm{ZrO}_{2}$ & - & - & - & - & - & - & - & - \\
\hline $\mathrm{Nb}_{2} \mathrm{O}_{5}$ & 0.29 & 0.20 & 0.17 & 0.21 & 0.42 & 0.35 & 0.16 & 0.46 \\
\hline $\mathrm{Ta}_{2} \mathrm{O}_{5}$ & 0.03 & 0.01 & 0.12 & 0.00 & 0.07 & 0.04 & 0.07 & 0.00 \\
\hline $\mathrm{V}_{2} \mathrm{O}_{5}$ & 0.55 & 0.48 & 0.45 & 0.50 & 0.46 & 0.45 & 0.47 & 0.54 \\
\hline $\mathrm{ThO}_{2}$ & 0.08 & 0.16 & 0.00 & 0.00 & 0.19 & 0.05 & 0.03 & 0.09 \\
\hline $\mathrm{La}_{2} \mathrm{O}_{3}$ & 0.61 & 0.61 & 0.52 & 0.69 & 0.65 & 0.56 & 0.54 & 0.55 \\
\hline $\mathrm{Ce}_{2} \mathrm{O}_{3}$ & 0.05 & 0.42 & 0.26 & 0.06 & 0.37 & 0.40 & 0.14 & 0.00 \\
\hline $\mathrm{Nd}_{2} \mathrm{O}_{3}$ & 0.06 & 0.57 & 0.41 & 0.00 & 0.16 & 0.10 & 0.00 & 0.00 \\
\hline $\mathrm{Y}_{2} \mathrm{O}_{3}$ & 0.06 & 0.00 & 0.00 & 0.03 & 0.00 & 0.00 & 0.00 & 0.00 \\
\hline Total & 99.74 & 99.94 & 99.38 & 99.22 & 100.26 & 99.79 & 99.02 & 99.85 \\
\hline
\end{tabular}


ANEXOS B:

PADRÕES E CALIBRAÇÕES 
Tabela B1. Configurações operacionais do SELFRAG ${ }^{\circledR}$ Lab S2.0 utilizadas na fragmentação das amostras do presente trabalho.

\begin{tabular}{lcccc}
\hline Tipo de Rocha & Voltagem $(\mathbf{k V})$ & Pulsos & Frequência $(\mathbf{H z})$ & Gap* $(\mathbf{m m})$ \\
\hline Bebedourito & 140 & 50 & 5.0 & 20 \\
Carbonatito & 100 & $50-75$ & 5.0 & 20 \\
Foscorito & 140 & $50-100$ & 5.0 & 20 \\
\hline
\end{tabular}

*Distância entre os eletrodos.

Tabela B2. Detalhes das configurações operacionais do separador magnético Frantz ${ }^{\circledR}$ - Montagem fixa, $25^{\circ}$ de inclinação para frente, $15^{\circ}$ de inclinação lateral e voltagem de 110 Volts.

\begin{tabular}{lcc}
\hline \multicolumn{1}{c}{ Mineral } & $\begin{array}{c}\text { Corrente Elétrica Indicada* } \\
(\mathbf{A})\end{array}$ & $\begin{array}{c}\text { Corrente Elétrica Aplicada** } \\
(\mathbf{A})\end{array}$ \\
\hline Apatita & $>1.70$ & $>1.80$ \\
Biotita (Phl) & $0.30-0.80$ & $0.60-0.90$ \\
Calcita & $>1.70$ & $>1.80$ \\
Diopsídio (Cpx) & $0.40-0.60$ & $1.00-1.20$ \\
Dolomita & $>1.70$ & $>1.80$ \\
Forsterita (Ol) & $0.50-1.00$ & $0.50-1.00$ \\
Granada & $0.30-0.60$ & 0.50 \\
Magnetita & 0.01 & $<0.20$ \\
Perovskita & $>1.70$ & $>1.80$ \\
Pirocloro & $0.90-1.70$ & $>1.80$ \\
\hline
\end{tabular}

*Valores tabelados de Rosenblum \& Brownfield, 2000.

**Melhores valores observados para as amostras do presente trabalho.

Tabela B3. Configuração dos coletores usados durante as medições isotópicas de $\mathrm{Sr}, \mathrm{Sm}$ e Nd por meio do Thermo Scientific TRITON ${ }^{\mathrm{TM}}$ Plus Thermal Ionization Mass Spectrometry (TIMS).

\begin{tabular}{|c|c|c|c|c|c|c|c|c|c|}
\hline $\begin{array}{l}\text { Faraday } \\
\text { Cups }\end{array}$ & L4 & L3 & $\mathbf{L} 2$ & L1 & Axial & H1 & H2 & H3 & H4 \\
\hline \multicolumn{10}{|l|}{ Elemento } \\
\hline $\mathrm{Sr}$ & & & ${ }^{84} \mathrm{Sr}$ & ${ }^{85} \mathrm{Rb}$ & ${ }^{86} \mathrm{Sr}$ & ${ }^{87} \mathrm{Sr}$ & ${ }^{88} \mathrm{Sr}$ & & \\
\hline $\mathrm{Sm}$ & & ${ }^{146} \mathrm{Nd}$ & ${ }^{147} \mathrm{Sm}$ & ${ }^{148} \mathrm{Nd}$ & ${ }^{149} \mathrm{Sm}$ & ${ }^{150} \mathrm{Sm}$ & ${ }^{152} \mathrm{Sm}$ & ${ }^{154} \mathrm{Sm}$ & \\
\hline $\mathrm{Nd}$ & & ${ }^{142} \mathrm{Nd}$ & ${ }^{143} \mathrm{Nd}$ & ${ }^{144} \mathrm{Nd}$ & ${ }^{145} \mathrm{Nd}$ & ${ }^{146} \mathrm{Nd}$ & ${ }^{147} \mathrm{Sm}$ & ${ }^{148} \mathrm{Nd}$ & ${ }^{150} \mathrm{Nd}$ \\
\hline
\end{tabular}


Tabela B4. Detalhe das composições isotópicas de Nd medidas para o padrão BHVO-1.

\begin{tabular}{lcccccc}
\hline Padrão & ${ }^{\mathbf{1 4 3}} \mathbf{N d} /{ }^{\mathbf{1 4 4}} \mathbf{N d}^{*}$ & $\mathbf{\pm 2 S E}$ & ${ }^{\mathbf{1 4 5}} \mathbf{N d} /{ }^{\mathbf{1 4 4}} \mathbf{N d}$ & $\mathbf{\pm 2 S E}$ & ${ }^{\mathbf{1 4 6}} \mathbf{N d} /{ }^{\mathbf{1 4 4}} \mathbf{N d}$ & $\begin{array}{c}\text { \# Razões } \\
\text { Aceitas }\end{array}$ \\
\hline BHVO1-3G & 0.512994 & 0.000008 & 0.348428 & 0.000007 & 0.7229 & $66(80)$ \\
BHVO1-1M & 0.512998 & 0.000006 & 0.348426 & 0.000006 & 0.7200 & $66(70)$ \\
BHVO1-6M & 0.512995 & 0.000015 & 0.348421 & 0.000010 & 0.7226 & $65(70)$ \\
BHVO1-1G & 0.512993 & 0.000009 & 0.348429 & 0.000007 & 0.7217 & $65(80)$ \\
BHVO1-5M & 0.513001 & 0.000008 & 0.348429 & 0.000005 & 0.7201 & $85(90)$ \\
BHVO1-6G & 0.512997 & 0.000007 & 0.348427 & 0.000005 & 0.7226 & $58(60)$ \\
BHVO1-7G & 0.512992 & 0.000008 & 0.348430 & 0.000005 & 0.7233 & $56(60)$
\end{tabular}

$*$ Valores corrigidos para interferentes e normalizado por ${ }^{146} \mathrm{Nd} /{ }^{144} \mathrm{Nd}=0.7219$.

SE - Standard Error.

\# Número de razões ${ }^{143} \mathrm{Nd} /{ }^{144} \mathrm{Nd}$ aceitas dentre o total de razões medidas (entre parênteses) num intervalo de confiança igual a 2 sigma $(2 \sigma)$.

Tabela B5. Detalhe das composições isotópicas de Sr medidas para o padrão NBS-987.

\begin{tabular}{|c|c|c|c|c|c|c|}
\hline Padrão & ${ }^{87} \mathrm{Sr} /{ }^{86} \mathrm{Sr}^{* *}$ & $\pm 2 S E$ & ${ }^{84} \mathrm{Sr} /{ }^{86} \mathrm{Sr}$ & $\pm 2 S E$ & ${ }^{85} \mathrm{Rb} /{ }^{86} \mathrm{Sr}$ & $\begin{array}{c}\text { \# Razões } \\
\text { Aceitas }\end{array}$ \\
\hline NBS 987* & 0.710260 & 0.000020 & & & & $50(50)$ \\
\hline NBS 987-1 & 0.710260 & 0.000010 & 0.056496 & 0.000003 & 0.000019 & $45(50)$ \\
\hline NBS 987-2 & 0.710259 & 0.000003 & 0.056492 & 0.000001 & 0.000004 & $139(150)$ \\
\hline NBS 987-3 & 0.710262 & 0.000004 & 0.056489 & 0.000001 & 0.000009 & $138(150)$ \\
\hline NBS 987-1 & 0.710250 & 0.000004 & 0.056495 & 0.000001 & 0.000002 & $138(150)$ \\
\hline NBS 987-2 & 0.710260 & 0.000003 & 0.056491 & 0.000001 & 0.000006 & $126(150)$ \\
\hline NBS 987-3 & 0.710255 & 0.000004 & 0.056491 & 0.000002 & 0.000006 & $130(150)$ \\
\hline NBS 987-4 & 0.710256 & 0.000003 & 0.056491 & 0.000001 & 0.000018 & $135(150)$ \\
\hline NBS 987-5 & 0.710259 & 0.000004 & 0.056495 & 0.000001 & 0.000011 & $136(150)$ \\
\hline NBS 987-6 & 0.710254 & 0.000003 & 0.056493 & 0.000001 & 0.000007 & $132(150)$ \\
\hline
\end{tabular}


Tabela B6. Detalhe das configurações operacionais utilizadas nas analises de química mineral por meio da microssonda eletrônica JEOL® JXA-8230 Superprobe.

\begin{tabular}{llccc}
\hline Mineral & Elementos & $\begin{array}{c}\text { Voltagem de } \\
\text { Aceleração } \\
(\mathbf{k V})\end{array}$ & $\begin{array}{c}\text { Corrente } \\
(\mathbf{n A})\end{array}$ & $\begin{array}{c}\text { Diâmetro } \\
\text { do Feixe } \\
(\boldsymbol{\mu m})\end{array}$ \\
\hline $\mathrm{Ap} / \mathrm{Cb} / \mathrm{Brt}$ & Maiores & 15 & 10 & 5 \\
$\mathrm{Ap} / \mathrm{Cb} / \mathrm{Brt}$ & ETR & 20 & 20 & 5 \\
$\mathrm{Spl}$ & Maiores & 15 & 15 & 3 \\
$\mathrm{Spl}$ & Traços & 20 & 20 & 3 \\
Outros* & Maiores & 15 & 10 & 3 \\
Outros* & ETR+HFSE & 20 & 20 & 3 \\
\hline
\end{tabular}

*Outros: Ol, Phl, Prv, Pcl, Bdy e Zrc.

Tabela B7. Detalhe dos padrões de calibração empregados nas analises por microssonda eletrônica JEOL ${ }^{\circledR}$ JXA-8230 Superprobe.

\begin{tabular}{|c|c|c|c|c|c|c|c|}
\hline Element & $\begin{array}{l}\text { X-ray } \\
\text { Peak } \\
\end{array}$ & Crystal & Standard & Element & $\begin{array}{l}\text { X-ray } \\
\text { Peak } \\
\end{array}$ & Crystal & Standard \\
\hline Major: & & & & HFSE: & & & \\
\hline $\mathrm{F}$ & $\mathrm{K} \alpha$ & LDE1 & Topaz & $\mathrm{Hf}$ & $\mathrm{M} \alpha$ & TAP & $\mathrm{HfO} 2$ \\
\hline $\mathrm{Mg}$ & $\mathrm{K} \alpha$ & TAP & Olivine & $\mathrm{Ta}$ & $\mathrm{M} \alpha$ & TAP & synthetic $\mathrm{LiTaO} 3$ \\
\hline $\mathrm{Na}$ & $\mathrm{K} \alpha$ & TAP & Albite & $\mathrm{Y}$ & $\mathrm{L} \alpha$ & TAP & synthetic $\mathrm{YFe} 2 \mathrm{O} 12$ \\
\hline $\mathrm{Si}$ & $\mathrm{K} \alpha$ & TAP & Wollastonite & $\mathrm{Nb}$ & $\mathrm{L} \alpha$ & PETJ & synthetic LiNbO3 \\
\hline $\mathrm{Al}$ & $\mathrm{K} \alpha$ & TAP & Corundum & $\mathrm{Zr}$ & $\mathrm{L} \alpha$ & PETJ & Zircon \\
\hline $\mathrm{Ca}$ & $\mathrm{K} \alpha$ & PETJ & Wollastonite & $\mathrm{U}$ & $\mathrm{M} \alpha$ & PETJ & Uraninite \\
\hline K & $\mathrm{K} \alpha$ & PETJ & Microcline & Th & $\mathrm{M} \alpha$ & PETJ & Thorite \\
\hline $\mathrm{Cl}$ & $\mathrm{K} \alpha$ & PETJ & Vanadinite & REE: & & & \\
\hline $\mathrm{Sr}$ & $\mathrm{L} \alpha$ & PETJ & SrSO4 & Dy & $\mathrm{L} \alpha$ & LIF & synthetic REE glass \\
\hline $\mathrm{P}$ & $\mathrm{K} \alpha$ & PETJ & Apatite & $\mathrm{Eu}$ & $\mathrm{L} \alpha$ & LIF & synthetic REE glass \\
\hline S & $\mathrm{K} \alpha$ & PETJ & BaSO4 & $\mathrm{Nd}$ & $\mathrm{L} \alpha$ & LIF & synthetic REE glass \\
\hline $\mathrm{Ti}$ & $\mathrm{K} \alpha$ & PETJ & synthetic MnTiO3 & $\mathrm{Tb}$ & $\mathrm{L} \alpha$ & LIF & synthetic REE glass \\
\hline $\mathrm{Cr}$ & $\mathrm{K} \alpha$ & PETJ & Cromite & $\mathrm{Gd}$ & $\mathrm{L} \alpha$ & LIF & synthetic REE glass \\
\hline $\mathrm{Fe}$ & $\mathrm{K} \alpha$ & LIFH & $\mathrm{Fe} 2 \mathrm{O} 3$ & $\mathrm{Ce}$ & $\mathrm{L} \alpha$ & LIF & synthetic REE glass \\
\hline $\mathrm{Ba}$ & $\mathrm{L} \alpha$ & LIFH & BaSO4 & $\operatorname{Pr}$ & $\mathrm{L} \alpha$ & LIF & synthetic REE glass \\
\hline $\mathrm{Mn}$ & $\mathrm{K} \alpha$ & LIFH & synthetic $\mathrm{MnTiO} 3$ & $\mathrm{Yb}$ & $\mathrm{L} \alpha$ & LIFH & synthetic REE glass \\
\hline $\mathrm{V}$ & $\mathrm{K} \alpha$ & LIFH & Vanadinite & $\mathrm{La}$ & $\mathrm{L} \alpha$ & LIFH & synthetic REE glass \\
\hline $\mathrm{Ni}$ & $\mathrm{K} \alpha$ & LIFH & $\mathrm{NiO}$ & $\mathrm{Er}$ & $\mathrm{L} \alpha$ & LIFH & synthetic REE glass \\
\hline $\mathrm{Zn}$ & $\mathrm{K} \alpha$ & LIFH & $\mathrm{ZnS}$ & $\mathrm{Sm}$ & $\mathrm{L} \alpha$ & LIFH & synthetic REE glass \\
\hline
\end{tabular}


ANEXOS C:

CONCENTRADOS MINERAIS 


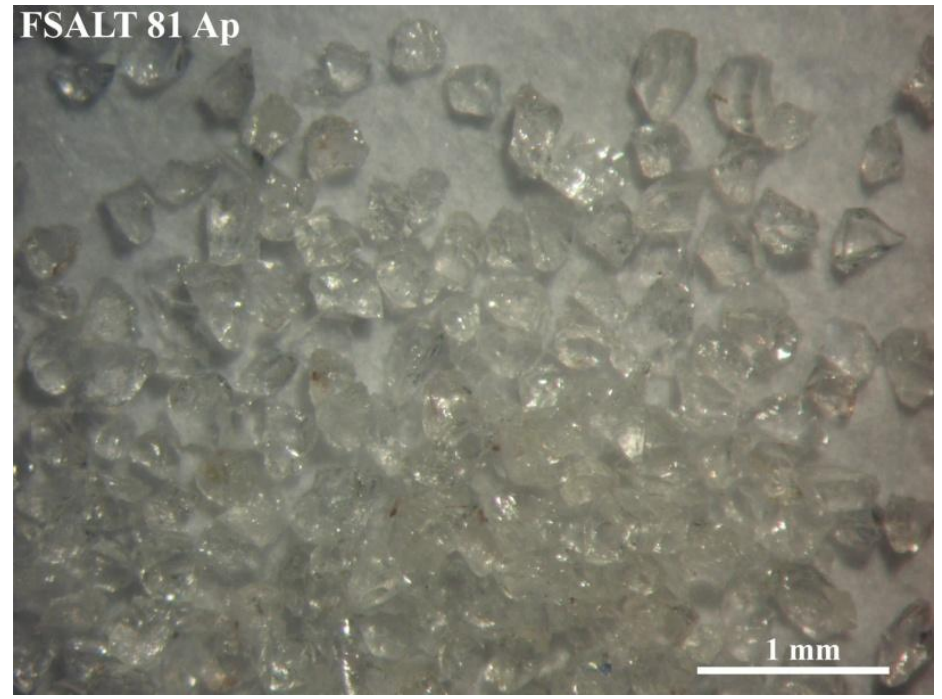

Figura C1. Fotografia do concentrado de apatita selecionado da amostra FSALT 81 (Salitre).

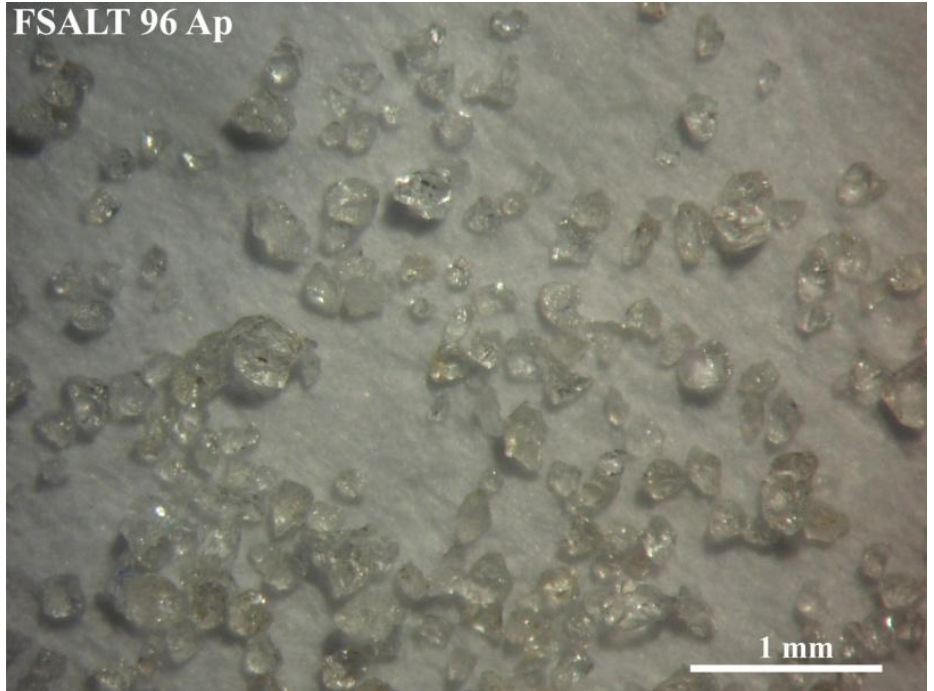

Figura C2. Fotografia do concentrado de apatita selecionado da amostra FSALT 96 (Salitre).

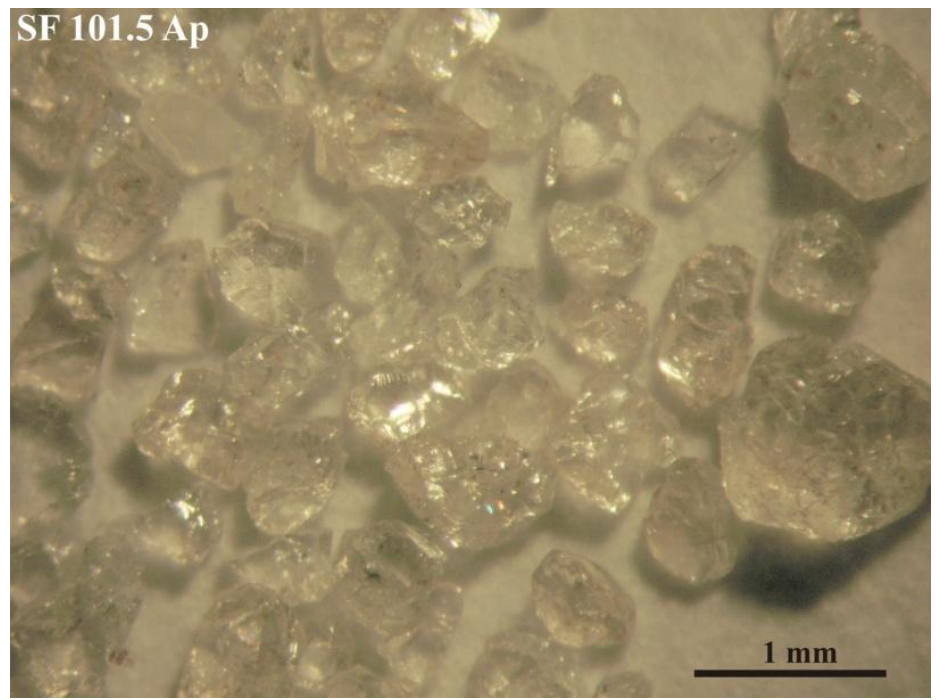

Figura C3. Fotografia do concentrado de apatita selecionado da amostra SF 101.5D1 (Salitre). 


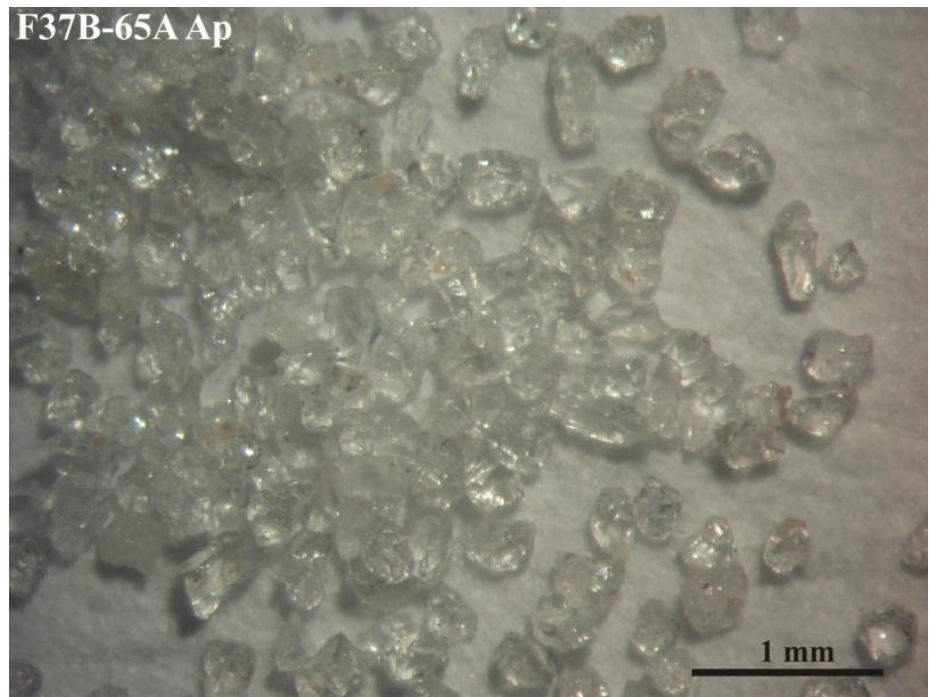

Figura C4. Fotografia do concentrado de apatita selecionado da amostra F37B-65A (Salitre).

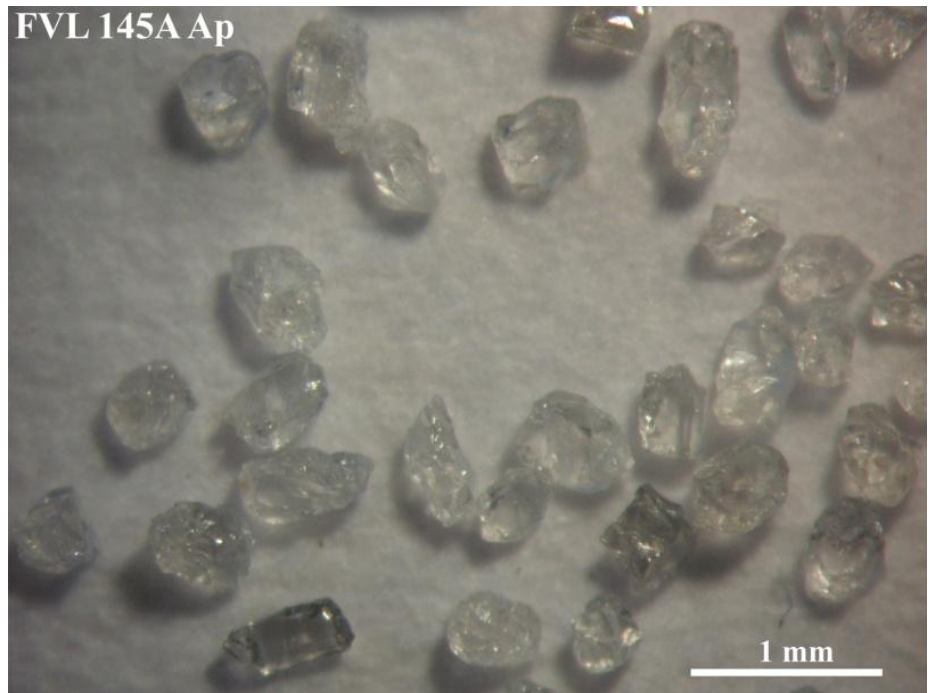

Figura C5. Fotografia do concentrado de apatita selecionado da amostra FVL 145A (Salitre).

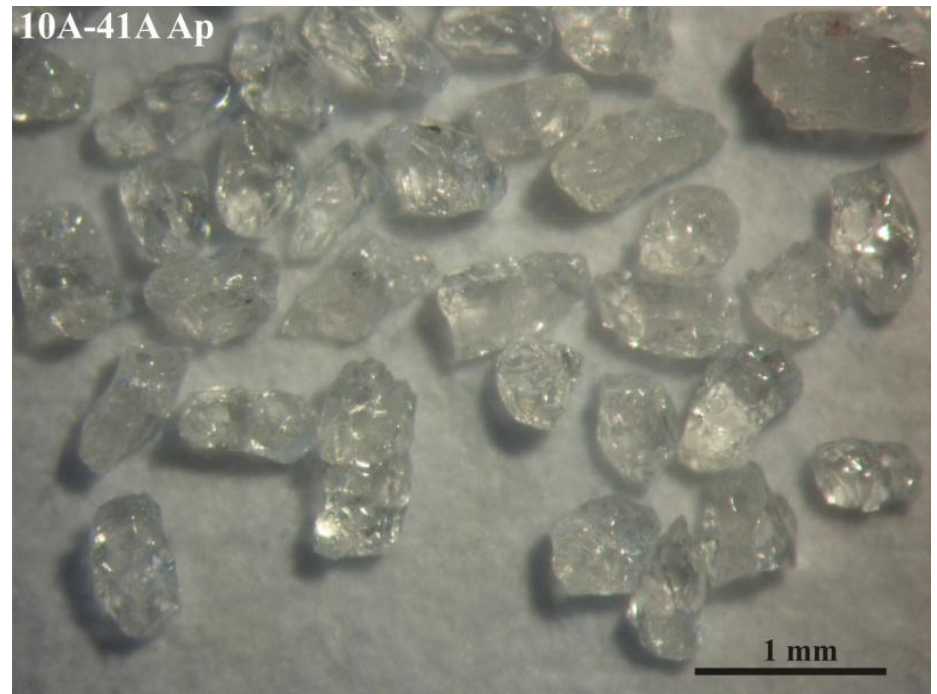

Figura C6. Fotografia do concentrado de apatita selecionado da amostra 10A-41A (Salitre). 


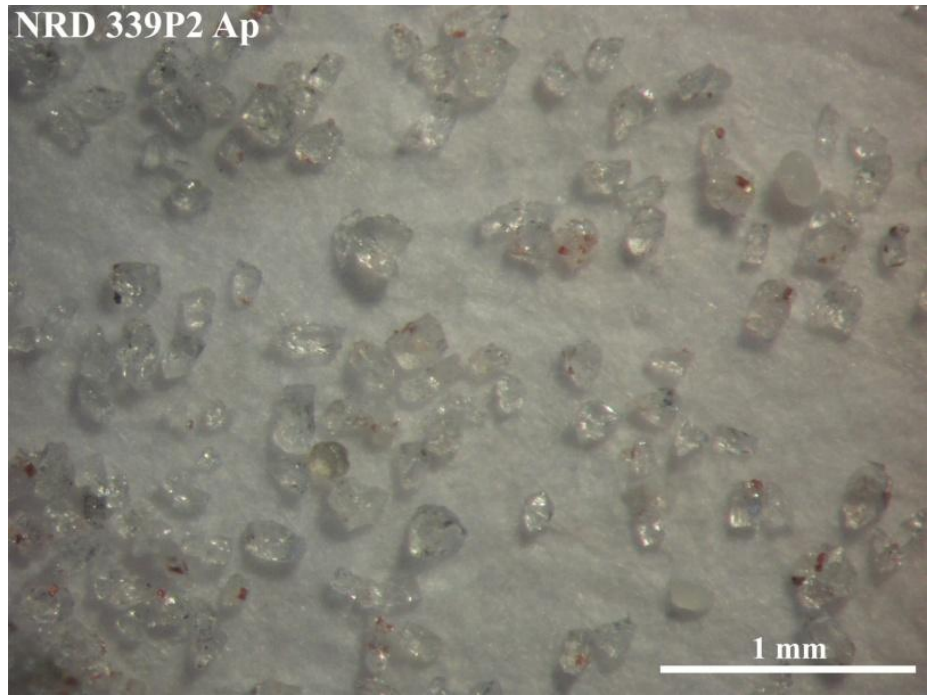

Figura C7. Fotografia do concentrado de apatita selecionado da amostra NRD 339P2 (Catalão I).

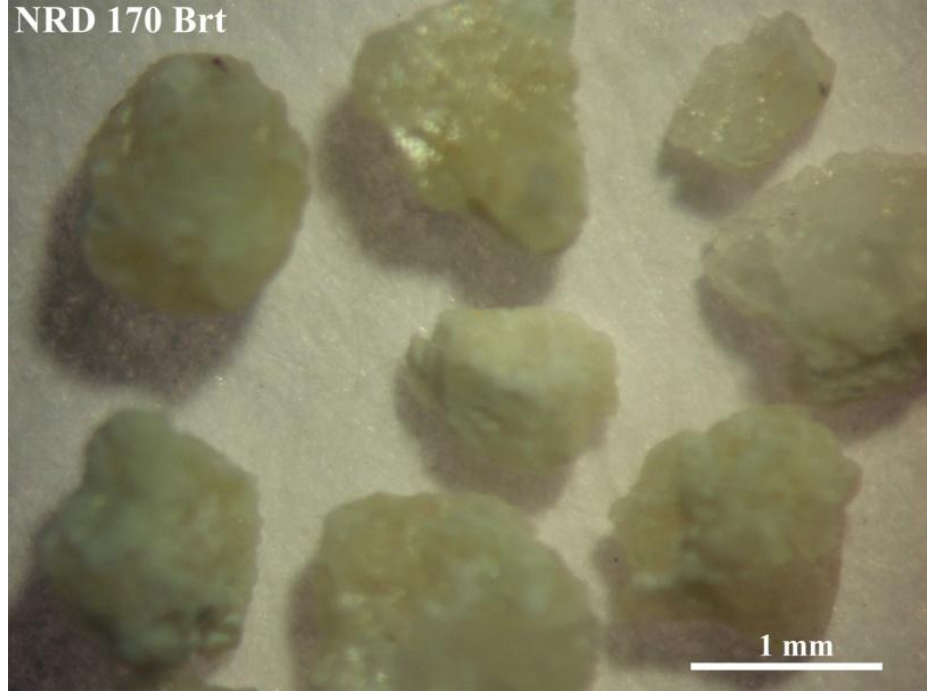

Figura C8. Fotografia do concentrado de barita selecionado da amostra NRD 170 (Catalão I).

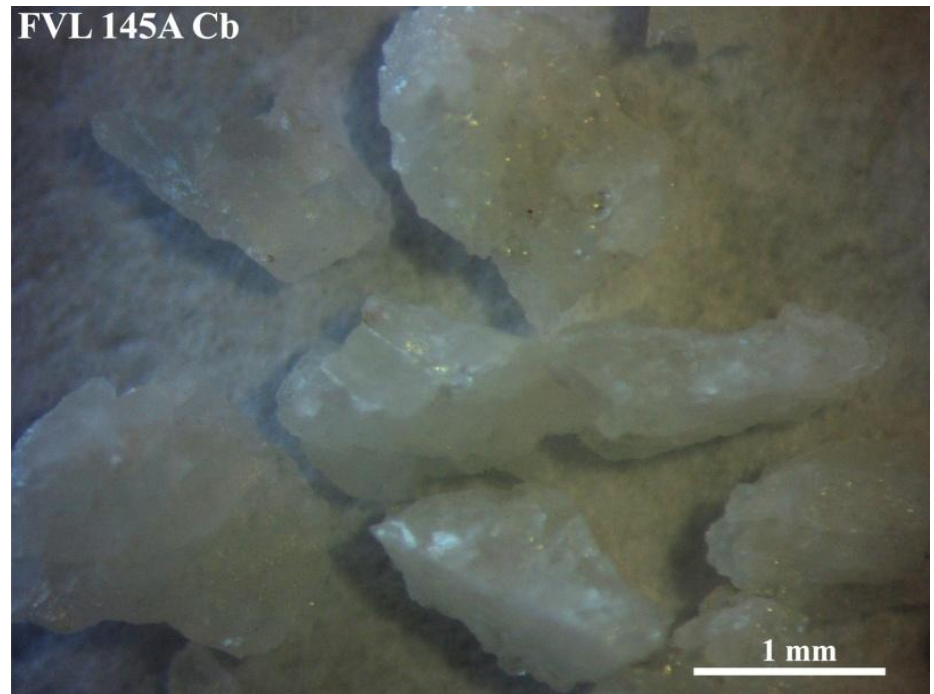

Figura C9. Fotografia do concentrado de calcita selecionado da amostra FVL 145A (Salitre). 


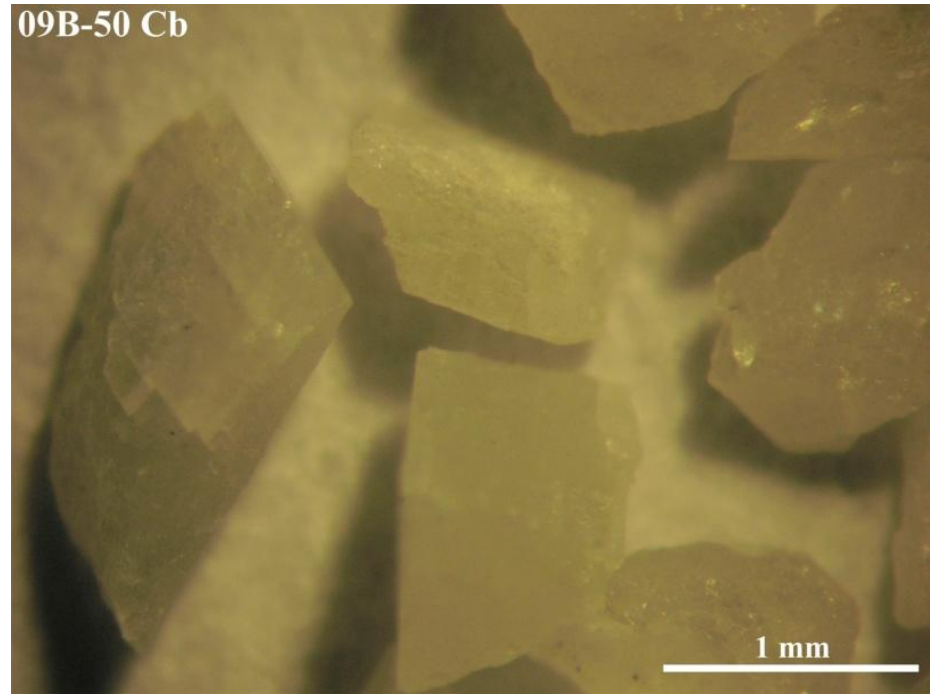

Figura C10. Fotografia do concentrado de dolomita selecionado da amostra 09B-50 (Salitre).

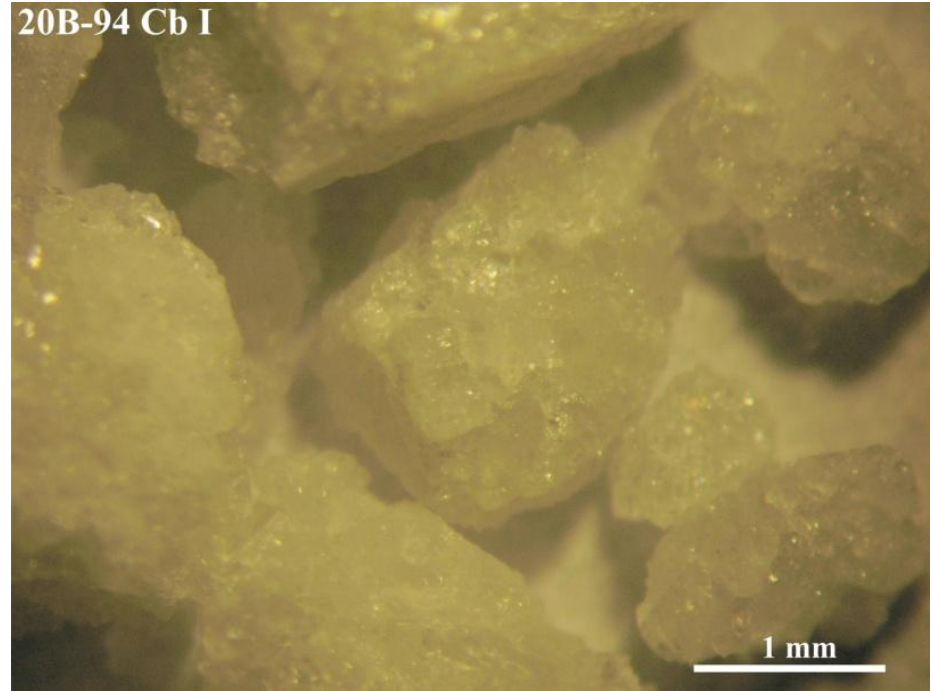

Figura C11. Fotografia do concentrado de dolomita granular selecionado da amostra 20B-94 (Salitre).

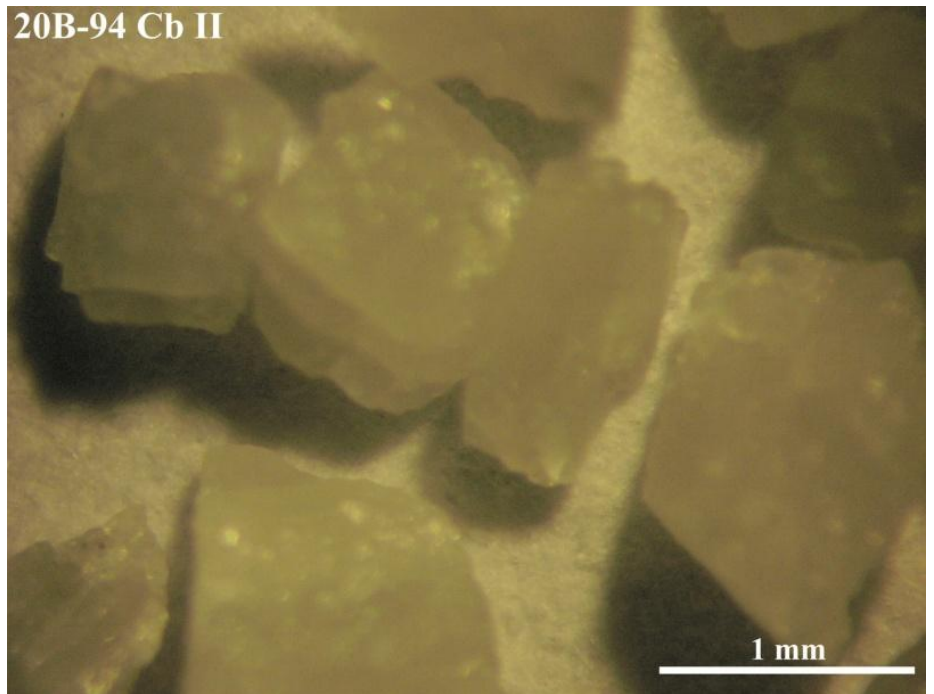

Figura C12. Fotografia do concentrado de dolomita euédrica selecionado da amostra 20B-94 (Salitre). 


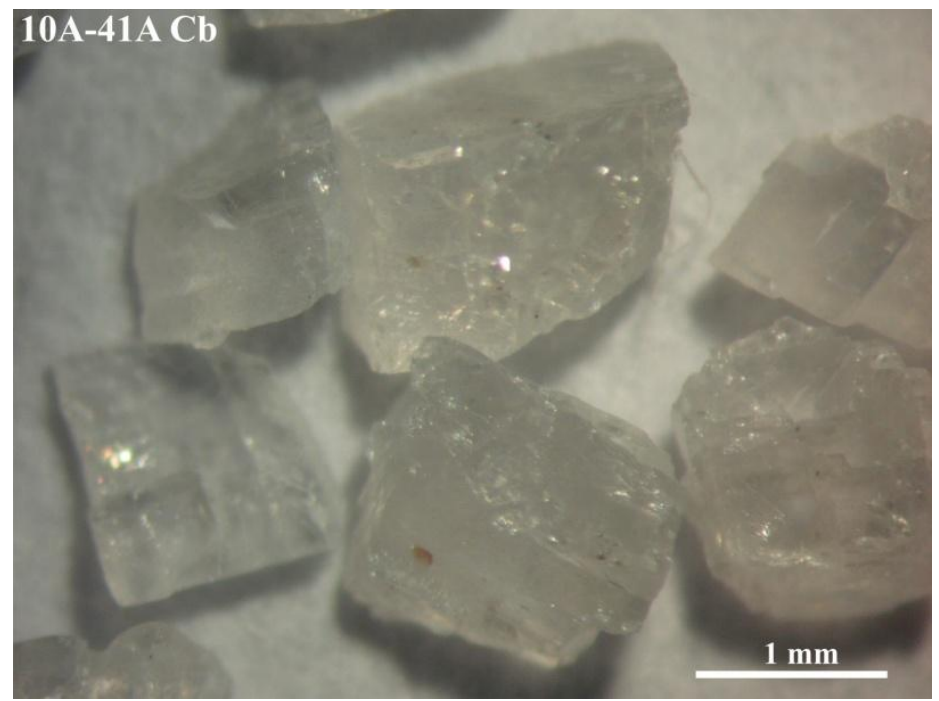

Figura C13. Fotografia do concentrado de calcita selecionado da amostra 10A-41A (Salitre).

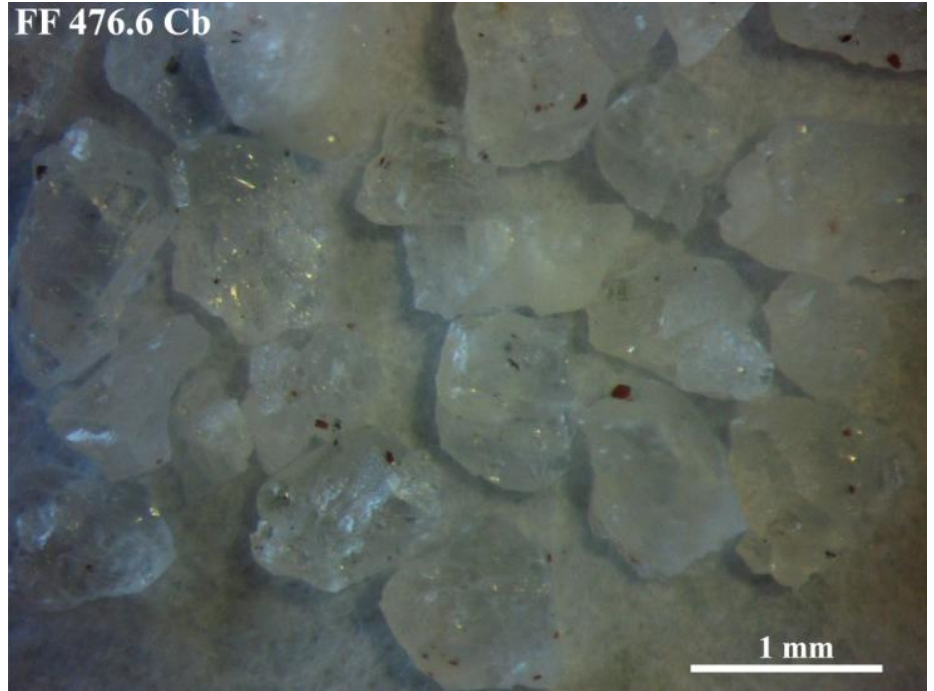

Figura C14. Fotografia do concentrado de calcita selecionado da amostra FF 476.6 (Salitre).

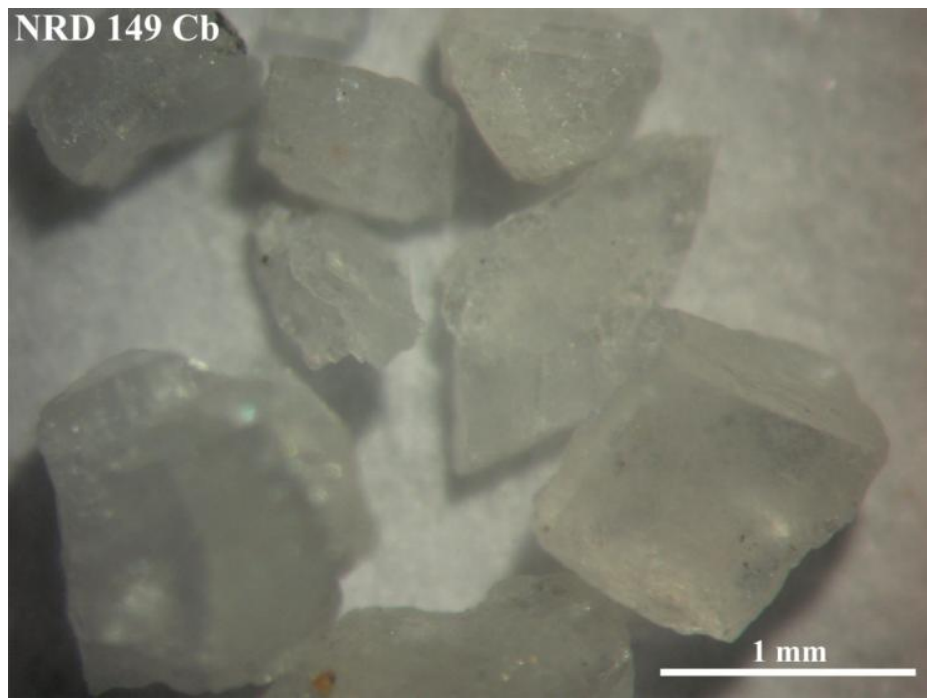

Figura C15. Fotografia do concentrado de dolomita selecionado da amostra NRD 149 (Catalão I). 


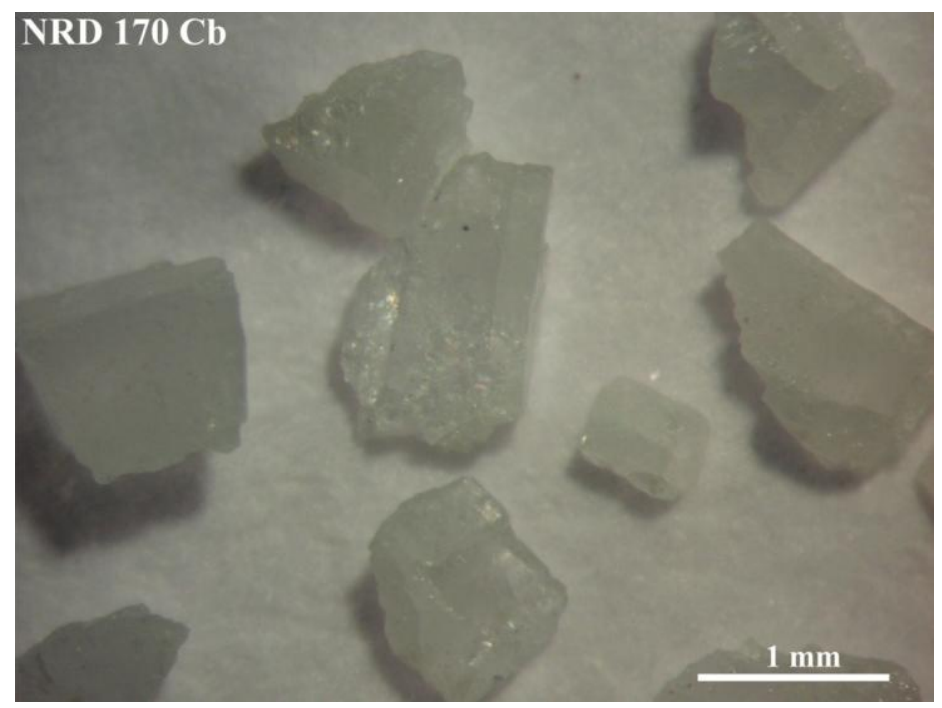

Figura C16. Fotografia do concentrado de dolomita selecionado da amostra NRD 170 (Catalão I).

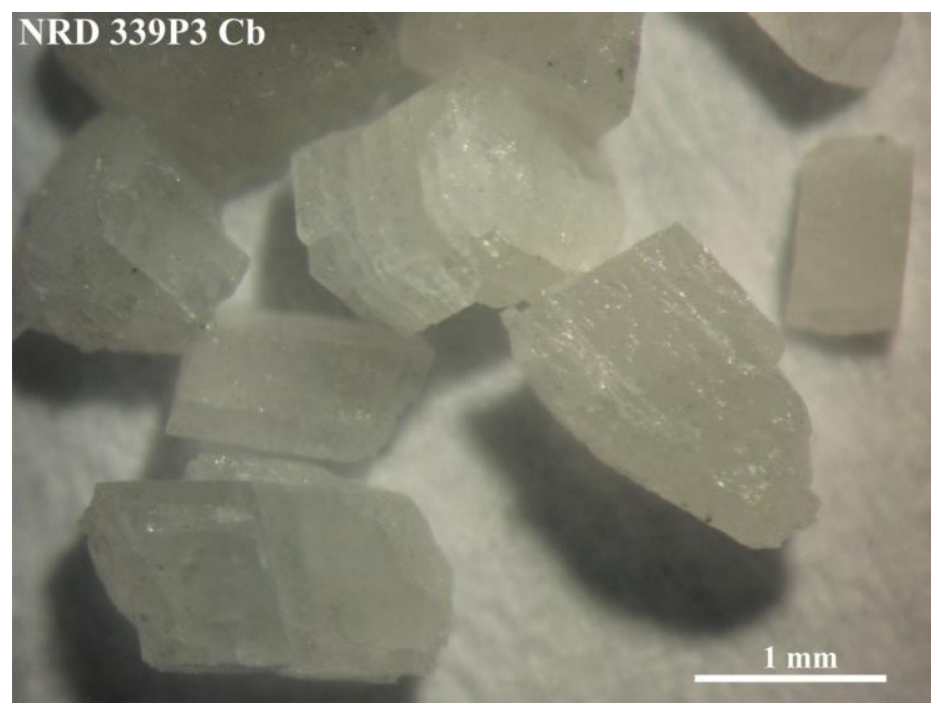

Figura C17. Fotografia do concentrado de dolomita selecionado da amostra NRD 339P3 (Catalão I).

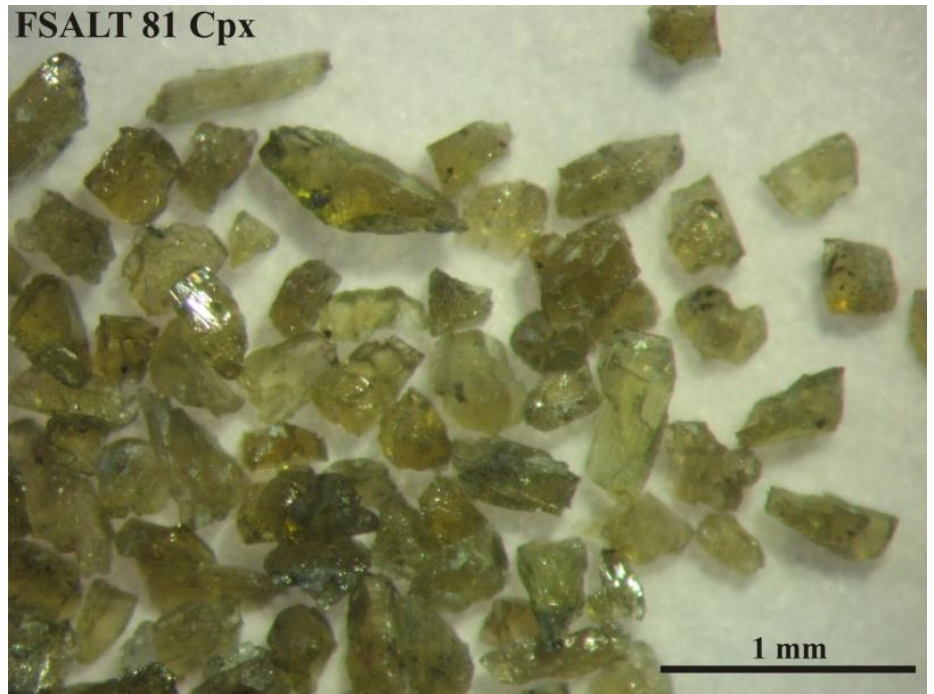

Figura C18. Fotografia do concentrado de clinopiroxênio selecionado da amostra FSALT 81 (Salitre). 


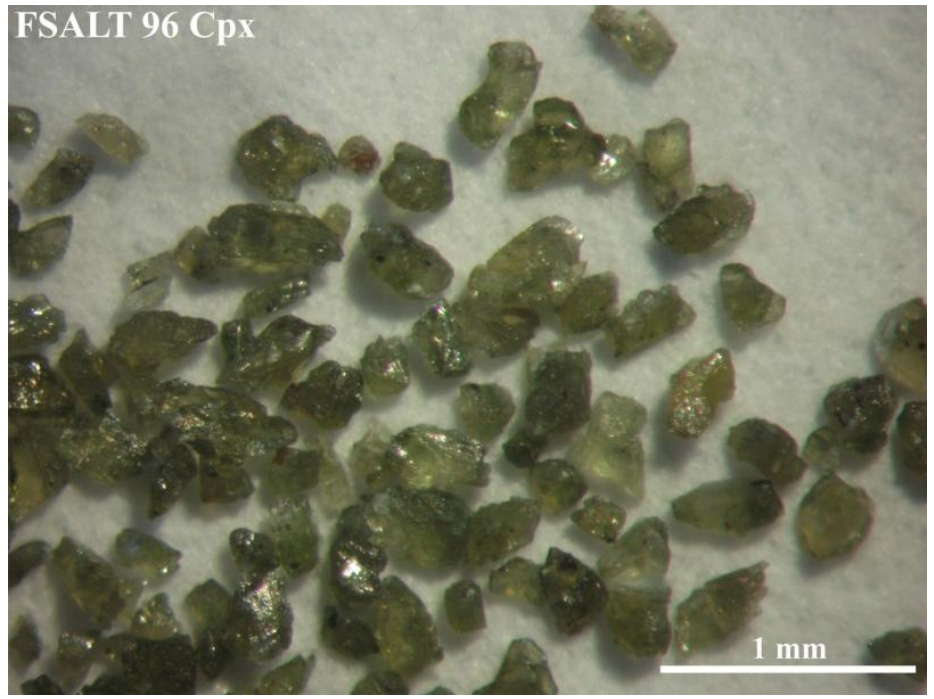

Figura C19. Fotografia do concentrado de clinopiroxênio selecionado da amostra FSALT 96 (Salitre).

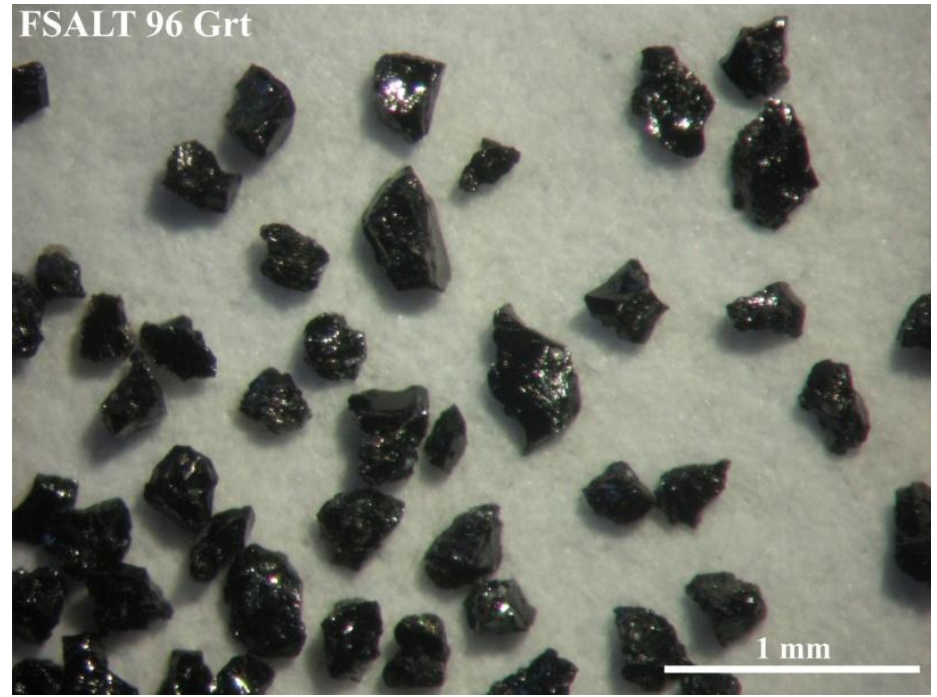

Figura C20. Fotografia do concentrado de granada selecionado da amostra FSALT 96 (Salitre).

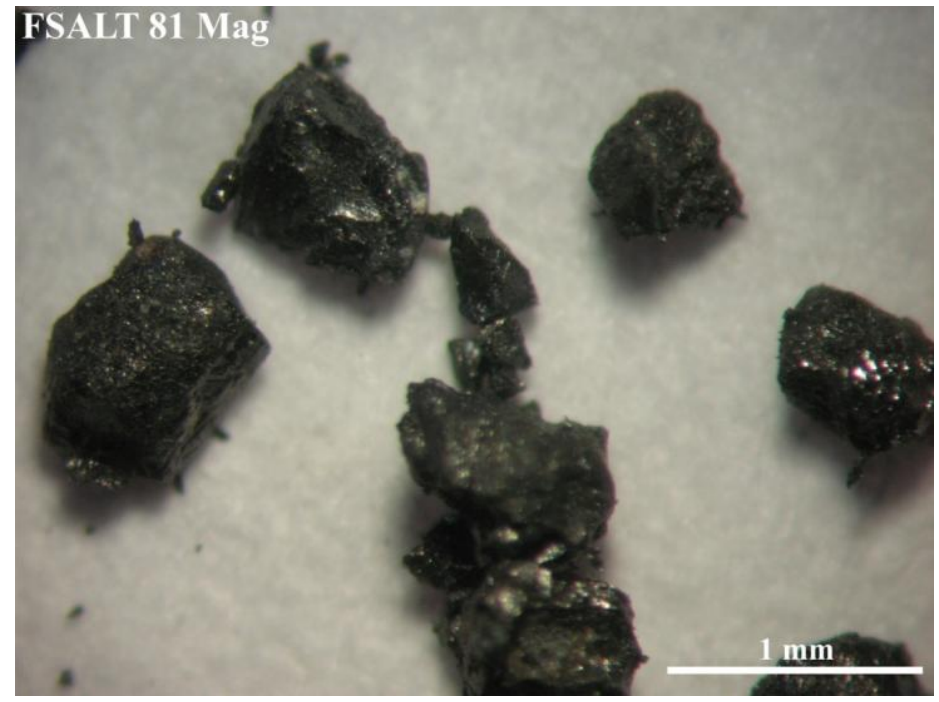

Figura C21. Fotografia do concentrado de magnetita selecionado da amostra FSALT 81 (Salitre). 


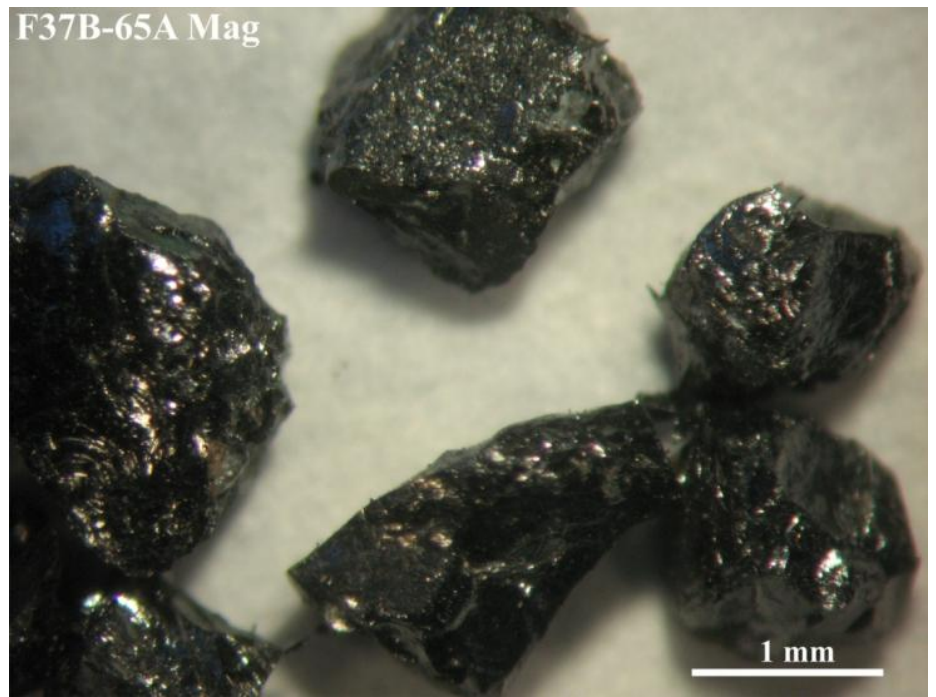

Figura C22. Fotografia do concentrado de magnetita selecionado da amostra F37B-65A (Salitre).

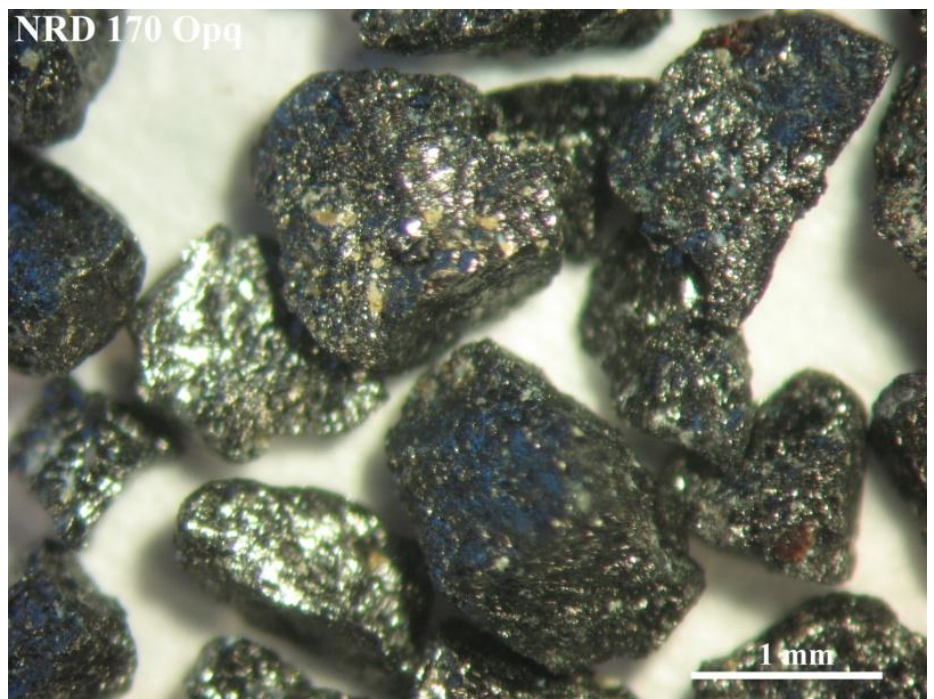

Figura C23. Fotografia do concentrado de magnetita/ilmenita obtido da amostra NRD 170 (Catalão I).

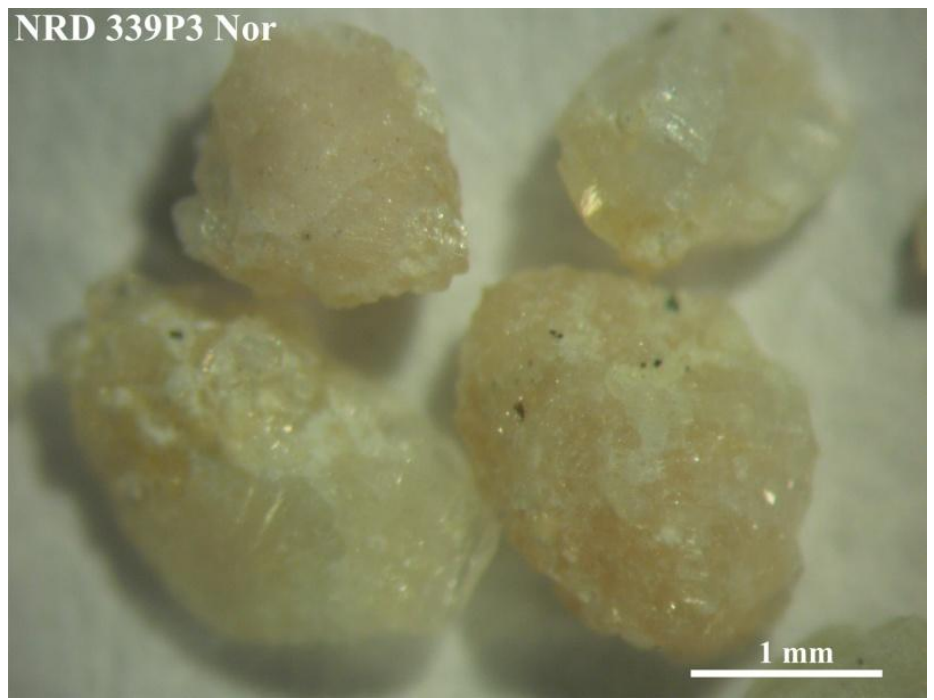

Figura C24. Fotografia do concentrado de norsethita selecionado da amostra NRD 339P3 (Catalão I). 


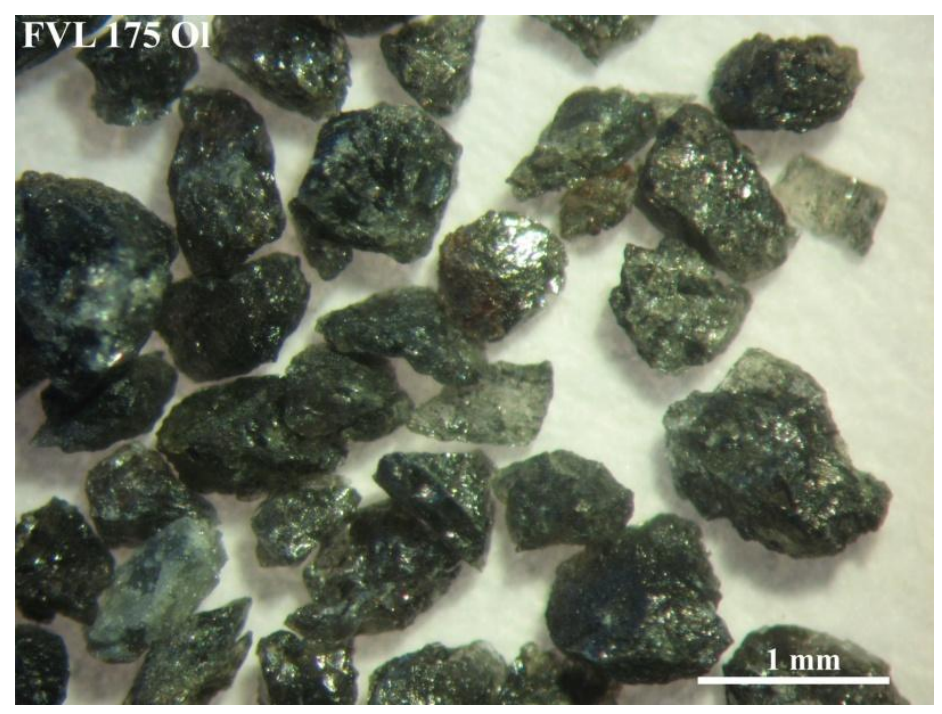

Figura C25. Fotografia do concentrado de olivina selecionado da amostra FVL 175 (Salitre).

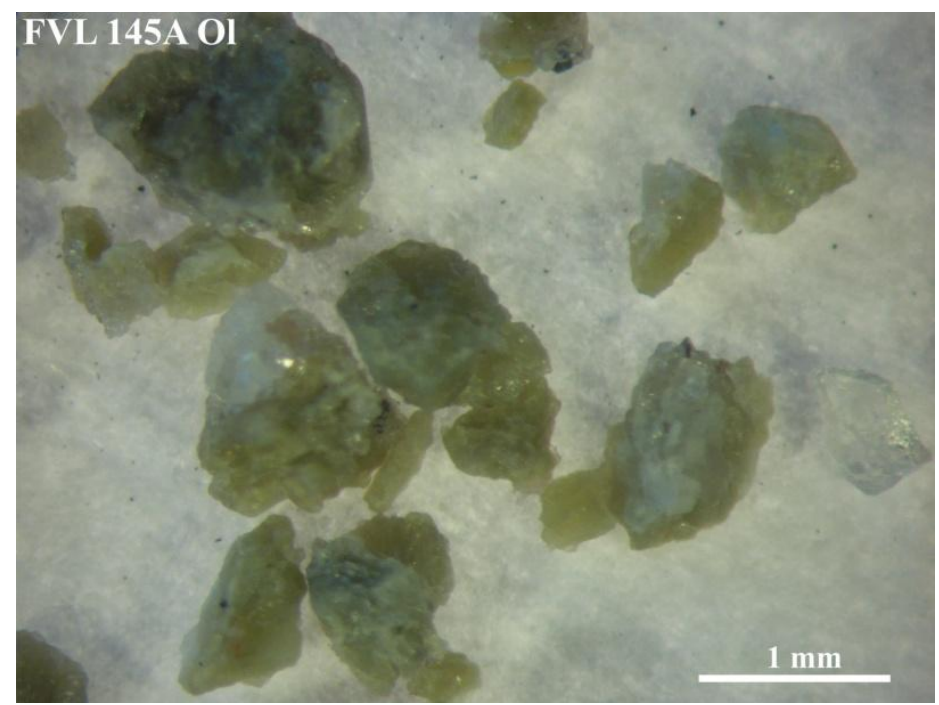

Figura C26. Fotografia do concentrado de olivina selecionado da amostra FVL 145A (Salitre).

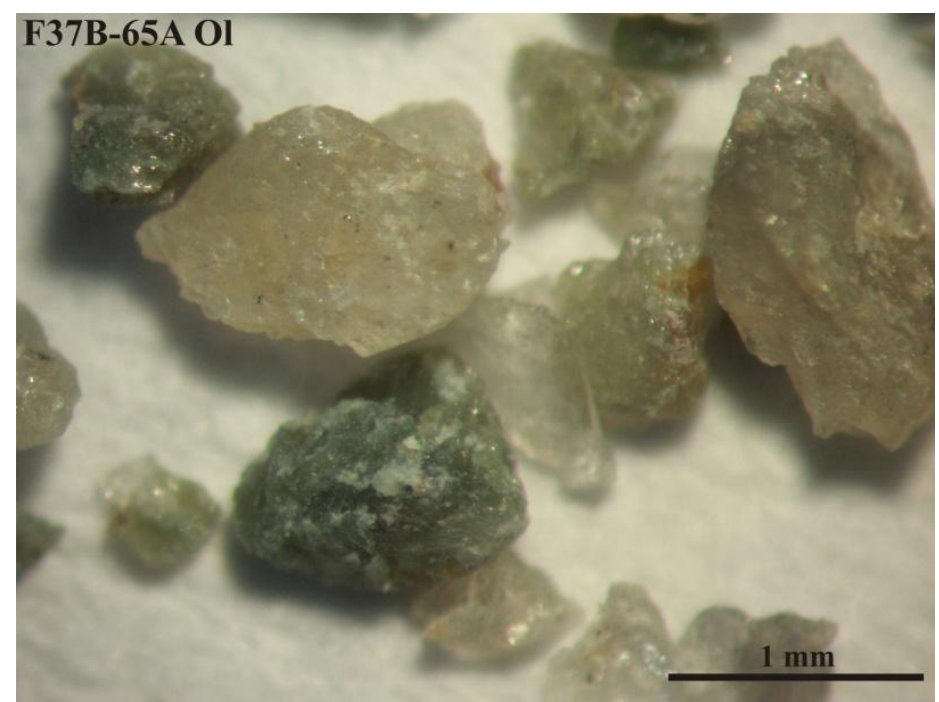

Figura C27. Fotografia do concentrado de olivina selecionado da amostra F37B-65A (Salitre). 


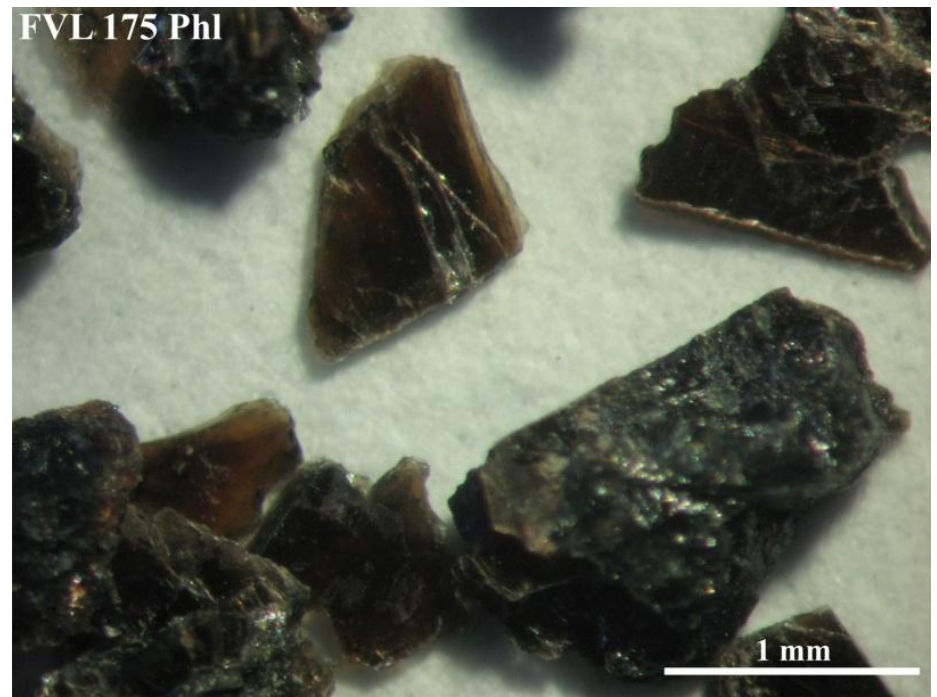

Figura C28. Fotografia do concentrado de flogopita selecionado da amostra FVL 175 (Salitre).

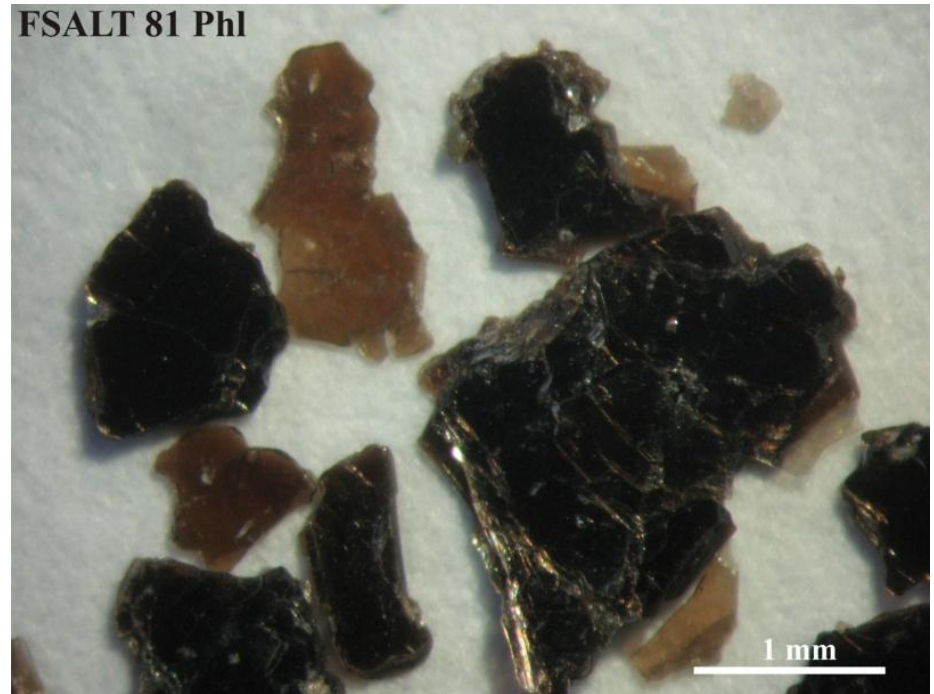

Figura C29. Fotografia do concentrado de flogopita selecionado da amostra FSALT 81 (Salitre).

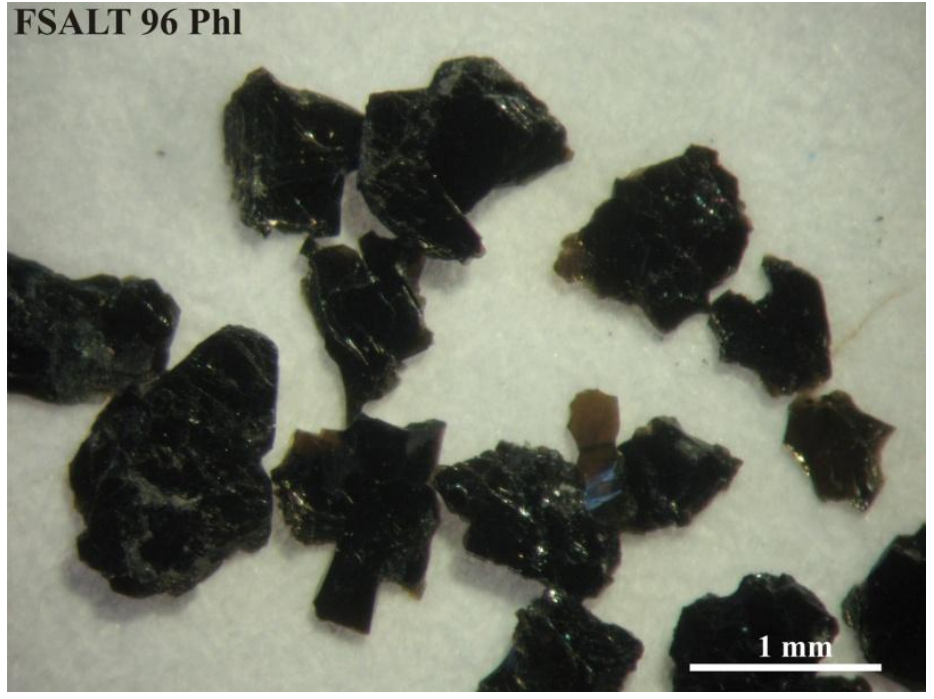

Figura C30. Fotografia do concentrado de flogopita selecionado da amostra FSALT 96 (Salitre). 


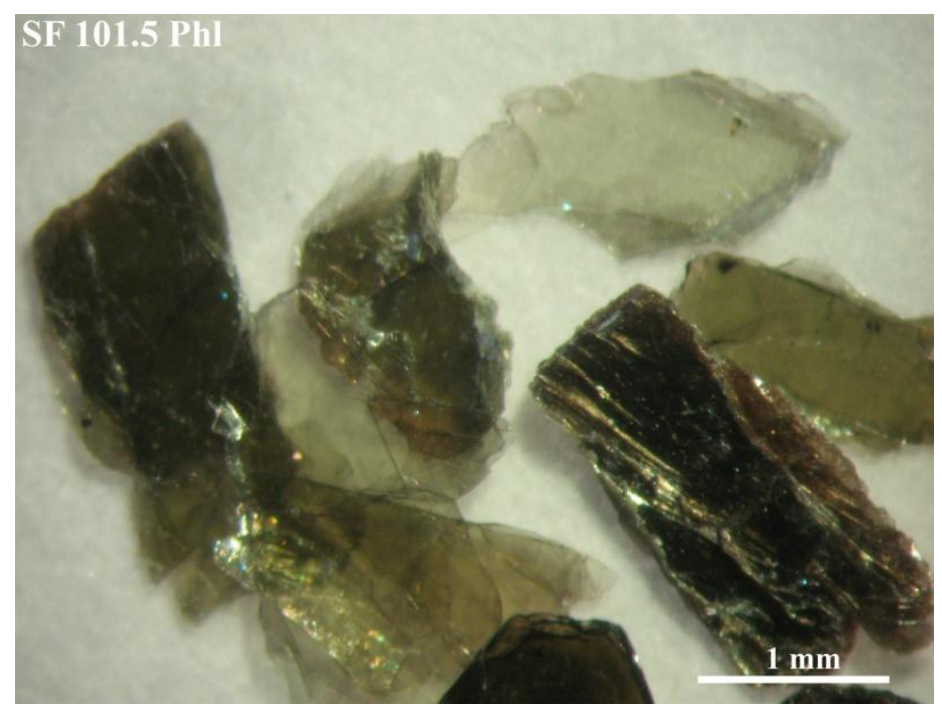

Figura C31. Fotografia do concentrado de flogopita selecionado da amostra SF 101.5D1 (Salitre).

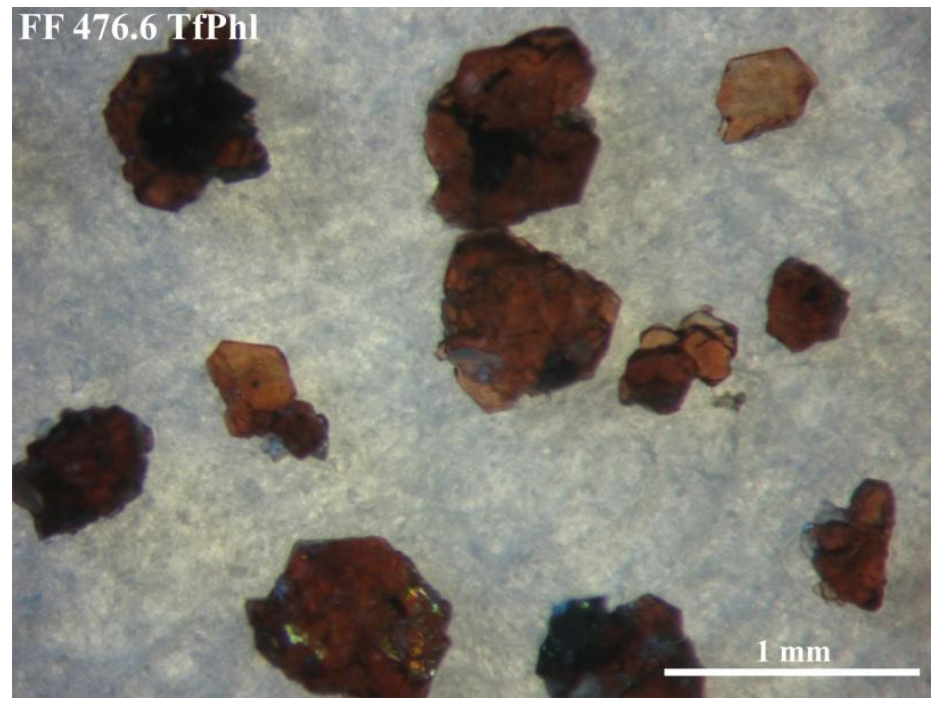

Figura C32. Fotografia do concentrado de tetraferriflogopita selecionado da amostra FF 476.6 (Salitre).

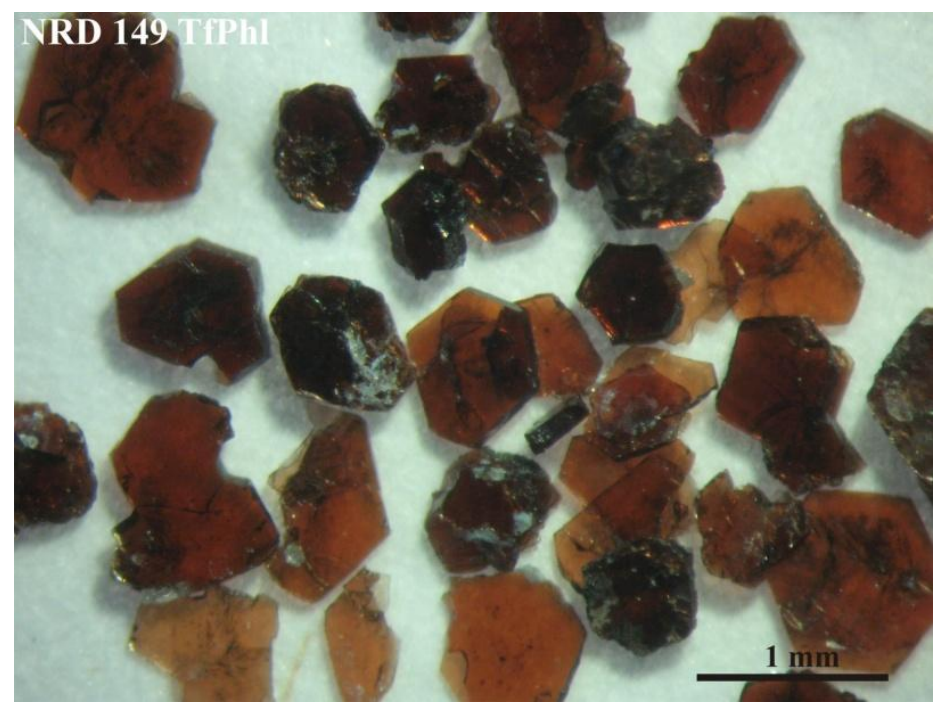

Figura C33. Fotografia do concentrado de tetraferriflogopita obtido da amostra NRD 149 (Catalão I). 


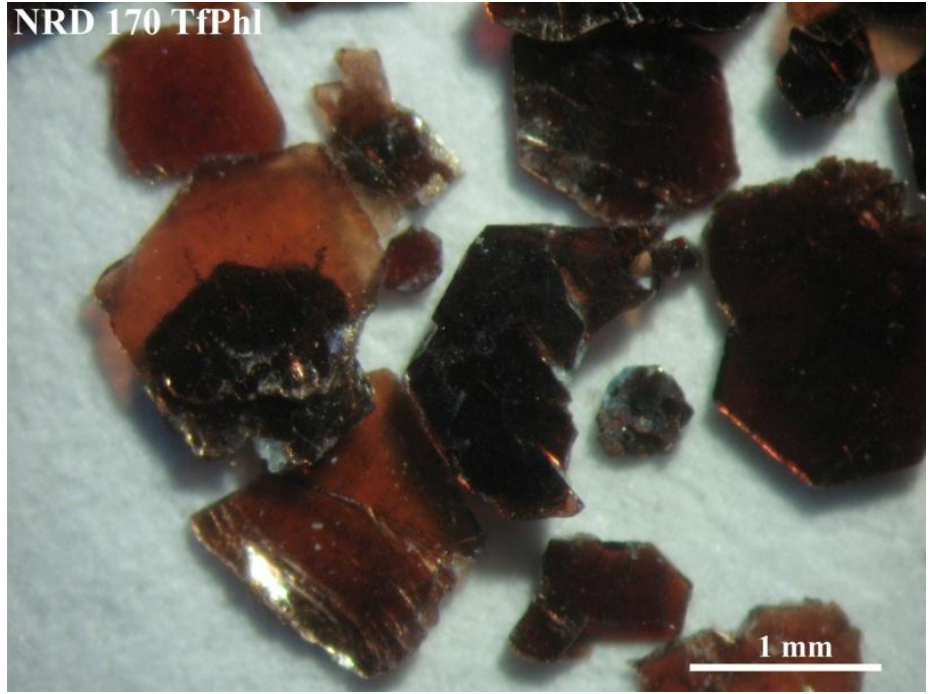

Figura C34. Fotografia do concentrado de tetraferriflogopita obtido da amostra NRD 170 (Catalão I).

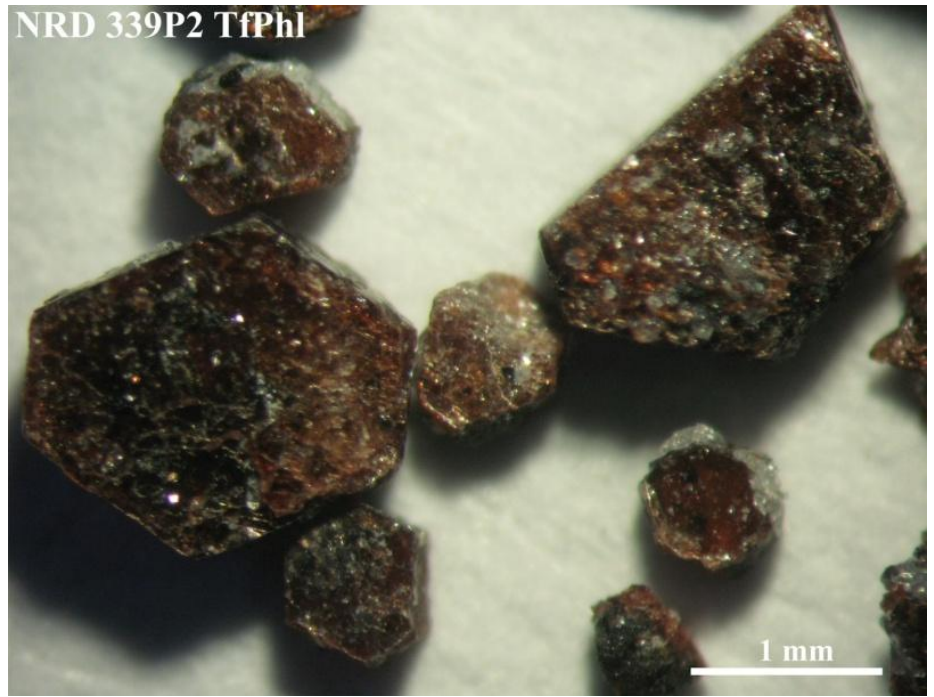

Figura C35. Fotografia do concentrado de tetraferriflogopita obtido da amostra NRD 339P2 (Catalão I).

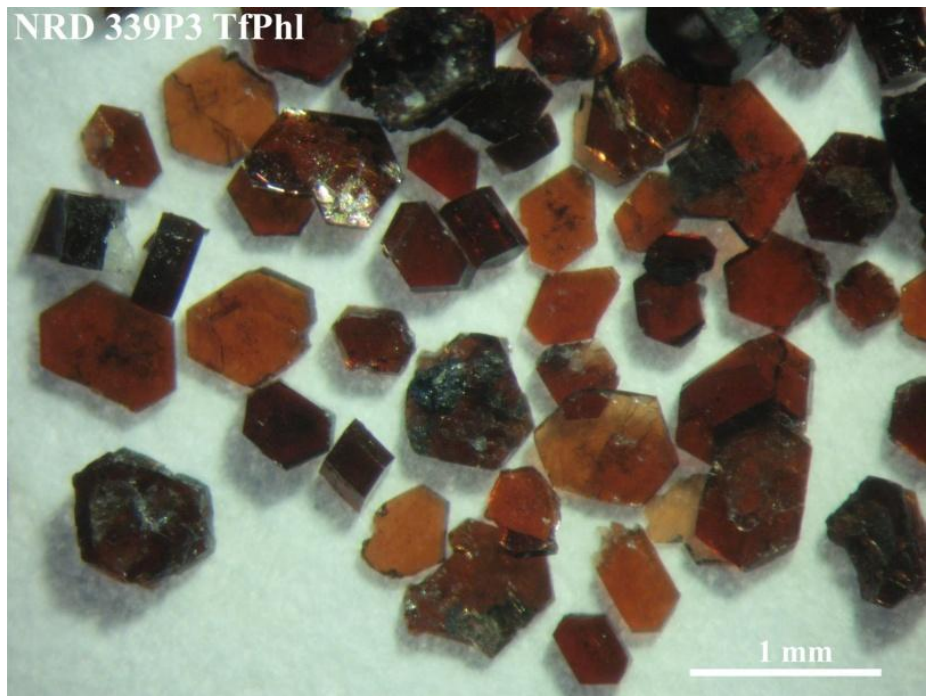

Figura C36. Fotografia do concentrado de tetraferriflogopita obtido da amostra NRD 339P3 (Catalão I). 


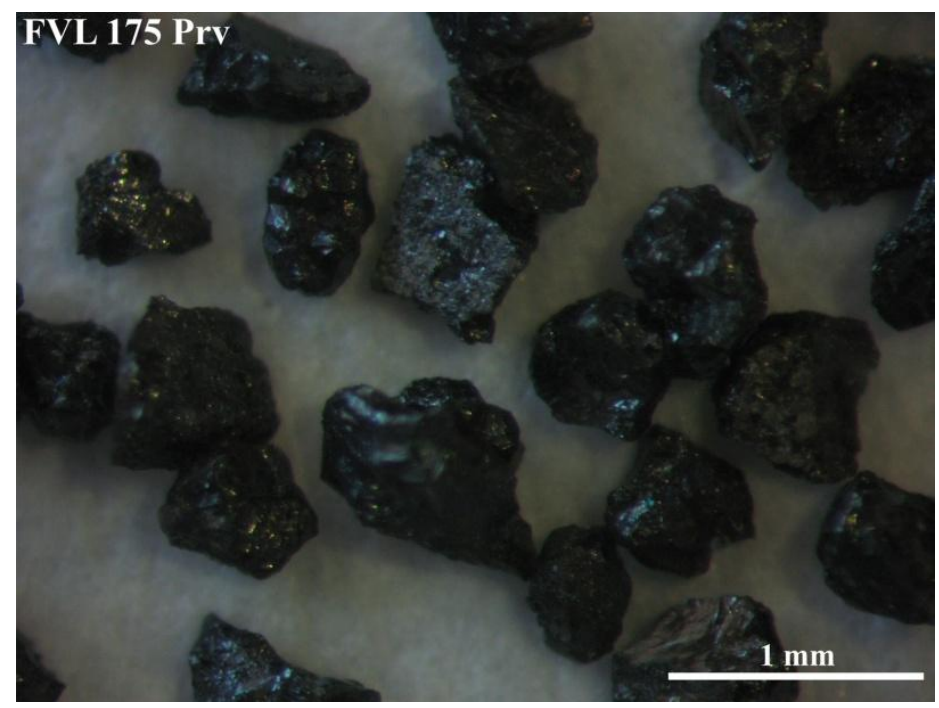

Figura C37. Fotografia do concentrado de perovskita selecionado da amostra FVL 175 (Salitre).

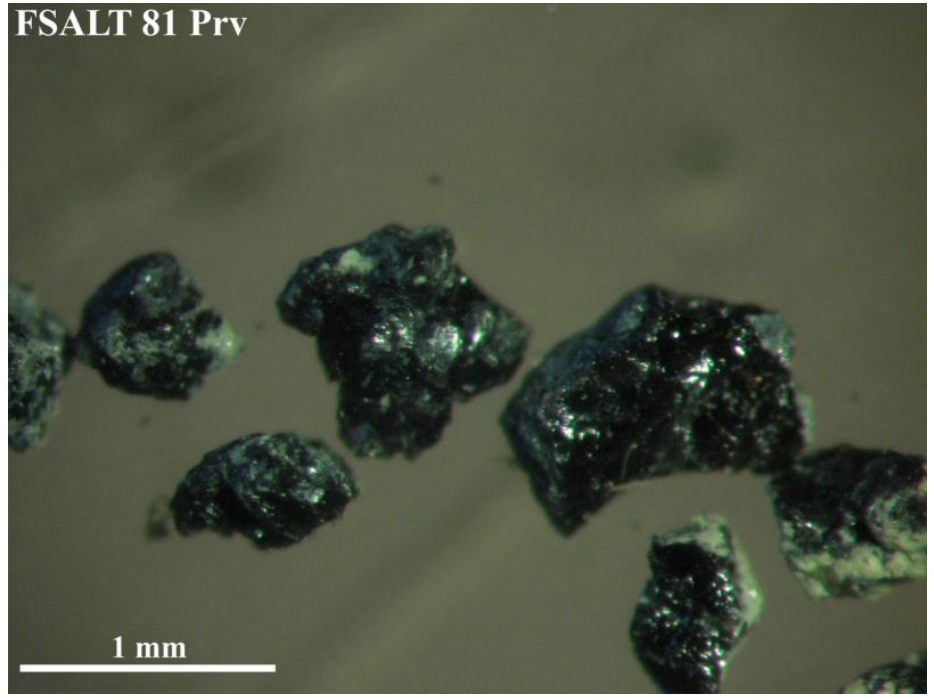

Figura C38. Fotografia do concentrado de perovskita selecionado da amostra FSALT 81 (Salitre).

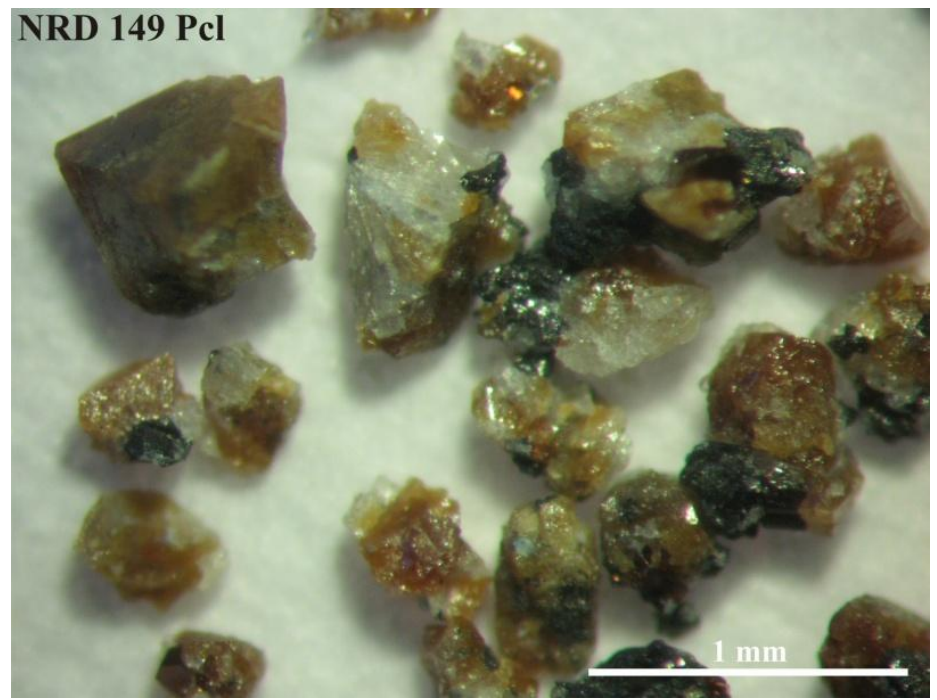

Figura C39. Fotografia do concentrado de pirocloro selecionado da amostra NRD 149 (Catalão I). 


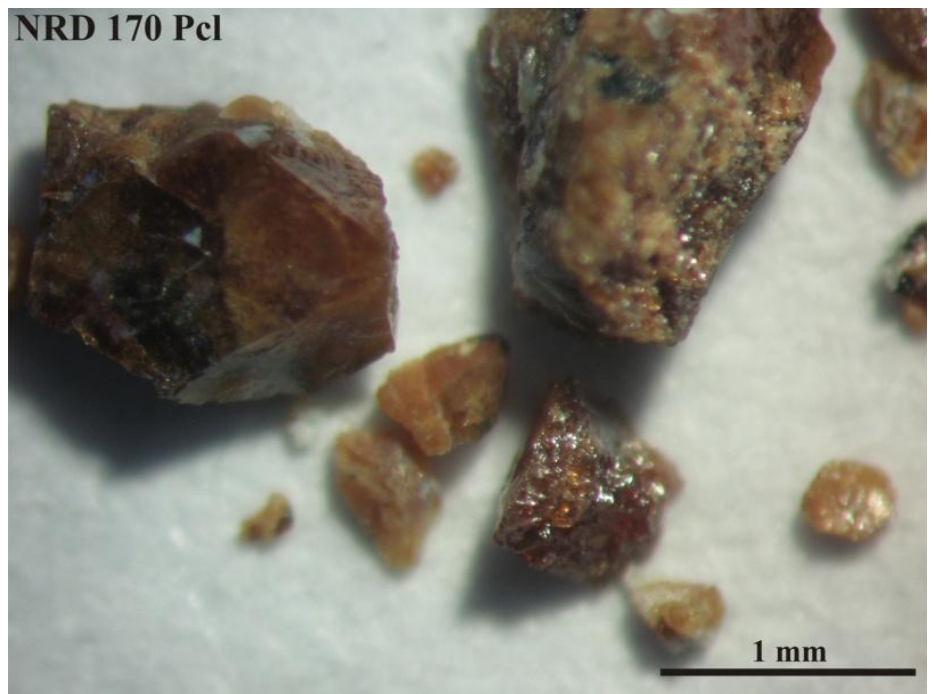

Figura C40. Fotografia do concentrado de pirocloro selecionado da amostra NRD 170 (Catalão I).

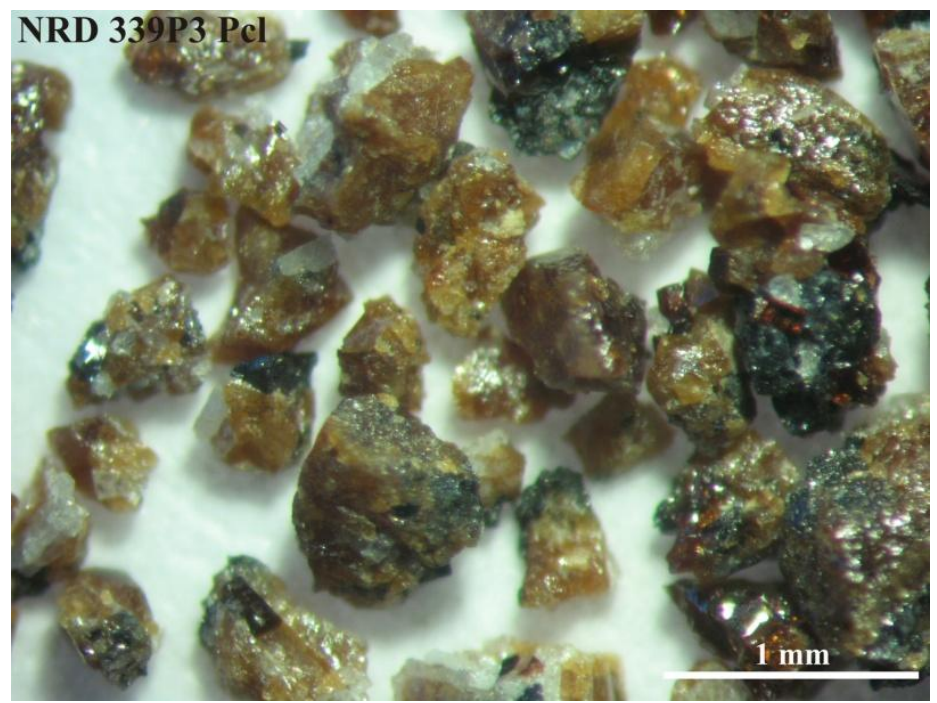

Figura C41. Fotografia do concentrado de pirocloro selecionado da amostra NRD 339P3 (Catalão I). 

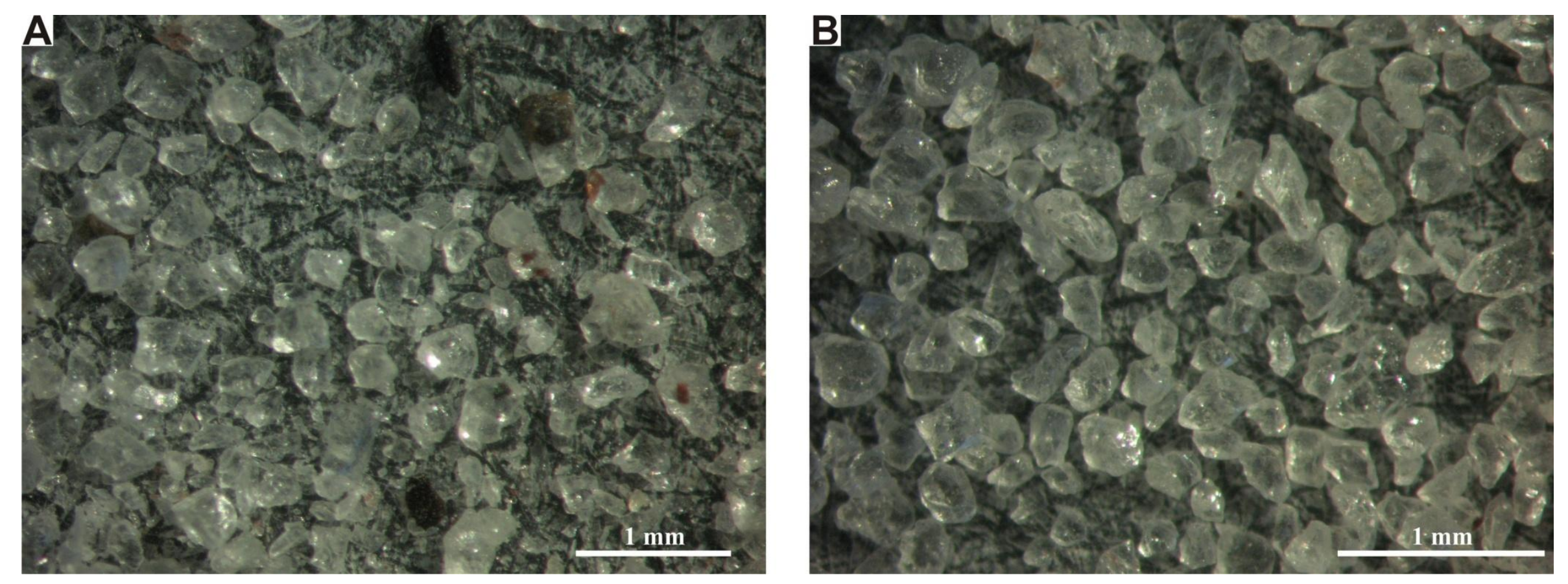

Figura C42. Fotografia do concentrado de flotação do minério de fosfato utilizado nos testes de lixiviação da mistura apatita-carbonato. A) concentrado mineral com impurezas de silicatos, óxidos e hidróxidos (Notar a presença de cristais escuros); B) concentrado mineral livre destas impurezas. 